\title{
BIOGEOCHEMICAL APPLICATIONS OF COMPOUND-SPECIFIC RADIOCARBON ANALYSIS
}

\author{
By \\ Ann Pearson \\ B.A., Oberlin College, 1992 \\ Submitted in partial fulfillment of the requirements for the degree of \\ Doctor of Philosophy \\ at the \\ MASSACHUSETTS INSTITUTE OF TECHNOLOGY \\ and the \\ WOODS HOLE OCEANOGRAPHIC INSTITUTION \\ October, 1999 \\ (C) Ann Pearson, 1999. All rights reserved.
}

The author hereby grants to MIT and WHOI the permission to reproduce and to distribute copies of this thesis document in whole or in part.

Signature of Author:

Joint Program in Oceanography,

Massachusetts Institute of Technology and

Woods Hole Oceanographic Institution, October 1, 1999.

Certified by:

Timothy I. Eglinton, Thesis Co-Supervisor

Certified by:

Ann P. McNichol, Thesis Co-Supervisor

Accepted by:

Martgaret K. Tivey

Chair, Joint Committee for Chemical Oceanography, Woods Hole Oceanographic Institution. 


\title{
BIOGEOCHEMICAL APPLICATIONS OF COMPOUND-SPECIFIC RADIOCARBON ANALYSIS
}

\author{
by \\ Ann Pearson \\ Submitted on October 1, 1999, in partial fulfillment of the requirements for the degree of \\ Doctor of Philosophy at the Massachusetts Institute of Technology and the Woods Hole \\ Oceanographic Institution
}

\section{$\underline{\text { ABSTRACT }}$}

Compound-specific carbon isotopic $\left(\delta^{13} \mathrm{C}\right.$ and $\left.\Delta^{14} \mathrm{C}\right)$ data are reported for lipid biomarkers isolated from Santa Monica Basin (SMB) and Santa Barbara Basin (SBB) surface sediments. These organic compounds represent phytoplanktonic, zooplanktonic, bacterial, archaeal, terrestrial, and fossil carbon sources. The lipids include long-chain $n$-alkanes, fatty acids (as FAMEs), $n$-alcohols, $\mathrm{C}_{30}$ mid-chain ketols and diols, sterols, hopanols, and ether-linked $\mathrm{C}_{40}$-biphytanes of Archaea.

The data show that the carbon source for most of the biomarkers is marine euphotic zone primary production or subsequent heterotrophic consumption of this biomass. Two lipid classes represent exceptions to this finding. $\Delta^{14} \mathrm{C}$ values for the $n$-alkanes are consistent with mixed fossil and contemporary terrestrial plant sources. The archaeal isoprenoid data reflect chemoautotrophic growth below the euphotic zone. The biomarker class most clearly representing marine phytoplanktonic production is the sterols. It is suggested, therefore, that the sterols could serve as paleoceanographic tracers for surface-water DIC.

The isotopic data are used to construct two algebraic models. The first calculates the contributions of fossil and modern vascular plant carbon to SMB $n$-alkanes. This model indicates that the $\Delta^{14} \mathrm{C}$ of the modern component is $+235 \%$ (post-bomb) or $0 \%$ (pre-bomb). The second model uses these values to determine the origin of sedimentary TOC. The results are comparable to estimates based on other approaches and suggest that $\sim 60 \%$ of SMB TOC is of marine origin, modern terrestrial and fossil sources contribute $\sim 10 \%$ each, and the remaining $\sim 20 \%$ is of unknown origin. 
For all of our mothers. 


\section{ACKNOWLEDGEMENTS}

I owe many thanks to the wonderful people who've made my graduate school experience some of the best years of my life.

Tim Eglinton continually gave me an empty slate and (seemingly) bottomless research budget. He let me take my research in any direction that was interesting and viable. Ann McNichol guided me through my first two years with patience, thoroughness, and friendship. Despite his busy schedule, John Hayes always made time to allow me access to his mental encyclopedia. Phil Gschwend taught me that a dozen pages of verbal hand-waving is not as persuasive as a simple, quantitative argument. Thank you, all, for your encouragement and acceptance of nothing less than excellence.

This thesis also required the help of colleagues and friends beyond the membership of my committee. Ellen Druffel organized the cruise in November 1996, on which I obtained the sediment samples. The Scripps Institution of Oceanography and the crew of $\mathrm{R} / \mathrm{V}$ Roger Revelle generously donated their time and resources for two days of sample collection in Santa Monica and Santa Barbara Basins. Every past and present member of the NOSAMS staff was critical to the completion of this project. Thank you especially to Bob, Karl, Al, Dana, and Sue for your flexibility and willingness to accommodate all of my unusual requests. Without Bryan Benitez-Nelson, I probably would have succeeded in eventually blowing up the Fye lab - an extra-special thank you for the thousand small ways in which you helped out. Carl Johnson and Leah Houghton provided the $\mathrm{irm}$-GC/MS data, including numerous re-runs and special requests; Rindy Ostermann, Eben Franks, and Ellen Roosen helped with foraminifera samples.

This work was supported by National Science Foundation grants to T. I. Eglinton (OCE-9415568, OCE-9809624, OCE-9708478), a National Institute of Standards and Technology contract to T. I. Eglinton (43NANB615740), and the NOSAMS/National Science Foundation cooperative agreements (OCE-9301015, OCE-9807266). I received support from an MIT Ida Green Graduate Student Fellowship and a US EPA STAR Graduate Student Fellowship.

I thank my family for their unending support over the years. They've always encouraged me to do all the crazy things I ever wanted, including this. I thank Mom, especially, for being the first scientist in the family and Dad, for expecting me to grow up to be just like her. Dave, I always know you'll get it - thanks. To everyone in WHOI 94, thanks for the potlucks, parties, stress-relief, memories. Thank you to the 24 Millfield crowd, including honorary residents, for giving me a home away from home these last couple of years. Finally, thanks to the Cape Cod Women's Hockey League, I always had something fun planned on Saturday nights. 


\section{TABLE OF CONTENTS}

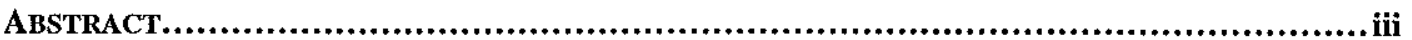

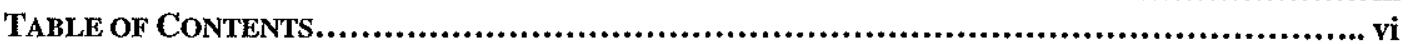

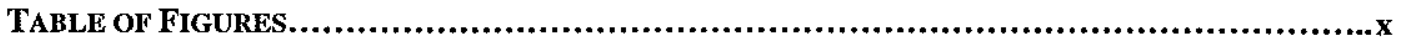

TABLE OF TABLES..............................................................................

CHAPTER 1 - INTRODUCTION..................................................... 17

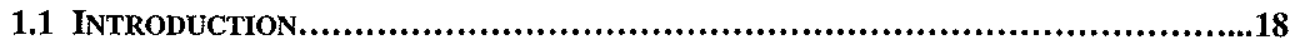

1.2 LIPID BIOMARKERS.............................................................20

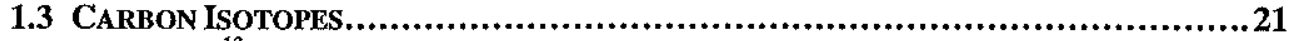

1.3.1 ${ }^{13} \mathrm{C}$ Systematics

1.3.2 ${ }^{14} \mathrm{C}$ Systematics

1.4 GLOBAL AND LOCAL ${ }^{14} \mathrm{C}$ Distributions..........................................29

1.4.1 Active Carbon Cycle

1.4.2 Bulk Reservoir Characteristics of ${ }^{14} \mathrm{C}$

1.4.3 Anthropogenic Perturbation of ${ }^{14} \mathrm{C}$ Reservoirs

1.4.4 Santa Monica Basin (SMB) and Santa Barbara Basin (SBB) Field Sites

1.5 GoALS OF THIS THESIS......................................................... 50

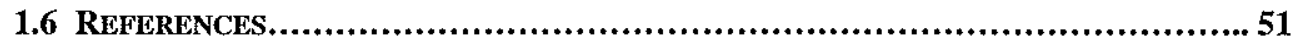

CHAPTER 2 - GEOCHEMICAL METHODS...........................................55

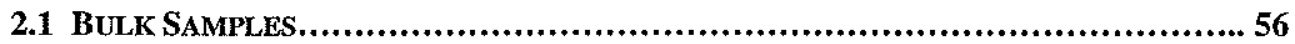

2.1.1 Samples

2.1.2 Bulk Sample Analyses

2.1.3 Foraminifera

2.2 ORganic GeOCHEMICAL Methods..............................................58

2.2.1 Lipid Analysis

2.2.2 High-Resolution Gas Chromatography (HRGC)

2.2.3 Gas Chromatography Mass Spectrometry (GC/MS)

2.2.4 Isotope Ratio Monitoring Gas Chromatography Mass Spectrometry (irm-GC/MS)

2.2.5 Preparative Capillary Gas Chromatography (PCGC)

2.2.6 Accelerator Mass Spectrometry (AMS)

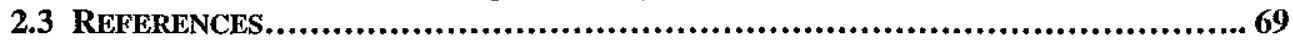

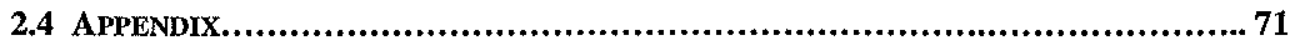

2.4.1 SMB Bulk Core Data

2.4.2 PCGC Sample Log

2.4.3 Sample Recoveries and Fractionation

2.4.3.1 Organic Geochemical Procedures

2.4.3.2 PCGC Sample Recoveries

CHAPTER 3 - MICROSCALE AMS ${ }^{14} \mathrm{C}$ MEASUREMENT AT NOSAMS.....................83

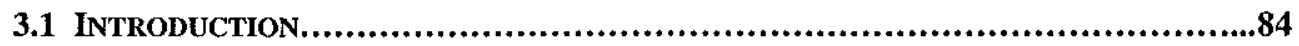


3.2.1 HOxI and HOxII Standards

3.2.2 Hydrolysis of Carbonates

3.2.3 Combustion Blanks: JME and HOxI Powders

3.2.4 Graphite Preparation

3.3 RESULTS AND Discussion.

3.3.1 Optimization of Graphite Production Reaction

3.3.2 AMS Performance of Small Samples

3.3.3 Compensation for Machine-Induced Fractionation: Accuracy of HOxI and HOxII $f_{m}$ Results

3.3.4 Contribution of Background Carbon in the Analysis of Small Samples

3.3.4.1 Machine or Source Blank

3.3.4.2 Graphitization Blank

3.3.4.3 Combustion Blank

3.4 Conclusions..................................................................... 104

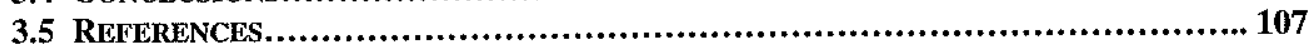

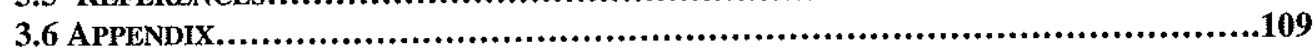

3.6.1 Erratum, Figure 2.1

3.6.2 Further Characteristics of Graphite Production on Cobalt Catalyst

3.6.3 Isotopic Fractionation Effects During Incomplete Graphitization

3.6.4 Accelerator Performance for Multiple Small Sample Wheels

CHAPTER 4 - AN ORGANIC TRACER FOR SURFACE OCEAN RADIOCARBON........ 119

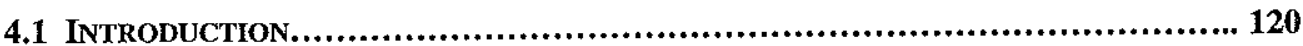

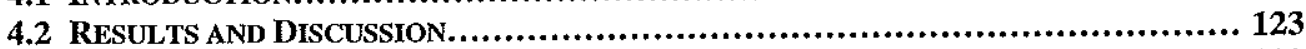

4.2 .1 Bulk Samples........................................................ 123

4.2.1.1 Surface Ocean $\Delta^{14} C_{D I C}$ Record

4.2.1.2 Core Chronologies

4.2.1.3 SMB Sediment Core $\triangle^{14} C$ : Foraminifera and TOC

4.2.1.4 Selection of Intervals for Compound-Specific Isotope Analysis

4.2.2 Organic Geochemical Analysis.

4.2.2.1 Sterol Lipid Fractions

4.2.2.2 PCGC Separations

4.2.3 Radiocarbon Analysis.

4.2.3.1 Sterol $\Delta^{14} \mathrm{C}$ Data

4.2.3.2 Discussion

4.2.3.3 Factors Affecting ${ }^{14} \mathrm{C}$ Isotopic Variability

4.2.4 Stable Isotope Analysis. 155

4.2.4.1 irm-GC/MS Data

4.2.4.2 Discussion: $C_{26}-C_{28}$ Sterols

4.2.4.3 Discussion: $C_{29}$ Sterols and Dinosterol

4.2.5 Fraction of Allochthonous Organic Carbon in SMB Sediment............. 164

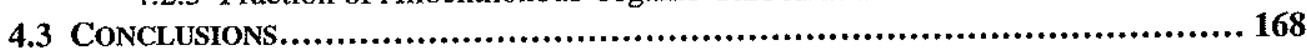

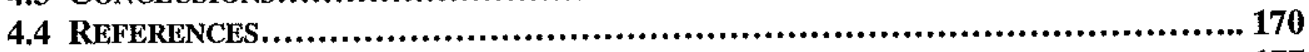

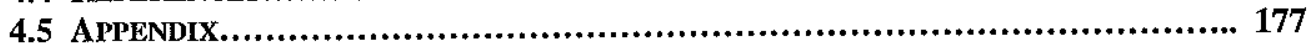

4.5.1 Additional SMB bulk core data 
4.5.2 ${ }^{13} \mathrm{C}$-Fractionation During Reaction of Alcohols with Acetic Anhydride

4.5.3 $\delta^{13} \mathrm{C}$ Comparison for PCGC Samples: Combusted $\mathrm{CO}_{2}$ and $\mathrm{irm}$-GC/MS Data

4.5.4 $\Delta^{14} \mathrm{C}$ Comparison vs. Sample Size

CHAPTER 5 - RADIOCARBON EVIDENCE FOR AUTOTROPHIC METABOLISM IN MARINE PLANKTONIC ARCHAEA .................. 191

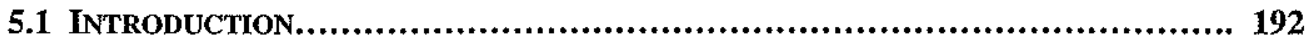

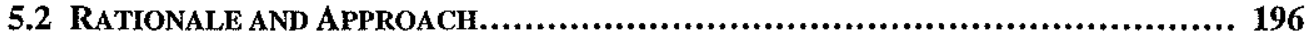

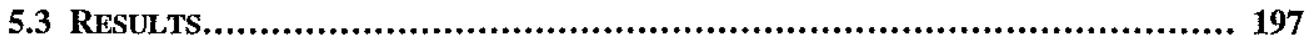

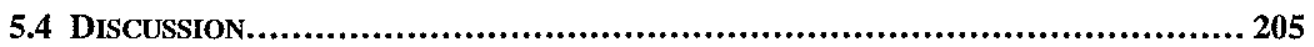

5.4.1 Radiocarbon Data

5.4.1.1 Data Comparison

5.4.1.2 DOC Incorporation Model

5.4.1.3 DIC Incorporation Model

5.4.2 Energy Source for Chemoautotrophy

5.4.3 Enzymatic Pathway of $\mathrm{CO}_{2}$ Fixation

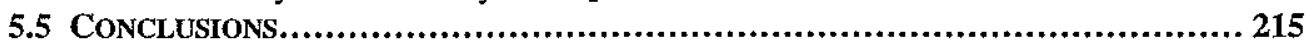

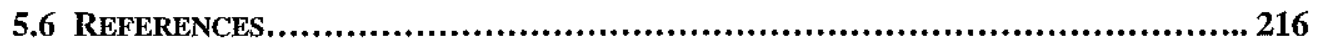

CHAPTER 6 - ORIGINS OF LIPID BIOMARKERS IN SANTA

MONICA BASIN SURFACE SEDIMENT: A CASE STUDY

USING COMPOUND-SPECIFIC ${ }^{13} \mathrm{C}$ AND ${ }^{14} \mathrm{C}$ ANALYSIS .................. 221

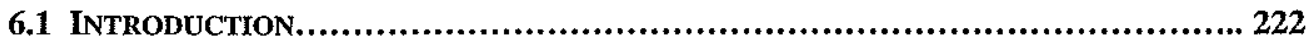

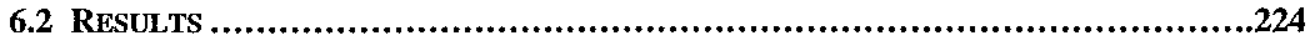

6.2.1 Bulk Core Data.................................................... 224

6.2.2 Organic Geochemical Analysis........................................... 227

6.2.2.1 Selection of Intervals for Compound-Specific

Isotopic Analysis

6.2.2.2 n-Alkanes

6.2.2.3 Fatty Acid Methyl Esters (FAMEs)

6.2.2.4 Alcohols

6.2.2.5 Diols and Archaeal Ether Lipids

6.2.3 PCGC Separations......................................................... 244

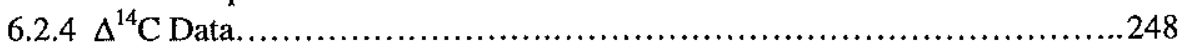

6.2.4.1 n-Alkanes

6.2.4.2 FAMEs

6.2.4.3 n-Alcohols, $C_{30}$-alkan-15-one-1-ol, and $\mathrm{C}_{30^{-}}$alkan-1,15-diol

6.2.4.4 Sterols

6.2.4.5 Hopanols

6.2.4.6 Archaeal Lipids

6.2.4.7 Measurement Errors: Replicates

and Recovery Standards 
6.2.5 $\delta^{13} \mathrm{C}$ Data.

6.2.5.1 n-Alkanes

6.2.5.2 FAMEs

6.2.5.3 n-Alcohols and Alkan-15-one-1-ols

6.2.5.4 Sterols and Hopanols

6.2.5.5 Archaeal Lipids and Alkan-1,15-diols

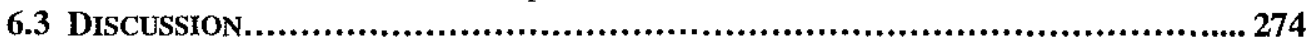

6.3.1 Multi-Dimensional Carbon Isotope Distribution(s):

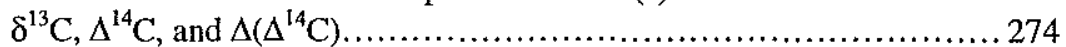

6.3.2 Sources of Lipid Biomarkers to SMB Sediment.......................... 278

6.3.2.1 FAMEs

6.3.2.2 Sterols and Hopanols

6.3.2.3 n-Alcohols, Alkan-15-one-1-ols, and Alkan-1,15-diols

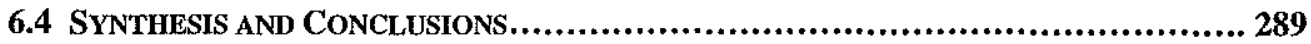

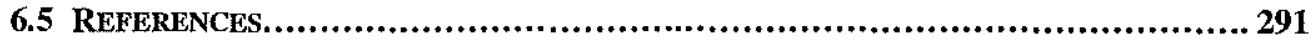

CHAPTER 7 - MODELS FOR THE ORIGIN OF $N$-ALKANES AND TOTAL ORGANIC CARBON IN SANTA MONICA BASIN

SURFACE SEDIMENT...................................................... 297

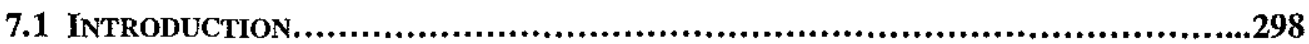

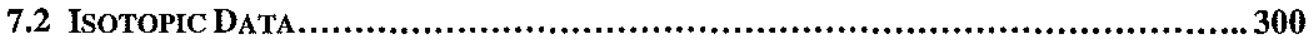

7.2.1 TOC

7.2 .2 n-Alkanes

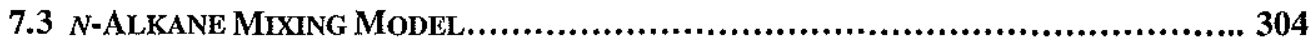

7.3.1 Quantitative Approach

7.3.2 Results and Discussion

7.3.3 Comparison to 2-Component n-Alkane Model

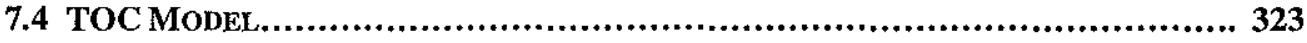

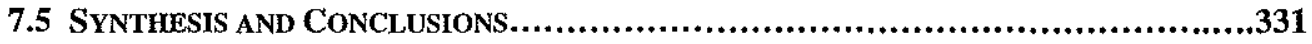

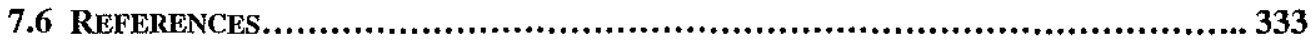

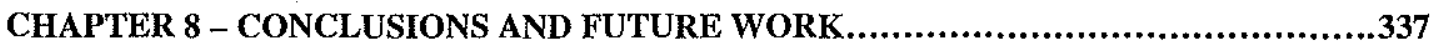

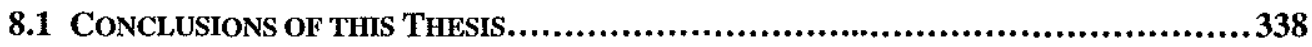

8.1.1 Quality Control for Small Sample AMS

8.1.2 Phytoplanktonic Tracer Suitable for

Paleoceanographic Applications

8.1.3 Exploration of Prokaryotic Metabolism

8.1.4 Sources of Lipid Biomarkers to SMB Sediment

8.1.5 Terrigenous Component of Continental Margin Sediments

8.2 FUTURE WORK 


\section{Table of Figures}

Figure 1.1 Example structures of lipids discussed in this thesis .21

Figure 1.2 Major global reservoirs involved in the active production, exchange, and cycling .......31 of organic carbon, based on Siegenthaler and Sarmiento (1993) and Hedges and Oades (1997). Reservoir sizes are shown in Gt carbon $\left(1 \mathrm{GtC}=10^{15} \mathrm{gC}\right)$. Numbers in parentheses are based on 1980s values; numbers without parentheses are estimates of the pre-anthropogenic values. Fluxes primarily mediated by biological reactions are shown with dashed arrows; physical transport processes are shown with solid arrows.

Figure 1.3 (a) Decay age $\left(I=1 / 8267 \mathrm{yr}^{-1}\right)$ as a function of $\Delta^{14} \mathrm{C}$; (b) mixing equal proportions......36 of modern and "dead" material yields $\Delta^{\mathrm{I} 4} \mathrm{C}=-500 \%$; while (c) the "age" is not equal to what would be considered a linear average of the ages of the two materials.

Figure 1.4 Evolution of atmospheric $\mathrm{CO}_{2}$, Southern California Bight surface water DIC, and.......38 Santa Monica Basin surface sediment TOC $\Delta^{14} \mathrm{C}$ values since 1950. The atmospheric $\Delta{ }^{14} \mathrm{C}$ record is based on the figures and references in Broecker and Peng (1982) and Hesshaimer et al. (1994); the surface water DIC record is based on references in Robinson (1981), Williams et al. (1992), and this thesis; the TOC record is from this thesis.

Figure 1.5 Santa Monica Basin core location for this thesis: $33^{\circ} 44.00^{\prime} \mathrm{N}, 118^{\circ} 49.99^{\prime} \mathrm{W}$, $905 \mathrm{~m}$ depth, using an Ocean Instruments ${ }^{\circledR}$ Multicorer, November, 1996, R/V Roger Revelle, cruise Pulse- 32 .

Figure 1.6 Santa Barbara Basin core location for this thesis: $34^{\circ} 13.5^{\prime} \mathrm{N}, 120^{\circ} 03.5^{\prime} \mathrm{W}$ 40 $595 \mathrm{~m}$ depth, using an Ocean Instruments ${ }^{\circledR}$ Multicorer, November, 1996, R/V Roger Revelle, cruise Pulse-32.

Figure 1.7 Pre-bomb $\Delta^{14} \mathrm{C}$ distribution in SMB; data from Table 1.6. .44

Figure 1.8 Post-bomb (1990s) $\Delta^{14} \mathrm{C}$ distribution in SMB; data from Table 1.6

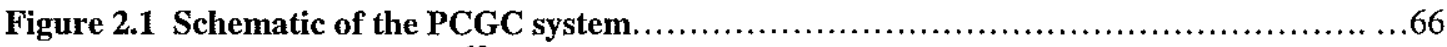

Figure 2.2 SMB sedimentary $\delta^{13} \mathrm{C}_{\mathrm{TOC}}$, measured on splits of $\mathrm{CO}_{2}$ prepared by closed-tube .........71 combustion.

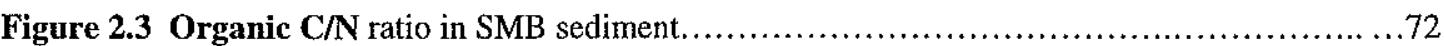

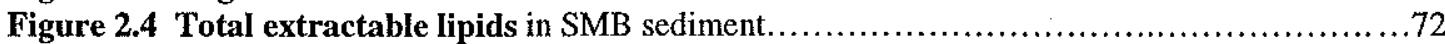

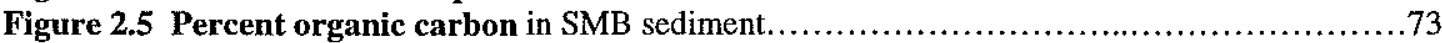

Figure 3.1 (a) Calculated error $\sigma_{F_{s}}$ for dilution to a conventional sample size of $500 \mu \mathrm{gC} \mathrm{(A)} \mathrm{\ldots ...86}$ and for dilution to $100 \mu \mathrm{gC}$ only (B). (b) Calculated error $\sigma_{F s}$ for dilution of a $10 \mu \mathrm{gC}$ sample up to $r_{x}=10$ using a variable $\sigma_{F x}=0.06 e^{-0.018 M x}$. Increased precision in $\sigma_{F x}$ partially offsets the dilution error.

Figure 3.2 (a) $2^{3}$ factorial analysis of $\mathrm{T}, \mathrm{R}$, and $\mathrm{H}$ effects on reaction yield. (b) $2^{4}$ factorial $\ldots \ldots . .92$ analysis of $T, R, H$, and $Q$ effects on reaction yield. A (+) indicates the upper range of the factor improves \% yield, while a (-) indicates the lower range improves $\%$ yield. The variables are described in the text.

Figure 3.3 Observations showing that the ${ }^{12} \mathrm{C}$ current measured for small samples varies .93 with size, according to the approximate relationship $\mathrm{I}_{12}=0.9 \mathrm{M} . \mathrm{M}=$ mass of carbon in micrograms; $\mathrm{I}_{12}={ }^{12} \mathrm{C}$ current in nanoamperes.

Figure 3.4 Dependence of the measured ${ }^{14} \mathrm{C}^{12} \mathrm{C}$ isotope ratios for (a) HOxI and (b) HOxII .......95 small samples on the generated ${ }^{12} \mathrm{C}$ ion current. Ratios have been normalized to average values obtained for HOxI and HOxII standards of conventional size. 
Figure 3.5 (a) ${ }^{13} \mathrm{C}$ fractionation of HOxI and HOxII small samples as a function of the. .96 generated ${ }^{12} \mathrm{C}$ ion current for all discrete time points. (b) $\Delta \delta^{13} \mathrm{C}$ and $\mathrm{I}_{12}$ variation within samples as a function of elapsed measurement time.

Figure 3.6 Results obtained for HOxI and HOxII small standards when $\mathrm{f}_{\mathrm{m}}$ values are calculated relative to adjacent small standards of similar size. $\Delta=$ sample for which Poisson error was used.

Figure 3.7 Graphitization blank as measured for IAEA C-1 carbonate

Figure 3.8 (a) Re-calculated error $\sigma F_{s}$ for dilution to a composite sample size of $100 \mu \mathrm{gC}, \ldots \ldots \ldots 110$ shown for a range of assumed values of $F_{s}$. (b) Re-calculated error $\sigma F_{s}$ for dilution of a $10 \mu \mathrm{gC}$ sample up to $r_{x}=10$, using a variable $\sigma F_{x}=0.06 \mathrm{e}^{-0.018 \mathrm{Mx}}$, assuming $F_{s}=0.5$.

Figure 3.9 Pressure vs. time graphs for a graphite reaction achieving $85 \%$ yield (a) and for one reaching only $60 \%$ yield (b).

Figure 3.10 Isotope effects observed as a function of graphite reaction yield. HOxI, .............115 diamonds; HOxII, circles.

Figure 3.11 (a) Cartoon of the decrease in ${ }^{14} \mathrm{C} /{ }^{12} \mathrm{C}$ for a set of HOxI standards arranged in order of decreasing $\mathrm{I}_{12}$. (b) Random insertion of samples between these standards. (c) Samples and standards arranged in order of decreasing $\mathrm{I}_{12}$.

Figure 3.12 (a) Correlation between $\mathrm{I}_{12}$ and $\mathrm{C} / \mathrm{Co}$ ratio for a small sample wheel. (b) The same $I_{12}$ data, plotted as a function of sample size (corrected for \% yield).

Figure 4.1 Evolution of SCB surface water $\Delta^{14} \mathrm{C}$ through the twentieth century, showing the $\ldots \ldots . .126$

Figure 4.2 Calendar year chronology of the Santa Monica Basin core used in this thesis as .......128 determined by ${ }^{210} \mathrm{~Pb}$ dating. The core was sectioned at $0.75-\mathrm{cm}$ intervals to $1.5 \mathrm{~cm}$, then at $1.0-\mathrm{cm}$ intervals to $8.5 \mathrm{~cm}$.

Figure 4.3 Bulk sample $\Delta^{14} \mathrm{C}$ data for the SMB core. Foraminifera are shown in hollow symbols (triangles, planktonics; circles and squares, benthics), TOC in solid diamonds, and the surface water $\Delta{ }^{14} \mathrm{C}_{\mathrm{DIC}}$ model created from literature data is shown as a dashed line.

Figure 4.4 HRGC traces for the three sterol fractions selected for compound-specific .136 isotopic analysis. (a) SBB $0-1 \mathrm{~cm}$, (b) SMB $0-0.75 \mathrm{~cm}$, (c) SMB $4.5-5.5 \mathrm{~cm}$, all derivatized to acetates for PCGC separation and ${ }^{14} \mathrm{C}$ analysis; (d) SMB 4.5-5.5 derivatized to trimethyl-silyl ethers as was necessary for $\delta^{13} \mathrm{C}$ analysis by $\mathrm{irm}$-GC/MS.

Figure 4.5 HRGC traces for two 4-methyl-sterol fractions (as acetates) for PCGC separation .....137 of dinosterol.

Figure 4.6 (a) Expanded $\mathrm{C}_{29}$ sterol region of the SMB $0-0.75 \mathrm{~cm}$ chromatogram originally obtained by HRGC. (b) The mass $45 / 44$ isotope ratio trace for the same region of this sample has four clear peaks, and (c) the corresponding mass 44 ion chromatogram shows the improved peak separation obtained on the $\mathrm{irm}$-GC/MS system.

Figure 4.7 HRGC traces of SMB $0-0.75 \mathrm{~cm}$ 4-desmethyl-sterol fraction. The original mixture is shown at the bottom. Re-analyzed aliquots of individual PCGC trap contents are shown above. Sterol isomer peaks are labeled as in Figure 4.4, and recovered quantities of the pure compounds are given.

Figure 4.8 Two-dimensional carbon isotope plot of sterol biomarkers, showing agreement of.. ...149 pre-bomb and post-bomb compound-specific $\Delta^{14} \mathrm{C}$ data with the record of surface water $\Delta^{14} \mathrm{C}_{\mathrm{DIC}}$. Surface water $\Delta^{14} \mathrm{C}_{\text {DIC }}$ measurements are shown as solid lines; dashed lines represent planktonic foraminifera.

Figure 4.9 The effect of differing degradation rates on the measured $\Delta^{14} \mathrm{C}$ of lipids having ........155 the same original source. (a) The $\Delta^{14} \mathrm{C}$ of the source material over time. (b) Compound $\boldsymbol{X}$ degrades at 5 times the rate of compound $\boldsymbol{Y}$. (c) The maximum difference between measured $\Delta^{14} \mathrm{C}$ values occurs over the interval when the source $\Delta^{14} \mathrm{C}$ was changing most rapidly. 
Figure 4.10 Comparison of $\delta^{13} \mathrm{C}$ data for individual sterols from SMB and SBB sediments,.......158 showing the similarity of the relative ${ }^{13} \mathrm{C}$ distribution among the isomers studied.

Figure 4.11 Comparison of $\delta^{13} \mathrm{C}$ data for individual sterols from the additional SMB .............159 sedimentary horizons, $0.75-1.5 \mathrm{~cm}$ and $5.5-6.5 \mathrm{~cm}$, for which ${ }^{14} \mathrm{C}$ isotopic data were not obtained.

Figure 4.12 The fraction of TOC in SMB sediment traceable to marine planktonic production. The linear fit was determined for $\Delta^{14} \mathrm{C}_{\mathrm{TOC}}$ relative to the $\Delta^{14} \mathrm{C}_{\mathrm{DrC}}$ model derived from data in Table 4.1 (diamonds). The triangles show the agreement between sterol $\Delta{ }^{14} \mathrm{C}$ data and the model solution.

Figure 4.13 Reaction mechanism and energy diagram for the formation of an acetate 179 derivative from an alcohol and isotopically heterogeneous acetic anhydride.

Figure 4.14 Sterols: ${ }^{13} \mathrm{C}$ difference between $\mathrm{CO}_{2}$ splits and $\mathrm{irm}$-GC/MS data..................... 188

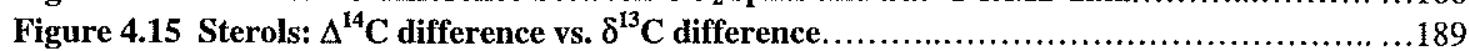

Figure 4.16 The difference between individual $\Delta^{14} \mathrm{Csterol}$ and $\Delta^{14} \mathrm{C}_{\mathrm{DIC}}$ as a function of .............190 sample size. There is no uniform bias toward more negative or positive offsets for the smaller samples, although there is more scatter observed.

Figure 5.1 (From DeLong et al., 1998) Phylogenetic division of the three Domains of life, including the division of Archaea into the two major Kingdoms, Crenarchaeota and Euryarchaeota.

Figure 5.2 Structure of caldarchaeol, an ether-linked $C_{80}$ isprenoid membrane lipid of . thermophilic and marine planktonic Archaea.

Figure 5.3 Structures of lipids used for compound-specific isotope analysis.....

Figure 5.4 Gas chromatograms of SBB 0-1 cm ether lipid fraction (as hydrocarbons). (a).........200 total mixture; (b) $n-\mathrm{C}_{33}$ standard as recovered by PCGC; (c) $\mathrm{C}_{40: 2 \mathrm{cy}}$ as recovered by PCGC; (d) $\mathrm{C}_{40: 3 c y}$ as recovered by PCGC; (e) FID output for total mixture during PCGC separation on the 1-m multi-capillary column.

Figure 5.5 $\Delta^{14} \mathrm{C}$ vs. $\delta^{13} \mathrm{C}$ for sterols (crosses) and archaeal ether lipids, SBB $0-1 \mathrm{~cm}$ (circles),....204 SMB 5.5-8.5 cm (squares). Also included are solid lines showing the $\Delta^{14} \mathrm{C}$ of surface water DIC during the 1990 s (upper line) and prior to atmospheric nuclear weapons testing (lower line).

Figure 5.6 Comparison of SMB and SBB $\Delta^{14} \mathrm{C}_{\mathrm{DIC}}$ and water column $\mathrm{O}_{2}$ and $\mathrm{NO}_{2}^{-}$profiles. $\mathrm{SBB}$ is shown in the upper section of the figure, SMB in the lower section. Wide horizontal arrows point to the ${ }^{\text {c14 }} \mathrm{C}$-projection depths" of archaeal biomass production and the corresponding regions of the nutrient profiles.

Figure 6.1 Bulk sample $\Delta^{14} \mathrm{C}$ data for the SMB core. Bottom water $\Delta^{14} \mathrm{C}_{\mathrm{DIC}}$ as recorded .226 by benthic foraminifera is shown as a thin solid line; the surface water $\Delta^{14} \mathrm{C}_{\mathrm{DIC}}$ model created from literature data is shown as a dashed line. Sedimentary $\Delta^{14} \mathrm{C}_{\mathrm{TOC}}$ (diamonds) is intermediate between the two water mass records.

Figure 6.2 (a) Total aliphatic hydrocarbon fraction for SMB $0-2.5 \mathrm{~cm}$ sediment horizon and (b) $n$-alkane fraction obtained following urea adduction of the same sample; letters identify compounds collected by PCGC for ${ }^{14} \mathrm{C}$-AMS analysis (data in Table 6.2).

Figure 6.3 Absolute and relative abundance of $\boldsymbol{n}$-alkanes in SMB sediment.....................230

Figure 6.4 (a) Total FAME plus ketone fraction for SMB $4.5-5.5 \mathrm{~cm}$ sediment horizon ...........233 (original chromatogram of SMB $0-0.75 \mathrm{~cm}$ fraction not available) and (b) purified FAME fraction from SMB $0-0.75 \mathrm{~cm}$ horizon; letters identify compounds collected by PCGC for ${ }^{14} \mathrm{C}$-AMS analysis (data in Table 6.2).

Figure 6.5 Absolute and relative abundance of fatty acids (as FAMEs) in SMB sediment..........2234 Figure 6.6 (a) Total alcohols (as acetates) (Fraction 7) from the SMB $0.75-1.5 \mathrm{~cm}$ 
horizon and $(\mathbf{b}, \mathbf{c}) n$-alcohol and non-adducted fractions obtained following urea adduction of the same sample; letters identify compounds collected by PCGC for ${ }^{14} \mathrm{C}$-AMS analysis (data in Table 6.2).

Figure 6.7 Absolute and relative abundance of $n$-alcohols and $\mathrm{C}_{30}$-alkan-15-one-1-ol in 238 SMB sediments. $\left(7^{*} n-\mathrm{C}_{24}=\right.$ seven times the abundance of $n$ - $\mathrm{C}_{24} ; 6^{*} n-\mathrm{C}_{24}=$ six times the abundance of $n-\mathrm{C}_{24}$.)

Figure 6.8 4-Desmethyl-sterols (as acetates) (Fraction 8) from the SMB $0-0.75 \mathrm{~cm}$ horizon; letters identify compounds collected by PCGC for ${ }^{14} \mathrm{C}$-AMS analysis (data in Table 6.2).

Figure 6.9 Absolute and relative abundance of sterols and hopanols in SMB sediments.

Figure 6.10 (a) Total diols and archaeal ether-linked isoprenoid lipids (Fraction 9) from ..........242 the SMB $0-0.75 \mathrm{~cm}$ horizon (not abundant enough for compound-specific ${ }^{14} \mathrm{C}$ analysis) and (b) hydrocarbon fraction generated by $\mathrm{HI}$ cleavage and $\mathrm{LiAlH}_{4}$ reduction of SMB $5.5-8.5 \mathrm{~cm}$ Fraction 9 ; letters identify compounds collected by PCGC for ${ }^{14} \mathrm{C}-\mathrm{AMS}$ analysis (data in Table 6.2).

Figure 6.11 Absolute and relative abundance of $\mathrm{C}_{30}$-alkan-1,15-diol and $\mathrm{C}_{40}$ isoprenoid $\ldots \ldots \ldots 243$ ether linked lipids of Archaea in SMB sediment.

Figure 6.12 HRGC traces of SMB $0-0.75 \mathrm{~cm}$ FAME fraction. The original mixture is shown at the bottom. Re-analyzed aliquots of individual PCGC trap contents are shown above. FAME isomer peaks are labeled as in Figure 6.4 and Tables 6.1 and 6.2 , and recovered quantities of the pure compounds are given.

Figure 6.13 irm-GC/MS data for SMB sediment $\boldsymbol{n}$-alkanes. Dark colored bars indicate the odd-chain $n$-alkanes, and colorless bars indicate the even-chain $n$-alkanes.

Figure 6.14 irm-GC/MS data for SMB and SBB sediment FAMEs. The saturated fatty acids, $\mathrm{C}_{12: 0}, \mathrm{C}_{14: 0}, \mathrm{C}_{16: 0}$, and $\mathrm{C}_{18: 0}$ are shown with black bars. The odd-chain, branchedchain, and unsaturated fatty acids are shown with colorless bars. Even-numbered, long-chain alkanes are shown with gray bars.

Figure 6.15 irm-GC/MS data for SMB post-bomb sediment $n$-alkanols.

Figure 6.16 irm-GC/MS data for SMB pre-bomb sediment $n$-alkanols .........................267

Figure 6.17 irm-GC/MS data for individual sterols from SMB and SBB sediments................269

Figure 6.18 irm-GC/MS data for sterols from the additional SMB sedimentary horizons, ...........270 $0.75-1.5 \mathrm{~cm}$ and $5.5-6.5 \mathrm{~cm}$, for which ${ }^{14} \mathrm{C}$ isotopic data were not obtained.

Figure 6.19 irm-GC/MS data for Fraction 9, alkyl-1,15-diols and archaeal lipids...............273

Figure 6.20 $\Delta^{14} \mathrm{C}$ vs. $\delta^{13} \mathrm{C}$ distribution for SMB biomarkers. Post-bomb data $(0-0.75, \ldots \ldots \ldots \ldots \ldots . .275$

$0.75-1.5,0-2.5 \mathrm{~cm}$ horizons) are shown with solid symbols and pre-bomb data

(4.5-5.5, 5.5-8.5, 2.5-7.5 cm horizons) with hollow symbols. $\wedge, n$-alkanes; •, FAMEs;

$\mathbf{1}, n$-alcohols; $\$$, sterols and hopanols; $\mathbf{\nabla}$, archaeal lipids and $\mathrm{C}_{30}$-diol (post-bomb data from SBB $0-1 \mathrm{~cm}$ ). Letters identify individual compounds as in Table 6.2 .

Figure 6.21 Three-dimensional plot of the post-bomb data presented in Figure 6.20. The .277 $\mathrm{z}$-axis shows the change in $\Delta^{14} \mathrm{C}$ recorded by individual biomarkers between pre-bomb and post-bomb horizons $\left(\Delta\left(\Delta^{14} \mathrm{C}\right)=\Delta^{14} \mathrm{Cpost}\right.$-bomb $-\Delta^{14} \mathrm{Cpre}$-bomb). The horizontal plane at $\Delta\left(\Delta^{14} \mathrm{C}\right)=+150 \%$ represents the change in surface water $\Delta^{14} \mathrm{C}_{\mathrm{DIC}}$ over the same time interval. All of the analyzed lipids except $n$-alkanes and archaeal isoprenoids fall within $\pm 30 \%$ of this plane.

Figure 7.1 Concentration distributions and $\delta^{13} \mathrm{C}$ values of the three assumed $\boldsymbol{n}$-alkane .312 sources used to create the $n$-alkane mixing model.

Figure 7.2 Results of the mixing model for SMB pre-bomb (2.5-7.5 cm) $n$-alkanes. (a) $\delta^{13} \mathrm{C}$ 313 data for $n$ - $\mathrm{C}_{24}$ to $n$ - $\mathrm{C}_{33} n$-alkanes (squares) and $\delta^{13} \mathrm{C}$ predicted by the best-fit model solution (bars). Residuals shown above are all $<1.0 \%$. (b) $\Delta^{14} \mathrm{C}$ data for composite even numbered $n$-alkanes $\left(n\right.$ - $\left.\mathrm{C}_{24+26+28+30}\right)$, and individual $n$ - $\mathrm{C}_{27}, n-\mathrm{C}_{29}$, and $n$ - $\mathrm{C}_{31}$ 
alkanes (circles) and $\Delta{ }^{14} \mathrm{C}$ for all $n$ - $\mathrm{C}_{24}$ to $n$ - $\mathrm{C}_{33}$ alkanes predicted by the best-fit model solution (bars).

Figure 7.3 Results of the mixing model for SMB post-bomb (0-2.5 cm) $n$-alkanes. (a) $\delta^{13} \mathrm{C} \ldots \ldots . .314$ data for $n$ - $\mathrm{C}_{24}$ to $n$ - $\mathrm{C}_{33} n$-alkanes (squares) and $\delta^{13} \mathrm{C}$ predicted by the best-fit model solution (bars). Residuals shown above are all $<1.0 \%$. (b) $\Delta^{14} \mathrm{C}$ data for composite even numbered $n$-alkanes $\left(n-\mathrm{C}_{24+26+28+30}\right)$, and individual $n-\mathrm{C}_{27}, n-\mathrm{C}_{29}$, and $n$ - $\mathrm{C}_{31}$ alkanes (circles) and $\Delta^{14} \mathrm{C}$ for all $n$ - $\mathrm{C}_{24}$ to $n$ - $\mathrm{C}_{33}$ alkanes predicted by the best-fit model solution (bars).

Figure 7.4 Relative contributions of each of the three endmembers to the $n$-alkane .315 samples. The petroleum source is relatively more important in the $0-2.5 \mathrm{~cm}$ horizon, terrestrial material is relatively enriched in the $2.5-7.5 \mathrm{~cm}$ horizon, and the shale fraction is the same in both. Agreement between the data and model is within $10 \%$ in the surface sediment and within $20 \%$ in the deeper sample.

Figure 7.5 A new representation of Figure 6.21. The $\Delta\left(\Delta^{14} \mathrm{C}\right)$ values for the $n$-alkanes are.... .320 replaced with the modeled result $\Delta\left(\Delta^{14} \mathrm{C}_{\text {terrestrial }}\right)=+235 \%$. The horizontal plane at $\Delta\left(\Delta^{14} \mathrm{C}\right)=+150 \%$ represents the change in surface water $\Delta^{14} \mathrm{C}$ since pre-bomb conditions.

Figure 7.6 Matlab model solution for the fractional contributions of planktonic $(P), \ldots \ldots \ldots \ldots \ldots . \ldots 325$ terrestrial $(T)$, fossil $(F)$, and unknown $(U)$ carbon to SMB TOC.

Figure 8.1 Lipid classes distributed around a simplified phylogenetic "tree of life". .346 Phylogenetic tree from Schlegel, 1989. 


\section{Table of Tables}

Table 1.1 Common source assignments of lipid biomarkers...............................20

Table 1.2 Equilibrium ${ }^{\mathbf{1 3}} \mathbf{C}$ fractionation effects, adapted from Hayes (1993) and Raven (1997)....23

Table 1.3 Kinetic fractionation effects associated with solute reactions and transport, adapted......24 from Raven (1997).

Table 1.4 Kinetic fractionation effects associated with enzymatic reactions, adapted from Bott......25 and Thauer (1989), Raven (1997), and specific references as noted below. Enzymes:

Ribulose bis-phosphate carboxylase-oxygenase (RUBISCO), Phosphoenolpyruvate carboxylase (PEPC), Phosphoenolpyruvate carboxykinase (PEPCK), Pyruvate synthase (PS), $\alpha$-Ketoglutarate synthase (KGS), Isocitrate dehydrogenase (IDH), Acetyl-CoA Carboxylase (AC), Propionyl-CoA carboxylase (PC).

Table 1.5 Pre-industrial, pre-nuclear $\Delta^{14} \mathrm{C}$ and translated "decay ages" for bulk carbon .34 reservoirs. Also included are the expected ranges of $\delta^{13} \mathrm{C}$ values for these carbon pools. The estimated ranges of $\Delta^{14} \mathrm{C}$ for soils are taken from Becker-Heidmann et al., 1996. Other references are from Lewan (1986); Emerson et al. (1987); and Druffel et al. (1992).

Table 1.6 $\Delta^{14} \mathrm{C}$ distribution in the local environment of SMB. The SBB environment is .... .46 similar except for a shallower water column and less negative deep-water $\Delta^{14} \mathrm{C}_{\mathrm{DIC}}$ value.

Table 2.1 Flash $\mathrm{SiO}_{2}$-gel chromatographic separation of lipid biomarker classes...............59

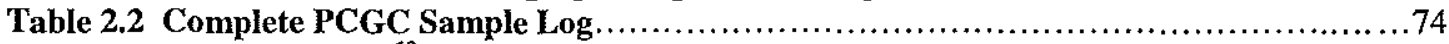

Table 2.3 Recoveries and ${ }^{13} \mathbf{C}$ fractionation for organic geochemical methods.......................

Table 2.4 Recoveries for PCGC samples as determined by various quantitation methods...........81

Table 3.1 Factorial Analysis Parameters .90

Table 4.1 A history of surface water $\Delta^{14} C_{D I C}$, mollusc shell $\Delta^{14} \mathrm{C}$, and pteropod $\Delta^{14} \mathrm{C}$ .125 measurements recorded in the SCB. Except for the 1996 sample (this study), the DIC data were previously gathered and published by Williams et al. (1992, and citations therein). The first three samples were collected off the Scripps Institution of Oceanography Pier $\left(32^{\circ} 52^{\prime} \mathrm{N}, 117^{\circ} 44^{\prime} \mathrm{W}\right)$; the fourth is a GEOSECS station $\left(28^{\circ} 30^{\prime} \mathrm{N}, 121^{\circ} 29^{\prime} \mathrm{W}\right)$; the fifth is south of San Diego $\left(31^{\circ} 9.9^{\prime} \mathrm{N}, 117^{\circ} 12^{\prime} \mathrm{W}\right)$; this sixth is from the central Santa Monica Basin. The mollusc shell data are from coastal California $\left(33-38^{\circ} \mathrm{N}\right)$ and were reported by Robinson (1981). The pteropod value is from Santa Barbara Basin sediment with a calendar data $1920 \mathrm{AD}$ (Baumgartner and Southon, 1996).

Table 4.2 Isotopic data for bulk samples, SMB core .133

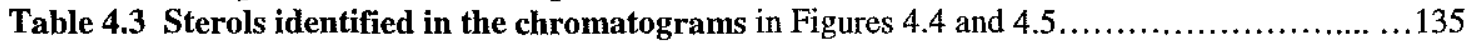

Table 4.4 Abundance of major sterols in SMB and SBB sediment samples......................138

Table 4.5 Isotopic data for individual sterols from SMB and SBB sediments....................145

Table 4.6 Sources of $\Delta^{\mathbf{1 4}} \mathbf{C}$ variability in phytoplanktonic biomarkers of common source............154

Table $4.7 \mathrm{irm}$-GC/MS $\delta^{\mathbf{1 3}} \mathbf{C}$ data for all sterol peaks as identified in Figures 4.4 and 4.5 . ..........157 Fractions were run in triplicate, and measurement precision is reported. The accuracy is estimated to be $\pm 0.4 \%$.

Table 4.8 irm-GC/MS $\delta^{13} \mathbf{C}$ data for the additional SMB sedimentary horizons, $0.75-1.5 \mathrm{~cm} \ldots \ldots 157$ and $5.5-6.5 \mathrm{~cm}$, as determined for -OTMS ethers. Fractions were run in triplicate, and measurement precision is reported. The accuracy is estimated to be $\pm 0.4 \%$. 
Table $4.9 \delta^{\mathbf{1 3}} \mathbf{C}$ data for bulk acetylation experiments and PCGC recovery standards...............182

Table 4.10 Androstanol standard $\delta^{13} \mathbf{C}$ measured by $i r m$-GC/MS .............................. 184 $\Delta \delta^{13} \mathrm{C}=\delta^{13} \mathrm{C}_{\text {measured }}-(-33.3 \% o)$.

Table 4.11 irm-GC/MS data for sterols run as acetates. The fractionation effect is always........185 in the regular sense (products lighter than original substrate), but the magnitude is not constant between batches.

Table 5.1 $\Delta^{14} \mathrm{C}$ data for individual lipids from surface and pre-bomb sediment horizons as. described in the text. Structures of compounds are shown in Figure 5.3. A dash indicates no value was determined.

Table 6.1 List of individual compounds isolated by PCGC for which $\Delta^{14} \mathrm{C}$ values were .247 obtained, in order of processing.

Table 6.2 Summary of compound-specific $\Delta^{14} \mathrm{C}$ and $\delta^{13} \mathrm{C}$ data. The $\delta^{13} \mathrm{C}$ values are based.......250 on irm-GC/MS measurements unless otherwise indicated.

Table 6.3 Recovery standards and replicate measurements used to assess the quality of the.......260 compound-specific $\Delta^{14} \mathrm{C}$ data.

Table 6.4 Sources of lipid biomarkers in SMB surface sediments.

Table 7.1 Sediment horizons as sectioned for the SMB core, the chronology determined .301 by ${ }^{210} \mathrm{~Pb}$ dating, and the associated $\Delta^{14} \mathrm{C}_{\mathrm{TOC}}$ values.

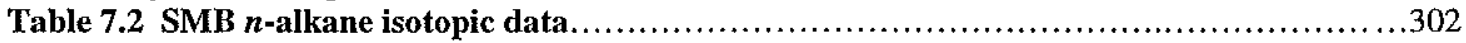

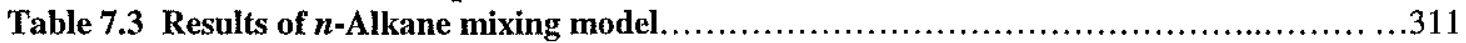

Table 7.4 Comparison of 2-component and 3-component $n$-alkane mixing models...............322

Table 7.5 Assumed $\Delta^{14} \mathrm{C}$ values used in the TOC mixing model.................................324

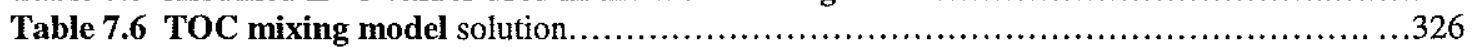

Table 7.7 Comparison of the $\Delta^{14} \mathbf{C}$ model with the results of other approaches to SMB .............329 sedimentary TOC. 
CHAPTER 1

INTRODUCTION 


\subsection{INTRODUCTION}

The total organic carbon (TOC) in marine sediments is a heterogeneous mixture of products derived from multiple sources. In most oceanic environments, the majority of TOC is believed to originate from autochthonous phytoplanktonic biomass and subsequent heterotrophic degradation of this material. Both open-ocean and continental margin sediments, however, also contain organic matter from other sources. Some fraction of TOC may be derived from land plant debris that spent significant time within terrestrial soils prior to erosion and deposition in marine sediments. Other carbon may come from weathered continental shales or ancient kerogen. Still other components of TOC could be derived from benthic chemoautotrophic processes, from in-situ bacterial production at sites of active petroleum or gas seeps, or from bacterial incorporation of refractory dissolved organic carbon (DOC).

Most of the allochthonous and chemosynthetic endmembers represent sources of organic carbon with lower radiocarbon $\left({ }^{14} \mathrm{C}\right)$ concentrations ("older" radiocarbon ages) than the fraction of TOC originating from phytoplanktonic production. The only exception is the rapid transport and sedimentation of recently-synthesized terrestrial plant material, which will have a ${ }^{14} \mathrm{C}$ concentration in equilibrium with atmospheric $\mathrm{CO}_{2}$, making it "younger" than marine biomass. Some of the allochthonous components may represent carbon fixed in the past, but which spent time in an intermediate reservoir before being transported to marine sediments. This scenario has different implications for atmospheric $\mathrm{CO}_{2}$ concentration, carbon sequestration, and nutrient distributions than the production of "old" biomass carbon by contemporary bacteria utilizing pre-aged carbon sources. Distinguishing between the different scenarios responsible for contributing pre-aged carbon to marine sediments is important to a general understanding of the carbon cycle.

Isotopic analysis of individual lipid biomarker molecules can provide more information about the biogeochemical processes affecting marine sedimentary composition than bulk-phase isotopic measurements on TOC alone. The compound- 
specific approach was initially developed for studies of the stable carbon isotope $\left({ }^{13} \mathrm{C}\right)$ distribution in lipids extracted from samples of modern and ancient geologic age (e.g. Freeman et al., 1990; Hayes et al., 1990), and it proved very useful as a tool to describe the diversity of these sources and the origins of specific biomarkers. More recently, Eglinton et al. (1996) developed a preparative capillary gas chromatographic (PCGC) separation method that is able to isolate lipids with sufficient purity and abundance for compound-specific ${ }^{14} \mathrm{C}$ measurement by accelerator mass spectrometry (AMS). Using this approach, Eglinton et al. (1997) demonstrated a wide range of ${ }^{14} \mathrm{C}$ ages within discrete sedimentary horizons from two separate environments. The data indicated that some co-occurring lipids either were formed at different times; or that the lipids were simultaneously biosynthesized, but utilized carbon source pools of differing initial isotopic composition. The implication of this work is that compound-specific ${ }^{14} \mathrm{C}$ measurements may be used to distinguish biogeochemical pathways of carbon utilization and transfer in a manner analogous to compound-specific ${ }^{13} \mathrm{C}$ analysis.

The overall goal of this project was to generate the first detailed molecular-level radiocarbon data set for a comprehensive suite of lipid biomarker compounds. It contributes to the general understanding of carbon cycle biogeochemistry and specifically examines some of the mechanisms responsible for contributing organic carbon of nonmarine photosynthetic source to ocean sediments. The study focuses on a $10-\mathrm{cm}$ core from Santa Monica Basin, California, USA, and is supplemented by a core-top sample from the adjacent Santa Barbara Basin. These cores were chosen because of the resolution of the sediment records, the availability of ancillary data, and because on a radiocarbon time-scale, the samples are all "contemporary". The variability in biomarker ${ }^{14} \mathrm{C}$ concentrations reflects differences in isotopic composition of the endmember sources only, with minimal in-situ ${ }^{14} \mathrm{C}$ decay. The primary tracer property of ${ }^{14} \mathrm{C}$ utilized in this thesis is the increase in atmospheric ${ }^{14} \mathrm{C}$ concentration caused by above-ground nuclear weapons testing in the 1950 s and 1960 s. This excess "bomb- ${ }^{14} \mathrm{C}$ " has invaded the modern surface ocean and terrestrial biota and allows the products of recent biological production to be identified easily. Pre-aged organic materials or biomass formed in 
locations physically removed from the influence of atmospheric $\mathrm{CO}_{2}$ (i.e. the deep ocean) are distinguished by their lack of incorporation of bomb- ${ }^{14} \mathrm{C}$.

\subsection{LIPID BIOMARKERS}

The organic matter in marine sediments consists of both recognizable biochemical constituents of organisms (carbohydrates, proteins, lipids, and nucleic acids), as well as more complex polymeric materials and non-extractable components (kerogen). Among the recognizable biochemicals, the lipids have a diversity of structures often assignable to specific biological sources. Lipids are also comparatively easy to analyze by gas chromatographic and mass spectrometric techniques, and many survive degradation to persist throughout the sedimentary geologic record. These characteristics have resulted in a long history of organic geochemical studies aimed at identifying and understanding the origins of "source-specific" lipid biomarker compounds. In this thesis, lipids from the following organic compound classes are studied (Table 1.1). The example structures listed in Table 1.1 are also shown in Figure 1.1.

Table 1.1 Common source assignments of lipid biomarkers.

\begin{tabular}{lll}
\hline Lipid Class & Source(s) & Example Structures $^{*}$ \\
\hline Hydrocarbons (n-Alkanes) & $\begin{array}{l}\text { Higher Plants, Fossil Organic } \\
\text { Materials }\end{array}$ & $n-\mathrm{C}_{29}$ \\
& $\begin{array}{l}\text { Phytoplankton, Zooplankton, } \\
\text { Fatty Acids }\end{array}$ & $\mathrm{C}_{16: 0}$ \\
& $\begin{array}{l}\text { Bacteria, Higher Plants } \\
\text { Fatty Alcohols }\end{array}$ & $n$-Coplankton, Higher Plants \\
Long-Chain Ketols/Diols & Phytoplankton \\
Hopanols & Bacteria & $\mathrm{C}_{30}$-alkan-15-one-1-ol \\
Sterols & $\begin{array}{l}\text { Phytoplankton, Zooplankton, } \\
\text { Higher Plants }\end{array}$ & $\mathrm{C}_{32}$ Hopanol \\
C & Archaea & $\mathrm{C}_{40: 2 \mathrm{cy}}$ \\
\hline
\end{tabular}

* These common abbreviations are used here and throughout this thesis. 


\section{Figure 1.1}

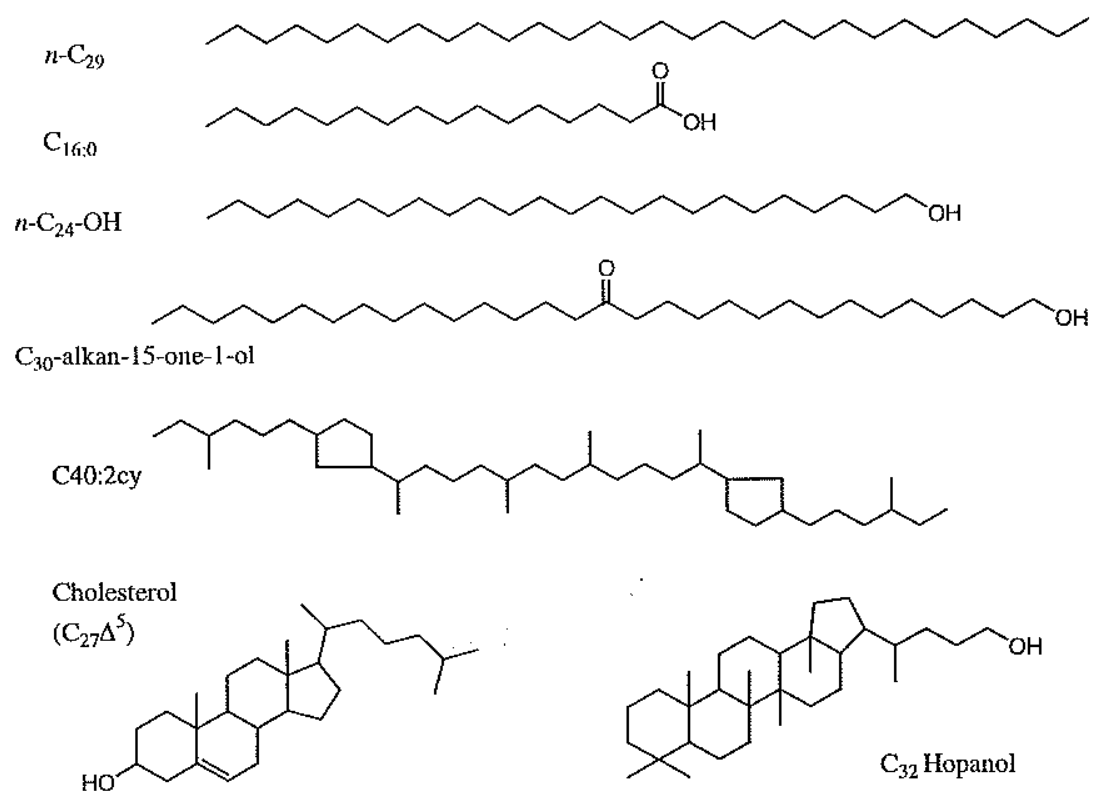

Figure 1.1 Example structures of lipids discussed in this thesis.

\subsection{CARBON ISOTOPES}

Carbon in the geosphere is composed of three naturally occurring isotopes, the stable isotopes ${ }^{12} \mathrm{C}(98.9 \%)$ and ${ }^{13} \mathrm{C}(1.1 \%)$, and the cosmogenic radionuclide, ${ }^{14} \mathrm{C}$ (radiocarbon). Natural ${ }^{14} \mathrm{C}$ is produced in the atmosphere by the collision of cosmic ray neutrons with ${ }^{14} \mathrm{~N}$, emitting a proton $(\mathrm{H})$. The ${ }^{14} \mathrm{C}$ is quickly incorporated into atmospheric $\mathrm{CO}_{2}$, and ${ }^{14} \mathrm{CO}_{2}$ occurs as approximately $1 / 10^{12}$ (one trillionth) of the total atmospheric abundance of $\mathrm{CO}_{2}$. The distribution of the minor isotopes of carbon is affected by thermodynamic and kinetic fractionation processes $\left({ }^{13} \mathrm{C}\right.$ and $\left.{ }^{14} \mathrm{C}\right)$, and by radioactive decay $\left({ }^{14} \mathrm{C}\right)$. Thermodynamic fractionation effects govern the distribution of ${ }^{13} \mathrm{C}$ and ${ }^{14} \mathrm{C}$ between reservoirs whose carbon exchange is slow enough to approach 
isotopic equilibrium, and typically the associated isotope effects are small. The relevant example is the speciation of dissolved inorganic carbon (DIC) in seawater: $\mathrm{CO}_{2}(\mathrm{aq}) \rightleftharpoons$ $\mathrm{HCO}_{3}{ }^{-} \rightleftharpoons \mathrm{CO}_{3}{ }^{2-}$. These equilibrium exchange reactions result in unequal isotope distribution between the dissolved species. Kinetic fractionation is the more important control on the ${ }^{13} \mathrm{C}$ and ${ }^{14} \mathrm{C}$ isotopic distribution during enzymatically-mediated carbon transfers, such as biological carbon fixation. Most biochemical reactions converting $\mathrm{CO}_{2}$ to biomass, or respiring biomass to $\mathrm{CO}_{2}$, involve catalytic binding of $\mathrm{CO}_{2}$ to enzymes and have large associated fractionation effects.

\subsection{1 ${ }^{13}$ C Systematics}

A more complete elaboration of the information presented in this section can be found in Hayes (1993) and Raven (1997); the notation used here follows the convention of Hayes (1993).

Most carbon on earth occurs as carbonate rocks; the PeeDeeBee Belemnite limestone serves as the ${ }^{13} \mathrm{C} /{ }^{12} \mathrm{C}$ isotopic ratio standard, and all stable carbon isotope concentrations are reported as $\delta^{13} \mathrm{C}$ "per mil" (\%o) values relative to this standard according to the formula:

$$
\delta^{13} C=\left(\frac{R_{A}}{R_{P D B}}-1\right) * 1000
$$

where $R \equiv{ }^{13} \mathrm{C} /{ }^{12} \mathrm{C}$. The relative isotopic ratios of any two chemical species are compared in the following manner:

$$
\begin{aligned}
& \frac{R_{A}}{R_{B}} \equiv \alpha_{A / B}=\frac{\left(1000+\delta_{A}\right)}{\left(1000+\delta_{B}\right)} \\
& \varepsilon_{A / B} \equiv\left(\alpha_{A / B}-1\right) * 1000 .
\end{aligned}
$$


More commonly, the comparison of interest is simply the difference between two measured $\delta^{13} \mathrm{C}$ values,

$$
\Delta_{A / B} \equiv \delta_{A}-\delta_{B} \approx \varepsilon_{A / B}
$$

This comparison of fractionation differences, $\Delta$, is often discussed and reported as the fractionation effect, $\varepsilon$, without distinction between the two parameters. In general, when the isotopic difference between chemical species $A$ and $B$ is small $(<30 \%$ ), the difference between $\Delta$ and $\varepsilon$ is negligible $(<1 \%$ ) and can be ignored.

The distribution of ${ }^{13} \mathrm{C}$ throughout the global inorganic and organic carbon reservoirs is governed by a combination of the fractionation processes mentioned above. Typical thermodynamic fractionation effects are in the range of 1-10\%o for inorganic processes. A brief table of relevant values at $25^{\circ} \mathrm{C}$ is shown here.

Table 1.2 Equilibrium ${ }^{13} \mathrm{C}$ fractionation effects, adapted from Hayes (1993) and Raven (1997).

\begin{tabular}{cc}
\hline Equilibrium Reaction & $\varepsilon(\% o)$ \\
\hline $\mathrm{CO}_{2}(\mathrm{aq}) \rightleftharpoons \mathrm{CO}_{2}(\mathrm{~g})$ & 1.1 \\
$\mathrm{CO}_{2}(\mathrm{aq})+\mathrm{H}_{2} \mathrm{O} \rightleftharpoons \mathrm{HCO}_{3}{ }^{-}+\mathrm{H}^{+}$ & 9.0 \\
$\mathrm{CO}_{2}(\mathrm{aq}) \rightleftharpoons \mathrm{CaCO}_{3}($ calcite $)$ & 9.6 \\
\hline
\end{tabular}

Typical kinetic isotope effects for biochemical processes are larger, usually tens of permil units. The following tables give fractionation effects associated with solute transport or inorganic reactions affected by biological activity (Table 1.3) and for enzymatic processes fixing or liberating $\mathrm{CO}_{2}$ (Table 1.4). A key feature of kinetic fractionation during carbon assimilation is the difference between utilization of $\mathrm{CO}_{2}(\mathrm{aq})$ and the utilization of $\mathrm{HCO}_{3}{ }^{-}$. Certain enzymes are specific for only one of these two dissolved carbon species. The smaller fractionation associated with $\mathrm{HCO}_{3}{ }^{-}$incorporation 
is a consequence of the smaller relative mass difference of $\mathrm{H}^{13} \mathrm{CO}_{3}{ }^{-}$and $\mathrm{H}^{12} \mathrm{CO}_{3}{ }^{-}$(62 vs. $61=1.6 \%$ mass difference) compared to ${ }^{13} \mathrm{CO}_{2}$ and ${ }^{12} \mathrm{CO}_{2}$ (45 vs. $44=2.3 \%$ mass difference). $\mathrm{HCO}_{3}{ }^{-}$in aquatic systems is also isotopically enriched (typical range in $\delta^{13} \mathrm{C}$ $=-2$ to $+2 \%$ ) relative to dissolved $\mathrm{CO}_{2}$ (typically -8 to $-12 \%$ ). Both these properties contribute to ${ }^{13} \mathrm{C}$ enrichment in organisms that acquire a significant fraction of their biomass directly from $\mathrm{HCO}_{3}$.

Table 1.3 Kinetic fractionation effects associated with solute reactions and transport, adapted from Raven (1997).

\begin{tabular}{lc}
\hline \multicolumn{1}{c}{ Non-Equilibrium Process } & $\varepsilon(\% o)$ \\
\hline Diffusion of $\mathrm{CO}_{2}$ in water & 0.7 \\
$\mathrm{HCO}_{3}^{-} \rightarrow \mathrm{CO}_{2}$, uncatalyzed & 22 \\
$\mathrm{HCO}_{3}{ }^{-} \rightarrow \mathrm{CO}_{2}$, catalyzed & 10 \\
by Carbonic anhydrase & \\
\hline
\end{tabular}


Table 1.4 Kinetic fractionation effects associated with enzymatic reactions, adapted from Bott and Thauer (1989), Raven (1997), and specific references as noted below. Enzymes: Ribulose bis-phosphate carboxylase-oxygenase (RUBISCO), Phosphoenolpyruvate carboxylase (PEPC), Phosphoenolpyruvate carboxykinase (PEPCK), Pyruvate synthase (PS), $\alpha$-Ketoglutarate synthase (KGS), Isocitrate dehydrogenase (IDH), Acetyl-CoA Carboxylase (AC), Propionyl-CoA carboxylase (PC).

\begin{tabular}{|c|c|c|}
\hline Enzymatic Process & $\begin{array}{l}\text { Substrate } \\
\text { or Product }\end{array}$ & $\varepsilon(\%)$ \\
\hline $\mathrm{CO}_{2}$ fixation, RUBISCO (Type IB, Eukaryotic) & $\mathrm{CO}_{2}$ & $29^{*}$ \\
\hline $\mathrm{CO}_{2}$ fixation, RUBISCO (Type IB, Cyanobacterial) & $\mathrm{CO}_{2}$ & $22^{\dagger}$ \\
\hline $\mathrm{CO}_{2}$ fixation, RUBISCO (Type II, Proteobacterial) & $\mathrm{CO}_{2}$ & $18-23^{\ddagger}$ \\
\hline $\mathrm{HCO}_{3}{ }^{-}$fixation by PEPC (relative to $\mathrm{CO}_{2(\mathrm{aq})}$ ) & $\mathrm{HCO}_{3}^{-}$ & 4.7 \\
\hline $\mathrm{HCO}_{3}{ }^{-}$fixation by $\mathrm{PEPCK}$ & $\mathrm{CO}_{2}$ & $24-40$ \\
\hline \multicolumn{3}{|l|}{ Carboxylation reactions: } \\
\hline Acetyl-CoA $\rightarrow$ Pyruvate by PS & $\mathrm{CO}_{2}$ & $\operatorname{maximum}=60 \%$, \\
\hline Succinyl-CoA $\rightarrow \alpha$-Ketoglutarate by KGS & $\mathrm{CO}_{2}$ & ble in-situ \\
\hline$\alpha$-Ketoglutarate $\rightarrow$ Isocitrate by IDH & $\mathrm{CO}_{2}$ & \\
\hline Acetyl-CoA $\rightarrow$ Malonyl-CoA by AC & $\mathrm{HCO}_{3}^{-}$ & $\sim 6^{\S}$ \\
\hline Propionyl-CoA $\rightarrow$ Methyl-Malonyl-CoA by PC & $\mathrm{HCO}_{3}^{-}$ & $\sim 6^{8}$ \\
\hline \multicolumn{3}{|l|}{ Decarboxylation reactions } \\
\hline $\begin{array}{l}\text { e.g. Oxaloacetate } \rightarrow \text { Pyruvate by } \\
\text { Oxaloacetate decarboxylase }\end{array}$ & $\mathrm{CO}_{2}$ & $\begin{array}{l}\text { maximum }=60 \% o \\
\text { probable } \text { in-situ } \\
=24-40 \% o\end{array}$ \\
\hline
\end{tabular}

\footnotetext{
* $\varepsilon$ for Spinacia oleracea; Roeske and O'Leary, 1984.

$\dagger \varepsilon$ for Anacystis nidulans; Guy et al., 1993

$\ddagger \varepsilon$ for Rhodospirillum rubrum; Roeske and O'Leary, 1985; Guy et al., 1993.

$\S \varepsilon_{\text {cell }} \approx 6 \%$ o for organisms dependent on these enzymes for carbon fixation via the 3-hydroxypropionate cycle (Holo and Sirevåg, 1986).
} 


\subsection{2 ${ }^{14} \mathrm{C}$ Systematics}

The information in this section is based on the equations of Stuiver and Robinson (1974), Stuiver and Polach (1977), and the National Ocean Sciences Accelerator Mass Spectrometry (NOSAMS) data reporting protocol.

The absolute international standard ${ }^{14} \mathrm{C}$ activity $\left(A_{a b s}\right)$ is defined as $95 \%$ of the ${ }^{14} \mathrm{C}$ activity of the original Oxalic Acid standard (HOxI), in the year 1950. This is equivalent to the activity of $19^{\text {th }}$ century wood, and represents the ${ }^{14} \mathrm{C}$ concentration of the atmosphere prior to anthropogenic influence. The measured activity of $\mathrm{HOxI}\left(\mathrm{A}_{\mathrm{ox}}\right)$ is corrected for fractionation effects using a defined $\delta^{13} \mathrm{C}_{\mathrm{ox}}$ value of $-19 \%$ (Equation 6) to yield the fractionation-normalized activity $\left(A_{O N}\right)$. It is subsequently corrected for radioactive decay between 1950 and the year of measurement (Equation 7). Thus on a ${ }^{14} \mathrm{C}$ time-scale, an age of zero years always corresponds to 1950 . In Equation 7, "y" equals the year of measurement and $\lambda$, the decay constant for ${ }^{14} \mathrm{C}$, equals $1 / 8267 \mathrm{yr}^{-1}$, equivalent to the true half-life of 5730 years.

$$
A_{O N}=0.95 A_{o x}\left(1-\frac{2\left(19+\delta^{13} C\right)}{1000}\right)
$$

$$
A_{a b s}=A_{O N} e^{\lambda(y-1950)}
$$

The measured ${ }^{14} \mathrm{C}$ activity of a sample $\left(A_{s}\right)$ is normalized $\left(A_{s n}\right)$ to a constant $\delta^{13} \mathrm{C}$ value of $-25 \%$ o to remove the influence of isotopic fractionation on the reported ${ }^{14} \mathrm{C}$ concentration:

$$
A_{s n}=A_{s}\left(1-\frac{2\left(25+\delta^{13} C_{\text {sample }}\right)}{1000}\right)
$$


To a first approximation, Equation 8 treats the ${ }^{14} \mathrm{C}$ fractionation as twice the ${ }^{13} \mathrm{C}$ fractionation; thus a carbonate sample with $\delta^{13} \mathrm{C}=0 \%$ will have a ${ }^{14} \mathrm{C}$ normalization correction of $2 *(25+0)=50 \%$ o to account for the greater ${ }^{14} \mathrm{C} /{ }^{12} \mathrm{C}$ mass difference. Equation 8 is a simplification of the more exact relationship:

$$
A_{s n}=A_{s}\left[\frac{\left(1+\frac{-25}{1000}\right)^{2}}{\left(1+\frac{\delta^{13} C_{\text {sample }}}{1000}\right)^{2}}\right]
$$

which is based on physical-chemical derivations that suggest the ${ }^{14} \mathrm{C}$ fractionation is approximately equal to the square of the ${ }^{13} \mathrm{C}$ fractionation.

The equations presented here were first developed for application to ${ }^{14} \mathrm{C}$ measurement by decay counting techniques; ${ }^{14} \mathrm{C}$ decays to ${ }^{14} \mathrm{~N}$ by emission of a $\beta^{-}$ particle. Modern ${ }^{14} \mathrm{C}$ dating of carbon-containing materials is generally done by AMS measurement of the absolute ratios of ${ }^{14} \mathrm{C}^{12} \mathrm{C}$ in a sample ${ }^{1}$, rather than by measuring the rate of ${ }^{14} \mathrm{C}$ decay. The equations above are still applicable, as activity and $\mathrm{R}^{14 / 12}$ are proportional via the decay constant, $\lambda$. AMS ${ }^{14} \mathrm{C}$ data are reported as fraction modern $\left(f_{m}\right)$ values, rather than activities:

$$
f_{m}=\frac{A_{s n}}{A_{O N}}=\frac{R^{14 / 12_{s n}}}{R^{14 / 12} O N} .
$$

When a radiocarbon age (year date) is not desired, data are reported as $\Delta^{14} \mathrm{C}$ values in one of two forms. Equation 11 is used when no age corrections are applied to the sample, and " $y$ " is the year of measurement,

${ }^{1}$ NOSAMS measures ${ }^{14} \mathrm{C} /{ }^{12} \mathrm{C}$, but many AMS laboratories measure ${ }^{14} \mathrm{C} /{ }^{13} \mathrm{C}$. 


$$
\Delta^{14} C=\left(\frac{A_{s n}}{A_{O N} e^{\lambda(y-1950)}}-1\right) * 1000=\left(f_{m} e^{-\lambda(y-1950)}-1\right) * 1000
$$

while Equation 12 is used to correct for decay-related changes in ${ }^{14} \mathrm{C}$ activity for samples of known geochronological age. Again, " $y$ " is the year of measurement, and " $x$ " is the year of sample formation:

$$
\Delta^{14} C=\left(\frac{A_{s n} e^{\lambda(y-x)}}{A_{O N} e^{\lambda(y-1950)}}-1\right) * 1000=\left(f_{m} e^{\lambda(1950-x)}-1\right) * 1000
$$

This thesis deals only with samples of known age, and Equation 12 has been applied to all reported $\Delta^{14} \mathrm{C}$ values. In other words, all of the following variables are considered to be known: the date of sample measurement, the date of sample collection (not statistically different), and the date at which the sample was "formed". The date of formation parameter is operationally defined in this thesis as the calendar age of deposition of the sedimentary horizon. Clearly the sediment is made of a mixture of components, not all of which were biosynthesized at the same time. However, the primary goal is to report all data as the $\Delta^{14} C$ value the sample would have had when it was deposited at the sedimentwater interface, thus preserving a record of the initial organic carbon inputs to the marine sedimentary environment.

The use of "radiocarbon age" is avoided throughout this thesis. The radiocarbon age of a sample is strictly defined as the age calculated using the Libby half-life (5568 years) for radiocarbon. In classical radiocarbon dating applications, the calculated radiocarbon ages are then converted to calendar ages using calibration curves. However, the true half-life of ${ }^{14} \mathrm{C}$ is 5730 years (see Stuiver and Polach, 1977, for further discussion). In this thesis, any conversion between measured $\Delta^{14} \mathrm{C}$ values and the estimated chronological age of a material has been calculated using the true half-life, but these ages cannot be called "radiocarbon ages". Here the terms "decay age", or simply "age", have been adopted to indicate the conversion was made using the true half-life. 


\subsection{Global and Local ${ }^{14}$ C Distributions}

\subsubsection{Active Carbon Cycle}

Eighty percent of the carbon on earth is stored in carbonate rocks $(60,000,000$ gigatons carbon, $1 \mathrm{Gt}=10^{15} \mathrm{~g}$ ). Nearly all the remaining 20 percent is organic carbon in the form of kerogen $(15,000,000 \mathrm{GtC}$; Berner, 1982; Hedges and Oades, 1997). The fraction of total carbon undergoing dynamic exchange is small compared to these large sedimentary reservoirs. Figure 1.2 illustrates the major, biogeochemically mediated fluxes between the active reservoirs of the global carbon cycle (inorganic carbonates not shown, adapted from Siegenthaler and Sarmiento, 1993, and Hedges and Oades, 1997).

Most of earth's organic matter is generated by photosynthetic fixation of inorganic carbon by terrestrial plants and marine phytoplankton from atmospheric $\mathrm{CO}_{2}$ and surface-ocean dissolved inorganic carbon (DIC), respectively. Subsequent heterotrophic transformation and degradation of this total primary production leads to the formation of the organic fraction of terrestrial soils and marine sediments, dissolved organic carbon (DOC), and the regeneration of respired $\mathrm{CO}_{2}$. Global marine primary production is approximately equal to primary production by the terrestrial biota (references in Hedges, 1992). The high efficiency of terrestrial and marine heterotrophy $(\gg 99 \%$ ) allows $\ll 1 \%$ of total global primary production to be preserved in either soils or marine sediments. However, most marine organic carbon burial ( $>80 \%)$ occurs in coastal deltaic and continental shelf sediments (Berner, 1982). These locations are also the primary repositories of organic carbon derived from terrestrial sources by erosion or short-range atmospheric deposition. The efficiency with which both weathered shales and contemporary terrestrial products (soils, plant litter) are remineralized remains an important but poorly-understood property of the global carbon cycle (Hedges, 1992). Some of this eroded continental material must escape remineralization, because coastal sediments contain a heterogeneous mixture of products representing both marine and terrestrial sources (e.g. Hedges and Parker, 1976; Prahl et al., 1994; Goñi et al., 1998). 
Even though the presence of lipid biomarker compounds characteristic of both endmembers is well documented, quantification of the fraction of TOC originating from any particular source has proved challenging.

The continental margins also contain the only localized regions in which $>1 \%$ of sedimentary organic carbon consistently escapes remineralization. In sediments where the overlying waters contain minimal oxygen (500-1500 m; e.g. Peru Margin) and in confined basins having restricted deep-water ventilation (e.g. Cariaco Basin, Santa Monica Basin), TOC concentrations are typically around 5\%. Both marine and terrigenous products are expected in these systems; and in addition, organic carbon representing prokaryotic chemoautotrophic biomass may be preserved. Under limited water-column or surface sedimentary $\mathrm{O}_{2}$ concentrations, both anaerobic heterotrophic and chemolithoautotrophic production occurs (e.g. Tuttle and Jannasch, 1979). Organic carbon buried within these anoxic sediments is believed to be the source of future organic-rich shales and petroleum. Biomarker molecules reflecting all the sources discussed above can be found in these complex sedimentary environments and their ancient analogues (e.g. Messel Shale, Hayes et al., 1990; Vena del Gesso Basin, Kohnen et al., 1992; Monterey Shale, Schouten, 1995).

Carbon isotopic studies of source-specific biomarkers are an important step toward identifying both the different organic fractions and the relative time-scales over which these materials are delivered to continental margin sediments. 
Figure 1.2

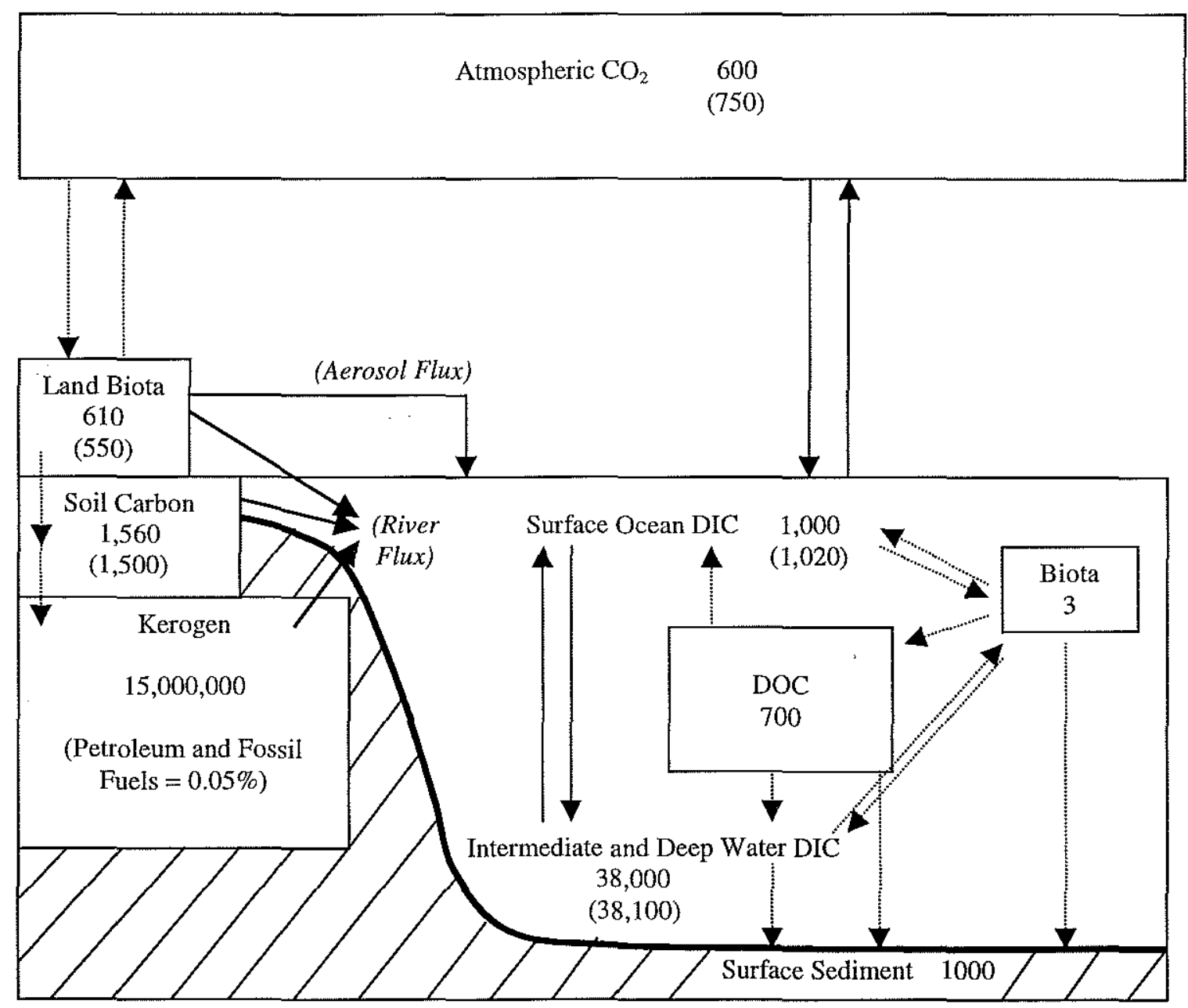

Figure 1.2 Major global reservoirs involved in the active production, exchange, and cycling of organic carbon, based on Siegenthaler and Sarmiento (1993) and Hedges and Oades (1997). Reservoir sizes are shown in $\mathrm{Gt}$ carbon $\left(1 \mathrm{GtC}=10^{15} \mathrm{gC}\right)$. Numbers in parentheses are based on 1980s values; numbers without parentheses are estimates of the pre-anthropogenic values. Fluxes primarily mediated by biological reactions are shown with dashed arrows; physical transport processes are shown with solid arrows. 


\subsubsection{Bulk Reservoir Characteristics of ${ }^{14} \mathrm{C}$}

Following production in the atmosphere, ${ }^{14} \mathrm{CO}_{2}$ is fixed and rapidly distributed throughout the active terrestrial biosphere. Both living plant biomass and its heterotrophic consumers (animals, bacteria) are therefore assumed to be in equilibrium

with the $\Delta^{14} \mathrm{C}$ of atmospheric $\mathrm{CO}_{2}$ until death ceases the assimilation and exchange of carbon. The natural decay of ${ }^{14} \mathrm{C}$ is the basis of the classical radiocarbon dating approach, which in this context is an index of the time elapsed since death of the animal or plant. In general, however, the ${ }^{14} \mathrm{C}$ concentration of a sample is only an indicator of the amount of time that has passed since its carbon was last in equilibrium with atmospheric $\mathrm{CO}_{2}$. When an organism assimilates a fraction of pre-aged carbon, correction for this component is achieved by subtracting an appropriate "reservoir age"the age of the carbon source utilized by the organism relative to the age of the atmosphere. As an extreme example, bacteria living exclusively on the products of an oil spill will assimilate carbon of infinite radiocarbon age $\left(\Delta^{14} \mathrm{C}=-1000 \%\right.$; limits of detection currently about 60,000 years) and be "radiocarbon dead" while they are in fact still alive. Therefore the reservoir age of all fossil materials is infinite ${ }^{14} \mathrm{C}$-years. This perspective is important to remember when interpreting the ${ }^{14} \mathrm{C}$ "ages" of all the organic carbon pools described in Figure 1.2 other than the land biota (zero ${ }^{14} \mathrm{C}$-years).

Another example of the complicated nature of the natural ${ }^{14} \mathrm{C}$ distribution is the accumulation of plant debris and its transformation into humus and soil organic matter. Terrestrial soils receive a continuous input of leaf litter, which through degradation and transformation processes is cycled through at least three reservoirs representing different time-scales; these are loosely defined as the 10-year, 100-year, and 1000-year pools (Trumbore, 1993). Estimates based on global turnover rates suggest the soil carbon category could instead be divided into living vegetation and soil litter (1-20 years) and soil humus ( 80 years), within the top meter of terrestrial soils (Hedges and Oades, 1997). The relative importance of the recalcitrant (1000-year) fraction is apparently a function of climate and is more important in temperate and/or dry regions (Trumbore, 1993; Becker- 
Heidmann et al., 1996). The products of any or all of these soil sub-fractions may be eroded and deposited in marine sediments. The $\Delta^{14} \mathrm{C}$ measured for total soil organic carbon represents an average of the contributions from all fractions.

The marine system is even more complicated, because no oceanic carbon pool begins with an "age" of zero years. Nearly half of the flux of $\mathrm{CO}_{2}$ out of the atmosphere occurs through dissolution in the surface ocean, where it becomes part of the DIC utilized for phytoplanktonic biomass production. While surface $\mathrm{CO}_{2}(\mathrm{aq})$ concentrations equilibrate with the atmosphere within a few years, carbon isotopic equilibration requires additional time to distribute the isotopes among the carbonate species: $\mathrm{CO}_{2} \rightleftharpoons \mathrm{HCO}_{3}{ }^{-} \rightleftharpoons$ $\mathrm{CO}_{3}{ }^{2-}$. This time lag helps keep $\Delta^{14} \mathrm{C}_{\mathrm{DIC}}$ out of equilibrium with the atmosphere. More significantly, however, the upwelling of deep-ocean waters through the thermocline also affects the $\Delta^{14} \mathrm{C}$ of surface water DIC. Continuous vertical mixing contributes a variable amount of DIC that has been removed from contact with the atmosphere for up to 1500 years. This pre-aged DIC component gives the entire ocean an average surface water reservoir age of about 400 years $\left(\Delta^{14} \mathrm{C} \sim-50 \%\right.$ ). However, local upwelling or downwelling, as well as changes in the general rate of ocean circulation, can affect the amount of deep water entrained and cause this parameter to vary. A constant reservoir age of 400 years is frequently subtracted from radiocarbon dates of marine materials, but in upwelling regions the reservoir age correction can approach as much as 1300 years ( $\Delta^{14} \mathrm{C}_{\mathrm{DIC}} \ll-50 \%$; e.g. Stuiver and Braziunas, 1986; Southon et al., 1990). The $\Delta^{14} \mathrm{C}$ of phytoplanktonic biomass and therefore the marine fraction of sedimentary TOC will reflect these regional differences.

In general, the global distribution of ${ }^{14} \mathrm{C}$ is complicated by these inter-reservoir mixing and exchange processes. The more endmember sources contributing to a sample, or the further a particular organic reservoir is removed from contact with the atmosphere, the more complicated the interpretation of a measured $\Delta^{14} \mathrm{C}$ value or age. Source-specific ${ }^{14} \mathrm{C}$ dating is needed, and this requires isotopic measurements at the molecular level. 
Table 1.5 gives a summary of the typical ranges of $\Delta^{14} \mathrm{C}$ and the corresponding reservoir "decay ages" (5730 year half-life) of global bulk carbon reservoirs. $\delta^{13} \mathrm{C}$ values are also shown for reference.

Table 1.5 Pre-industrial, pre-nuclear $\Delta^{14} \mathrm{C}$ and translated "decay ages" for bulk carbon reservoirs. Also included are the expected ranges of $\delta^{13} \mathrm{C}$ values for these carbon pools. The estimated ranges of $\Delta^{14} \mathrm{C}$ for soils are taken from BeckerHeidmann $e t$ al., 1996. Other references are from Lewan (1986); Emerson $e t$ al. (1987); and Druffel et al. (1992).

\begin{tabular}{lccc}
\hline \multicolumn{1}{c}{ Reservoir } & $\Delta^{14} \mathrm{C}(\% o)$ & Decay Age & $\delta^{13} \mathrm{C}(\% o)$ \\
\hline Atmospheric $\mathrm{CO}_{2}$ & 0 & 0 & -6.5 \\
Land Plants & 0 & 0 & -25 to $-30\left(\mathrm{C}_{3}\right)^{*}$ \\
& & & -10 to $-15\left(\mathrm{C}_{4}\right)^{* *}$ \\
$\begin{array}{l}\text { Soils and Humus } \\
\quad(0-1 \mathrm{~m})\end{array}$ & 0 to -250 & $0-3000$ & -25 to $-30\left(\mathrm{C}_{3}\right)^{*}$ \\
$\begin{array}{l}\text { Surface Ocean DIC } \\
\text { Marine Biota } \\
\quad \text { (excluding } \\
\quad \text { Chemoautotrophs) }\end{array}$ & $\sim-50$ & & -10 to $-15\left(\mathrm{C}_{4}\right)^{* *}$ \\
$\begin{array}{l}\text { Marine } \\
\quad \text { Chemoautotrophs }\end{array}$ & -50 to -250 & 400 to 2800 & +1 to +2 \\
$\begin{array}{l}\text { DoC } \\
\text { Surface Sediments } \\
\quad(0-1 \text { cm) }\end{array}$ & -150 to -525 & 1000 to 6000 & -20 to -30 \\
$\begin{array}{l}\text { Carbonate Rocks } \\
\text { Kerogen/Fossil Fuels }\end{array}$ & -50 to -350 & 400 to 3500 & -20 to -25 \\
\hline
\end{tabular}

* fractionation for plants with $\mathrm{C}_{3}$ metabolism;

** fractionation for plants with $\mathrm{C}_{4}$ metabolism (O'Leary, 1981).

When the initial "age" of the carbon source is not zero, comparing differences in $\Delta^{14} \mathrm{C}$ does not translate to uniform differences in the measured ages. For this reason, it is generally more revealing to deal with the global organic carbon ${ }^{14} \mathrm{C}$ distribution in terms 
of $\Delta^{14} \mathrm{C}$ rather than "age". A simple cartoon (Figure 1.3) shows the effect of mixing equal amounts of modern (zero years) and fossil (infinite ${ }^{14} \mathrm{C}$ years) carbon. The resulting $\Delta^{14} \mathrm{C}$ is obviously a simple average of the composite, while the calculated decay age obscures the fact that half of the carbon in the sample could have experienced extensive geological recycling. This is significant when interpreting organic carbon ${ }^{14} \mathrm{C}$ concentrations based on mass-balance mixing of $\Delta^{14} \mathrm{C}$ data or when comparing the differences among suites of $\Delta^{14} \mathrm{C}$ values. For any carbon-containing mixture, the calculated "age" may not correspond to the true age of any of the individual components. In addition, "age" is not a linear function of component concentrations or isotopic ratios. For these reasons, this thesis only reports $\Delta^{14} \mathrm{C}$ values for all samples; decay ages in terms of years are not discussed. 
Figure 1.3

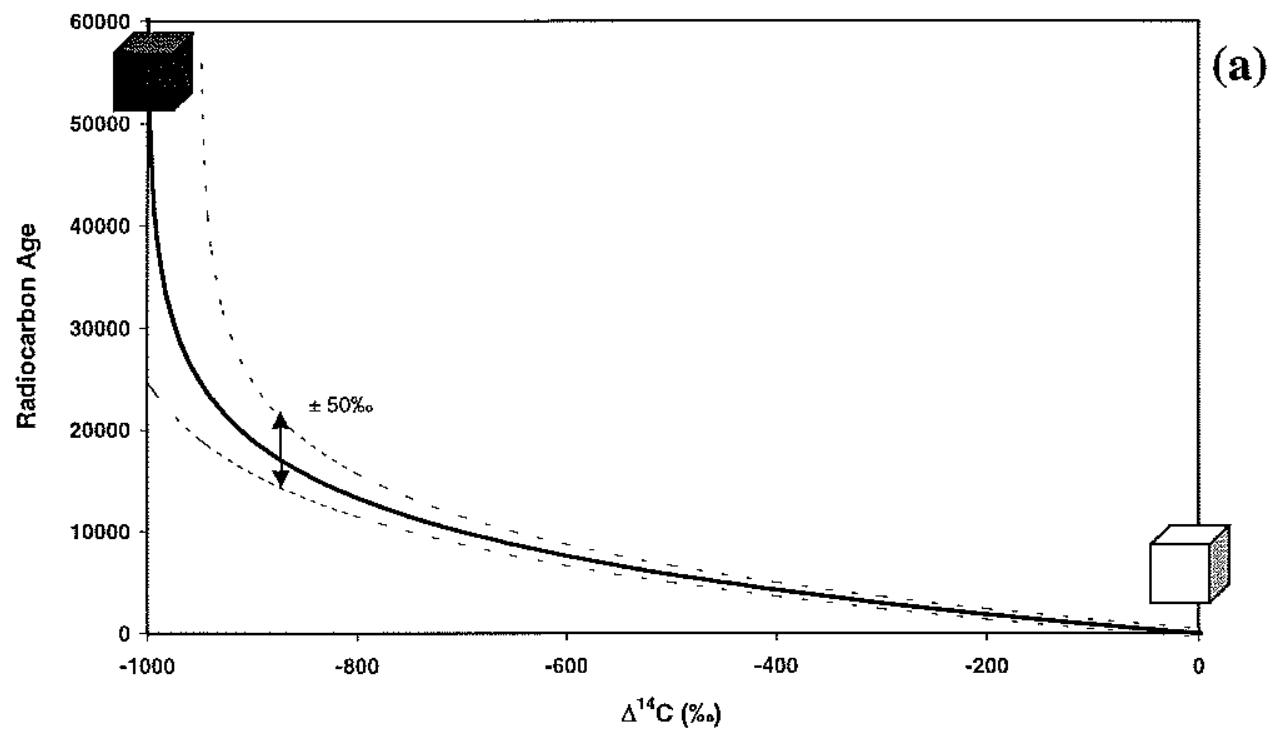

(b)

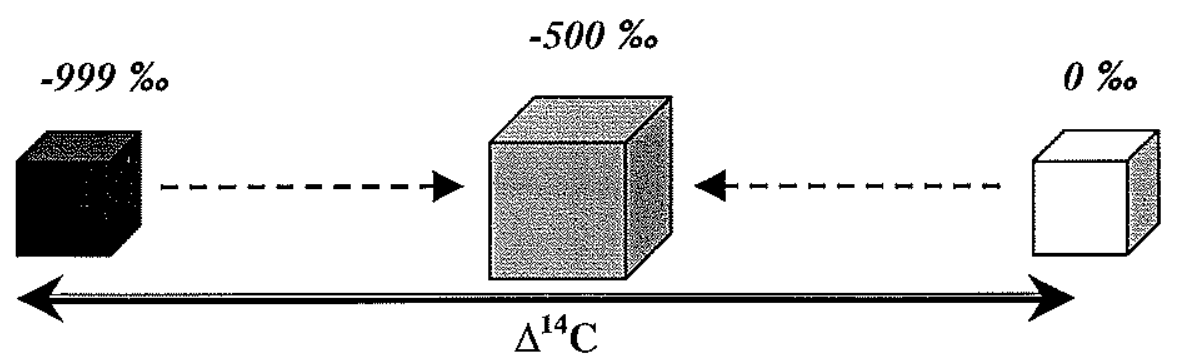

(c)

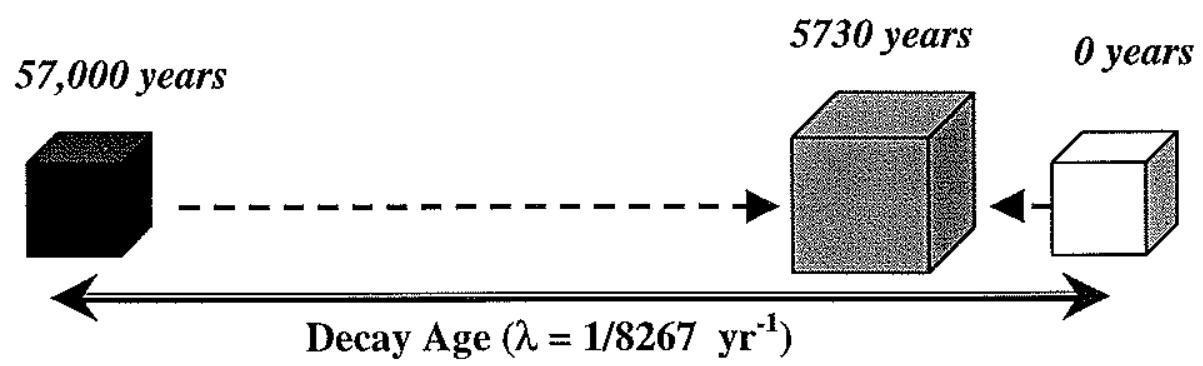

Figure 1.3 (a) Decay age $\left(l=1 / 8267 \mathrm{yr}^{-1}\right)$ as a function of $\Delta^{14} \mathrm{C}$; (b) mixing equal proportions of modern and "dead" material yields $\Delta^{14} \mathrm{C}=-500 \%$; while (c) the "age" is not equal to what would be considered a linear average of the ages of the two materials. 


\subsubsection{Anthropogenic Perturbation of ${ }^{14} \mathrm{C}$ Reservoirs}

Nuclear weapons testing in the 1950s and 1960s introduced an additional source of ${ }^{14} \mathrm{C}$ to the atmosphere. The amount of ${ }^{14} \mathrm{C}$ in the atmosphere nearly doubled, and the $\Delta^{14} \mathrm{C}$ of tropospheric $\mathrm{CO}_{2}$ increased to a maximum value $>+900 \%$ in the early $1960 \mathrm{~s}$ (Levin et al., 1985). Following the above-ground weapons test ban treaty of 1962, this value has been decreasing as the excess ${ }^{14} \mathrm{C}$ is taken up by oceanic and terrestrial sinks for $\mathrm{CO}_{2}$. Anthropogenic ${ }^{14} \mathrm{CO}_{2}$ serves as a useful tracer for the rate at which carbon moves through its global cycle. Any carbon reservoir currently having a $\Delta^{14} \mathrm{C}$ value $>$ $0 \%$ has taken up some of this "bomb- ${ }^{14} \mathrm{C}$ ". Figure 1.4 shows the atmospheric $\Delta^{14} \mathrm{C}_{\mathrm{CO} 2}$ record for the Northern Hemisphere since 1950. The invasion of "bomb- ${ }^{14} \mathrm{C}$ " into the oceanic mixed layer is also shown. The $\Delta^{14} \mathrm{C}$ signal in DIC lags the atmospheric maximum by $\sim 10$ years, reflecting the time needed for isotopic equilibration. For comparison, the record of $\Delta^{14} \mathrm{C}_{\mathrm{TOC}}$ in Santa Monica Basin sediments is also shown. The maximum $\Delta^{14} \mathrm{C}_{\mathrm{TOC}}$ occurs at the same time as the maximum $\Delta^{14} \mathrm{C}_{\mathrm{DIC}}$, due to the rapid vertical transport of organic detritus derived from surface water phytoplanktonic production to the sea floor. The negative offset between $\Delta{ }^{14} \mathrm{C}_{\mathrm{TOC}}$ and $\Delta^{14} \mathrm{C}_{\mathrm{DIC}}$, however, shows that there are components of the TOC mixture with ${ }^{14} \mathrm{C}$-depleted sources and which are presumably free of bomb- ${ }^{14} \mathrm{C}$ influence. Carbon pools that exhibit no increase in $\Delta^{14} \mathrm{C}$ over their "pre-bomb" values are therefore assumed to be removed from exchange with atmospheric $\mathrm{CO}_{2}$ during the last 50 years. It is this contrast between "prebomb" and "post-bomb" $\Delta^{14} \mathrm{C}$ values, or the relative extent of bomb- ${ }^{14} \mathrm{C}$ uptake, that serves as the primary biogeochemical tracer property utilized in this thesis. 
Figure 1.4

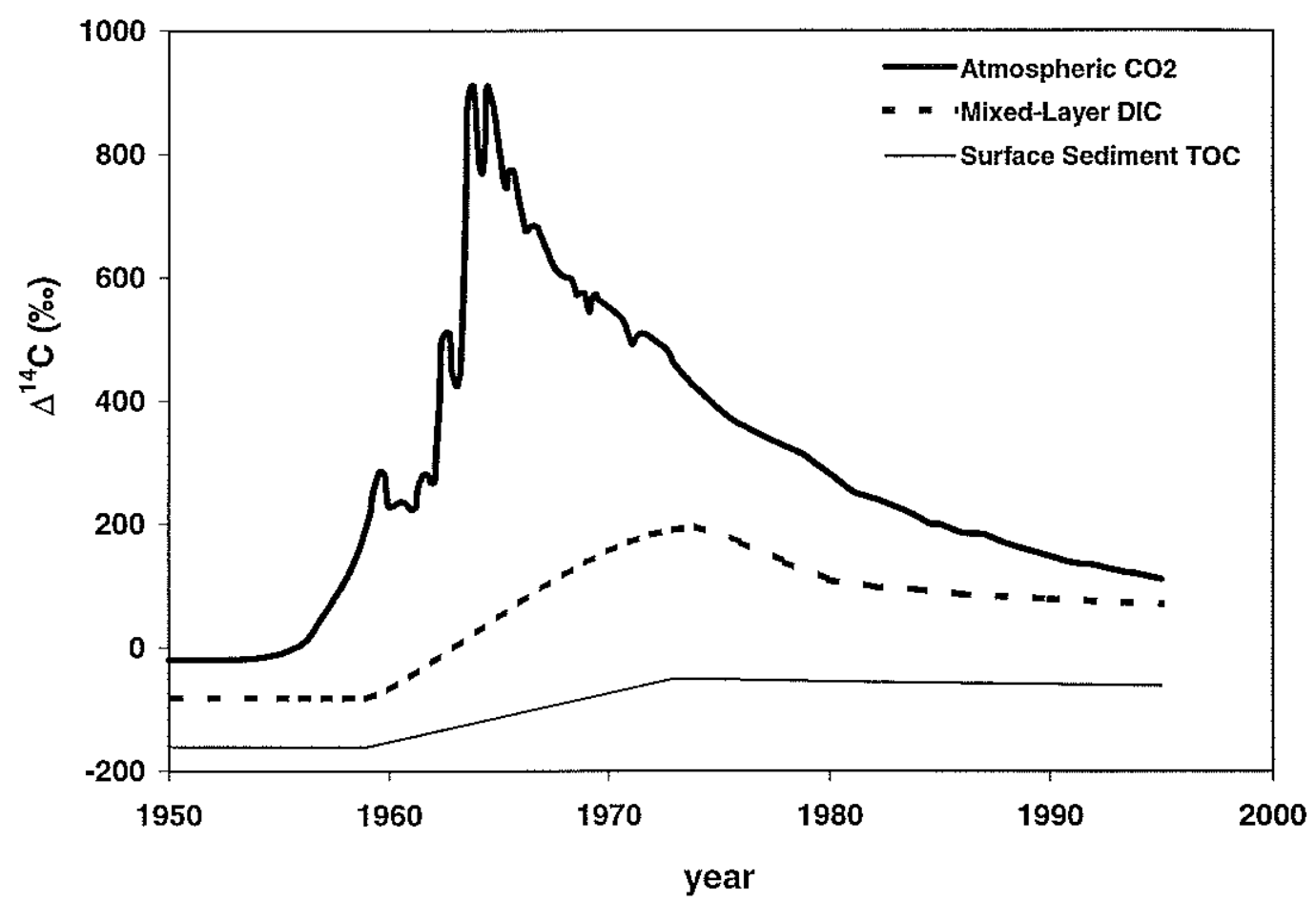

Figure 1.4 Evolution of atmospheric $\mathrm{CO}_{2}$, Southern California Bight surface water DIC, and Santa Monica Basin surface sediment TOC $\Delta^{14} \mathrm{C}$ values since 1950 . The atmospheric $\Delta^{14} \mathrm{C}$ record is based on data from Levin et al. (1985) and Levin and Kromer (1997); the surface water DIC record is based on references in Robinson (1981), Williams et al. (1992), and this thesis; the TOC record is from this thesis.

\subsubsection{Santa Monica Basin (SMB) and Santa Barbara Basin (SBB) Field Sites}

The California Continental Borderland region includes the continental margins of southern California, USA, and northern Baja California, Mexico. Parallel rows of shallow submarine banks and ridges effectively divide the borderland marine environment into a series of natural sediment traps of intermediate depth $(500-1500 \mathrm{~m})$. Bottom water circulation is impeded by ridges and sills, and as a result, some of the basins are continuously suboxic or anoxic. 


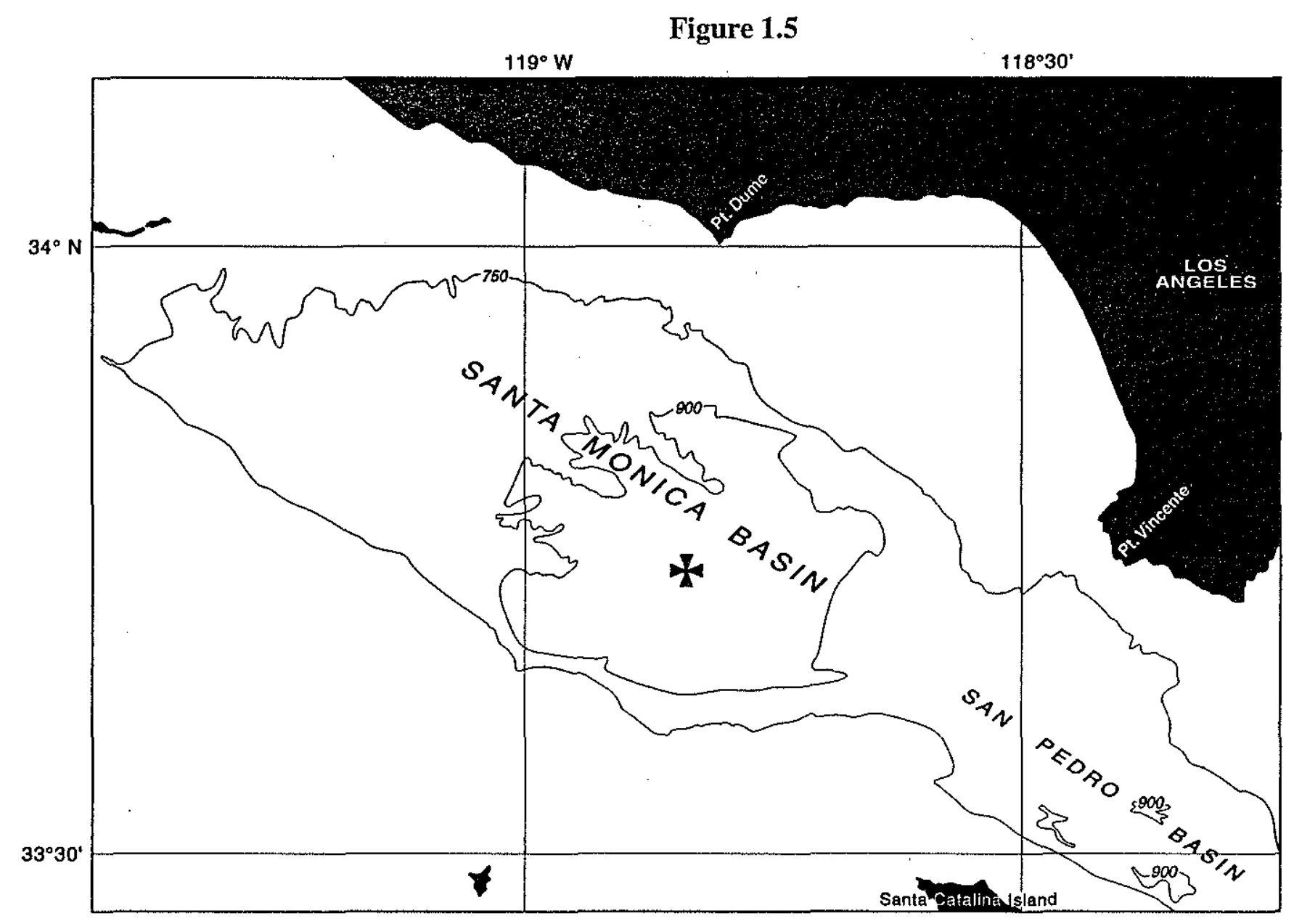

Figure 1.5 Santa Monica Basin core location for this thesis: $33^{\circ} 44.00^{\prime} \mathrm{N}, 118^{\circ} 49.99^{\prime} \mathrm{W}, 905 \mathrm{~m}$ depth, using an Ocean Instruments ${ }^{\circledR}$ Multicorer, November, 1996, R/V Roger Revelle, cruise Pulse-32. 


\section{Figure 1.6}

$120^{\circ} \mathrm{W}$

$119^{\circ} 30^{\prime}$

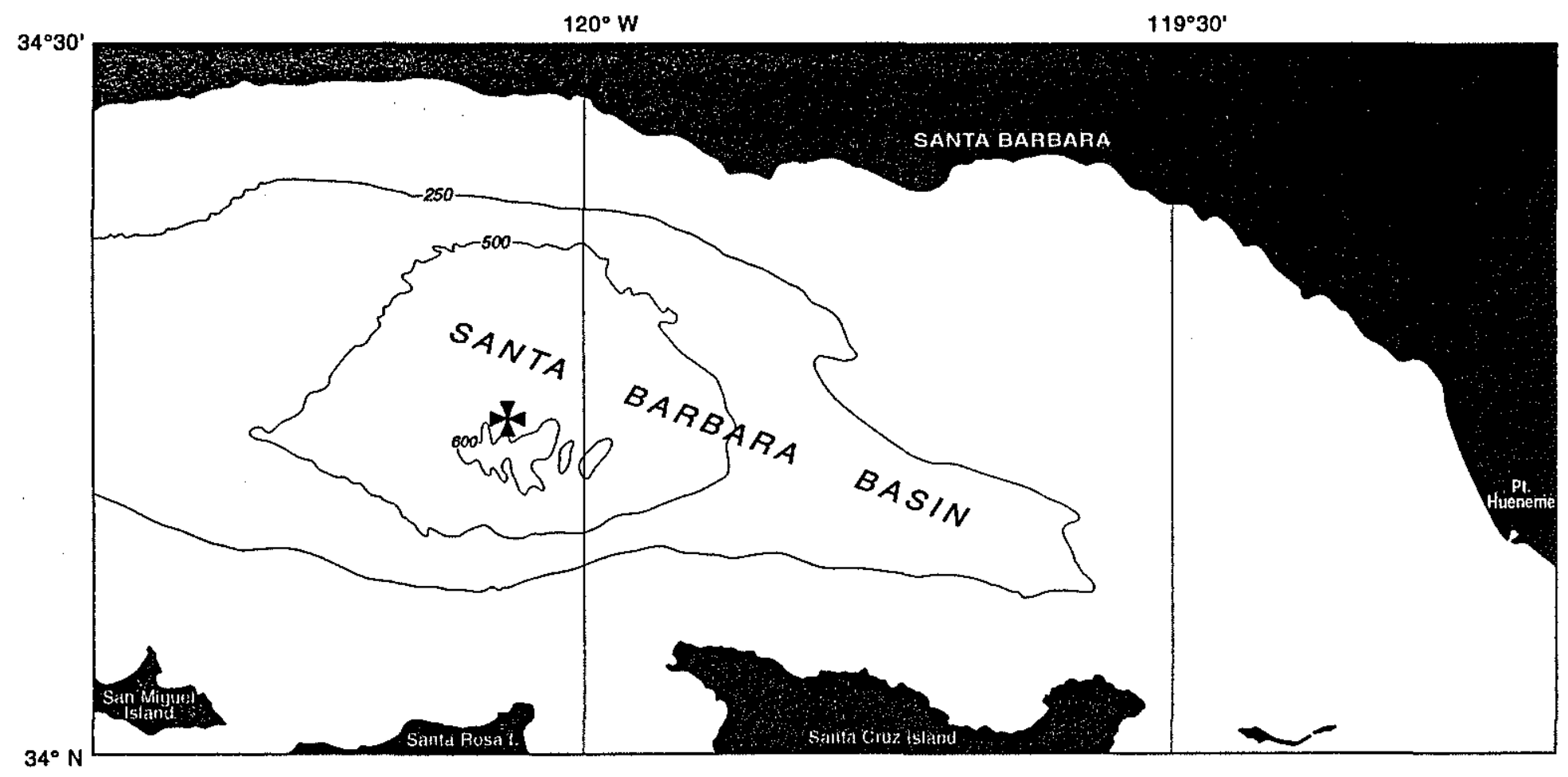

Figure 1.6 Santa Barbara Basin core location for this thesis: $34^{\circ} 13.5^{\prime} \mathrm{N}, 120^{\circ} 03.5^{\prime} \mathrm{W}, 595 \mathrm{~m}$ depth, using an Ocean Instruments ${ }^{\circledR}$ Multicorer, November, 1996, R/V Roger Revelle, cruise Pulse-32. 
The Santa Monica Basin (SMB) serves as the primary study site for this thesis. It (Figure 1.5) is an interior basin with a maximum depth of $\sim 910 \mathrm{~m}$. At depths below $850 \mathrm{~m}$, the bottom waters are anoxic $(\leq 0.1 \mathrm{~mL} / \mathrm{L})$; suboxic conditions prevail below the sill depth of $737 \mathrm{~m}$. Deep water in the basin is renewed every one to three years with a fresh inflow of low-oxygen Pacific Intermediate Water $\left(0.4-0.7 \mathrm{~mL} / \mathrm{L} \mathrm{O}_{2}\right)$. The suboxic conditions inhibit bioturbation, and sediment accumulation ranges from $16-30 \mathrm{mg} / \mathrm{cm}^{2} / \mathrm{yr}$ (approximately $0.04 \mathrm{~cm} / \mathrm{yr}$ below the upper $2 \mathrm{~cm}$; Huh et al., 1987). The major sources of material are biological detritus settling from the productive overlying surface waters and river-borne particulate material from the adjacent coast. The Santa Clara River is the most important single source of sediment to the California basins (Eganhouse and Venkatesan, 1993). Biogenic sedimentary components are calcium carbonate (2\% wt.), organic carbon (4\% wt.), and silica (0.2-2\% wt.; Gorsline, 1992). Sedimentary layers representing 3-6 year intervals have been observed and may be driven by surface productivity variations corresponding to EI Nino-Southern Oscillation (ENSO) cycles (Hagadorn et al., 1995). The light-banded laminae are of lower bulk density and may correlate with the formation of bacterial mats at the sediment-water interface during the transition to suboxic conditions; dark banding may correspond to increased oxygenation of bottom waters or increased input of terrigenous detritus from runoff during ENSO events (Christensen et al., 1994). The central basin area is located only about $30 \mathrm{~km}$ west of shore; as a result the seaward Santa Ana winds bring terrestrial detritus and urban aerosol particles to surface waters from March to July (Venkatesan and Kaplan, 1992). Brush fires, common to this season, increase the atmospheric particulate loading. The basin also receives organic material from natural submarine oil seeps and erosion of exposed shales (Miocene Monterey Formation) on the coast.

The Santa Barbara Basin (SBB; Figure 1.6) is shallower than SMB, with a maximum basin depth of $\sim 600 \mathrm{~m}$. Its bottom waters are suboxic below the western sill depth of $475 \mathrm{~m}$. During the spring, upwelling Pacific Intermediate Water flows over the sill and renews the deep basin water, after which respiration of organic matter quickly returns the deep water to anoxic $\left(<0.1 \mathrm{~mL} / \mathrm{L} \mathrm{O}_{2}\right)$ conditions. Bioturbation by benthic 
infauna is inhibited, and alternating light-dark laminations are easily visible in the sediment. The sedimentation rate is $0.3-0.4 \mathrm{~cm} / \mathrm{yr}$ in the upper sediment column, and a single light-dark couplet is apparently formed each year. These conditions yield very high resolution records of both recent (Schimmelmann and Tegner, 1991; Kennedy and Brassell, 1992) and long-term climatic changes (Behl and Kennett, 1996). The rapid sedimentation rate is due to higher primary production, less water-column organic matter degradation, and greater fluxes of inorganic (terrigenous) material in SBB than in SMB. The millimeter-scale laminations observed in SBB sediments appear to correlate with the cycle of oxygen renewal associated with deep basin flushing (Reimers et al., 1990), not with variations in rainfall-related transport of terrigenous debris as originally postulated by Hulsemann and Emery (1961).

The phytoplanktonic population in SMB is dominated by intense blooms of diatoms associated with upwelling in late spring and early summer. Episodic blooms of dinoflagellates also occur and extend into early fall. These two taxa represent most of the primary productivity in the Southern California Bight (SCB); coccolithophorids (haptophyte algae), such as Emiliana huxleyi, are of minor importance during all seasons (Beers, 1986). Lower abundance of diatoms and dinoflagellates in winter is associated with increased populations of chrysophyte and cryptophyte algae. Total primary production in the SCB is estimated at $\sim 700 \mathrm{mgC} / \mathrm{m}^{2} / \mathrm{day}$. In SMB, $\sim 120 \mathrm{mgC} / \mathrm{m}^{2} /$ day of this production is exported below the euphotic zone and $\sim 50 \mathrm{mgC} / \mathrm{m}^{2} /$ day reaches the basin floor (Landry et al., 1992). Both primary production and particle export are higher in SBB, due to closer proximity to the intense upwelling zone off Point Conception (Eppley, 1992). Organic fluxes to SBB sediments are also higher due to the shallower water column of SBB. The carbon arriving at the sediment-water interface in both basins is dominated by the degraded products of this phytoplanktonic production.

The role of the microbial population in both Santa Monica and Santa Barbara Basin organic carbon cycling has received prior attention. The low-oxygen central basins support abundant sedimentary bacterial populations. In SBB the surficial sediment is dominated by a thick mat of filamentous sulfur bacteria (Beggiatoa spp.) which develops 
prior to the onset of anoxic conditions following a flushing event. Beggiatoa in marine systems are chemoautotrophic and chemoorganotrophic sulfide-oxidizing species which are commonly found at the oxic-anoxic interface (Nelson, 1992). SMB also supports a small density of Beggiatoa filaments at its sediment-water interface. The bacterial mats are thinner and more dispersed, and may have a smaller influence on the sedimentary biogeochemistry than in SBB. Total microbial activity, however, is abundant in the top 1 $\mathrm{cm}$ of SMB sediment, where living biomass accounts for $5-10 \%$ of TOC (Craven and Jahnke, 1992).

In the water column, bacteria constitute a large fraction of particulate organic carbon (POC) and are responsible for recycling the majority of phytoplanktonic primary production. Azam et al. (1992) report that bacterial carbon accounts for $14-62 \%$ of POC in the euphotic zone. From depth profiles of bacterial abundance and POC in the water column of the central North Pacific and in Santa Monica Basin, Cho and Azam (1988) estimated bacterial heterotrophy exceeded zooplankton carbon demand. They suggested that bacterial growth produces suspended (0.3-0.6 $\mu \mathrm{m})$ POC in the form of bacterial cells and consumes sinking POC. Additionally, recent work by Massana et al. (1997) shows that $\sim 20 \%$ of the prokaryotic rRNA below the euphotic zone in the Santa Barbara Channel is contributed by planktonic Archaea (archaebacteria) with a previously uninvestigated ecological and biogeochemical role. Heterotrophic bacteria must be consuming organic solutes (DOC), probably produced from algal lysis or enzymatic degradation of phytoplanktonic carbon. These bacteria will have the same ${ }^{14} \mathrm{C}$ concentration as the photosynthetic biomass from which their substrates are derived. Chemoautotrophic bacteria fix biomass from DIC, presumably in ${ }^{14} \mathrm{C}$-equilibrium with water-column DIC. Below the depth of bomb $-{ }^{14} \mathrm{C}$ penetration, these organisms will have ${ }^{14} \mathrm{C}$ concentrations significantly lower than the biomass of heterotrophic prokaryotes. Both Bacteria and Archaea may contribute significantly to the recycling of organic carbon and energy in the California Borderland Basins, and lipid biomarkers characteristic of these organisms are preserved in the sedimentary record. 
A compilation of the available $\Delta^{14} \mathrm{C}$ data for the local environment of SMB, both for pre-bomb and current conditions, is shown in Figures 1.7 and 1.8 (data and references, Table 1.6).

Figure 1.7

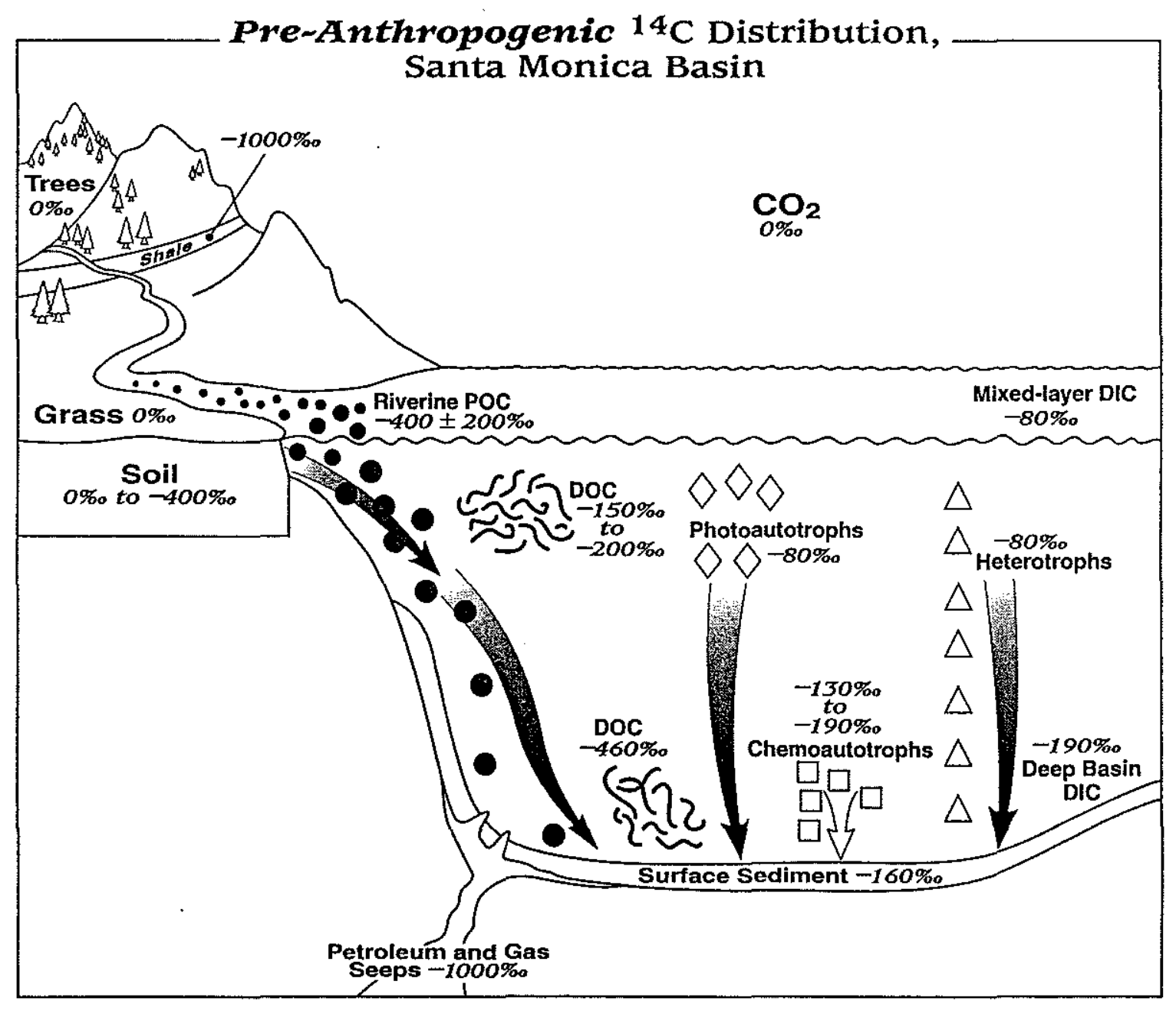

Figure 1.7 Pre-bomb $\Delta^{14} \mathrm{C}$ distribution in SMB; data from Table 1.6. 
Figure 1.8

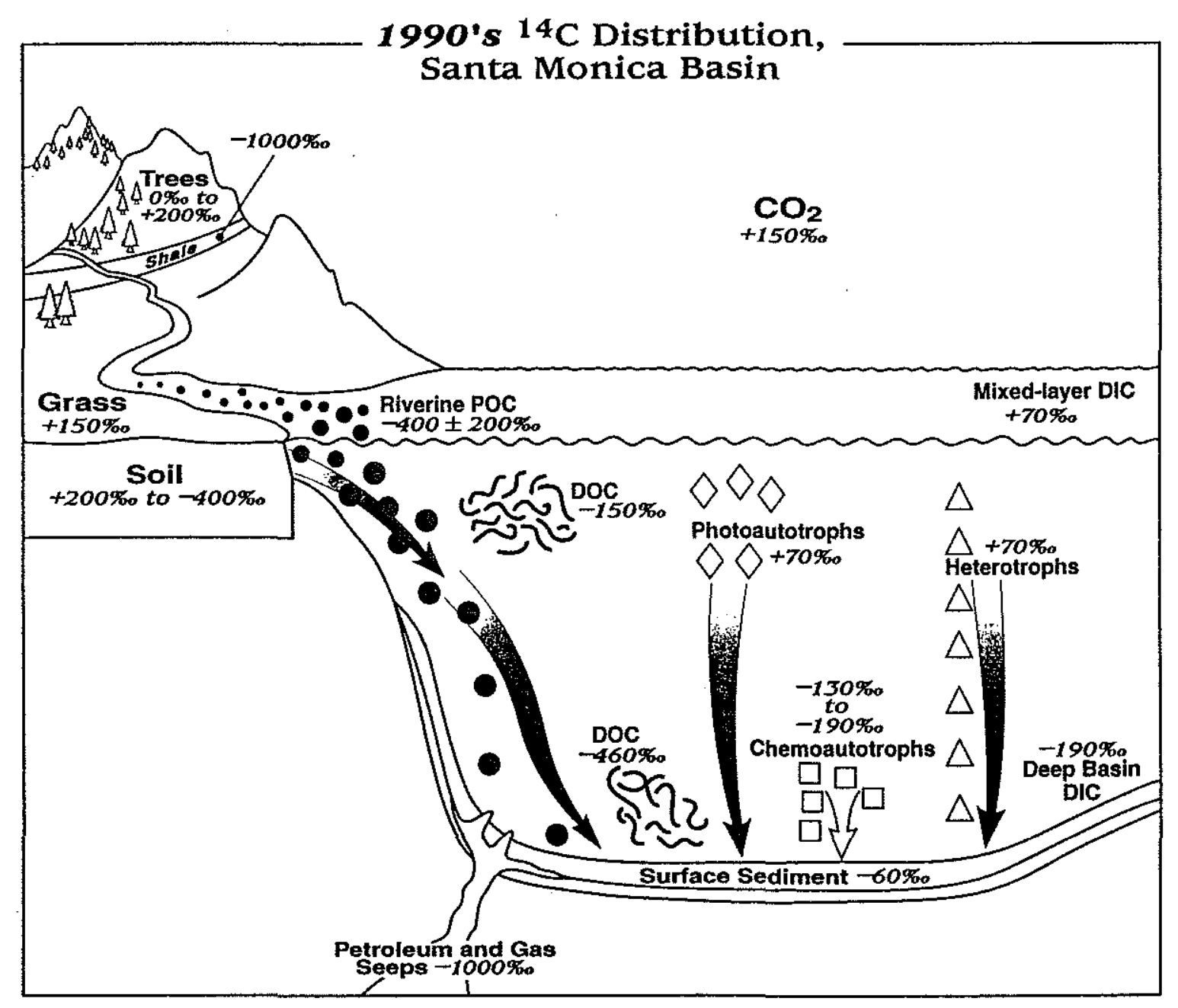

Figure 1.8 Post-bomb (1990s) $\Delta^{14} \mathrm{C}$ distribution in SMB; data from Table 1.6. 
Table 1.6 $\triangle^{14} \mathrm{C}$ distribution in the local environment of SMB. The SBB environment is similar except for a shallower water column and less negative deep-water $\Delta^{14} \mathrm{C}_{\text {DIC }}$ value.

\begin{tabular}{|c|c|c|c|}
\hline & $\begin{array}{c}\Delta^{14} \text { C Pre-bomb } \\
(\% o)\end{array}$ & $\begin{array}{c}\Delta^{14} \text { C Post-bomb } \\
(1990 \mathrm{~s})(\% o)\end{array}$ & $\begin{array}{c}\text { References and } \\
\text { Notes }\end{array}$ \\
\hline Atmospheric $\mathrm{CO}_{2}$ & 0 & $\sim+150$ & Hesshaimer et al. (1994) \\
\hline Trees & 0 & $\geq+150$ & $*$ \\
\hline Grass & 0 & +150 & \\
\hline Riverine POC & $-400 \pm 200$ & $-400 \pm 200$ & $\dagger$ \\
\hline Soils & 0 to -400 & +250 to -400 & $\ddagger$ \\
\hline Shale/Ancient Kerogen & -1000 & -1000 & \\
\hline Mixed-Layer DIC & -82 & +71 & $\#$ \\
\hline Marine Photoautotrophs & -82 & +71 & \\
\hline Marine Heterotrophs & -82 & +71 & \\
\hline Deep Basin DIC & -190 & -190 & $\S$ \\
\hline $\begin{array}{l}\text { Marine } \\
\text { Chemoautotrophs }\end{array}$ & -130 to -190 & -130 to -190 & $\$$ \\
\hline Mixed-Layer DOC & -150 to -200 & -150 & Druffel et al., 1992 \\
\hline Deep Basin DOC & -462 & -462 & Bauer et al., 1995 \\
\hline Surface Sediment & -160 & -60 & this thesis \\
\hline $\begin{array}{l}\text { Petroleum and Gas } \\
\text { Seeps }\end{array}$ & -1000 & -1000 & \\
\hline
\end{tabular}

* Assumes woody tissue residence time $\sim 20$ years (Hedges and Oades, 1997)

$\dagger$ Riverine POC $\Delta^{14} \mathrm{C}$ highly variable (Masiello et al., manuscript in preparation)

‡ Soil values assumed based on upper range of $\Delta^{14} \mathrm{C}$ for plant litter, with lower value arbitrarily chosen to match the average river-borne POC.

\# Pre-bomb value from Robinson (1981), Williams et al. (1992), and Baumgartner and Southon (1996); post-bomb value measured as part of this thesis.

$\S \Delta^{14} C_{\text {DIC }}$ lower limit from benthic foraminifera, this thesis; chemoautotroph upper limit from $\Delta^{14} \mathrm{C}$ of SMB archaeal lipids, this thesis. 
Freshly-synthesized phytoplanktonic material should reflect the $\Delta^{14} \mathrm{C}$ of surface water DIC in both the pre-bomb and post-bomb environments. Likewise, the biomass of marine heterotrophic consumers, their fecal pellets, and all other planktonic detritus will have the same $\Delta^{14} \mathrm{C}$, because they are merely transformation and degradation products of carbon fixed by euphotic zone primary producers.

Druffel and Williams (1990) reported that the $\Delta^{14} \mathrm{C}$ of suspended POC decreased with depth in the water column, while the value for sinking POC was equal to that of DIC in the surface water. According to estimates of the residence time of suspended POC (510 years) (Bacon and Anderson, 1982), it is possible that the physically older suspended fraction could actually have a ${ }^{14} \mathrm{C}$ concentration, since surface water $\Delta^{14} \mathrm{C}_{\mathrm{DIC}}$ has been decreasing since the middle 1970s. Accordingly, the observation that the $\Delta^{14} \mathrm{C}$ of suspended POC is lower than that of sinking POC led Druffel and Williams (1990) to postulate that the suspended POC had incorporated radiocarbon-poor DOC, either through physical adsorption onto particles and/or through heterotrophic activity of attached bacteria. DOC in the SMB deep basin is quite ${ }^{14} \mathrm{C}$-depleted $(-462 \%$ ) and could serve as a source of old carbon (Bauer et al., 1995).

Bomb-derived ${ }^{14} \mathrm{C}$ is currently present in the top $3 \mathrm{~cm}$ of SMB sediment (Figure 1.8). However, in both the pre-bomb and post-bomb horizons, the $\Delta^{14} \mathrm{C}$ of TOC is significantly lower than can be explained by the $\Delta^{14} \mathrm{C}$ of sinking or suspended biogenic detritus alone. Preliminary work demonstrating the presence of "old" carbon in POC and sediments from the north central Pacific Ocean (Station M, $4100 \mathrm{~m}$ depth) showed successive enrichment of an aged component through a series of fractions. Specifically, $\Delta \Delta^{14} \mathrm{C}$ POC $>\Delta{ }^{14} \mathrm{C}$ detrital aggregate $>\Delta{ }^{14} \mathrm{C}$ sediment "floc" $>\Delta{ }^{14} \mathrm{C}$ surface sediment (Wang et al., 1996). The low ${ }^{14} \mathrm{C}$ content of the detrital aggregates may be the most interesting finding, as it is unlikely the aggregates persist at the sediment-water interface long enough for the observed $\sim 100 \%{ }^{14} \mathrm{C}$ depletion ( $~ 800$ years) to occur by radioactive decay alone. 
There are three general mechanisms for successive depletion of ${ }^{14} \mathrm{C}$ in marine organic materials as they follow the pathway from phytoplanktonic production through sedimentary TOC burial.

(1) The first hypothesis invokes adsorption of the ${ }^{14} \mathrm{C}$-depleted, refractory component of dissolved organic carbon (DOC) to suspended and sinking particles, where it is perhaps utilized by bacteria (e.g. Druffel and Williams, 1990).

(2) The second hypothesis explains lower benthic $\Delta^{14} \mathrm{C}$ values as a consequence of the uptake of ${ }^{14} \mathrm{C}$-depleted DIC at depth. This could occur either via anaplerotic $\beta$ carboxylation reactions (e.g. Rau et al., 1986; Rau 1991) common to the metabolism of most organisms, or it could reflect DIC consumption by chemoautotrophic prokaryotic species that assimilate nearly $100 \%$ of their carbon from DIC below the euphotic zone. The first mechanism would distribute ${ }^{14} \mathrm{C}$-depleted carbon throughout the products of many groups of marine species. The second would concentrate ${ }^{14} \mathrm{C}$-depleted carbon in the products of some species and leave the biomass of other organisms relatively unaltered in ${ }^{14} \mathrm{C}$ concentration.

(3) A third possibility calls for preferential degradation of the more labile organic fractions of POC and sediments (recently-synthesized biomass) and enrichment of the remainder in pre-aged, refractory material (terrestrial detritus or advected, re-suspended sediments). This form of selective diagenesis is known as the "multi-g" model for organic carbon degradation (Berner, 1974), and in this case, assumes the refractory material is allochthonous and has a lower $\Delta^{14} \mathrm{C}$ value than the marine material with which it is concurrently sedimented.

These three hypotheses have different implications for the distribution of ${ }^{14} \mathrm{C}$ throughout the lipid biomarker classes of SMB sediments. In the first scenario, the lipids of heterotrophic bacteria would be ${ }^{14} \mathrm{C}$-depleted in proportion to the extent of DOC 
utilization. That utilization would need to be high enough to explain the measured depletion of ${ }^{14} \mathrm{C}$ within the entire POC carbon pool, yet not require an unreasonable DOC turnover rate. Under the second hypothesis, it would be possible to identify prokaryotic lipids having $\Delta^{14} \mathrm{C}$ signatures matching the ${ }^{14} \mathrm{C}$-depleted value of deep basin DIC, but only if the relevant organisms have taxonomically-unique lipids. On the other hand, if $\beta$ carboxylation reactions provide a universal, small fraction of the carbon incorporated by benthic organisms, then the lipids of all deep biota may be ${ }^{14} \mathrm{C}$-depleted (only if extensive cycling distributes this carbon through the intracellular acetate and isoprene pools). Isotopically, this effect could be difficult to distinguish from the DOC incorporation scenario. Finally, if selective degradation explains why sedimentary TOC is ${ }^{14} \mathrm{C}$-poor, estimating the $\Delta^{14} \mathrm{C}$ of the pre-aged (terrestrial) fraction is dependent on whether the terrestrial lipids have the same $\Delta^{14} \mathrm{C}$ signature as the bulk eroded material. In this third scenario, however, the lipids of marine organisms would remain entirely unaffected and their $\Delta^{14} \mathrm{C}$ would match the surface water $\Delta^{14} \mathrm{C}_{\text {DIC. }}$.

The discussions presented in the chapters of this thesis address the ability of compound-specific ${ }^{14} \mathrm{C}$ analysis to explain the relative importance of these three mechanisms. In general, the first hypothesis seems least likely to explain why POC and surface sediments have low ${ }^{14} \mathrm{C}$ concentrations. This is largely because the amount of DOC consumption required to produce the observed effects could consume the oceanic inventory of DOC more quickly than its presumed residence time of 5,000-6,000 years. There is direct evidence for a contribution of chemoautotrophic biomass to SMB sediments, as suggested by the second hypothesis (Chapters 5 and 6 , this thesis). However, the importance of this process with respect to the total amount of TOC remains unknown. Also, mass-balance calculations require that the $\Delta^{14} \mathrm{C}$ value of the pre-aged material in SMB sediment is lower than the $\Delta^{14} \mathrm{C}$ of bottom water DIC (Chapters 4 and 7). This suggests that the "multi-g" hypothesis may in fact be the most important cause of the relative ${ }^{14} \mathrm{C}$-depletion in SMB sediments. The remineralization of weathered continental organic carbon is incomplete and preservation may occur because this material is chemically refractory. This is supported by the observation that there are no 
terrestrial lipids in SMB sediment with "old" ${ }^{14} \mathrm{C}$ signatures other than a small percentage of fossil $n$-alkanes (Chapter 7). Lipid biomarkers are apparently only indicative of the labile fraction of organic carbon. The refractory, ${ }^{14} \mathrm{C}$-poor components of TOC remain to be identified.

\subsection{GoALS OF THIS THESIS}

The goal of this thesis is to help establish the reliability of the new compoundspecific ${ }^{14} \mathrm{C}$ methods, and especially to show the utility of dual-isotopic $\left({ }^{13} \mathrm{C}\right.$ and $\left.{ }^{14} \mathrm{C}\right)$ investigation of biogeochemical processes. The main focus on a single sampling location (Santa Monica Basin) generated a comprehensive baseline data set as groundwork for further interpretations of compound-specific ${ }^{14} \mathrm{C}$ data. The topics addressed in the following chapters are:

Microscale AMS analysis at NOSAMS (Chapter 3),

An organic tracer for surface ocean radiocarbon (Chapter 4),

Radiocarbon evidence for autotrophic metabolism in marine planktonic Archaea (Chapter 5),

Origins of lipid biomarkers in Santa Monica Basin surface sediment: A case study using compound-specific ${ }^{13} \mathrm{C}$ and ${ }^{14} \mathrm{C}$ analysis (Chapter 6),

Models for the origin of $n$-alkanes and total organic carbon in Santa Monica Basin surface sediment (Chapter 7). 


\subsection{REFERENCES}

Azam, F., Smith, D. C. and Carlucci, A. F. (1992) Bacterial transformation and transport of organic matter in the Southern California Bight. Prog. Oceanog. 30, 151-166.

Bacon, M. P. and Anderson, R. F. (1982) Distribution of Thorium between dissolved and particulate forms in the deep sea. J. Geophys. Res. 87, 2045-2056.

Bauer, J. E., Reimers, C. E., Druffel, E. R. M., and Williams, P. M. (1995) Isotopic constraints on carbon exchange between deep ocean sediments and sea water. Nature 373, 686-689.

Baumgartner, T. R. and Southon, J. (1996) A 1500-year radiocarbon record of nearsurface ocean reservoir ages obtained from the varved sediments of the Santa Barbara Basin, California. EOS, Transactions, 1996 Fall Meeting, p. F298.

Becker-Heidmann, P. Scharpenseel, H.-W. and Wiechman, H. (1996) Hamburg radiocarbon thin layer soils database. Radiocarbon 38, 295-345.

Beers, J. R. (1986) In Plankton Dynamics of the Southern California Bight, Ed. R. W. Eppley, Springer-Verlag, New York, pp. 84-175.

Behl, R. J. and Kennett, J. P. (1996) Brief interstadial events in the Santa Barbara basin, NE Pacific, during the past 60 kyr. Nature 379, 243-246.

Benoit, G. J., Turekian, K. K., and Benninger L. K. (1979) Radiocarbon dating of a core from Long Island Sound. Estuarine Coastal Mar. Sci. 9, 171-180.

Berner, R. A. (1974) Kinetic models for the early diagenesis of nitrogen, sulfur, phosphorus, and silicon in anoxic marine sediments. In The Sea, 5. Ed. E. D. Goldberg, Wiley, New York, 427-450.

Berner, R. A. (1982) Burial of organic carbon and pyrite sulfur in the modern ocean: Its geochemical and environmental significance. Am. J. of Science 282, 451-473.

Bott, M. and Thauer, R. K. (1989) The active species of " $\mathrm{CO}_{2}$ " formed by carbon monoxide dehydrogenase from Peptostreptococcus productus. Z. Naturforsch. 44c, 392-396.

Broecker, W. S. and Peng, T.-H. (1982) Tracers in the Sea, Lamont Doherty Geological Observatory Press, Columbia University, New York. pp. 383-439.

Cho, B. C. and Azam, F. (1988) Major role of bacteria in biogeochemical fluxes in the ocean's interior. Nature 332, 441-443.

Christensen, C. J., Gorsline, D. S., Hammond, D. E., and Lund, S. P. (1994) Non-annual laminations and expansion of anoxic basin-floor conditions in Santa Monica Basin, California Borderland, over the past four centuries. Mar. Geol. 116, 399418.

Craven, D. B. and Jahnke, R. A. (1992) Microbial utilization and turnover of organic carbon in Santa Monica Basin sediments. Prog. Oceanog. 30, 313-333.

Druffel, E. R. M. and Williams, P. (1990) Identification of a deep marine source of particulate organic carbon using bomb ${ }^{14} \mathrm{C}$. Nature 347, 172-174.

Druffel, E. R. M., Williams, P. M., Bauer, J. E., and Ertel, J. R. (1992) Cycling of dissolved and particulate organic matter in the open ocean. J. Geophys. Res. 97 (C10), 15,639-15,659. 
Eglinton, T. I., Aluwihare, L. I., Bauer, J. E., Druffel, E. R. M., and McNichol, A. P. (1996) Gas chromatographic isolation of individual compounds from complex matrices for radiocarbon dating. Anal. Chem. 68, 904-912.

Eglinton, T. I., Benitez-Nelson, B. C., Pearson, A., McNichol, A. P., Bauer, J. E., and Druffel, E. R. M. (1997) Variability in radiocarbon ages of individual organic compounds from marine sediments. Science 277, 796-799.

Emerson, S., Stump, C., Grootes, P. M., Stuiver, M., Farwell, G. W. and Schmidt, F. H. (1987) Estimates of degradable organic carbon in deep-sea surface sediments from ${ }^{14} \mathrm{C}$ concentrations. Nature $329,51-53$.

Eppley, R. W. (1992) Chlorophyll, photosynthesis and new production in the Southern California Bight. Prog. Oceanog. 30, 117-150.

Freeman, K. H., Hayes, J. M., Trendel, J.-M. and Albrecht, P. (1990) Evidence from GCMS carbon-isotopic measurements for multiple origins of sedimentary hydrocarbons. Nature 353, 254-256.

Goñi, M. A., Ruttenberg, K. C., and Eglinton, T. I. (1998) A reassessment of the sources and importance of land-derived organic matter in surface sediments from the Gulf of Mexico. Geochim. Cosmochim. Acta 62, 3055-3075.

Gorsline, D. S. (1992) The geological setting of Santa Monica and San Pedro Basins, California Continental Borderland. Prog. Oceanog. 30, 1-36.

Grice, K., Klein Breteler, W. C. M., Schouten, S., Grossi, V., de Leew, J. W., and Sinninghe Damsté, J. S. (1998) Effects of zooplankton herbivory on biomarker proxy records. Paleoceanography 13, 686-693.

Guy, R. D., Fogel, M. D., and Berry, J. A. (1993) Photosynthetic fractionation of the stable isotopes of oxygen and carbon. Plant Physiol. 101, 37-47.

Hagadorn, J. W., Stott, L. D., Sinha, A. and Rincon, M. (1995) Geochemical and sedimentologic variations in inter-annually laminated sediments from Santa Monica Basin. Mar. Geology 125, 111-131.

Hayes, J. M. (1993) Factors controlling the ${ }^{13} \mathrm{C}$ content of sedimentary organic compounds: Principles and evidence. Mar. Geol. 113, 111-125.

Hayes, J. M., Freeman, K. H., Popp, B. N., and Hoham, C. H. (1990) Compound-specific isotopic analyses: A novel tool for reconstruction of ancient biogeochemical processes. Org. Geochem. 16, 1115-1128.

Hedges, J. I. (1992) Global biogeochemical cycles: progress and problems. Mar. Chem. $39,67-93$.

Hedges, J. I. and Oades, J. M. (1997) Comparative organic geochemistries of soils and marine sediments. Org. Geochem. 27, 319-361.

Hedges, J. I. and Parker, P. L. (1976) Land-derived organic matter in surface sediments from the Gulf of Mexico. Geochim. et Cosmochim. Acta 40, 1019-1029.

Holo, H. and Sirevåg, R. (1986) Autotrophic growth and $\mathrm{CO}_{2}$ fixation of Chloroflexus aurantiacus. Arch. Microbiol. 145, 173-180.

Huh, C.-A., Zahnle, D. L., and Small, L. F. (1987) Budgets and behaviors of uranium and thorium series isotopes in Santa Monica Basin sediments. Geochim. et Cosmochim. Acta 51, 1743-1754. 
Hulsemann, J. and Emery, K. O. (1961) Stratification in recent sediments of Santa Barbara Basin as controlled by organisms and water character. J. Geol. 69, 279290.

Jones, G.A. and Gagnon, A.R. (1994) Radiocarbon chronology of Black Sea sediments. Deep-Sea Res. 41, 531- .

Kennedy, J. A. and Brassell, S. C. (1991) Molecular stratigraphy of the Santa Barbara basin: comparison with historical records of annual climate change. Org. Geochem. 19, 235-244.

Kohnen, M. E. L., Schouten, S., Sinninghe Damsté, J. S., de Leew, J. W., Merritt, D. A., and Hayes, J. M. (1992) Recognition of paleobiochemicals by a combined molecular sulfur and isotope geochemical approach. Science 256, 358-362.

Landry, M. R., Peterson, W. K. and Andrews, C. C. (1992) Particulate flux on the water column overlying Santa Monica Basin. Prog. Oceanog. 30, 167-195.

Levin, I. and Kromer, B. (1997) Twenty years of atmospheric ${ }^{14} \mathrm{CO}_{2}$ observations at Schauinsland. Radiocarbon 39, 205-218.

Levin, I., Kromer, B., Schoch-Fischer, H., Bruns, M., Münnich, M., Berdau, D., Vogel, J. C., and Münnich, K. O. (1985) 25 years of tropospheric ${ }^{14} \mathrm{C}$ observations in Central Europe. Radiocarbon 27, 1-19.

Lewan, M. D. (1986) Stable carbon isotopes of amorphous kerogens from Phanerozoic sedimentary rocks. Geochim. Cosmochim. Acta 50, 1583-1591.

Masiello, C. A., Druffel, E. R. M. and Griffin, S. (in preparation, 1999) The isotope geochemistry of a small mountainous river.

Massana, R., Murray, A. E., Preston, C. M., and DeLong, E. F. (1997) Vertical distribution and phylogenetic characterization of marine planktonic Archaea in the Santa Barbara Channel. Appl. Environ. Microbiol. 63, 50-56.

Nelson, D. C. (1992) The genus Beggiatoa. In The Prokaryotes, Eds. A. Balows, H.G. Truper, M. Dworkin, W. Harder, and K. H. Schliefer, p. 1371-3180.

O'Leary, M. H. (1981) Carbon isotope fractionation in plants. Phytochem. 20, 553-567.

Prahl, F. G., Erterl, J. R., Goni, M. A., Sparrow, M. A. and Eversmeyer, B. (1994) Terrestrial organic carbon contributions to sediments on the Washington margin. Geochim. Cosmochim. Acta 58, 3035-3048.

Rau, G.H., Karl, D.M. and Carney, R.S. (1986) Does inorganic carbon assimilation cause ${ }^{14} \mathrm{C}$ depletion in deep-sea organisms? Deep-Sea Res. 33, 349-357.

Rau, G.H. Another recipe for bomb ${ }^{14} \mathrm{C}$ dilution. (1991) Nature 350, 116.

Raven, J. A. (1997) Inorganic carbon acquisition by marine autotrophs. Advances in Botanical Research 27, 85-209.

Reimers, C. E., Lange, C. B., Tabak, M., and Bernhard, J. M. (1990) Seasonal spillover and varve formation in the Santa Barbara Basin, California. Limnol. Oceanogr. 35, 1577-1585.

Robinson, S. W. (1981) Natural and man-made radiocarbon as a tracer for coastal upwelling processes. Coastal and Estuarine Sciences 1, 298-302.

Roeske, C. A. and O'Leary, M. H. (1984) Carbon isotope effects on the enzymecatalyzed carboxylation of ribulose bisphosphate. Biochemistry 23, 6275-6284. 
Roeske, C. A. and O'Leary, M. H. (1985) Carbon isotope effect on carboxylation of ribulose bisphosphate catalyzed by ribulosebisphosphate carboxylase from Rhodospirillum rubrum. Biochemistry 24, 1063-1067.

Schimmelmann, A., and Tegner, M. J. (1991) Historical oceanographic events reflected in the ${ }^{13} \mathrm{C} /{ }^{12} \mathrm{C}$ ratio of total organic carbon in laminated Santa Barbara Basin Sediment. Global Biogeochem. Cycles 5, 173-188.

Schouten, S. (1995) Structural and stable carbon isotope studies of lipids in immature sulphur-rich sediments. Ph.D. Thesis, University of Groningen, The Netherlands.

Siegenthaler, U. and Sarmiento, J. L. (1993) Atmospheric carbon dioxide and the ocean. Nature 365, 119-125.

Southon, J. R., Nelson, D. E., and Vogel, J. S. (1990) A record of past ocean-atmosphere radiocarbon differences from the Northeast Pacific. Paleoceanography 5, 197206.

Stuiver, M., Pearson, G. W., and Braziunas, T. F. (1986) Radiocarbon age calibration of marine samples back to 9000 cal yr BP. Radiocarbon 28,980-1021.

Stuiver, M. and Polach, H. A. (1977) Discussion: Reporting of ${ }^{14} \mathrm{C}$ data. Radiocarbon 19, 355-363.

Stuiver, M. and Robinson, S. W. (1974) University of Washington GEOSECS North Atlantic carbon-14 results. Earth and Planetary Science Letters 23, 87-90.

Trumbore, S. E. (1993) Comparison of carbon dynamics in tropical and temperate soils using radiocarbon measurements. Global Biogeochem. Cycles 7, 275-290.

Tuttle, J. H. and Jannasch, H. W. (1979) Microbial dark assimilation of $\mathrm{CO}_{2}$ in the Cariaco Trench. Limnol. Oceanogr. 24, 746-753.

Venkatesan, M. I. and Kaplan, I. R. (1992) Vertical and lateral transport of organic carbon and the carbon budget in Santa Monica Basin, California. Prog. Oceanog. 30, 291-312.

Wang, X.-C., Druffel, E. R. M., Griffin, S., Lee, C., and Kashgarian, M. (1998) Radiocarbon studies of organic compound classes in plankton and sediment of the northeastern Pacific Ocean. Geochim. Cosmochim. Acta 62, 1365-1378.

Williams, P.M., Robertson, K.J., Soutar, A., Griffin, S.M. and Druffel, E.R.M. (1992) Isotopic signatures $\left({ }^{14} \mathrm{C},{ }^{13} \mathrm{C},{ }^{15} \mathrm{~N}\right)$ as tracers of sources and cycling of soluble and particulate organic matter in the Santa Monica Basin, California. Prog. Oceanog. 30, 253-290. 


\section{CHAPTER 2}

GEOCHEMICAL METHODS 


\subsection{BulK SAMPLeS}

\subsubsection{Samples}

Samples were collected in November 1996 (R/V Roger Revelle, cruise Pulse-32) from the central Santa Monica Basin (SMB) (33⒋ $\left.40^{\prime} \mathrm{N}, 118^{\circ} 50.0 \mathrm{~W}\right)$, California, USA. A 500-mL surface water sample (20 $\mathrm{m}$ water depth) for $\Delta^{14} \mathrm{C}_{\text {DIC }}$ was collected according to the WOCE protocol (McNichol and Jones, 1991). An Ocean Instruments ${ }^{\circledR}$ Multicorer was used to collect identical $10-\mathrm{cm}$ diameter sediment subcores in sets of 8 per deployment. Seven subcores from one deployment in the basin depocenter ( $905 \mathrm{~m}$ water depth) were selected for this study. The cores were sectioned at 0.75 -cm intervals to 1.5 $\mathrm{cm}$ and then $1.0-\mathrm{cm}$ intervals to $8.5 \mathrm{~cm}$. Equivalent horizons were combined, homogenized, and freeze-dried, yielding samples of 53 (surface) to $>170$ (below $1.5 \mathrm{~cm}$ ) grams dry weight ( $\mathrm{gdw}$ ). All cores were recovered with minimal sediment re-suspension or disruption. Macroscopic filamentous sulfur bacteria were visible at the sediment-water interface; discrete detrital aggregates (separate orange, green, and black particles) constituted the majority of the surficial material; and the overlying water in the core tubes was clear.

The tops (0-1 cm) of two subcores from Santa Barbara Basin (SBB) $\left(34^{\circ} 13.5^{\prime} \mathrm{N}\right.$, $120^{\circ} 03.5^{\prime} \mathrm{W}, 595 \mathrm{~m}$ water depth) were also collected, homogenized and freeze-dried (22 $\mathrm{gdw}$ ). This material was used for the analysis of sedimentary sterols and archaeal lipids. The sample consisted of a gelatinous, pale green layer of filamentous bacteria (colorless, Beggiatoa spp.), apparently mixed with phytodetritus (the green material). Immediately beneath, a thin ( $\sim 2-\mathrm{mm})$ black horizon was observed. This sample represents approximately 2-3 years deposition based on published sedimentation rates (Schimmelman and Tegner, 1991), but physical observation of the laminae showed only one light-dark couplet and suggested it represented a single year's record.

The sediments were sectioned on-board ship and stored frozen $\left(-20^{\circ} \mathrm{C}\right)$ until analysis. 


\subsubsection{Bulk Sample Analysis}

Subsamples of dry mud were reserved for bulk isotopic analyses $\left(\Delta^{14} \mathrm{C}_{\mathrm{TOC}}\right.$, $\delta^{13} \mathrm{C}_{\mathrm{TOC}}$ ) and for measurement of excess ${ }^{210} \mathrm{~Pb}$ activity to assign a calendar-year chronology to the SMB core. Values of $\Delta^{14} \mathrm{C}_{\mathrm{TOC}}$ and $\delta^{13} \mathrm{C}_{\mathrm{TOC}}$ were determined using 100-mg samples prepared using standard procedures (McNichol et al., 1994a). Inorganic carbon ( $<5$ wt \%) was removed with $\mathrm{HCl}$ and the remaining residue combusted to $\mathrm{CO}_{2}$ $\left(850^{\circ} \mathrm{C}, 5 \mathrm{hr}\right)$ in quartz tubes containing an excess of $\mathrm{CuO}$ (Elemental Microanalysis; $4 \mathrm{~mm} \times 0.5 \mathrm{~mm}$ wires). Values of $\delta^{13} \mathrm{C}_{\mathrm{TOC}}$ were measured off-line on splits of the purified $\mathrm{CO}_{2}$ by conventional isotope ratio mass spectrometry (VG Prism / VG Optima Mass Spectrometers). The remaining $\mathrm{CO}_{2}$ was reduced to graphite (Vogel et al., 1987) and $\Delta^{14} \mathrm{C}_{\mathrm{TOC}}$ measured at the National Ocean Sciences Accelerator Mass Spectrometry facility (NOSAMS). The value of $\Delta^{14} \mathrm{C}_{\mathrm{DIC}}$ was measured for $\mathrm{CO}_{2}$ stripped from the $20-\mathrm{m}$ water sample according to McNichol et al. (1994b) and the WOCE protocol (McNichol and Jones, 1991).

Samples containing $8 \mathrm{gdw}$ SMB sediment were homogenized and finely ground for measurement of ${ }^{210} \mathrm{~Pb}$ activity using a Canberra GeLi detector coupled to a PC-based Ortec multi-channel analyzer. The gamma emission at $46.5 \mathrm{KeV}$ was measured. Supported ${ }^{210} \mathrm{~Pb}$ activity was subtracted from total ${ }^{210} \mathrm{~Pb}$ activity (supported was taken as the activity at $7.5 \mathrm{~cm}$ depth, below which the activity was unchanging). The excess- ${ }^{210} \mathrm{~Pb}$ data yield a sedimentation rate and core chronology that is in agreement with previous reports (Huh et al., 1987; Christensen et al., 1994; Hagadorn et al., 1995). Organic C/N ratios, percent TOC, extractable lipid (TLE) and $\delta^{13} \mathrm{C}$ profiles for the SMB core are shown in the appendix to this chapter.

\subsubsection{Foraminifera}

The sediment residue was washed with $\mathrm{Calgon}{ }^{\circledR} / \mathrm{HOOH}$ solution and sieved through $150-\mu \mathrm{m}$ and $63-\mu \mathrm{m}$ mesh sieves. The benthic foraminifera Uvigerina peregrina 
and Bolivina spp. (mainly Bolivina spissa) were picked from the $>150 \mu \mathrm{m}$ fraction. Planktonic foraminifera were difficult to obtain in high mass abundance for $\Delta^{14} \mathrm{C}$; samples were picked from the $>150 \mu \mathrm{m}$ fraction and contained a mixture of Neogloboquadrina pachyderma (d.)., Neogloboquadrina dutertrei, and pachydermadutertrei (P-D) intergrade species (K. Elder, personal communication). The $\delta^{13} \mathrm{C}$ and $\Delta^{14} \mathrm{C}$ of the foraminifera (4-11 mg $\mathrm{CaCO}_{3}$ prior to hydrolysis) were measured using $\mathrm{CO}_{2}$ prepared according to McNichol et al., (1994a).

\subsection{ORganic Geochemical Methods}

\subsubsection{Lipid Analysis}

For each of the horizons selected for isotopic analyses of individual lipids $(0-$ $0.75 \mathrm{~cm}, 0.75-1.5 \mathrm{~cm}, 4.5-5.5 \mathrm{~cm}$, and materials combined from the $5.5-8.5 \mathrm{~cm}$ horizons), the remainder of the dry sample was extracted with $93: 7 \mathrm{CH}_{2} \mathrm{Cl}_{2} / \mathrm{CH}_{3} \mathrm{OH}$ (Fisher GC Resolv or Burdick \& Jackson $\mathrm{GC}^{2}$ ) using a large Soxhlet apparatus. A mixture of recovery standards representing the compound classes of interest was added to the total lipid extract (TLE). The standards selected were $n-C_{21}$ fatty acid $\left(\delta^{13} \mathrm{C}=-\right.$ $28.6 \%$ o, $\Delta^{14} \mathrm{C}=-389 \%$ o $)$ and $n-\mathrm{C}_{19}$ alcohol $\left(\delta^{13} \mathrm{C}=-30.6 \%\right.$ o $\Delta^{14} \mathrm{C}=-999 \%$ o $)\left(n-\mathrm{C}_{19}\right.$ ketone and $n$ - $\mathrm{C}_{18}$-diol were also added, but were not recovered by PCGC.) In addition,

$n-\mathrm{C}_{33}$ alkane $\left(\delta^{13} \mathrm{C}=-28.6 \%\right.$ o, $\Delta{ }^{14} \mathrm{C}=+146 \%$ ) was added to the polar lipid fractions just prior to $\mathrm{HI}$ cleavage and $\mathrm{LiAlH}_{4}$ reduction. This standard was recovered with the archaeal isoprenoid lipids.

The total lipid extracts (TLE) were transesterified to release bound lipids and produce fatty acid methyl esters. No isotopic distinctions were made between free and bound fatty acids or alcohols in this work, but a preliminary study suggested that the concentration of free fatty acids was much lower than the amount released during the gentle hydrolysis procedure (A. Pearson, unpublished data). Therefore the fatty acid 
samples are probably dominated by the hydrolyzed side-chains of phospholipids and triglycerides present in the original TLE. This transesterification step $\left(5 \% \mathrm{HCl} / \mathrm{CH}_{3} \mathrm{OH}\right.$, $70^{\circ} \mathrm{C}$ for $\left.12 \mathrm{hr}\right)$ used methanol of known isotopic composition $\left(\delta^{13} \mathrm{C}=-51.3 \%\right.$ o, $\Delta^{14} \mathrm{C}=$ $-992.5 \%$ ). Excess $\mathrm{H}_{2} \mathrm{O}\left(\mathrm{KMnO}_{4}\right.$-distilled) was added to the hydrolyzed products and the lipids were partitioned into hexane $(8 \times 30 \mathrm{~mL})$.

The hexane extracts were dried onto quartz sand and separated into 10 fractions on a Biotage ${ }^{(1)}$ Flash $40 \mathrm{Mi}$ pressurized chromatography system (column: $15 \mathrm{~cm} \mathrm{x} 40 \mathrm{~mm}$,

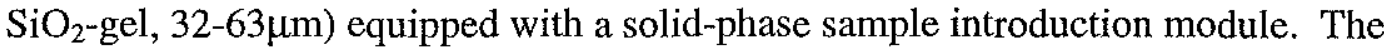
solvent polarity gradient was based on the methods of McCaffrey (1990). Each of the resulting samples was split into $5 \%$ for $\delta^{13} \mathrm{C}$ analysis and $95 \%$ for $\Delta^{14} \mathrm{C}$ analysis. Table 2.1 lists the solvent mixtures and corresponding lipid classes separated during this initial chromatographic step; an asterisk indicates a lipid fraction for which compound-specific isotopic analyses were obtained.

Table 2.1 Flash $\mathrm{SiO}_{2}$-gel chromatographic separation of lipid biomarker classes.

\begin{tabular}{|c|c|c|c|c|c|}
\hline & \multicolumn{4}{|c|}{ Solvent ( $250 \mathrm{~mL} /$ Fraction) } & Organic Compound Class \\
\hline $1 *$ & Hexane & $100 \%$ & & & Alkanes, Alkenes \\
\hline 2 & Hexane & $75 \%$ & $25 \%$ & Toluene & Alkenes, PAHs \\
\hline 3 & Hexane & $50 \%$ & $50 \%$ & Toluene & PAHs \\
\hline 4 & Hexane & $95 \%$ & $5 \%$ & Ethyl Acetate & $\begin{array}{c}\mathrm{C}_{37} \text { Alkenones and Steroidal } \\
\text { Ketones }\end{array}$ \\
\hline $5^{*}$ & Hexane & $90 \%$, & $10 \%$ & Ethyl Acetate & $\begin{array}{l}\text { Fatty Acid Methyl Esters, } \\
\mathrm{C}_{37} \text { Alkenones, other Ketones }\end{array}$ \\
\hline 6 & Hexane & $85 \%$, & $15 \%$ & Ethyl Acetate & (Minor Alcohols) \\
\hline $7^{*}$ & Hexane & $80 \%$ & $20 \%$ & Ethyl Acetate & $\begin{array}{l}n \text {-Alcohols, 4-Methyl-Sterols, } \\
\text { Hopanols, Alkan-15-one-1-ols }\end{array}$ \\
\hline $8^{*}$ & Hexane & $75 \%$ & $25 \%$ & Ethyl Acetate & $\begin{array}{l}\text { Desmethyl-Sterols, } \\
\text { Alkan-15-one-1-ols }\end{array}$ \\
\hline $9 *$ & & & $100 \%$ & Ethyl Acetate & $\begin{array}{l}\text { Ether-Linked Isoprenoids, } \\
\text { Alkan-1,15-diols, Polar Lipids }\end{array}$ \\
\hline 10 & & & $100 \%$ & Methanol & Polar Lipids \\
\hline
\end{tabular}

*used for compound-specific ${ }^{14} \mathrm{C}$ analysis 
The $n$-alkanes eluted in Fraction 1, along with a series of highly-branched isoprenoid alkenes characteristic of diatoms (not analyzed). Most of the Fraction 1 biomarkers were obscured by the presence of an abundant unresolved complex mixture (UCM), characteristic of weathered petroleum or fossil carbon. The $n$-alkanes for isotopic analysis were separated from the UCM by urea adduction. Dry samples were dissolved in a minimum of iso-octane. Supersaturated urea/ $\mathrm{CH}_{3} \mathrm{OH}\left(50^{\circ} \mathrm{C}\right)$ was added dropwise, and the solutions were swirled and cooled to promote growth of the crystalline adducts. Solvents were evaporated and two additional aliquots of urea/ $\mathrm{CH}_{3} \mathrm{OH}$ added. Non-adducts were separated by rinsing the final crystals with iso-octane. The adducted $n$-alkanes (and alkenes) were partitioned into hexane after addition of $\mathrm{H}_{2} \mathrm{O}$ to dissolve the urea crystals. The $n$-alkane mixtures were further purified by eluting first through acidcleaned granular $\mathrm{Cu}$ to remove elemental sulfur; the samples (in hexane) were then passed through a mini-column packed with $\mathrm{AgNO}_{3}$-impregnated $\mathrm{SiO}_{2}$ gel $\left(10 \% \mathrm{AgNO}_{3}\right.$, prepared by $\mathrm{L}$. $\mathrm{Xu}$ ) to remove linear alkenes. The resulting $n$-alkane fractions for compound-specific isotope analysis were quite pure.

Fatty acid methyl esters (FAMEs) and ketones co-eluted in Fraction 5. The two compound classes were separated from each other using Varian ${ }^{\circledR}$ aminopropyl-bonded $\mathrm{SiO}_{2}$ gel $\left(\mathrm{NH}_{2}, 40 \mu \mathrm{m}\right.$, Lot \# 110597). Approximately $2 \mathrm{~g}$ sorbent was cleaned with $\mathrm{CH}_{2} \mathrm{Cl}_{2}$, then equilibrated with hexane and loaded into a liquid chromatography gravityflow column. The samples were added in hexane, and eluted with $15 \mathrm{~mL}$ hexane (Fraction SPC-5_1, FAMEs), another $15 \mathrm{~mL}$ hexane (Fraction SPC-5_2, polyunsaturated FAMEs, not analyzed), and then $2 \times 15 \mathrm{~mL}$ 9:1 hexane: $\mathrm{CH}_{2} \mathrm{Cl}_{2}$ followed by $15 \mathrm{~mL} \mathrm{50:50}$ hexane: $\mathrm{CH}_{2} \mathrm{Cl}_{2}$ (Fractions SPC-5_3, 4, 5; combined to yield all ketones, not analyzed). This step was especially critical because the $\mathrm{C}_{19}$ ketone recovery standard exactly coeluted with $\mathrm{C}_{18: 1 \omega 7}$ FAME during gas chromatographic separation. Only the FAME fraction (SPC_1) was used for compound-specific isotopic analysis in this work.

Dinosterol, other 4-methyl-sterols, and the hopanols were separated by urea adduction from the $n$-alcohols and alkan-15-one-1-ols in Fraction 7. The procedure was the same as described for the separation of $n$-alkanes as urea adducts. Both the adducted 
alcohols and the non-adducted fractions were used for compound-specific isotopic analysis. The 4-desmethyl-sterols eluted in Fraction 8, occasionally with a small amount of the alkan-15-one-1-ols, but otherwise as a very pure mixture of sterol isomers only. No further purification of this fraction was needed.

Derivatives resistant to hydrolysis are necessary for PCGC separation and $\Delta^{14} \mathrm{C}$ measurement of individual lipids. The $95 \%$ splits of each alcohol fraction were acetylated using an Alltech Acetylation kit (Lot \#11689, $\delta^{13} \mathrm{C}=-27.1 \%$ o, $\Delta^{14} \mathrm{C}=-997 \%$ ). Samples were dissolved in 2:1 pyridine/acetic anhydride, purged with $\mathrm{N}_{2}$, and stirred $\left(25^{\circ} \mathrm{C}, 12 \mathrm{hr}\right)$. Excess $\mathrm{CH}_{3} \mathrm{OH}$ was then added, and the samples were dried and dissolved in $\mathrm{CH}_{2} \mathrm{Cl}_{2}$ for PCGC separation. The contribution of derivative carbon to the $\Delta^{14} \mathrm{C}$ values is removed by mass balance, where $N$ is the number of carbon atoms in the alcohol carbon skeleton:

$$
\Delta^{14} C_{\text {alcohol }}=\left\lfloor(N+2) * \Delta^{14} C_{\text {measured }}-2 * \Delta^{14} C_{\text {OAc }}\right\rfloor / N .
$$

TMS-ether derivatives of the alcohols were prepared for accurate determination of compound-specific $\delta^{13} \mathrm{C}$ by $\mathrm{irm}$-GC/MS. The $\delta^{13} \mathrm{C}$ subsamples were derivatized with Alltech BSTFA + 1\% TMS (Lot \# $12960, \delta^{13} \mathrm{C}=-45.3 \%$ for carbon in the TMS group, pre-determined by addition to a standard of known isotopic composition, 2 replicates (S. Sylva, personal communication) ) mixed $1: 1$ with pyridine $\left(60^{\circ} \mathrm{C}, 5 \mathrm{~min}\right)$. The contribution of derivative carbon to the $\delta^{13} \mathrm{C}$ values is removed by mass balance:

$$
\delta^{13} C_{\text {alcohol }}=\left\lfloor(N+3) * \delta^{13} C_{\text {measured }}-3 * \delta^{13} C_{T M S}\right\rfloor / N
$$

where $N$ is again the number of carbon atoms. There is no additional fractionation to consider because no carbon-containing bonds are made or broken during the silylation reaction. This was confirmed by adding a reference standard (androstanol, Sigma Lot \# $22 \mathrm{~F} 4013, \delta^{13} \mathrm{C}=-33.3 \%$ ) to each sample. Acetylation of alcohols, on the other hand, 
involves breaking and forming bonds between carbon and oxygen. There is an associated primary isotope effect on the measured $\delta^{13} \mathrm{C}$, and we have found the fractionation is inconsistent from sample to sample. This variability is due to unknown factors but probably is not related to the fractional utilization (Hayes, 1993) of acetic anhydride, as it was always present in great excess. Irregular fractionation renders acetates unacceptable derivatives for determination of compound specific $\delta^{13} \mathrm{C}$ by irm-GC/MS. Acetates pose no problem for ${ }^{14} \mathrm{C}$ analyses because $\Delta^{14} \mathrm{C}$ values are always normalized to a constant $\delta^{13} \mathrm{C}=-25 \%$.

The FAME fractions were used for isotopic analysis without further modification. The contribution of the methyl carbon obtained from methanol during the transesterification step was removed by isotopic mass balance:

$$
\delta^{13} C_{F A M E}=\left\lfloor(N+1) * \delta^{13} C_{\text {measured }}-\delta^{13} C_{\text {MeOH }}\right\rfloor / N
$$

for ${ }^{13} \mathrm{C}$ and

$$
\Delta^{14} C_{F A M E}=\left\lfloor(N+1) * \Delta^{14} C_{\text {measured }}-\Delta^{14} C_{\text {MeOH }}\right\rfloor / N
$$

for ${ }^{14} \mathrm{C}$.

Ether-linked membrane lipids characteristic of Archaea eluted in 100\% ethyl acetate (Fraction 9). The ether linkage was cleaved by reflux in $55 \mathrm{wt} \% \mathrm{HI}$, followed by reduction under $\mathrm{LiAlH}_{4}$ following the procedure described in Hoefs et al. (1997). This treatment generated $\mathrm{C}_{40}$ isoprenoid hydrocarbons from the archaeal membrane lipid, caldarchaeol, and a series of even carbon number $n$-alkanes from the reduction of alkan1,15-diols also present in Fraction 9. 


\subsubsection{High-Resolution Gas Chromatography (HRGC)}

Routine gas chromatography (GC) was performed on a HP 5890 Series II GC equipped with dual columns and FID detectors. The GC uses a Gerstel Cooled Injection System 3 (CIS-3), programmed from $30^{\circ} \mathrm{C}(0.3 \mathrm{~min})$ by $12^{\circ} \mathrm{C} / \mathrm{sec}$ to $350^{\circ} \mathrm{C}(8 \mathrm{~min})$ with purge valves "off" between $0.3 \mathrm{~min}$ and $2.0 \mathrm{~min}$, "on" otherwise. Capillary columns were 2 of the following (in various combinations): J \& W Scientific DB-5, Chrompack CP-Sil 5CB, Restek RTX 200, all 60m x $0.32 \mathrm{~mm} \times 0.25 \mu \mathrm{m}$ (length $\mathrm{x}$ i.d. $\mathrm{x}$ film thickness). Samples were run using constant flow mode. GC temperature programs for $n$-alkane samples (in hexane) were $40^{\circ} \mathrm{C}(1 \mathrm{~min}), 4^{\circ} \mathrm{C} / \mathrm{min}$ to $320^{\circ} \mathrm{C}(35 \mathrm{~min})$; for FAME samples (in $\mathrm{CH}_{2} \mathrm{Cl}_{2}$ ), $40^{\circ} \mathrm{C}(1 \mathrm{~min}), 20^{\circ} \mathrm{C} / \mathrm{min}$ to $160^{\circ} \mathrm{C}, 4^{\circ} \mathrm{C} / \mathrm{min}$ to $320^{\circ} \mathrm{C}(35 \mathrm{~min}$ ); for acetylated alcohols (in $\left.\mathrm{CH}_{2} \mathrm{Cl}_{2}\right), 40^{\circ} \mathrm{C}\left(1 \mathrm{~min}\right.$ ), $30^{\circ} \mathrm{C} / \mathrm{min}$ to $120^{\circ} \mathrm{C}, 10^{\circ} \mathrm{C} / \mathrm{min}$ to $260^{\circ} \mathrm{C}$, $2.5^{\circ} \mathrm{C} / \mathrm{min}$ to $320^{\circ} \mathrm{C}$ ( $25 \mathrm{~min}$ ); for ether-linked isoprenoid hydrocarbons (in hexane), $40^{\circ} \mathrm{C}$ $(1 \mathrm{~min}), 20^{\circ} \mathrm{C} / \mathrm{min}$ to $130^{\circ} \mathrm{C}, 4^{\circ} \mathrm{C} / \mathrm{min}$ to $320^{\circ} \mathrm{C}$ (40 min).

Temperature programs for alcohols in pyridine (-OTMS samples for $\mathrm{irm}$-GC/MS) were $100^{\circ} \mathrm{C}(1 \mathrm{~min}), 20^{\circ} \mathrm{C} / \mathrm{min}$ to $260^{\circ} \mathrm{C}, 2.5^{\circ} \mathrm{C} / \mathrm{min}$ to $320^{\circ} \mathrm{C}(20 \mathrm{~min})$.

\subsubsection{Gas Chromatography Mass Spectrometry (GC/MS)}

Compound identities were confirmed on either a HP 6890 GC with attached HP 5973 mass selective detector (EI, 70eV), or on a high-resolution VG AutoSpec mass spectrometer (VG Autospec-Q hybrid MS; EI ionization energy, $70 \mathrm{eV}$ ) interfaced with a HP 5890 Series II GC. J \& W Scientific DB-5 columns were used, and GC conditions were as stated above.

Alkane, $n$-alcohol, and FAME structures were easily determined by examination of the mass spectra. Branched-chain and unsaturated fatty acid identities were confirmed by comparison with relative retention times (e.g. Perry et al. (1979), Volkman (1986)) reported in the literature, and in the case of anteiso- and iso- $\mathrm{C}_{15: 0}$ and $\mathrm{C}_{18: 1 \omega 7}$, by injection of authentic standards. Sterol identities were confirmed as both-OTMS ethers and 
acetates by examination of the mass fragmentograms, retention characteristics (e.g. Volkman (1986); Filley et al. (1997)), and comparison with previous assignments (e.g. Smith (1984), for-OTMS; and McCaffrey (1990) for acetates); the identity of $\beta$ sitosterol was also confirmed with an authentic standard. The hopanols were identified by examination of the acetate-derivative mass spectra, and these were compared to the spectra published by McCaffrey (1990); the mass-191 ion chromatogram was also compared to the mass-191 trace published by Venkatesan et al. (1990) for Santa Monica Basin sedimentary triterpenoids. Alkan-1,15-diols and alkan-15-one-1-ols were identified based on the previously published mass spectra of -OTMS ethers (e.g. de Leeuw et al. (1981), Volkman et al. (1992)) and acetates (e.g. McCaffrey (1990)). All of these biomarkers were analyzed on the VG Autospec-Q mass spectrometer.

$\mathrm{C}_{40}$ isoprenoids derived from hydrolysis of archaebacterial ether lipids were identified by comparison of GC retention characteristics and individual mass spectra with the reports of Hoefs et al., (1997), DeLong et al. (1998), and King et al. (1998). These reaction products were analyzed on a HP 6890/5973 GC/MS system using similar conditions as in DeLong et al. (1998).

\subsubsection{Isotope Ratio Monitoring Gas Chromatography Mass Spectrometry (irm- GC/MS)}

Compound-specific $\delta^{13} \mathrm{C}$ values for all samples were determined in triplicate on a Finnigan Delta ${ }^{\text {Plus }}$ stable isotope mass spectrometer with attached Finnigan GC combustion III interface and HP 6890 GC, configured similarly to the system described in Hayes et al. (1990). Samples were injected via cool on-column injection and separated on a J \& W Scientific DB-5MS (60m x $0.25 \mathrm{~mm}$ i.d. x $25 \mu \mathrm{m}$ film thickness) column equipped with a $1-\mathrm{m}$ deactivated silica guard column. Isotope ratios for all peaks were calculated relative to multiple pulses of $\mathrm{CO}_{2}$ reference gas of known isotopic composition, introduced both before and after the sample peaks of interest. The standard 
deviations of the replicate measurements are reported individually for each peak, and are generally $< \pm 0.3 \%$. $\quad \delta^{13} \mathrm{C}$ is reported relative to the PDB standard.

Accuracy was confirmed by adding standards of known isotopic composition to the sample vials, or by running separate standard solutions before or after a series of analytical runs. Alkane and $\mathrm{C}_{40}$ isoprenoid data were checked by separate measurement of a series of standard $n$-alkanes $\left(n-\mathrm{C}_{24}, n-\mathrm{C}_{32}, n-\mathrm{C}_{34}\right.$, and $n-\mathrm{C}_{40}$; obtained from the laboratory of $\mathrm{J}$. M. Hayes) of known isotopic composition. The measurement precision (three replicates) for these hydrocarbon samples was $\pm 0.4 \%$, and the absolute accuracy of the $\delta^{13} \mathrm{C}$ values was within $0.5 \%$ of the "true" $\delta^{13} \mathrm{C}$ of the standards (average error, $0.3 \%$ depleted relative to "true" $\delta^{13} \mathrm{C}$ ). FAME samples were compared to independent injections of $n-\mathrm{C}_{18}$ FAME, prepared from stearic acid $\left(\delta^{13} \mathrm{C}=-29.9 \%\right.$ ) and derivatized with methanol of known isotopic composition $\left(\delta^{13} \mathrm{C}=-51.3 \%\right.$ ). The two replicates differed by $\pm 0.2 \%$ in their measurement precision, and the error was $0.3 \%$ (enrichment relative to "true" $\delta^{13} \mathrm{C}=-30.4 \%$ ).

Eleven alcohol fractions were analyzed by irm-GC/MS as -OTMS ethers, in triplicate. Accuracy was confirmed by adding a standard of known isotopic composition (androstanol) to each sample and determining its $\delta^{13} \mathrm{C}$. The average $\delta^{13} \mathrm{C}$ values for androstanol were compared to the "true" value of $-33.3 \%$. The $\mathrm{irm}$-GC/MS data for alcohols are not biased in any particular direction (the average deviation from $-33.3 \%$ is only $\pm 0.1 \%$, but measurement precision, as estimated from the average of the absolute values of the measurement errors, appears to be $\pm 0.4 \%$.

\subsubsection{Preparative Capillary Gas Chromatography (PCGC)}

Collection of microgram quantities of purified individual lipids by PCGC was described in detail by Eglinton et al. (1996). A drawing of the PCGC system in shown in Figure 2.1. A HP 5890 series II GC, equipped with HP 7673 auto-injector, Gerstel CIS-2 injection system, and Gerstel preparative trapping device (PTD) is fitted with a SGE BPX-5 (95\%-dimethyl-5\%-phenyl-polysiloxane), ultra-low-bleed, "megabore" (60m x 
$0.53 \mathrm{~mm}$ i.d. $\times 0.5 \mu \mathrm{m}$ film thickness) capillary column. The high sample loadings are accommodated through use of a cooled injection system (CIS) combined with a "megabore" capillary column. The CIS accepts an injection volume of $5 \mu \mathrm{L}$ by using a rapid temperature ramp to eliminate solvent before the sample is introduced to the column. Baseline separation of peaks can be achieved on the high-capacity capillary column, even at concentrations that are $>100$-fold higher than typical analytical GC conditions. The automated computer control of the entire system also results in peak retention times that vary by less than 1 second throughout an entire 100-run series, provided sample loadings remain constant.

\section{Figure 2.1}

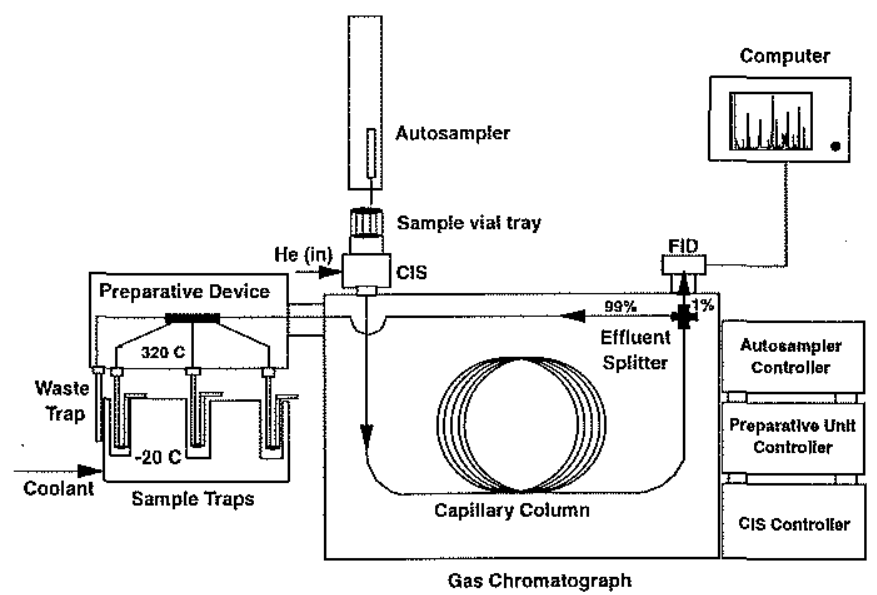

Figure 2.1 Schematic of the PCGC system.

One percent of the effluent passes to the FID and the remaining $99 \%$ is collected in a series of seven U-tube traps. Computer control synchronizes injection and trapping time windows, permitting collection of multiple identical runs (often $>100$ consecutive injections). Six traps are programmed to collect compounds of interest, while the seventh receives the remainder of the mixture. This configuration was used for all FAME and 
alcohol samples. GC temperature programs for FAME samples (in $\mathrm{CH}_{2} \mathrm{Cl}_{2}$ ) were $40^{\circ} \mathrm{C}$ (1 $\mathrm{min}$ ), $20^{\circ} \mathrm{C} / \mathrm{min}$ to $160^{\circ} \mathrm{C}, 4^{\circ} \mathrm{C} / \mathrm{min}$ to $320^{\circ} \mathrm{C}$ (28 $\mathrm{min}$ ); and for alcohols (in $\mathrm{CH}_{2} \mathrm{Cl}_{2}$ ), $40^{\circ} \mathrm{C}(1 \mathrm{~min}), 20^{\circ} \mathrm{C} / \mathrm{min}$ to $270^{\circ} \mathrm{C}, 2.5^{\circ} \mathrm{C} / \mathrm{min}$ to $320^{\circ} \mathrm{C}(25 \mathrm{~min})$. The PTD was operated at $320^{\circ} \mathrm{C}$ and the U-tube traps at room temperature for alcohol samples; the compounds were observed to condense in the U-tubes as solids. FAMEs smaller than the $n-C_{21: 0}$ FAME standard were collected with the U-tube traps chilled to $0^{\circ} \mathrm{C}$ to prevent volatile losses.

The $n$-alkane samples were separated using a "megabore" Chrompak CP-Sil 5 CB capillary column (100\% dimethyl-polysiloxane, $100 \mathrm{~m} \times 0.53 \mathrm{~mm}$ i.d. $\mathrm{x} 0.5 \mu \mathrm{m}$ film thickness). GC temperature programs for $n$-alkane samples (in hexane) were $40^{\circ} \mathrm{C}(1$ $\mathrm{min}), 20^{\circ} \mathrm{C} / \mathrm{min}$ to $160^{\circ} \mathrm{C}, 4^{\circ} \mathrm{C} / \mathrm{min}$ to $320^{\circ} \mathrm{C}(25 \mathrm{~min})$. The U-tube traps were left at room temperature, as no compounds with carbon number below $n-\mathrm{C}_{24}$ were collected.

The $\mathrm{C}_{40}$ isoprenoid hydrocarbons and $n$ - $\mathrm{C}_{30}$ alkane (from reduction of $\mathrm{C}_{30}$-alkan1,15-diol) were isolated using an Alltech ${ }^{\circledR} 1$-m multicapillary column (film thickness 0.2 $\mu \mathrm{m}, 900$ microscopic capillaries in a bundle with overall diameter $\sim 5 \mathrm{~mm})$. GC temperature programs for these samples (in hexane) were, $40^{\circ} \mathrm{C}(0.5 \mathrm{~min}), 20^{\circ} \mathrm{C} / \mathrm{min}$ to $280^{\circ} \mathrm{C}(7 \mathrm{~min})=19.5$ minutes total with a measured flow rate of $\geq 60 \mathrm{~mL} / \mathrm{min}$ He carrier gas. An internal standard $\left(n-\mathrm{C}_{33}\right.$ alkane) of known ${ }^{14} \mathrm{C}$ isotopic composition $\left(\Delta^{14} \mathrm{C}=\right.$ $+146 \%$ $\pm 5 \%$ ) was added to the lipid mixture and subsequently recovered to check for ${ }^{14} \mathrm{C}$-contamination during PCGC procedures.

In some PCGC runs, the purified compounds (especially those with carbon number $\geq 30$ ) were occasionally recovered and observed to contain a faint yellow-orange color. The source of this color was probably column bleed that could have migrated into the traps. To remove this component, alcohol samples (for all $\geq \mathrm{C}_{24}$ biomarkers) were eluted with $10 \%$ ethyl acetate/hexane through $\mathrm{SiO}_{2}$-gel columns (prepared in Pasteur pipettes, then combusted at $450^{\circ} \mathrm{C}, 8 \mathrm{hr}$ ); and $n$-alkanes and $\mathrm{C}_{40}$ isoprenoids were eluted 
with hexane only ( both solvents, Fisher GC Resolv ${ }^{\circledR}$ ). The solvent was evaporated under ultra-high-purity $\mathrm{N}_{2}$. The faint color is always retained on the $\mathrm{SiO}_{2}$-gel ${ }^{1}$.

\subsubsection{Accelerator Mass Spectrometry (AMS)}

The purified compounds were sealed in evacuated quartz tubes with $100 \mathrm{mg} \mathrm{CuO}$ and combusted to $\mathrm{CO}_{2}\left(850^{\circ} \mathrm{C}, 5 \mathrm{hr}\right)$. The $\mathrm{CO}_{2}$ was reduced to graphite over cobalt catalyst (McNichol et al., 1992; Pearson et al., 1998). ${ }^{14} \mathrm{C}-\mathrm{AMS}$ analysis was performed using special methods (Pearson et al., 1998; von Reden et al., 1998) necessary for the accurate determination of $\Delta^{14} \mathrm{C}$ in samples containing $<0.5-1.0 \mathrm{mgC}$, the amount normally used for ${ }^{14} \mathrm{C}$-AMS measurements. For our samples, which all have known geochronological ages, the reported $\Delta^{14} \mathrm{C}=\left[\mathrm{f}_{\mathrm{m}} \mathrm{e}^{(1950-\mathrm{x}) \lambda}-1\right] * 1000$ (Stuiver and Polach, 1977), where $\lambda=1 / 8267\left(\mathrm{yr}^{-1}\right), \mathrm{f}_{\mathrm{m}}=$ fraction modern ${ }^{14} \mathrm{C}$, corrected for isotopic fractionation using $\delta^{13} \mathrm{C}$, and " $\mathrm{x}$ " equals the year of deposition (determined from the ${ }^{210} \mathrm{~Pb}$ chronology). This removes the effects of in-situ ${ }^{14} \mathrm{C}$ decay and normalizes the $\Delta^{14} \mathrm{C}$ data to the values each sample would have had when deposited at the sediment-water interface. The errors reported are NOSAMS "external error", unless the "internal" (counting statistics) error was larger.

$10 \%$ splits of the purified $\mathrm{CO}_{2}$ from each sample were also used to independently confirm $\delta^{13} \mathrm{C}$ of the biomarkers by off-line conventional isotope ratio mass spectrometry (see appendix).

\footnotetext{
${ }^{1}$ This clean-up procedure was performed for all PCGC series BU-CN. For series AS-BK, this clean-up was not used. Many of the high-boiling compounds from these early series were therefore contaminated by column bleed, and the data from several entire series were rejected. This problem especially affected the alcohol samples, but it was not a large problem for FAME fractions. A complete table of all PCGC series, including rejected samples and the reasons for rejection is included in the appendix to this chapter.
} 


\subsection{REFERENCES}

Christensen, C. J., Gorsline, D. S., Hammond, D. E., and Lund, S. P. (1994) Non-annual laminations and expansion of anoxic basin-floor conditions in Santa Monica Basin, California Borderland, over the past four centuries. Mar. Geol. 116, 399 418.

De Leeuw, J. W., Rijpstra, I. C., and Schenck, P. A. (1981) The occurrence and identification of $\mathrm{C}_{30}, \mathrm{C}_{31}$ and $\mathrm{C}_{32}$ alkan-1,15-diols and alkan-15-one-1-ols in Unit I and Unit II Black Sea sediments. Geochim. Cosmochim. Acta 45, 2281-2285.

DeLong, E. F. (1992) Archaea in coastal marine environments. Proc. Natl. Acad. Sci. 89, 5685-5689.

Eglinton, T. I., Aluwihare, L. I., Bauer, J. E., Druffel, E. R. M., and McNichol, A. P. (1996) Gas chromatographic isolation of individual compounds from complex matrices for radiocarbon dating. Anal. Chem. 68, 904-912.

Filley, T. R., Freeman, K. H., and Hatcher, P. G. (1997) Carbon isotope relationships between sulfide-bound steroids and proposed functionalized lipid precursors in sediments from the Santa Barbara Basin, California. Org. Geochem. 25, 367-377.

Hagadorn, J. W., Stott, L. D., Sinha, A. and Rincon, M. (1995) Geochemical and sedimentologic variations in inter-annually laminated sediments from Santa Monica Basin. Mar. Geology 125, 111-131.

Hayes, J. M. (1993) Factors controlling the ${ }^{13} \mathrm{C}$ content of sedimentary organic compounds: Principles and evidence. Mar. Geol. 113, 111-125.

Hayes, J. M., Freeman, K. H., Popp, B. N., and Hoham, C. H. (1990) Compound-specific isotopic analyses: A novel tool for reconstruction of ancient biogeochemical processes. Org. Geochem. 16, 1115-1128.

Hoefs, M. J. L., Schouten, S., deLeeuw, J. W., King, L. L., Wakeham, S. G., and Sinninghe Damsté, J. S. (1997) Ether lipids of planktonic Archaea in the marine water column. Appl. Environ. Microbiol. 63, 3090-3095.

Huh, C.-A., Zahnle, D. L., and Small, L. F. (1987) Budgets and behaviors of uranium and thorium series isotopes in Santa Monica Basin sediments. Geochim. et Cosmochim. Acta 51, 1743-1754.

King, L. L., Pease, T. K., and Wakeham, S. G. (1998) Archaea in Black Sea water colummn particulate matter and sediments - evidence from ether lipid derivatives. Org. Geochem. 28, 677-688.

McCaffrey, M. A. (1990) Sedimentary lipids as indicators of depositional conditions in the coastal Peruvian upwelling regime. Ph.D. thesis, Woods Hole Oceanographic Institution/Massachusetts Institute of Technology.

McNichol, A. P. and Jones, G. A. (1991) Measuring ${ }^{14} \mathrm{C}$ in seawater $\Sigma \mathrm{CO}_{2}$ by accelerator mass spectrometry, WHP operations and methods. In Joyce, T., Corry, C., and Stalcup, M., Eds. 1991 WOCE Operations Manual, Part 3.1.2, Requirements for WHP Data Reporting, WHPO Publication 90-1, 71p. 
McNichol, A. P., Gagnon, A. R., Jones, G. A., and Osborne, E. A. (1992) Illumination of a black box: Analysis of gas composition during graphite target preparation. Radiocarbon 34, 321-329.

McNichol, A. P., Osborne, E. A., Gagnon, A. R., Fry, B. and Jones, G. A. (1994a) TIC, TOC, DIC, DOC, PIC, POC - unique aspects in the preparation of oceanographic samples for ${ }^{14} \mathrm{C}$-AMS. Nucl. Instr. Meth. Phys. Res. B92, 162-165.

McNichol, A. P., Jones, G. A., Hutton, D. L. and Gagnon, A. R. (1994b) The rapid preparation of seawater $\Sigma \mathrm{CO}_{2}$ for radiocarbon analysis at the National Ocean Sciences AMS facility. Radiocarbon 36, 237-246.

Pearson, A., McNichol, A. P., Schneider, R. J., and von Reden, K. F. (1998) Microscale AMS ${ }^{14} \mathrm{C}$ measurement at NOSAMS. Radiocarbon 40, 61-76.

Perry, G. J., Volkman, J. K., Johns, R. B., and Bavor, H. J., Jr. (1979) Fatty acids of bacterial origin in contemporary marine sediments. Geochim. Cosmochim. Acta $43,1715-1725$.

Schimmelmann, A., and Tegner, M. J. (1991) Historical oceanographic events reflected in the ${ }^{13} \mathrm{C} /{ }^{12} \mathrm{C}$ ratio of total organic carbon in laminated Santa Barbara Basin Sediment. Global Biogeochem. Cycles 5, 173-188.

Smith, D. J. (1984) Biogeochemistry of lipids in recent organic-rich marine sediments. $\mathrm{Ph}$. D. Thesis, University of Bristol, UK, $333 \mathrm{pp}$.

Stuiver, M. and Polach, H. A. (1977) Discussion: Reporting of ${ }^{14} \mathrm{C}$ data. Radiocarbon 19, 355-363.

Venkatesan, M. I., Ruth, E., and Kaplan, I. R. (1990) Triterpenols from sediments of Santa Monica Basin, Southern California Bight, USA. Org. Geochem. 16, 10151024.

Vogel, J. S., Southon, J. R., and Nelson, D. E. (1987) Catalyst and binder effects in the use of filamentous graphite for AMS. In Gove, H.E., Litherland, A.E. and Elmore, D., eds., Proceedings of the 4th International Symposium on Accelerator Mass Spectrometry. Nuclear Instruments and Methods B 29, 50-56.

Volkman, J. K. (1986) A review of sterol markers for marine and terrigenous organic matter. Org. Geochem. 9, 83-99.

Volkman, J. K., Barrett, S. M., Dunstan, G. A., and Jeffrey, S. W. (1992) $C_{30}-C_{32}$ alkyl diols and unsaturated alcohols in microalgae of the class Eustigmatophyceae. Org. Geochem. 18, 131-138.

von Reden, K. F., Schneider, R. J., McNichol, A. P., and Pearson, A. (1998) ${ }^{14}$ C AMS measurements of $<100 \mathrm{mg}$ samples with a high-current system. Proceedings of the $16^{\text {th }}$ International ${ }^{14} \mathrm{C}$ conference, edited by W. G. Mook and J. van der Plicht, Radiocarbon, 40, 247- . 


\subsection{APPENDIX}

\subsubsection{SMB Bulk Core Data}

The SMB core profiles of $\delta^{13} \mathrm{C}_{\mathrm{TOC}}$, organic C/N, mass of extractable lipids (TLE), and percent organic $\mathrm{C}$ are presented below in Figures 2.2, 2.3, 2.4, and 2.5.

Figure 2.2

Santa Monica Basin $\delta^{13} \mathrm{C}$ TOC

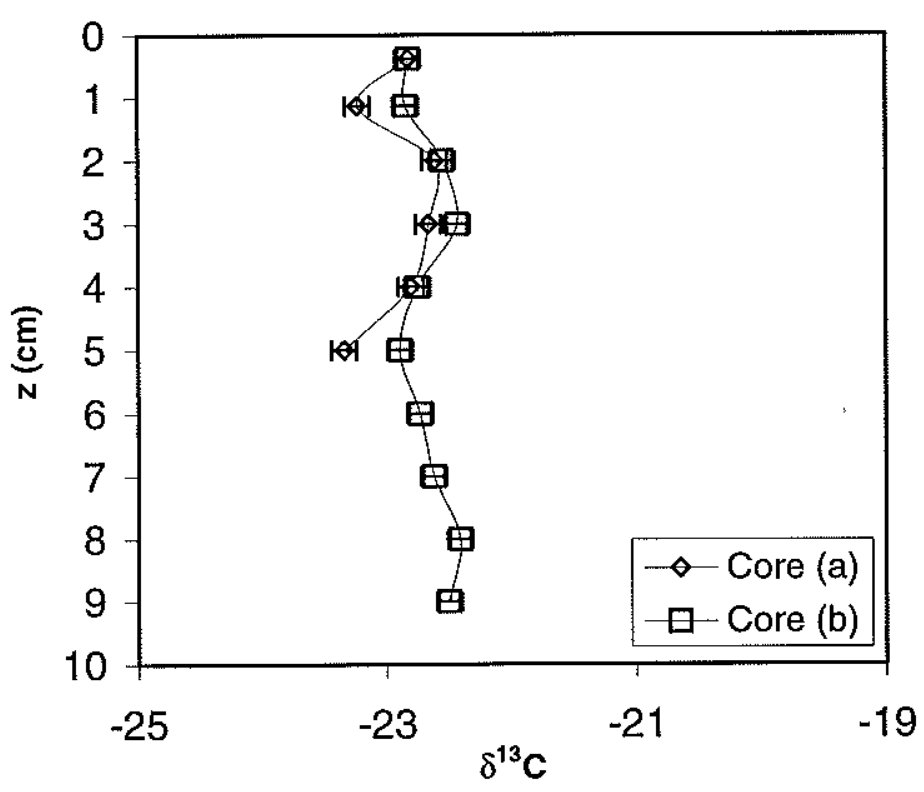

Figure 2.2 SMB sedimentary $\delta^{13} \mathrm{C}_{\mathrm{TOC}}$, measured on splits of $\mathrm{CO}_{2}$ prepared by closedtube combustion. 
Figure 2.3

SMB Organic $\mathrm{C} / \mathrm{N}$

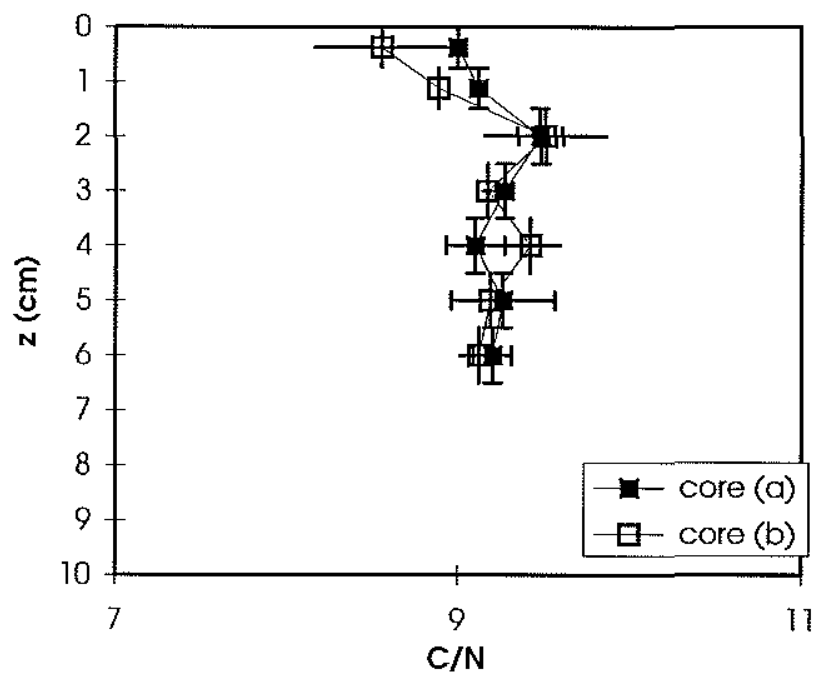

Figure 2.3 Organic $\mathrm{C} / \mathrm{N}$ ratio in SMB sediment.

\section{Figure 2.4}

mg TLE/gdw

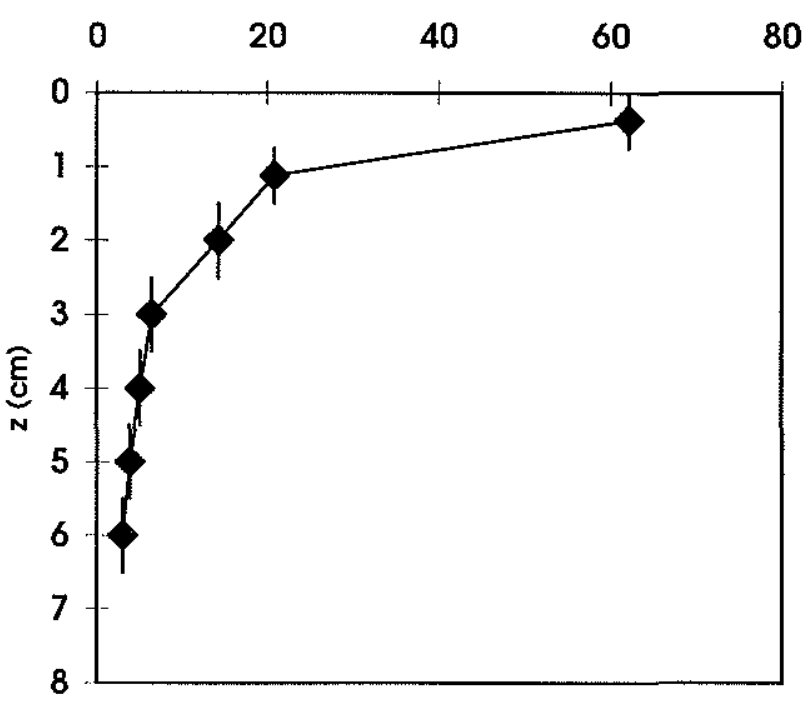

Figure 2.4 Total extractable lipids in SMB sediment. 
Figure 2.5

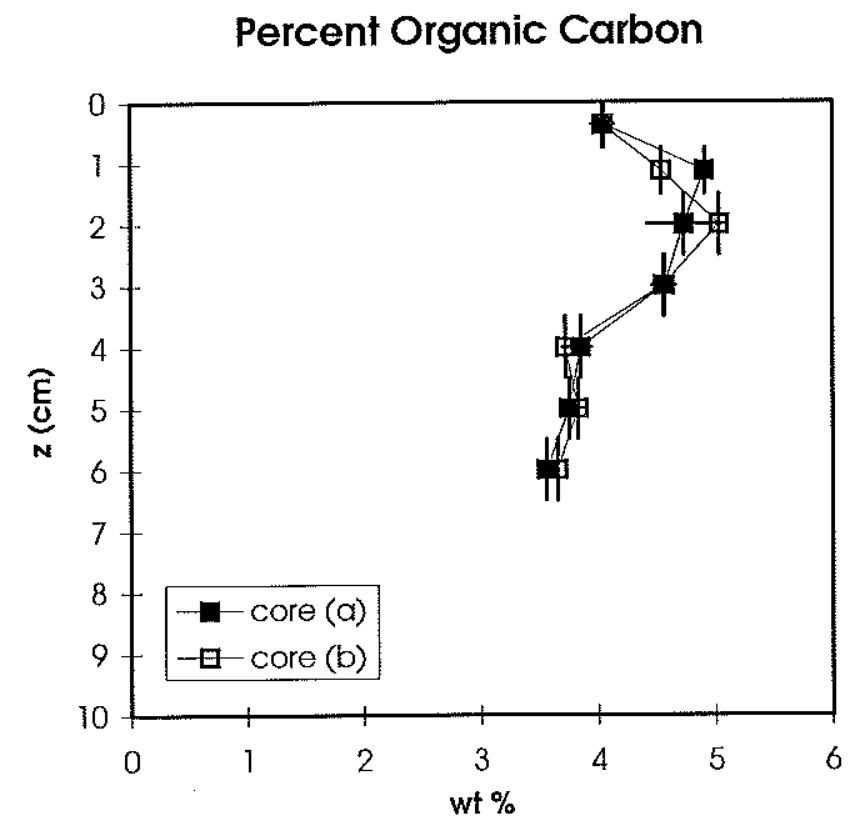

Figure 2.5 Percent organic carbon in SMB sediment.

\subsubsection{PCGC Sample Log}

All attempted PCGC series are shown below, listing the biomarkers that were trapped for each series. The compound structures are listed by their common organic geochemical abbreviations. The Letter Code column contains the letters used to identify the individual compounds and data points in Tables 6.1 and 6.2 and Figures 6.20, 6.21, and 7.5. The QA/QC column contains number codes for the reasons why particular samples yielded no ${ }^{14} \mathrm{C}$-AMS data or yielded data that was subsequently rejected. The number of acceptable data points increased greatly after the column-bleed clean-up procedure was introduced. 
The guide to the QA/QC number codes is as follows:

1 graphite too small, or low $\mathrm{C} / \mathrm{Co}$, or low AMS current $\left(\mathrm{I}_{12}\right)$

2 sample lost as $\mathrm{CO}_{2}$

3 column bleed or apparent contamination

3(nc) column bleed perhaps specifically due to new column

4 no apparent peaks trapped or unsatisfactory peak purity on PCGC

5 AMS dilution samples (failed)

Table 2.2 Complete PCGC Sample Log.

\begin{tabular}{|c|c|c|c|c|c|}
\hline Series and Trap & Compound & Horizon & Graphite Yield & $\mathrm{QA} / \mathrm{QC}$ & Letter Code \\
\hline AS-1 & $a-\mathrm{C}_{15: 0}$ & SMB $4.5-5.5 \mathrm{~cm}$, & 61 & & f \\
\hline AS-2 & $\mathrm{C}_{16: 0}$ & Pre-Bomb & 86,159 & & $\mathrm{~h}$ \\
\hline AS-3 & $\mathrm{C}_{18: \mathrm{I} \omega 7}$ & & 21 & 1 & \\
\hline AS-4 & $\mathrm{C}_{21: 0}$ std. & & 64,118 & & \\
\hline AS-5 & $\mathrm{C}_{24: 0}$ & & 85 & & $\mathrm{k}$ \\
\hline AS-6 & $\mathrm{C}_{26: 0}$ & & 49 & & 1 \\
\hline $\mathrm{AU}-1$ & $C_{26} \Delta^{5,22}+\Delta^{22}$ & SMB $4.5-5.5 \mathrm{~cm}$, & -- & 2 & \\
\hline AU-2 & $C_{27} \Delta^{5}$ & Pre-Bomb & 39 & & $\mathrm{w}$ \\
\hline AU-3 & $5 \alpha-C_{27}$ & & -- & 2 & \\
\hline AU-4 & $\mathrm{C}_{28} \Delta^{5,22}$ & & 63 & & $\mathrm{x}$ \\
\hline $\mathrm{AU}-5$ & $\mathrm{C}_{29} \Delta^{5}$ & & 48 & & $\mathrm{y}$ \\
\hline AU-6 & $5 \alpha-C_{29}$ & & 37 & & $\mathrm{z}$ \\
\hline$A V-1$ & $\mathrm{C}_{16}-\mathrm{OH}$ & SMB $4.5-5.5 \mathrm{~cm}$, & 21 & 3 & \\
\hline$A V-2$ & $\mathrm{C}_{19}$-OHstd. & Pre-Bomb & 79 & & \\
\hline $\mathrm{AV}-3$ & $\mathrm{C}_{30}-15$-one-1-ol & & 65 & 3 & \\
\hline $\mathrm{AV}-4$ & $\mathrm{C}_{32}$-15-one-1-ols & & 45 & 3 & \\
\hline $\mathrm{AV}-5$ & $\mathrm{C}_{31}$ hopanol & & 32 & 1,3 & \\
\hline AV-6 & $\mathrm{C}_{32}$ hopanol & & 25 & 1,3 & \\
\hline $\mathrm{AW}-1$ & $\mathrm{C}_{24: 1}-\mathrm{OH}$ & SMB $4.5-5.5 \mathrm{~cm}$, & -- & 4 & \\
\hline AW-2 & $\mathrm{C}_{24} \ldots \mathrm{OH}$ & Pre-Bomb & 47 & 3 & \\
\hline AW-3 & $\mathrm{C}_{26}-\mathrm{OH}$ & & 41 & 3 & \\
\hline AW-4 & Dinosterol & & 98 & & $q$ \\
\hline AW-5 & Tetra/C 30 hopanol & & 34 & 3 & \\
\hline AW-6 & -- & & & & \\
\hline
\end{tabular}




\begin{tabular}{|c|c|c|c|c|c|}
\hline $\mathrm{AX}-1$ & $\mathrm{C}_{24: \mathrm{I}^{-}} \mathrm{OH}$ & SMB $3.5-4.5 \mathrm{~cm}$, & -- & 4 & \\
\hline AX-2 & $\mathrm{C}_{24}-\mathrm{OH}$ & Pre-Bomb & 31 & 1,3 & \\
\hline $\mathrm{AX}-3$ & Dinosterol & & -- & 4 & \\
\hline $\mathrm{AX}-4$ & Tetra/ $C_{30}$ hopanol & & 28 & 1,3 & \\
\hline AX-5 & $\mathrm{C}_{31}$ hopanol & & 26 & 3 & \\
\hline AX-6 & $\mathrm{C}_{32}$ hopanol & & 30 & 1,3 & \\
\hline $\mathrm{AY}-1$ & $C_{26} \Delta^{5,22}+\Delta^{22}$ & SMB $3.5-4.5 \mathrm{~cm}$, & 19 & 1 & \\
\hline AY -2 & $C_{27} \Delta^{5,22}$ & Pre-Bomb & -- & 2 & \\
\hline$A Y-3$ & $\mathrm{C}_{27} \Delta^{5}$ & & -- & 2 & \\
\hline $\mathrm{AY}-4$ & $\mathrm{C}_{29} \Delta^{5}+5 \alpha-\mathrm{C}_{29}$ & & 172 & & $\mathrm{z}$ \\
\hline AY-5 & $\mathrm{C}_{30}$-15-one-1-ol & & 47 & & $\mathrm{p}$ \\
\hline AY -6 & $\mathrm{C}_{32}$-15-one-1-ols & & -- & 4 & \\
\hline BF-1 & $C_{26} \Delta^{5,22}+\Delta^{22}$ & SMB $0-0.75 \mathrm{~cm}$ & 37 & $3(\mathrm{nc})$ & \\
\hline $\mathrm{BF}-2$ & $\mathrm{C}_{27} \Delta^{5}$ & Post-Bomb & 86 & (nc) & \\
\hline $\mathrm{BF}-3$ & $5 \alpha-C_{27}$ & & 54 & $3(\mathrm{nc})$ & \\
\hline $\mathrm{BF}-4$ & $\mathrm{C}_{28} \Delta^{5,22}$ & & 126 & (nc) & \\
\hline $\mathrm{BF}-5$ & $C_{29} \Delta^{5}$ & & 113 & $3(\mathrm{nc})$ & \\
\hline $\mathrm{BF}-6$ & $5 \alpha-C_{29}$ & & - & 2 & \\
\hline BG-1 & $\mathrm{C}_{14: 0}$ & SMB $0-0.75 \mathrm{~cm}$ & -- & 2 & \\
\hline BG-2 & $a-\mathrm{C}_{15: 0}$ & Post-Bomb & 31 & & f \\
\hline BG-3 & $\mathrm{C}_{16: 0}$ & & 81,57 & & $\mathrm{~h}$ \\
\hline BG-4 & $\mathrm{C}_{18: 1 \omega 7}$ & & 78 & & I \\
\hline BG-5 & $\mathrm{C}_{18: 0}$ & & 39 & & $\mathrm{j}$ \\
\hline BG-6 & $\mathrm{C}_{21: 0}$ std. & & -- & 2 & \\
\hline BH-1 & $i-\mathrm{C}_{15: 0}$ & SMB 0-0.75 cm, & 52 & & $\mathrm{e}$ \\
\hline $\mathrm{BH}-2$ & $a-\mathrm{C}_{15: 0}$ & Post-Bomb & 46 & & $\mathrm{f}$ \\
\hline BH-3 & $\mathrm{C}_{15: 0}$ & & 36 & & $\mathrm{~g}$ \\
\hline BH-4 & $C_{23: 0+25: 0+27: 0}$ & & 24 & 1,3 & \\
\hline $\mathrm{BH}-5$ & $\mathrm{C}_{24: 0}$ & & 57 & & $\mathrm{k}$ \\
\hline BH-6 & $\mathrm{C}_{26: 0}$ & & 44 & & 1 \\
\hline BI-1 & $C_{26} \Delta^{5,22}+\Delta^{22}$ & SMB $0-0.75 \mathrm{~cm}$, & 46 & & $\mathrm{u}$ \\
\hline BI-2 & $\mathrm{C}_{27} \Delta^{5,22}$ & Post-Bomb & 113 & & $\mathrm{v}$ \\
\hline BI-3 & $\mathrm{C}_{27} \Delta^{5}$ & & 50,74 & & w \\
\hline BI-4 & $5 \alpha-C_{29}$ & & 96 & & $\mathrm{y}$ \\
\hline BI-5 & $\mathrm{C}_{30}$-15-one-1-ol & & 50 & & $\mathrm{p}$ \\
\hline BI-6 & $\mathrm{C}_{32}$-15-one-1-ols & & & 4 & \\
\hline BJ-1 & $\mathrm{C}_{16}-\mathrm{OH}$ & SMB 0-0.75 cm, & 18 & 1 & \\
\hline $\mathrm{BJ}-2$ & $\mathrm{C}_{19}$-OHstd. & Post-Bomb & 60,94 & & \\
\hline $\mathrm{BJ}-3$ & $\mathrm{C}_{24: 1}-\mathrm{OH}$ & & -- & 4 & \\
\hline BJ -4 & $\mathrm{C}_{24}-\mathrm{OH}$ & & 20 & 1 & \\
\hline $\mathrm{BJ}-5$ & $\mathrm{C}_{26^{m}} \mathrm{OH}$ & & 16 & 1 & \\
\hline BJ -6 & $\mathrm{C}_{30}$-15-one-1-ol & & 23 & 1,3 & \\
\hline
\end{tabular}




\begin{tabular}{|c|c|c|c|c|c|}
\hline$\overline{\mathrm{BK}-1}$ & Dinosterol & SMB $0-0.75 \mathrm{~cm}$ & 48,85 & & $\mathrm{q}$ \\
\hline BK-2 & Tetra/C $\mathrm{C}_{30}$ hopanol & Post-Bomb & 24 & 1,3 & \\
\hline BK-3 & $\mathrm{C}_{31}$ hopanol & & 20 & 1,3 & \\
\hline BK-4 & $\mathrm{C}_{32}$ hopanol & & 27 & 3 & \\
\hline BK-5 & -- & & & & \\
\hline BK-6 & -- & & & & \\
\hline \multicolumn{6}{|c|}{ Begin routine column bleed clean-up procedure. } \\
\hline BV -1 & $n-\mathrm{C}_{28}$ & $\mathrm{SBB} 0-1 \mathrm{~cm}$, & -- & 4 & \\
\hline BV -2 & $n-\mathrm{C}_{30}$ & Post-Bomb & -- & 2 & \\
\hline BV-3 & $n-\mathrm{C}_{33}$ std. & & 88 & & \\
\hline BV -4 & $\mathrm{C}_{40: 2 c y}$ & & 22 & & $\mathrm{C}$ \\
\hline BV-5 & $\mathrm{C}_{40: 3 \mathrm{cy}}$ & & 20 & & $\mathrm{D}$ \\
\hline BV -6 & -- & & & & \\
\hline BX-1 & $\mathrm{C}_{18}$-diol std. & SMB 5.5-8.5 cm, & 22 & & \\
\hline $\mathrm{BX}-2$ & $n-C_{28}$ & Pre-Bomb & -- & 4 & \\
\hline $\mathrm{BX}-3$ & $n-\mathrm{C}_{30}$ & & 26 & & A \\
\hline BX-4 & $\mathrm{C}_{40: 0 c y}$ & & 20 & & B \\
\hline $\mathrm{BX}-5$ & $\mathrm{C}_{40: 2 c y}$ & & 22 & & $\mathrm{C}$ \\
\hline BX-6 & $\mathrm{C}_{40: 3 c y}$ & & 21 & & $\mathrm{D}$ \\
\hline CA-1 & $\mathrm{C}_{27} \Delta^{5,22}$ & SBB 0-1 cm, & 44 & & $\mathrm{v}$ \\
\hline $\mathrm{CA}-2$ & $\mathrm{C}_{27} \Delta^{5}$ & Post-Bomb & 73 & & w \\
\hline $\mathrm{CA}-3$ & $5 \alpha-C_{27}$ & & 39 & & \\
\hline $\mathrm{CA}-4$ & $\mathrm{C}_{28} \Delta^{5,22}$ & & 29 & & $\mathrm{x}$ \\
\hline CA-5 & $\mathrm{C}_{29} \Delta^{5}$ & & 38 & & $\mathrm{y}$ \\
\hline $\mathrm{CA}-6$ & $5 \alpha-C_{29}$ & & 24 & & $\mathrm{z}$ \\
\hline $\mathrm{CB}-1$ & Dinosterol & SMB 5.5-8.5 cm, & -- & 5 & \\
\hline $\mathrm{CB}-2$ & $\mathrm{C}_{31}$ hopanol & Pre-Bomb & 22 & & $\mathrm{~s}$ \\
\hline CB-3 & $\mathrm{C}_{32}$ hopanol & & 40 & & $\mathrm{t}$ \\
\hline CB-4 & -- & & & & \\
\hline CB-5 & -- & & & & \\
\hline CB-6 & -- & & & & \\
\hline $\mathrm{CC}-1$ & Dinosterol & SMB $0.75-1.5 \mathrm{~cm}$ & -- & 5 & \\
\hline $\mathrm{CC}-2$ & Tetra/ $\mathrm{C}_{30}$ hopanol & Post-Bomb & 33 & & $\mathrm{r}$ \\
\hline $\mathrm{CC}-3$ & $\mathrm{C}_{31}$ hopanol & & & & \\
\hline $\mathrm{CC}-4$ & $\mathrm{C}_{32}$ hopanol & & 46 & & $t$ \\
\hline $\mathrm{CC}-5$ & -- & & & & \\
\hline $\mathrm{CC}-6$ & -- & & & & \\
\hline CD-1 & $\mathrm{C}_{16}-\mathrm{OH}$ & SMB $0.75-1.5 \mathrm{~cm}$, & 33 & & $\mathrm{~m}$ \\
\hline CD-2 & $\mathrm{C}_{19}-\mathrm{OHstd}$ & Post-Bomb & -- & 5 & \\
\hline $\mathrm{CD}-3$ & $\mathrm{C}_{22}-\mathrm{OH}$ & & 67 & & $\mathrm{n}$ \\
\hline CD-4 & $\mathrm{C}_{24}-\mathrm{OH}$ & & 74 & & o \\
\hline $\mathrm{CD}-5$ & $\mathrm{C}_{30}$-15-one-1-ol & & 48 & & $\mathrm{p}$ \\
\hline
\end{tabular}




\begin{tabular}{|c|c|c|c|c|c|}
\hline$\overline{\mathrm{CD}-6}$ & $\mathrm{C}_{32}$-15-one-1-ols & & - & 4 & \\
\hline CI-1 & Androstane std. & SMB $0-2.5 \mathrm{~cm}$ & 33 & 4 & \\
\hline $\mathrm{CI}-2$ & $n-C_{24+26+28+30}$ & Post-Bomb & 27 & & a \\
\hline $\mathrm{CI}-3$ & $n-\mathrm{C}_{27}$ & & 19 & & b \\
\hline CI- 4 & $n-\mathrm{C}_{29}$ & & 35 & & $\mathrm{c}$ \\
\hline $\mathrm{CI}-5$ & $n-\mathrm{C}_{31}$ & & 27 & & d \\
\hline CI-6 & -- & & & & \\
\hline CJ-1 & -- & SMB $2.5-8.5 \mathrm{~cm}$ & & & \\
\hline CJ-2 & $n-\mathrm{C}_{24+26+28+30}$ & Pre-Bomb & 33 & & a \\
\hline $\mathrm{CJ}-3$ & $n-\mathrm{C}_{27}$ & & 40 & & $\mathrm{~b}$ \\
\hline CJ-4 & $n-\mathrm{C}_{29}$ & & 86 & & $\mathrm{c}$ \\
\hline CJ.5 & $n-C_{31}$ & & 34 & & d \\
\hline $\mathrm{CJ}-6$ & - & & & & \\
\hline $\mathrm{CN}-1$ & $\mathrm{C}_{16}-\mathrm{OH}$ & SMB $5.5-8.5 \mathrm{~cm}$ & -- & 2 & \\
\hline $\mathrm{CN}-2$ & $\mathrm{C}_{19}$ oHstd. & Pre-Bomb & 76 & & \\
\hline $\mathrm{CN}-3$ & $\mathrm{C}_{22}-\mathrm{OH}$ & & 53 & & $\mathbf{n}$ \\
\hline $\mathrm{CN}-4$ & $\mathrm{C}_{24^{-}} \mathrm{OH}$ & & 37 & & o \\
\hline $\mathrm{CN}-5$ & $\mathrm{C}_{30}-15$-one-1-ol & & -- & 4 & \\
\hline $\mathrm{CN}-6$ & $\mathrm{C}_{32}$-15-one-1-ols & & -- & 4 & \\
\hline
\end{tabular}




\subsubsection{Sample Recoveries and Fractionation}

\subsubsection{Organic Geochemical Procedures}

Table 2.3 shows three examples of FAME fractions at various stages of geochemical separation. The amount of $\mathrm{C}_{21: 0}$ FAME standard recovered is shown after completion of the laboratory steps indicated in the table. Large losses of material are not apparently associated with the extraction, transesterification, and flash chromatographic separation of TLE samples. The addition of a thin layer chromatography (TLC) step to remove interfering ketones from one of the FAME fractions was accompanied by a large loss of the standard. Only $43 \%$ of the original mixture was recovered. Loss of standard was still experienced when the ketones were removed using a solid-phase extraction cartridge (Varian aminopropyl $\mathrm{SiO}_{2}$ gel). However, the extent of loss was not as great, and $75 \%$ of the original total FAMEs were recovered. The sample in this stage was transferred to PCGC for isolation of individual compounds. At the bottom of Table 2.3, the $\mathrm{irm}$-GC/MS values determined for each of these $\mathrm{C}_{21: 0}$ standards are also shown. In parentheses beneath the raw data (corrected for derivative carbon), the numbers are seen to be uniformly $\sim 1 \%$ o heavier than the true $\delta^{13} \mathrm{C}$ of the standard. Although the fractionation is slightly larger for the lowest yield sample ( $1.3 \%$ o for $45 \%$ yield), this is probably insignificantly different than a $1 \%$ fractionation for $96 \%$ yield. The question arises, then, whether this is an irm-GC/MS bias or a real effect. Unfortunately, there is very little other data with which to address this question. Only one $\delta^{13} \mathrm{C}$ value is available for $\mathrm{CO}_{2}$ sample obtained by PCGC separation and combustion of $\mathrm{C}_{21: 0}$. This number $\left(-27.8 \%\right.$ ) is also slightly heavier than the "true" $\delta^{13} \mathrm{C}(-28.56 \%$ ). Regardless, it does not appear that routine laboratory procedures introduce more than a 1.0-1.5\%o fractionation effect on the samples used for PCGC separations. 
Table 2.3 Recoveries and ${ }^{13} \mathrm{C}$ fractionation for organic geochemical methods.

\begin{tabular}{|c|c|c|}
\hline SMB $3.5-4.5 \mathrm{~cm}$ FAMEs & SMB $4.5-5.5 \mathrm{~cm}$ FAMEs & SMB 0-0.75 cm FAMEs \\
\hline Extraction & Extraction & Extraction \\
\hline Transesterification & Transesterification & Transesterification \\
\hline Flash Chromatography & Flash Chromatography & Flash Chromatography \\
\hline & $\begin{array}{l}\text { TLC (to separate FAMEs } \\
\text { from ketones) }\end{array}$ & $\begin{array}{l}\text { Solid Phase Extraction } \\
\left(\mathrm{NH}_{2}-\mathrm{SiO}_{2} \text {, separate }\right. \\
\text { FAMEs from ketones })\end{array}$ \\
\hline $\begin{array}{c}\mathrm{C}_{21: 0} \text { FAME standard } \\
\text { yield: } 96 \%\end{array}$ & $\begin{array}{c}\mathrm{C}_{21: 0} \text { FAME standard } \\
\text { yield: } 43 \%\end{array}$ & $\begin{array}{c}\mathrm{C}_{21: 0} \text { FAME standard } \\
\text { yield: } 75 \%\end{array}$ \\
\hline \multicolumn{3}{|c|}{$\delta^{13} \mathrm{C} \mathrm{C}_{21: 0}$ FAME standard } \\
\hline$-27.6 \%$ & $-27.2 \%$ & $-27.3 \%$ \\
\hline (1.0\% too heavy) & (1.3\%o too heavy) & (1.2\%o too heavy) \\
\hline \multicolumn{3}{|c|}{ PCGC recovery, $\mathrm{C}_{21: 0}$ standard, combusted to $\mathrm{CO}_{2}$} \\
\hline $\begin{array}{c}-27.8 \% \text { o } \\
(0.7 \% \text { o too heavy })\end{array}$ & - & -- \\
\hline
\end{tabular}




\subsubsection{PCGC Sample Recoveries}

In Table 2.4, several PCGC series are examined for the yields of individual compounds. The expected yield based on the known amount of sample introduced into the machine is compared to the amount recovered in the waste trap (Zero-Trap). This yield is translated into expected recoveries for the individual compounds in Traps 1-6. These numbers are compared to HRGC quantitation of the individual traps (with generally good agreement). Then the individual compound recoveries as determined by HRGC are compared to the amount of $\mathrm{CO} 2$ gas recovered from the combusted samples. In most cases, the biggest discrepancy involves the amount of sample injected into the PCGC and the amount recovered in the preparative trapping device (waste trap and individual compounds). The recoveries ranged between $42-78 \%$ and averaged $58 \%$. A large fraction of the sample is apparently lost before reaching the preparative splitting device. The $\sim 40 \%$ loss may occur within the CIS injector, and steps should be taken to optimize the CIS parameters to improve this result. Alternatively, the FID split ratio could be larger than the theoretical $1 \%$ (99\% sent to the preparative trapping device), although it is very difficult to believe this could account for a $40 \%$ loss of material.

There is irregular agreement between the HRGC quantitation of individual compounds and the amount recovered as $\mathrm{CO}_{2}$. Sometimes the two measurements are comparable, or are at least offset in a regular manner, suggesting a systematic measurement problem in either the HRGC or manometric methods for that particular batch. In other sets, the $\mathrm{CO}_{2}$ yields are sometimes larger and sometimes smaller than the HRGC yields. There is no known explanation for this. Possibilities include a small amount of contaminant carbon in the samples, an insufficient water trap step for some of the samples, or errors in both quantitation methods. Previous work by Eglinton et al., (1996) showed that ${ }^{13} \mathrm{C}$ isotopic fractionation within the PCGC system is $<5 \%$; the limited data available here support that conclusion. 
Table 2.4 Recoveries for PCGC samples as determined by various quantitation methods.

\begin{tabular}{|c|c|c|c|c|}
\hline Sample & Amount Injected & $\begin{array}{c}\text { Expected Recovery } \\
\text { (based on HRGC of } \\
\text { 0-Trap) } \\
\end{array}$ & $\begin{array}{l}\text { HRGC Yield for } \\
\text { Individual Traps }\end{array}$ & $\mathrm{CO}_{2}$ yield \\
\hline & & $\begin{array}{l}0 \text {-Trap: } 45 \pm 6 \% \text { of } \\
\text { injected amount }\end{array}$ & & \\
\hline BG-1 & 139 & 63 & 60 & -- \\
\hline BG-2 & 69 & 31 & 32 & 38 \\
\hline BG-3 & 354 & 159 & 161 & 188 \\
\hline BG-4 & 193 & 87 & 78 & 100 \\
\hline BG-5 & 78 & 35 & 36 & 46 \\
\hline \multirow[t]{2}{*}{ BG-6 } & 164 & 74 & 70 & -- \\
\hline & & $\begin{array}{l}0 \text {-Trap: } 60 \pm 6 \% \text { of } \\
\text { injected amount }\end{array}$ & & \\
\hline $\mathrm{BH}-1$ & 103 & 62 & 67 & 60 \\
\hline BH-2 & 114 & 68 & 89 & 52 \\
\hline $\mathrm{BH}-3$ & 63 & 38 & 41 & 40 \\
\hline BH-4 & -- & -- & -- & -- \\
\hline BH-5 & 111 & 67 & 81 & 69 \\
\hline \multirow[t]{2}{*}{ BH-6 } & 77 & 46 & 29 & 54 \\
\hline & & $\begin{array}{l}0 \text {-Trap: } 60 \pm 8 \% \text { of } \\
\text { injected amount }\end{array}$ & & \\
\hline BI-1 & 47 & 28 & 28 & 55 \\
\hline BI-2 & 179 & 107 & 66 & 130 \\
\hline BI-3 & 185 & 111 & 136 & 142 \\
\hline BI-4 & 126 & 76 & -- & 113 \\
\hline BI-5 & 46 & 28 & -- & 56 \\
\hline \multirow[t]{2}{*}{ BI- 6} & 34 & 20 & -- & 53 \\
\hline & & $\begin{array}{l}0 \text {-Trap: } 65 \pm 8 \% \text { of } \\
\text { injected amount }\end{array}$ & & \\
\hline BJ-1 & 26 & 17 & -- & 18 \\
\hline BJ-2 & 292 & 190 & -- & 181 \\
\hline BJ-3 & 20 & 13 & -- & 16 \\
\hline BJ-4 & 33 & 21 & -- & 21 \\
\hline BJ-5 & 30 & 20 & -- & 21 \\
\hline BJ-6 & 32 & 21 & -- & 32 \\
\hline
\end{tabular}




\begin{tabular}{|c|c|c|c|c|}
\hline \multirow[b]{2}{*}{ BK-1 } & \multirow[b]{2}{*}{232} & \multicolumn{3}{|c|}{$\begin{array}{l}0 \text {-Trap: } 78 \pm 8 \% \text { of } \\
\text { injected amount }\end{array}$} \\
\hline & & 181 & -- & 123 \\
\hline BK-2 & 25 & 20 & -- & 22 \\
\hline BK-3 & 24 & 19 & -- & 21 \\
\hline \multirow[t]{2}{*}{ BK-4 } & 25 & 20 & -- & 24 \\
\hline & & \multicolumn{3}{|c|}{$\begin{array}{l}\text { 0-Trap: } 42 \pm 7 \% \text { of } \\
\text { injected amount }\end{array}$} \\
\hline $\mathrm{BH}-1$ & 44 & 18 & 20 & 42 \\
\hline BH-2 & 175 & 74 & 58 & 108 \\
\hline $\mathrm{BH}-3$ & 82 & 34 & 39 & 62 \\
\hline $\mathrm{BH}-4$ & 255 & 107 & 79 & 142 \\
\hline $\mathrm{BH}-5$ & 225 & 94 & 67 & 130 \\
\hline BH-6 & 116 & 49 & 42 & -- \\
\hline
\end{tabular}




\section{CHAPTER 3}

\section{MICROSCALE AMS ${ }^{14} \mathrm{C}$ MEASUREMENT AT NOSAMS}

(This manuscript appeared in Proceedings of the $16^{\text {th }}$ International ${ }^{14} \mathrm{C}$ Conference, edited by W. G. Mook and J. van der Plicht, RADIOCARBON, Vol. 40, No. 1, 61-75 (1998); it is re-printed here with permission of the publisher.)

Ann Pearson, Ann P. McNichol, Robert J. Schneider, Karl F. von Reden

National Ocean Sciences Accelerator Mass

Spectrometry (NOSAMS) Facility

Woods Hole Oceanographic Institution,

Woods Hole, Massachusetts 02543 USA

and Yan Zheng

Lamont-Doherty Earth Observatory, Columbia University, Palisades, New York 10964 USA

\section{AbstraCT}

Techniques for making precise and accurate radiocarbon accelerator mass spectrometry (AMS) measurements on samples containing less than a few hundred micrograms of carbon are being developed at the NOSAMS facility. A detailed examination of all aspects of the sample preparation and data analysis process shows encouraging results. Small quantities of $\mathrm{CO}_{2}$ are reduced to graphite over cobalt catalyst at an optimal temperature of $605^{\circ} \mathrm{C}$. Measured ${ }^{14} \mathrm{C} /{ }^{12} \mathrm{C}$ ratios of the resulting targets are affected by machine-induced isotopic fractionation, which appears directly related to the decrease in ion current generated by the smaller sample sizes. It is possible to compensate effectively for this fractionation by measuring samples relative to small standards of identical size. Examination of the various potential sources of background ${ }^{14} \mathrm{C}$ contamination indicates the sample combustion process is the largest contributor, adding $c a .1 \mu \mathrm{g}$ of carbon with a less-than-modern ${ }^{14} \mathrm{C}$ concentration. 


\subsection{INTRODUCTION}

The development of techniques for ${ }^{14} \mathrm{C}$ analysis by AMS has greatly reduced carbon sample size requirements compared to what is needed for beta counting. The 0.5$1.0 \mathrm{mg}$ of carbon now used to make routine ${ }^{14} \mathrm{C}$ measurements has allowed many fields to take advantage of the opportunities provided by AMS, but there are still some classes of oceanographic and environmental samples that cannot meet this carbon requirement. At the National Ocean Sciences Accelerator Mass Spectrometry (NOSAMS) facility we are seeking a reliable protocol for the analysis of samples that supply less than a few hundred micrograms of carbon $(\mu \mathrm{gC})$; this paper describes in detail our approach to analyzing samples containing no more than $150 \mu \mathrm{gC}$.

Although sample size problems can potentially be resolved by adding sufficient diluent carbon of known isotopic composition, an analysis of the uncertainties associated with this approach suggests it may not yield results at a useful level of precision. The mass balance equations

$$
m_{x} F_{x}=m_{s} F_{s}+m_{d} F_{d}
$$

and

$$
m_{x}=m_{s}+m_{d}
$$

(where $m$ designates mass, $F$ the ${ }^{14} \mathrm{C}$ fractional abundance, and $x, s$, and $d$ are the composite, the sample, and the diluent) can be rewritten as

$$
F_{s}=r_{x} F_{x}-\left(r_{x}-1\right) F_{d}
$$

where $r_{x} \equiv m_{x} / m_{s}$ is the dilution factor. Propagation of error then results in the following equation, where $\sigma$ is the standard deviation and measurement precision $P \equiv \sigma_{m} / m$ : 


$$
\sigma_{F s}^{2}=r_{x}^{2} \sigma_{F x}^{2}+\left(I-r_{x}\right)^{2} \sigma_{F d}^{2}+\left(F_{x}-F_{d}\right)^{2}\left(2 P^{2}\right) r_{x}^{2}
$$

a

Term a dominates the result; the other two terms can be manipulated toward zero by 1 ) the use of a ${ }^{14} \mathrm{C}$-“dead" diluent ( $\sigma_{F d}$ approaches zero in b), 2) choosing a diluent of isotopic composition identical to the sample $\left(F_{x}-F_{d}\right.$ goes to zero in $\left.\mathbf{c}\right)$, and/or 3$)$ optimizing measurement precision, $P$, in c. Choosing optimal realistic values of $P=0.01, F_{s}-F_{d}=0.5, \sigma_{F d}=0.004, \sigma_{F x}=0.005$ at $500 \mu \mathrm{gC}$, and $\sigma_{F x}=0.010$ at $100 \mu \mathrm{gC}$, Figure 2.1(a) shows the calculated error in the ${ }^{14} \mathrm{C}$ content of the original sample, $\sigma_{F s}$, is inversely related to sample size, rendering dilution least practical in the size range where it would be most useful.

Detailed examination of equation (4) clarifies the potential as well as limitations of dilution. While term $\mathbf{c}$ is always small due to the $P^{2}$ multiple, and term $\mathbf{b}$ can be kept artificially small, it is evident that in a precise formulation of this equation, $\sigma_{F x}^{2}$ in term $\mathbf{a}$ is a function of the size of the composite. This creates a potential situation in which the increased uncertainty due to the dilution factor is partially offset by the better precision obtainable when measuring the larger sample. Figure 3.1(b) highlights $\sigma_{F s}$ for a representative $10 \mu \mathrm{gC}$ sample diluted over a range of $\mathrm{r}_{\mathrm{x}}$, where the size dependence of $\sigma_{F x}$ has been approximated as $\sigma_{F x}=0.06 e^{-0.018 M x}$ and the other variables of equation (4) are given the same values as in Figure 3.1(a). The improved measurement precision at larger sample size makes dilution by a factor of 10 just as precise as 5 -fold dilution, but uncertainties ca. $100 \%$ remain impractical for most applications. Dilution may still be the option of choice, however, for extremely small, irreplaceable samples for which the risks involved with uncertain graphitization and AMS performance are too great.

At NOSAMS, we have been working to achieve precise, accurate analysis of small carbon samples without requiring the addition of a diluent. Here we report our method for preparing graphite targets containing microgram quantities of carbon along with the results of AMS analyses of standard materials (HOxI, HOxII, JME graphite powder, and IAEA C-1 Carrara marble carbonate) having known fraction modern carbon 
$\left(f_{m}\right)$, and we discuss the complex issue of evaluating background carbon contamination during sample preparation and analysis.

\section{Figure 3.1}

(a)

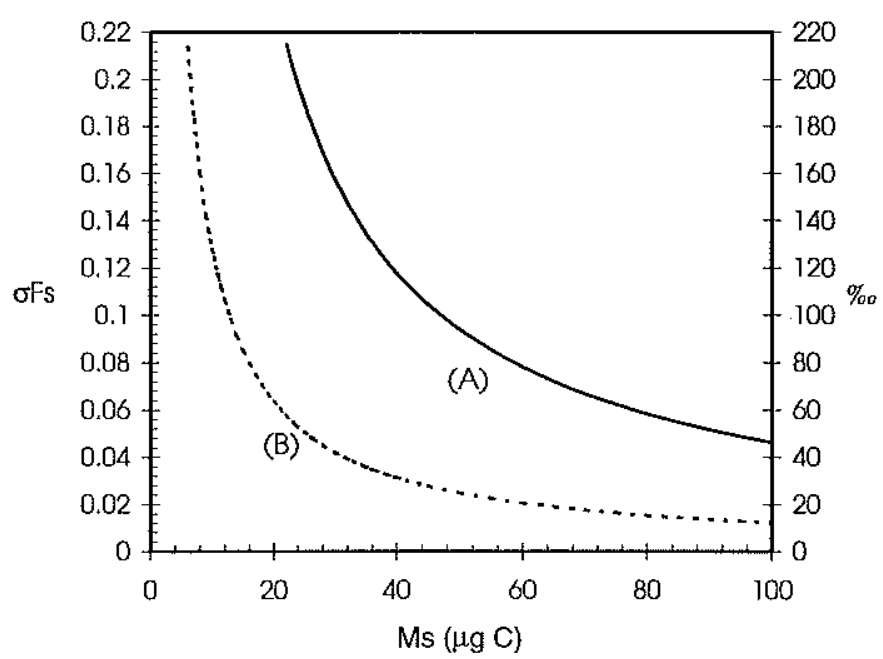

(b)

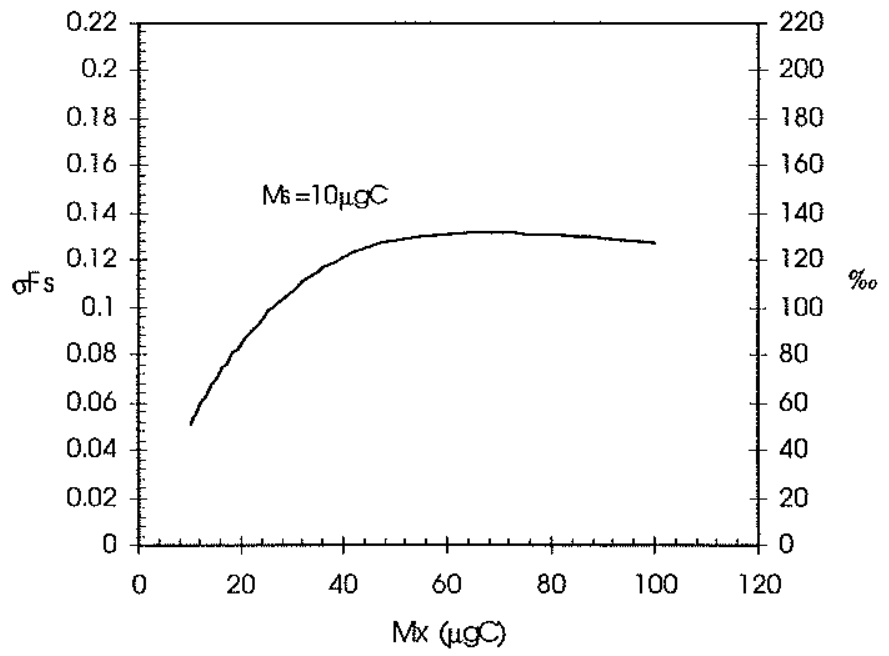

Figure 3.1 (a) Calculated error $\sigma_{F s}$ for dilution to a conventional sample size of $500 \mu \mathrm{gC}$ (A) and for dilution to $100 \mu \mathrm{gC}$ only (B). (b) Calculated error $\sigma_{F s}$ for dilution of a $10 \mu \mathrm{gC}$ sample up to $r_{x}=10$ using a variable $\sigma_{F x}=0.06 e^{-0.018 M x}$. Increased precision in $\sigma_{F x}$ partially offsets the dilution error. 


\subsection{METHODS}

\subsubsection{HOxI and HOxII Standards}

Large batches of $\mathrm{CO}_{2}$ are prepared from NIST Oxalic Acid I (HOxI, $\left.\mathrm{f}_{\mathrm{m}} \equiv 1 / 0.95\right)$ and Oxalic Acid II (HOxII, $\left.\mathrm{f}_{\mathrm{mHOxII}} / \mathrm{f}_{\mathrm{mHOxI}}=1.2933 \pm 0.0004\right)$ standard reference materials (SRM 4990B and SRM 4990C, Currie and Polach, 1980; Stuiver, 1983) once every two or three years. These standard gases have a minimal associated processing blank due to large batch preparation, and are used for routine preparation of AMS standards. Subsamples of the 1992 and 1995 batches of these gases were used to prepare all the HOxI and HOxII small graphite targets discussed in this paper.

\subsubsection{Hydrolysis of Carbonates}

Six aliquots of $\mathrm{CO}_{2}$ were prepared from a single chip of IAEA C-1 carbonate $\left(f_{\mathrm{m}}=0.0000 \pm 0.0002\right.$ (Rozanski et al., 1992)) to use in evaluation of background carbon added during the graphitization and target preparation procedures. The $\mathrm{CO}_{2}$ was prepared by $\mathrm{H}_{3} \mathrm{PO}_{4}$ hydrolysis of a single $\mathrm{HCl}$-etched $\mathrm{C}-1$ chip and six sub-samples were taken of between 1.7 and $4.0 \mu \mathrm{mol}$ carbon. Because our interest was in determining the amount of background carbon added during graphitization and target preparation, a large amount of carbonate was hydrolyzed $(>1 \mathrm{mg}$ ) relative to the subsamples of gas taken for analysis. In this way the contribution of the hydrolysis processing blank was minimized and the $\mathrm{CO}_{2}$ generated is the "dead" analogue to our "modern" HOxI and HOxII bulk standard reference gases.

\subsubsection{Combustion Blanks: JME and HOxI Powders}

To determine the contribution of blank carbon added to organic samples that must be combusted to obtain $\mathrm{CO}_{2}$, two small aliquots of HOxI powder and five of JME pure 
graphite (median $\mathrm{f}_{\mathrm{m}}=0.0002,>68 \mathrm{kY}$ ) were converted to $\mathrm{CO}_{2}$ by standard methods. The $\mathrm{CO}_{2}$ obtained was reduced to graphite and its $\mathrm{f}_{\mathrm{m}}$ was compared to the standards' original values. In addition, numerous empty tube combustion blanks were prepared in an attempt to measure directly the organic carbon combustion blank size and $\mathrm{f}_{\mathrm{m}}$.

For combustion, 9-mm diameter Vycor ${ }^{\circledR}$ combustion tubes containing $2 \mathrm{~g} \mathrm{CuO}$ and $100 \mathrm{mg} \mathrm{Ag}$ crystals were pre-baked at $850^{\circ} \mathrm{C}$ for $5 \mathrm{~h}$. The tubes were loaded with weighed HOxI or JME powder, or left empty in the case of blanks. The tubes were evacuated, flame-sealed, and converted to $\mathrm{CO}_{2}$ by a second, identical combustion step. The $\mathrm{CO}_{2}$ obtained from the $\mathrm{HOxI}$ and JME samples was purified by passing through an isopropanol/dry ice water trap and was converted to graphite according to the methods described below.

$\mathrm{CO}_{2}$ from the "empty" blank tubes was quantified for each tube using a variety of methods. The majority were cracked open and their $\mathrm{CO}_{2}$ purified and quantified on a special micro-manometer vacuum system. Using this approach, enough gas was obtained to prepare two "pooled blank" graphite targets, one containing $c a .25 \mu \mathrm{gC}$ and the other containing $c a .20 \mu \mathrm{gC}$. The carbon in six additional samples was quantified on a HP 5890 Series GC system equipped with a flame ionization detector (FID). The $\mathrm{CO}_{2}$ from these samples was released into the GC after being trapped on a Porapak ${ }^{\circledR}$ column under pure $\mathrm{O}_{2}$. Helium was the GC carrier gas, and carbon was detected as $\mathrm{CH}_{4}$ by the FID. Finally, the contents of eight more combustion blanks were analyzed on a Dycor Residual Gas Analyzer (RGA).

\subsubsection{Graphite Preparation}

We have adapted the standard reduction procedure as described by Vogel et al. (1987a) for the preparation of graphite samples containing microgram quantities of carbon.

$\mathrm{CO}_{2}$ samples are introduced into small-volume graphite reactors that have geometries similar to the NOSAMS automated systems, but that have been scaled down 
to accommodate 6-mm diameter tubing. Graphite is formed in a horizontal 50-mm-long Vycor $^{\circledR}$ tube, while a $75-\mathrm{mm}$ vertical Pyrex ${ }^{\circledR}$ cold finger is kept at $c a .-40^{\circ} \mathrm{C}$. The average total reactor volume is $c a .3 .5 \mathrm{~mL}$. An excess of $\mathrm{H}_{2}\left(2.5-3.5 \mathrm{H}_{2}: \mathrm{CO}_{2}\right)$ is added to the reactors, and the $\mathrm{CO}_{2}$ is reduced to graphite on twice-cleaned $\left(400^{\circ} \mathrm{C}\right.$ for $0.5 \mathrm{~h}$ under $0.7 \mathrm{~atm} . \mathrm{H}_{2}$, twice), 325 mesh, spherical cobalt catalyst. Co, rather than dendritic Fe, was chosen because it provides a minimum catalyst surface area to volume ratio. This increases the physical size of the small samples by allowing a Co: $\mathrm{C}$ mass ratio of 20-100, the larger ratios corresponding to the smallest samples. Reaction temperature for reduction varied between 595 and $645^{\circ} \mathrm{C}$, until $605^{\circ} \mathrm{C}$ was chosen as the optimal reaction temperature (see discussion below); individual temperature controllers regulate each reactor. Reactions are allowed to continue for a maximum of $6 \mathrm{~h}$, and gas pressure is monitored throughout. Conversion to graphite is calculated as a percent yield based on the original and final gas pressures within the reactor.

The mixture of graphite and Co is pressed into aluminum AMS targets that have been drilled with $1.0-\mathrm{mm}$ diameter holes. The holes are top-loaded with a compression pin, a layer of silver powder, and then the graphite mixture.

\subsection{Results AND Discussion}

Between September 1994 and September 1996 we analyzed a total of five small sample wheels at NOSAMS, one of which was composed almost entirely of standards containing $\leq 150 \mu \mathrm{gC}$, for the purpose of evaluating AMS performance in the analysis of microgram-sized targets. The rest of the wheels each contained 10-20 specially prepared small HOxI and HOxII standards spanning the range of sample sizes being analyzed, in place of the usual 1-mg standards. We therefore have raw data for a total of 51 small HOxI and 32 small HOxII standards with which to assess AMS performance within this size range. 


\subsubsection{Optimization of Graphite Production Reaction}

There are many variables that could potentially control the outcome of the $\mathrm{CO}_{2} \rightarrow \mathrm{C}(\mathrm{gr})$ reduction; our goal was to identify and optimize reaction conditions for the most critical of these factors. The percent conversion of $\mathrm{CO}_{2}$ to graphite was used as a direct index of reaction performance. Preliminary examination of the reaction yield data showed that production of high-quality small samples is highly sensitive to minor variations in reaction conditions, but the scatter exhibited in the results and the large number of variables precluded the use of standard regression analysis methods.

Verkouteren and Klouda (1992) have previously demonstrated the utility of bilevel factorial design analysis in unraveling the complexities associated with graphite preparation. A preliminary inspection of our data suggested which variables were likely to be the most significant controls on the graphite reaction. A two-level, $2^{3}$ factorial design was applied to determine the relative dependence of reaction yield on temperature (T), carbon:cobalt ratio $(\mathrm{R})$, and $\mathrm{H}_{2}: \mathrm{CO}_{2}$ ratio $(\mathrm{H})$. The assumption had been made that a fourth variable, the sample quantity $(\mathrm{Q})$, has a positive correlation with reaction success large samples are easier to reduce. To test this assumption, the effect of size on reaction yield was added, creating a $2^{4}$ factorial.

Table 3.1 Factorial Analysis Parameters

\begin{tabular}{llll}
\hline Variable & Median & $(-)$ & $(+)$ \\
\hline Temperature (T) & $608^{\circ} \mathrm{C}$ & $\leq 606$ & $\geq 610^{\circ} \mathrm{C}$ \\
Carbon:Cobalt (R) & $59.2 \mu \mathrm{gC} / \mathrm{mg} \mathrm{Co}$ & $\leq 58.8$ & $\geq 59.6$ \\
$\mathrm{H}_{2}: \mathrm{CO}_{2}(\mathrm{H})$ & $3.20(\mathrm{~mol}: \mathrm{mol})$ & $\leq 3.16$ & $\geq 3.24$ \\
Quantity (Q) & $40 \mu \mathrm{g} \mathrm{C}$ & $\leq 39.6$ & $\geq 40.4$ \\
\hline
\end{tabular}


The $2^{3}$ matrix [T $\times \mathrm{R} \times \mathrm{H}$ ] and the $2^{4}$ matrix [ $\mathrm{T} \times \mathrm{R} \times \mathrm{Q} \times \mathrm{H}$ ] were calculated using a table of contrast coefficients (equivalent to Yates' algorithm) (Box et al., 1978). Data from our first batches of small HOxI and HOxII standards were divided into two levels, (-) and (+), around the median of the range of each variable (Table 3.1); data whose analytical error crossed the median were eliminated. The 46 acceptable samples were distributed fairly uniformly among the 8 categories of the $2^{3}$ matrix $\left(\min \left\{\mathrm{n}_{\mathrm{i}}\right\}=3\right)$. The result of the $2^{4}$ matrix is less robust due to a lack of replicate data points for many of the 16 run categories. In both cases error bars are calculated from a pooled estimate of run variance. Results of the factorial analyses (Figure 3.2) confirmed qualitative trends that had been observed in the data: reaction yield improves at lower temperatures and larger samples favor better yields. Cobalt-catalyzed reduction appears to be more successful at temperatures below $608^{\circ} \mathrm{C}$, lower than the $625^{\circ} \mathrm{C}$ normally employed when using dendritic Fe. Since this discovery, we have adopted $605^{\circ} \mathrm{C}$ as our reaction temperature when preparing small samples on cobalt. Yields are routinely $>90 \%$ under these conditions. We have no direct evidence of the mechanistic effect the low temperature has on the system, but one possibility includes partial inactivation of the catalyst surface at higher temperatures. Variation in $\mathrm{H}$ is not significant over the small range of values studied, and the slight negative dependence on $\mathrm{R}$ is probably unimportant as well. 


\section{Figure 3.2}

(a)

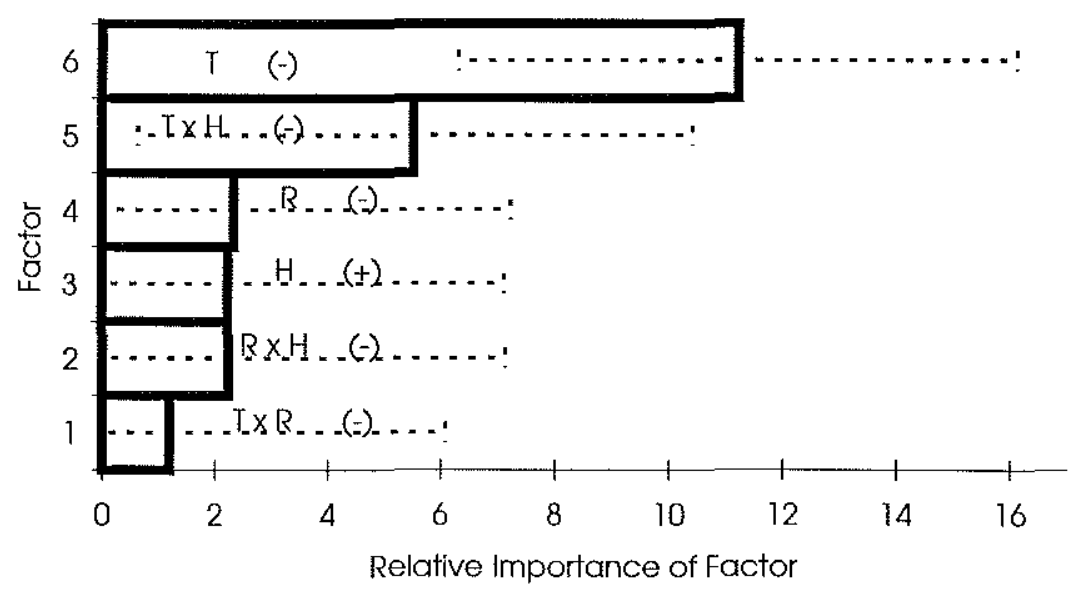

(b)

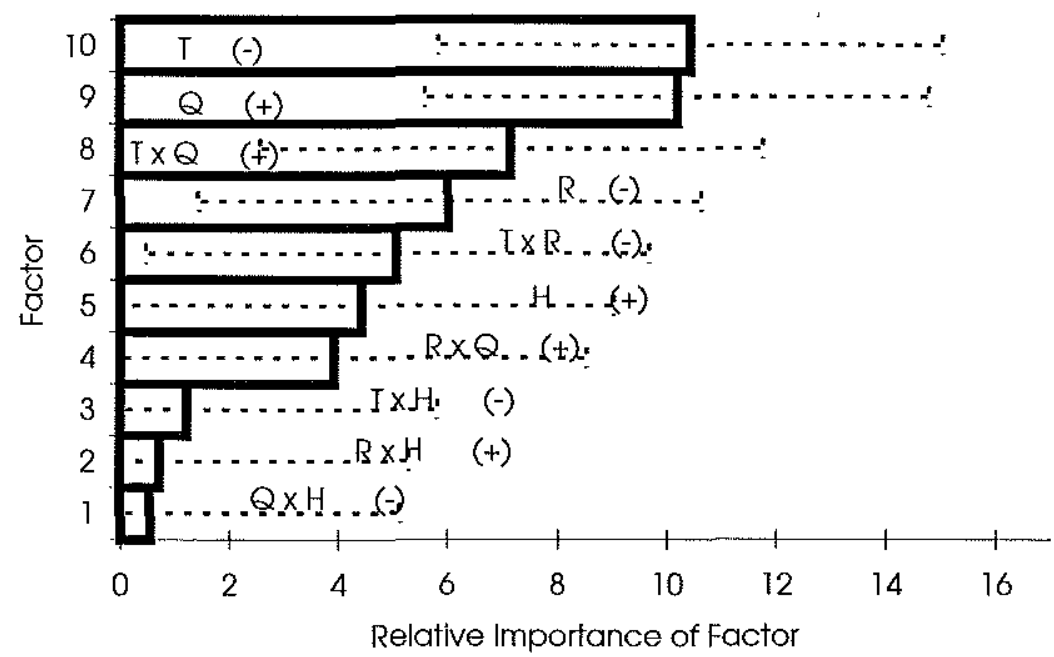

Figure 3.2 (a) $2^{3}$ factorial analysis of $\mathrm{T}, \mathrm{R}$, and $\mathrm{H}$ effects on reaction yield. (b) $2^{4}$ factorial analysis of T, R, H, and Q effects on reaction yield. A ( + ) indicates the upper range of the factor improves \% yield, while a $(-)$ indicates the lower range improves $\%$ yield. The variables are described in the text. 


\subsubsection{AMS Performance of Small Samples}

Since we are interested in determining AMS performance under conditions of reduced carbon ion beam intensity, all the isotope ratio data reported here have been compared to measured ${ }^{12} \mathrm{C}$ ion current $\left(\mathrm{I}_{12}\right)$ rather than sample size. The $\mathrm{I}_{12}$ beam is measured in a Faraday cup after the $110^{\circ}$ spectrometer magnet, after being chopped by a factor of ca. 95. The currents shown are electrical currents of the ${ }^{12} \mathrm{C}^{3+}$ ions; particle currents would be $1 / 3$ of these values. Figure 3.3 shows that $I_{12}$ is a reasonable proxy for sample size, and we believe that the precision of the measured isotope ratios is likely to be related more directly to $I_{12}$ than to the overall sample size. Both $I_{12}$ and measured isotope ratios are also found to be time-variant within the accelerator as discussed below, a further indication that bulk sample size is not as informative a performance index as is the measured $\mathrm{I}_{12}$.

\section{Figure 3.3}

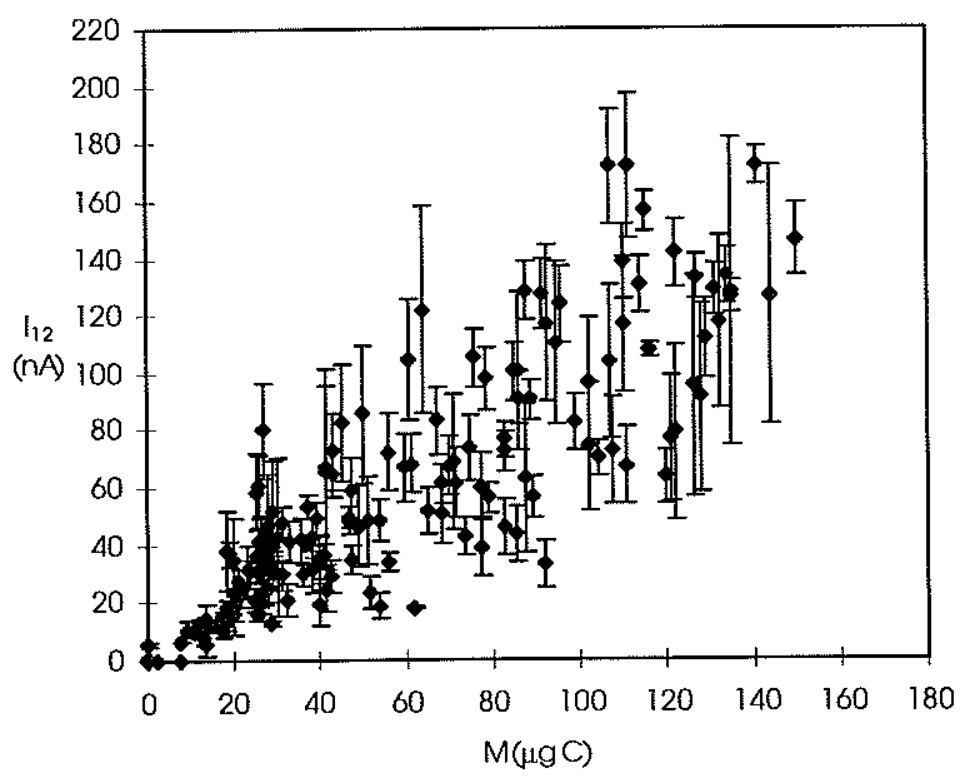

Figure 3.3 Observations showing that the ${ }^{12} \mathrm{C}$ current measured for small samples varies with size, according to the approximate relationship $\mathrm{I}_{12}=0.9 \mathrm{M}$. $\mathrm{M}=\mathrm{mass}$ of carbon in micrograms; $\mathrm{I}_{12}={ }^{12} \mathrm{C}$ current in nanoamperes. 
Figure 3.4 shows the dependence on current of the ${ }^{14} \mathrm{C} /{ }^{12} \mathrm{C}$ ratios obtained for small standards. Individual time-point measurements obtained for each target are compared to the average isotope ratios of HOxI and HOxII standards of regular $(1 \mathrm{mg})$ size that were included in the small-sample wheels. These data represent an average of 4 min per point (roughly $10^{3}$ counts), with 3-6 points recorded per standard. Three samples that failed to generate any stable, measurable current have been excluded. These contained $<10 \mu \mathrm{gC}$, and are defined as "AMS failures". Both HOxI and HOxII small standards show a characteristic decrease in ${ }^{14} \mathrm{C} /{ }^{12} \mathrm{C}$ below $100 \mu \mathrm{gC}$; a relationship that has been observed previously by Klinedinst et al. (1994), Brown and Southon (1997), and other groups.

Concurrent AMS measurement of the ${ }^{13} \mathrm{C} /{ }^{12} \mathrm{C}$ ratio for small standards also shows apparent fractionation at lower sample currents, although the relationship is somewhat less pronounced for ${ }^{13} \mathrm{C}$ than for ${ }^{14} \mathrm{C}$. It is possible that instrument tuning affects ${ }^{13} \mathrm{C}$ detection differently than it affects ${ }^{14} \mathrm{C}$, and therefore generates a slightly less uniform relationship between ${ }^{13} \mathrm{C}$ and $\mathrm{I}_{12}$. Figure 3.5(a) shows the difference between the AMS measured $\delta^{13} \mathrm{C}$ for small HOxI and HOxII standards and the pre-graphite $\delta^{13} \mathrm{C}$ values of the $\mathrm{CO}_{2}$ from which they were prepared (measured on a VG Prism stable isotope mass spectrometer). The difference is expressed as $\Delta \delta^{13} \mathrm{C}=\delta^{13} \mathrm{C}_{\mathrm{AMS}}-\delta^{13} \mathrm{C}_{\mathrm{VG}}$. The VG Prism $\delta^{13} \mathrm{C}$ values for HOxI are -19.0 to $-19.3 \%$ and for HOxII are -17.6 to $-17.7 \%$.

There are several potential reasons for the observed isotope ratio dependence on sample size. Explanations that invoke fractionation or contamination during the graphite production step are among the more popular candidates. Van der Borg et al. (1997) showed that fractionation can occur during the graphitization process: reactions that failed to reach completion produced graphite that was depleted in ${ }^{14} \mathrm{C}$ and ${ }^{13} \mathrm{C}$, and left residual $\mathrm{CO}_{2}$ that was isotopically enriched. However, examination of our yield data indicates there is no apparent correlation between percent conversion of $\mathrm{CO}_{2}$ to graphite and the isotope ratios subsequently measured during AMS analysis. This argues against a fractionation effect induced during any phase of the sample preparation. Similar results have also been obtained by McNichol et al. (1992). 
Figure 3.4

(a) $\mathrm{HOXl}$

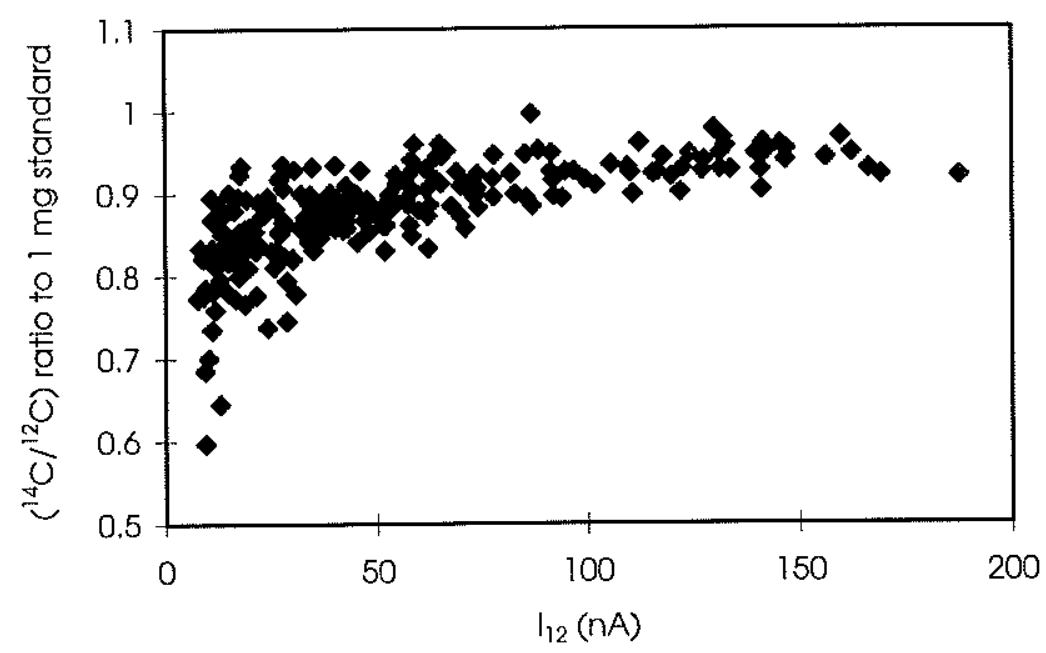

(b) HOxll

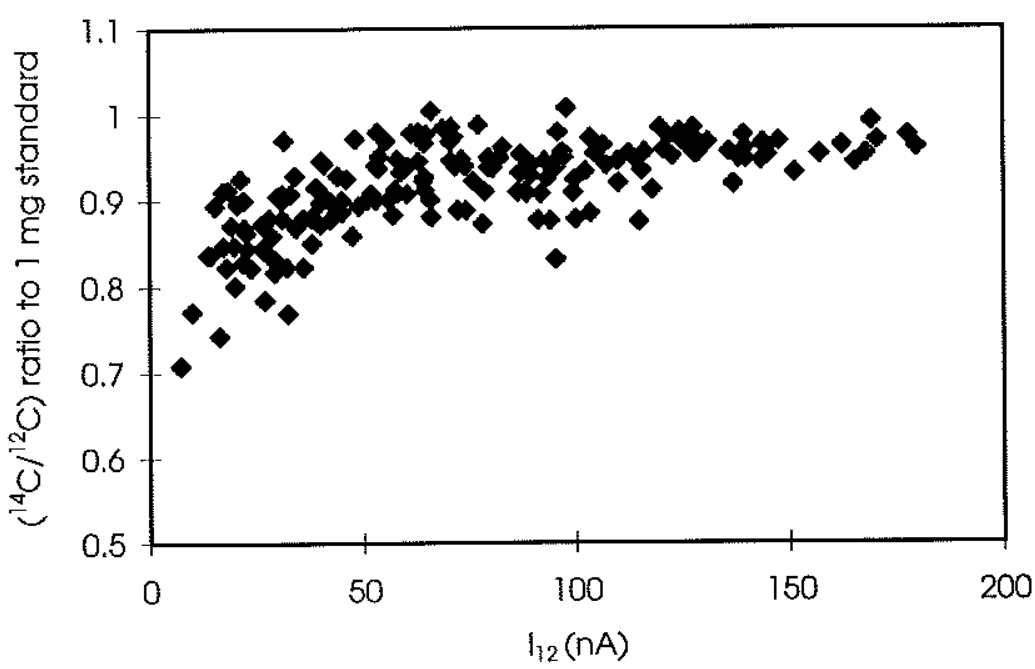

Figure 3.4 Dependence of the measured ${ }^{14} \mathrm{C} /{ }^{12} \mathrm{C}$ isotope ratios for (a) $\mathrm{HOxI}$ and (b) HOxII small samples on the generated ${ }^{12} \mathrm{C}$ ion current. Ratios have been normalized to average values obtained for HOxI and HOxII standards of conventional size. 
Figure 3.5

(a)

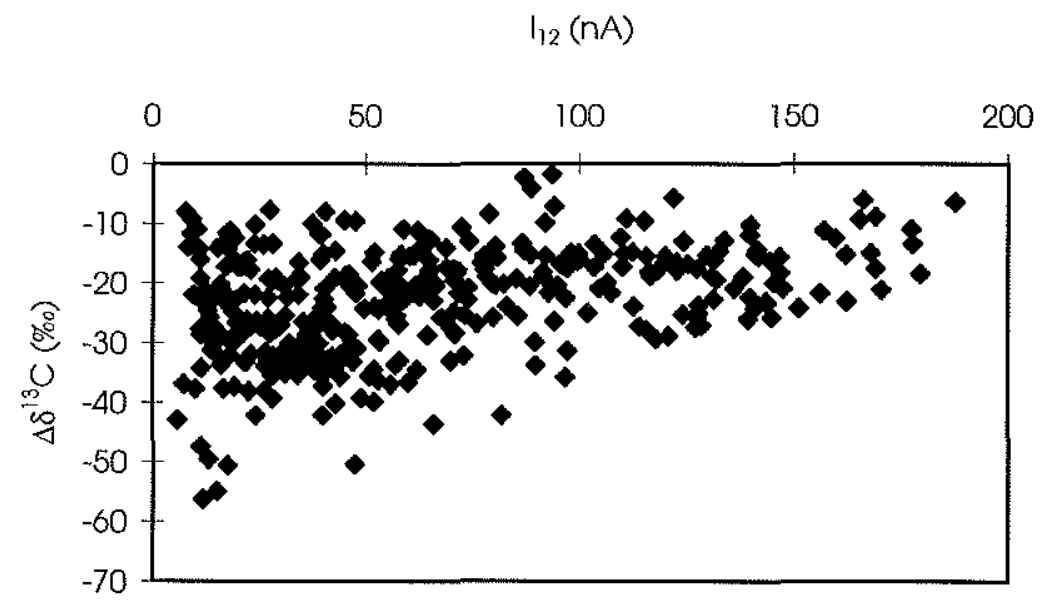

(b)

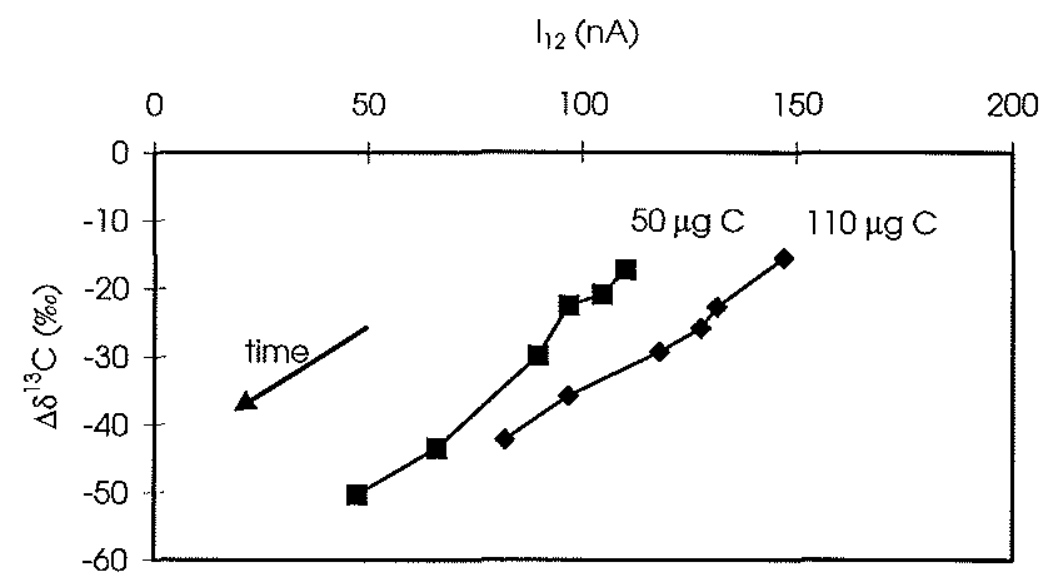

Figure 3.5 (a) ${ }^{13} \mathrm{C}$ fractionation of HOxI and HOxII small samples as a function of the generated ${ }^{12} \mathrm{C}$ ion current for all discrete time points. (b) $\Delta \delta^{13} \mathrm{C}$ and $\mathrm{I}_{12}$ variation within samples as a function of elapsed measurement time. 
Another possible explanation for the decrease in isotope ratios is the addition of a background carbon contaminant during graphite production or during analysis of the AMS targets. Data published by Brown and Southon (1997) for a very similarly behaving suite of small standards indicate that our source of contamination, if any, may be independent of sample size. They suggest carbon contained within the catalyst matrix or residual carbon in the AMS ion source. At NOSAMS, ${ }^{14} \mathrm{C}$-“dead" graphite measured immediately following modern samples fails to show significant sample crosstalk or other problems inherent to the source. We believe it is also unlikely that the isotope ratios are being altered by the presence of large amounts of background carbon within the Co catalyst. This is based on observation of instances when isotope ratios and ${ }^{12} \mathrm{C}$ currents co-vary within individual samples (Figure 3.5(b)). If background carbon were incorporated within the sample during processing or were contained in the Co matrix, a time-series plot would be expected to show a constant or randomly varying isotope ratio over the course of analysis, not the systematic decrease in isotope ratio we have observed for these and many additional samples. The $\Delta \delta^{13} \mathrm{C}$ and $\mathrm{I}_{12}$ changes in Figure $3.5(\mathrm{~b})$ appear to be a function of elapsed measurement time. These data suggest that the effective fractionation we have observed is primarily a function of machine conditions, not the result of isotopically light carbon incorporated uniformly within the sample during preparation.

Support for this hypothesis comes from consideration of the differing beam dynamics at high and low current levels. Instrument tuning is always carried out using 1-mg standards. The current beams generated by these large targets have a correspondingly higher beam divergence than do beams generated by small samples, due to increased Coulomb repulsion in the presence of higher space charge density. The instrument is tuned to compensate for the fractionation induced within the large sample. Because Coulomb repulsion affects lighter isotopes more strongly, it is possible that ${ }^{12} \mathrm{C}$ detection is less efficient relative to ${ }^{14} \mathrm{C}$ detection for large samples, but that the detection difference may be less pronounced for low-density small samples. The net effect would be an apparently lower ${ }^{14} \mathrm{C} /{ }^{12} \mathrm{C}$ ratio for small samples. While this argument is 
qualitative, it provides a physically plausible mechanism for the observed effects. Details of the beam dynamics model can be found in von Reden et al. (1998).

At NOSAMS, we have found different explanations for the sources of background contamination and fractionation than have previously been identified by some of the AMS groups mentioned in the above discussion. This points to the need for individual AMS facilities to conduct independent and thorough evaluations of their analytical procedure, because it is likely that the results will display characteristics unique to each facility.

\subsubsection{Compensation for Machine-Induced Fractionation: Accuracy of HOxI and HOxII $f_{m}$ Results}

It is apparent from the preceding discussion that machine-induced fractionation effects are an important constraint on the accuracy of small sample measurements. The significant correlations between $\mathrm{I}_{12},{ }^{14} \mathrm{C} /{ }^{12} \mathrm{C}$, and $\Delta \delta^{13} \mathrm{C}$ might allow a ${ }^{14} \mathrm{C}$ correction factor model based on $\mathrm{I}_{12}$ and/or $\Delta \delta^{13} \mathrm{C}$. For example, ${ }^{14} \mathrm{C} /{ }^{12} \mathrm{C}$ could be corrected using the assumed exponential relationship to $I_{12}$, but the true relation is clearly more complex and remains unknown. Instead we have attempted to assess the level of precision and accuracy that can be achieved by matching samples with identically prepared, sizematched small standards to provide machine-based compensation for isotopic effects. The standards and adjacent samples are expected to behave similarly with regard to timevariant machine conditions and tuning. The $\mathrm{f}_{\mathrm{m}}$ values calculated relative to these standards no longer show a size-dependent fractionation.

To confirm that this approach is effective, $28 \mathrm{HOxI}$ and HOxII standards ranging from 2 to $71 \mu \mathrm{gC}$ were analyzed in descending order of size on a single AMS wheel devoted to assessing small standard performance. Their ${ }^{14} \mathrm{C} /{ }^{12} \mathrm{C}$ ratios relative to 1 -mg standards are part of Figure 3.4, where isotopic fractionation is apparent. 
The data from the wheel were then reanalyzed by the NOSAMS automatic data analysis program (Seguin et al., 1994) by carefully rotating the 28 targets through 4 permutations of the classifications "sample" and "standard". Analysis \#1 computed $\mathrm{f}_{\mathrm{m}}$ values for 17 "samples" relative to 11 designated HOxI and HOxII "standards" chosen randomly throughout the wheel. Analysis \#2 computed $f_{m}$ values for "samples" relative to a different subset of randomly selected HOxI and HOxII "standards". Analysis \#3 designated all 8 HOxII targets as "standards", while analysis \#4 designated 8 similar HOxI targets as the "standards". This scheme was implemented to remove as much bias as possible from the analysis procedure, while generating at least two, and usually three, $\mathrm{f}_{\mathrm{m}}$ values for each target. The NOSAMS data analysis program made this possible through built-in flexibility that allows any AMS target to be designated a "standard" if desired.

The $f_{m}$ results from this approach were averaged for each sample (Figure 3.6). The error bars shown are the standard deviations of the multiple results for each sample, unless this value is smaller than the Poisson error calculated based on the number of ${ }^{14} \mathrm{C}$ counts, in which case the Poisson error is shown. The HOxI targets yielded an average $f_{m}=1.048 \pm 0.018$; the HOxII targets averaged $f_{m}=1.363 \pm 0.018$. Neither set of standards, when analyzed in this way, shows any apparent size dependent fractionation effect. Based on this outcome, the NOSAMS facility has begun routinely analyzing microgram samples relative to size-matched small standards to minimize size-related effective fractionation effects.

The three samples that "failed AMS" as defined above are not included in Figure 3.6, as they gave no measurable ion current. At NOSAMS, very few conventional filamentous graphite targets containing $<10 \mu \mathrm{gC}$ have generated a sustained ion current, and when current is produced the isotope measurements are greatly affected by the internal fractionation effects mentioned above. For this reason we try to maintain a minimum sample size of $15-20 \mu \mathrm{gC}$ to increase the probability of a successful measurement. 
Figure 3.6

Res ults For HOxl and HOxll S mall Standards

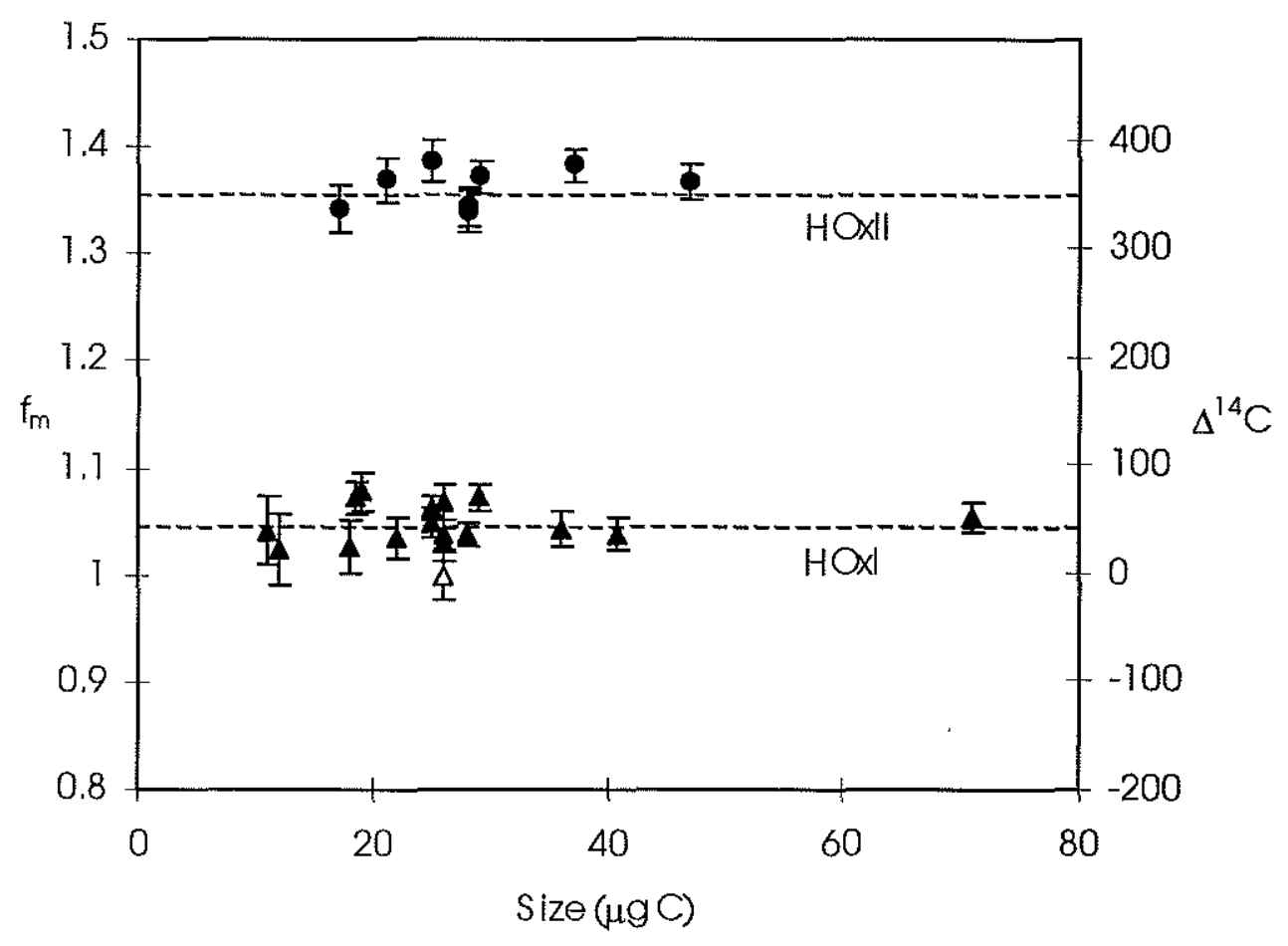

Figure 3.6 Results obtained for HOxI and HOxII small standards when $\mathrm{f}_{\mathrm{m}}$ values are calculated relative to adjacent small standards of similar size. $\Delta=$ sample for which Poisson error was used. 


\subsubsection{Contribution of Background Carbon in the Analysis of Small Samples}

To evaluate further the contributions of background carbon, and to increase our confidence that the machine effects discussed above were not due to carbon contamination, we performed several additional analyses.

\subsubsection{Machine or Source Blank}

Measurement of pure JME powder is routine at NOSAMS for assessing and correcting for machine background on every wheel that is run. The JME data on average indicate a machine background ${ }^{14} \mathrm{C}$ level of $0.0002 \mathrm{f}_{\mathrm{m}}$. This value represents the total number of scattered particles such as ${ }^{13} \mathrm{C}^{2+},{ }^{7} \mathrm{Li}_{2}$ dimers, and true ${ }^{14} \mathrm{C}^{3+}$ ions from internal contamination, all normalized to $\mathrm{I}_{12}$ output. A "memory" effect between samples has never been seen. ${ }^{14} \mathrm{C}$ "dead" standards measured between modern samples show no contamination, nor was any effect observed when samples containing five times modern ${ }^{14} \mathrm{C}$ concentration were inadvertently run on the machine.

\subsubsection{Graphitization Blank}

Background carbon added during graphite production can be ascertained by preparing small graphite samples from large batches of $\mathrm{CO}_{2}($ Vogel et al., 1987b ). In this way, sample processing blanks are minimized and the $\mathrm{CO}_{2}$ used in graphite preparation is assumed to reflect the true composition of the standard reference material. This principle was applied for preparation and analysis of the HOxI and HOxII standards discussed above. The observation of intra-sample isotopic variability in the HOxI and HOxII targets argues against a large ${ }^{14} \mathrm{C}$-dead blank being uniformly incorporated during sample processing. Because it is also possible that a substantial modern carbon equivalent bank is incorporated during graphite preparation, six IAEA C-1 samples were included on the wheel devoted to analysis of small standards. These targets were the 
"dead" carbon analogues to our "modern" HOxI and HOxII small targets. Within the precision of the determination, the cumulative blank associated with cobalt-catalyzed reduction and AMS target preparation is ca. $0.12 \mu \mathrm{gC}$ equivalent modern carbon (Figure 3.7). This is nearly indistinguishable from one of our two JME graphite powder reference materials (JME D24B28).

Figure 3.7

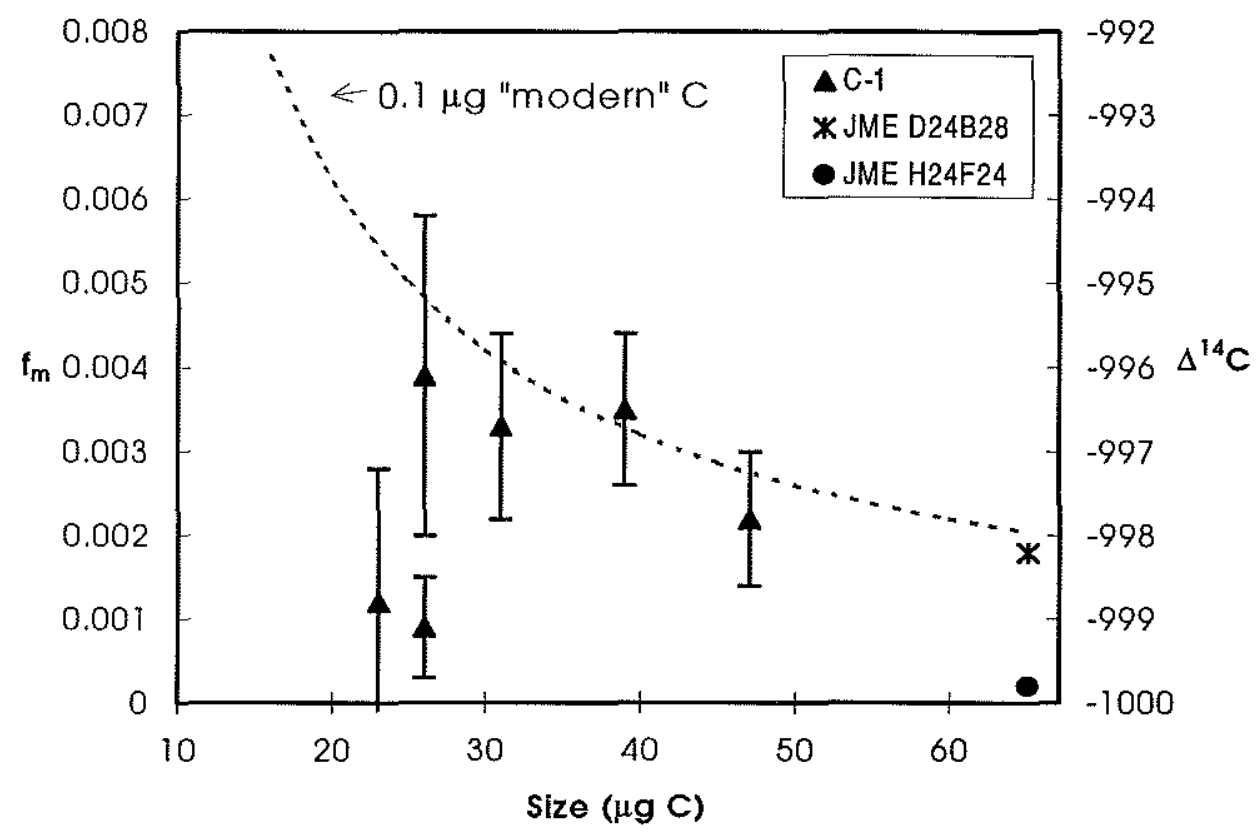

Figure 3.7 Graphitization blank as measured for IAEA C-1 carbonate.

\subsubsection{Combustion Blank}

Most small samples that we anticipate analyzing are from organic carbon sources and require combustion to $\mathrm{CO}_{2}$ prior to graphite preparation. This represents an 
additional processing step that could contribute significant amounts of background carbon to the samples. We have taken several approaches to assessing both the quantity and $f_{m}$ of the carbon introduced during the combustion process.

The first approach involved preparation of a bulk combustion blank for direct analysis by AMS. The $\mathrm{CO}_{2}$ obtained from combustion of multiple "empty" Vycor ${ }^{\oplus}$ tubes was quantified using a small-volume vacuum line and manometer. The tubes yielded $0.16 \pm 0.09 \mu \mathrm{mol}$ gas on average (range $0.08-0.33$ ) for batch \#1, prepared in 1995; and $0.08 \pm 0.02 \mu \mathrm{mol}$ gas on average (range $0.05-0.14$ ) for batch \#2, prepared in 1996. The gas in batch \#1 likely contains a large fraction water vapor, as the vacuum line was flushed with $\mathrm{H}_{2} \mathrm{O}$-saturated $\mathrm{N}_{2}$ between cracking three of the individual tubes. Those three tubes subsequently yielded an average of $0.23 \mu \mathrm{mol}$ gas each. Multiple water traps were used for purifying the samples in the second batch, and the vacuum line was allowed to pump down at room temperature for $45 \mathrm{~min}$ between cracking each sample. The largest difference between the gas collected in the two batches is probably the average amount of water vapor contained in each.

For each batch, the $\mathrm{CO}_{2}$ was then combined to form a bulk combustion blank sample containing ca. $20 \mu \mathrm{gC}$ for batch \#1 and $25 \mu \mathrm{gC}$ for batch \#2. While this method of measuring the ${ }^{14} \mathrm{C}$ content of the combustion blank obscures variability between samples, its advantage is that it allows a direct, rather than modeled estimate of the blank's $f_{m}$. AMS analysis of the graphite prepared from these samples in both cases indicated that the combustion blank is not primarily composed of modern carbon. Batch $\# 1$ had a composite $\mathrm{f}_{\mathrm{m}}=0.379 \pm 0.012$ and batch \#2 had $\mathrm{f}_{\mathrm{m}}=0.250 \pm 0.013$.

Because manometric determination of the gas obtained from the individual combustion blank tubes was considered uncertain, especially on the first set of attempts (batch \#1), two additional approaches were taken to assess the size and chemical composition of the combustion blank. The $\mathrm{CO}_{2}$ from six tubes was measured by gas chromatography as an alternative, carbon-specific method of determining the combustion background. Quantification was based on the ratio of peak area to that of a standard volume $\mathrm{CO}_{2}$ injection. The six samples yielded $0.08 \pm 0.02 \mu \mathrm{molC}$, in good agreement 
with the more precisely prepared manometric batch \#2 samples. The total gas composition of eight combustion tubes was also examined using a Dycor RGA, since it is reasonable to assume $\mathrm{CO}_{2}$ and $\mathrm{H}_{2} \mathrm{O}$ are not the only products of the combustion process. The results indicated that in addition to $\mathrm{CO}_{2}$ and $\mathrm{H}_{2} \mathrm{O}$, minor amounts of $\mathrm{CO}$ and $\mathrm{N}_{2}$ may contribute to the total gas generated in an empty combustion tube.

A completely independent approach to assessing the organic carbon blank is possible through combustion of small quantities of standard materials of known isotopic composition. Toward this goal, we have combusted a few small HOxI powder and JME graphite samples and converted the $\mathrm{CO}_{2}$ into graphite for AMS small-sample analysis. The graphite prepared from these small-batch combustion standards appears to confirm that the combustion blank is not primarily composed of modern carbon. The $f_{m}$ measurements of these targets are not significantly different from values predicted by a simple mass balance model that incorporates the $0.08 \mu \mathrm{molC}, 0.25 \mathrm{f}_{\mathrm{m}}$ blank carbon contribution. Model curves can also be fit to the data to provide an independent estimate of the blank contribution. However, accurate determination of the appropriate $f_{m}$ may be difficult using this approach, as the measurement error increases greatly for samples smaller than $20 \mu \mathrm{gC}$.

\subsection{Conclusions}

At NOSAMS, preparation and AMS analysis of samples containing 10-150 $\mu \mathrm{gC}$ has exhibited an encouraging level of success. These results have promising implications for several oceanographic and environmental research areas, including the pore water carbon cycle, oceanic dissolved organic carbon studies, and molecular-level ${ }^{14} \mathrm{C}$ analysis. All are areas in which available sample size has been the main limitation on the use of ${ }^{14} \mathrm{C}$ AMS. 
1. Small quantities of $\mathrm{CO}_{2}$ can be converted reliably into high-quality graphite for AMS. Reduction is carried out over cobalt catalyst at $605^{\circ} \mathrm{C}$ in smallvolume reactors. The reaction appears especially sensitive to temperature, showing a decrease in reaction yield at high temperature.

2. AMS targets containing $\leq 150 \mu \mathrm{gC}$ are prone to machine-induced isotopic fractionation, which appears directly related to the lower levels of carbon ion current generated by these samples. This may be caused by inherent limitations in the instrument design and tuning capabilities of the NOSAMS accelerator.

3. Carbon contamination within the NOSAMS source does not appear to be significant enough to affect the outcome of small target analyses; neither does addition of modern-equivalent carbon during the graphitization process. Time-variant data for HOxI and HOxII targets is evidence against the addition of a large amount of "dead" carbon during graphitization, although amounts equivalent to less than the machine fractionation effect may be present. Carbon added during the combustion of small organic samples is still under investigation, but preliminary work indicates this blank is $c a .1 \mu \mathrm{g}$ and has significantly less than modern ${ }^{14} \mathrm{C}$ concentration.

4. It is possible to compensate effectively for machine fractionation and blank carbon contributions by measuring small samples relative to size-matched small standards. There are two possible options for preparation of the small standards: reduction of small splits of a large, homogeneous gas standard, or combustion and subsequent reduction of individual small aliquots of the original standards. When analyzing small, combusted organic samples relative to small HOxI and HOxII standards, choosing the first option requires a subsequent blank correction to the sample $f_{m}$, while the second option would 
eliminate this correction. Because it is more difficult and less time-efficient to prepare individually combusted standards of precise mass, we continue to perform our routine analyses with small splits of a large standard and then apply a separate combustion blank correction. Small HOxI and HOxII standards measured relative to each other using this approach no longer show a size-dependent isotopic fractionation. 


\subsection{REFERENCES}

Box, G. E. P., Hunter, W. G., and Hunter, J. S. (1978) Statistics for Experimenters: An Introduction to Design, Data Analysis, and Model Building. New York, J. Wiley and Sons, $653 \mathrm{pp}$.

Brown, T. A. and Southon, J. R. (1997) Corrections for contamination background in AMS ${ }^{14} \mathrm{C}$ measurements. In Jull, A.J.T., Beck, J.W., and Burr, G.S., eds., Proceedings of the 7th International Symposium on Accelerator Mass Spectrometry. Nuclear Instruments and Methods B 123, 97-101.

Currie, L. A. and Polach, H. A. (1980) Explaratory analysis of the international radiocarbon cross-calibration data: Consensus values and interlaboratory error. In Stuiver, M. and Kra, R.S., eds., Proceedings of the 10 th International ${ }^{14} \mathrm{C}$ Conference. Radiocarbon 22(3), 933-935.

Klinedinst, D. B., McNichol, A. P., Currie, L. A., Schneider, R. J., Klouda, G. A., von Reden, K. F., Verkouteren, R. M., and Jones, G. A. (1994) Comparative study of Fe-C bead and graphite target performance with the National Ocean Science AMS (NOSAMS) facility recombinator ion source. Nuclear Instruments and Methods B 92, 166-171.

McNichol, A. P., Gagnon, A. R., Jones, G. A., and Osborne, E. A. (1992) Illumination of a black box: Analysis of gas composition during graphite target preparation. Radiocarbon 34(3), 321-32.9.

Rozanski, K., Stichler, W., Gonfiantini, R., Scott, E. M., Beukens, R. P., Kromer, B., and van der Plicht, J. (1992) The IAEA ${ }^{14} \mathrm{C}$ intercomparison exercise 1990. Radiocarbon 34(3), 506-519.

Seguin, F. H., Schneider, R. J., Jones, G. A., and von Reden, K. F. (1994) Optimized data analysis for AMS radiocarbon dating. Nuclear Instruments and Methods B 92 , 176-181.

Stuiver, M. (1983) International agreements and the use of the new Oxalic Acid Standard. Radiocarbon 25(2), 793-795.

van der Borg, K., Alderliesten, C., de Jong, A. F. M., van den Brink, A., de Haas, A. P., Kersemaekers, H. J. H., and Raaymakers, J. E. M. J. (1997) Precision and mass fractionation in ${ }^{14} \mathrm{C}$ analysis with AMS. In Jull, A.J.T., Beck, J.W., and Burr, G.S., eds., Proceedings of the 7th International Symposium on Accelerator Mass Spectrometry. Nuclear Instruments and Methods B 123, 97-101.

Verkouteren, R. M., and Klouda, G. A. (1992) Factorial design techniques applied to optimization of AMS graphite target preparation. Radiocarbon 34(3), 335-343.

Vogel, J. S., Southon, J. R., and Nelson, D. E. (1987a) Catalyst and binder effects in the use of filamentous graphite for AMS. In Gove, H.E., Litherland, A.E. and Elmore, D., eds., Proceedings of the 4th International Symposium on Accelerator Mass Spectrometry. Nuclear Instruments and Methods B 29, 50-56.

Vogel, J. S., Nelson, D. E., and Southon, J. R. (1987b) ${ }^{14} \mathrm{C}$ background levels in an accelerator mass spectrometry system. Radiocarbon 29(3), 323-333. 
von Reden, K. F., Schneider, R. J., McNichol, A. P., and Pearson, A. (1998) ${ }^{14}$ C AMS measurements of $<100 \mathrm{mg}$ samples with a high-current system. Proceedings of the $16^{\text {th }}$ International ${ }^{14} \mathrm{C}$ conference, edited by W. G. Mook and J. van der Plicht, Radiocarbon, Vol 40, No. 1, xx-xx.

\section{Acknowledgements}

The authors wish to thank J. M. Hayes for providing the analysis of uncertainties associated with diluted samples, D. McCorkle for use of his vacuum line and GC system, S. Griffin for preparation of large-batch HOxI and HOxII standards, and A.R. Gagnon for general laboratory assistance. This research was supported by NSF cooperative agreement OCE-9301015. The first author also received support from a MIT Ida Green Graduate Student Fellowship. This is WHOI contribution number 9612. 


\subsection{APPENDIX}

This appendix contains supplementary information for Chapter 3 and is not part of the original manuscript.

\subsubsection{Erratum, Figure 2.1}

Figures 3.1(a) and (b) contain a small error and are re-printed here to include the correction. This error does not significantly alter the previous discussion.

In equation (4), the assumed value $F_{s}-F_{d}=0.5$ (where $F_{d}=0$, "dead diluent") was mistakenly substituted for the $F_{x}-F_{d}$ portion of term $\mathbf{c}$. The correct substitution in term $\mathbf{c}$ is as follows:

$$
\left(F_{x}-F_{d}\right)^{2}\left(2 P^{2}\right) r_{x}^{2}=\left(\frac{F_{s}}{r_{x}}-F_{d}\right)^{2}\left(2 P^{2}\right) r_{x}^{2}
$$

Calculation of the model equation, (4), therefore requires an assumed value for $F_{s}$. Figure 3.8(a) shows the old (incorrect) version, as well as the corrected results for $F_{s}=0.25, F_{s}=0.5$, and $F_{s}=0.9$. The results are not greatly different from the original figure. Figure 3.8(b) shows the modeled uncertainty (applied using $F_{s}=0.5$ only) for diluting a $10 \mathrm{mgC}$ sample to $100 \mathrm{mgC}$. This corrected version clearly shows how the increased measurment precision at a larger sample size can partially offset the uncertainty contributed by a high dilution ratio. However, the uncertainties shown by these corrected model equations are still much larger than can be obtained by analysis of small AMS targets without dilution. 
Figure 3.8

(a)

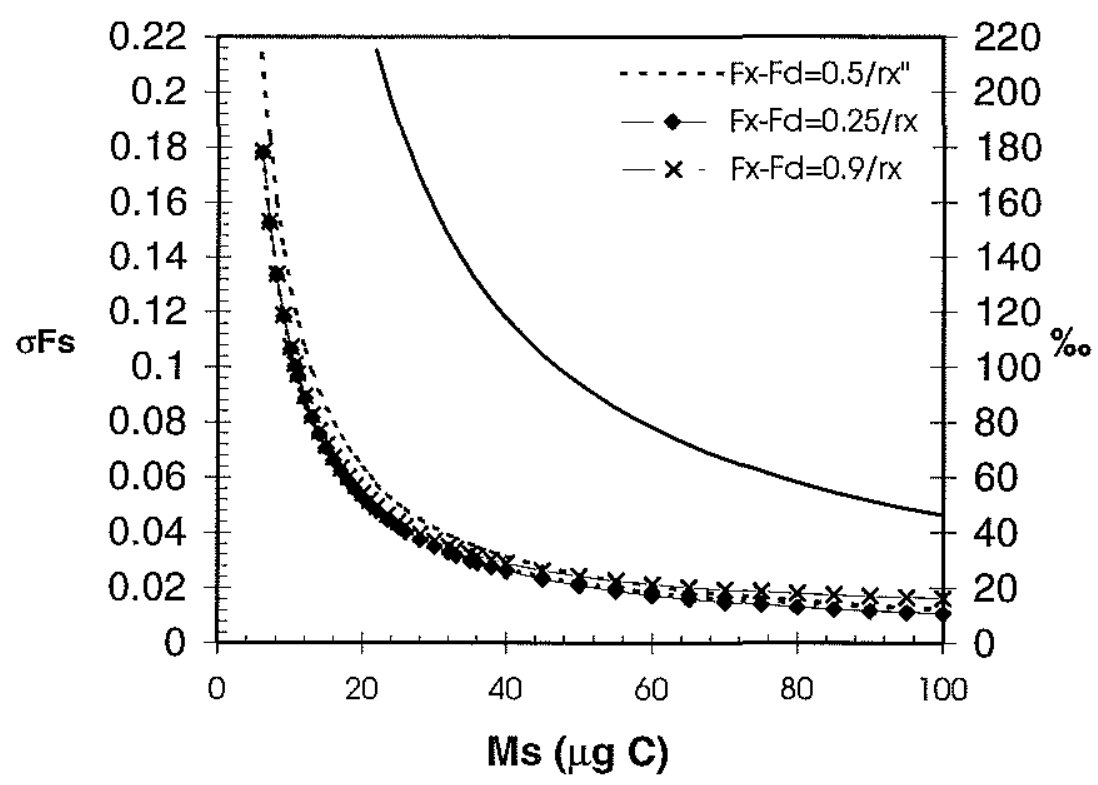

(b)

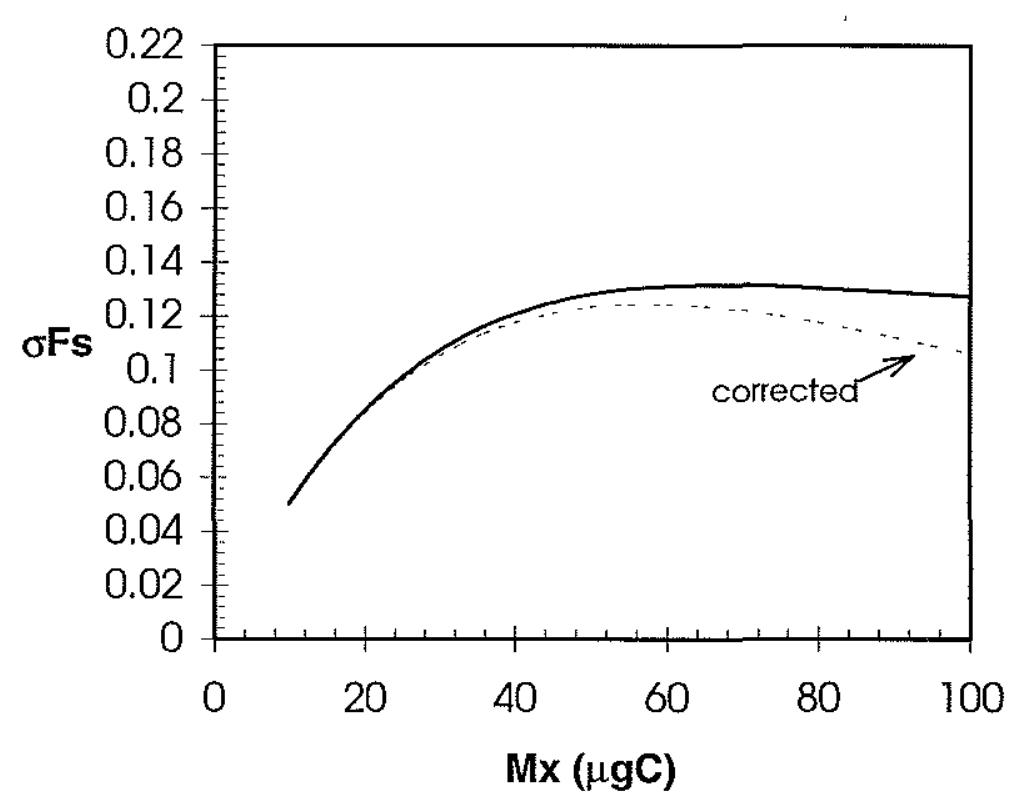

Figure 3.8 (a) Re-calculated error $\sigma F_{s}$ for dilution to a composite sample size of 100 $\mu \mathrm{gC}$, shown for a range of assumed values of $F_{s}$. (b) Re-calculated error $\sigma F_{s}$ for dilution of a $10 \mu \mathrm{gC}$ sample up to $r_{x}=10$, using a variable $\sigma F_{x}=0.06 \mathrm{e}^{-0.018 \mathrm{Mx}}$, assuming $F_{s}=0.5$. 


\subsubsection{Further characteristics of graphite production on cobalt catalyst}

High yield during conversion of $\mathrm{CO}_{2}$ to graphite is a critical step when making small graphite targets. Problems with this reaction are apparently limiting both other AMS facilities' small sample capabilities as well as posing a challenge to NOSAMS automation of the process.

Two considerations not described in the preceding manuscript are discussed here:

1. The first is concerned with the characteristic shape of pressure vs. time plots recorded over the course of the graphite reaction (Figure 3.9). It was often observed that the lower reaction yield samples experienced both a delayed onset of reaction initiation and a slower subsequent rate of pressure decrease. In contrast, better performance was associated with a rapid initiation and steep decrease in $\mathrm{CO}_{2}$ pressure within the reactor. Catalytic quality is the easiest explanation for this effect, especially since low total or partial $\mathrm{CO}_{2}$ gas pressures within the reactors were not always correlated with lower reaction yields.

2. The second observation concerns the configuration and temperature of the water traps. At the same time that reactor temperature control was converted to 4 individual, thermostat controllers set to $605^{\circ} \mathrm{C}$, a modification was also made to the water trap tubes. Previously, 50-mm pyrex or quartz tubes identical to those used for reactions had been used as water traps. The 75-mm tubes described in this manuscript seemed to produce better reaction yields, however, and were usually filled with small glass beads to help increase surface area for water adsorption as well as reduce the total reactor volume. The longer tubes maintained a colder temperature as the isopropanol/dry ice slush baths began to thaw over the course of the reaction.

The new, small volume, automated 10-reactor line recently built at NOSAMS was installed with a re-circulating chiller instead of individual isopropanol/dry ice slush baths for the water traps. The original configuration could not maintain the $-60^{\circ} \mathrm{C}$ temperature 
achieved using dry ice slushes. Initial attempts to make small HOxI and HOxII (2-10 $\mu$ molC) standards using this system resulted in 17 failures out of 20 attempts. The only discernable difference in the entire process was the temperature of the water trap. Improvements have since been made, and the new small volume reactors work well as long as the water traps are maintained at a sufficiently low temperature.

Both these observations help explain the earlier observation that reaction temperature is a major player in reaction yields. It is possible that the true control is governed by the partial pressure of $\mathrm{H}_{2} \mathrm{O}$ and its effect on the cobalt catalyst; hotter reactors, water traps with less surface area, and water traps not chilled to $-60^{\circ} \mathrm{C}$ would all contribute to higher $\mathrm{pH}_{2} \mathrm{O}$, catalyst deactivation, and low reaction yields. This observation also reinforces the practice of pre-reducing the cobalt under $\mathrm{H}_{2}$ at $400^{\circ} \mathrm{C}$ immediately prior to loading the samples into the reactors. 
Figure 3.9

P VS. t, $30 \mu \mathrm{g} \mathrm{C,} \mathrm{m2a94222}$ (ox II)

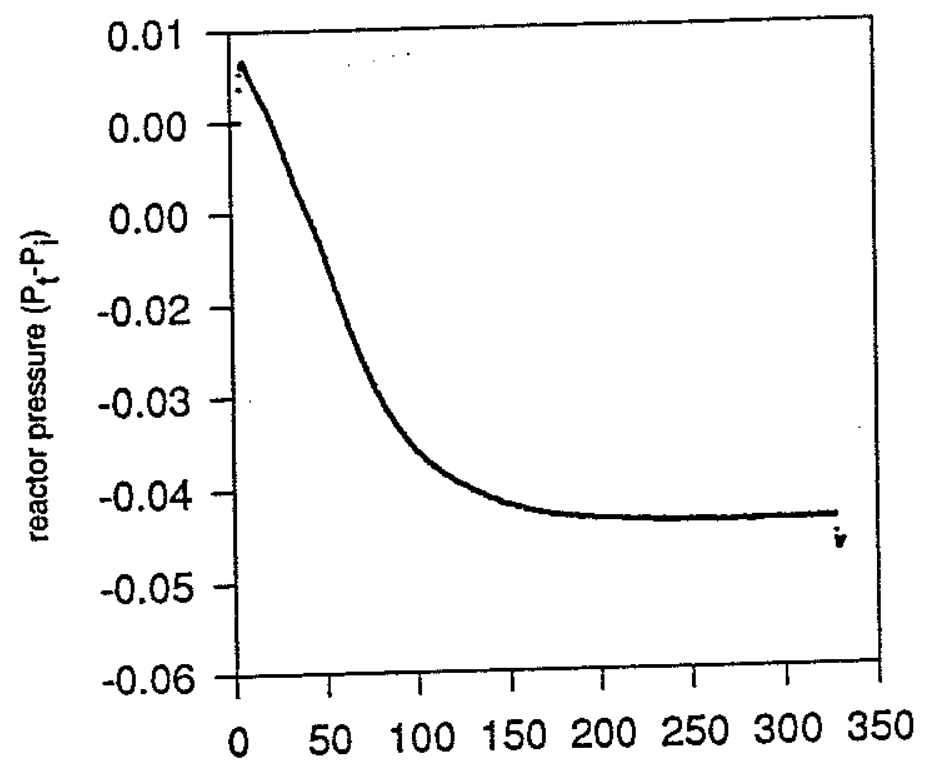

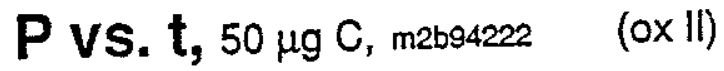

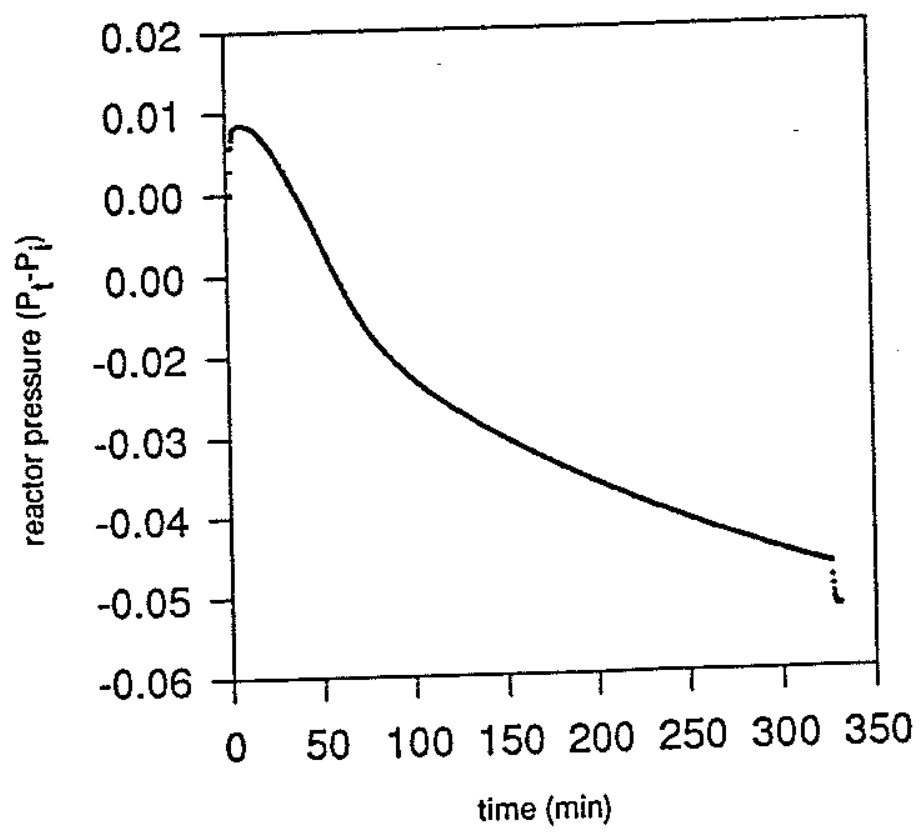

Figure 3.9 Pressure vs. time graphs for a graphite reaction achieving $85 \%$ yield (a) and for one reaching only $60 \%$ yield (b). 


\subsubsection{Isotopic fractionation effects during incomplete graphitization}

Reaction yields of less than $100 \%$ indicate incomplete conversion of $\mathrm{CO}_{2}$ to graphite in the sample reactors. This leads to the potential for isotopic fractionation. Some evidence for this effect was obtained (under different conditions, with Fe catalyst) by van der Borg et al. (1997), who observed ${ }^{13} \mathrm{C}$ and ${ }^{14} \mathrm{C}$ depletion in the graphite produced when making small samples. The isotopic depletion was more pronounced the smaller the sample, but van der Borg et al. do not attempt to correlate these results with the percentage yield of graphite from original $\mathrm{CO}_{2}$.

Even if they had attempted to correlate yields with either the isotopic composition of the graphite or more interestingly, the residual $\mathrm{CO}_{2}$, this analysis is theoretically complicated by the mathematics of isotopic fractionation in a closed system. The initial graphite product will be isotopically depleted as ${ }^{12} \mathrm{CO}_{2}$ reacts faster than ${ }^{13} \mathrm{CO}_{2}$ or ${ }^{14} \mathrm{CO}_{2}$. As the reaction progresses, the ${ }^{13} \mathrm{C}$ and ${ }^{14} \mathrm{C}$ concentrations in the graphite will approach the initial value, while the isotopic enrichment of the remaining $\mathrm{CO}_{2}$ increases exponentially. As a result, using isotopic measurements of the residual gas to evaluate fractionation effects is difficult. Assessment of such effects is, however, feasible when applied to isotopic analysis of the graphite produced.

As an approach to this question, the data from Figure 3.4 were re-analyzed and replotted as a function of reaction yield rather than sample size. Figure 3.10 shows the average ${ }^{14} \mathrm{C} /{ }^{12} \mathrm{C}$ ratio obtained for each HOxI and HOxII standard shown in Figure 3.4. There is no clearly apparent trend in the ${ }^{14} \mathrm{C}$ depletion observed at a variety of reaction yields. The isotopic ratios of standards and samples seem to be more strongly influenced by factors other than simple fractionation during graphite preparation. 
Figure 3.10

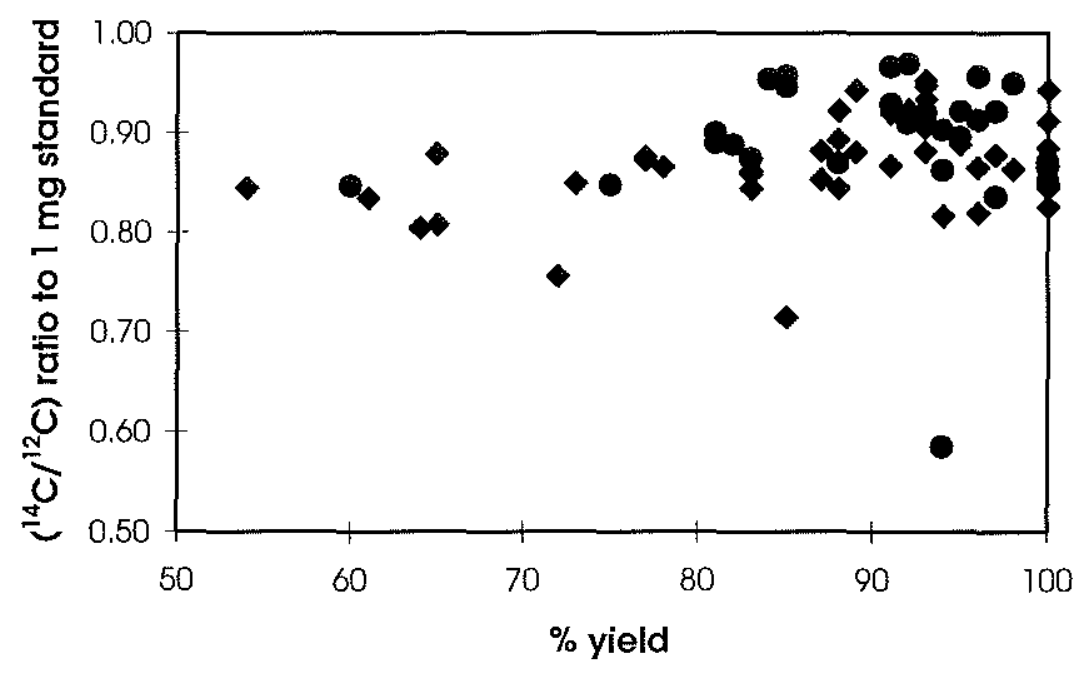

Figure 3.10 Isotope effects observed as a function of graphite reaction yield. HOxI, diamonds; HOxII, circles. 


\subsubsection{Accelerator performance for multiple small sample wheels}

The arrangement of small samples in an AMS wheel is designed to make the machine-induced isotopic fractionation effects as systematic as possible. This is motivated by considering the NOSAMS automated data analysis program, which uses a time-moving average of the standard (HOxI or HOxII) ${ }^{14} \mathrm{C} /{ }^{12} \mathrm{C}$ ratio as the denominator in the "fraction modern" calculation. Under the assumption that for a given set of HOxI standards (having the same "true" ${ }^{14} \mathrm{C} /{ }^{12} \mathrm{C}$ ), the observed ${ }^{14} \mathrm{C} /{ }^{12} \mathrm{C}$ ratio will appear to decrease as $I_{12}$ decreases, the optimum arrangement for these standards is one of descending (or ascending) order of predicted $\mathrm{I}_{12}$ (Figure 3.11(a)). The same holds true for samples. In the hypothetical situation where all samples had the same "true" ${ }^{14} \mathrm{C} /{ }^{12} \mathrm{C}$ as HOxI, a random arrangement of samples with respect to the generated $I_{12}$ would result in errors if the samples were compared to the surrounding standards (Figure 3.11(b)). A perfect prediction of their $I_{12}$ values and arrangement of the wheel in that order would minimize these errors (Figure 3.11(c)).

The small sample wheels run to date were examined for the relation between $I_{12}$ generated and both sample size $(\mathrm{C}, \%$ yield-corrected) and size:catalyst ratio $(\mathrm{C} / \mathrm{Co})$. The best example is shown in Figures 3.12(a) and (b). In general, both size and C/Co ratio are good predictors of the ${ }^{12} \mathrm{C}$ ion current, but in all cases, $\mathrm{C} / \mathrm{Co}$ had slightly higher correlation (range, $\mathrm{R}^{2}=0.64-0.88$ for $\mathrm{C}, \mathrm{R}^{2}=0.80-0.97$ for $\mathrm{C} / \mathrm{Co}$ ). For this reason, wheels have been arranged in descending order of $\mathrm{C} / \mathrm{Co}$, with slight modifications applied when strict "C/Co-order" would have led to gross mismatches in terms of absolute size.

There are still inconsistencies in accelerator performance between different wheels, however. The $\mathrm{I}_{12}$ generated per sample size or C/Co is not always constant, and some wheels also have much more scatter in the C/Co vs. $I_{12}$ data than is shown in Figure 3.12. This may be the result of different machine tuning or other unknown variability in system conditions between runs. 
Figure 3.11

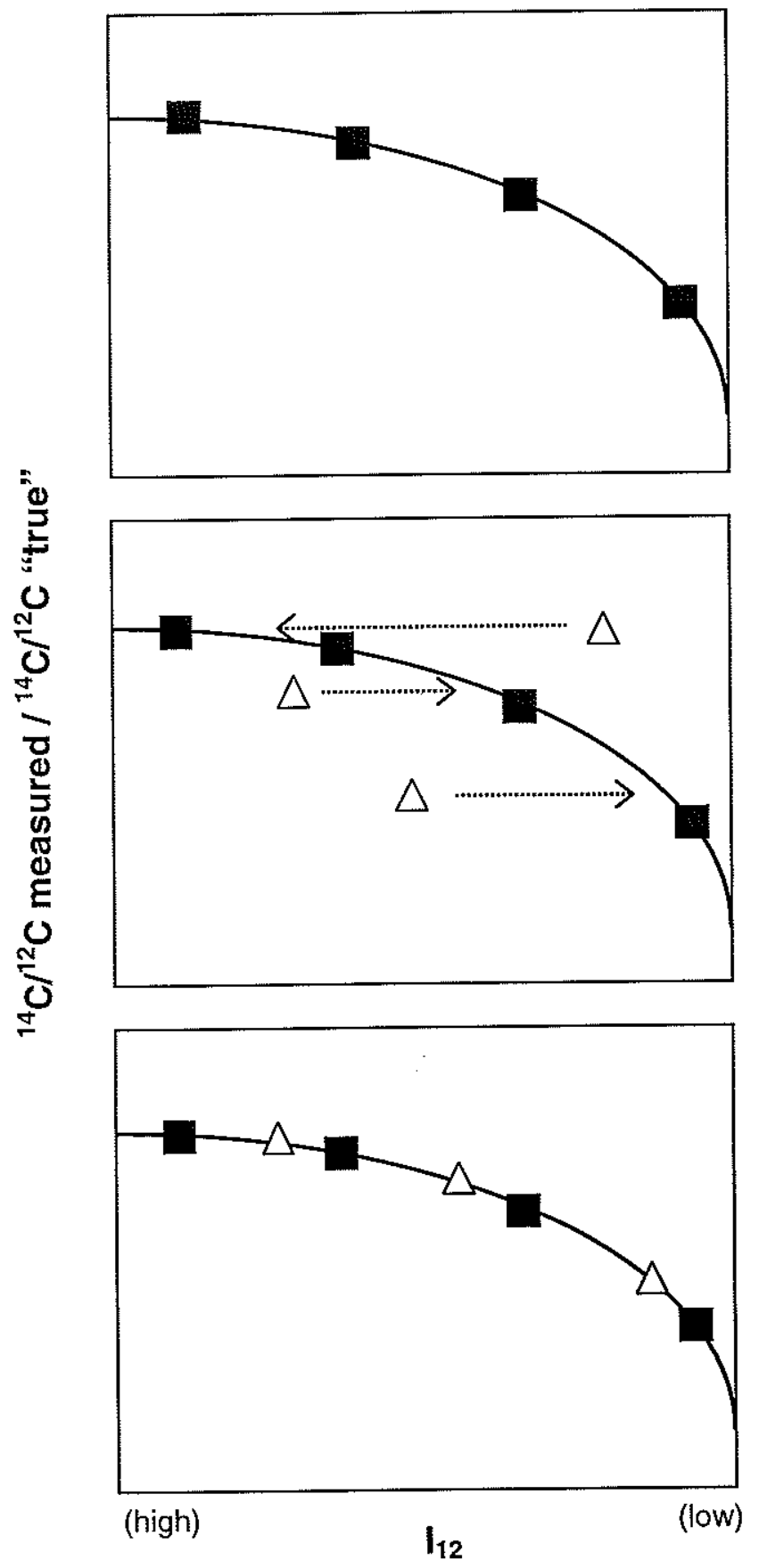

(a)

(b)

(c)

Figure 3.11 (a) Cartoon of the decrease in ${ }^{14} \mathrm{C} /{ }^{12} \mathrm{C}$ for a set of HOxI standards arranged in order of decreasing $\mathrm{I}_{12}$. (b) Random insertion of samples between these standards. (c) Samples and standards arranged in order of decreasing $I_{12}$. 
Figure 3.12

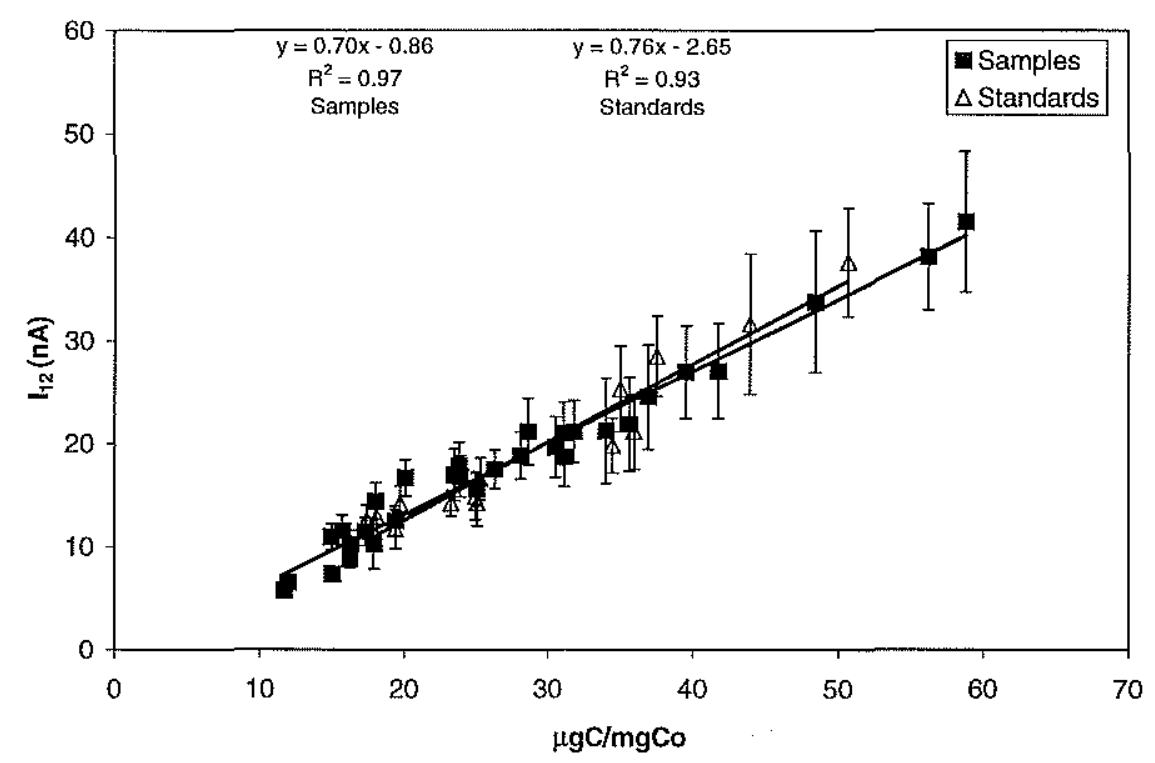

(a)

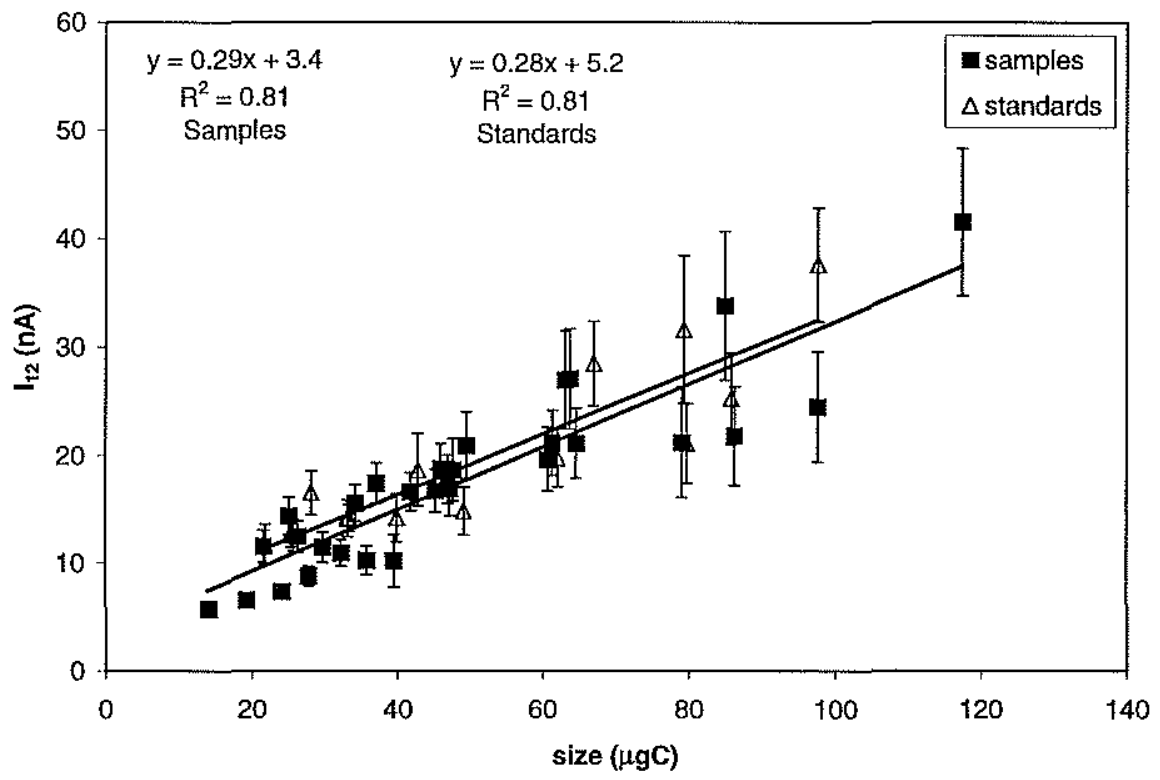

(b)

Figure 3.12 (a) Correlation between $\mathrm{I}_{12}$ and $\mathrm{C} / \mathrm{Co}$ ratio for a small sample wheel. (b) The same $I_{12}$ data, plotted as a function of sample size (corrected for $\%$ yield). 


\section{CHAPTER 4}

\section{AN ORGANIC TRACER FOR SURFACE OCEAN RADIOCARBON}

\section{AbSTRACT}

The historical record of the $\Delta^{14} \mathrm{C}$ of surface water dissolved inorganic carbon (DIC) in the Southern California Bight, USA, is compared to the record of euphotic zone $\Delta^{14} \mathrm{C}$ as recorded by sterol biomarkers extracted from the laminated sediments of Santa Monica and Santa Barbara Basins. All sterol compounds studied in this work, including $\mathrm{C}_{26}, \mathrm{C}_{27}, \mathrm{C}_{28}$, and $\mathrm{C}_{29}$ isomers, as well as dinosterol, have ${ }^{14} \mathrm{C}$ concentrations equal to the $\Delta^{14} \mathrm{C}$ of surface water DIC, suggesting that all the major sedimentary sterols are derived from phytoplanktonic detritus. The tracer capability of these biomarkers was confirmed by comparing the change in surface water $\Delta^{14} \mathrm{C}_{\mathrm{DrC}}$ due to the invasion of "bomb- ${ }^{14} \mathrm{C}^{\text {" }}$ with the change in $\Delta^{14} \mathrm{C}_{\text {sterol }}$ over the same time interval. The "pre-bomb" $\Delta^{14} \mathrm{C}_{\text {DIC }}$ is estimated to have been $-82 \%$, and "pre-bomb" sedimentary sterols ( 5 isomers) average $-75 \pm 19 \%$. The $\Delta^{14} \mathrm{C}$ of surface water DIC in 1996 was $+71 \%$ o. Eighteen measurements of 8 sterol isomers from the sediment-water interface of both Santa Monica and Santa Barbara Basin sediments average $+62 \pm 23 \%$. If three of these values are eliminated because of suspected contamination, the remaining 15 data points average $+71 \pm 12 \%$. There is no detectable, systematic terrestrial component to any of the sterols analyzed from either basin. The entire compound class could serve as an excellent proxy for the ${ }^{14} \mathrm{C}$ concentration of ocean surface waters. 


\subsection{INTRODUCTION}

The concentration of ${ }^{14} \mathrm{C}$ in surface-ocean dissolved inorganic carbon (DIC) varies with time (Stuiver et al., 1986; Druffel, 1989; Broecker et al., 1990). Over glacialinterglacial time scales, it is a function of the ventilation rate and dynamics of deep-water formation (Broecker et al., 1990; Edwards et al., 1993; Bard et al., 1994; Adkins and Boyle, 1997). Over decadal and centennial time scales, variations in ${ }^{14} \mathrm{C}$ reservoir age can reflect rapid changes in the $\Delta^{14} \mathrm{C}$ of atmospheric $\mathrm{CO}_{2}$ (Stuiver and Braziunas, 1993; Goslar et al., 1995), abrupt climatic changes (e.g. Adkins et al., 1998; Hughen et al., 1998), the uptake of ${ }^{14} \mathrm{CO}_{2}$ generated by atmospheric weapons testing ("bomb- ${ }^{14} \mathrm{C}$ ") (Druffel, 1989; Weidman and Jones, 1993), and subtle changes in patterns of ocean circulation (Guilderson and Schrag, 1998).

Short- and long-term records of oceanic $\Delta^{14} \mathrm{C}$ and ventilation rate have been restricted to $\Delta^{14} \mathrm{C}$ measurements on organic materials from extreme coastal environments (wood fragments and remains of marine mammals (Southon et al., 1990; Stuiver and Braziunas, 1986)); on clam shells from temperate and polar coastal areas (Mangerud and Gulliksen, 1975; Southon et al., 1990; Weidman and Jones, 1993); on corals from tropical surface waters (Druffel, 1989; Edwards et al., 1993; Guilderson and Schrag, 1998) or the deep ocean (Adkins et al., 1998); and on planktonic foraminifera from fastsedimentation-rate topographical highs (Duplessy et al., 1989; Broecker et al., 1990; Bard et al., 1994; Hughen et al., 1998). Nearly all these methods require preservation of calcium carbonate. In sediments where dissolution of calcite is extensive and in areas dominated by siliceous production, other means are needed to determine accurately the records of surface water $\Delta^{14} \mathrm{C}_{\mathrm{DIC}}$ and paleo-circulation. This is especially critical for the Southern Ocean, where the ventilation rate during glacial periods and its effect on atmospheric $\mathrm{CO}_{2}$ have been inferred from isotopic proxies other than carbon (e.g. François et al., 1997).

The total organic carbon (TOC) in marine sediments derives from multiple sources and is isotopically heterogeneous (e.g. Hedges and Parker, 1976; Eglinton et al., 
1997). Neither the stable carbon isotopic composition $\left(\delta^{13} \mathrm{C}_{\mathrm{TOC}}\right)$ nor the total organic radiocarbon content $\left(\Delta^{14} C_{\text {TOC }}\right)$ can be assumed to exclusively reflect surface water primary productivity. In continental-shelf sediments, organic carbon includes autochthonous contributions (phytodetritus, fecal pellets, and bacterial biomass) and allochthonous components (terrestrial vascular plant remains, soil organic matter, and weathered shale and kerogen; Hedges, 1992).

Therefore, down-core measurements of $\Delta^{14} \mathrm{C}_{\mathrm{TOC}}$ commonly do not correspond to the known depositional ages of the sedimentary horizons (Benoit et al., 1979; Jones and Gagnon, 1994; Masiello and Druffel, 1998); or in the case of core-tops, do not equal the $\Delta^{14} \mathrm{C}$ of overlying surface water DIC, even in regions of high primary productivity (Emery and Bray, 1962; Bauer et al., 1995; Wang et al., 1998). The ${ }^{13} \mathrm{C}$ and ${ }^{14} \mathrm{C}$ isotopic endmembers are complicated by variable modes of metabolism in both prokaryotic and eukaryotic organisms and by the unknown terrestrial residence time of many of the allochthonous components. Terrestrial soils may include both recently-formed leaves from trees using a $\mathrm{C}_{3}$ metabolism $\left(\delta^{13} \mathrm{C} \sim-25\right.$ to $-30 \%$, Collister et al., 1994) as well as the remains of grasses with a primarily $\mathrm{C}_{4}$ metabolism $\left(\delta^{13} \mathrm{C} \sim-10\right.$ to $-16 \%$ o, Goñi et al., 1997), and each of these components may have a significantly different soil residence time (Trumbore, 1993). In addition, marine detritus can include both phytoplanktonic and zooplanktonic biomass, heterotrophic bacteria, and autotrophic bacteria that incorporate carbon from deep-water DIC (Tuttle and Jannasch, 1979). The autotrophic components have $\Delta^{14} \mathrm{C}$ values more negative than surface water DIC (Rau et al., 1986; Chapter 5, this thesis), while the heterotrophic components are enriched in ${ }^{13} \mathrm{C}$ (DeNiro and Epstein, 1977). Several attempts have been made to determine the sources, ${ }^{14} \mathrm{C}$-ages, and relative concentrations of the pre-aged components, as well as attribute them to allochthonous or autochthonous sources (Eglinton et al., 1997; Masiello and Druffel, 1998; Wang et al., 1998; Goñi et al., 1998).

Compound-specific $\delta^{13} \mathrm{C}$ measurements (Hayes et al., 1990) have been shown to yield numerous insights into the sources, pathways, and transformation of carbon in the marine environment. Hopanols and archaeal lipids with $\delta^{13} \mathrm{C}$ near $-100 \%$ are indicative 
of methanotrophy (e.g. Freeman et al., 1990; Hinrichs et al., 1999). The phenolic oxidation products of lignin (Hedges and Parker, 1976) serve as isotopic markers for terrestrial plants $\left(\delta^{13} \mathrm{C} \sim-30 \%\right.$; Goñi et al., 1998), and the $\mathrm{C}_{37}$ alkenones ( 37 carbon atoms, $\delta^{13} \mathrm{C} \sim-24 \%$ ) are used as phytoplanktonic tracers (e.g. Brassell et al., 1986; Marlowe et al., 1990; Jasper and Hayes, 1990). Isotopic apportionment of sources has recently been expanded into a second dimension with the development of methods to measure $\Delta^{14} \mathrm{C}$ on individual biomarker lipids (Eglinton et al., 1996, Eglinton et al., 1997). Tens of micrograms of pure compounds are obtained by preparative capillary gas chromatography (PCGC) separation, and $\Delta^{14} \mathrm{C}$ values are measured by accelerator mass spectrometry (AMS). Initial compound-specific ${ }^{14} \mathrm{C}$ work shows that molecules having similar chemical structures or displaying similar $\delta^{13} \mathrm{C}$ signatures do not necessarily have the same $\Delta^{14} \mathrm{C}$ values within a single TOC sample. This heterogeneity is analogous to the diversity of $\delta^{13} \mathrm{C}$ values displayed by biomarkers of different origins.

The specific goal of the current study was to identify a biomarker or organic compound class suitable for use as a universal ${ }^{14} \mathrm{C}$ tracer of marine phytoplanktonic production and therefore of euphotic-zone $\Delta^{14} C_{\text {DIC }}$. The disadvantage of $C_{37}$ alkenones as planktonic paleotracers is that their production is confined exclusively to the haptophyte algae. Recently there has been renewed interest in the possibility that sterols, or specifically cholesterol, a $\mathrm{C}_{27}$ sterol, could serve as isotopic tracers for integrated marine primary production (Schouten et al., 1998; Grice et al., 1998). The $\mathrm{C}_{27}$ and $\mathrm{C}_{28}$ sterols have previously been used as marine biomass tracers (e.g. Volkman et al., 1987; McCaffrey et al., 1991; Wakeham and Beier, 1991). Unlike the alkenones, sterols are membrane lipid components of all eukaryotes; cholesterol $\left(\mathrm{C}_{27}\right)$ is usually the dominant sterol of zooplankton grazers (Goad, 1981), while $\mathrm{C}_{28}$ sterols are common in prymnesiophytes and diatoms (Volkman, 1986, and references therein). As a compound class, sterols appear more likely to represent the activity of total annual euphotic zone production (Grice et al., 1998) than do the $\mathrm{C}_{37}$ alkenones.

To evaluate a biomarker proxy for $\Delta^{14} C_{\text {DIC }}$, we established the following criteria: (i) the compound must record temporal changes in the ${ }^{14} \mathrm{C}$ isotopic composition of 
surface water DIC, (ii) the surface water $\Delta^{14} \mathrm{C}_{\mathrm{DIC}}$ record should be independently verified through direct measurement(s) and/or a $\mathrm{CaCO}_{3}$ proxy, and (iii) the biomarker should be shown to preserve the surface water $\Delta^{14} \mathrm{C}_{\mathrm{DIC}}$ signature even in an environment in which the TOC contains a significant fraction of non-marine organic carbon. Accordingly, we first compare the historical record of bomb- ${ }^{14} \mathrm{C}$ invasion into marine surface waters to the record of $\Delta^{14} C_{\text {DIC }}$ as preserved by planktonic foraminifera in Santa Monica Basin, California. The major sterols of Santa Monica and Santa Barbara Basin sediments are subsequently identified and their isolation by PCGC methods is described. Then the sterol $\Delta^{14} \mathrm{C}$ values, which represent both "pre-bomb" and "post-bomb" sedimentary horizons, are compared to the historical water sample and $\mathrm{CaCO}_{3} \Delta \Delta^{14} \mathrm{C}_{\mathrm{DIC}}$ records. The $\delta^{13} \mathrm{C}$ distribution among these biomarkers is used to re-examine the ${ }^{14} \mathrm{C}$ data and evaluate possible biases caused by heterotrophic carbon consumption or contributions from terrestrial sources. Finally, the records of $\Delta^{14} \mathrm{C}_{\mathrm{TOC}}$ and $\Delta^{14} \mathrm{C}_{\text {sterol }}$ in the Santa Monica Basin core are used to calculate both the fraction of TOC originating from marine primary production and the percentage and ${ }^{14} \mathrm{C}$ age of the pre-aged components.

The data are in agreement with other studies suggesting that not only cholesterol, but all the major sterols found in marine sediments, are representative of autochthonous biomass production (Volkman, 1986; McCaffrey et al., 1991; Filley et al., 1997).

\subsection{RESUltS AND DiscusSION}

\subsubsection{Bulk Samples}

Productivity is high in surface waters of the Santa Monica and Santa Barbara Basis. The prevailing suboxia in deep waters of these basins prohibits the growth of large benthic infauna, and as a result, the sediments are laminated and organic-rich. The high sedimentation rates allow decadal resolution of the changes in surface ocean $\Delta^{14} \mathrm{C}$ and their subsequent translation into the sedimentary record. In the SMB, values of $\Delta^{14} \mathrm{C}$ 
were determined for samples of bulk TOC, planktonic foraminifera, and benthic foraminifera. These values have been used to compare the reconstructed history of water mass $\Delta^{14} \mathrm{C}_{\mathrm{DIC}}$ with the sterol biomarker $\Delta^{14} \mathrm{C}$ record. The horizons studied here have experienced little ${ }^{14} \mathrm{C}$ decay, and minor decay corrections (Stuiver and Polach, 1977) were applied using the ${ }^{210} \mathrm{~Pb}$ chronology.

\subsubsection{Surface Ocean $\Delta^{14} C_{D I C}$ Record}

Surface-ocean $\Delta^{14} \mathrm{C}_{\text {DIC }}$ reached a maximum in the middle $1970 \mathrm{~s}$, about ten years after the maximum in atmospheric ${ }^{14} \mathrm{CO}_{2}$ concentration caused by above-ground testing of nuclear weapons (Levin et al., 1985; Levin and Kromer, 1997). The results of previous measurements of $\Delta^{14} \mathrm{C}_{\text {DIC }}$ from the Southern California Bight (SCB) are summarized in Table 4.1. The data are sufficient to make a time-series plot of the evolution of surface water ${ }^{14} \mathrm{C}$ concentration during the $20^{\text {th }}$ century. These data are shown as crosses in Figure 4.1. A simple bi-modal cubic spline was fit to the data to produce a smooth model curve. The model is shown as a dashed line. The "pre-bomb" values are 7 distinct data points, with an average $\Delta^{14} C_{\text {DIC }}=-82 \%$; this value has been extrapolated throughout the years $1850-1950$, under the assumption that $\Delta^{14} C_{\mathrm{DIC}}$ of surface waters remained nearly constant prior to atmospheric weapons testing. This assumption ignores small deviations in $\Delta^{14} C_{\text {DIC }}$ due to the Suess effect (Suess, 1953; Druffel and Suess, 1983); the resolution of this study is probably not sensitive enough to detect this small shift. The values of $\Delta^{14} C_{D I C}$ are also assumed to be equal in SMB and SBB surface waters, because the basins are adjacent and share similar water masses. 
Table 4.1 A history of surface water $\Delta^{14} \mathrm{C}_{\mathrm{DIC}}$, mollusc shell $\Delta^{14} \mathrm{C}$, and pteropod $\Delta^{14} \mathrm{C}$ measurements recorded in the SCB. Except for the 1996 sample (this study), the DIC data were previously gathered and published by Williams et al. (1992, and citations therein). The first three samples were collected off the Scripps Institution of Oceanography Pier $\left(32^{\circ} 52^{\prime} \mathrm{N}, 117^{\circ} 44^{\prime} \mathrm{W}\right)$; the fourth is a GEOSECS station $\left(28^{\circ} 30^{\prime} \mathrm{N}\right.$, $\left.121^{\circ} 29^{\prime} \mathrm{W}\right)$; the fifth is south of San Diego $\left(31^{\circ} 9.9^{\prime} \mathrm{N}, 117^{\circ} 12^{\prime} \mathrm{W}\right)$; this sixth is from the central Santa Monica Basin. The mollusc shell data are from coastal California (33 $38^{\circ} \mathrm{N}$ ) and were reported by Robinson (1981). The pteropod value is from Santa Barbara Basin sediment with a calendar data 1920 AD (Baumgartner and Southon, 1996).

\begin{tabular}{ccc}
\hline Year Collected & Sample Type & $\Delta^{14} \mathrm{C}(\% o)$ \\
\hline 1920 & Pteropod (L. helicina) & $\sim-78$ \\
Pre-1950s & Mollusc (n = 5 specimens) & $-81 \pm 5$ \\
& & \\
1959 & DIC & $-88 \pm 10$ \\
1965 & DIC & $49 \pm 8$ \\
1969 & DIC & $138 \pm 15$ \\
1974 & DIC & $195 \pm 4$ \\
1980 & DIC & $109 \pm 8$ \\
1996 & DIC & $71 \pm 3$ \\
\hline
\end{tabular}




\section{Figure 4.1}

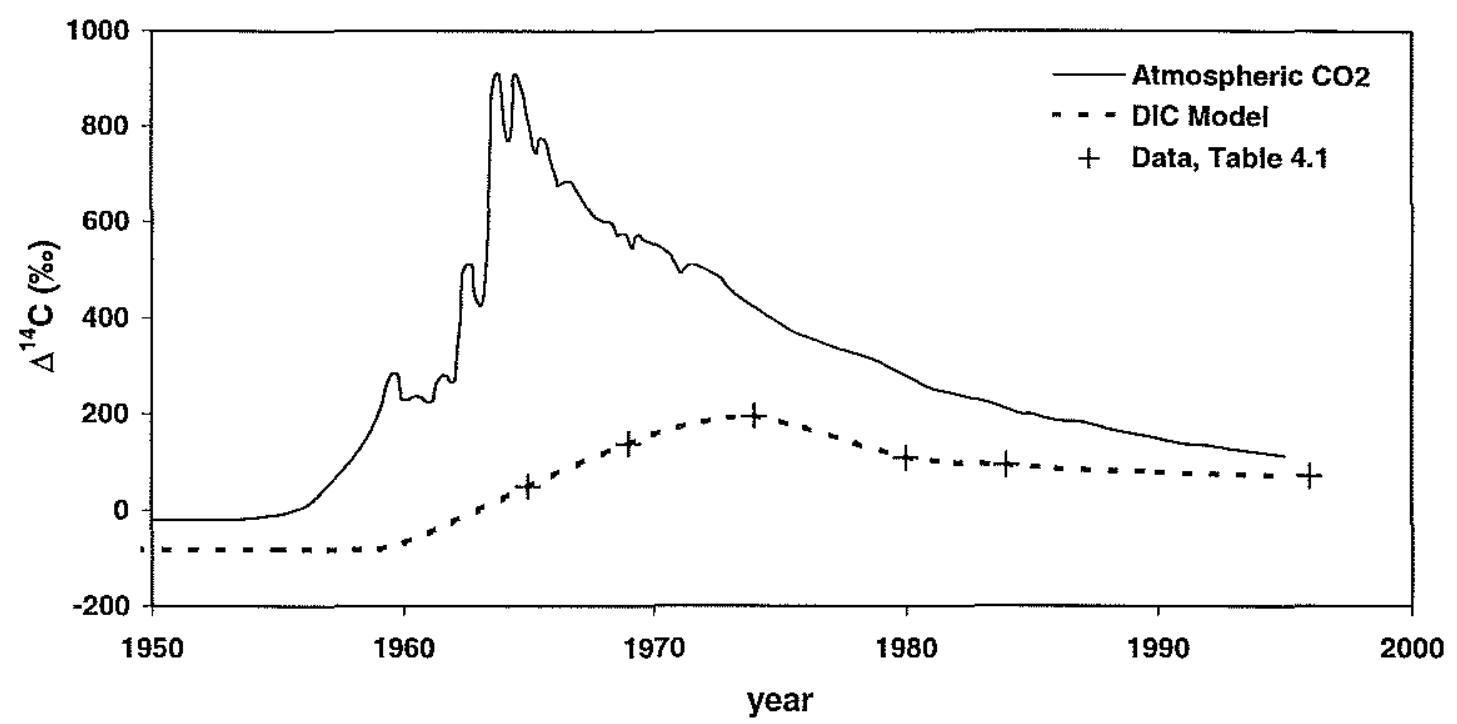

Figure 4.1 Evolution of SCB surface water $\Delta^{14} \mathrm{C}_{\mathrm{DIC}}$ through the twentieth century, showing the uptake of ${ }^{14} \mathrm{CO}_{2}$ produced by atmospheric nuclear weapons testing.

\subsubsection{Core Chronologies}

$\mathrm{A}{ }^{210} \mathrm{~Pb}$ chronology was determined for the SMB core and was used to assign calendar dates to the sectioned horizons (Figure 4.2). This chronology agrees with previously published rates of sediment accumulation (Huh et al., 1987; Christensen et al., 1994) and laminae counts based on X-Ray stratigraphy (Hagadorn et al., 1995). The calendar year assignment in Figure 4.2 also accurately places the maximum entrainment of bomb- ${ }^{14} \mathrm{C}$ in the 1961-1985 sediment interval (next section). The major feature observed in the ${ }^{210} \mathrm{~Pb}$ profile is an extreme slope break in $\ln \left({ }^{210} \mathrm{~Pb}_{\text {excess }}\right)$ at $1.5 \mathrm{~cm}$, resulting in an estimated $0.14 \mathrm{~cm} / \mathrm{yr}$ accumulation rate in the upper two horizons, and a constant $0.041 \mathrm{~cm} / \mathrm{yr}$ accumulation rate between 1.5 and $7.5 \mathrm{~cm}\left(\ln \left({ }^{210} \mathrm{~Pb}_{\text {excess }}\right)\right.$ vs. depth, $\mathrm{R}^{2}=0.99$ ). A similar feature was observed by Huh et al. (1987). The cause of this 
difference is perhaps two-fold. It coincides with a transition between extremely porous $(\phi>0.95)$ material near the surface and more compacted sediment $(\phi \sim 0.85)$ below the core top. The porous surface layer also contains discrete organic particles and living biomass (bacterial filaments) clearly at an earlier state of degradation than the deeper horizons. Extractable lipids from the $0-0.75 \mathrm{~cm}$ layer are 10 -fold more abundant than at depths below $3 \mathrm{~cm}$.

Sedimentation in the anoxic central Santa Barbara Basin is much more rapid than in SMB. Alternating light-dark laminae are easily observed by eye and are thought to indicate growth cycles of filamentous sulfur bacteria (light, low-density layers) and subsequent degradation (dark layers). Seasonal fluctuations in bottom-water oxygen concentration, driven by coastal upwelling, may be the control on this annual feature (Reimers et al., 1990). The $0-1 \mathrm{~cm}$ core top sample used here represents approximately 2-3 years deposition based on published sedimentation rates (Schimmelman and Tegner, 1991); but physical observation showed only one light-dark couplet and suggested it represented a single year's record. The sample consisted of a gelatinous, pale green layer of filamentous bacteria (colorless, Beggiatoa spp.), apparently entraining phytodetritus (the green material). Immediately beneath, a thin $\quad(\sim 2-\mathrm{mm})$ black horizon was observed. 
Figure 4.2

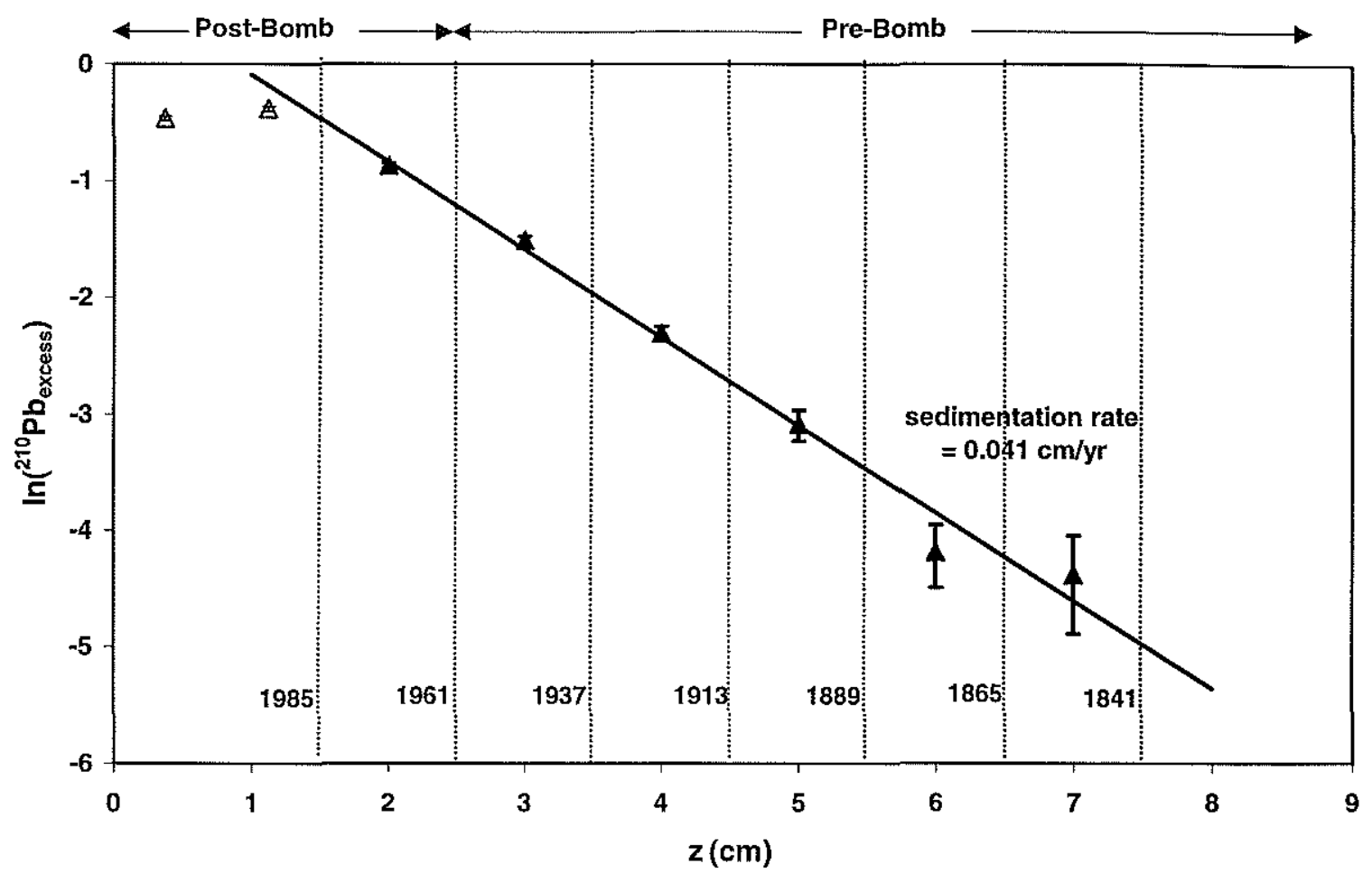

Figure 4.2 Calendar year chronology of the Santa Monica Basin core used in this thesis as determined by ${ }^{210} \mathrm{~Pb}$ dating. The core was sectioned at $0.75-\mathrm{cm}$ intervals to $1.5 \mathrm{~cm}$, then at $1.0-\mathrm{cm}$ intervals to $8.5 \mathrm{~cm}$.

\subsubsection{SMB Sediment Core $\Delta^{14} C$ : Foraminifera and TOC}

The surface water $\Delta^{14} \mathrm{C}_{\mathrm{DIC}}$ model and ${ }^{210} \mathrm{~Pb}$ chronology are combined and shown in the sediment core profile (Figure 4.3). The $\Delta^{14} \mathrm{C}_{\mathrm{DIC}}$ model is again represented by a dashed line (right-hand side of Figure 4.3). Sedimentary horizons below $2.5 \mathrm{~cm}$ have calendar year dates before the time of significant change in surface water ${ }^{14} \mathrm{C}$ 
concentration. The upper three horizons were deposited during the time of elevated $\Delta \Delta^{14} \mathrm{C}_{\text {DIC }}$. Bulk sample $\Delta{ }^{14} \mathrm{C}$ data are shown in Table 4.2

The values recorded by foraminifera provide an independent verification of the reconstructed surface water $\Delta^{14} \mathrm{C}_{\mathrm{DIC}}$ model (planktonics) and of the stability of bottom water $\Delta^{14} \mathrm{C}_{\text {DIC }}$ (benthics) over the time interval preserved in this core. Planktonic species were picked from the upper six horizons, and the foraminiferal calcite $\Delta{ }^{14} \mathrm{C}$ values are represented by hollow triangles in Figure 4.3. The assemblage was dominated by $N$. pachyderma (d.), although a significant percentage was $N$. dutertrei and/or pachyderma/dutertrei intergrade species (K. Elder, personal commumication). The sediments of SMB have very low $\mathrm{CaCO}_{3}$ abundance $(<5 \%)$; the $4-11 \mathrm{mg} \mathrm{CaCO}$ eventually processed for $\Delta^{14} \mathrm{C}$ measurements required washing and sieving $25-50 \mathrm{~g}$ (dry weight) sediment for each sample, and careful selection of uniform individuals of one species was not possible.

Two kinds of benthic foraminifera were also picked from the samples to serve as proxies for the $\Delta^{14} \mathrm{C}$ of bottom water DIC in SMB. Bolivina species (dominated by $B$. spissa) were the most abundant. B. spissa is tolerant of very low oxygen concentrations, and is commonly found in sediments underlying suboxic or seasonally anoxic bottom waters, including the California Borderland Basins (Bernhard, 1992; McCorkle et al., 1990; McCorkle et al., 1997). Samples as large as $5-10 \mathrm{mg}$ were obtained easily for $\Delta^{14} \mathrm{C}$ measurements. The data are shown as hollow circles in Figure 4.3. The three horizons below $2.5 \mathrm{~cm}$ also contained $U$. peregrina in high abundance; a transition in the benthic environment apparently occurred in the middle $20^{\text {th }}$ century, however. No U. peregrina individuals were found in the upper horizons. U. peregrina is not a low- $\mathrm{O}_{2}$ tolerant species and may only flourish immediately following strong bottom-water flushing events (Behl and Kennett, 1996). It is possible the intensity and/or frequency of these events abruptly changed. The U. peregrina data are shown as hollow squares in Figure 4.3 . 


\section{Figure 4.3}

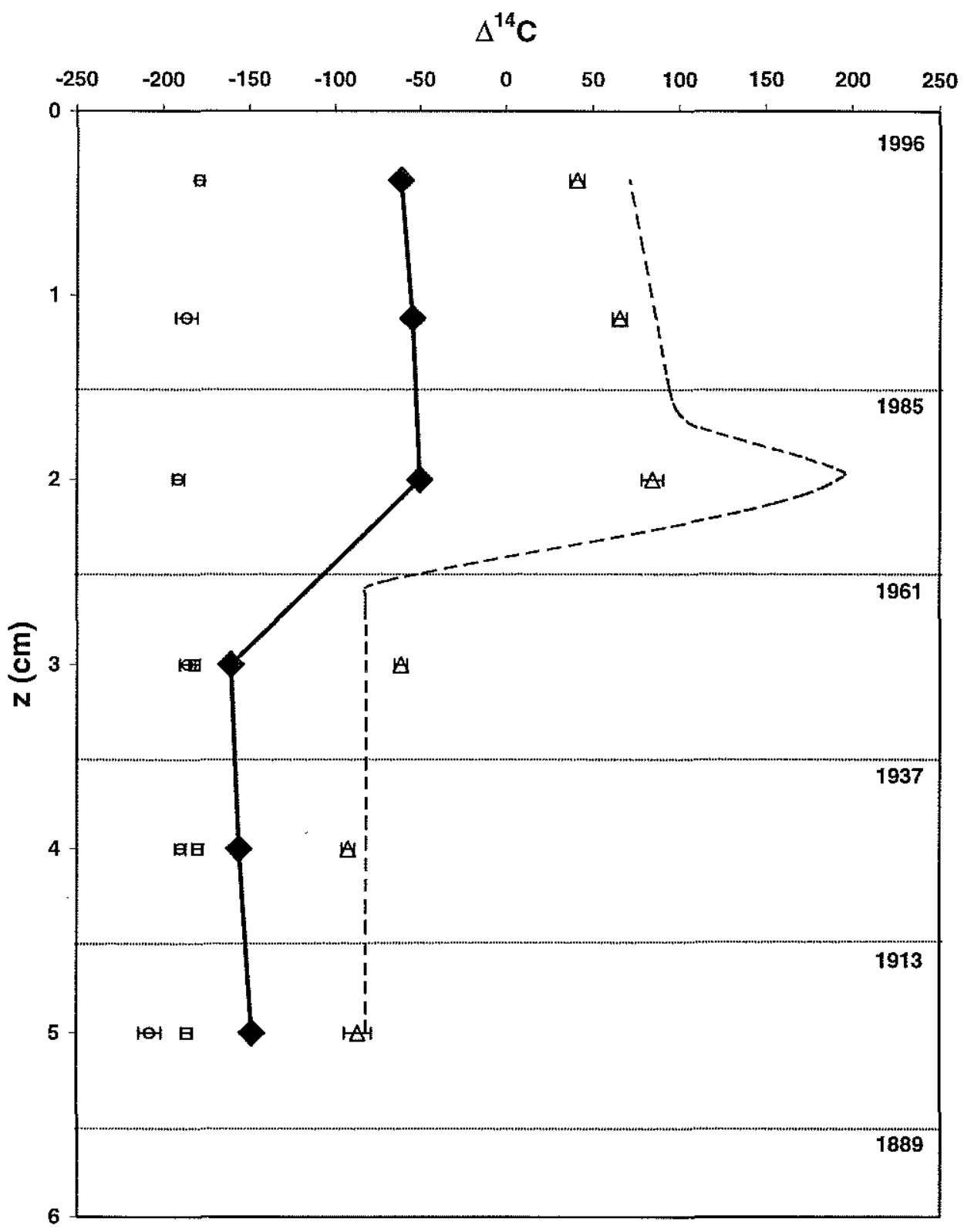

Figure 4.3 Bulk sample $\Delta^{14} \mathrm{C}$ data for the SMB core. Foraminifera are shown in hollow symbols (triangles, planktonics; circles and squares, benthics), TOC in solid diamonds, and the surface water $\Delta^{14} \mathrm{C}_{\mathrm{DIC}}$ model created from literature data is shown as a dashed line. 
The primary feature in Figure 4.3 is the appearance of excess ${ }^{14} \mathrm{C}$ after 1960 . As expected, this corresponds to the uptake of bomb-produced ${ }^{14} \mathrm{CO}_{2}$ into the surface DIC pool. The bomb- ${ }^{14} \mathrm{C}$ signal reaches its maximum in the $1.5-2.5 \mathrm{~cm}$ sediment horizon as recorded by the planktonic foraminifera, N. pachyderma (d.) and N. dutertrei. However, a persistent negative offset does exist between the foraminiferal $\Delta^{14} \mathrm{C}$ and the surface water $\Delta^{14} \mathrm{C}_{\text {DIC }}$ model in the 3 post-bomb sediment horizons. The low abundance of planktonic foraminifera in the core required picking heterogeneous samples, and this probably explains why the data are not of ideal quality. No discrimination was made on the basis of size (other than $>150 \mathrm{~mm}$ ), growth stage, or species morphology. The carbon isotopic composition of $N$. pachyderma, $N$. dutertrei, and P-D intergrade morphotypes is known to vary with shell size (Kroon and Darling, 1995; Sautter, 1998). Isotopic variation in $N$. dutertrei occurs at least partly because gametogenic $N$. dutertrei populate the ${ }^{13} \mathrm{C}$ and ${ }^{14} \mathrm{C}$-depleted waters at the base of the thermocline (Curry and Crowley, 1987; Ravelo and Fairbanks, 1992). Species that live in the upper $20 \mathrm{~m}$ (e.g. Globigerinoides ruber) are better tracers of surface-water masses. The gradient in $\Delta^{14} \mathrm{C}_{\mathrm{DIC}}$ between surface and thermocline waters became steeper following the uptake of bomb-derived ${ }^{14} \mathrm{CO}_{2}$. This may have caused the isotopic composition of the planktonic foraminiferal assemblage analyzed here to become increasingly biased by the presence of the deeperdwelling $N$. dutertrei species. This would result in a negative offset in $\Delta^{14} \mathrm{C}_{\text {calcite }}$ relative to surface water $\Delta^{14} \mathrm{C}_{\text {DIC }}$ in the post-bomb samples.

Pre-bomb values of $\Delta^{14} \mathrm{C}_{\mathrm{DIC}}$ in surface waters, as recorded by the planktonic foraminifera below $2.5 \mathrm{~cm}$, are in good agreement with the average literature value of $-82 \%$; the three samples average $-80 \pm 16 \%$ o. The two species of benthic foraminifera also show that the isotopic composition of bottom water DIC has remained essentially constant during the past 100 years. The $B$. spiss $a$ and $U$. peregrina data indicate a mean benthic $\Delta^{14} \mathrm{C}_{\mathrm{DIC}}$ of $-188 \pm 8 \%$. There is no significant trend with time in these values, as bomb- ${ }^{14} \mathrm{C}$ has not yet penetrated below a depth of $\sim 500 \mathrm{~m}$ in the northeastern Pacific Ocean (Broecker and Peng, 1982; WOCE Data Report 94-093, 1994). 
Bomb- $-{ }^{14} \mathrm{C}$ also appears in the TOC pool in the upper three sedimentary horizons (solid diamonds, Figure 4.3). The change in the concentration of ${ }^{14} \mathrm{C}$ in organic carbon reflects uptake of DIC by phytoplankton during photosynthesis, partial re-working by heterotrophic consumers, and subsequent sedimentation of organic detritus. The critical characteristic for $\Delta^{14} \mathrm{C}_{\mathrm{TOC}}$ in this core, however, is that even though the timing of bomb${ }^{14} \mathrm{C}$ uptake is identical to that observed for the DIC pool, the ${ }^{14} \mathrm{C}$ concentration is always less than that measured in the surface waters or recorded by planktonic foraminifera. There are clearly components within the TOC pool other than products of marine phytoplanktonic primary production. TOC must, therefore, be a heterogeneous mixture of organic material derived from multiple sources. The pre-aged, possibly non-marine fraction of TOC has a net ${ }^{14} \mathrm{C}$ concentration less than surface water DIC. Whether its primary source represents terrigenous carbon (e.g. Eglinton et al., 1997; Goñi et al., 1998), incorporation of deep-water DIC (Rau et al., 1986; Rau, 1991), refractory dissolved organic carbon (DOC) (e.g. Druffel et al., 1992; Wang et al., 1998), or "black carbon" (Masiello and Druffel, 1998), this component of TOC is not turned over on a time-scale fast enough to have incorporated atmospheric, bomb- ${ }^{14} \mathrm{C}$ labelled $\mathrm{CO}_{2}$. The down-core profile of $\Delta^{14} \mathrm{C}_{\mathrm{TOC}}$ therefore does not accurately record the evolution of surface water $\Delta^{14} \mathrm{C}_{\mathrm{DIC}}$ concentration and cannot be used as a direct proxy for the isotopic composition of surface waters. 
Table 4.2 Isotopic data for bulk samples, SMB core.

\begin{tabular}{|c|c|c|}
\hline Sample & $\delta^{13} \mathrm{C}(\% o)$ & $\Delta^{14} \mathrm{C}(\% 0)$ \\
\hline \multicolumn{3}{|l|}{ Surface Water DIC } \\
\hline $20 \mathrm{~m}$ & 1.57 & $71 \pm 3$ \\
\hline \multicolumn{3}{|l|}{ TOC } \\
\hline $0-0.75 \mathrm{~cm}$ & -22.8 & $-62 \pm 3$ \\
\hline $0.75-1.5$ & -23.2 & $-55 \pm 2$ \\
\hline $1.5-2.5$ & -22.6 & $-51 \pm 3$ \\
\hline $2.5-3.5$ & -22.7 & $-161 \pm 3$ \\
\hline $3.5-4.5$ & -22.8 & $-156 \pm 2$ \\
\hline $4.5-5.5$ & -23.3 & $-149 \pm 2$ \\
\hline \multicolumn{3}{|l|}{ Foraminifera } \\
\hline \multicolumn{3}{|c|}{ Neogloboquadrina spp. } \\
\hline $0-0.75 \mathrm{~cm}$ & 1.3 & $41 \pm 4$ \\
\hline $0.75-1.5$ & 1.6 & $65 \pm 4$ \\
\hline $1.5-2.5$ & 1.5 & $84 \pm 6$ \\
\hline $2.5-3.5$ & 1.7 & $-62 \pm 4$ \\
\hline $3.5-4.5$ & 1.4 & $-93 \pm 4$ \\
\hline $4.5-5.5$ & 1.9 & $-87 \pm 8$ \\
\hline \multicolumn{3}{|l|}{ Bolivina spp. } \\
\hline $0-0.75 \mathrm{~cm}$ & -0.5 & $-179 \pm 3$ \\
\hline $0.75-1.5$ & -0.6 & $-187 \pm 6$ \\
\hline $1.5-2.5$ & -0.8 & $-191 \pm 4$ \\
\hline $2.5-3.5$ & -0.8 & $-186 \pm 4$ \\
\hline $3.5-4.5$ & -0.5 & $-190 \pm 3$ \\
\hline $4.5-5.5$ & -0.8 & $-208 \pm 6$ \\
\hline \multicolumn{3}{|l|}{$U$. peregrina } \\
\hline $2.5-3.5 \mathrm{~cm}$ & -0.3 & $-182 \pm 3$ \\
\hline $3.5-4.5$ & -0.3 & $-180 \pm 2$ \\
\hline $4.5-5.5$ & -0.4 & $-186 \pm 3$ \\
\hline
\end{tabular}




\subsubsection{Selection of Intervals for Compound-Specific Isotope Analysis}

A pre-bomb sediment horizon $(4.5-5.5 \mathrm{~cm})$ and the shallowest post-bomb horizon $(0-0.75 \mathrm{~cm})$ from the SMB core were initially selected for compound-specific analysis of ${ }^{14} \mathrm{C}$ and ${ }^{13} \mathrm{C}$ in individual sterols. These samples provide a clear contrast between the isotopic composition of photosynthetic biomarkers from pre- and post-bomb, surface waters. The best data to verify the surface-water $\Delta^{14} C_{\text {DIC }}$ values at the time of biosynthesis is available for these samples. Excellent agreement between pre-bomb DIC literature data and our planktonic foraminiferal measurements provide independent verification that $\Delta^{14} \mathrm{C}_{\mathrm{DIC}}=-82 \%$ at the time the $4.5-5.5 \mathrm{~cm}$ sample was formed. The surface horizon $(0-0.75 \mathrm{~cm}$ corresponds to $<10$ years deposition) can be compared to the $\Delta^{14} \mathrm{C}_{\text {DIC }}$ sample collected at the same time as the sediment core $\left(\Delta^{14} \mathrm{C}_{\text {DIC }}=+71 \%\right.$, Table 4.2).

The SBB $0-1 \mathrm{~cm}$ sample was included to corroborate the results from the SMB 0 $-0.75 \mathrm{~cm}$ sample and to sort out a potential contamination problem. The initial batch of data for SMB $0-0.75 \mathrm{~cm}$ suggested that a few of the sterol samples might have been contaminated with a small amount of column bleed during preparation (more discussion, next section). This component was removed during preparation of the SBB $0-1 \mathrm{~cm}$ sterols by including an additional purification step. The SBB environment provides an excellent comparison to SMB surface sediments. The shallower SBB has a higher sedimentation rate and provided a sample of very recently-fixed phytoplanktonic detritus. The immediate geographical proximity to SMB means they share very similar surface water masses, with comparable DIC isotopic composition, and they probably have a similar phytoplanktonic species distribution. The SBB biomarker isotopic data were expected to be similar to the data obtained from SMB sediment. 


\subsubsection{Organic Geochemical Analysis}

\subsubsection{Sterol Lipid Fractions}

Partial, high-resolution gas chromatograms (HRGC) of the three 4-desmethylsterol fractions selected for isotopic analysis are shown in Figure 4.4. The sterols were derivatized to acetates (-OAc) for preparative capillary gas chromatographic (PCGC) separation of individual compounds for ${ }^{14} \mathrm{C}$ analysis. However, ${ }^{13} \mathrm{C}$ analysis also required a portion of each sample to be converted to trimethyl-silyl ethers (-OTMS). Small differences in chromatographic separation occur between the two types of derivatives. Figure 4.4 therefore shows the three samples as acetates in parts (a), (b), and (c), and for comparison also shows the SMB $4.5-5.5 \mathrm{~cm}$ sterols as -OTMS derivatives in part (d). Peaks are identified in Table 4.3. The 4-methyl-sterol sub-fractions, from which dinosterol was the only compound selected for isotopic analysis, are shown in Figure 4.5.

Table 4.3 Sterols identified in the chromatograms in Figures 4.4 and 4.5.

\begin{tabular}{|c|c|c|}
\hline Peak & Sterol & Abbreviation \\
\hline $\mathbf{I}$ & 24 -nor-cholesta-5,22-dien-3 $\beta$-ol & $\mathrm{C}_{26} \Delta^{5,22}$ \\
\hline II & 24 -nor- $5 \alpha$-cholest- 22 -en-3 $\beta$-ol & $\mathrm{C}_{26} \Delta^{22}$ \\
\hline III & 27 -nor-24-methylcholesta-5,22-dien-3 $\beta$-ol & $\mathrm{C}_{27} \Delta^{5,22 *}$ \\
\hline IV & cholesta-5,22-dien-3 $\beta$-ol & $\mathrm{C}_{27} \Delta^{5,22}$ \\
\hline $\mathbf{V}$ & $5 \alpha$-cholest-22-en-3 $\beta$-ol & $\mathrm{C}_{27} \Delta^{22}$ \\
\hline VI & cholest-5-en-3 $\beta$-ol & $\mathrm{C}_{27} \Delta^{5}$ (Cholesterol) \\
\hline VII & $5 \alpha$-cholestan- $3 \beta$-ol & $5 \alpha-\mathrm{C}_{27}$ \\
\hline VIII & 24-methylcholesta-5,22-dien-3 $\beta$-ol & $\mathrm{C}_{28} \Delta^{5,22}$ \\
\hline IX & 24 -methyl-5 $\alpha$-cholest-22-en-3 $\beta$-ol & $\mathrm{C}_{28} \Delta^{22}$ \\
\hline $\mathbf{X}$ & 24-ethylcholest-5-en-3 $\beta$-ol & $\mathrm{C}_{29} \Delta^{5}$ \\
\hline XI & 24-ethyl-5 $\alpha$-cholestan- $3 \beta$-ol & $5 \alpha-\mathrm{C}_{29}$ \\
\hline XII & 4, 23, 24-trimethyl-5 $\alpha$-cholest-22-en-3 $\beta$-ol & Dinosterol \\
\hline
\end{tabular}




\section{Figure 4.4}

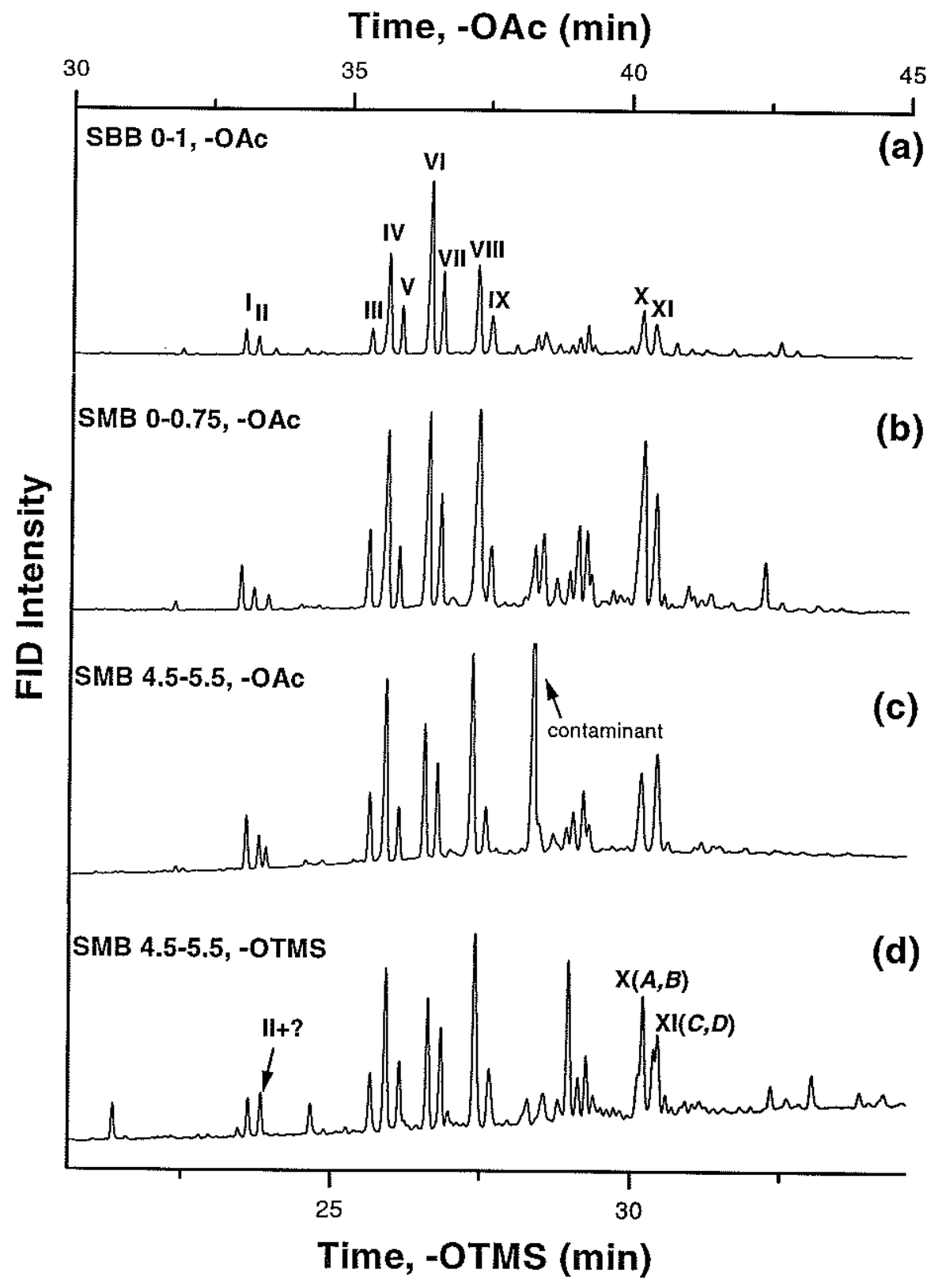

Figure 4.4 HRGC traces for the three sterol fractions selected for compound-specific isotopic analysis. (a) SBB 0-1 cm, (b) SMB 0-0.75 cm, (c) SMB 4.5-5.5 cm, all derivatized to acetates for PCGC separation and ${ }^{14} \mathrm{C}$ analysis; (d) SMB 4.5-5.5 derivatized to trimethyl-silyl ethers as was necessary for $\delta^{13} \mathrm{C}$ analysis by irm-GC/MS. 


\section{Figure 4.5}

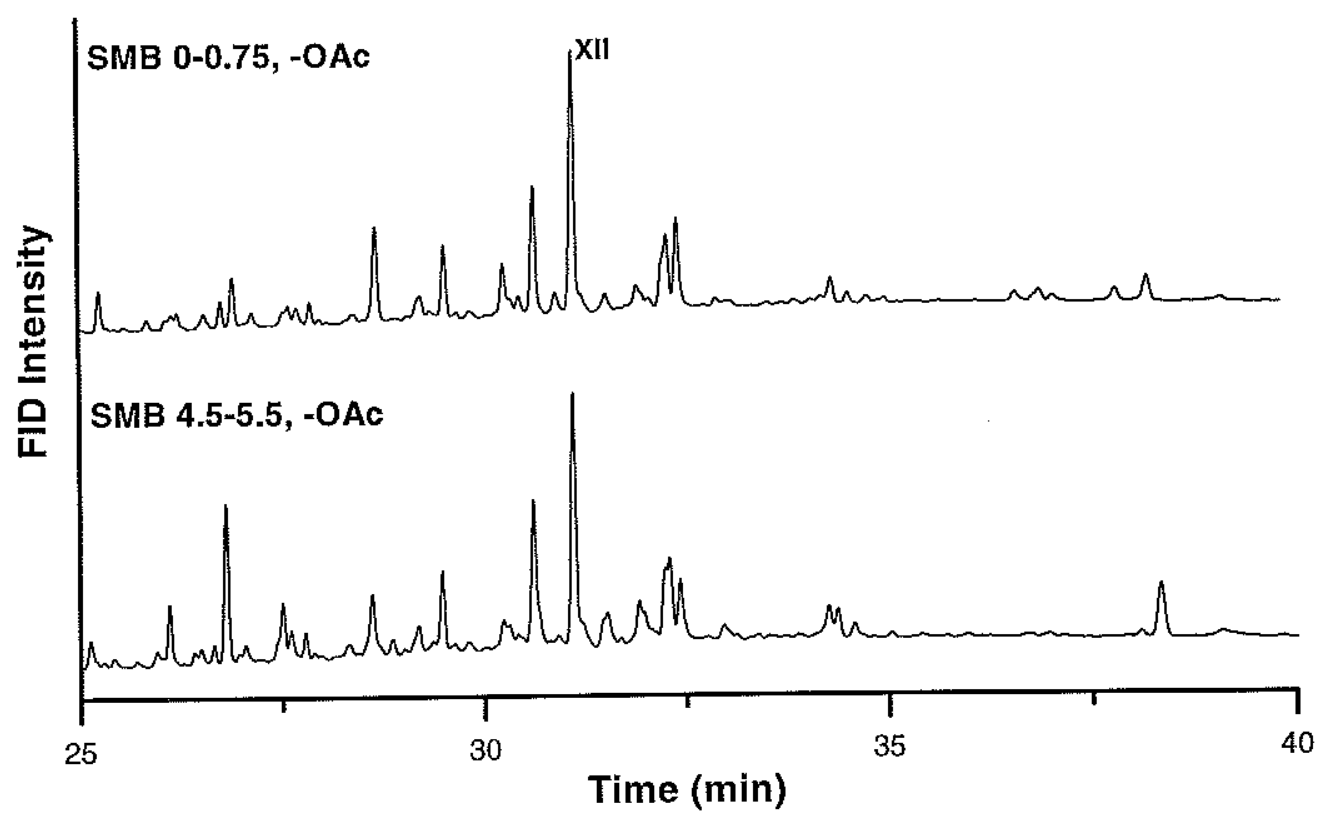

Figure 4.5 HRGC traces for two 4-methyl-sterol fractions (as acetates) for PCGC separation of dinosterol.

The sterol acetate chromatograms (Figure 4.4(a),(b),(c)) for all three samples are quite similar. In Table 4.4, the abundances of the major sterols relative to cholesterol, as well as the stanol/stenol ratio for each isomeric pair, is shown for the three samples. In the surface sediment of SBB, cholesterol is the most abundant free sterol, although dinosterol was not quantified and may equal or exceed cholesterol in this environment (Filley et al., 1997). The absolute abundance of all sterols is also higher in SBB sediment than in SMB sediment ( 31 vs. $11 \mu \mathrm{g}$ cholesterol per gram dry weight sediment). For both SMB horizons, $\mathrm{C}_{28} \Delta^{5,22}$ is the most abundant isomer. $\mathrm{C}_{29} \Delta^{5}$ and dinosterol were also more abundant than cholesterol in both SMB horizons, while $\mathrm{C}_{27} \Delta^{5,22}$ and $5 \alpha-\mathrm{C}_{29}$ exceeded cholesterol in the deeper SMB horizon only. The absolute abundance of all 
sterols decreased with depth in the SMB core, although the percent TOC remained approximately constant (TOC data in appendix).

Table 4.4 Abundance of major sterols in SMB and SBB sediment samples.

\begin{tabular}{llcccccc}
\hline & & SBB 0-1 cm & \multicolumn{3}{c}{ SMB 0 0.75 cm } & \multicolumn{2}{c}{ SMB 4.5-5.5 cm } \\
\hline & Sterol & $\begin{array}{c}\text { \% of } \\
\text { cholesterol }\end{array}$ & $\begin{array}{c}\text { Stanol/ } \\
\text { Stenol }\end{array}$ & $\begin{array}{c}\text { \% of } \\
\text { cholesterol }\end{array}$ & $\begin{array}{c}\text { Stanol/ } \\
\text { Stenol }\end{array}$ & $\begin{array}{c}\text { \% of } \\
\text { cholesterol }\end{array}$ & $\begin{array}{c}\text { Stanol/ } \\
\text { Stenol }\end{array}$ \\
I & $\mathrm{C}_{26} \Delta^{5,22}$ & 11 & $\mathrm{II} / \mathrm{I}=$ & 17 & & 27 & \\
II & $\mathrm{C}_{26} \Delta^{22}$ & 8 & 0.70 & 9 & 0.53 & 16 & 0.58 \\
III & $\mathrm{C}_{27} \Delta^{5,22^{*}}$ & 12 & & 35 & & 46 & \\
IV & $\mathrm{C}_{27} \Delta^{5,22}$ & 54 & $\mathrm{~V} / \mathrm{IV}=$ & 96 & & 129 & \\
V & $\mathrm{C}_{27} \Delta^{22}$ & 21 & 0.38 & 24 & 0.25 & 46 & 0.36 \\
VI & ${ }^{\dagger} \mathrm{C}_{27} \Delta^{5}$ & $(31 \mu \mathrm{g} / \mathrm{gdw})$ & $\mathrm{VII} / \mathrm{VI}=$ & $(11 \mu \mathrm{ggdw})$ & & $(2.3 \mu \mathrm{g} / \mathrm{gdw})$ & \\
VII & $5 \alpha-\mathrm{C}_{27}$ & 35 & 0.35 & 47 & 0.47 & 74 & 0.74 \\
VIII & $\mathrm{C}_{28} \Delta^{5,22}$ & 54 & $\mathrm{IX} / \mathrm{VIII}=$ & 146 & & 173 & \\
IX & $\mathrm{C}_{28} \Delta^{22}$ & 31 & 0.57 & 32 & 0.22 & 60 & 0.35 \\
X & $\mathrm{C}_{29} \Delta^{5}$ & 33 & $\mathrm{XI} / \mathrm{X}=$ & 129 & & $142^{\ddagger}$ & \\
XI & $5 \alpha-\mathrm{C}_{29}$ & 21 & 0.62 & 66 & 0.51 & $120^{\ddagger}$ & 0.85 \\
XII & $\mathrm{Dinosterol}^{5}$ & -- & & 102 & & 146 & \\
\hline
\end{tabular}

$\dagger$ Concentration of cholesterol per gram dry weight of sediment. $\ddagger$ Quantified in -OTMS fraction rather than acetate fraction.

SBB surface sediment has consistently higher stanol/stenol ratios than the SMB surface horizon; the only exception is a higher cholestanol/cholesterol ratio in the SMB sample. The variation in stanol/stenol ratio between SMB horizons appears to be less systematic, however. Large increases in cholestanol/cholesterol and $\mathrm{C}_{29} \mathrm{stanol} / \mathrm{stenol}$ ratios at depth in the sediment are not equaled by comparable increases in the unsaturated isomers of other pairs. The sterol lipid fraction of the $4.5-5.5 \mathrm{~cm}$ sample was not separated identically from the total lipid extract as were the two surface samples, however, so it is possible the high cholestanol/cholesterol ratio in this sample is partially an analytical artifact rather than a diagenetic effect. Sterol sources, diagenetic effects, 
and redox conditions (stanol/stenol ratios) will be addressed in the discussion of the ${ }^{14} \mathrm{C}$ and ${ }^{13} \mathrm{C}$ compound-specific data.

The same major sterols were identified as -OTMS ethers in Figure 4.4(d). However two major differences are noted between this chromatogram and the corresponding sterol acetate fraction. First, a shift in chromatographic retention time for a non-sterol isomer has caused an unidentified compound to co-elute with peak II. This co-elution has probably biased the ${ }^{13} \mathrm{C}$ results determined by $\mathrm{irm}$-GC/MS for the $\mathrm{C}_{26} \Delta^{22}$ sterol. Second, improved peak resolution in the $\mathrm{C}_{29}$ sterol region suggests very strongly that the two peaks previously identified as single isomers of $\mathrm{C}_{29} \Delta^{5}(\mathbf{X})$ and $5 \alpha-\mathrm{C}_{29}(\mathbf{X I})$, in fact each represent two isomers. The two peaks are re-labelled $\mathbf{X}(\boldsymbol{A}, \boldsymbol{B})$ and $\mathbf{X I}(\boldsymbol{C}, \boldsymbol{D})$. This was investigated and confirmed by examining the $\mathrm{irm}$-GC/MS chromatograms and mass $45 / 44$ ratio traces for all the samples studied. The resolution of the capillary column used for irm-GC/MS was superior to the columns used for previous HRGC analyses, and four isomers were easily distinguished. To further verify that the effect was not simply due to differing behavior of the samples upon derivatization to -OTMS ethers, all samples were re-analyzed by $\mathrm{irm}-\mathrm{GC} / \mathrm{MS}$ as acetates. Figure 4.6 compares (a) the $\mathrm{C}_{29}$ sterol region as originally determined by HRGC, (b) the corresponding mass 45/44 ratio trace, and (c) the $\mathrm{irm}$-GC/MS chromatogram (mass 44 ion current), all for the SMB 0$0.75 \mathrm{~cm}$ sterol acetate sample. New attempts to achieve this degree of resolution on a GC/MS system (HP 6890/HP5973) using a similar capillary column, GC oven program, and very dilute mixtures, were unsuccessful. The two peaks originally identified had mass spectra generally consistent with $\mathrm{C}_{29} \Delta^{5}(\mathbf{X}(A, B))$ and $\mathrm{C}_{29}$ stanol $(\mathbf{X I}(C, D))$ structures. Based on retention times, the two isomers represented by peak $\mathbf{X}$ may be 24-ethylcholest-

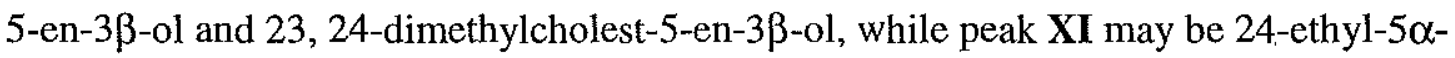

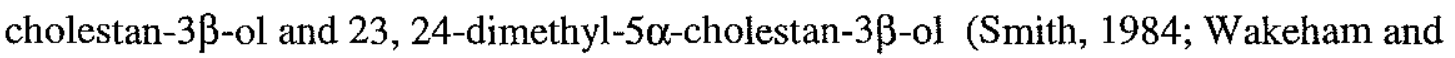
Beier, 1991), although in the absence of authentic comparison standards, these assignments are very tentative. The additional isomers are probably of marine source (Volkman, 1986) and complicate the interpretation of the $\mathrm{C}_{29}$ sterol isotopic data with regard to the presence of a terrigenous component. 


\section{Figure 4.6}
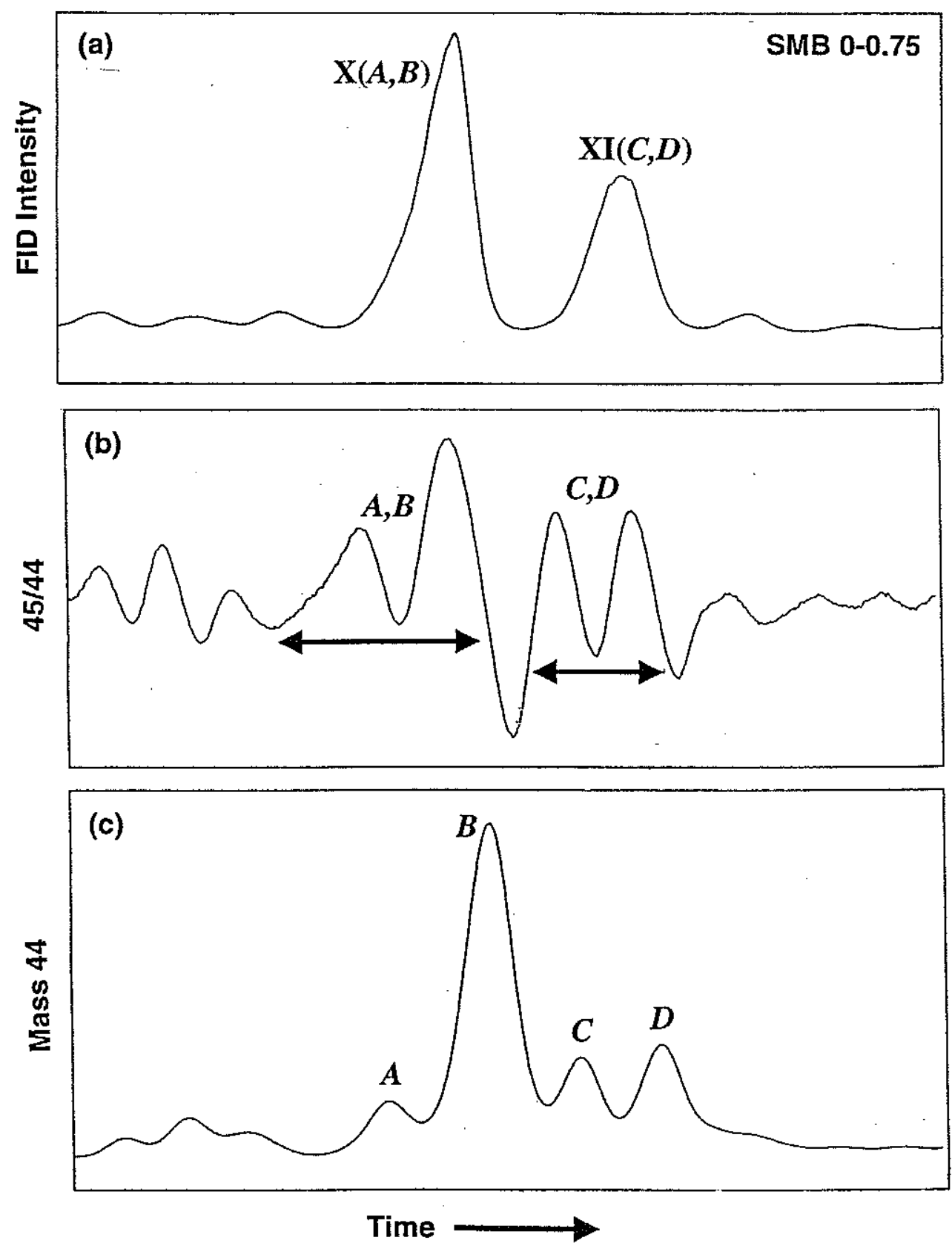

Figure 4.6 (a) Expanded $\mathrm{C}_{29}$ sterol region of the $\mathrm{SMB} 0-0.75 \mathrm{~cm}$ chromatogram originally obtained by HRGC. (b) The mass $45 / 44$ isotope ratio trace for the same region of this sample has four clear peaks, and (c) the corresponding mass 44 ion chromatogram shows the improved peak separation obtained on the irm-GC/MS system. 


\subsubsection{PCGC separations}

Individual sterols were purified in sufficient quantities for ${ }^{14} \mathrm{C}$-AMS analysis using automated preparative capillary gas chromatography (PCGC). Details of the PCGC system and methods are described in Eglinton et al. (1996). The PCGC preparative trapping device allows up to six compounds to be recovered from a lipid fraction, and a typical run consists of about 100 consecutive injections at a concentration of $\sim 0.5-1.5$ $\mu \mathrm{gC} /$ peak/injection.

Two separate PCGC runs were performed to collect 4-desmethyl-sterols from the SMB $0-0.75 \mathrm{~cm}$ fraction. In the first run, the following six isomers were collected: $\mathrm{C}_{26} \Delta^{5,22}+\mathrm{C}_{26} \Delta^{22}$ (composite sample), $\mathrm{C}_{27} \Delta^{5}, 5 \alpha-\mathrm{C}_{27}, \mathrm{C}_{28} \Delta^{5,22}, \mathrm{C}_{29} \Delta^{5}$, and $5 \alpha-\mathrm{C}_{29}$ (subsequently lost during analysis). Sufficient sample remained to allow a second separation, and $\mathrm{C}_{26} \Delta^{5,22}+\mathrm{C}_{26} \Delta^{22}$ (composite sample), $\mathrm{C}_{27} \Delta^{5,22}, \mathrm{C}_{27} \Delta^{5}$, and $5 \alpha-\mathrm{C}_{29}$ were selected. The repeat collections of $C_{26} \Delta^{5,22}+C_{26} \Delta^{22}$ and $C_{27} \Delta^{5}$ provided independent replicates with which to assess the quality of the ${ }^{14} \mathrm{C}$ data obtained. After combustion to $\mathrm{CO}_{2}$, the second collection of $\mathrm{C}_{27} \Delta^{5}$ was also split into two samples of identical gas $\left(\mathrm{C}_{27} \Delta^{5} \mathrm{a}, \mathrm{b}\right)$ to provide additional replicates. Aliquots of each trapped compound were reanalyzed by HRGC to verify compound identity and purity. Figure 4.7 shows chromatograms of the sterols recovered from the first run, as an example of the quality of isolation typically achieved by PCGC separation. Chromatographic resolution is not as high when using the "megabore" PCGC column as it is when examining the recovered products, and closely-eluting isomers are sometimes seen to have entrained small amounts $(<5 \%)$ of adjacent peaks. In the case of adjacent stanol/stenol pairs, however, the resulting ${ }^{14} \mathrm{C}$ isotopic biases should be small. All PCGC separations were similar to the example shown in Figure 4.7.

For the pre-bomb, SMB $4.5-5.5 \mathrm{~cm}$ 4-desmethyl-sterol sample, the following compounds were collected: $\mathrm{C}_{27} \Delta^{5}, \mathrm{C}_{28} \Delta^{5,22}, \mathrm{C}_{29} \Delta^{5}$, and $5 \alpha-\mathrm{C}_{29} \cdot \mathrm{C}_{26} \Delta^{5,22}+\mathrm{C}_{26} \Delta^{22}$ and $5 \alpha-$ $\mathrm{C}_{27}$ were lost during analysis. To compare the SBB $0-1 \mathrm{~cm}$ sediment horizon to the SMB surface sediments, $\mathrm{C}_{27} \Delta^{5,22}, \mathrm{C}_{27} \Delta^{5}, 5 \alpha-\mathrm{C}_{27}, \mathrm{C}_{28} \Delta^{5,22}, \mathrm{C}_{29} \Delta^{5}$, and $5 \alpha-\mathrm{C}_{29}$ were collected 
from the SBB sample. This collection was performed substantially after the prior separations, after refinements to PCGC techniques and AMS measurements had been made; they generated the highest quality data obtained in this work. Finally, dinosterol was obtained from the two SMB horizons during PCGC separations that were part of another study (Chapter 6). Two splits were made of the gas obtained from SMB 0-0.75 $\mathrm{cm}$ dinosterol, and two ${ }^{14} \mathrm{C}$ measurements were obtained. 


\section{Figure 4.7}

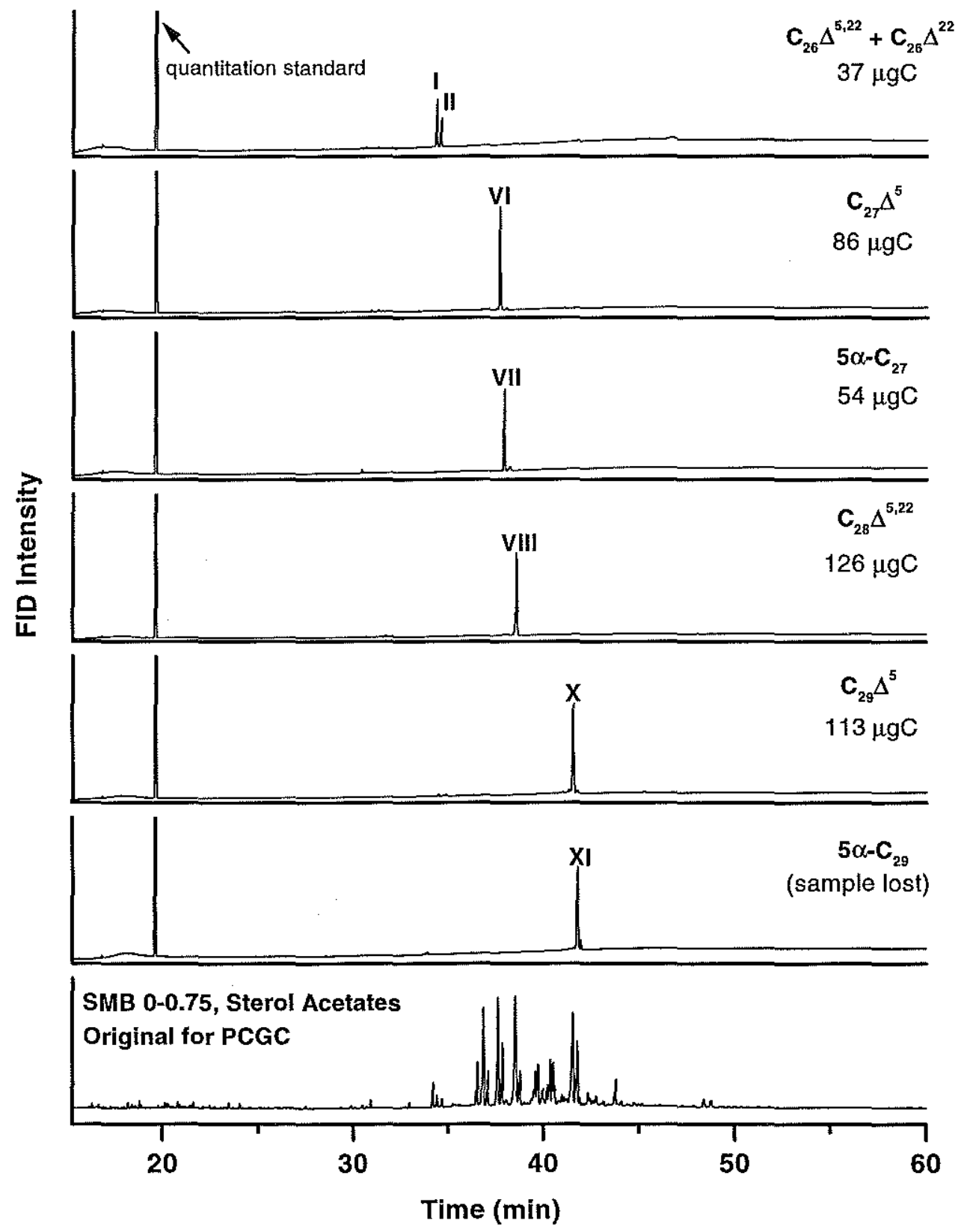

Figure 4.7 HRGC traces of SMB $0-0.75 \mathrm{~cm}$ 4-desmethyl-sterol fraction. The original mixture is shown at the bottom. Re-analyzed aliquots of individual PCGC trap contents are shown above. Sterol isomer peaks are labeled as in Figure 4.4, and recovered quantities (as $\mathrm{CO}_{2}$ ) of the pure compounds are given. 


\subsubsection{Radiocarbon Analysis}

The purified individual sterols were combusted to $\mathrm{CO}_{2}$, and the yield of pure, dry gas was determined manometrically for each compound. Details of the sample treatment, graphite production, and AMS machine conditions specific to the analysis of very small graphite samples can be found in Eglinton et al. (1996), Pearson et al. (1998), and von Reden et al. (1998). All recoveries are listed in Table 4.5, along with the isotopic data.

\subsubsection{Sterol $\Delta^{14} C$ Data}

$\Delta^{14} \mathrm{C}$ values determined for individual sterols in the SMB pre-bomb sedimentary horizon $(4.5-5.5 \mathrm{~cm})$ ranged from $-59 \%$ to $-102 \%$. The average of the five data points was $-75 \pm 19 \%$. The first set of samples isolated from the post-bomb, SMB $0-0.75 \mathrm{~cm}$ horizon gave $\Delta^{14} \mathrm{C}$ values in the range $+13 \%$ o to $+73 \%$, while the $\Delta^{14} \mathrm{C}$ results for the second set of sterols obtained from this lipid fraction were between $+61 \%$ and $+90 \%$. The average for batch \#1 was $+38 \% \circ \pm 27 \%$, while batch $\# 2$ averaged $+73 \pm 12 \%$. The two measurements made on a single isolation of dinosterol from SMB $0-0.75 \mathrm{~cm}$ yielded $\Delta^{14} \mathrm{C}=+61 \%$ and $+81 \%$. Finally, $\Delta^{14} \mathrm{C}$ data for the $\mathrm{SBB} 0-1 \mathrm{~cm}$ interval, postbomb sterols ranged between $+50 \%$ and $+93 \%$; their average was $+69 \pm 14 \%$. The entire set of 18 measurements made for post-bomb sedimentary sterols has a mean value of $+62 \pm 23 \%$. All results are summarized in Table 4.5 . 
Table 4.5 Isotopic data for individual sterols from SMB and SBB sediments.

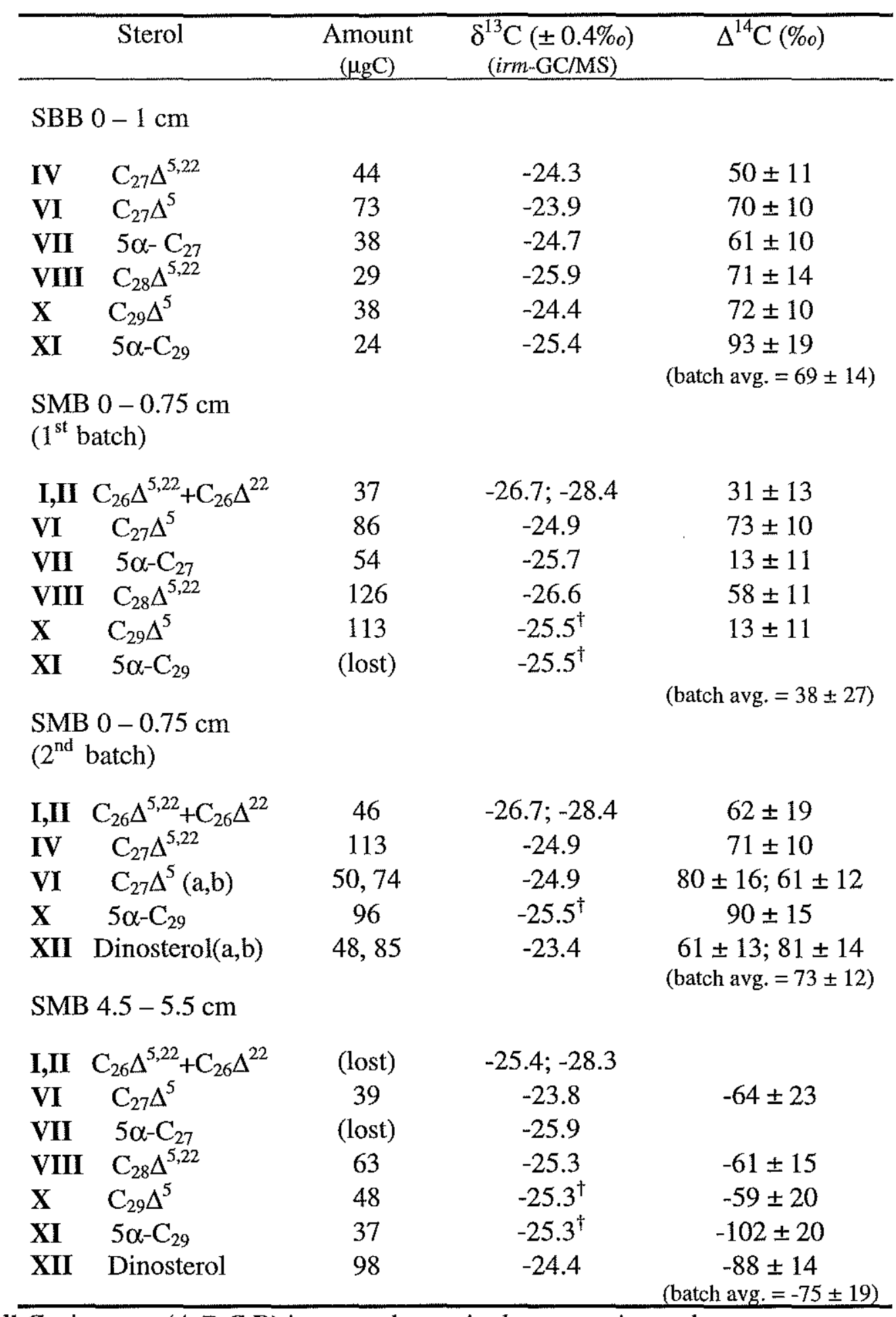

$\dagger$ All $\mathrm{C}_{29}$ isomers $(\boldsymbol{A}, \boldsymbol{B}, \boldsymbol{C}, \boldsymbol{D})$ integrated as a single composite peak. 
The quality of the $\Delta^{14} \mathrm{C}$ data is evaluated first by comparing the replicate measurements made on SMB $0-0.75 \mathrm{~cm}$ sterols. Cholesterol $\left(\mathrm{C}_{27} \Delta^{5}\right)$ from batch \#1 $\left(\Delta^{14} \mathrm{C}=+73 \pm 10 \%\right.$ ) agrees within measurement error with both cholesterol samples " $\mathrm{a}$ " and " $\mathrm{b}$ " from batch $\# 2\left(\Delta{ }^{14} \mathrm{C}=+61 \pm 12 \%\right.$ and $+80 \pm 16 \%$, but the replicates of $\mathrm{C}_{26} \Delta^{5,22}+\mathrm{C}_{26} \Delta^{22}$ differ by $31 \%$, and their values barely overlap within measurement error. How much of this difference could be due to AMS instrumental effects rather than differences in sample isotopic composition (contamination during sample preparation)? The replicate analyses made on identical splits of cholesterol and dinosterol each differ by $\sim 20 \%$, and since all aspects of sample preparation except graphite production and AMS analysis were identical for these samples, $\pm 20 \%$ is taken as the estimate of the absolute accuracy of the ${ }^{14} \mathrm{C}$ data. This is slightly larger than the measurement precision, which averages about $\pm 15 \%$.

The difference between the two collections of $\mathrm{C}_{26} \Delta^{5,22}+\mathrm{C}_{26} \Delta^{22}$ may be due to a general contamination problem in the SMB $0-0.75 \mathrm{~cm}$, batch \#1 sample set.

Comparison of the mean $\Delta^{14} \mathrm{C}$ of batch \#1 with the mean of batch \#2 reveals that the two data sets are statistically different (Student's $t, \mathrm{P}<0.05$ ), even though they were prepared from the same lipid extract and contain two identical isomeric replicates. The mean of batch \#1 is also significantly different than the mean of the SBB $0-1 \mathrm{~cm}$ data, by the same criterion. However, the SMB $0-0.75 \mathrm{~cm}$ batch \#2 and SBB $0-1 \mathrm{~cm}$ sterol data are quite similar; mean $\Delta^{14} \mathrm{C}$ values of $+69 \%$ and $+73 \%$ are virtually identical for the two groups. The first batch of samples is believed to be affected by contamination from PCGC column bleed $\left(\Delta^{14} \mathrm{C}\right.$ assumed $=-1000 \%$ ). It was the first series collected following the installation of a new capillary column, and the column may not have been conditioned thoroughly before the sample runs were begun. Two of the three low $\Delta^{14} \mathrm{C}$ values from batch \#1 are the two smallest samples (37 and $54 \mu \mathrm{gC}, \mathrm{C}_{26} \Delta^{5,22}+\Delta^{22}$ and $5 \alpha-$ $\mathrm{C}_{27}$ ) from this set. Column bleed would represent a larger fraction of total carbon analyzed and present a greater negative bias in ${ }^{14} \mathrm{C}$ concentration. The third low value is for $\mathrm{C}_{29} \Delta^{5}$, the highest-boiling isomer, which elutes in the region of the chromatogram where thermal degradation of the column stationary phase is detected as part of the FID 
background. These three data points are not eliminated from the following discussion. Instead, the data are evaluated both including and excluding this entire batch. The questionable quality of these few data points does not affect the fundamental conclusions.

The contamination problem did not apparently affect SMB $0-0.75 \mathrm{~cm}$ batch \#2. Perhaps the column had become fully conditioned, or perhaps there was an undetected difference in the run conditions. The SBB sterols were also analyzed as a follow-up to the initial SMB pre-bomb/post-bomb comparison. Additional purification steps (to remove column bleed) were added when processing the SBB samples. When the compounds showing probable contamination artifacts in SMB batch \#1 were re-analyzed as part of these two additional batches of post-bomb sterols, ${ }^{14} \mathrm{C}$ isotopic depletion was no longer observed. $\mathrm{C}_{26} \Delta^{5,22}+\mathrm{C}_{26} \Delta^{22}$ increased from $+31 \%$ o to $+62 \%$ o between batch \#1 and \#2. This effect is within the estimated range of AMS measurement accuracy, but may also indicate that the second sample was of higher purity. $5 \alpha-\mathrm{C}_{27}$ yielded $\Delta \Delta^{14} \mathrm{C}=$ $+13 \%$ o for SMB batch \#1, but $+61 \%$ in SBB surface sediment. This is a bigger difference than could be induced simply by measurement artifacts, indicating the presence of isotopically different carbon in the samples. Comparing the data for $5 \alpha-\mathrm{C}_{27}$ between the two different basins may introduce additional uncertainties, but surface waters and algal populations in the two basins are similar. This implies the sterol isotopic compositions in the two environments should be comparable. Also, because $5 \alpha-\mathrm{C}_{27}$ is produced by reductive hydrogenation of the $\Delta^{5}$ isomer, it is difficult to explain why the $\Delta^{14} \mathrm{C}$ data for SMB batch \#1 cholestanol $\left(5 \alpha-\mathrm{C}_{27}\right)$ and cholesterol should be so different $\left(+13 \% o\right.$ and $+73 \%$, respectively). The more consistent explanation is that $\Delta^{14} \mathrm{C}$ for $5 \alpha-$ $\mathrm{C}_{27}$ in both SMB and SBB surface sediments should approximately equal the values observed for cholesterol $(\sim+70 \%)$ in both locations.

It is more difficult to evaluate the case of the $\mathrm{C}_{29}$ sterols between SMB and SBB surface samples. $\mathrm{C}_{29} \Delta^{5}$ is ${ }^{14} \mathrm{C}$-enriched in SBB $(+72 \%$ ) compared to the value of $+13 \%$ o obtained for SMB surface sediment, while $5 \alpha-\mathrm{C}_{29}$ is comparable between the two sites $(\sim+90 \%)$. Again, it is hard to explain how the $\mathrm{C}_{29} \Delta^{5}$ isomer could be relatively depleted in SMB batch \#1, unless there is a separate, low- ${ }^{14} \mathrm{C}$ source for $\mathrm{C}_{29} \Delta^{5}$, but not for $5 \alpha-\mathrm{C}_{29}$. 
Unfortunately, analysis of $\mathrm{C}_{29} \Delta^{5}$ was not repeated in SMB batch \#2. The fact that each of these samples surely contains multiple $\mathrm{C}_{29}$ sterols (i.e. 24-ethylcholest-5-en-3 $\beta$-ol, plus 23, 24-dimethylcholest-5-en-3 $\beta$-ol ) in unknown proportions further complicates the interpretation. Based on the $\delta^{13} \mathrm{C}$ data for the sterols (next section) and on the high $\Delta^{14} \mathrm{C}$ values obtained for $5 \alpha-C_{29}$, it is likely that the one low $\Delta^{14} \mathrm{C}$ value for $\mathrm{C}_{29} \Delta^{5}$ also represents a sample that was compromised by column bleed.

The pre-bomb, SMB $4.5-5.5 \mathrm{~cm}$ sterol data are harder to assess in terms of quality, because there are so few data points and no replicates. In this horizon, the quality of the AMS analyses was not as high, and there were larger measurement errors. The $\mathrm{C}_{29}$ sterols represent the only stanol/stenol pair for which $\Delta^{14} \mathrm{C}$ values were obtained.

In Figure 4.8, the two-dimensional carbon isotope distribution $\left(\Delta^{14} \mathrm{C}\right.$ vs. $\left.\delta^{13} \mathrm{C}\right)$ is shown for the entire sterol data set. The $\Delta^{14} \mathrm{C}$ vs. $\delta^{13} \mathrm{C}$ comparison allows discrimination among biosynthetic sources (terrestrial $\delta^{13} \mathrm{C}<$ marine $\delta^{13} \mathrm{C}$ ) while examining the $\Delta^{14} \mathrm{C}$ record of bomb- ${ }^{14} \mathrm{C}$ uptake between the deeper and surface sedimentary horizons. (A full discussion of the ${ }^{13} \mathrm{C}$ distribution is included in the next section.) The solid line at the bottom of the figure is the mean $\Delta^{14} \mathrm{C}$ value for pre-bomb surface water DIC as obtained from the literature data $(-82 \%)$; the dashed line just beneath it is the value for planktonic foraminifera picked from the $4.5-5.5 \mathrm{~cm}$ horizon of the SMB core $(-87 \%)$. The data for individual pre-bomb sterols from SMB $4.5-5.5 \mathrm{~cm}$ are shown as squares. The standard deviation of the sterol data is shown as a large error bar to the left of the figure; the central bar indicates the mean $\Delta^{14} \mathrm{C}_{\text {sterol }}$ value. The agreement between the DIC, foraminifera, and sterol data is excellent; as a group, the sterols match the ${ }^{14} \mathrm{C}$ isotopic composition of surface water DIC at the time of biomass production. The scatter is probably entirely due to the relatively low AMS precision obtained for these samples.

The solid line at the top of Figure 4.8 is the value measured for 1996 surface water DIC $\left(+71 \%\right.$ ), while the dashed line is the $\Delta^{14} \mathrm{C}$ of SMB $0-0.75 \mathrm{~cm}$ planktonic foraminifera. The post-bomb sterol data are shown as solid circles (SMB) and open circles (SBB). The large error bar at the left is the standard deviation of the entire data set; the central bar marks the mean $\Delta^{14} \mathrm{C}(+62 \%$ ). Removing the SMB $0-0.75 \mathrm{~cm}$ batch 
\#1 sterol data because of suspected contamination would result in a mean $\Delta^{14} \mathrm{C}$ exactly equal to the measured $+71 \%$. Again, the overall agreement between DIC and sterol $\Delta^{14} \mathrm{C}$ values is good, despite the presence of the outlier values from SMB batch \#1. These are the three data points observed to have lower $\Delta^{14} \mathrm{C}$ values than the planktonic foraminifera. The planktonic foraminifera are apparently less accurate tracers of $\Delta^{14} C_{\text {DIC }}$ than the remainder of the sterols, however, as this value $(+41 \%$ o does not agree as well as the majority of the individual sterol compounds, which cluster tightly around the $\Delta^{14} C_{\text {DIC }}$ line at $+71 \%$.

Figure 4.8

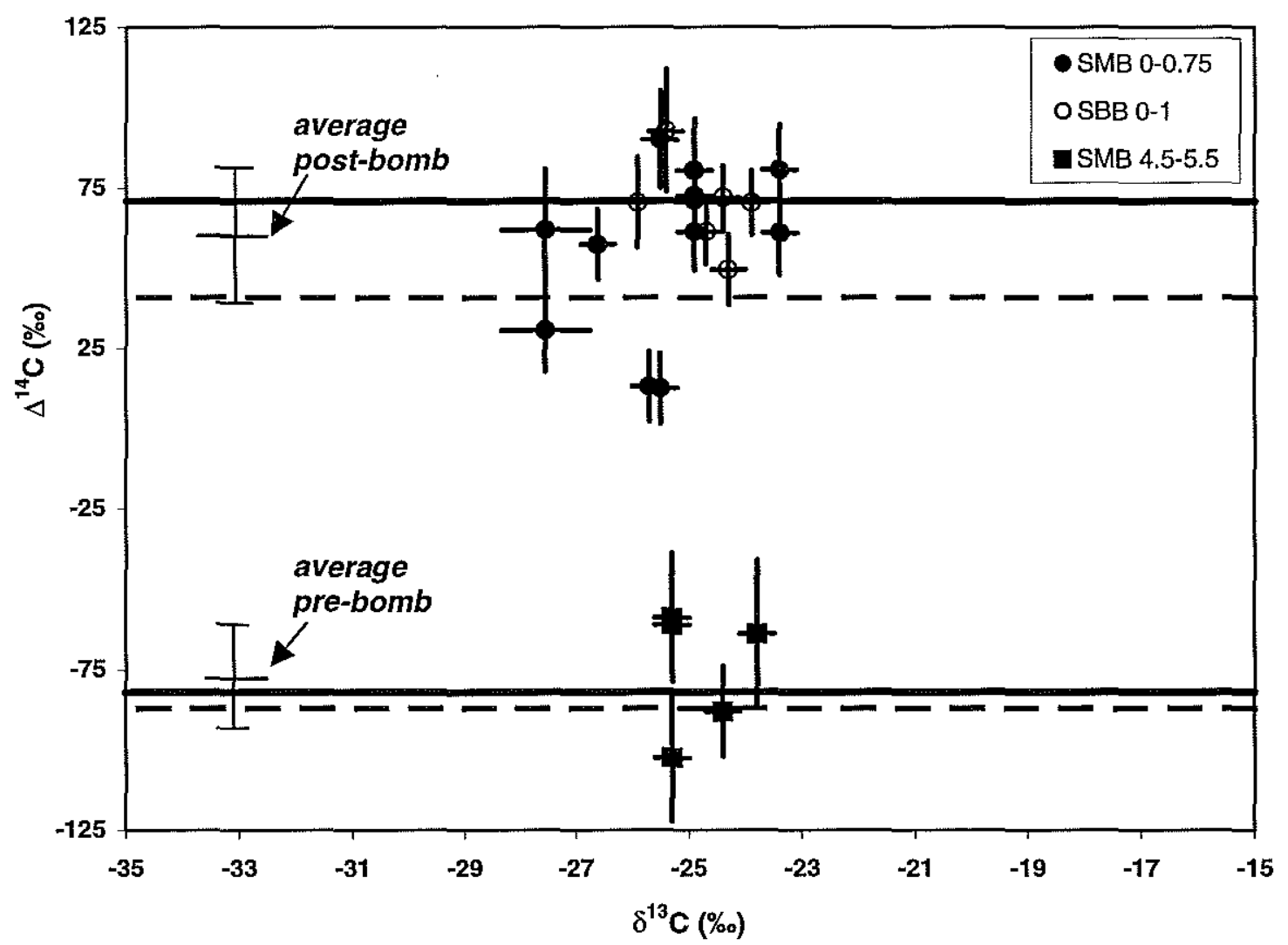

Figure 4.8 Two-dimensional carbon isotope plot of sterol biomarkers, showing agreement of pre-bomb and post-bomb compound-specific $\Delta^{14} \mathrm{C}$ data with the record of surface water $\Delta^{14} C_{\text {DIC }}$. Surface water $\Delta^{14} C_{\text {DIC }}$ measurements are shown as solid lines; dashed lines represent planktonic foraminifera. 


\subsubsection{Discussion}

Steroidal lipids are biosynthetic products of eukaryotes. Previous studies of their distribution in the marine water column and sediments have assigned a predominantly marine origin to all but the $\mathrm{C}_{29}$ sterols, which in many cases are thought to also represent the input of vascular land plants (e.g. Volkman et al., 1987). Our compound-specific data show that individual sterols isolated from marine sediment accurately track the evolution of surface water $\Delta^{14} C_{\text {DIC }}$. Sterols from both pre-bomb and post-bomb SMB and SBB sedimentary horizons reflect the uptake of $\mathrm{CO}_{2}$ in isotopic equilibrium with surface water DIC by photosynthetic autotrophs. There appear to be no obvious exceptions. No single sterol isomer is systematically enriched or depleted in ${ }^{14} \mathrm{C}$ relative to the corresponding surface water $\Delta^{14} \mathrm{C}_{\mathrm{DIC}}$, and no sterol fails to make the transition between pre-bomb and post-bomb endmember isotopic composition. This result has two major implications for interpreting the sources of marine sedimentary sterols.

The first implication is that heterotrophic consumers (zooplankton) incorporate essentially all of their sterols by ingesting and modifying freshly-synthesized algal biomass (e.g. Harvey et al., 1987; Grice et al., 1998). In other words, there is no significant lag time between algal photosynthesis and heterotrophic consumption of this material. Surface water $\Delta^{14} \mathrm{C}_{\mathrm{DIC}}$ and by extension, algal biomass, had values $>+110 \%$ as recently as 1980 (Figure 4.1), but the zooplanktonic sterols (e.g. cholesterol), are not showing ${ }^{14} \mathrm{C}$-enrichment relative to algal sterols (e.g. $\mathrm{C}_{28} \Delta^{5,22}$, dinosterol). Therefore the majority of heterotrophic carbon consumption and subsequent sedimentation must proceed without a decadal-scale lag in the water column suspended POC pool. This is consistent with many other observations of rapid particle re-working and transport to sediments on time-scales of weeks to months (e. g. Deuser, 1986). There is also no systematic ${ }^{14} \mathrm{C}$-depletion other than the three apparently contaminated data points from SMB batch \#1, indicating the fraction of carbon steroidal carbon derived from pre-aged sources is negligible. For example, uptake of refractory DOC by bacteria and subsequent zooplanktonic ingestion of this bacterial carbon does not affect the sterol ${ }^{14} \mathrm{C}$ signal. In 
heterotrophic consumers, cholesterol is usually derived from direct ingestion and modification of algal $\mathrm{C}_{28}$ and $\mathrm{C}_{29}$ sterol precursors rather than de novo biosynthesis (Goad, 1981); therefore all carbon in the sedimentary sterol isomers apparently is derived directly from photoautotrophic biomass production and carries a surface mixed-layer $\triangle^{14} C_{\text {DIC }}$ signal.

Second, the data suggest pre-aged terrestrial carbon contributes insignificantly to the sterol lipid class. The $\mathrm{C}_{29}$ sterols are traditionally used as indicators of the terrestrial organic carbon contribution to marine sediments (e.g. Huang and Meinschein, 1976). However, the uniformity in our $\Delta^{14} \mathrm{C}_{\text {sterol }}$ data implies that no quantitatively significant fraction of any analyzed sterol is derived from old terrestrial soil. While it is possible that by coincidence, the terrestrial residence time and surface ocean reservoir age are equal in the pre-bomb interval (670 radiocarbon years $\sim-80 \%$ ), it is unlikely that this condition could also be conserved in the post-bomb interval. The presence of bomb radiocarbon at approximately equal concentrations in all the surface sedimentary sterols (no systematic ${ }^{14} \mathrm{C}$-depletion in the $\mathrm{C}_{29}$ isomers), rules out the possibility that a large fraction of any major isomer spent more than a few decades in an intermediate continental reservoir before transport to the marine system. A similar conclusion was reached by fundamentally different methods for sediments of the Peru margin, where a significant marine source for $\mathrm{C}_{29} \Delta^{5}$ was invoked to explain the sterol concentration distribution (Volkman et al., 1987). This work was later supported by a detailed study of multiple classes of lipids in Peru sediments, in which principal component analysis indicated the four biomarkers most strongly correlated with phytoplanktonic sources were $\mathrm{C}_{27} \Delta^{5}, \mathrm{C}_{28} \Delta^{5,22}, \mathrm{C}_{29} \Delta^{5}$, and phytol (McCaffrey et al., 1991). Volkman (1986) also noted that $\mathrm{C}_{29} \Delta^{5}$ is a significant sterol in an Antarctic lake near which there are clearly no vascular plants, and therefore it must have an aquatic source. Based on the similarity between $\Delta^{14} \mathrm{C}$ values determined for the $\mathrm{C}_{29}$ sterols and for the algal $\mathrm{C}_{26}-\mathrm{C}_{28}$ sterols, we find no clear evidence of a quantitatively significant terrestrial component. This conclusion will be addressed further in the discussion of the stable isotope data. 


\subsubsection{Factors Affecting ${ }^{14}$ C Isotopic Variability}

Most of the scatter in the sterol $\Delta{ }^{14} \mathrm{C}$ data is probably related to the analytical issues discussed previously. These factors include the presence of contaminant carbon, possibly derived from column bleed, as well as variable AMS instrumental conditions (Chapter 3). The following table summarizes what effect, if any, natural water column and sedimentary processes could have on the range of isotopic values measured for SMB sterols. These processes are of comparable or smaller magnitude than the estimated $\pm 20 \%$ analytical uncertainty.

The factors affecting the ${ }^{14} \mathrm{C}$ concentrations of individual phytoplanktonic biomarkers can be divided into two general categories: $(i)$ effects caused by variations in the isotopic composition of the source carbon (DIC), and (ii) isotopic effects induced during sedimentary diagenesis. The first category includes the changes in mixed-layer $\Delta{ }^{14} \mathrm{C}$ caused by seasonal upwelling of deeper, ${ }^{14} \mathrm{C}$-poor waters. It also includes isotopic variability caused by phytoplanktonic species succession and effects caused by the presence of vertical structure within the euphotic zone ("mixed" layer and euphotic zone discontinuity). The second category reflects biased preservation of the original ${ }^{14} \mathrm{C}$ signatures due to differing rates of sedimentary diagenesis for compounds of different structure or reactivity.

The most intense upwelling in the California Borderland region occurs north of SMB, near Pt. Conception at the border of SBB and in other regions to the north of this area. A secondary region of localized upwelling occurs between Oceanside, San Diego, and other points to the south (Dorman and Palmer, 1981). The intense coastal upwelling north of Pt. Conception was recorded in a seasonal study of near-shore $\Delta^{14} \mathrm{C}$ variability at Half Moon Bay (Robinson, 1981). This study took place in 1978, at the time of maximum bomb- ${ }^{14} \mathrm{C}$ influence and in a region of more intense upwelling than expected for central SMB or SBB. The seasonal $\Delta^{14} \mathrm{C}$ cycle at Half Moon Bay had a range of $\sim 80 \%$ or the coastal measurement, and $\sim 40 \%$ at a station $50 \mathrm{~km}$ offshore, under conditions more likely to resemble SMB and SBB surface waters. However, the gradient 
between surface and thermocline $\Delta^{14} \mathrm{C}_{\mathrm{DIC}}$ is today only about half of the maximum gradient in the mid-1970s. Considering that upwelling in SBB and especially in SMB is less intense than near Half Moon Bay, it is reasonable to assume that the current phytoplanktonic $\Delta^{14} \mathrm{C}$ signature (1990a) should not vary by more than $\pm 20 \%$ o due to seasonal changes in mixed-layer $\Delta{ }^{14} \mathrm{C}_{\mathrm{DIC}}$. This interpretation is probably valid for coastal upwelling regions where the isotopic gradient between surface and thermocline waters is reduced due to continual vertical mixing. However, in more stratified regions such as central ocean gyres, lower rates of vertical mixing may cause a larger isotopic gradient throughout the upper $100 \mathrm{~m}$. In this case, organisms growing at the top and at the base of the euphotic zone could incorporate DIC with different $\Delta^{14} \mathrm{C}$ values.

The effect of differing rates of diagenesis for different phytoplanktonic biomarkers is most easily illustrated with a figure (Figure 4.9). Lipids of marine origin have been found, through both incubation experiments and field measurements to exhibit different rates of degradation within sediments (e.g. Sun et al., 1997). Commonly, the incubation and tracer-experiment-derived rates appear much faster than what in-situ lipid biomarker concentrations would suggest based on the down-core persistence of seemingly labile biomarkers (McCaffrey et al., 1991; Canuel and Martens, 1996; Sun and Wakeham, 1998). However, both types of studies clearly show that the relative degradation rates for different lipids can vary by a factor of $2-10$. In Figure 4.9 , the ${ }^{14} \mathrm{C}$ isotopic values for SMB sediments sectioned at $0.5-\mathrm{cm}$ intervals are compared for cholesterol (compound $\mathrm{Y}$ ) and an arbitrary compound having a 5 times greater degradation rate (compound $\mathrm{X}$ ). The difference is greatest where the $\Delta{ }^{14} \mathrm{C}_{\mathrm{DIC}}$ is changing most rapidly, but the values measured for the two compounds still do not differ by more than $\sim 20 \%$. 
Table 4.6 Sources of $\Delta^{14} \mathrm{C}$ variability in phytoplanktonic biomarkers of common source.

\begin{tabular}{lc}
\hline Process Affecting ${ }^{14} \mathrm{C}$ Concentration & $\Delta^{14} \mathrm{C}$ Effect $(\% o)$ \\
\hline $\begin{array}{l}\text { Water Column } \\
\text { Coastal upwelling and } \\
\quad \text { Mixed layer structure }\end{array}$ & $\pm 0-20$ \\
Sediments & \\
$\quad$ Differing lipid degradation rates & $\pm 0-22$ \\
Analytical Error & \pm 20 \\
\hline
\end{tabular}




\section{Figure 4.9}

(a) Planktonic Carbon $\Delta^{14} \mathrm{C}$

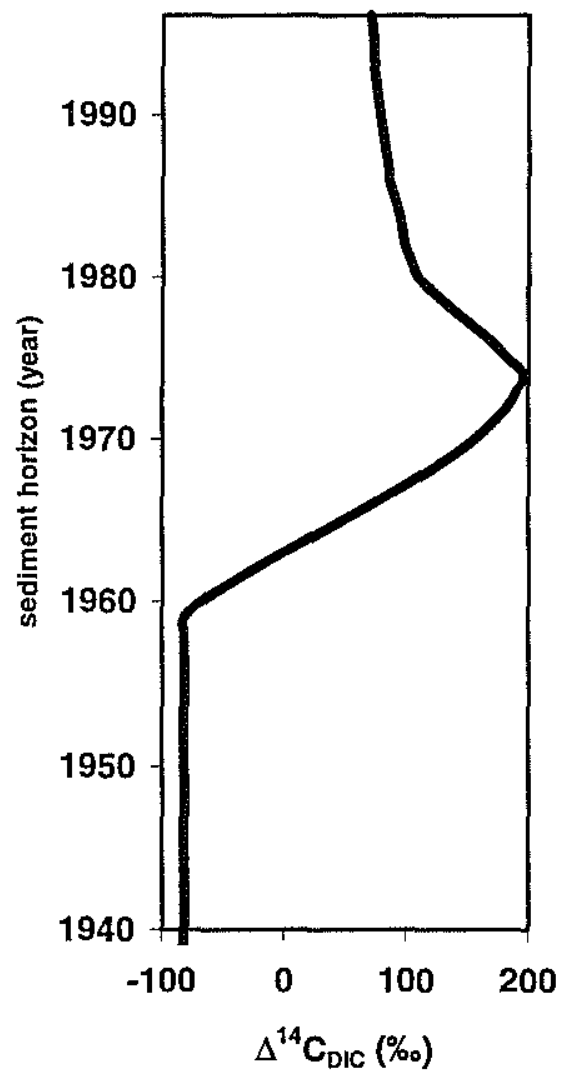

(b) Biomarker Concentration

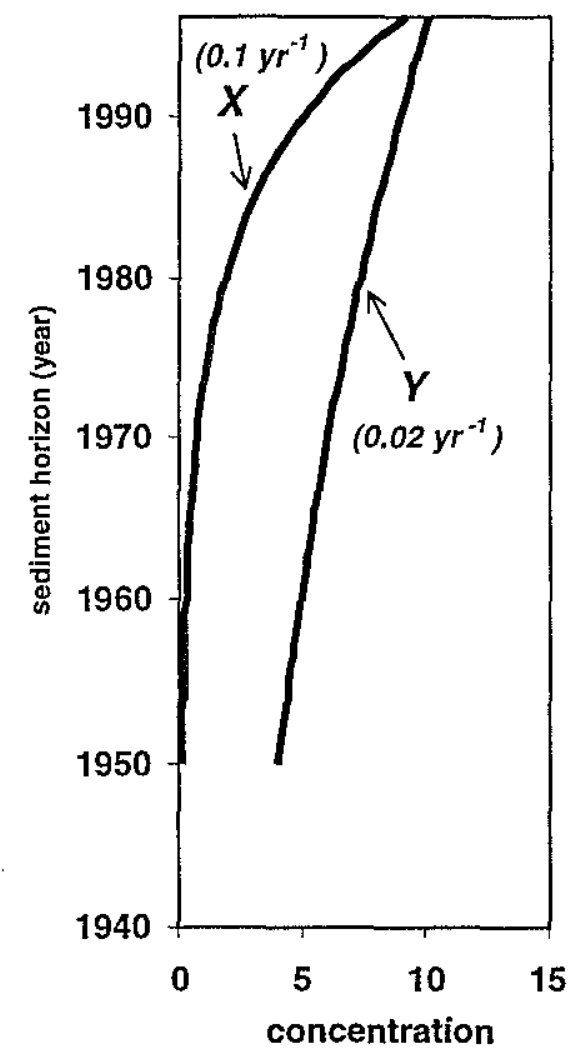

(c) Weighted $\Delta^{14} \mathrm{C}$

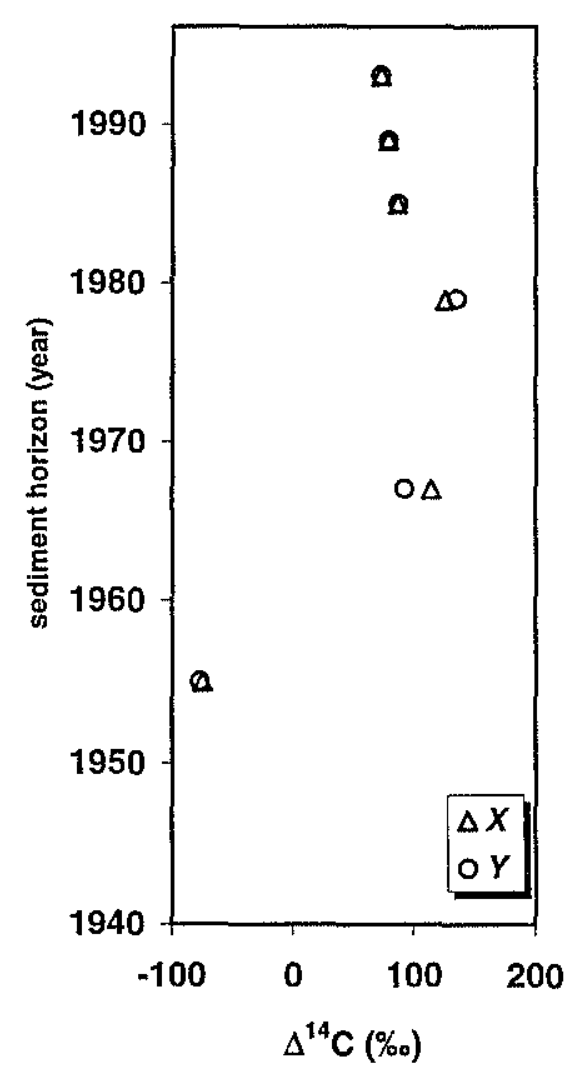

Figure 4.9 The effect of differing degradation rates on the measured $\Delta^{14} \mathrm{C}$ of lipids having the same original source. (a) The $\Delta^{14} \mathrm{C}$ of the source material over time. (b) Compound $X$ degrades at 5 times the rate of compound $Y$. (c) The maximum difference between measured $\Delta^{14} \mathrm{C}$ values occurs over the interval when the source $\Delta^{14} \mathrm{C}$ was changing most rapidly. 


\subsubsection{Stable Isotope Analysis}

Sterol degradation and transformation processes are known to produce changes in the sedimentary sterol distribution relative to the isomers present in the input flux (POC). The processes responsible for sterol diagenesis may or may not be associated with concomitant isotopic variations. Some factors affecting the isomeric distribution include hydrogenation of $\Delta^{5}$ sterols to produce ${ }^{13} \mathrm{C}$-depleted stanols and ${ }^{13} \mathrm{C}$ enrichment during zooplanktonic re-processing of phytoplankton sterols. Differing relative degradation rates of the various isomers may also result in preferential preservation of sterols from some sources relative to other components or isomers. These processes are examined here within the context of the ${ }^{13} \mathrm{C}$ isotopic data. The $\delta^{13} \mathrm{C}$ data are used here to lend support to the interpretation of the $\Delta^{14} \mathrm{C}$ data and confirm the sedimentary sterols appear to be of marine biosynthetic origin.

\subsubsection{1 irm-GC/MS Data}

Figure 4.10 shows the $\delta^{13} \mathrm{C}$ data obtained by $\mathrm{irm}$-GC/MS for the three sterol fractions (plus dinosterol) discussed here. All samples were run in triplicate, and the standard deviations of the measurements are reported as the analytical precision for each integrated peak (Table 4.7). Based on added standards of known isotopic composition, the accuracy of the $\delta^{13} \mathrm{C}$ measurements is $\pm 0.4 \%$ (see appendix). Measurement precision is occasionally observed to be $> \pm 0.4 \%$. This is usually a combined result of the interference of adjacent isomers and inconsistent integration of the chromatograms, although in general the peak resolution obtained on the $\mathrm{irm}$-GC/MS system was very high. 
Table 4.7 irm-GC/MS $\delta^{13} \mathrm{C}$ data for all sterol peaks as identified in Figures 4.4 and 4.5. Fractions were run in triplicate, and measurement precision is reported. The accuracy is estimated to be $\pm 0.4 \%$.

\begin{tabular}{llccc}
\hline Sterol & $\begin{array}{c}\text { SMB 0-0.75 cm } \\
(\% o)\end{array}$ & $\begin{array}{c}\text { SMB 4.5-5.5 cm } \\
(\% \circ)\end{array}$ & $\begin{array}{c}\text { SBB 0-1 cm } \\
(\% \circ)\end{array}$ \\
\hline I & $\mathrm{C}_{26} \Delta^{5,22}$ & $-26.7 \pm 0.6$ & $-25.4 \pm 0.2$ & $-26.0 \pm 0.1$ \\
II & $\mathrm{C}_{26} \Delta^{22}$ & $-28.4 \pm 1.0$ & $-28.3 \pm 0.3$ & $-27.5 \pm 0.1$ \\
III & $\mathrm{C}_{27} \Delta^{5,22}$ & $-25.6 \pm 0.1$ & $-25.4 \pm 0.2$ & $-26.1 \pm 0.2$ \\
IV & $\mathrm{C}_{27} \Delta^{5,22}$ & $-24.9 \pm 0.1$ & $-24.2 \pm 0.1$ & $-24.3 \pm 0.1$ \\
V & $\mathrm{C}_{27} \Delta^{22}$ & $-26.3 \pm 0.4$ & $-25.7 \pm 0.3$ & $-25.4 \pm 0.1$ \\
VI & $\mathrm{C}_{27} \Delta^{5}$ & $-24.9 \pm 0.2$ & $-23.8 \pm 0.1$ & $-23.9 \pm 0.2$ \\
VII & $5 \alpha-\mathrm{C}_{27}$ & $-25.7 \pm 0.2$ & $-26.0 \pm 0.2$ & $-24.7 \pm 0.2$ \\
VIII & $\mathrm{C}_{28} \Delta^{5,22}$ & $-26.6 \pm 0.2$ & $-25.2 \pm 0.1$ & $-25.9 \pm 0.1$ \\
IX & $\mathrm{C}_{28} \Delta^{22}$ & $-28.4 \pm 0.6$ & $-26.9 \pm 0.1$ & $-26.7 \pm 0.1$ \\
X/XI & $\mathrm{C}_{29} \Delta^{5}+5 \alpha-\mathrm{C}_{29}$ & $-25.5 \pm 0.2$ & $-25.3 \pm 0.1$ & $-24.9 \pm 0.2$ \\
XII & $\mathrm{Dinssterol}$ & $-23.4 \pm 0.1$ & $-24.4 \pm 0.2$ & -- \\
\hline
\end{tabular}

Table 4.8 $\mathrm{irm}$-GC/MS $\delta^{13} \mathrm{C}$ data for the additional SMB sedimentary horizons, $0.75-1.5 \mathrm{~cm}$ and $5.5-6.5 \mathrm{~cm}$, as determined for-OTMS ethers. Fractions were run in triplicate, and measurement precision is reported. The accuracy is estimated to be $\pm 0.4 \%$.

\begin{tabular}{llcc}
\hline & Sterol & SMB 0.75-1.5 cm $(\% o)$ & SMB 5.5-6.5 cm (\%o) \\
\hline I & $\mathrm{C}_{26} \Delta^{5,22}$ & $-26.7 \pm 0.1$ & $-26.7 \pm 0.1$ \\
II & $\mathrm{C}_{26} \Delta^{22}$ & $-28.2 \pm 0.1$ & $-28.0 \pm 0.1$ \\
III & $\mathrm{C}_{27} \Delta^{5,22}$ & $-26.8 \pm 0.1$ & $-26.2 \pm 0.1$ \\
IV & $\mathrm{C}_{27} \Delta^{5,22}$ & $-25.5 \pm 0.1$ & $-25.4 \pm 0.1$ \\
V & $\mathrm{C}_{27} \Delta^{22}$ & $-27.2 \pm 0.3$ & $-26.9 \pm 0.2$ \\
VI & $\mathrm{C}_{27} \Delta^{5}$ & $-24.4 \pm 0.1$ & $-24.7 \pm 0.2$ \\
VII & $5 \alpha-\mathrm{C}_{27}$ & $-25.9 \pm 0.1$ & $-27.3 \pm 0.2$ \\
VIII & $\mathrm{C}_{28} \Delta^{5,22}$ & $-26.9 \pm 0.1$ & $-26.9 \pm 0.3$ \\
IX & $\mathrm{C}_{28} \Delta^{22}$ & $-28.1 \pm 0.2$ & $-27.9 \pm 0.5$ \\
X/XI & $\mathrm{C}_{29} \Delta^{5}+5 \alpha-\mathrm{C}_{29}$ & $-25.2 \pm 0.1$ & $-26.3 \pm 0.2$ \\
XII & Dinosterol & $-24.1 \pm 0.1$ & $-25.0 \pm 0.2$ \\
\hline
\end{tabular}


Figure 4.10
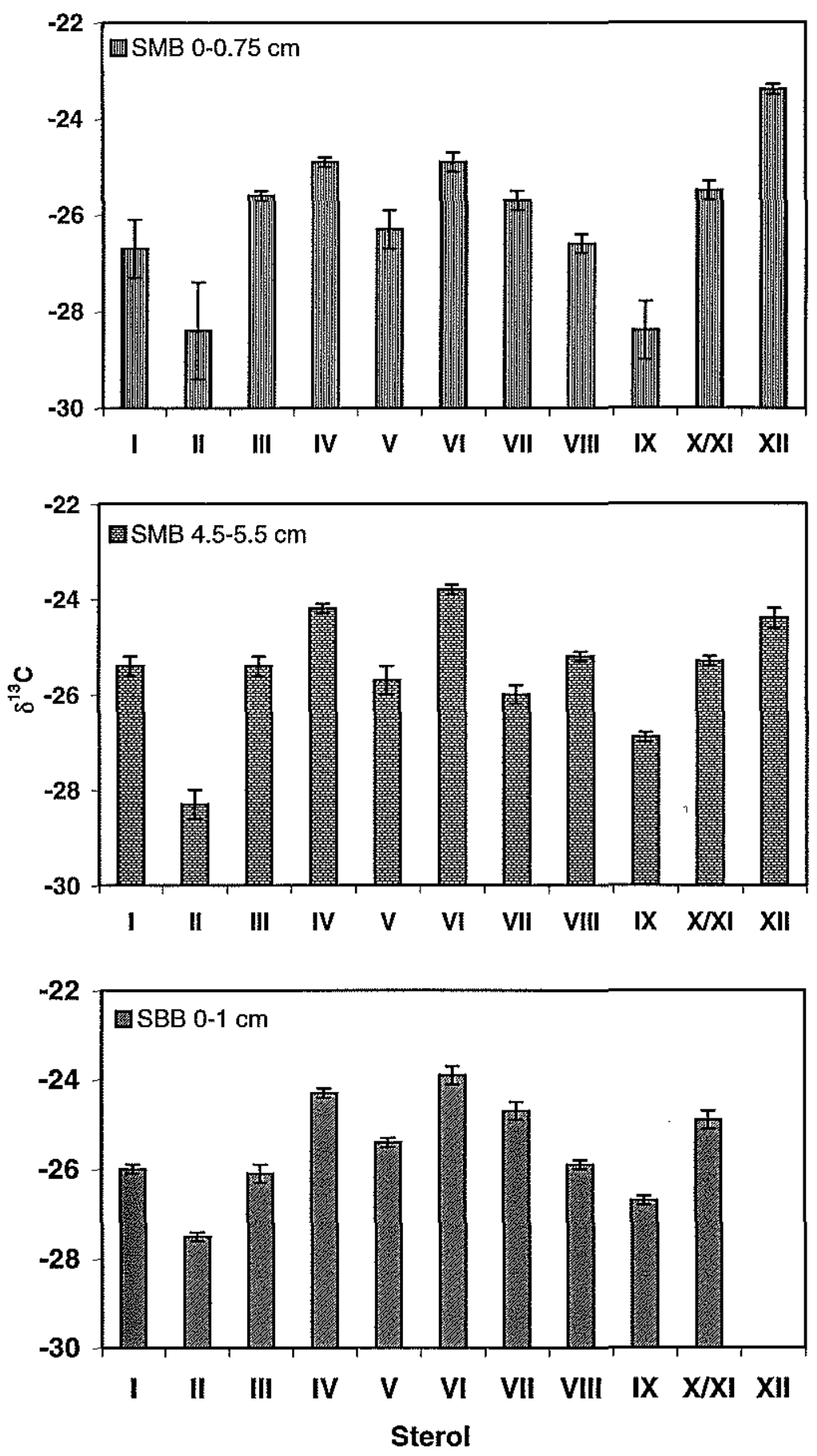

Figure 4.10 Comparison of $\delta^{13} \mathrm{C}$ data for individual sterols from SMB and SBB. sediments, showing the similarity of the relative ${ }^{13} \mathrm{C}$ distribution among the isomers studied. 
Figure 4.11
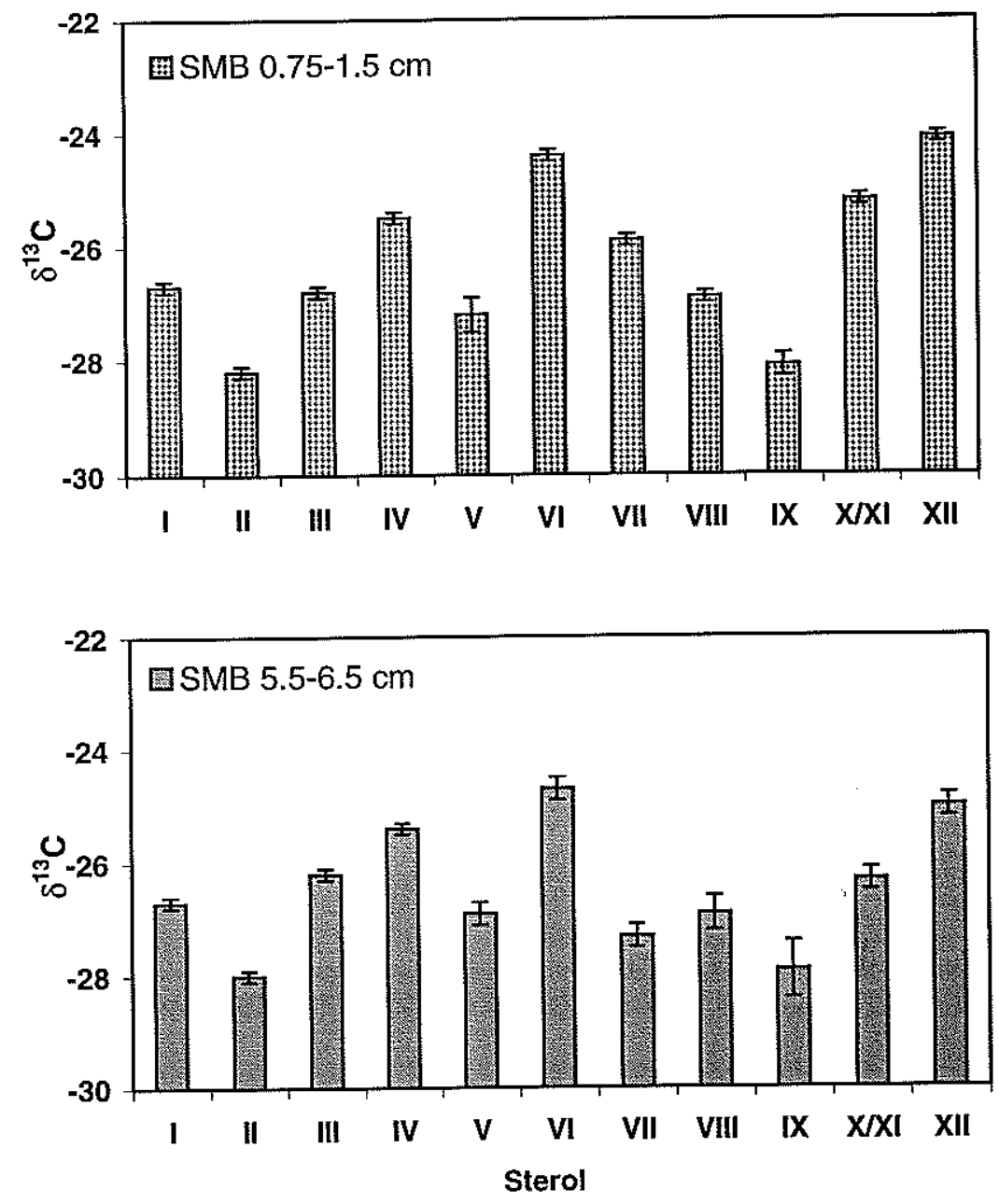

Figure 4.11 Comparison of $\delta^{13} \mathrm{C}$ data for individual sterols from the additional SMB sedimentary horizons, $0.75-1.5 \mathrm{~cm}$ and $5.5-6.5 \mathrm{~cm}$, for which ${ }^{14} \mathrm{C}$ isotopic data were not obtained.

The $\delta^{13} \mathrm{C}$ values for the SMB $0-0.75 \mathrm{~cm}$ sterol fraction ranged from low values of $-28.4 \%$ for $C_{26} \Delta^{22}$ and $C_{28} \Delta^{22}$ to high values of $-24.9 \%$ for $C_{27} \Delta^{5,22}$ and $C_{27} \Delta^{5}$ (cholesterol) and $-23.4 \%$ for dinosterol. A similar ${ }^{13} \mathrm{C}$ distribution was observed for the SMB $4.5-5.5 \mathrm{~cm}$ horizon, where $\mathrm{C}_{26} \Delta^{22}$ and $\mathrm{C}_{28} \Delta^{22}$ are again the most isotopically 
depleted isomers $\left(-28.3 \%\right.$ and $-26.9 \%$, respectively), while $\mathrm{C}_{27} \Delta^{5,22}, \mathrm{C}_{27} \Delta^{5}$, and dinosterol are again the most ${ }^{13} \mathrm{C}$-enriched. Slight isotopic enrichment in the zooplanktonic sterols, $\mathrm{C}_{27} \Delta^{5}$ and $\mathrm{C}_{27} \Delta^{5,22}$, relative to the algal sterol precursors of these compounds ( $\mathrm{C}_{28}$ and $\mathrm{C}_{29}$ sterols), is consistent with a heterotrophic source for these isomers (DeNiro and Epstein, 1977). Dinosterol is apparently even more ${ }^{13} \mathrm{C}$-enriched in the SMB surface sample, but it had poor chromatographic separation and the samples contained no internal standards, so the accuracy of the dinosterol numbers is more uncertain than for the other sterol isomers. Elevated ${ }^{13} \mathrm{C}$ values for dinosterol, if the data are in fact accurate, could be associated with rapid growth and/or a temporary reduction in $\mathrm{CO}_{2}$ supply during bloom conditions (e.g. Laws et al., 1995; Bidigare et al., 1997). The other consistent feature in all samples is the ${ }^{13} \mathrm{C}$-depletion of $5 \alpha$-stanol isomers relative to their $\Delta^{5}$ counterparts. This difference is approximately $1 \%$ to $1.5 \%$ in the surface sediments of both SMB and SBB and is between $1.5 \% \circ$ and $2 \%_{\circ}$ in the deeper SMB horizon; it may be due to isotopic discrimination against ${ }^{13} \mathrm{C}$ during bacterial hydrogenation of $\Delta^{5}$ stenols.

The same relative pattern of $\delta^{13} \mathrm{C}$ values for the 4-desmethyl-sterols and dinosterol was also observed for two additional SMB sedimentary horizons $(0.75-1.5$ $\mathrm{cm}$ and $5.5-6.5 \mathrm{~cm}$, Table 4.8). These additional data help show the ${ }^{13} \mathrm{C}$ distribution among the major sterol isomers in SMB sediments is quite uniform with depth (Figures $4.10,4.11)$. The relative isotopic distribution is also very consistent when comparing the sterols between SMB and SBB surface sediments (Figure 4.10). In the SBB 0-1 cm sample, $C_{27} \Delta^{5}$ and $C_{27} \Delta^{5,22}$ have the highest $\delta^{13} C$ values, while $C_{26} \Delta^{22}$ and $C_{28} \Delta^{22}$ have the lowest values.

\subsubsection{Discussion: $C_{26^{-}} C_{28}$ Sterols}

The overall ${ }^{13} \mathrm{C}$ distribution among the $\mathrm{C}_{26}-\mathrm{C}_{28}$ sterols in both environments can be summarized as follows: $(i)$ isotopic enrichment of the $\mathrm{C}_{27}$ isomers may result from 
heterotrophic activity; (ii) correspondingly lower $\delta^{13} \mathrm{C}$ values for the $\mathrm{C}_{26}$ and $\mathrm{C}_{28}$ sterols is due to a primarily algal (phytoplanktonic) source; and (iii) ${ }^{13} \mathrm{C}$ depletion of all $5 \alpha$ stanol isomers relative to their $\Delta^{5}$ stenol sources results from isotopic discrimination during bacterial reduction. The current knowledge about sources of $\mathrm{C}_{26}-\mathrm{C}_{28}$ sterols in marine systems supports this interpretation of the data.

A recent review of algal biomarker sources (Volkman et al., 1998) and a systematic study of the distribution of sterols in diatoms (Barrett et al., 1995) provide additional information about the probable sources of major sterols in SMB and SBB sediments. Diatoms are the major primary producers in the surface waters of this region (Beers, 1986). Haptophyte algae, diatoms, and cryptophytes are sources of $\mathrm{C}_{28} \Delta^{5,22}$, and the $\mathrm{C}_{27} \Delta^{5,22}$ found in zooplankton fecal pellets is produced from ingestion of algal $\mathrm{C}_{28} \Delta^{5,22}$ (Prahl et al., 1984). $\mathrm{C}_{27} \Delta^{5,22}$ is also present in diatoms and in the rhodophytes (red algae; Volkman et al., 1998). $C_{26} \Delta^{5,22}$ is found in copepods and algae (Volkman et al., 1981; Nichols et al., 1990), and its occurrence in the marine environment (along with the hydrogenated $\mathrm{C}_{26} \Delta^{22}$ ) was correlated with the presence of other $\Delta^{5,22}$ sterols in an Arctic estuary (Yunker et al., 1995). However, $\mathrm{C}_{26} \Delta^{5,22}$ was not present in the survey of cultured diatom species conducted by Barrett et al. (1995). Pancost et al. (1999) recently reported that ${ }^{13} \mathrm{C}$ fractionation effects measured for $\mathrm{C}_{26} \Delta^{5,22}, \mathrm{C}_{27} \Delta^{5}, \mathrm{C}_{28} \Delta^{5,22}$, and $\mathrm{C}_{29} \Delta^{5}$ sterols in the Peru upwelling environment were all correlated. They suggested a diatom source for all these isomers, either directly, or from zooplanktonic grazing with minimal associated fractionation. In addition to $\mathrm{C}_{27} \Delta^{5}$ and $\mathrm{C}_{27} \Delta^{5,22}$, zooplankton are perhaps sources of 27-nor-24-methyl- $\mathrm{C}_{27} \Delta^{5,22}$, which in our samples is isotopically similar to $\mathrm{C}_{27} \Delta^{22} .27$-nor-24-methyl- $\mathrm{C}_{27} \Delta^{5,22}$ and $\mathrm{C}_{28} \Delta^{5,22}$ are also major sterols of Gymodinium simplex, a dinoflagellate (Goad and Withers, 1982).

Pancost et al. (1999) report $\mathrm{C}_{27} \Delta^{5}$ is ${ }^{13} \mathrm{C}$-enriched relative to $\mathrm{C}_{28} \Delta^{5,22}, \mathrm{C}_{28} \Delta^{22}$, $\mathrm{C}_{29} \Delta^{5}$, and $5 \alpha-\mathrm{C}_{29}$ by about $2 \%$ in POC smaller than $20 \mu \mathrm{m}$ in the Peru upwelling region, but enriched only by $\sim 0-1 \%$ in particles $>20 \mu \mathrm{m}$. However, Grice et al. (1998) reported that in feeding experiments, $\delta^{13} \mathrm{C}$ values of copepod $\mathrm{C}_{27} \Delta^{5}$ were not significantly different 
than the algal food source. Our data and the data of Pancost et al. (1999) for small particles suggest that zooplanktonic sterols $\left(\mathrm{C}_{27} \Delta^{5}, \mathrm{C}_{27} \Delta^{5,22}\right.$, and associated $5 \alpha$-stanol isomers) generally do track the $\delta^{13} \mathrm{C}$ of the algal sterols, but unlike the results of laboratory studies, are slightly ${ }^{13} \mathrm{C}$-enriched in the natural environment.

Sterols have no bacterial source, but their distribution in marine sediments is affected by bacterial activity. Anaerobic microbial reduction of $\Delta^{5}$ stenols is a well-

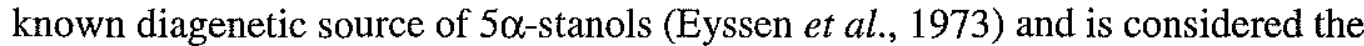
dominant source of the latter compounds in marine sediments, rather than de novo production by biota. $5 \alpha$-stanols are only very minor components of some Rhodophyceae, diatoms, and dinoflagellates (4-methyl-stanols) (Barrett et al., 1995). The stanol/stenol ratio in marine sediments correlates with increasing degree of anoxia (Wakeham, 1989; Wakeham and Beier 1991), and this probably explains the slightly higher ratios observed in SBB compared to SMB samples. Our $5 \alpha$-stanol data agree with the previous work of Filley et al. (1997), who report $2 \%{ }^{13} \mathrm{C}$-depletion compared to the associated sterols in SBB sediments and suggest this effect is caused by isotopic discrimination during bacterially-mediated hydrogenation.

In general, there appears to be a great diversity of sterol isomers produced by phytoplankton (Volkman et al., 1998 and references therein). The similar relative concentrations, $\delta^{13} \mathrm{C}$ values, and $\Delta^{14} \mathrm{C}$ values for the major sterols in SMB and SBB surface sediments probably implies the phytoplanktonic species distribution and growth factors in these basins are quite similar; this is not surprising considering their immediate geographical proximity.

\subsubsection{Discussion: $C_{29}$ Sterols and Dinosterol}

The $\mathrm{C}_{29}$ sterols, $\mathrm{C}_{29} \Delta^{5}(\mathbf{X}(\boldsymbol{A}, \boldsymbol{B}))$ and $5 \alpha-\mathrm{C}_{29}(\mathrm{XI}(\boldsymbol{C}, \boldsymbol{D}))$ were integrated to yield a single combined $\delta^{13} \mathrm{C}$ value in each sample because of incomplete chromatographic separation of any of the four peaks (Figure $4.6 ; \delta^{13} \mathrm{C}$ data, Figures $4.10,4.11$ ). It is 
probable that the most abundant of the $\mathrm{C}_{29}$ sterol isomers $(\mathbf{X}(\boldsymbol{B}))$ is $\mathrm{C}_{29} \Delta^{5}$, but there is no direct evidence to verify this assumption.

In general the $\delta^{13} \mathrm{C}$ data for the $\mathrm{C}_{29}$ isomers are similar to the values observed for algal $\mathrm{C}_{26}-\mathrm{C}_{28}$ sterols (Tables $4.7,4.8$ ), with no evident isotopic depletion as would be expected from a significant terrestrial $\mathrm{C}_{3}$-plant contribution. Compound-specific ${ }^{13} \mathrm{C}$ data for $\mathrm{C}_{29} \Delta^{5}$ isolated from temperate, deciduous trees yielded $\delta^{13} \mathrm{C}$ values between $-28 \%$ o and $-36 \%$ (average $\sim-33 \%$ ), slightly depleted compared to $\delta^{13} \mathrm{C}$ of the total bulk organic carbon $(\sim-28 \%$ ) (Lockheart et al., 1996). A value of $-33 \%$ is considerably more ${ }^{13} \mathrm{C}$-depleted than the $\delta^{13} \mathrm{C}$ values determined for $\mathrm{C}_{29}$ sterols in the SMB and SBB sediments. Rather, the $\mathrm{C}_{29}$ sterol isotopic values are quite comparable to the algal sterol, $\mathrm{C}_{28} \Delta^{5,22}$, in these SMB and SBB sediments and appear to confirm the $\Delta^{14} \mathrm{C}$ data in suggesting the $\mathrm{C}_{29}$ sterols do not contain a quantitatively significant terrestrial component.

At least two classes of marine algae, the Raphidophyceae (Nichols et al., 1987) and Xanthophyceae, produce $\mathrm{C}_{29} \Delta^{5}$ as their major sterol, while significant amounts are also components of the Eustigmatophyceae, Euglenophyceae, and several diatoms, chlorophytes, and haptophytes (Barrett et al., 1995; Volkman et al., 1998, Volkman et al., 1999). Additional contributions to the $\mathrm{C}_{29}$ sterol peaks from 23,24-dimethyl sterols probably also have a phytoplanktonic source (Volkman, 1986), perhaps from haptophytes or dinoflagellates (Wakeham and Beier, 1991).

The 4-methylsterols are believed to be derived uniquely from dinoflagellates (Robinson et al., 1984), but the presence of dinosterol as a major sterol in marine sediments is not always correlated with a predominance of dinoflagellates among the genera of the phytoplanktonic assemblage. Suggestions have been made that selective sedimentary enrichment of dinosterol is a diagenetic effect (de Leeuw et al., 1983; Wakeham and Beier, 1991). Wakeham and Beier observed that $\mathrm{C}_{29} \Delta^{5}$ and dinosterol were dominant sterols in Black Sea sediments, but $\mathrm{C}_{27} \Delta^{5}$ and $\mathrm{C}_{28} \Delta^{5,22}$ were the major sterols in the POC source material, indicating differing preservation potential for the various sterols. In Peru margin sediments, the abundance of $\mathrm{C}_{29}$ sterols also increases 
relative to $\mathrm{C}_{27}$ sterols below the surface $0-2 \mathrm{~cm}$ horizon. Volkman et al. (1987) concluded that this effect was the result of a dual source for the $\mathrm{C}_{29}$ sterols, representing both marine and terrestrial components. They hypothesized that the marine fraction of $\mathrm{C}_{29}$ (and $\mathrm{C}_{27}$ ) sterols were rapidly degraded, while the $\mathrm{C}_{29}$ terrestrial sterols were physically packaged in a way that was more resistant, perhaps associated with a complex organic matrix or higher plant biopolymer. The different relative degradation rates were used to estimate that terrestrial $\mathrm{C}_{29} \Delta^{5}$ represented $30 \%$ of total $\mathrm{C}_{29} \Delta^{5}$ from $0-1 \mathrm{~cm}$ but $65 \%$ by $2-3 \mathrm{~cm}$.

The concentration data for this study (Table 4.4) also show apparent enrichment of $\mathrm{C}_{29}$ sterols and dinosterol relative to $\mathrm{C}_{27} \Delta^{5}$ over time. The SBB sediment, representing 1-3 years' material, has the highest relative and absolute concentrations of $C_{27}$ sterols, while by the deeper SMB interval, dinosterol, $C_{29} \Delta^{5}$, and $C_{28} \Delta^{5,22}$ average $\sim 150 \%$ of the cholesterol abundance. It is unlikely that terrestrial material accounts for this relative preservation effect, since $\Delta^{14} \mathrm{C}$ values appear to be uniformly marine in both surface and deep horizons. Preferential preservation of some fraction of the marine sterols is a more likely explanation. The growing interest in insoluble cell-wall materials of algae, termed "algaenans" (Philp and Calvin, 1976; Derenne et al., 1992; Gelin et al., 1997), has produced several studies showing the distribution of these persistent biomacromolecules in marine organisms. Gelin et al. (1999) recently described the presence of algaenans in the Eustigmatophyceae and Chlorophyceae (green algae) and in one dinoflagellate. Dinoflagellates also produce resistant biopolymers of a different type as part of their resting cysts (Kokinos et al., 1998). Eustigmatophytes are not thought to be major components of the marine phytoplanktonic community, but they are known producers of $\mathrm{C}_{29}$ sterols, $\mathrm{C}_{30}$-alkyl-diols and $\mathrm{C}_{30}$ mid-chain ketols, all of which we also find in $\mathrm{SMB}$ and SBB sediments. It is possible that the algaenan-producing algae or related organisms produce $\mathrm{C}_{29}$ sterols that resist degradation due to intimate association with a complex organic matrix; the same type of mechanism could explain relative enrichments of dinosterol by association with dinoflagellate biopolymers. It is interesting that the algae 
primarily responsible for mineral precipitation, diatoms $\left(\mathrm{SiO}_{2}\right)$ and haptophytes $\left(\mathrm{CaCO}_{3}\right)$, are not known to produce algaenans or other rigid organic structures (Gelin et al., 1999).

In summary, the sterol ${ }^{13} \mathrm{C}$ data support the previous conclusion based on ${ }^{14} \mathrm{C}$ measurements: all major sterol isomers in SMB and SBB surface sediments are tracers of surface water primary productivity and surface water DIC isotopic composition.

\subsubsection{Fraction of Allochthonous Organic Carbon in SMB Sediment}

The profile of bomb- ${ }^{14} \mathrm{C}$ invasion into SMB TOC (Figure 4.3) can be used to determine how much of the organic carbon preserved in the sediment was originally fixed into biomass by euphotic zone primary producers; most of the remainder is thought to derive from allochthonous sources. The ${ }^{14} \mathrm{C}$ signature of the marine component is conserved regardless of the number of times it is re-worked by heterotrophic processes. A mass-balance calculation in which only two organic fractions are defined, recent photosynthetically-fixed organic carbon $\left(\mathrm{C}_{\mathrm{P}}\right)$ and integrated detrital organic carbon $\left(\mathrm{C}_{\mathrm{D}}\right)$, is easily solved. The two terms separate the fraction of TOC derived from isotopic sources with $\Delta^{14} \mathrm{C}$ equal to surface water DIC (algal, zooplanktonic, and heterotrophic bacterial components $=f_{P}$ ) from all other organic carbon in the system. This other material $\left(f_{D}\right)$ includes weathered terrigenous organic carbon (modern soils and ancient kerogen), chemoautotrophic marine biomass produced in deeper waters, and sedimentary organic matter redistributed by turbidity currents and other sediment focusing processes. This simplified approach assumes that in steady state the relative fractions of $f_{P}$ and $f_{D}$, as well as the contributions of the individual components of $\mathrm{C}_{\mathrm{D}}\left(f_{D} C_{D}=\Sigma f_{i} C_{i}\right)$, remain constant. This assumption is supported by the lack of any major trends in either $\delta^{13} C_{\text {TOC }}$ or $\mathrm{C} / \mathrm{N}$ ratios throughout the SMB core interval studied (profiles in the appendix to Chapter 2). The $\mathrm{C} / \mathrm{N}$ ratio at the top of the core is somewhat depleted relative to the deeper horizons, and therefore $f_{P}$ is probably not truly uniform. However, the following 
exercise provides a reasonable initial estimate of the composition of SMB sedimentary TOC.

The mass balance equation,

$$
\Delta^{14} C_{T O C}=f_{P} \Delta^{14} C_{P}+\left(1-f_{P}\right) \Delta^{14} C_{D},
$$

where $f_{P}+f_{D}=1$, is a simple linear equation $(y=m x+b)$. Assuming $\Delta{ }^{14} \mathrm{C}_{\mathrm{P}}=\Delta \Delta^{14} \mathrm{C}_{\mathrm{DIC}}$, the slope of $\Delta{ }^{14} \mathrm{C}_{\mathrm{TOC}}$ vs. the evolution of surface water $\Delta{ }^{14} \mathrm{C}_{\mathrm{DIC}}$ will yield $m=f_{P}$ and $\Delta \Delta^{14} \mathrm{C}_{\mathrm{D}}=b /\left(1-f_{P}\right)$.

For any sediment core in which the $\Delta{ }^{14} \mathrm{C}_{\mathrm{TOC}}$ and $\Delta{ }^{14} \mathrm{C}$ of surface water DIC have changed in synchrony, an equation of this type can be evaluated if a reasonable estimate of $\Delta{ }^{14} C_{P}=\Delta{ }^{14} C_{D I C}$ is available. The data presented in this chapter include both a $\Delta{ }^{14} C_{P}$ record, in the form of individual sterol isotopic data, and a $\Delta{ }^{14} C_{D I C}$ record, available from the history of actual surface water DIC measurements and from the foraminifera samples. When solved using the $\Delta^{14} \mathrm{C}_{\mathrm{DIC}}$ literature data model (Figure 4.1), the mass balance calculation indicates $59 \%$ of the TOC preserved in SMB sediments comes from marine euphotic zone production. If the sterol data (pre-bomb and post-bomb averages) are compared to this solution, as shown in Figure 4.12 (triangles), the marine fraction is $64 \%$. If the first batch of sterol samples from the SMB $0-0.75 \mathrm{~cm}$ horizon is disregarded because of potential contamination artifacts, the solution is the same as the solution derived using the $\Delta^{14} \mathrm{C}_{\mathrm{DIC}}$ model (59\%). Even though the foraminiferal data appear biased toward low $\Delta{ }^{14} \mathrm{C}$ values, the solution using $\Delta{ }^{14} C_{P}=\Delta{ }^{14} C_{\text {foram }}$ yields $66 \%$ planktonic carbon. Given the uncertainties associated with this model, values of $f_{P}$ between 59 and $66 \%$ are all insignificantly different.

$\Delta{ }^{14} C_{D}$ obtained by this approach is merely the weighted average isotopic composition of the many possible allochthonous and/or deep-water carbon sources. Integrated detrital carbon contributes $34-41 \%$ of the organic material in recent SMB sediments, depending on the choice of $\Delta{ }^{14} C_{\mathrm{P}}$ used above. It carries an average $\Delta^{14} \mathrm{C}$ 
signature between $-260 \%$ and $-290 \%$, equivalent to 2400 to 2700 radiocarbon years. This ${ }^{14} \mathrm{C}$ concentration is more depleted than the $\Delta^{14} \mathrm{C}$ of SMB deep-water DIC $\left(\Delta^{14} \mathrm{C}\right.$ $-190 \%$ ). However, if a small contribution of $f_{D}$ is derived from fossil carbon (i.e. 10\%), this might suggest that the bulk of $f_{D}$ is traceable to sources of similar radiocarbon age as deep-basin inorganic carbon. The most likely components may be continental detritus with century or millenial-scale residence times (weathered soils) and the deep DIC itself.

Regardless of the detrital carbon source, $\sim 40 \%$ of the organic material in this near-shore basin is not traced to marine primary production. A large component is likely to originate from the continents, consistent with other studies suggesting the importance of land-plant or other terrestrial carbon in the near-shore region (e.g. Goñi et al., 1998). The data of Goñi et al. (1998) are consistent with a higher than previously inferred contribution of allochthonous carbon in coastal sediments of the Gulf of Mexico.

Previous estimates for the Washington Margin based on lignin (Hegdes and Mann, 1979) and $n$-alkane distributions (Prahl et al., 1994) yielded significantly smaller estimates of the contribution of terrestrial material ( $<10 \%$ and $\sim 30 \%$, respectively). By independent methods based on $\Delta^{14} \mathrm{C}$ only, we find a significant fraction and old age of the net detrital carbon in SMB sediment. When integrated over similar continental margin environments, this is surely an important consideration for models of the global carbon cycle. However, any isotopic evidence for a contribution of this magnitude to the steroidal lipids is completely absent. The compound-specific ${ }^{14} \mathrm{C}$ data presented here cannot significantly account for any of the $\sim 40 \%$ non-marine fraction of TOC. It is quite likely that much of the input of terrestrial organic carbon to marine sediments arrives in the form of highly degraded organic matter. Functionalized lipids produced by terrestrial organisms may be too labile to survive transport to the oceanic water column and subsequent sedimentation. Further study is needed to determine if this characteristic also applies to other biomarker lipids that have been used previously as tracers of terrestrial biomass in marine sediments. 
Figure 4.12

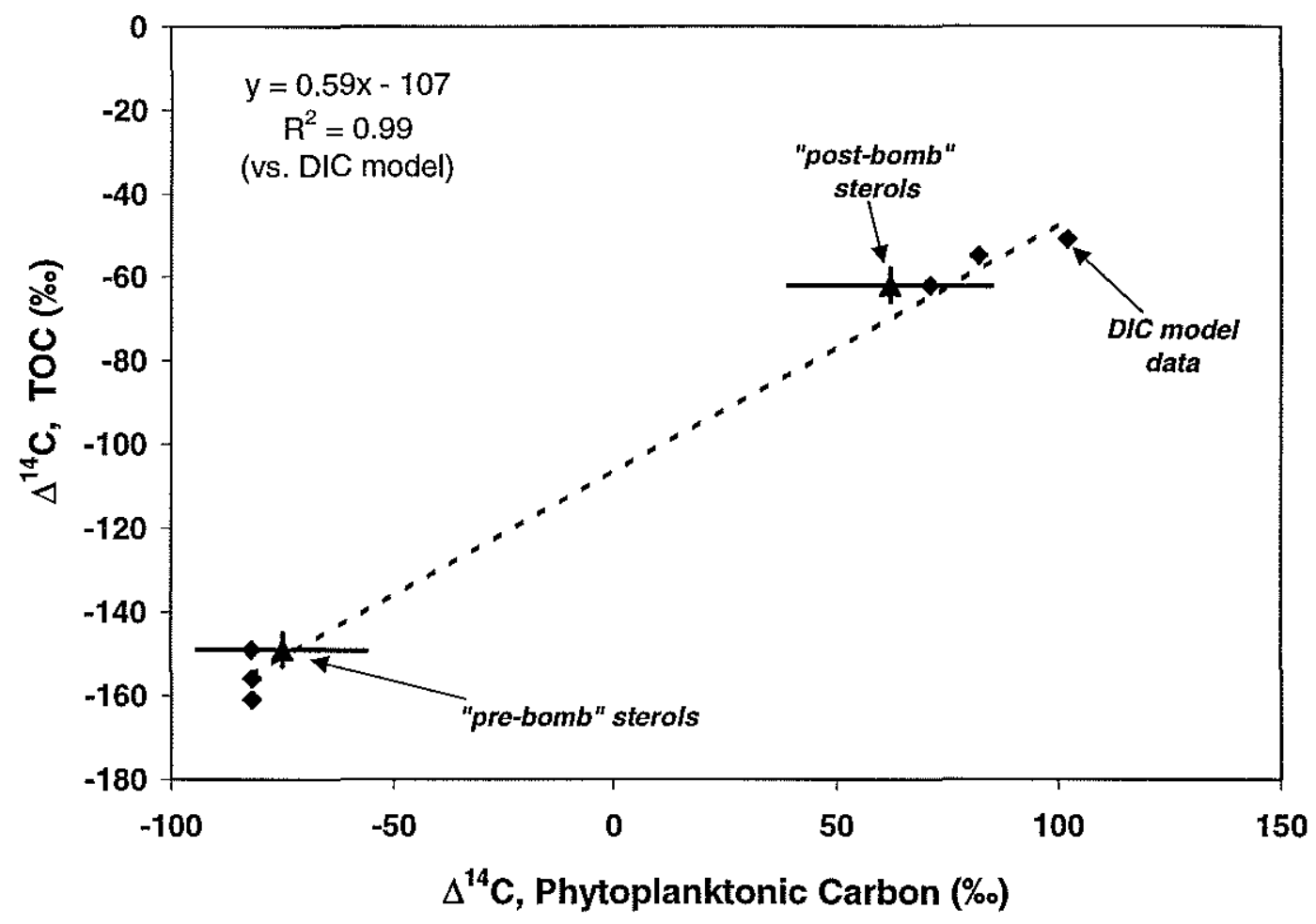

Figure 4.12 The fraction of TOC in SMB sediment traceable to marine planktonic production. The linear fit was determined for $\Delta^{14} C_{\text {ToC }}$ relative to the $\Delta^{14} C_{\text {DIC }}$ model derived from data in Table 4.1 (diamonds). The triangles show the agreement between sterol $\Delta^{14} \mathrm{C}$ data and the model solution. 


\subsection{Conclusions}

The utility of a marine photosynthetic biomarker proxy for $\Delta^{14} C_{\text {DIC }}$ lies in the universal nature of its application. One of the fundamental implications of the agreement between individual sterol $\Delta^{14} \mathrm{C}$ values and the surface water $\Delta^{14} \mathrm{C}_{\mathrm{DIC}}$ record is that any marine sediment sample containing sufficient organic carbon could potentially yield a record of surface water ${ }^{14} \mathrm{C}$ reservoir age. This finding could open problematic geographical regions such as the Southern Ocean to new investigations of paleocirculation. It is also independent of biologically-determined "vital effects" or variations in calcification depth that may affect the foraminiferal isotopic signal.

Since the sterol ${ }^{14} \mathrm{C}$ data correspond so well to the $\Delta^{14} \mathrm{C}_{\mathrm{DIC}}$ record, and the $\delta^{13} \mathrm{C}$ data apparently confirm these isomers are all of primarily marine origin, it is possible the entire sterol lipid class could be used as a surface water isotopic tracer. This could eliminate the time-consuming, tedious, and expensive nature of compound-specific PCGC isolations. Combining all the sterols would also effectively reduce the sample size requirement. This is an advantage when dealing with more highly-degraded, deeper core horizons in which diagenetic processes have affected the sterol concentrations.

The conclusions of this study are summarized as follows:

1. Values of $\Delta^{14} \mathrm{C}$ for nine different sterols isolated from Santa Monica and Santa Barbara Basin sediments show that these lipids preserve the record of $\Delta^{14} C_{\text {DIC }}$ at the time of biomass production. The data show the sterols accurately track a temporal change in surface water isotopic composition. In this case, they record the increase in mixed-layer ${ }^{14} \mathrm{C}$ concentration caused by uptake of ${ }^{14} \mathrm{CO}_{2}$ generated during atmospheric nuclear weapons tests.

2. The rapid translation of the change in $\Delta^{14} C_{\text {DIC }}$ into the sedimentary record indicates that heterotrophic processing and export of euphotic zone primary 
production proceeds very rapidly. The absence of a ${ }^{14} \mathrm{C}$ isotopic offset implies that most exported carbon probably resides within the suspended POC pool for not more than a decade. The agreement of $\Delta{ }^{14} \mathrm{C}_{\text {sterol }}$ and $\Delta{ }^{14} \mathrm{C}_{\mathrm{DIC}}$ values also confirms that recently produced phytoplanktonic carbon is the major food source for heterotrophic consumers.

3. Both the $\Delta^{14} \mathrm{C}$ and $\delta^{13} \mathrm{C}$ data for the $\mathrm{C}_{29}$ sterols in these sediments are very similar to the data for algal and zooplanktonic $\left(\mathrm{C}_{26}-\mathrm{C}_{28}\right)$ sterols. No significant fraction of the $\mathrm{C}_{29}$ isomers appears to be of terrestrial origin. This is consistent with several new studies that have shown a widespread occurrence of $\mathrm{C}_{29}$ sterols in marine organisms and questioned their use as a tracer of terrestrial inputs.

4. A mass-balance calculation applied to the Santa Monica Basin core $\Delta^{14} \mathrm{C}_{\mathrm{TOC}}$ profile requires that $\sim 40 \%$ of the organic matter preserved in the sediment originated from sources other than euphotic zone primary production. These allochthonous carbon sources have an average $\Delta^{14} \mathrm{C}$ value near $-250 \%$. However, there is no clear indication of this pre-aged component anywhere within the sterol isotopic data. This finding calls into question the use of lipid biomarkers as tracers of the bulk terrestrial carbon flux into marine systems. Our data suggest that the lipid fraction of continental carbon experiences different export, degradation, and preservation potential than the majority of allochthonous inputs to marine sediments. 


\subsection{REFERENCES}

Adkins, J. F. and Boyle, E. A. (1997) Changing atmospheric $\Delta^{14} \mathrm{C}$ and the record of deep water paleoventilation ages. Paleoceanography 12, 337-344.

Adkins, J. F., Cheng, H., Boyle, E. A., Druffel, E. R. M., and Edwards, R. L. (1998) Deep-sea coral evidence for rapid change in ventilation of the deep North Atlantic 15,400 years ago. Science 280, 725-728.

Bard, E., Arnold, M., Mangerud, J., Paterne, M., Labeyrie, L., Duprat, J., Mélières, M.A., Sønstegaard, E., and Duplessy, J.-C. (1994) The North Atlantic atmospheresea surface ${ }^{14} \mathrm{C}$ gradient during the Younger Dryas climatic event. Earth and Planetary Sci. Lett. 126, 275-287.

Barrett, S. M., Volkman, J. K., Dunstan, G. A. and LeRoi, J.-M. (1995) Sterols of 14 species of marine diatoms (Bacillariophyta). Journal of Phycology 31, 360-369.

Bauer, J. E., Reimers, C. E., Druffel, E. R. M., and Williams, P. M. (1995) Isotopic constraints on carbon exchange between deep ocean sediments and sea water. Nature 373, 686-689.

Baumgartner, T. R. and Southon, J. (1996) A 1500-year radiocarbon record of nearsurface ocean reservoir ages obtained from the varved sediments of the Santa Barbara Basin, California. EOS, Transactions, 1996 Fall Meeting, p. F298.

Beers, J. R. (1986) . In Plankton Dynamics of the Southern California Bight, Ed. R. W. Eppley, Springer-Verlag, New York, pp. 84-175.

Behl, R. J. and Kennett, J. P. (1996) Brief interstadial events in the Santa Barbara basin, NE Pacific, during the past 60 kyr. Nature 379, 243-246.

Benoit, G. J., Turekian, K. K., and Benninger L. K. (1979) Radiocarbon dating of a core from Long Island Sound. Estuarine Coastal Mar. Sci. 9, 171-180.

Bernhard, J. M. (1992) Benthic foraminiferal distribution and biomass related to pore water oxygen content: central California continental slope and rise. Deep Sea Research 39, 585-605.

Bidigare, R. R., Fluegge, A., Freeman, K. H., Hanson, K. L., Hayes, J. M., Hollander, D., Jasper, J. P., King, L. L., Laws, E. A., Millero, F. J., Pancost, R. D., Popp, B. N., Steinberg, P. A. and Wakeham, S. G. (1997) Consistent fractionation of ${ }^{13} \mathrm{C}$ in nature and in the laboratory: Growth-rate effects in some haptophyte algae. Global Biogeochem. Cycles 11, 179-192.

Brassell, S. C., Eglinton, G., Marlowe, I. T., Pflaumann, U., and Sarnthein, M. (1986) Molecular stratigraphy: A new tool for climatic assessment. Nature 320, 129-133.

Broecker, W. S. and Peng, T.-H. (1982) Tracers in the Sea, Lamont Doherty Geological Observatory Press, Columbia University, New York. pp. 383-439.

Broecker, W. S., Peng, T.-H., Trumbore, S., Bonani, G., and Wolfli, W. (1990) The glacial distribution of radiocarbon in the glacial ocean. Global Biogeochem. Cycles 4, 103-117.

Canuel, E. A. and Martens, C. S. (1996) Reactivity of recently deposited organic matter: Degradation of lipid compounds near the sediment-water interface. Geochim. Cosmochim. Acta 60, 1793-1806. 
Christensen, C. J., Gorsline, D. S., Hammond, D. E., and Lund, S. P. (1994) Non-annual laminations and expansion of anoxic basin-floor conditions in Santa Monica Basin, California Borderland, over the past four centuries. Mar. Geol. 116, 399418.

Collister, J. W., Rieley, G., Stern, B., Eglinton, G., and Fry, B. (1994) Compoundspecific $\delta^{13} \mathrm{C}$ analyses of leaf lipids from plants with differing carbon dioxide metabolisms. Org. Geochem. 21, 619-627.

Curry, W. B. and Crowley, T. J. (1987) The $\delta^{13} \mathrm{C}$ of Equatorial Atlantic surface waters: Implications for ice age $\mathrm{pCO}_{2}$ levels. Paleoceanography 2, 489-517.

De Leeuw, J. W., Rijpstra, W. I. C., Schenck, P. A. and Volkman, J. K. (1983) Free, esterified and residual bound sterols in Black Sea Unit I sediments. Geochim. Cosmochim. Acta 47, 455-465.

DeNiro, M. J. and Epstein, S. (1977) Mechanism of carbon isotope fractionation associated with lipid synthesis. Science 197, 261-263.

Derenne, S., Le Berre, F., Largeau, C., Hatcher, P., Connan, J. and Raynaud, J.-F. (1992) Formation of ultralaminae in marine kerogens via selective preservation of thin resistant outer walls of microalgae. Org. Geochem. 19, 345-350.

Deuser, W. G. (1986) Seasonal and interannual variations in deep water particle fluxes in the Sargasso Sea and their relation to surface hydrography. Deep-Sea Research 33, 225-246.

Dorman, C. E. and Palmer, D. P. (1981) Southern California summer coastal upwelling. Coastal and Estuarine Sciences 1, 44-56.

Druffel, E. M. and Suess, H. E. (1983) On the radiocarbon record in banded corals: Exchange parameters and net transport of ${ }^{14} \mathrm{CO}_{2}$ between atmosphere and surface ocean. J. Geophys. Res. 88(C2), 1271-1280.

Druffel, E. R. M. (1989) Decade time scale variability of ventilation in the North Atlantic: High-precision measurements of bomb radiocarbon in banded corals. $J$. Geophys. Res. 94(C3), 3271-3285.

Druffel, E. R. M., Williams, P. M., Bauer, J. E., and Ertel, J. R. (1992) Cycling of dissolved and particulate organic matter in the open ocean. J. Geophys. Res. 97 (C10), 15,639-15,659.

Duplessy, J.-C., Arnold, M., Bard, E., Juillet-Leclerc, A., Kallel, N., and Labeyrie, L. (1989) AMS ${ }^{14} \mathrm{C}$ study of transient events and of the ventilation rate of the Pacific intermediate water during the last deglaciation. Radiocarbon 31, 493-502.

Edwards, R. L., Beck, J. W., Burr, G. S., Donahue, D. J., Chappell, J. M. A., Bloom, A. L., Druffel, E. R. M., and Taylor, F. W. (1993) A large drop in atmospheric ${ }^{14} \mathrm{C} /{ }^{12} \mathrm{C}$ and reduced melting in the Younger Dryas documented with ${ }^{230} \mathrm{Th}$ of corals. Science 260, 962-968.

Eglinton, T. I., Aluwihare, L. I., Bauer, J. E., Druffel, E. R. M., and McNichol, A. P. (1996) Gas chromatographic isolation of individual compounds from complex matrices for radiocarbon dating. Anal. Chem. 68, 904-912.

Eglinton, T. I., Benitez-Nelson, B. C., Pearson, A., McNichol, A. P., Bauer, J. E., and Druffel, E. R. M. (1997) Variability in radiocarbon ages of individual organic compounds from marine sediments. Science 277, 796-799. 
Emery, K. O. and Bray, E. E. (1962) Radiocarbon dating of California Basin sediments. Bull. Am. Assoc. Petrol. Geol. 46, 1839-1856.

Eyssen, H. J., Parmentier., G. G., Compernolle, F. C., De Pauw, G. and Piessens-Denef, M. (1973) Biohydrogenation of sterols by Eubacterium ATCC 21,408-Nova species. Eur. J. Biochem. 36, 411-421.

Filley, T. R., Freeman, K. H., and Hatcher, P. G. (1997) Carbon isotope relationships between sulfide-bound steroids and proposed functionalized lipid precursors in sediments from the Santa Barbara Basin, California. Org. Geochem. 25, 367-377.

François, R., Altabet, M. A., Yu, E.-F., Sigman, D. M., Bacon, M. P., Frank, M., Bohrmann, G., Bareille, G., and Labeyrie, L. D. (1997) Contribution of Southern Ocean surface-water stratification to low atmospheric $\mathrm{CO}_{2}$ concentrations during the last glacial period. Nature 389, 929-935.

Freeman, K. H., Hayes, J. M., Trendel, J.-M. and Albrecht, P. (1990) Evidence from GCMS carbon-isotopic measurements for multiple origins of sedimentary hydrocarbons. Nature 353, 254-256.

Gelin, F., Boogers, I., Noordeloos, A. A. M., Sinninghe Damsté, J. S., Riegman, R. and de Leeuw, J. W. (1997) Resistant biomacromolecules in marine microalgae of the classes Eustigmatophyceae and Chlorophyceae: geochemical implications. Org. Geochem. 26, 659-675.

Gelin, F., Volkman, J. K., Largeau, C., Derenne, S., Sinninghe Damsté, J. S. and de Leeuw, J. W. (1999) Distribution of aliphatic, nonhydrolyzable biopolymers in marine microalgae. Org. Geochem. 30, 147-159.

Goad, L. J. (1981) Sterol biosynthesis and metabolism in marine invertebrates. Pure Appl. Chem. 51, 837-852.

Goad, L. J. and Withers, N. (1982) Identification of 27-nor-(24R)-24-methyl-cholesta5,22-dien-3 $\beta$-ol and brassicasterol as the major sterols of the marine dinoflagellate Gymodinium simplex. Lipids 17, 852-858.

Goñi, M. A., Ruttenberg, K. C., and Eglinton, T. I. (1997) Sources and contribution of terrigenous organic carbon to surface sediments in the Gulf of Mexico. Nature 389, 275-278.

Goñi, M. A., Ruttenberg, K. C., and Eglinton, T. I. (1998) A reassessment of the sources and importance of land-derived organic matter in surface sediments from the Gulf of Mexico. Geochim. Cosmochim. Acta 62, 3055-3075.

Goslar, T. et al. (1995) High concentration of atmospheric ${ }^{14} \mathrm{C}$ during the Younger Dryas cold episode. Nature 377, 414-417.

Grice, K., Klein Breteler, W. C. M., Schouten, S., Grossi, V., de Leew, J. W., and Sinninghe Damsté, J. S. (1998) Effects of zooplankton herbivory on biomarker proxy records. Paleoceanography 13, 686-693.

Guilderson, T. P. and Schrag, D. P. (1998) Abrupt shift in subsurface temperatures in the tropical Pacific associated with changes in El Niño. Science 281, 240-243.

Hagadorn, J. W., Stott, L. D., Sinha, A. and Rincon, M. (1995) Geochemical and sedimentologic variations in inter-annually laminated sediments from Santa Monica Basin. Mar. Geology 125, 111-131. 
Harvey, R. H., Eglinton, G., O'Hara, S. C. M., and Corner, E. D. S. (1987)

Biotransformation and assimilation of dietary lipids by Calanus feeding on a dinoflagellate. Geochim. Cosmochim. Acta 51, 3031-3040.

Hayes, J. M. (1993) Factors controlling the ${ }^{13} \mathrm{C}$ content of sedimentary organic compounds: Principles and evidence. Mar. Geol. 113, 111-125.

Hayes, J. M., Freeman, K. H., Popp, B. N., and Hoham, C. H. (1990) Compound-specific isotopic analyses: A novel tool for reconstruction of ancient biogeochemical processes. Org. Geochem. 16, 1115-1128.

Hedges, J. I. (1992) Global biogeochemical cycles: progress and problems. Mar. Chem. 39, 67-93.

Hedges, J. I. and Mann, D. C. (1979) The lignin geochemistry of marine sediments from the southern Washington coast. Geochim. Cosmochim. Acta 43, 1809-1818.

Hedges, J. I. and Parker, P. L. (1976) Land-derived organic matter in surface sediments from the Gulf of Mexico. Geochim. et Cosmochim. Acta 40, 1019-1029.

Hinrichs, K.-U., Hayes, J. M, Sylva, S. P., Brewer, P. G. and DeLong, E. F. (1999) Methane-consuming archaebacteria in marine sediments. Nature 398, 802-805.

Huang, W.-Y. and Meinschein, W. G. (1976) Sterols as source indicators of organic materials in sediments. Geochim. et Cosmochim. Acta 40, 323-330.

Hughen, K. A., Overpeck, J. T., Lehman, S. J., Kashgarian, M., Southon, J., Peterson, L. C., Alley, R., and Sigman, D. M. (1998) Deglacial changes in ocean circulation from an extended radiocarbon calibration. Nature 391, 65-68.

Huh, C.-A., Zahnle, D. L., and Small, L. F. (1987) Budgets and behaviors of uranium and thorium series isotopes in Santa Monica Basin sediments. Geochim. et Cosmochim. Acta 51, 1743-1754.

Jasper, J. P. and Hayes, J. M. (1990) A carbon isotope record of $\mathrm{CO}_{2}$ levels during the late Quaternary. Nature 347, 462-464.

Jones, G.A. and Gagnon, A.R. (1994) Radiocarbon chronology of Black Sea sediments. Deep-Sea Res. 41, 531- .

Kokinos, J. P., Eglinton, T. I., Goñi, M. A., Boon, J. J., Martoglio, P. A., and Anderson, D. A. (1998) Characterization of a highly resistant biomacromolecular material in the cell wall of a marine dinoflagellate resting cyst. Org. Geochem. 28, 265288.

Kroon, D. and Darling, K. (1995) Size and upwelling control of the stable isotope composition of Neogloboquadrina dutertrei (D'Orbigny), Globigerinoides ruber (D'Orbigny) and Globigerina bulloides D'Orbigny: Examples from the Panama Basin and Arabian Sea. J. Foram. Research 25, 39-52.

Laws, E. A., Popp, B. N., Bidigare, R. R., Kennicutt, M. C., and Macko, S. A. (1995) Dependence of phytoplankton isotopic composition on growth rate and $\left[\mathrm{CO}_{2}\right]_{\mathrm{aq}}$ : Theoretical considerations and experimental results. Geochim. Cosmochim. Acta 59, 1131-1138.

Levin, I. and Kromer, B. (1997) Twenty years of atmospheric ${ }^{14} \mathrm{CO}_{2}$ observations at Schauinsland. Radiocarbon 39, 205-218. 
Levin, I., Kromer, B., Schoch-Fischer, H., Bruns, M., Münnich, M., Berdau, D., Vogel, J. C., and Münnich, K. O. (1985) 25 years of tropospheric ${ }^{14} \mathrm{C}$ observations in Central Europe. Radiocarbon 27, 1-19.

Lockheart, M. J., van Bergen, P. F. and Evershed, R. P. (1996) Variations in the stable carbon isotope compositions of individual lipids from the leaves of modern angiosperms: implications for the study of higher land plant-derived sedimentary organic matter. Org. Geochem. 26, 137-153.

Mangerud, J. and Gulliksen, S. (1975) Apparent radiocarbon ages of recent marine shells from Norway, Spitsbergen, and Arctic Canada. Quaternary Research 5, 263-273.

Marlowe, I. T., Brassell, S. C., Eglinton, G., and Green, J. C. (1990) Long-chain alkenones and alkyl alkenoates and the fossil coccolith record of marine sediments. Chem. Geol. 88, 349-375.

Masiello, C. A. and Druffel, E. R. M. (1998) Black carbon in deep-sea sediments. Science 280, 1911-1913.

McCaffrey, M.A., Farrington, J.W. and Repeta, D.J. (1991) The organic geochemistry of Peru margin surface sediments: II. Paleoenvironmental implications of hydrocarbon and alcohol profiles. Geochim. et Cosmochim. Acta 55, 483-498.

McCorkle, D. C., Keigwin, L. D., Corliss, B. H., and Emerson, S. R. (1990) The influence of microhabitats on the carbon isotopic composition of deep-sea benthic foraminifera. Paleoceanography 5, 161-185.

McCorkle, D. C., Corliss, B. H., and Farnham, C. A. (1997) Vertical distributions and stable isotopic compositions of live (stained) benthic foraminifera from the North Carolina and California continental margins. Deep-Sea Research I 44, 983-1024.

Nichols, P. D., Volkman, J. K., Hallegraeff, G. M. and Blackburn, S. I. (1987) Sterols and fatty acids of the red tide flagellates Heterosigma akashiwo and Chattonella antiqua (Raphidophyceae). Phytochemistry 26, 2537-2541.

Nichols, P. D., Palmisano, A. C., Rayner, M. S., Smith, G. A. and White D. C. (1990) Occurrence of novel $\mathrm{C}_{30}$ sterols in Antarctic sea ice diatom communities during a spring bloom. Org. Geochem. 15, 503-508.

Pancost, R. D., Freeman, K. H. and Wakeham, S. G. (1999) Controls on the carbonisotopic compositions of compounds in Peru surface waters. Org. Geochem. 30, 319-340.

Pearson, A., McNichol, A. P., Schneider, R. J., and von Reden, K. F. (1998) Microscale AMS ${ }^{14} \mathrm{C}$ measurement at NOSAMS. Radiocarbon 40, 61-76.

Philp, R. P. and Calvin, M. (1976) Possible origin for insoluble organic (kerogen) debris in sediments from insoluble cell-wall materials of algae and bacteria. Nature 262, 134-136.

Prahl, F. G., Eglinton, G., Corner, E. D. S., O'Hara, S. C. M. and Forsberg, T. E. V. (1984) Changes in plant lipids during passage through the gut of Calanus. J. Mar. Biol. Ass. U. K. 64, 317-334.

Prahl, F. G., Erterl, J. R., Goni, M. A., Sparrow, M. A. and Eversmeyer, B. (1994) Terrestrial organic carbon contributions to sediments on the Washington margin. Geochim. Cosmochim. Acta 58, 3035-3048. 
Rau, G.H., Karl, D.M. and Carney, R.S. (1986) Does inorganic carbon assimilation cause ${ }^{14} \mathrm{C}$ depletion in deep-sea organisms? Deep-Sea Res. 33, 349-357.

Rau, G.H. Another recipe for bomb ${ }^{14} \mathrm{C}$ dilution. (1991) Nature 350, 116.

Ravelo, C. and Fairbanks, R. G. (1992) Oxygen isotope composition of multiple species of planktonic foraminifera: recorders of the modern photic zone temperature gradient. Paleoceanography 7, 815-831.

Reimers, C. E., Lange, C. B., Tabak, M., and Bernhard, J. M. (1990) Seasonal spillover and varve formation in the Santa Barbara Basin, California. Limnol. Oceanogr. $35,1577-1585$.

Robinson, S. W. (1981) Natural and man-made radiocarbon as a tracer for coastal upwelling processes. Coastal and Estuarine Sciences 1, 298-302.

Robinson, N., Eglinton, G., Brassell, S. C. and Cranwell, P. A. (1984) Dinoflagellate origin for sedimentary $4 \alpha-$ methylsteroids and $5 \alpha(\mathrm{H})$-stanols. Nature 308, 439442.

Sautter, L. R. (1998) Morphologic and stable isotopic variability within the planktic foraminiferal genus Neogloboquadrina. J. Foram. Research 28, 220-232.

Schimmelmann, A., and Tegner, M. J. (1991) Historical oceanographic events reflected in the ${ }^{13} \mathrm{C} /{ }^{12} \mathrm{C}$ ratio of total organic carbon in laminated Santa Barbara Basin Sediment. Global Biogeochem. Cycles 5, 173-188.

Schouten, S., Klein Breteler, W. C. M., Blokker, P., Schogt, N., Rijpstra, W. I. C., Grice, K., Baas, M., and Sinninghe Damsté, J. S. (1998) Biosynthetic effects on the stable carbon isotopic compositions of algal lipids: Implications for deciphering the carbon isotopic biomarker record. Geochim. Cosmochim Acta. 62, 13971406.

Smith, D. J. (1984) Biogeochemistry of lipids in recent organic-rich marine sediments. Ph. D. Thesis, University of Bristol, UK, $333 \mathrm{pp}$.

Southon, J. R., Nelson, D. E., and Vogel, J. S. (1990) A record of past ocean-atmosphere radiocarbon differences from the Northeast Pacific. Paleoceanography 5, 197206.

Stuiver, M. and Braziunas, T. F. (1993) Modeling atmospheric ${ }^{14} \mathrm{C}$ influences and ${ }^{14} \mathrm{C}$ ages of marine samples to $10,000 \mathrm{BC}$. Radiocarbon 35, 137-189.

Stuiver, M., Pearson, G. W., and Braziunas, T. F. (1986) Radiocarbon age calibration of marine samples back to 9000 cal yr BP. Radiocarbon 28, 980-1021.

Stuiver, M. and Polach, H. A. (1977) Discussion: Reporting of ${ }^{14} \mathrm{C}$ data. Radiocarbon 19, 355-363.

Suess, H. E. (1953) Natural radiocarbon and the rate of exchange of $\mathrm{CO}_{2}$ between the atmosphere and the sea, in Proc. Of the Conf. On Nuclear Processes in Geological Settings, pp. 52-56, University of Chicago Press, Chicago, Ill..

Sun, M.-Y., Wakeham, S. G., and Lee, C. (1997) Rates and mechanisms of fatty acid degradation in oxic and anoxic coastal marine sediments of Long Island Sound, New York, USA. Geochim. Cosmochim. Acta 61, 341-355.

Sun, M.-Y. and Wakeham, S. G. (1998) A study of oxic/anoxic effects on degradation of sterols at the simulated sediment-water interface of coastal sediments. Org. Geochem. 28, 773-784. 
Trumbore, S. E. (1993) Comparison of carbon dynamics in tropical and temperate soils using radiocarbon measurements. Global Biogeochem. Cycles 7, 275-290.

Tuttle, J. H. and Jannasch, H. W. (1979) Microbial dark assimilation of $\mathrm{CO}_{2}$ in the Cariaco Trench. Limnol. Oceanogr. 24, 746-753.

Volkman, J. K., Gillan, F. T., Johns, R. B. and Eglinton, G. (1981) Sources of neutral lipids in a temperate intertidal sediment. Geochim. Cosmochim. Acta 45, 18171828 .

Volkman, J. K. (1986) A review of sterol markers for marine and terrigenous organic matter. Org. Geochem. 9, 83-99.

Volkman, J. K., Farrington, J. W., and Gagosian, R. B. (1987) Marine and terrigenous lipids in coastal sediments from the Peru upwelling region at $15^{\circ} \mathrm{S}$ : Sterols and triterpene alcohols. Org. Geochem. 11, 463-477.

Volkman, J. K., Barrett, S. J., Blackburn, S. I., Mansour, M. P., Sikes, E. L. and Gelin, F. (1998) Microalgal biomarkers: A review of recent research developments. Org. Geochem. 29, 1163-1179.

Volkman, J .K., Barrett, S. M. and Blackburn S. I. (1999) Eustigmatophyte microalgae are potential sources of $\mathrm{C}_{29}$ sterols, $\mathrm{C}_{22}-\mathrm{C}_{28} n$-alcohols and $\mathrm{C}_{28}-\mathrm{C}_{32} n$-alkyl diols in freshwater environments. Org. Geochem. 30, 307-318.

von Reden, K. F., Schneider, R. J., McNichol, A. P., and Pearson, A. (1998) ${ }^{14}$ C AMS measurements of $<100 \mathrm{mg}$ samples with a high-current system. Proceedings of the $16^{\text {th }}$ International ${ }^{14} \mathrm{C}$ conference, edited by W. G. Mook and J. van der Plicht, Radiocarbon, 40, 247- .

Wang, X.-C., Druffel, E. R. M., Griffin, S., Lee, C., and Kashgarian, M. (1998) Radiocarbon studies of organic compound classes in plankton and sediment of the northeastern Pacific Ocean. Geochim. Cosmochim. Acta 62, 1365-1378.

Wakeham, S. G. (1989) Reduction of stenols to stanols in particulate matter at oxicanoxic boundaries in seawater. Nature 342, 787-790.

Wakeham, S. G. and Beier, J. A. (1991) Fatty acid and sterol biomarkers as indicators of particulate matter source and alteration processes in the Black Sea. Deep-Sea Research 38, S943-S968.

Weidman, C. R. and Jones, G. A. (1993) A shell-derived time history of bomb ${ }^{14} \mathrm{C}$ on Georges Bank and its Labrador Sea implications. J. Geophys. Res. 98, 14,57714,588 .

Williams, P.M., Robertson, K.J., Soutar, A., Griffin, S.M. and Druffel, E.R.M. (1992) Isotopic signatures $\left({ }^{14} \mathrm{C},{ }^{13} \mathrm{C},{ }^{15} \mathrm{~N}\right)$ as tracers of sources and cycling of soluble and particulate organic matter in the Santa Monica Basin, California. Prog. Oceanog. 30, 253-290.

WOCE Data Report 94-093, (1994) Radiocarbon Results: WOCE Report 3, WOCE transect P17C, National Ocean Sciences AMS Facility, Woods Hole, MA.

Yunker, M. B., Macdonald, R. W., Veltkamp, D. J., and Cretney, W. J. (1995) Terrestrial and marine biomarkers in a seasonally ice-covered Arctic estuary - integration of multivariate and biomarker approaches. Marine Chemistry 49, 1-50. 


\subsection{APPENDIX}

\subsection{1 ${ }^{13}$ C-Fractionation During Reaction of Alcohols with Acetic Anhydride}

Alcohols were acetylated using acetic anhydride in order to form derivatives resistant to hydrolysis and suitable for PCGC work. Samples were dissolved in excess pyridine/acetic anhydride (2:1 volume ratio). The solution was purged with $\mathrm{N}_{2}$ and stirred with a magnetic bar for $12 \mathrm{hr}$ at room temperature. Acetylation occurs via nucleophilic attack by the alcohol oxygen at one of the carbonyl groups of acetic anhydride. The rate-determining step in acyl substitution is the formation of a tetrahedral intermediate during the initial association of the alcohol and acetic anhydride. The intermediate quickly releases the most favorable leaving group, acetate, yielding acetic acid and an ester of the original alcohol as products.

Isotopic fractionation is associated with formation of the initial carbon-oxygen bond between the alcohol oxygen and a carbonyl carbon. Kinetic discrimination against ${ }^{13} \mathrm{C}$ is expected during this rate-determining step. During the addition of isotopically heterogeneous acetic anhydride (i.e. $\mathrm{CH}_{3}{ }^{12} \mathrm{COO}^{13} \mathrm{COCH}_{3}$ ), the intermediate should favor formation of a ${ }^{12} \mathrm{C}-\mathrm{O}$ bond, while the ${ }^{13} \mathrm{C}$ carbonyl becomes the acetate leaving group. Figure 4.13 shows the presumed energy diagram for this two-step reaction. The acetylated derivatives should have $\delta^{13} \mathrm{C}$ values more negative than would be produced by simple addition of two acetyl carbons with isotopic composition identical to the $\delta^{13} \mathrm{C}$ of the original acetic anhydride. The fractionation factor, $\varepsilon$, is therefore in the regular sense: $\delta^{13} \mathrm{C}_{\text {reactant }}-\delta^{13} \mathrm{C}_{\text {product }}$ is a positive number. The following experiments seemed to confirm this hypothesis. 
Figure 4.13

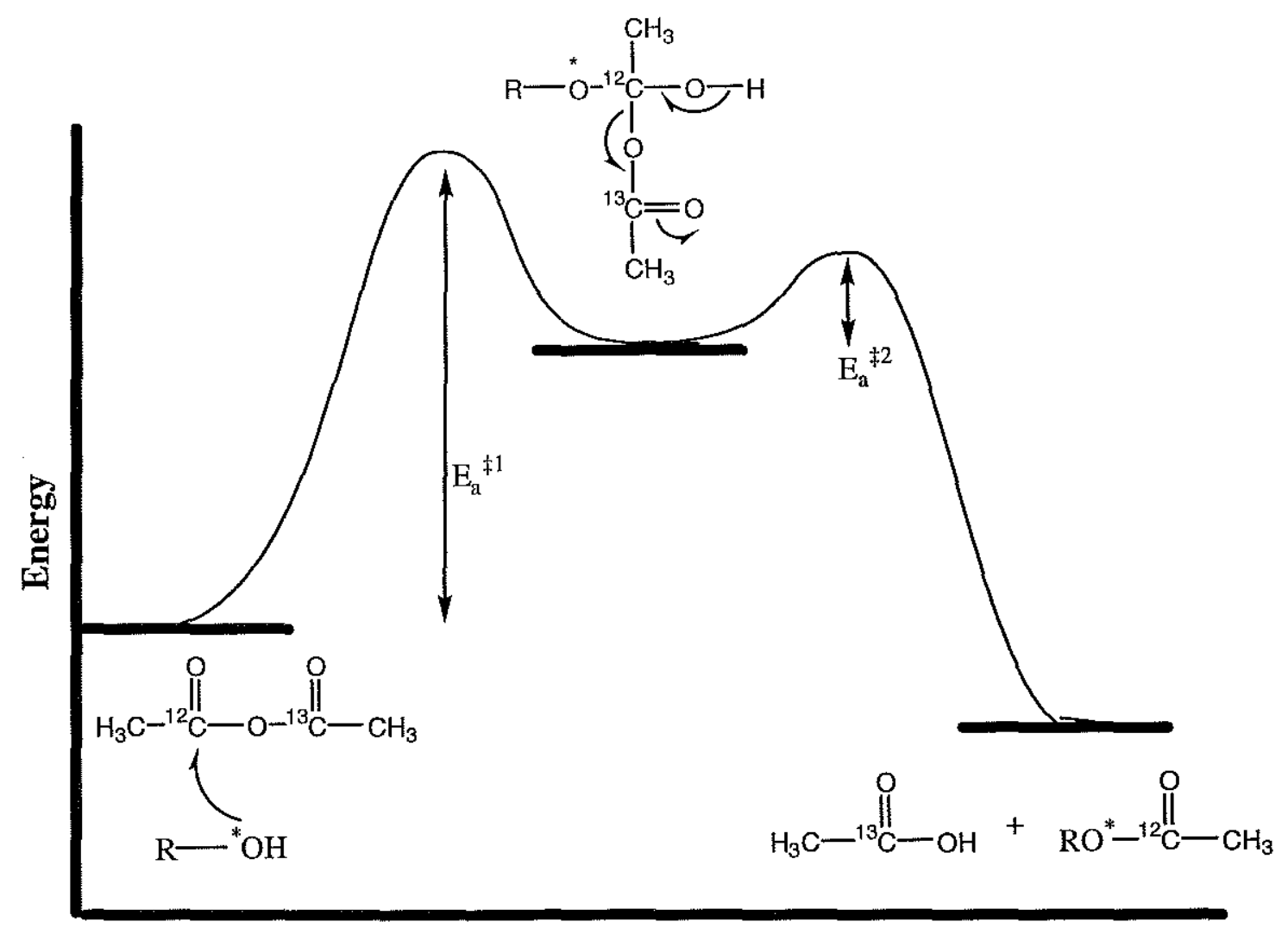

Figure 4.13 Reaction mechanism and energy diagram for the formation of an acetate derivative from an alcohol and isotopically heterogeneous acetic anhydride.

Several experiments were performed to attempt to quantify the magnitude of this fractionation effect and determine a correction factor that could be applied to the $\delta^{13} \mathrm{C}$ values obtained for alcohol acetates. The original idea was to avoid determining $\delta^{13} \mathrm{C}$ on separately prepared -OTMS derivatives, if $\mathrm{irm}$-GC/MS data for acetates could simply be corrected for the "effective $\delta^{13} \mathrm{C}$ " of the added acetate group. 


\section{Experiment \#1.}

The first experiment to determine the fractionation factor used three standards of known isotopic composition, cholesterol (Sigma Lot\# 54H8478), n- $\mathrm{C}_{19}-\mathrm{OH}$ (Aldrich, Lot\# 03902HP), and $n-\mathrm{C}_{26}-\mathrm{OH}$ (Aldrich, no Lot \#). Milligram-sized samples of these pure standards were combusted in quartz tubes, the $\mathrm{CO}_{2}$ purified, and $\delta^{13} \mathrm{C}$ measured by off-line isotope ratio MS. The same $n-\mathrm{C}_{19}$ alcohol was added to the SMB total lipid extracts for use as a recovery standard. Two $\delta^{13} \mathrm{C}$ measurements for pure cholesterol, three for $n-\mathrm{C}_{19}-\mathrm{OH}$, and one for $n-\mathrm{C}_{26}-\mathrm{OH}$ are reported in Table 4.9. Two samples of pure acetic anhydride (Alltech Acetylation Kit, sealed in 10-mL ampules and stored below $0^{\circ} \mathrm{C}$ until use) were also combusted in quartz tubes, and the $\mathrm{CO}_{2}$ was analyzed to determine $\delta^{13} \mathrm{C}$ of the derivative carbon $(-19.4 \%$, Table 4.9$)$. Then two aliquots of each standard (1.7 - $3.8 \mathrm{mg}$ compound, only one aliquot for $\left.n-\mathrm{C}_{26}-\mathrm{OH}\right)$ were weighed into reaction vials, and $2 \mathrm{~mL}$ pyridine plus $1.5 \mathrm{~mL}$ acetic anhydride were added to each. Samples were bubbled with $\mathrm{N}_{2}$, sealed, and allowed to stir at room temperature overnight. The mole ratio of acetic anhydride to reactant is $>100$ and the observed isotopic effect should not be affected by a high fractional consumption of acetic anhydride.

The derivatized products were transferred using $\mathrm{MeOH}$ to a Turbovap ${ }^{\circledR}$ flask, and blown to dryness. A residual yellow color was observed, indicating the presence of something other than pure cholesterol acetate or $n$-alkyl acetate. This contaminant would have biased the isotopic results to an unknown extent and had to be removed. This was achieved by a crude re-crystallization step. The samples were dissolved in a minimum of hot $\mathrm{MeOH}$ and rapidly quenched in ice water. The yellow color stayed behind in solution, while the acetylated standards precipitated as white crystals. The yellow solution was removed by pipette and the re-crystallization step repeated until the crystals, when blown to dryness, were pure white. The crystals were transferred to quartz tubes, combusted to $\mathrm{CO}_{2}$, and $\delta^{13} \mathrm{C}$ measured (data, Table 4.9). The re-crystallization step introduced a potentially significant source of error into the experiment, since the solubility of the acetylated standards in $\mathrm{MeOH}$ is accompanied by fractionation (the 
heavier isotope should prefer the solid phase). The MeOH solution was removed, possibly causing isotopic enrichment in the solids left behind. Because of this concern, a second bulk-phase acetylation experiment was performed.

\section{Experiment \#2.}

The second experiment used new acetic anhydride, ordered fresh from Aldrich (Lot \# ES $10720 \mathrm{KR}$ ). One sample of the Aldrich acetic anhydride was combusted to $\mathrm{CO}_{2}$ and $\delta^{13} \mathrm{C}$ was measured for the derivative carbon (Table 4.9). Then one sample of each standard analyzed previously (cholesterol, $n-\mathrm{C}_{19}-\mathrm{OH}$, and $n-\mathrm{C}_{26}-\mathrm{OH}$ ) were acetylated using the same method. The acetates were again evaporated to dryness in Turbovap ${ }^{\circledR}$ flasks. However, prior to combustion, the bulk acetylated products were eluted through pre-combusted $\left(450^{\circ} \mathrm{C}\right)$ silica gel (100-200 mesh) with a mixture of $20: 80$ ethyl acetate/hexane. Any color in the mixture was retained on the $\mathrm{SiO}_{2}$ and the products after solvent evaporation were pure white. This clean-up step was expected to have a negligible effect on the $\delta^{13} \mathrm{C}$ of the products and $\delta^{13} \mathrm{C}$ data for these three samples are also shown in Table 4.9. Samples and experiments are distinguished by identifying the acetic anhydride manufacturer.

\section{Experiment \#3, PCGC recovery standards.}

Two $\delta^{13} \mathrm{C}$ values are available for $n-\mathrm{C}_{19}-\mathrm{OH}$ that had been added to total lipid extracts, acetylated, collected by PCGC, and combusted to $\mathrm{CO}_{2}$. The acetic anhydride used for all PCGC samples was from an Alltech Acetylation Kit, Lot $\# 11689, \delta^{13} \mathrm{C}=$

$-27.1 \%$ o, $\Delta^{14} \mathrm{C}=-997 \%$, one analysis). Mass balance addition of 2 carbons from acetic anhydride to a 19 -carbon standard with $\delta^{13} \mathrm{C}=-30.45 \%$ gives an expected value of $-30.13 \%$. The two recovered samples gave $\delta^{13} \mathrm{C}$ values of $-31.5 \%$ and $-32.0 \%$. The $\delta^{13} \mathrm{C}$ of the alcohol acetates is again about $1.5 \%$ more negative than expected if no fractionation had occurred. 
The data from all these experiments are summarized in Table 4.9. The "theoretical" $\delta^{13} \mathrm{C}$ of the acetylated alcohols is the $\delta^{13} \mathrm{C}$ calculated assuming no fractionation occurred upon addition of carbon from acetic anhydride:

$$
\delta^{13} \mathrm{C}=\left(2 * \delta^{13} \mathrm{C}_{\mathrm{OAc}}+\mathrm{N}_{\text {standard }} * \delta^{13} \mathrm{C}_{\text {standard }}\right) /(\mathrm{N}+2)
$$

Table 4.9 $\delta^{13} \mathrm{C}$ data for bulk acetylation experiments and PCGC recovery standards.

\begin{tabular}{|c|c|c|c|c|c|}
\hline $\begin{array}{c}\delta^{13} \mathrm{C} \\
\text { acetic } \\
\text { anhydride }\end{array}$ & Sample & $\begin{array}{c}\text { "True" } \delta^{13} \mathrm{C} \\
\text { of alcohol } \\
\text { standard } \\
(\%)\end{array}$ & $\begin{array}{c}\text { Predicted } \\
\delta^{13} \mathrm{C} \text {, acetate } \\
\text { product } \\
(\% o)\end{array}$ & $\begin{array}{c}\text { Measured } \\
\delta^{13} \mathrm{C} \text {, acetate } \\
\text { product } \\
(\% o)\end{array}$ & $\begin{array}{c}\Delta \delta^{13} \mathrm{C}= \\
\text { predicted - } \\
\text { measured } \\
(\% o)\end{array}$ \\
\hline & $n-\mathrm{C}_{19}-\mathrm{OH}$ & -30.45 & & & \\
\hline-19.4 & $\begin{array}{l}n-\mathrm{C}_{19}-\mathrm{OAc} \text {, } \\
\text { (Alltech) }\end{array}$ & & -29.4 & -30.8 & 1.4 \\
\hline-23.1 & $\begin{array}{l}n-\mathrm{C}_{19}-\mathrm{OAc} \\
\text { (Aldrich) }\end{array}$ & & -29.8 & -32.1 & 2.3 \\
\hline-27.1 & $\begin{array}{l}n-\mathrm{C}_{19}-\mathrm{OAc}, \\
(\mathrm{PCGC})\end{array}$ & & -30.1 & -31.5 & 1.4 \\
\hline \multirow[t]{2}{*}{-27.1} & $\begin{array}{l}n-\mathrm{C}_{19}-\mathrm{OAc}, \\
(\mathrm{PCGC})\end{array}$ & & -30.1 & -32.0 & 1.9 \\
\hline & $n-\mathrm{C}_{26}-\mathrm{OH}$ & -26.54 & & & \\
\hline-19.4 & $\begin{array}{l}n-\mathrm{C}_{26}-\mathrm{OAc}, \\
\text { (Alltech) }\end{array}$ & & -26.0 & -27.1 & 1.1 \\
\hline \multirow[t]{2}{*}{-23.1} & $\begin{array}{l}n-\mathrm{C}_{26}-\mathrm{OAc} \\
\text { (Aldrich) }\end{array}$ & & -26.3 & -27.8 & 1.5 \\
\hline & Cholesterol & -25.16 & & & \\
\hline-19.4 & $\begin{array}{l}\text { Cholesterol-OAc } \\
\text { (Alltech) }\end{array}$ & & -24.8 & -26.2 & 1.4 \\
\hline-19.4 & $\begin{array}{l}\text { Cholesterol-OAc } \\
\text { (Alltech) }\end{array}$ & & -24.8 & -26.0 & 1.2 \\
\hline-23.1 & $\begin{array}{l}\text { Cholesterol-OAc } \\
\text { (Aldrich) }\end{array}$ & & -25 & -26.8 & 1.8 \\
\hline
\end{tabular}


The data for these bulk phase experiments show a relatively consistent fractionation of about $1.4 \%$, i.e. the acetylated alcohols are $1.4 \%$ more ${ }^{13} \mathrm{C}$-depleted than they would be if the acetyl groups were added without any associated isotopic fractionation. The results are consistent with the reaction mechanism as shown in Figure 4.13 .

Experiment \#4. Comparison of acetylation and silylation of alcohols by irm-GC/MS.

There was still concern that these bulk phase experiments were in some way producing biased results. A fundamentally different approach was taken by adding aliquots of an alcohol standard (androstanol, $\delta^{13} \mathrm{C}=-33.3 \%$, one off-line measurement on $\mathrm{CO}_{2}$ generated by closed-tube combustion) to the sub-fractions destined for $\delta^{13} \mathrm{C}$ analysis by $\mathrm{irm}-\mathrm{GC} / \mathrm{MS}$. The androstanol standard in each mixture provided further information about the fractionation induced by acetylation as well as the accuracy of the irm-GC/MS measurements of -OTMS derivatives.

The first question concerns the accuracy of the $\mathrm{irm}-\mathrm{GC} / \mathrm{MS} \delta^{13} \mathrm{C}$ data: Eleven alcohol fractions were analyzed by $\mathrm{irm}$-GC/MS as -OTMS ethers, in triplicate. After data processing, the contribution of derivative carbon $\left(3^{*}-45.3 \%\right.$ ) was subtracted from all the compounds analyzed. The average $\delta^{13} \mathrm{C}$ values for androstanol were compared to the "true" value of $-33.3 \%$ (Table 4.10 ). The $\mathrm{irm}$-GC/MS data are not biased in any particular direction (the average deviation from $-33.3 \%$ is only $0.1 \%$, but measurement precision, as shown by the average of the absolute values of these measurement errors, appears to be $\pm 0.4 \%$. With this in mind, we can evaluate the differences between alcohols as acetate derivatives and as -OTMS derivatives. 
Table 4.10 Androstanol standard $\delta^{13} \mathrm{C}$ measured by irm-GC/MS:

$$
\Delta \delta^{13} \mathrm{C}=\delta^{13} \mathrm{C}_{\mathrm{irm}-\mathrm{GC} / \mathrm{MS}}-(-33.3 \% \text { ) }
$$

\begin{tabular}{lcc}
\hline Alcohol Fraction & $\begin{array}{c}\Delta \delta^{13} \mathrm{C} \\
(\% o)\end{array}$ & $\begin{array}{c}\left|\Delta \delta^{13} \mathrm{C}\right| \\
\text { (absolute value) }\end{array}$ \\
\hline SMB 0-0.75 sterols & & \\
SMB 0.75-1.5 sterols & -0.5 & 0.5 \\
SMB 4.5-5.5 sterols & 0.2 & 0.2 \\
SMB 5.5-6.5 sterols & -0.4 & 0.4 \\
& & \\
SMB 0-0.75 non-adducts & -0.4 & 0.4 \\
SMB 0.75-1.5 non-adducts & 0.1 & 0.1 \\
SMB 4.5-5.5 non-adducts & 0.2 & 0.2 \\
SMB 5.5-8.5 non-adducts & 0.6 & 0.6 \\
& & \\
SMB 0-0.75 adducts & 1.2 & 1.2 \\
SMB 0.75-1.5 adducts & -0.4 & 0.4 \\
SMB 4.5-5.5 adducts & 0.5 & 0.5 \\
SMB 5.5-8.5 adducts & 0 & 0 \\
$\quad$ Average & 0.1 & 0.4 \\
$\quad$ Standard Deviation & 0.5 & 0.3 \\
\hline
\end{tabular}

For two of the alcohol fractions shown in Table 4.10, irm-GC/MS data were obtained for both the mixture as -OTMS derivatives $\left(\delta^{13} \mathrm{C}_{\mathrm{TMS}}=-45.3 \%\right.$, S. Sylva, personal communication) and as acetates (Aldrich acetic anhydride, $-23.3 \%$ ), including the added androstanol standard. The predicted $\delta^{13} \mathrm{C}$ when 2 carbons from acetic anhydride are added to androstanol without additional fractionation is $-32.4 \%$. The measured $\delta^{13} \mathrm{C}$ for androstanol acetate was $-34.1 \pm 0.2 \%$ and $-33.7 \pm 0.4 \%$. The apparent fractionation is again $\sim 1.4 \%$ o $(1.7,1.3 \%$ ) .

Five entire desmethyl-sterol fractions were analyzed as both acetates and-OTMS derivatives by $\mathrm{irm}$-GC/MS (only the two mentioned above had androstanol added). Since the -OTMS derivatives are assumed to yield "true" $\delta^{13} \mathrm{C}$ values after the contribution of 
the derivative carbon is subtracted, we can make the additional comparison of all individual peaks for which $\delta^{13} \mathrm{C}$ was obtained for both derivative types.

Table 4.11 irm-GC/MS data for sterols run as acetates. The fractionation effect is always in the regular sense (products lighter than original substrate), but the magnitude of the fractionation is not constant between batches.

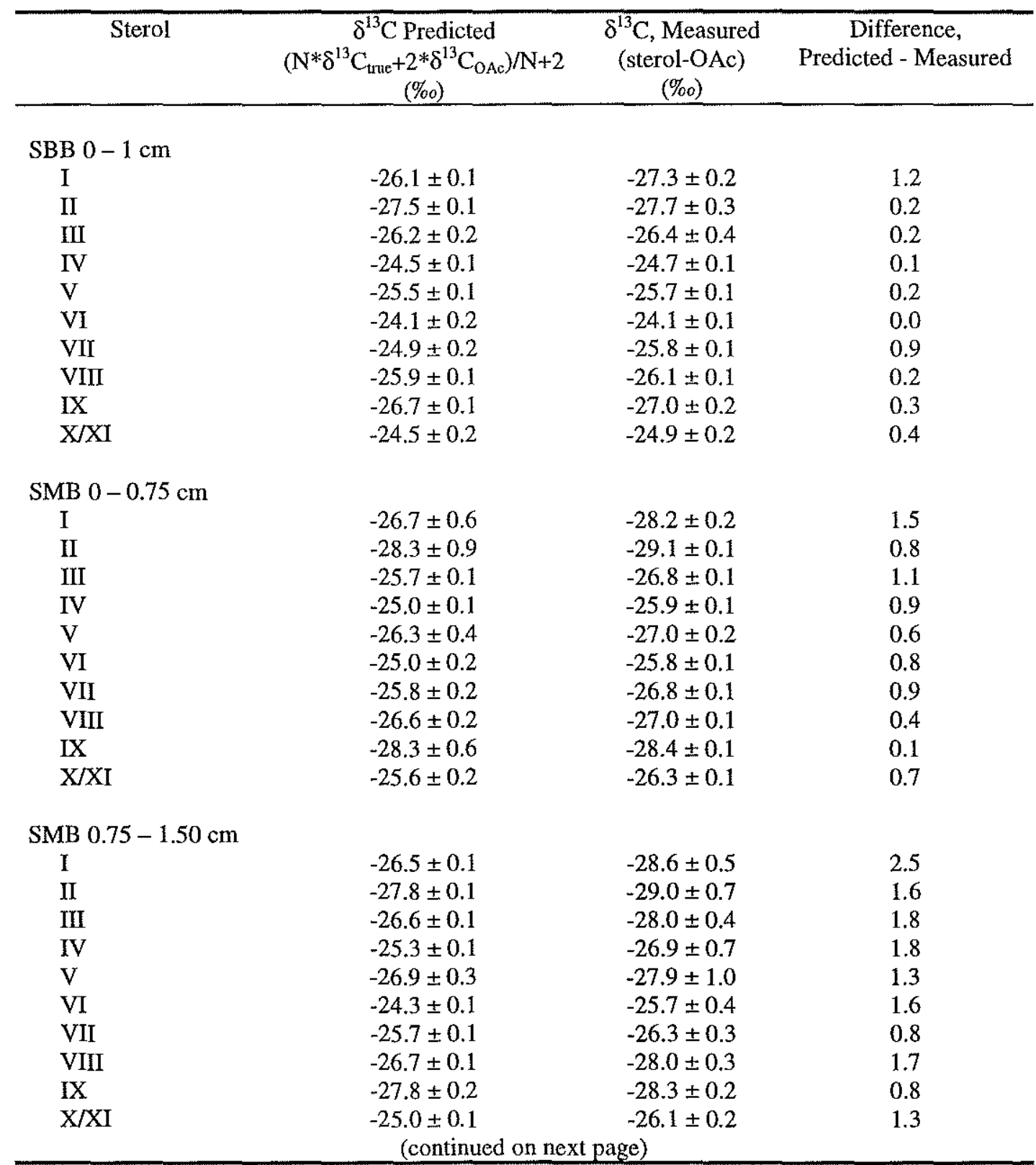




\begin{tabular}{llll}
\hline SMB $4.5-5.5 \mathrm{~cm}$ & $-25.6 \pm 0.2$ & $-28.5 \pm 0.2$ & 3.0 \\
I & $-28.2 \pm 0.3$ & $-29.3 \pm 0.3$ & 1.1 \\
II & $-25.5 \pm 0.2$ & $-26.5 \pm 0.1$ & 1.0 \\
III & $-24.4 \pm 0.1$ & $-25.5 \pm 0.1$ & 1.1 \\
IV & $-25.8 \pm 0.3$ & $-26.7 \pm 0.2$ & 0.8 \\
V & $-24.0 \pm 0.1$ & $-25.3 \pm 0.1$ & 1.3 \\
VI & $-26.1 \pm 0.2$ & $-27.2 \pm 0.2$ & 1.2 \\
VII & $-25.4 \pm 0.1$ & $-27.2 \pm 0.1$ & 1.8 \\
VIII & $-26.9 \pm 0.1$ & $-28.3 \pm 0.7$ & 1.5 \\
IX & $-25.4 \pm 0.1$ & $-26.2 \pm 0.1$ & 0.8 \\
X/XI & & & \\
& & & \\
SMB 5.5-6.5 cm & $-26.4 \pm 0.1$ & $-29.5 \pm 0.4$ & 3.0 \\
I & $-27.6 \pm 0.1$ & $-29.8 \pm 1.2$ & 2.2 \\
II & $-26.0 \pm 0.1$ & $-28.3 \pm 0.3$ & 2.3 \\
III & $-25.3 \pm 0.1$ & $-27.4 \pm 0.5$ & 2.2 \\
IV & $-26.6 \pm 0.2$ & $-29.2 \pm 0.8$ & 2.6 \\
V & $-24.6 \pm 0.2$ & $-26.5 \pm 0.1$ & 1.9 \\
VI & $-27.0 \pm 0.2$ & $-27.7 \pm 0.3$ & 0.7 \\
VII & $-26.7 \pm 0.3$ & $-28.9 \pm 0.3$ & 2.1 \\
VIII & $-27.6 \pm 0.5$ & $-28.5 \pm 0.6$ & 0.9 \\
IX & $-26.1 \pm 0.2$ & $-27.1 \pm 0.3$ & 1.0 \\
X/XI & & & \\
\hline
\end{tabular}

Another way to approach this observed fractionation is to consider the "effective $\delta^{13} \mathrm{C}$ " of the two carbons contributed by acetic anhydride, compared to the isotopic composition of the bulk acetic anhydride: $\delta^{13} \mathrm{C}_{\mathrm{OAc}}-\left[\left((\mathrm{N}+2) * \delta^{13} \mathrm{C}_{\text {measured }}-\mathrm{N}^{*} \delta^{13} \mathrm{C}_{\text {true }}\right) / 2\right]$. The $\delta^{13} \mathrm{C}$ difference between total acetate and added acetate, averaged by sample, was: $3 \pm 5 \%$ for SBB $0-1 \mathrm{~cm}, 10 \pm 6 \%$ for SMB $0-0.75 \mathrm{~cm}, 17 \pm 7 \%$ for SMB $0.75-1.5 \mathrm{~cm}$, $20 \pm 9 \%$ for SMB $4.5-5.5 \mathrm{~cm}$, and $23 \pm 10 \%$ for SMB 5.5-6.5 cm. It is unknown why the fractionation seems to increase with depth of origin of the sediment sample, but this may just be a coincidence. Also, different batches of acetic anhydride were used for derivatization of these samples (Alltech $\left(\delta^{13} \mathrm{C}=-27.1 \%\right.$ ) for SMB 0-0.75 cm, 4.5-5.5 $\mathrm{cm}$, and SMB 0-1 cm; and Aldrich $\left(\delta^{13} \mathrm{C}=-23.3 \%\right.$ ) for SMB 0.75-1.5 $\mathrm{cm}$ and 5.5-6.5 $\mathrm{cm}$, so it is unlikely to be a reagent effect. It is possible that side-reactions, including consumption of acetic anhydride by reaction with water, could have occurred in these samples to varying degrees. 
In summary, the observed fractionation associated with formation of acetate derivatives was not of constant magnitude, and therefore it was not possible to apply a simple correction factor to the measured $\delta^{13} \mathrm{C}$ of an acetate and determine the $\delta^{13} \mathrm{C}$ of the original alcohol. For $\delta^{13} \mathrm{C}$ analysis by $\mathrm{irm}$-GC/MS, alcohols were derivatized to trimethyl-silyl ethers, and all on-line $\delta^{13} \mathrm{C}$ data for alcohol biomarkers in this thesis were determined for these compounds (a few exceptions were necessary and have been noted). No fractionation correction was applied, because no carbon-containing bonds are formed or broken, and the contribution of -OTMS carbon is easily subtracted by a mass balance equation.

\subsection{2 $\delta^{13} \mathrm{C}$ Comparison for PCGC Samples: Combusted $\mathrm{CO}_{2}$ and $\mathrm{irm}$-GC/MS Data}

The unpredictable fractionation caused by acetylation makes it difficult to compare the $\delta^{13} \mathrm{C}$ data obtained for $\mathrm{CO}_{2}$ splits of combusted PCGC samples (acetates) and "true" values as determined by irm-GC/MS (-OTMS). This is unfortunate, because if the data were not affected by fractionation, the difference between the two values could be used as an index of the amount of contaminant carbon (i.e. column bleed) contained in the sample. If column bleed is the major source of extra carbon (one measurement of $\delta^{13} \mathrm{C} \sim-35 \%$; assumed $\Delta^{14} \mathrm{C}=-1000 \%$ ) it would be possible to correlate the $\delta^{13} \mathrm{C}$ difference with a relative depletion in $\Delta^{14} \mathrm{C}$ for a specific compound. For example, if the three low $\Delta^{14} \mathrm{C}$ values in SMB $0-0.75 \mathrm{~cm}$ batch \#1 sterols had larger $\delta^{13} \mathrm{C}$ differences, this would support the previous conclusion that the $\Delta^{14} \mathrm{C}$ offset was due to the contribution of a contaminant. However, there are apparently too many complicating factors to use the data in this way. The following two figures show that the amount of scatter observed is much larger than any visible trends in the data. Figure 4.14 compares the $\delta^{13} \mathrm{C}$ difference $\left(\delta^{13} \mathrm{C}_{\mathrm{CO} 2}-\delta^{13} \mathrm{C}_{i r m-G \mathrm{C} / \mathrm{MS}}\right)$ to the amount of total carbon in the combusted samples. Constant contamination might be expected to cause larger isotopic errors in smaller samples, but the data appear rather random. In Figure 4.15, the $\Delta^{14} \mathrm{C}$ difference, compared as the deviation between $\Delta^{14} \mathrm{C}_{\text {sterol }}$ and the average $\Delta^{14} \mathrm{C}$ for the total suite of 
comparable samples, is even less well correlated with $\delta^{13} \mathrm{C}$ offset. The dashed lines in the middle of the figure represent the average $\pm 15 \%$ error bars associated with $\Delta^{14} \mathrm{C}$ measurement precision. Some ${ }^{14} \mathrm{C}$-depleted samples are also ${ }^{13} \mathrm{C}$-depleted, others are ${ }^{13} \mathrm{C}$-enriched.

\section{Figure 4.14}

Sterols: ${ }^{13} \mathrm{C}$ difference between $\mathrm{CO}_{2}$ splits and irm-GC/MS data

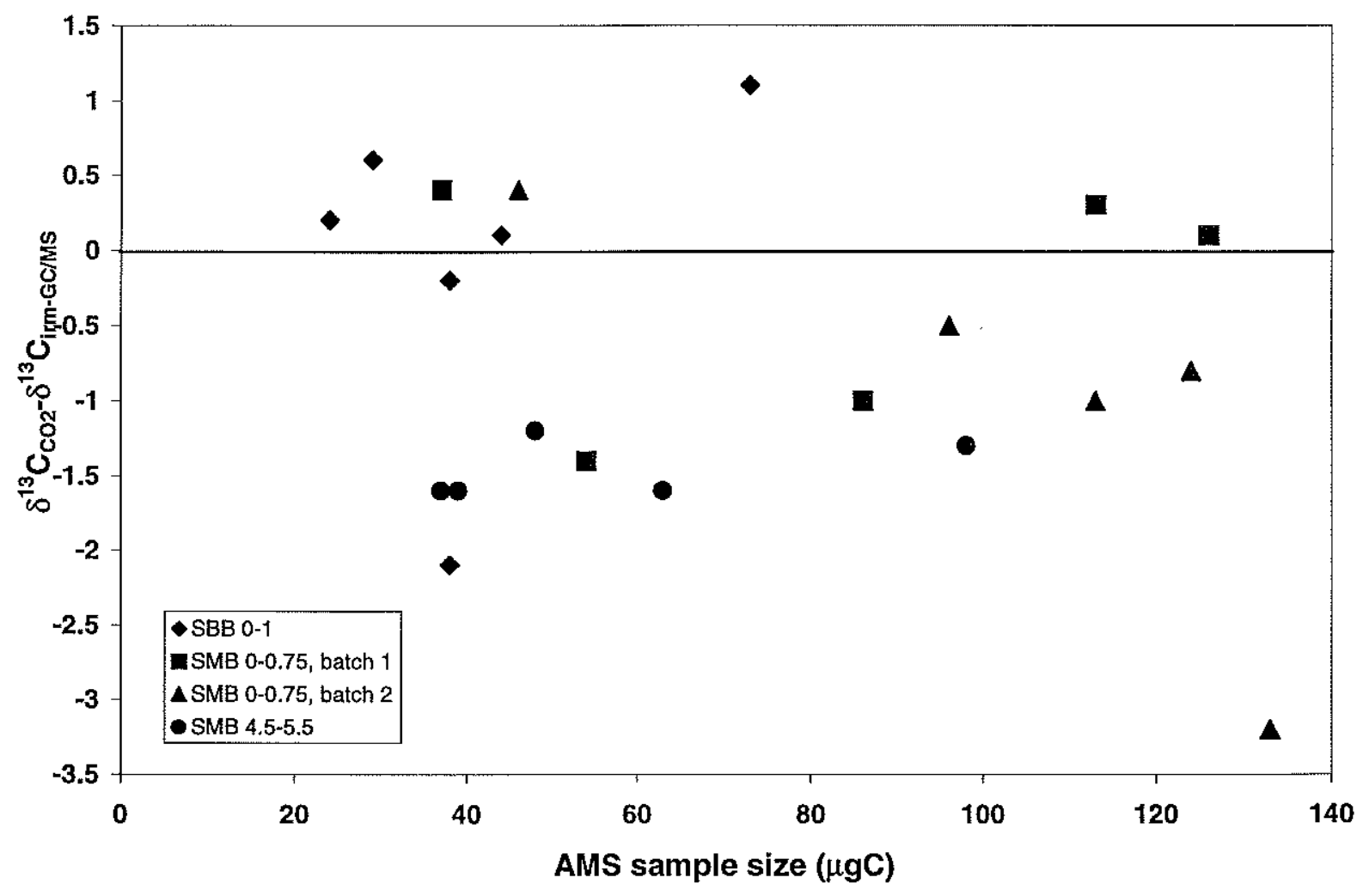


Figure 4.15

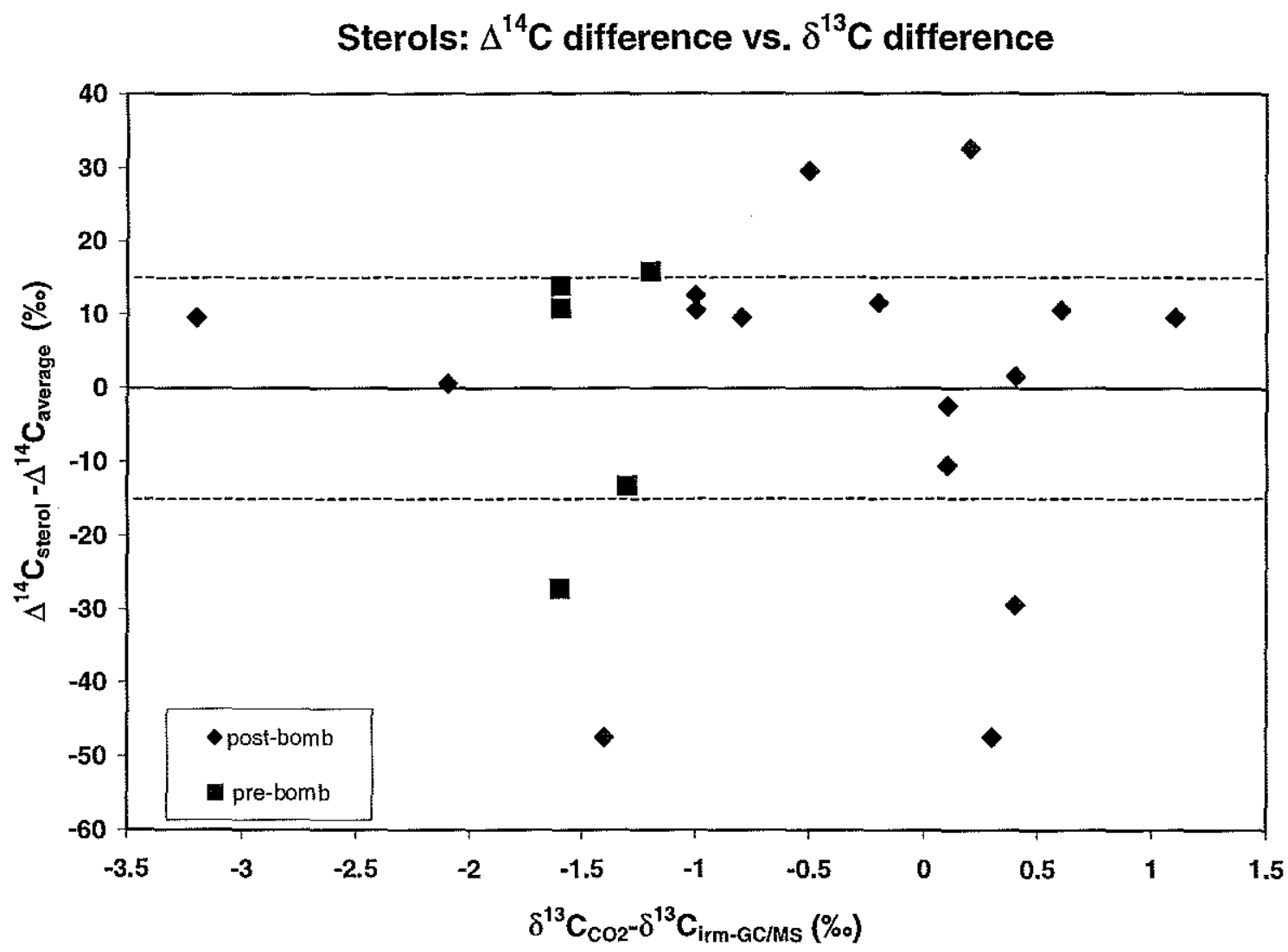

\subsection{3 $\Delta^{14} \mathrm{C}$ Comparison vs. Sample Size}

It is also possible to examine whether the $\Delta^{14} \mathrm{C}$ values for the sterols deviate systematically from the predicted values $\left(\Delta^{14} \mathrm{C}_{\mathrm{DIC}}\right)$ as a function of the size of the sample. In Figure 4.16, this comparison shows that there is no apparent general trend, and only SMB $0-0.75$ batch \#1 has significant outliers. $\left(\Delta \Delta^{14} C=\Delta^{14}\right.$ Csterol $-71 \%$ o for post-bomb samples; $\Delta \Delta^{14} \mathrm{C}=\Delta^{14} \mathrm{Csterol}-(-82 \%$ o $)$ for pre-bomb samples. 
Figure 4.16

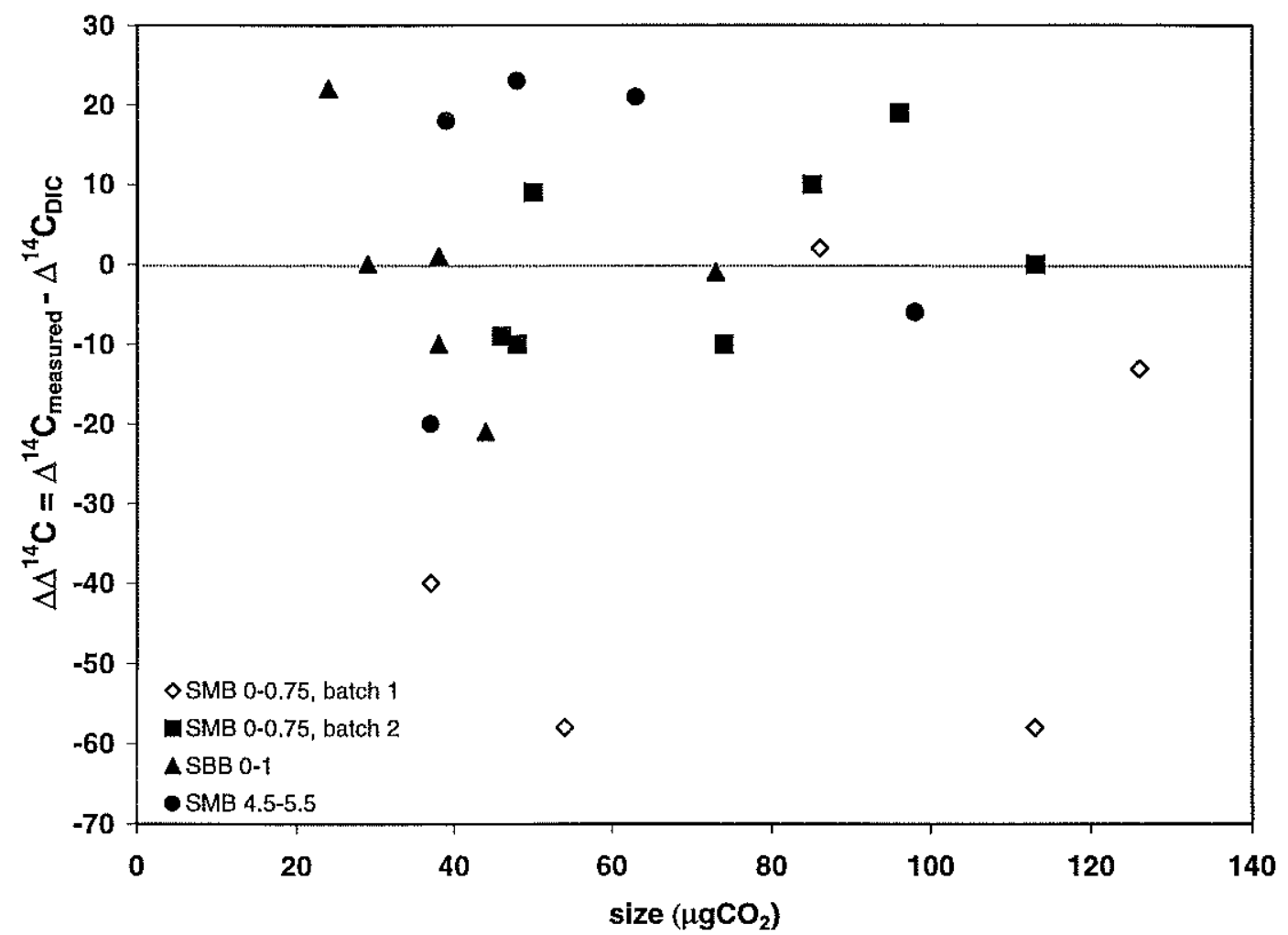

Figure 4.16 The difference between individual $\Delta^{14}$ Csterol and $\Delta^{14} C_{D I C}$ as a function of sample size. There is no uniform bias toward more negative or positive offsets for the smaller samples, although there is more scatter observed. 


\title{
CHAPTER 5
}

\section{RADIOCARBON EVIDENCE FOR AUTOTROPHIC METABOLISM IN MARINE PLANKTONIC ARCHAEA}

\begin{abstract}
Compound-specific radiocarbon analyses of lipids derived from marine planktonic Crenarchaeota suggest these organisms are chemoautotrophic, utilizing dissolved inorganic carbon below the euphotic zone in Santa Monica and Santa Barbara Basins. Stable carbon isotope data indicate these non-thermophilic Archaea may function like the closely related hyperthermophiles in their use of the 3-hydroxypropionate (3-HP) pathway of carbon assimilation. Archaeal autotrophy may be a universal deep-ocean process with significant implications for nutrient and energy cycles.
\end{abstract}




\subsection{INTRODUCTION}

Numerous recent studies document the widespread distribution of archaeoplankton in the World Ocean (e.g. DeLong 1992; Fuhrman and Davis, 1997; Massana et al., 1997; Murray et al., 1998) and raise questions about their metabolic pathways, ecological niches, and impact on marine biogeochemical cycles. The marine planktonic Archaea appear to belong to two distinct groups (Figure 5.1, from DeLong et al., 1998). Group I organisms of the kingdom Crenarchaeota, relatives of the hyperthermophiles, are the dominant Archaea below the euphotic zone, and are also abundant in Antarctic surface waters (DeLong et al., 1994; Murray et al., 1998). Group II Euryarchaeota, relatives of the methanogens and halophiles, seem to be less important quantitatively and are found in some regions of the surface ocean (DeLong, 1992;

Fuhrman and Davis 1997; Massana et al., 1997; van der Maarel et al., 1998).

Archaea are unique in their synthesis of membrane lipids containing polar head groups and hydrophobic tails connected by ether rather than ester linkages. The carbon skeletons of a monolayer membrane are 40 -carbon $\left(\mathrm{C}_{40}\right)$ isoprenoids with a head-head linkage connecting the two $\mathrm{C}_{20}$ halves (Figure 5.2). This biphytane structure is characteristic of the Crenarchaeota (DeRosa et al., 1986; Trincone et al., 1992; Sprott et $a l ., 1997)$. Additional isomers also contain one, two, or three pentacyclic rings. These lipids have been identified in water column suspended particulate matter (Hoefs et al., 1997; DeLong et al.,1998; King et al., 1998), recent sediments (Chappe et al., 1982; Hoefs et al., 1997; King et al., 1998), and in deposits of geologic age (Chappe et al., 1982; Kohnen et al., 1992; Hoefs et al., 1997). The distribution of isomers is quite similar among the samples and environments studied: nearly equal concentrations of the 2- and 3-ring isomers $\left(\mathrm{C}_{40: 2}, \mathrm{C}_{40: 3}\right)$, much less of the 1-ring isomer $\left(\mathrm{C}_{40: 1}\right)$, and a variable amount of the isomer containing no ring structures $\left(\mathrm{C}_{40: 0}\right)$. 
Figure 5.1

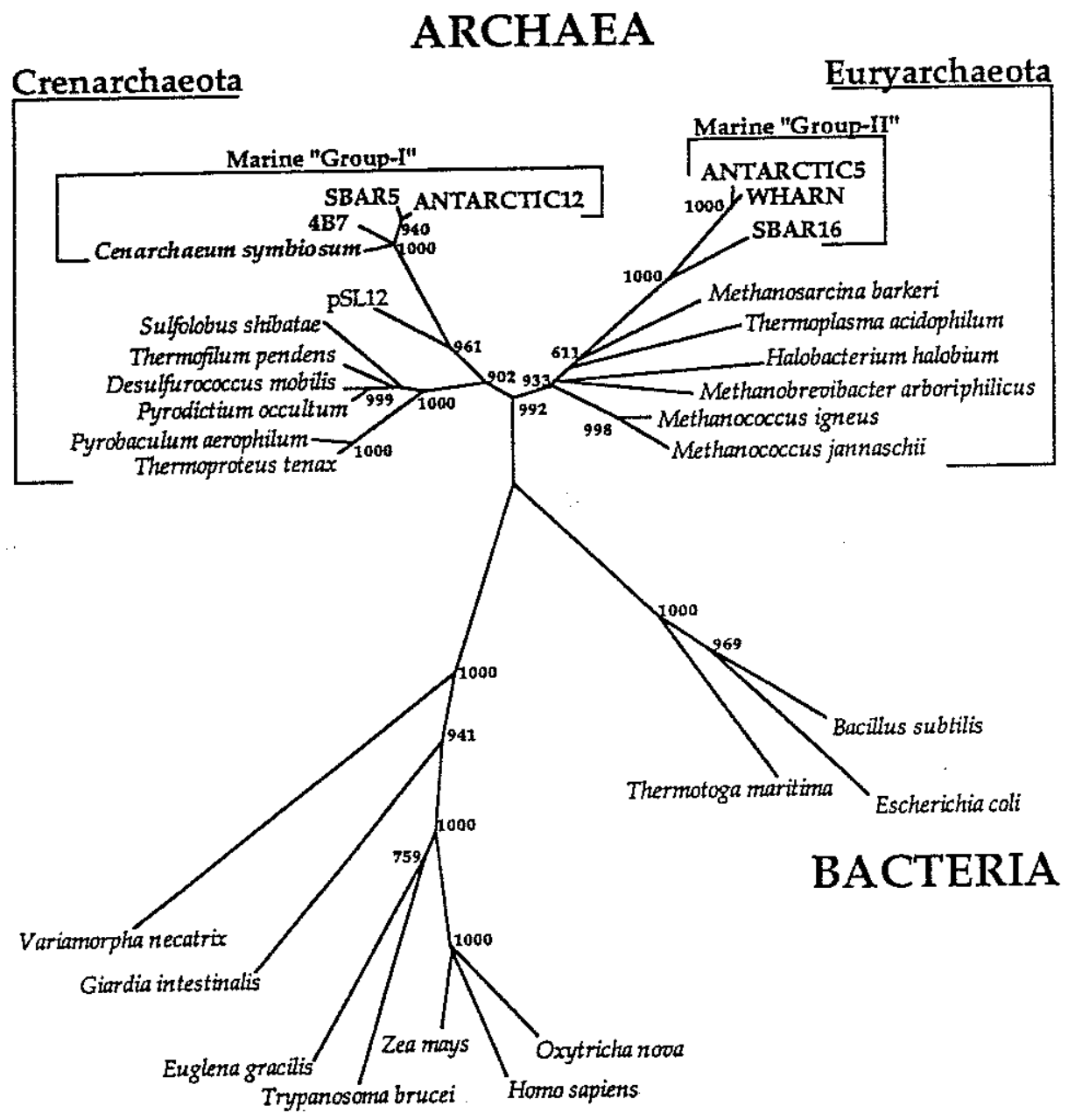

EUCARYA

Figure 5.1 (From DeLong et al., 1998) Phylogenetic division of the three Domains of life, including the division of Archaea into the two major Kingdoms, Crenarchaeota and Euryarchaeota. 


\section{Figure 5.2}

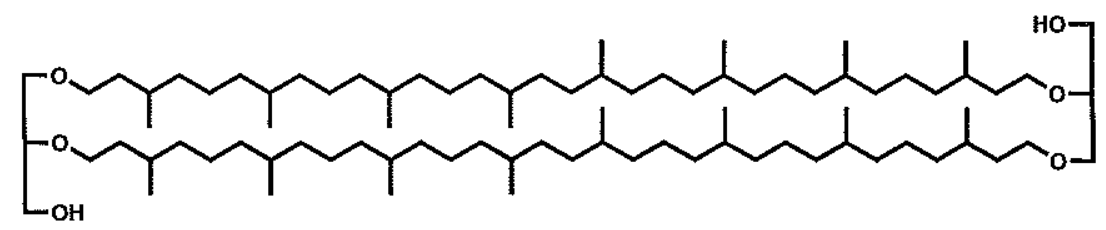

Figure 5.2 Structure of caldarchaeol, an ether-linked $\mathrm{C}_{80}$ isprenoid membrane lipid of thermophilic and marine planktonic Archaea.

To date, two groups also report the stable carbon isotopic values $\left(\delta^{13} \mathrm{C}\right)$ of these compounds. These measurements show the archaeal biphytanes are consistently ${ }^{13} \mathrm{C}$ enriched relative to most sedimentary lipids. Kohnen et al. (1992) determined $\delta^{13} \mathrm{C}$ values between $-20.5 \%$ and $-21.1 \%$ for the three ring-containing isomers and $-23.9 \%$ o for $\mathrm{C}_{40: 0}$ in a sample of Messinian age. Hoefs et al. (1997) report similar values (average $=-21 \pm 1 \% o, \mathrm{n}=23$ ) for the same compounds from a range of environments, including oxic and anoxic water columns and sediments. Overall, these data suggest that the Crenarchaeota responsible for producing these lipids are ubiquitous in marine environments, are physiologically similar, and that growth conditions have remained comparable over geologic time-scales. While many of the samples analyzed by these investigators were sedimentary lipid extracts, it is believed this archaeal carbon is of water column origin, subsequently exported to the sediments. This interpretation is supported by quantitative rRNA hybridization experiments that show a high fraction of total planktonic prokaryotic biomass is archaeal (e.g. 10-30\% below $100 \mathrm{~m}$ in the Santa Barbara Channel (Massana et al., 1997)) and by the presence of archaeal lipids in sediment trap material (e.g. King et al., 1998).

Marine sedimentary lipids commonly have $\delta^{13} \mathrm{C}$ values around -24 to $-28 \%$ (see Chapter 6 for examples). These values usually reflect carbon isotopic depletion relative to cellular biomass. In comparison, the $\delta^{13} \mathrm{C}$ values of the archaeal isoprenoids are quite isotopically heavy. Hoefs et al. (1997) hypothesized two possible explanations: (i) 
heterotrophic uptake of isotopically-enriched carbohydrates and proteins or (ii) significant assimilation of dissolved bicarbonate during autotrophic growth.

The information currently available about metabolic pathways in Crenarchaeota is based on the growth of hyperthermophilic species in culture studies. Marine group I Archaea are a distinct lineage, and 16S rRNA phylogenetic analysis suggests these organisms are tightly related (DeLong, 1998). Crenarchaeal relatives for which the results of metabolic and biochemical investigations have been reported include members of the Sulfolobales, including Sulfolobus acidocaldarius, Sulfolobus metallicus, and Sulfolobus (now Acidianus) brierleyi; and the Thermoproteales, including Thermoproteus neutrophilus. In general these studies reveal a pattern of facultative, but not obligate, chemoautotrophy. For example, the anaerobic T. neutrophilus grows as a heterotroph in the presence of abundant acetate, but it can also fix $\mathrm{CO}_{2}$ directly via the reductive tricarboxylic acid (rTCA) cycle (Schafer et al., 1986, Beh et al., 1993).

The rTCA cycle, however, is only known to operate in anaerobic or microaerophilic organisms, while the marine group I Archaea clearly occupy an oxygenated ocean. Although the Archaea could inhabit anoxic microzones associated with large particles or live strictly within the oxygen minimum, several studies suggest they are free-living planktonic species and are distributed in oxic water columns (e.g. Massana et al., 1998; Fuhrman and Davis, 1997). Recently there has been increased interest in a newly-discovered pathway of autotrophic carbon fixation, the 3hydroxypropionate (3-HP) cycle (Holo, 1989; Strauss and Fuchs, 1993). Early reports of $\mathrm{CO}_{2}$ assimilation via the rTCA pathway in Sulfolobus (Acidianus) brierleyi (Kandler and Stetter, 1981) are now discounted (Ishii et al., 1997). The work of Ishii et al. describes enzymatic activity consistent with 3-HP in A. brierleyi, and this result was recently extended by Menendez et al. (1999) to also include the aerobic Crenarchaeota, Acidianus infernus, Sulfolobus metallicus, and Metallosphaera sedula. It appears there is precedent for speculating that marine group I Crenarchaeota could function as autotrophs regulating 3-HP, but the question of a heterotrophic component must be addressed. 


\subsection{RATionale AND APPROACH}

To investigate the biogeochemical role of planktonic Archaea, we took a compound-specific isotopic approach similar to that used by Hoefs et al. (1997), except that both ${ }^{13} \mathrm{C}$ and ${ }^{14} \mathrm{C}$ concentrations were measured for the $\mathrm{C}_{40}$ side-chains of caldarchaeol. Three sediment horizons were selected for lipid analysis: 0-1 cm in Santa Barbara Basin (SBB), representing the most recent 2-3 years of detrital sedimentation (Schimmelmann and Tegner, 1991); and 0-0.75 $\mathrm{cm}$ and 5.5-8.5 $\mathrm{cm}$ in Santa Monica Basin (SMB), representing the most recent 5-10 years and the late nineteenth century, respectively (Huh et al., 1987; Christensen et al., 1994). Eglinton et al. (1997) have shown that compound-specific ${ }^{14} \mathrm{C}$ analysis of lipid biomarkers yields important new insights into biogeochemical pathways and sources of carbon in the marine environment.

SMB ( $\sim 920 \mathrm{~m}$ deep) and SBB ( $\sim 600 \mathrm{~m}$ deep) have suboxic bottom waters and their sediments experience no bioturbation by benthic infauna. The SMB and SBB field sites were picked because these laminated sediments provide superb historical records of ocean biogeochemistry, and because organic carbon concentrations are high. Both SMB and SBB bottom waters periodically flush with Pacific Intermediate Water entering at the basin sill depths, after which oxygen concentrations rapidly return to low levels $(<0.1$ $\mathrm{mL} / \mathrm{L})$.

The distribution of ${ }^{14} \mathrm{C}$ in the water column is particularly suitable for distinguishing euphotic zone from deep water processes. The ${ }^{14} \mathrm{C}$ concentration of dissolved inorganic carbon $\left(\Delta^{14} \mathrm{C}_{\mathrm{DIC}}\right)$ in the deep basins reflects the isotopic composition of the water entering oven the basin sills. Decay-corrected values for benthic foraminifera indicate SMB deep basin $\Delta^{14} \mathrm{C}_{\mathrm{DIC}}$ has remained constant for at least the last 150 years at a value of $\sim-190 \%$ (Chapter 4 ). Surface water $\Delta^{14} \mathrm{C}_{\mathrm{DIC}}$ should be nearly identical in the two basins due to geographical proximity, constant mixing, and contact with atmospheric $\mathrm{CO}_{2}$. Its value, however, has not been constant over the last century. ${ }^{14} \mathrm{CO}_{2}$ generated by atmospheric testing of nuclear weapons has invaded the DIC pool, producing an enhanced gradient in ${ }^{14} \mathrm{C}$ concentration between surface and deep waters. 
Current mixed-layer $\Delta^{14} \mathrm{C}_{\mathrm{DIC}}$ in SMB is $+70 \%$; the "pre-bomb" value was $\sim-82 \%$ o (Robinson, 1981; Williams et al., 1992; Baumgartner et al., 1996).

The record of human-induced change in ${ }^{14} \mathrm{C}$ distribution is present in the SMB and SBB sedimentary horizons studied here. The ${ }^{14} \mathrm{C}$ concentrations in lipids derived from primary producers (phytoplanktonic sterols), eubacteria (hopanols), and fatty acids (mixed autochthonous sources) in SMB and SBB sediments are all approximately equal to $\Delta^{14} \mathrm{C}$ of surface water DIC at the time of formation (Chapter 6). The range of $\Delta^{14} \mathrm{C}$ values for these lipids from a SMB "pre-bomb" sedimentary horizon is $-75 \pm 19 \%$ o (sterols only), and from the SMB and SBB "post-bomb" sediment water interfaces is +62 $\pm 23 \%$. These values are comparable to the surface water $\Delta^{14} \mathrm{C}_{\text {DIC }}$ record and reflect the products of photoautotrophy as well as the biomass of eukaryotic and prokaryotic heterotrophic consumers.

The implication of these data is that organic carbon cycling in SMB and SBB is dominated by heterotrophic processes. However, the presence of a redox gradient associated with the water column oxycline suggests that there is potential for significant water column chemoautotrophy at the oxic-anoxic interface. This zone is located near both basin floors, beneath the depth of bomb- ${ }^{14} \mathrm{C}$ penetration. Thus the possibility exists to use ${ }^{14} \mathrm{C}$ measurements to identify the products of deep-water chemoautotrophic biomass producers. If the group I planktonic Archaea are as physiologically uniform as $\delta^{13} \mathrm{C}$ and phylogenetic analyses have suggested, their lipid ${ }^{14} \mathrm{C}$ values may be interpretable within this context.

\subsection{RESULTS}

The archaeal lipids analyzed were 40 -carbon-atom $\left(\mathrm{C}_{40}\right)$ isoprenoid hydrocarbon sidechains of caldarchaeol (Figure 5.2), a dibiphytanyldiglycerol tetraether membrane lipid of thermophilic and non-thermophilic Crenarchaeota (DeRosa et al., 1986; Trincone et al., 1992; Sprott et al., 1997). Four $\mathrm{C}_{40}$ isomers (Figure 5.3) were identified 
among the caldarchaeol cleavage products, three cyclic biphytanes (containing 1-3 cyclopentane rings, $\mathrm{C}_{40: 1 c y}, \mathrm{C}_{40: 2 c y}, \mathrm{C}_{40: 3 c y}$ ) and their acyclic isomer, $\mathrm{C}_{40: 0 c y}$ (Hoefs et al., 1997; DeLong et al., 1997). A GC trace of the hydrocarbon fractions obtained after $\mathrm{LiAlH}_{4}$ reduction of the cleaved products is shown in Figure 5.4(a). This sample, from the SBB 0-1 cm sediment horizon, is representative of the isomeric distribution found throughout all samples studied. Concentrations of each isomer for the SBB 0-1 cm, SMB 0-0.75 cm, and SMB 5.5-8.5 cm horizons are shown in Table 5.1.

Figure 5.3

C40:0cy

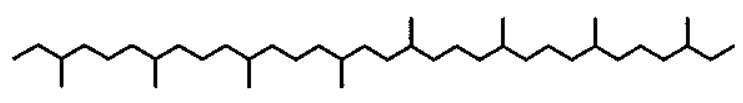

C40:1cy
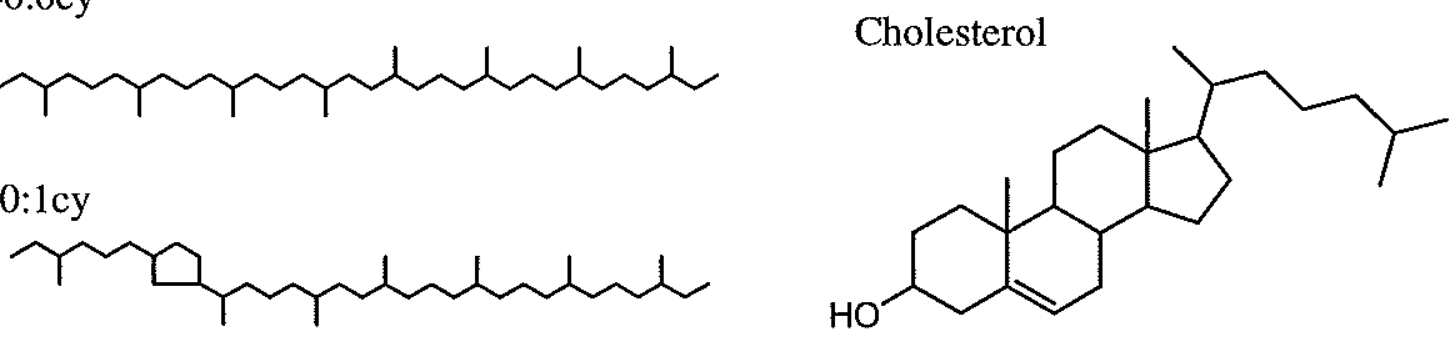

C40:2cy
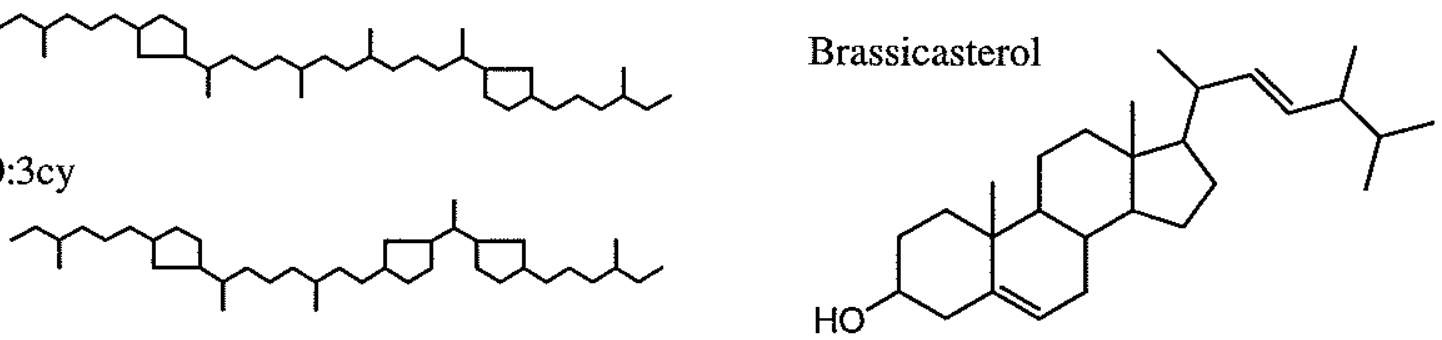

Figure 5.3 Structures of lipids used for compound-specific isotope analysis. 
Table 5.1 $\Delta^{14} \mathrm{C}$ data for individual lipids from surface and pre-bomb sediment horizons as described in the text. Structures of compounds are shown in Figure 5.3. A dash indicates no value was determined.

\begin{tabular}{|c|c|c|c|c|c|c|}
\hline Compound & $\begin{array}{l}\text { Basin / } \\
\text { Interval (cm) }\end{array}$ & $\begin{array}{c}\text { Year of } \\
\text { Deposition }\end{array}$ & $\begin{array}{l}\text { Abundance } \\
(\mu \mathrm{g} / \mathrm{gOC})^{*}\end{array}$ & $\begin{array}{l}\delta^{13} \mathrm{C} \\
(\% o)\end{array}$ & $\Delta^{14} \mathrm{C}(\% o)$ & $\begin{array}{c}\Delta\left(\Delta^{14} \mathrm{C}\right) \dagger \\
(\% \circ)\end{array}$ \\
\hline \multirow[t]{4}{*}{ Brassicasterol } & $\mathrm{SBB} / 0-1$ & 1995 & 420 & -25.9 & $70 \pm 14$ & \\
\hline & $\mathrm{SMB} / 0-0.75$ & 1990 & 400 & -26.6 & $56 \pm 11$ & \\
\hline & SMB / $4.5-5.5$ & 1910 & 100 & $-26.9 \ddagger$ & $-72 \pm 15$ & \\
\hline & & & & & & 142,128 \\
\hline \multirow[t]{4}{*}{ Cholesterol } & $\mathrm{SBB} / 0-1$ & 1995 & 775 & -23.9 & $70 \pm 10$ & \\
\hline & SMB / $0-0.75$ & 1990 & 275 & -24.9 & $69 \pm 13$ & \\
\hline & $\mathrm{SMB} / 4.5-5.5$ & 1910 & 58 & $-24.7 \ddagger$ & $-75 \pm 15$ & \\
\hline & & & & & & 145,144 \\
\hline \multirow[t]{4}{*}{ C40:0cy } & $\mathrm{SBB} / 0-1$ & 1995 & 70 & -21.9 & - & \\
\hline & $\mathrm{SMB} / 0-0.75$ & 1990 & 6 & -21.5 & - & \\
\hline & $\mathrm{SMB} / 5.5-8.5$ & 1863 & 7 & -20.8 & $-123 \pm 35$ & \\
\hline & & & & & & \\
\hline \multirow[t]{4}{*}{ C40:1cy } & $\mathrm{SBB} / 0-1$ & 1995 & 15 & - & - & \\
\hline & $\mathrm{SMB} / 0-0.75$ & 1990 & 0.3 & -21.4 & - & \\
\hline & $\mathrm{SMB} / 5.5-8.5$ & 1863 & 2 & -21.1 & 一 & \\
\hline & & & & & & - \\
\hline \multirow[t]{4}{*}{ C40:2cy } & $\mathrm{SBB} / 0-1$ & 1995 & 69 & -22.1 & $-101 \pm 21$ & \\
\hline & $\mathrm{SMB} / 0-0.75$ & 1990 & 7 & -21.2 & - & \\
\hline & $\mathrm{SMB} / 5.5-8.5$ & 1863 & 9 & -20.3 & $-141 \pm 24$ & \\
\hline & & & & & & 40 \\
\hline \multirow[t]{4}{*}{ C40:3cy } & $\mathrm{SBB} / 0-1$ & 1995 & 67 & -22.5 & $-100 \pm 25$ & \\
\hline & SMB / $0-0.75$ & 1990 & 5 & -21.1 & - & \\
\hline & $\mathrm{SMB} / 5.5-8.5$ & 1863 & 10 & -20.5 & $-121 \pm 21$ & \\
\hline & & & & & & 21 \\
\hline
\end{tabular}

* Micrograms compound per gram total organic carbon.

$\uparrow$ Difference between $\Delta^{14} \mathrm{C}$ values for post-bomb and pre-bomb sample(s).

$\ddagger$ Value reported is from SMB $5.5-6.5 \mathrm{~cm}$. 
Figure 5.4

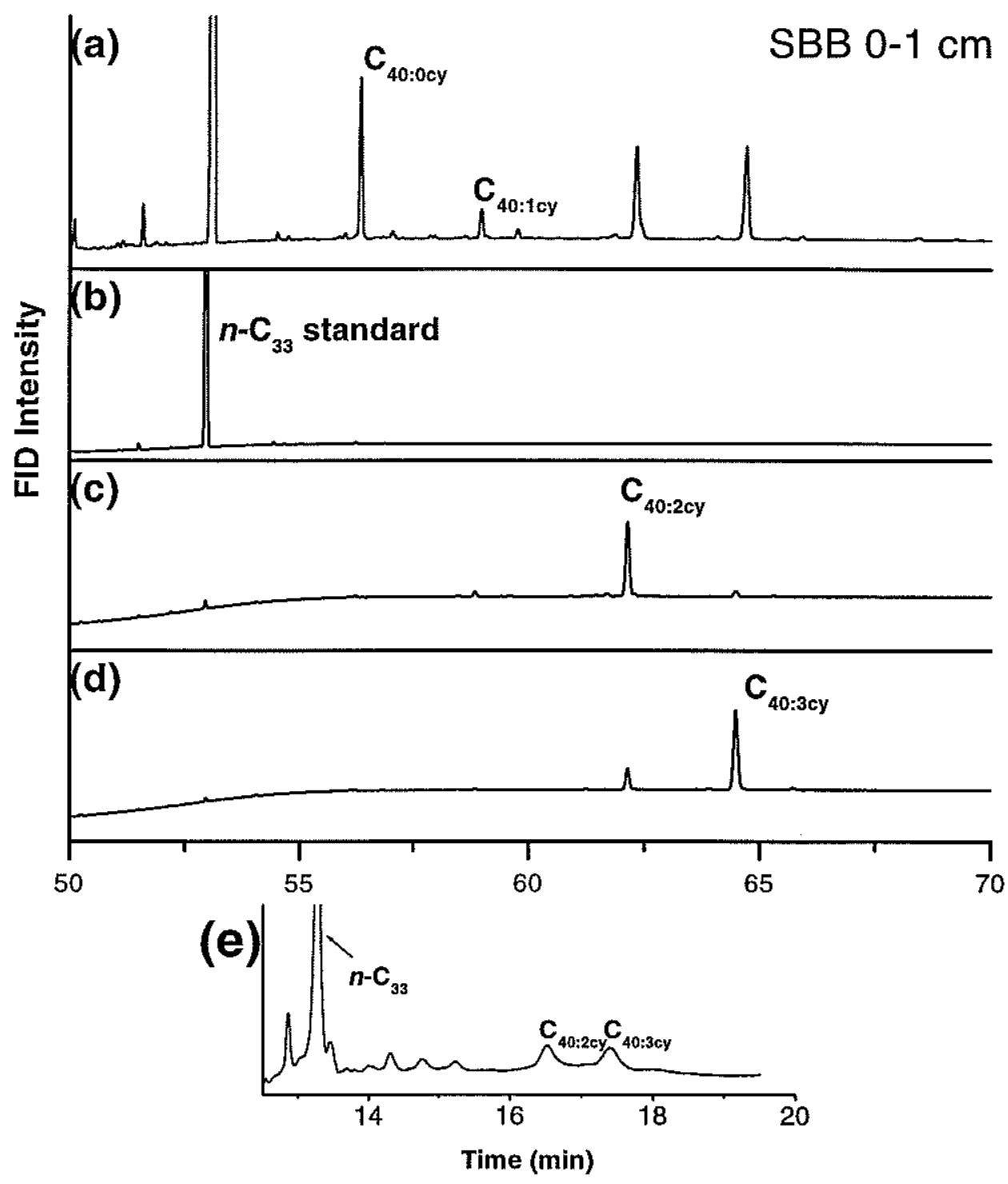

Figure 5.4 Gas chromatograms of SBB 0-1 cm ether lipid fraction (as hydrocarbons). (a) total mixture; (b) $n$ - $\mathrm{C}_{33}$ standard as recovered by PCGC; (c) $\mathrm{C}_{40: 2 \mathrm{cy}}$ as recovered by PCGC; (d) $\mathrm{C}_{40: 3 c y}$ as recovered by PCGC; (e) FID output for total mixture during PCGC separation on the 1-m multi-capillary column. 
Preparative capillary gas chromatography (PCGC), as described in detail in Eglinton et al. (1996), was developed to achieve separation and purification of biomarker lipids in sufficient quantity for ${ }^{14} \mathrm{C}$ measurement by AMS. Small sample AMS analysis still requires a minimum of $20 \mu \mathrm{gC}$ for reliable results; therefore water-column sampling was not an option for this study (requires filtration of $>10,000 \mathrm{~L}$ seawater). The low concentrations of biphytanes and the available quantities of sediment precluded measurement of ${ }^{14} \mathrm{C}$ concentrations in the surface SMB horizon; however, $\delta^{13} \mathrm{C}$ values were obtained. $\delta^{13} \mathrm{C}$ values of the archaeal biphytanes in all samples ranged from -20.3 to $-22.5 \%$ (Table 5.1). These results are comparable to previous reports by Kohnen et al. (1992) and Hoefs et al. (1997) and suggest similar formation conditions.

PCGC separation of high molecular weight (> 30 carbons) lipids using a typical $0.53 \mathrm{~mm}$ i.d. "megabore" capillary column (Eglinton et al., 1996) is inefficient. Long run times are required and sample recovery is typically low for high-boiling compounds. These factors were expected to cause severe complications for the separation of $\mathrm{C}_{40}$ isoprenoid hydrocarbons. An alternative approach was taken to circumvent these problems. A 1-m, Alltech ${ }^{\circledR}$ Multicapillary Column (900 microscopic capillaries encased in a $5-\mathrm{mm}$ diameter bundle) was used. This column greatly reduced the necessary run time per PCGC injection, and it required only minor sacrifices in peak resolution. Figure 5.4(e) shows a single PCGC injection of the SBB $0-1 \mathrm{~cm}$ archaeal lipid fraction. The resolution is comparable to a typical high-pressure liquid chromatography (HPLC) chromatogram. The $n-\mathrm{C}_{33}$ recovery standard, $\mathrm{C}_{40: 2 \mathrm{cy}}$ and $\mathrm{C}_{40: 3 c y}$ archaeal biphytanes were separated from the mixture, and aliquots of the individual compounds were re-analyzed by conventional high-resolution GC to check for adequate peak identification and purity (Figure 5.4(b,c,d)). There is some cross-over of the $\mathrm{C}_{40: 2 c y}$ isomer into the $\mathrm{C}_{40: 3 c y}$ fraction (about 15\%), but this was not expected to affect the isotopic results significantly. The purified lipids were combusted to $\mathrm{CO}_{2}$ and reduced to graphite for ${ }^{14} \mathrm{C}$-AMS analysis at the National Ocean Sciences AMS facility (NOSAMS). Carbon recoveries for the archaeal lipids resulted in samples containing only 20-30 $\mu \mathrm{g}$ carbon, so particular care 
was taken to determine the ${ }^{14} \mathrm{C}$ content of these samples according to the procedures described in Pearson et al. (1998).

Two recovered samples of the internal standard, $n-C_{33}$ alkane, yielded $\Delta^{14} \mathrm{C}$ values of $+194 \pm 14 \%$ and $+125 \pm 8 \%$. The sample with $\Delta^{14} \mathrm{C}=+194 \%$ o was recovered and analyzed with the SBB horizon, while the sample with $\Delta^{14} \mathrm{C}=+125 \%$ was recovered and analyzed with a trial sample (Arabian Sea sediment) not described here. This Arabian Sea sample is significant, however, in that it was the first use of the Alltech $®$ multicapillary column. Contamination by column bleed $\left(\Delta^{14} \mathrm{C}=-1000 \%\right.$, assumed value $)$, if any, was expected to be highest for this set of recovered lipids. In comparison, the independently measured $\Delta^{14} \mathrm{C}$ value for $n-\mathrm{C}_{33}$ alkane, $+146 \%$, is in reasonably good agreement with the samples recovered by PCGC separation, although the $n-\mathrm{C}_{33}$ recovered with the Arabian Sea sample may be biased toward negative $\Delta^{14} \mathrm{C}$ values by the presence of column bleed. A complication is introduced by the presence of a small amount of naturally-occurring $n-\mathrm{C}_{33}$ alkane (from $n$ - $\mathrm{C}_{33}$-diol?) in the samples. This material, plus other co-eluting compounds, may serve to account for some of the $21-48 \%$ offset between the "true" $\Delta^{14} \mathrm{C}$ of the standard and the values measured for recovered fractions. The $\mathrm{C}_{40: 2 c y}$ and $\mathrm{C}_{40: 3 c y}$ archaeal lipids are in a "cleaner" region of the chromatogram and are probably less affected by the presence of co-eluting peaks. Nonetheless, a conservative estimate of the error in accuracy of the archaeal $\Delta^{14} \mathrm{C}$ measurements would be $40-50 \%$; an optimistic estimate would be $20 \%$, nearly equivalent to the measurement precision.

The $\Delta^{14} \mathrm{C}$ values measured for the SBB $0-1 \mathrm{~cm}$ and SMB $5.5-8.5 \mathrm{~cm}$ archaeal lipids are shown in Table 5.1. For the SBB surface horizon, the two $\mathrm{C}_{40}$ compounds yielded the same ${ }^{14} \mathrm{C}$ concentration, -100\%o. In the SMB deeper, pre-bomb horizon, more scatter was observed $(-121 \%$ o to $-141 \%$ ), although these values are all equivalent within measurement error. The large error bars associated with these values also render both sets of measurements (SBB and SMB) statistically equivalent, although the SMB data do seem to be systematically more ${ }^{14} \mathrm{C}$-depleted than the SBB data. 
In Table 5.1, $\Delta^{14} \mathrm{C}$ and $\delta^{13} \mathrm{C}$ values for individual sterols obtained from $0-1 \mathrm{~cm}$ and pre-bomb sedimentary horizons are also reported for comparison purposes. The sterols (structures, Figure 4.3) include a diatom sterol, brassicasterol, and cholesterol, a mixed zooplanktonic and phytoplanktonic product (Volkman, 1986). (For sterols, the pre-bomb interval used was SMB $4.5-5.5 \mathrm{~cm}$.) Figure 5.5 shows the 2-dimensional carbon isotope distribution $\left(\Delta^{14} \mathrm{C}\right.$ vs. $\left.\delta^{13} \mathrm{C}\right)$ for archaeal and planktonic lipids from SMB and SBB. The large dashed-line boxes surrounding the sterol values represent the total range of results obtained for sterols from both pre-bomb (lower box, $n=5$ ) and postbomb (upper box, $\mathrm{n}=19$ ) sedimentary horizons (Chapter 4) from SMB and SBB. The solid horizontal lines running through these boxes are the values for SMB surface water $\Delta^{14} \mathrm{C}_{\mathrm{DIC}}$ in 1996 (upper line, $\Delta^{14} \mathrm{C}=+71 \%$, 1996 (Chapter 4)) and for Southern California Bight surface water $\Delta^{14} C_{\text {DIC }}$ prior to atmospheric weapons testing (average $=-82 \%$; Robinson, 1981; Williams et al., 1992; Baumgartner et al., 1996). The SBB post-bomb archaeal lipids are significantly ${ }^{14} \mathrm{C}$-depleted relative to these surface water values and to the sterol measurements. The SMB pre-bomb lipids show a smaller difference relative to surface water $\Delta^{14} \mathrm{C}_{\mathrm{DIC}}$, but one which also may be significant. The main feature in the data is the relative similarity of the post-bomb and pre-bomb values. 
Figure 5.5

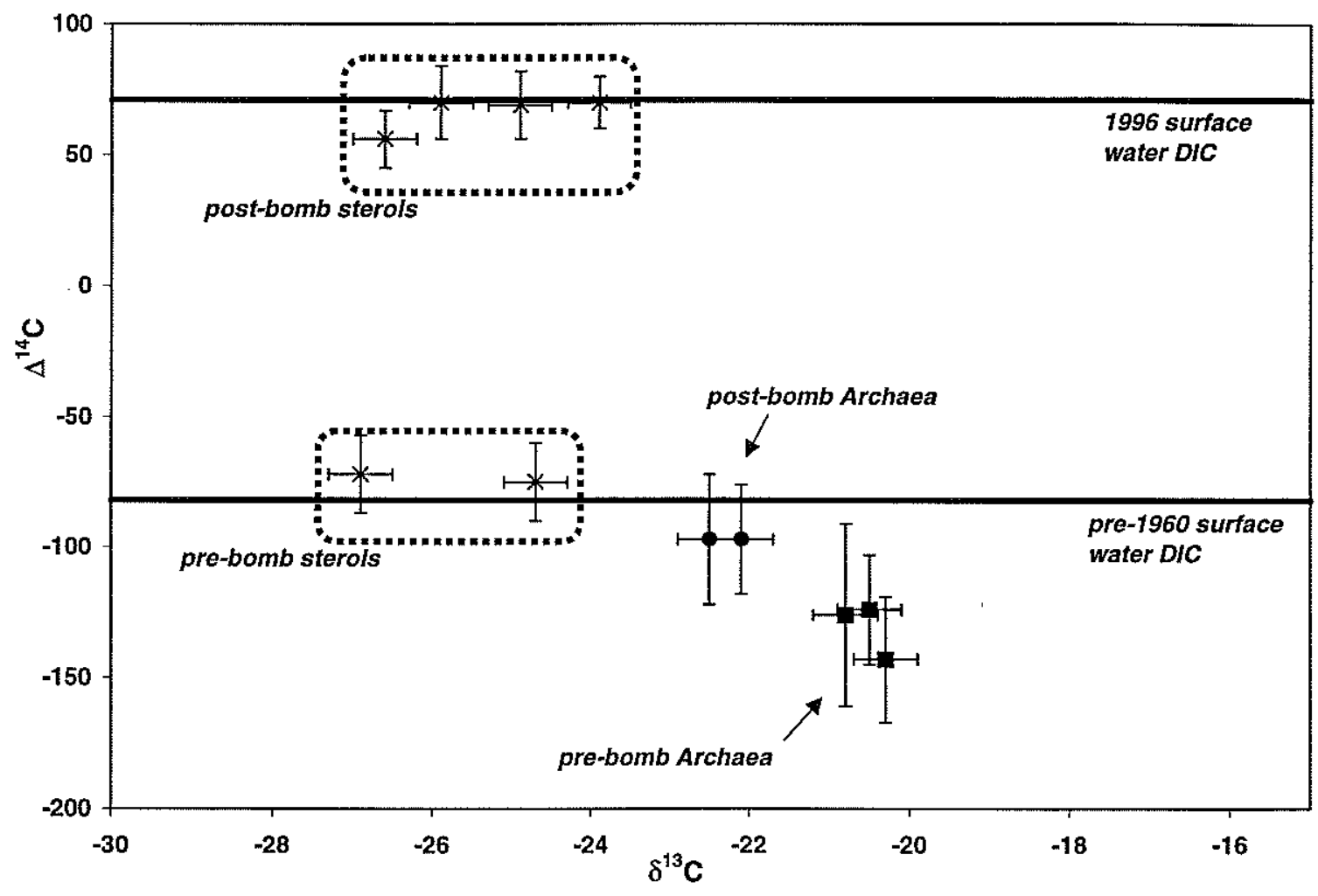

Figure 5.5 $\Delta^{14} \mathrm{C}$ vs. $\delta^{13} \mathrm{C}$ for sterols (crosses) and archaeal ether lipids, SBB $0-1 \mathrm{~cm}$ (circles), SMB 5.5-8.5 cm (squares). Also included are solid lines showing the $\Delta^{14} \mathrm{C}$ of surface water DIC during the 1990s (upper line) and prior to atmospheric nuclear weapons testing (lower line). 


\subsection{DISCUSSION}

\subsubsection{Radiocarbon Data}

\subsubsection{Data Comparison}

The change observed for sterol $\Delta^{14} \mathrm{C}$ values between the early part of this century and the present day reflects the incorporation of bomb- ${ }^{14} \mathrm{C}$ into the surface ocean DIC pool. Phytoplankton fix carbon with the same $\Delta^{14} \mathrm{C}$ as euphotic zone DIC; and heterotrophic consumers conserve this $\Delta^{14} \mathrm{C}$ signature through their consumption of fresh organic biomass. These compound-specific measurements show the sterol $\Delta^{14} \mathrm{C}$ values correlate with the pre-bomb surface water $\Delta^{14} C_{\text {DIC }}$ in this region $(-82 \%$ ) and a surface water DIC sample $(+71 \%$ ) taken in 1996 . The results confirm that phytoplanktonic sterols from both SMB and SBB trace the approximately $150 \%$ increase in carbon source $\Delta^{14} \mathrm{C}$ during the latter half of the twentieth century (Figure 5.5).

In sharp contrast to the sterols, the ether-lipid $\Delta^{14} \mathrm{C}$ data do not show a large transition between pre-bomb and post-bomb sedimentary horizons. The archaeal lipids remain more ${ }^{14} \mathrm{C}$-depleted than the average sterols, regardless of depth in sediment or geographic origin. The SBB biphytanes are $21-40 \%$ enriched in ${ }^{14} \mathrm{C}$ compared to the SMB samples (Table 5.1), but this may be due to differences in the $\Delta^{14} C_{\text {DIC }}$ profiles of these basins, as explained below, rather than to uptake of small amounts of bomb- ${ }^{14} \mathrm{C}$ influenced biomass. In all cases, the data reflect the isotopic composition of the carbon source for the organisms producing these lipids, not in-situ ${ }^{14} \mathrm{C}$ decay. The $\Delta{ }^{14} \mathrm{C}$ values have been corrected for ${ }^{14} \mathrm{C}$ decay since deposition, and they are also, by definition, corrected for biologically induced isotope fractionation effects. 
Previous observations of ${ }^{14} \mathrm{C}$ depletion in bulk suspended and sinking particulate organic carbon (POC) (e.g. Druffel et al., 1992; Druffel et al., 1996) and benthic animals (e.g. Pearcy and Stuiver, 1983) have been explained in terms of two alternate hypotheses. The first hypothesis invokes adsorption of ${ }^{14} \mathrm{C}$-depleted dissolved organic carbon (DOC) to the particles, perhaps followed by bacterial consumption (Druffel et al., 1996). The second involves incorporation of deep water-column DIC, either through the anaplerotic reactions of benthic heterotrophs or by chemoautotrophic uptake (Rau et al., 1986).

\subsubsection{DOC Incorporation Model}

The DOC $\Delta{ }^{14} \mathrm{C}$ distribution can be modeled in terms of a two-component mixture (e.g. Santschi et al., 1995; Bauer et al., 1998; Aluwihare, 1999), in which DOC consists of a portion of recently-synthesized algal exudate (probably a carbohydrate polymer, Aluwihare et al., 1997) combined with a refractory, ${ }^{14} \mathrm{C}$-poor, component. We do not have a complete ${ }^{14} \mathrm{C}$ data set with which to apply this model to analysis of our SMB and SBB data; however, with some reasonable approximations, the following analysis is possible.

Bauer et al. (1995) report $\Delta^{14} \mathrm{C}_{\mathrm{DOC}}$ in SMB deep water $=-462 \%$. In addition, waters of the central and eastern North Pacific have $\Delta^{14} C_{D O C}$ values between $-400 \%$ and $-500 \%$ between $400-1000 \mathrm{~m}$ (Williams and Druffel, 1987; Druffel et al., 1992; Bauer et al., 1998). Since SBB deep waters also flush with Pacific Intermediate Water, it is reasonable to assume deep basin $\Delta^{14} \mathrm{C}_{\mathrm{DOC}}$ for $\mathrm{SBB}$ is also $\simeq-460 \%$. This is similar to SMB, and for the purpose of these calculations, $-460 \%$ will be used for both locations. Of this total DOC, the modern (post-bomb) fraction will have $\Delta \Delta^{14} \mathrm{C}_{\text {mod }} \simeq+70 \%$. Aluwihare (1999) estimates this component comprises 2-3\% of the total DOC, while Santschi et al. (1995) reported the modern component is 3-5\% of total DOC. A mass balance calculation using $3 \%$ modern ${ }^{14} \mathrm{C}$ leaves the $97 \%$ (refractory) component $\simeq-476 \%$. If DOC uptake is the cause of the ${ }^{14} \mathrm{C}$-depleted archeal biomass, then some portion of the refractory fraction $(-476 \%)$ must be bioavailable. 
The archaeal lipid $\Delta^{14} \mathrm{C}$ data can now be analyzed as follows. It was previously assumed that due to lateral mixing of similar water masses, the archaeal populations in the two basins are likely to be similar physiologically, even if the exact conditions of growth are slightly different due to environmental factors. If that were true, it would be reasonable to assume one basin's population is not more or less suited to the consumption of refractory DOC than the other (especially in the presence of a "fresh" DOC component). Heterotrophic growth of Archaea in SBB requires 64-70\% utilization of "fresh" $(+70 \%$ ) photosynthetic products and 30-36\% utilization of refractory DOC $\left(-476 \%\right.$ ) to produce biomass with $\Delta^{14} \mathrm{C}=-100 \%$. Altering the mass balance calculation to reflect pre-bomb photosynthetic biomass consumption, the Archaea from the deeper SMB interval would have consisted of $80-95 \%$ "fresh" and 5-10\% refractory material to yield $\Delta^{14} \mathrm{C}=-130 \%$ ).

These results indicate DOC incorporation is an unlikely mechanism to explain the "old" archaeal ${ }^{14} \mathrm{C}$ concentrations for three reasons. The first was stated above - it is hard to explain metabolically why the percentage of refractory DOC utilized would be different between the two locations. Second, the relative utilization of refractory DOC in the two basins is in the opposite sense to what would be expected. SBB receives a higher export carbon flux than SMB (Eppley, 1992), and therefore the SBB water column Archaea have a greater supply of labile substrate to utilize in preference to refractory DOC. Instead, the data show a higher percentage of "old" carbon in the SBB lipids. However, the third and most persuasive argument is that such high DOC consumption results in an unreasonable DOC turnover rate. Even assuming very slow growth of planktonic Archaea $\left(0.01 \mathrm{~d}^{-1}\right)$, the estimate of $10^{5}$ archaeal cells $/ \mathrm{mL}$ (Massana et al., 1997 ) with $0.5 \times 10^{-12} \mathrm{gC} /$ cell would consume $5 \times 10^{-7} \mathrm{gC} / \mathrm{L} / \mathrm{day}$. If $5-36 \%$ of the carbon in archaeal biomass is derived from refractory DOC $(40 \mu \mathrm{M})$, then only $\sim 3 \times 10^{3}$ to $2 \times 10^{4}$ days would be needed for the Archaea to consume all the DOC in one liter of seawater. This is much more rapid than the average residence time of refractory DOC, which is thousands of years $\left(\sim 2 \times 10^{6}\right.$ days $)$. 


\subsubsection{DIC Incorporation Model}

The second hypothesis to explain benthic ${ }^{14} \mathrm{C}$ depletion is the uptake of ${ }^{14} \mathrm{C}$ depleted DIC at depth via anaplerotic $\beta$-carboxylation reactions (Rau et al., 1986; Rau 1991). The carboxylation of pyruvate to form oxaloacetate in the citric acid cycle is one such example; it can provide up to $10 \%$ of total biomass- $\mathrm{C}$ in heterotrophic consumers (Sorokin, 1978). Both this hypothesis and the DOC-incorporation hypothesis have been invoked as mechanisms for causing ${ }^{14} \mathrm{C}$ depletion in the bulk POC. However, they usually assume this "old" carbon is distributed uniformly throughout the particle or at least throughout the fraction of living biomass. A variant of the second hypothesis is proposed here: certain prokaryotic species in the marine water column, including group I Archaea, function as chemoautotrophs and assimilate nearly $100 \%$ of their biomass from DIC below the euphotic zone. This would concentrate ${ }^{14} \mathrm{C}$-depleted carbon in the products of some species (Archaea), leaving the lipids (sterols, fatty acids) of other organisms unaltered in ${ }^{14} \mathrm{C}$ concentration, even at depth. This explanation is the most consistent with our results.

In the case of group I planktonic Archaea, this amounts to estimating that $\geq 45 \%$ of the carbon in SMB (pre-bomb) archaeal lipids came from deep water DIC $\left(\Delta^{14} \mathrm{C}=\right.$ $-190 \%$, while nearly $100 \%$ of biomass carbon in SBB must come from deep water DIC $\left(\Delta^{14} \mathrm{C} \simeq-100 \%\right.$ (WOCE NOSAMS Data Report 94-093, 1994). This approach is oversimplified, in that it considers only two endmembers: deep basin and surface waters.

An alternative approach to looking at this question also assumes $100 \%$ of the archaeal biomass in both basins is fixed from DIC. If the water column profile of $\Delta^{14} \mathrm{C}_{\text {DIC }}$ is known, then a "14 C-projection depth" can be found. This is the depth at which $\Delta \Delta^{14} C_{\text {biphytane }}=\Delta^{14} C_{D I C}$, and it is the water column depth from which the average (integrated) archaeal biomass appears to originate. The water column profile of $\Delta^{14} \mathrm{C}_{\mathrm{DIC}}$ in the California Bight $\left(34^{\circ} 34.9^{\prime} \mathrm{N}, 126^{\circ} 24.0^{\circ} \mathrm{W}\right.$, WOCE NOSAMS Data Report 94-093, 1994) is shown in Figure 5.6(a) and (b) for Santa Barbara and Santa Monica Basins, respectively. The profiles in Figure 5.6 eliminate the WOCE early 1990 s surface water 
$(1.5 \mathrm{~m})$ measurement and instead include our measurement of SMB 1996 mixed layer $\Delta^{14} \mathrm{C}_{\text {DIC }}(+71 \%$ o $)$. Profiles are also adjusted to reflect deep basin $\Delta^{14} \mathrm{C}_{\mathrm{DIC}}$ limitations controlled by the water flushing over the basin sills; water in the deep basins cannot be more ${ }^{14} \mathrm{C}$-depleted than its sill-water source. Figure 5.6(c) and (d) show the corresponding $\mathrm{O}_{2}$ and $\mathrm{NO}_{2}{ }^{-}$(SBB only) concentration profiles for these basins (CalCOFI Database, http://nemo.ucsd.edu; Sholkovitz, 1972). The large arrows connecting the two sides of the figure point to the archaeal lipid $\Delta^{14} \mathrm{C}$ "projection depths". This representation shows that average SBB archaeal biomass originates from a water column depth of 400-550 m, while SMB Archaea apparently grow about 100 meters deeper. In both basins the Archaea appear to live just above the depth where $\mathrm{O}_{2}$ concentration reaches undetectable levels. The Archaea may be chemolithoautotrophs utilizing the flux of reduced substrates at this redox interface.

In this discussion, it is assumed that the archaeal lipids reflect biomass produced in the water column. This assumption is based on the previous observation of free-living planktonic group I Archaea in the Santa Barbara Channel (Massana et al., 1997). If, however, the SMB and SBB lipids reflect in-situ sedimentary production by as yet unidentified archaeal groups, this could affect the data interpretation. It is unlikely that the SBB lipids reflect in-situ production, however, because the $\Delta^{14} \mathrm{C}$ value $(\sim-100 \%)$ is equal to the minimum expected $\Delta^{14} \mathrm{C}$ for bottom water DIC. Below a few $\mathrm{mm}$ depth in the sediment, respiration-derived $\mathrm{CO}_{2}$ will cause the $\Delta^{14} \mathrm{C}$ value of pore-water $\mathrm{DIC}$ to be $>-100 \%$ due to the presence of bomb $-{ }^{14} \mathrm{C}$. No pore-water $\Delta^{14} \mathrm{C}$ data are currently available for SBB sediments to confirm this hypothesis, but SMB pore water DIC indeed shows a $70 \%$ enrichment in $\Delta^{14} \mathrm{C}$ by $2 \mathrm{~cm}$ depth (Bauer et al., 1995).

The same type of argument can be applied to argue against significant archaeal biomass production within "anoxic microenvironments" of water column particulate matter. While it is more likely that a higher concentration of reduced inorganic substrates (e.g. $\mathrm{NH}_{4}{ }^{+}, \mathrm{S}^{2-}$ ) would be available to fuel chemoautotrophic carbon fixation, the DIC in these microenvironments would also contain respired $\mathrm{CO}_{2}$, and the $\Delta^{14} \mathrm{C}_{\text {DIC }}$ values would be greater than the background water-column $\Delta^{14} \mathrm{C}_{\mathrm{DIC}}$ value. 
Figure 5.6

(a)

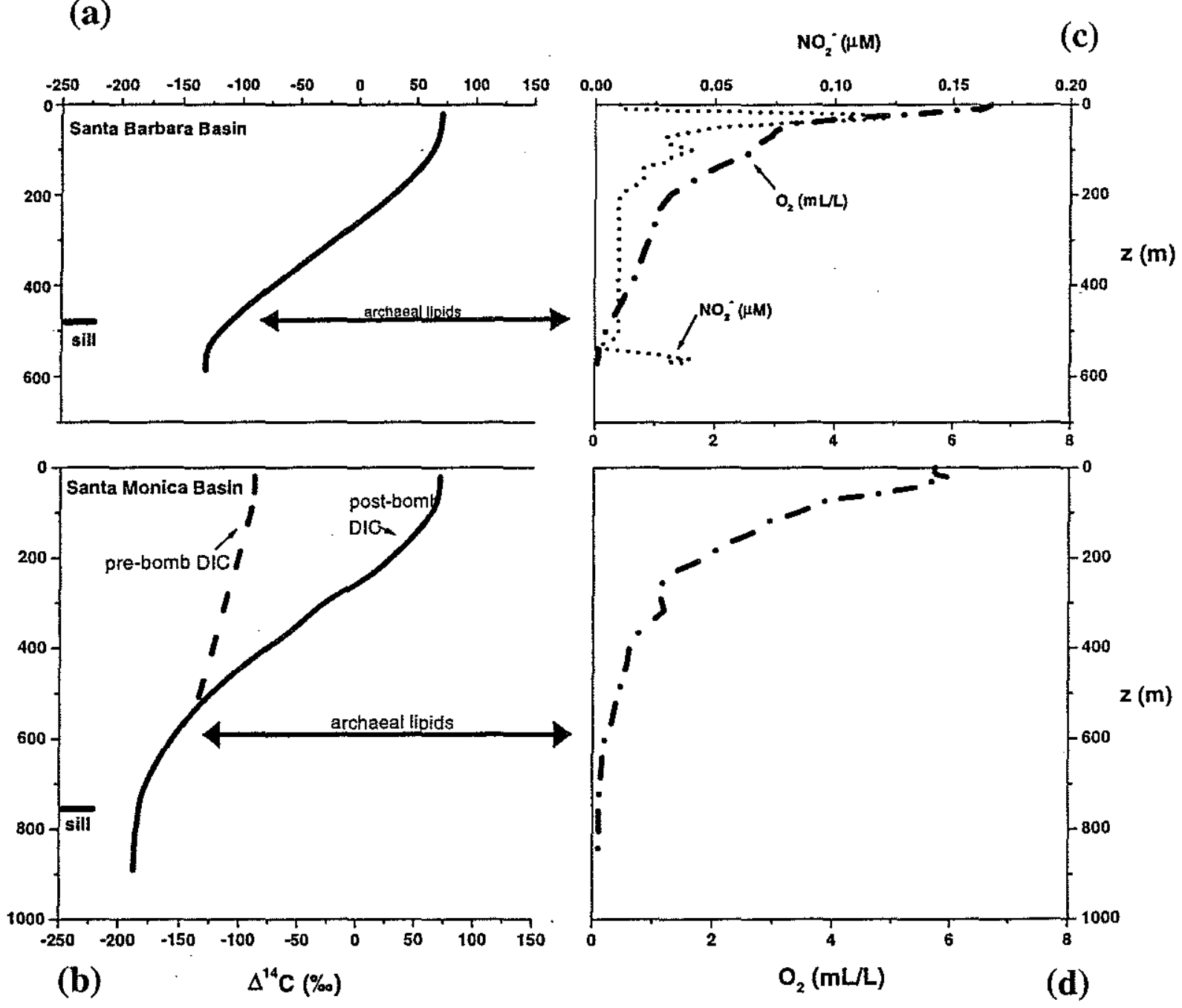

Figure 5.6 Comparison of SMB and SBB $\Delta^{14} \mathrm{C}_{\mathrm{DIC}}$ and water column $\mathrm{O}_{2}$ and $\mathrm{NO}_{2}^{-}$ profiles. SBB is shown in the upper section of the figure, SMB in the lower section. Wide horizontal arrows point to the " ${ }^{14} \mathrm{C}$-projection depths" of archaeal biomass production and the corresponding regions of the nutrient profiles. 


\subsubsection{Energy Source for Chemoautotrophy}

While it is possible the archaeal species found in SBB and SMB are not metabolically representative of the majority of oceanic strains, prior detection of group I planktonic Archaea (or archaeal lipids) in the oxygen-rich surface waters off Palmer station, Antarctica (DeLong et al., 1994; Murray et al., 1998), in deep samples from both the Atlantic and Pacific basins (Fuhrman and Davis, 1997), and in the Santa Barbara Channel (Massana et al., 1997) suggests the non-thermophilic marine Archaea are oxygen tolerant. Here we assume that the close phylogenetic association of group I strains SBAR5 (Santa Barbara), and ANT12 (Antarctic) (Figure 5.1) indicates group I Crenarchaeota are functionally similar in their metabolic systems. Although this is quite uncertain, we presently lack sufficient evidence to suggest otherwise.

The availability of a critical redox partner may determine the extent of archaeal biomass production. The ubiquity of group I Archaea suggests the inorganic electron donor is widely available and can be oxidized by $\mathrm{O}_{2}$. Ammonia is the reduced species most likely to fulfill these criteria. Degradation of organic matter releases $\mathrm{NO}_{3}{ }^{-}$and $\mathrm{NH}_{4}{ }^{+}$to the water column. $\mathrm{NO}_{3}{ }^{-}$and $\mathrm{NH}_{4}{ }^{+}$can both supply nutrient nitrogen for most organisms, but $\mathrm{NH}_{4}{ }^{+}$oxidation can also supply energy for chemoautotrophy. Oxidation of $\mathrm{NH}_{4}{ }^{+}$by $\mathrm{O}_{2}$ provides $349 \mathrm{~kJ}$ free energy per mole of $\mathrm{N}$ oxidized. Two scenarios emerge by which ammonia oxidation may fuel archaeal growth: $(i)$ an oxic environment in which $\mathrm{NH}_{4}{ }^{+}$demand by eukaryotes is reduced due to environmental factors, or (ii) a suboxic environment in which successful competition with eubacterial nitrifiers could play an ecological role in archaeal abundance.

The seasonality of Antarctic group I Archaea, as observed by Murray et al. (1998) may reflect the first scenario. The Antarctic archaeal population varies in inverse relation to phytoplanktonic chlorophyll- $a$, suggesting resource competition. Archaea are abundant at the beginning and end of austral winter, and decrease in spring and summer. Phytoplankton growth during polar winter is limited by the lack of sunlight, and the corresponding reduction in eukaryotic demand for $\mathrm{NH}_{4}{ }^{+}$may permit uptake by 
archaeoplankton during the months of darkness. This type of substrate competition also supports the hypothesis that the Archaea are not heterotrophs.

The second scenario may instead apply to the SMB and SBB environments, where the water-column depth of group I archaeal production seems to coincide with intense nutrient regeneration and $\mathrm{O}_{2}$ depletion. Dissolved $\mathrm{O}_{2}$ in SBB is approximately $9 \%$ saturated $(0.6 \mathrm{~mL} / \mathrm{L})$ at $400 \mathrm{~m}$ and falls to about $1 \%(0.06 \mathrm{~mL} / \mathrm{L})$ at $550 \mathrm{~m}$, spanning the $\Delta^{14} \mathrm{C}$ region of archaeal lipids in this location. SMB dissolved $\mathrm{O}_{2}$ decreases from $6 \%$ to $1 \%$ atmospheric saturation between $500-700 \mathrm{~m}$ (Sholkovitz, 1972). Within this region, $\mathrm{NH}_{4}{ }^{+}$oxidation by $\mathrm{O}_{2}$-respiring Eukarya and Bacteria may be limited by $\mathrm{O}_{2}$ concentration or fluctuations in the oxic/anoxic boundary. Microaerophilic Archaea may exploit this opportunity to utilize $\mathrm{NH}_{4}{ }^{+}$before it is consumed by other species. It is also possible that a syntrophic or symbiotic (Preston et al., 1996) relationship is required to provide an adequate supply of $\mathrm{NH}_{4}{ }^{+}$or an alternative electron donor.

Ammonia oxidation is already known to fuel chemoautotrophic production by nitrifying Bacteria of the genera Nitrosomonas and Nitrosococcus in the open ocean oxygen minimum between $700-900 \mathrm{~m}$ (Karl et al., 1984). Karl et al. theorized the $\mathrm{NH}_{4}{ }^{+}$ supply for chemoautotrophic oxidation is provided by the decomposition of sinking organic matter. The oxidation of $\mathrm{NH}_{4}{ }^{+}$produces $\mathrm{NO}_{2}{ }^{-}$as the initial product. If the group I Archaea are indeed nitrifiers, their abundance should be associated with the water column $\mathrm{NO}_{2}{ }^{\prime \prime}$ maxima and $\mathrm{O}_{2}$ minima. The limited information we have regarding the depth of archaeal biomass production suggests a close proximity to the increase in $\mathrm{NO}_{2}{ }^{-}$ concentration in the deep SBB (Figure 5.6(c)) and is consistent with this hypothesis.

\subsubsection{Enzymatic Pathway of $\mathrm{CO}_{2}$ Fixation}

No Archaea are known to express Rubisco enzymatic activity, but among the other mechanisms of autotrophic carbon fixation in Archaea, the Acetyl-CoA (Zeikus et al., 1977), reductive tricarboxylic acid (rTCA) (Evans et al., 1966; Fuchs et al., 1980), 
and 3-hydroxypropionate (3-HP) (Holo, 1989; Strauss and Fuchs, 1993) pathways, there may be a suitable candidate.

Direct synthesis of Acetyl-CoA from two molecules of $\mathrm{CO}_{2}$ is widespread in anaerobic Eubacteria (especially sulfate reducers and acetogens) and Euryarchaeota (methanogens). Total cell carbon in prokaryotes using this metabolism is depleted by 35$45 \%$ o relative to $\delta^{13} \mathrm{C}$ of the carbon substrate (Games et al., 1978; Krzycki et al., 1987; Takigiku, 1987). Large isotopic fractionations are associated with reduction of $\mathrm{CO}_{2}$ to the carboxyl and methyl carbon positions of Acetyl-CoA, reactions mediated by carbon monoxide dehydrogenase ( $\mathrm{CODH})$ and formate dehydrogenase; the initial acetate product is up to $52 \%$ depleted relative to its $\mathrm{CO}_{2}$ source (Gelwicks et al., 1989). Direct synthesis of Acetyl-CoA for incorporation into biomass is inconsistent with the enriched $\delta^{13} \mathrm{C}$ values observed in marine archaeal biphytanes (this work; Kohnen et al., 1992; Hoefs et al., 1997). Laboratory assays of Thermoproteus neutrophilus and Acidianus (formerly Sulfolobus) brierleyi species are consistently negative for the presence of CODH (e.g. Beh et al., 1993; Ishii et al., 1997), and we are unaware of the existence of any Crenarchaeon for which this enzymatic activity has been demonstrated.

The rTCA pathway is only known to function in anaerobic (occasionally microaerophilic) organisms, while 3-HP is present in aerobic species. Both pathways could be consistent with the presumed habitat(s) of marine group I Archaea, although $\mathrm{O}_{2}$ tolerance would favor 3-HP. Autotrophic growth by rTCA was originally postulated for the aerobic Crenarchaeon, A. brierleyi, but this was recently questioned by a study showing the presence of some enzymes of 3-HP (Ishii et al., 1997) in this species. Menendez et al., (1999) confirmed and extended the results of Ishii et al., showing that species from several different groups of aerobic Crenarchaeota express enzymes of the 3-HP cycle. This new study favors a 3-HP-like rather than rTCA pathway of autotrophic carbon fixation in marine group I Archaea.

Little information exists about the isotopic fractionation effects associated with these pathways $\left(\varepsilon_{\text {cell }} \simeq \delta^{13} \mathrm{C}_{\text {substrate }}-\delta^{13} \mathrm{C}_{\text {cell }}\right)$. Isotope data are only available for an archaeal strain grown at hyperthermal conditions $\left(85^{\circ} \mathrm{C}\right)$ (Preu $\beta$ et al., 1989). More 
reports exist for Eubacteria at a variety of temperatures (Quandt et al., 1977; Sirevåg et al., 1977; Holo and Sirevåg, 1986; Preu $\beta$ et al., 1989), but in some cases the isotopic values were measured for batch cultures in which the degree of control over growth stage or fractional utilization of substrate was either not regulated or not specified. It is unclear how well the data could approximate mesophilic Crenarchaeota growing in the natural environment, but one generalization is evident: the observed $\varepsilon_{\text {cell }}$ for both pathways is smaller than for direct synthesis of Acetyl-CoA by the method discussed above. In both Archaea and Eubacteria this is a direct result of the requirement of key enzymes in each cycle for $\mathrm{HCO}_{3}{ }^{\circ}$ rather than $\mathrm{CO}_{2}$ as a substrate. Phosphoenolpyruvate (PEP) carboxylase, Acetyl-CoA carboxylase, and Propionyl-CoA carboxylase all use $\mathrm{HCO}_{3}{ }^{-}$, while the 2oxoacid carboxylases and Pyruvate synthase are specific for $\mathrm{CO}_{2}$ (Bott and Thauer, 1989; Falkowski and Raven, 1997). The fractionation effect during enzymatic binding of $\mathrm{HCO}_{3}{ }^{-}$ ( $\varepsilon=3$ to $5 \%$ ) is much smaller than for fixation of $\mathrm{CO}_{2}(\varepsilon=20$ to $40 \%$ ) (Falkowski and Raven, 1997), and in addition, $\mathrm{HCO}_{3}{ }^{-}$is typically $\sim 8-10 \%{ }^{13} \mathrm{C}$-enriched relative to dissolved $\mathrm{CO}_{2}$ in seawater.

The Eubacterium, Chloroflexus aurantiacus, had $\varepsilon_{\text {cell }} \simeq 6 \%$ (Holo and Sirevåg, 1986), and the only archaeal study of which we are aware shows similar depletion in $T$. neutrophilus $\left(\varepsilon_{\mathrm{cell}}=8.2 \%\right.$ o $)($ Preu $\beta$ et al., 1989). C. aurantiacus grows anaerobically using 3-HP, although none of the critical 3-HP enzymes are deactivated by $\mathrm{O}_{2}$ (Strauss and Fuchs, 1993). T. neutrophilus grows anaerobically by $\mathrm{CO}_{2}$ assimilation via the rTCA pathway (Schafer et al., 1986). The fractionation factors are relatively similar given the different pathways of $\mathrm{CO}_{2}$ fixation. Unfortunately there appear to be no data on ${ }^{13} \mathrm{C}$ fractionation for other hyperthermophiles whose pathways of $\mathrm{CO}_{2}$ assimilation have been studied. If marine group I Archaea express the rTCA, 3-HP, or a hybrid cycle, their biomass apparently would be depleted by $\sim 10 \%$ relative to dissolved $\mathrm{CO}_{2}$, resulting in $\delta^{13} \mathrm{C}_{\text {cell }} \simeq-18$ to $-20 \%$. The extent of intracellular fractionation during archaeal lipid biosynthesis remains unknown, but the observed $\delta^{13} \mathrm{C}$ values near $-20 \%$ are reasonably consistent with this estimate. 
The question of intracellular isotope fractionation remains extremely important, however. Van der Meer et al. (1998) recently studied carotenoids of Chlorobium limicola and determined $\delta^{13} \mathrm{C}$ values 2-5\%o greater than cell material. Isotopic enrichment of lipids relative to biomass is very unusual, and it is unclear if this effect in Chlorobiaceae is the result of an alternative synthesis of isoprene (Rohmer et al., 1996). Lipids from Messinian-age (5 my) sediments (Kohnen et al., 1992) yielded $\delta^{13} \mathrm{C}$ values for archaeal biphytanes equal to contemporary data $(\sim-20 \%$ o), but which are $10 \%$ o depleted in ${ }^{13} \mathrm{C}$ relative to a carotenoid derived from Chlorobiaceae. At the time the data were published, it was not recognized that mesophilic relatives of the hyperthermophiles existed. The biphytane source was tentatively ascribed to methanogens; we now hypothesize these are crenarchaeal products. If similar pathways of $\mathrm{CO}_{2}$ fixation operate in planktonic Archaea and in the green sulfur bacteria, differing lipid $\delta^{13} \mathrm{C}$ values could be produced by: ( $i$ ) intracellular fractionation effects during the distribution of metabolic intermediates, (ii) isotope effects associated with different biosynthetic pathways to isoprene, and/or (iii) variable importance of oxo-acid carboxylations relative to AcetylCoA and PEP carboxylations. The ${ }^{14} \mathrm{C}$-depleted, ${ }^{13} \mathrm{C}$-enriched biphytanyl lipids of marine Crenarchaeota may be consistent with an autotrophic metabolism incorporating a significant fraction of cellular carbon as $\mathrm{HCO}_{3}{ }^{-}$rather than $\mathrm{CO}_{2}$.

\subsection{CONCLUSIONS}

The preliminary $\Delta^{14} \mathrm{C}$ data presented here for lipids specific to Crenarchaeota suggest that these organisms grow in SBB without incorporating carbon that contains "bomb- ${ }^{14} \mathrm{C}$ ". These "post-bomb" $\Delta^{14} \mathrm{C}$ data are not significantly different from "prebomb" data for archaeal lipids from SMB sediment. Together the data suggest the group I marine Archaea could be primary producers, fixing biomass beneath the euphotic zone in SMB and SBB. More data, ideally a repeated pre-bomb/post-bomb comparison from SBB sediments only, are desirable to increase confidence in these conclusions. 
Nitrification (oxidation of ammonia by oxygen) is a potential source of energy to drive chemoautotrophic carbon fixation. The marine group I Archaea may regulate a pathway of $\mathrm{CO}_{2}$ assimilation related to the 3-HP cycle, or which is similar in its significant reliance on enzymes specific for $\mathrm{HCO}_{3}{ }^{-}$. Archaea apparently are a significant fraction of the deep prokaryotic biosphere throughout the oceans (Fuhrman and Davis, 1997). If autotrophic metabolism is universal, its implications will affect global carbon, energy, and nutrient budgets.

\subsection{REFERENCES}

Aluwihare, L. I. (1999) High molecular weight (HMW) dissolved organic matter in seawater: Chemical structure, sources, and cycling. Ph.D. Thesis, Woods Hole Oceanographic Institution/Massachusetts Institute of Technology.

Aluwihare, L. I., Repeta, D. J., and Chen, R. J. (1997) A major biopolymeric component to dissolved organic carbon in surface sea water. Nature 387, 166-169.

Bauer, J. E., Druffel, E. R. M., Williams, P. M., Wolgast, D. M., and Griffin, S. (1998) Temporal variability in dissolved organic carbon and radiocarbon in the eastern North Pacific Ocean. J. Geophys. Res. 103 (C2), 2867-2881.

Bauer, J. E., Reimers, C. E., Druffel, E. R. M., and Williams, P. M. (1995) Isotopic constraints on carbon exchange between deep ocean sediments and sea water. Nature 373, 686-689.

Baumgartner, T. R. and Southon, J. (1996) A 1500-year radiocarbon record of nearsurface ocean reservoir ages obtained from the varved sediments of the Santa Barbara Basin, California. EOS, Transactions, 1996 Fall Meeting, p. F298.

Beh, M., Strauß, G., Huber, R., Stetter, K.-O., and Fuchs,G. (1993) Enzymes of the reductive citric acid cycle in the autotrophic eubacterium Aquifex pyrophilus and in the archaebacterium Thermoproteus neutrophilus. Arch. Microbiol. 160, 306311.

Bott, M. and Thauer, R. K. (1989) The active species of " $\mathrm{CO}_{2}$ " formed by carbon monoxide dehydrogenase from Peptostreptococcus productus. Z. Naturforsch. 44c, 392-396.

CalCOFI Cruise 9610, SIO Reference Series, CalCOFI Database, http://nemo.ucsd.edu, University of California, San Diego, Scripps Institution of Oceanography (1996).

Chappe, B., Albrecht., P., and Michaelis, W. (1982) Polar lipids of archaebacteria in sediments and petroleums. Science 217, 65-66.

Christensen, C. J., Gorsline, D. S., Hammond, D. E., and Lund, S. P. (1994) Non-annual laminations and expansion of anoxic basin-floor conditions in Santa Monica 
Basin, California Borderland, over the past four centuries. Mar. Geol. 116, 399418.

DeLong, E. F. (1992) Archaea in coastal marine environments. Proc. Natl. Acad. Sci. 89, 5685-5689.

DeLong, E. F. (1998) Everything in moderation: Archaea as "non-extremophiles". Current Opinion in Genetics and Development 8, 649-654.

DeLong, E. F., Wu, K. Y., Prézelin, B. B., and Jovine, R. V. M. (1994) High abundance of Archaea in Antarctic marine picoplankton. Nature 371, 695-697.

DeLong, E. F., King, L. L., Massana, R., Cittone, H., Murray, A., Schleper, C., and Wakeham, S. G. (1998) Dibiphytanyl ether lipids in nonthermophilic crenarchaeotes. Appl. Environ. Microbiol. 64, 1133-1138.

DeRosa, M., Gambacorta, A., and Gliozzi, A. (1986) Structure, biosynthesis, and physicochemical properties of archaebacterial lipids. Microbiol Rev. 50, 70-80.

Druffel, E. R. M., Williams, P. M., Bauer, J. E., and Ertel, J. R. (1992) Cycling of dissolved and particulate organic matter in the open ocean. J. Geophys. Res. 97 (C10), 15,639-15,659.

Druffel, E. R. M., Bauer, J. E., Williams, P. M., Griffin, S., and Wolgast, D. (1996) Seasonal variability of particulate organic radiocarbon in the northeast Pacific Ocean. J. Geophys. Res. 101 (C9), 20,543-20,552.

Eglinton, T. I., Aluwihare, L. I., Bauer, J. E., Druffel, E. R. M., and McNichol, A. P. (1996) Gas chromatographic isolation of individual compounds from complex matrices for radiocarbon dating. Anal. Chem. 68, 904-912.

Eglinton, T. I., Benitez-Nelson, B. C., Pearson, A., McNichol, A. P., Bauer, J. E., and Druffel, E. R. M. (1997) Variability in radiocarbon ages of individual organic compounds from marine sediments. Science 277, 796-799.

Eppley, R. W. (1992) Chlorophyll, photosynthesis and new production in the Southern California Bight. Prog. Oceanog. 30, 117-150.

Evans, M. C. W., Buchanan, B. B., and Arnon, D. I. (1966) A new ferredoxin-dependent carbon reduction cycle in a photosynthetic bacterium. Proc. Natl. Acad. Sci. 55, 928-934.

Falkowski, P. G. and Raven, J. R. (1997) Aquatic Photosynthesis, Blackwell Science Ltd, UK, pp. 128-162.

Fuchs, G., Stupperich, E., and Eden, G. (1980) Autotrophic $\mathrm{CO}_{2}$ fixation in Chlorobium limicola. Evidence for the operation of a reductive tricarboxylic acid cycle. Arch. Microbiol. 128, 64-71.

Fuhrman, J. A. and Davis, A. A. (1997) Widespread Archaea and novel Bacteria from the deep sea as shown by 16 S rRNA gene sequences. Mar. Ecol. Progr. Ser. 150, 275-285.

Games, L., Hayes, J., and Gunsalus, R. (1978) Methane producing bacteria: natural fractionation of the stable carbon isotopes. Geochim. Cosmochim. Acta 42, 12951297.

Gelwicks, J. T., Risatti, J. B., and Hayes, J. M. (1989) Carbon isotope effects associated with autotrophic acetogenesis. Org. Geochem. 14, 441-446. 
Hayes, J. M., Freeman, K. H., Popp, B. N., and Hoham, C. H. (1990) Compound-specific isotopic analyses: A novel tool for reconstruction of ancient biogeochemical processes. Org. Geochem. 16, 1115-1128.

Hoefs, M. J. L., Schouten, S., deLeeuw, J. W., King, L. L., Wakeham, S. G., and Sinninghe Damsté, J. S. (1997) Ether lipids of planktonic Archaea in the marine water column. Appl. Environ. Microbiol. 63, 3090-3095.

Holo, H. (1989) Chloroflexus aurantiacus secretes 3-hydroxypropionate, a possible intermediate in the assimilation of $\mathrm{CO}_{2}$ and acetate. Arch. Microbiol. 151, 252256.

Holo, H. and Sirevăg, R. (1986) Autotrophic growth and $\mathrm{CO}_{2}$ fixation of Chloroflexus aurantiacus. Arch. Microbiol. 145, 173-180.

Huh, C.-A., Zahnle, D. L., and Small, L. F. (1987) Budgets and behaviors of uranium and thorium series isotopes in Santa Monica Basin sediments. Geochim. et Cosmochim. Acta 51, 1743-1754.

Ishii, M., Miyake, T., Satoh, T., Sugiyama, H., Oshima, Y., Kodama, T., and Igarashi, Y. (1997) Autotrophic carbon dioxide fixation in Acidianus brierleyi. Arch. Microbiol. 166, 368-371.

Kandler, O., and Stetter, K.-O. (1981) Evidence for autotrophic $\mathrm{CO}_{2}$ assimilation in Sulfolobus brierleyi via a reductive carboxylic acid pathway. Zbl. Bakt. Hyg., I. Abt. Orig. C 2, 111-121.

Karl, D. M., Knauer, G. A., Martin, J. H., and Ward, B. B. (1984) Bacterial chemolithoautotrophy in the ocean is associated with sinking particles. Nature 309, 54-56.

King, L. L., Pease, T. K., and Wakeham, S. G. (1998) Archaea in Black Sea water colummn particulate matter and sediments - evidence from ether lipid derivatives. Org. Geochem. 28, 677-688.

Kohnen, M. E. L., Schouten, S., Sinninghe Damsté, J. S., de Leew, J. W., Merritt, D. A., and Hayes, J. M. (1992) Recognition of paleobiochemicals by a combined molecular sulfur and isotope geochemical approach. Science 256, 358-362.

Krzycki, J., Kenealy, W., DeNiro, M., and Zeikus, J. (1987) Stable carbon isotope fractionation by Methanosarcina barkeri during methanogenesis from acetate, methanol, or carbon dioxide-hydrogen. Appl. Environ. Microbiol. 53, 2597-2599.

Massana, R., Murray, A. E., Preston, C. M., and DeLong, E. F. (1997) Vertical distribution and phylogenetic characterization of marine planktonic Archaea in the Santa Barbara Channel. Appl. Environ. Microbiol. 63, 50-56.

McCaffrey, M. A. (1990) Sedimentary lipids as indicators of depositional conditions in the coastal Peruvian upwelling regime. Ph.D. thesis, Woods Hole Oceanographic Institution/Massachusetts Institute of Technology.

Menendez, C, Bauer, Z., Huber, H., Gad'on, N., Stetter, K.-O., and Fuchs, G. (1999) Presence of Acetyl Coenzyme A (CoA) carboxylase and Propionyl-CoA carboxylase in autotrophic Crenarchaeota and indication for operation of a 3hydroxypropionate cycle in autotrophic carbon fixation. J. Bacteriol. 181, 10881098. 
Murray, A. E., Preston, C. M., Massana, R., Taylor, L. T., Blakis, A., Wu, K., and DeLong, E. F. (1998) Seasonal and spatial variability of bacterial and archaeal assemblages in the coastal waters near Anvers Island, Antarctica. Appl. Environ. Microbiol. 64, 2585-2595.

NOSAMS Data Report 94-093, (1994), WOCE (World Ocean Circulation Experiment) $\Delta^{14} \mathrm{C}_{\text {DIC }}$ data, $34^{\circ} 34.9^{\prime} \mathrm{N}, 126^{\circ} 24.0^{\prime} \mathrm{W}$.

Olsson, I. U. (1970) The use of Oxalic acid as a standard, In: Radiocarbon variations and absolute chronology, Nobel Symposium, $12^{\text {th }}$ Proc., ed. I. U. Olsson, Wiley, p. 17.

Pearcy, W. G. and Stuiver, M. (1983) Vertical transport of ${ }^{14} \mathrm{C}$ into deep-sea food webs. Deep-Sea Res. 30, 427-440.

Pearson, A., McNichol, A. P., Schneider, R. J., and von Reden, K. F. (1998) Microscale AMS ${ }^{14} \mathrm{C}$ measurement at NOSAMS. Proceedings of the $16^{\text {th }}$ International ${ }^{14} \mathrm{C}$ conference, edited by W. G. Mook and J. van der Plicht, Radiocarbon 40, 61-75.

Preston, C. M., Wu, K. Y., Molinski, T. F., and DeLong, E. F. (1996) A psychrophilic crenarchaeon inhabits a marine sponge: Cenarchaeum symbiosum gen. nov., sp. nov. . Proc. Natl. Acad. Sci. 93, 6241-6246.

Preuß, A., Schauder, R., Fuchs, G., and Stichler, W. (1989) Carbon isotope fractionation by autotrophic bacteria with three different $\mathrm{CO}_{2}$ fixation pathways. $Z$. Naturforsch. 44c, 397-402.

Quandt, L., Gottschalk, G., Zeigler, H., and Stichler, W. (1977) Isotope discrimination by photosynthetic bacteria. FEMS Microbiol. Lett. 1, 125-128.

Rau, G. H. (1991) Another recipe for bomb ${ }^{14} \mathrm{C}$ dilution. Nature 350, 116.

Rau, G. H., Karl, D. M., and Carney, R. S. (1986) Does inorganic carbon assimilation cause ${ }^{14} \mathrm{C}$ depletion in deep-sea organisms. Deep-Sea Res. 33, 349-357.

Rohmer, M., Seeman, M., Horbach, S., Bringer-Meyer, S., and Sahm, H. (1996) Glyceraldehyde-3-phosphate and pyruvate as precursors of isoprenic units in an alternative nonmevalonate pathway for terpenoid biosynthesis. J. Am. Chem. Soc. 118, 2564 (1996).

Santschi, P. H., Guo, L., Baskaran, M., Trumbore, S., Southon, J., Bianchi, T. S., Honeyman, B., and Cifuentes, L. (1995) Isotopic evidence for the contemporary origin of high-molecular weight organic matter in oceanic environments. Geochim. Cosmochim. Acta 59, 625-631.

Schäfer, S., Barkowski, C., and Fuchs, G. (1986) Carbon assimilation by the autotrophic thermophilic archaebacterium Thermoproteus neutrophilus. Arch. Micrbiol. 146, 301-308.

Schimmelmann, A., and Tegner, M. J. (1991) Historical oceanographic events reflected in the ${ }^{13} \mathrm{C} /{ }^{12} \mathrm{C}$ ratio of total organic carbon in laminated Santa Barbara Basin Sediment. Global Biogeochem. Cycles 5, 173-188.

Sholkovitz, E. R. (1972) Ph.D. thesis, University of California, San Diego.

Sirevåg, R., Buchanan, B. B., Berry, J. A., and Troughton, J. H., (1977) Mechanisms of $\mathrm{CO}_{2}$ fixation in bacterial photosynthesis studied by the carbon isotope fractionation technique. Arch. Microbiol. 112, 35-38.

Sorokin, Y. I. (1978) Decomposition of organic matter and nutrient regeneration. In: Marine ecology, Vol. IV, Dynamics, O. Kinne, ed., Wiley, pp. 501-616. 
Sprott, G. D., Agnew, B. J., and Patel, G. B. (1997) Structural features of ether lipids in the archaeobacterial thermophiles Pyrococcus furiousus, Methanopyrus kandleri, Methanothermus fervidus, and Sulfolobus acidocaldarius. Can. J. Microbiol. 43, 467-476.

Strauss, G., and Fuchs, G. (1993) Enzymes of a novel autotrophic $\mathrm{CO}_{2}$ fixation pathway in the phototrophic bacterium Chloroflexus aurantiacus, the 3-hydroxypropionate cycle. Eur. J. Biochem. 215, 633-643.

Stuiver, M. and Polach, H. A. (1977) Discussion: Reporting of ${ }^{14} \mathrm{C}$ data. Radiocarbon 19, 355-363.

Takigiku, R. (1987) Isotopic and molecular indicators of origins of organic compounds in sediments. Ph.D. thesis, Indiana University, Bloomington (1987).

Trincone, A. et al., (1992) Distribution of complex and core lipids within new hyperthermophilic members of the Archaea domain. System. Appl. Microbiol. 15, 11-17.

van der Maarel, M. J. E. C., Artz, R. R. E., Haanstra, R., and Forney, L. (1998) Association of marine Archaea with the digestive tracts of two marine fishes. Appl. Environ. Microbiol. 64, 2894-2898.

van der Meer, M. T. J., Schouten, S., and Sinninghe-Damste, J. S. (1998) The effect of the reversed tricarboxylic acid cycle on the ${ }^{13} \mathrm{C}$ contents of bacterial lipids. Org. Geochem. 28, 527-533.

Volkman, J. K. (1986) A review of sterol markers for marine and terrigenous organic matter. Org. Geochem. 9, 83-99.

von Reden, K. F., Schneider, R. J., McNichol, A. P., and Pearson, A. (1998) ${ }^{14}$ C AMS measurements of $<100 \mathrm{mg}$ samples with a high-current system. Proceedings of the $16^{\text {th }}$ International ${ }^{14} \mathrm{C}$ conference, edited by W. G. Mook and J. van der Plicht, Radiocarbon, 40, 247- .

Williams, P. M. and Druffel, E. R. M. (1987) Radiocarbon in dissolved organic matter in the central North Pacific Ocean. Nature 330, 246-248.

Williams, P. M., Robertson, K. J., Soutar, A., Griffin, S. M., and Druffel, E. R. M. (1992) Isotopic signatures $\left({ }^{14} \mathrm{C},{ }^{13} \mathrm{C},{ }^{15} \mathrm{~N}\right)$ as tracers of sources and cycling of soluble and particulate organic matter in the Santa Monica Basin, California. Prog. Oceanog. 30, 253-290.

Zeikus, J. G., Fuchs, G., Kenealy, W., and Thauer, R. K. (1977) Oxidoreductases involved in cell carbon synthesis of Methanobacterium thermoautotrophicum. J. Bacteriol. 132, 604-613. 


\section{CHAPTER 6}

\section{ORIGINS OF LIPID BIOMARKERS IN SANTA MONICA BASIN SURFACE SEDIMENT: A CASE STUDY USING COMPOUND-SPECIFIC $\delta^{13} \mathrm{C}$ AND $\Delta^{14} \mathrm{C}$ ANALYSIS}

\section{Abstract}

Compound-specific carbon isotopic $\left(\delta^{13} \mathrm{C}\right.$ and $\left.\Delta^{14} \mathrm{C}\right)$ values are reported for 31 different lipid biomarker molecules obtained from Santa Monica Basin (SMB) and Santa Barbara Basin (SBB) surface sediments. The organic compound classes analyzed represent phytoplanktonic, zooplanktonic, bacterial, archaeal, terrestrial higher plant, and fossil carbon sources. These compound classes include: long-chain $n$-alkanes, fatty acids (as methyl esters; FAMEs) $n$-alcohols, $\mathrm{C}_{30}$ mid-chain ketols and diols, sterols, hopanols, and $\mathrm{C}_{40}$ head-head biphytanyl side-chains of the ether-linked glycerols of Archaea.

The data show that the carbon source for the majority of the analyzed biomarkers is marine euphotic zone primary production or subsequent heterotrophic consumption of this biomass. A small amount of benthic incorporation of ${ }^{14} \mathrm{C}$-depleted DIC was identified for the bacterial hopanols and $\mathrm{C}_{15}$ linear and branched-chain fatty acids. However, there is no apparent uptake of ${ }^{14} \mathrm{C}$-depleted DIC in SMB by the bacteria producing $\mathrm{C}_{18: 1 \omega 7} \mathrm{FAME}$, including the filamentous Beggiatoa spp..

Two of the above lipid classes did not reflect carbon originally fixed by marine photoautotrophs. These were the $n$-alkanes, for which the $\Delta^{14} \mathrm{C}$ data are consistent with mixed fossil and contemporary terrestrial higher plant sources, and the archaeal isoprenoids, for which the $\Delta^{14} \mathrm{C}$ data are consistent with exclusively chemoautotrophic production below the euphotic zone. 


\subsection{INTRODUCTION}

Compound-specific isotopic measurements of individual lipid biomarkers can help identify some of the sources of organic carbon to marine sediments. This approach was developed originally to investigate the stable carbon isotopic ratios $\left(\delta^{13} \mathrm{C}\right)$ of organic materials in recent and ancient geological materials (Hayes et al., 1990). The large range of naturally occurring $\delta^{13} \mathrm{C}$ values proved useful to identify the presence of diverse carbon sources in many environments. Hopanols and archaeal lipids with $\delta^{13} \mathrm{C}$ values near $-100 \%$ are indicative of methanotrophy (e.g. Freeman et al., 1990; Hinrichs et al., 1999). Isorenieratene $\left(\delta^{13} \mathrm{C} \sim-10\right.$ to $-15 \%$ ) records the presence of bicarbonateutilizing green sulfur bacteria (Kohnen et al., 1992; Sinninghe Damsté et al., 1993). The phenolic oxidation products of lignin (Hedges and Parker, 1976) and long-chain $n$ alkanes (Collister et al., 1994a) serve as isotopic markers for terrestrial plants, while the $\mathrm{C}_{37}$ alkenones (37 carbon atoms, $\delta^{13} \mathrm{C} \sim-24 \%$ ) and the $\mathrm{C}_{27}$ and $\mathrm{C}_{28}$ sterols are commonly used as phytoplanktonic tracers (e.g. Marlowe et al., 1990; Jasper and Hayes, 1990; Volkman et al., 1998).

More recently, Eglinton et al. (1996) developed a preparative capillary gas chromatographic (PCGC) separation method that is able to isolate lipids with sufficient purity and abundance for compound-specific radiocarbon $\left({ }^{14} \mathrm{C}\right)$ measurement by accelerator mass spectrometry (AMS). Using this approach, Eglinton et al. (1997) demonstrated a wide range of ${ }^{14} \mathrm{C}$ concentrations for biomarkers extracted from a single sedimentary horizon. The data indicated that some co-occurring lipids probably spent different lengths of time in intermediate reservoirs prior to sedimentary deposition. An alternative explanation is that the lipids were simultaneously biosynthesized, but the source organisms had utilized carbon pools of differing initial isotopic composition. Considering the number of potential carbon sources and metabolic pathways, it is not surprising that the $\Delta^{14} \mathrm{C}$ of bulk TOC commonly does not correspond to the known depositional age of its associated sediment (e.g. Emery and Bray, 1962; Benoit et al., 1979). Most of the additional allochthonous or chemosynthetic carbon sources represent 
organic matter with lower ${ }^{14} \mathrm{C}$ concentrations than the fraction of TOC originating from autochthonous marine production. Only the rapid transport of recently synthesized terrestrial plant material, which has a ${ }^{14} \mathrm{C}$ concentration in equilibrium with atmospheric $\mathrm{CO}_{2}$, can provide a fraction of TOC with a $\Delta^{14} \mathrm{C}$ value higher than marine primary production.

The heterogeneous $\Delta^{14} \mathrm{C}$ distribution within discrete sedimentary horizons is analogous to prior observations of a wide range of co-occuring $\delta^{13} \mathrm{C}$ values (e.g. Freeman et al. 1990). Compound-specific ${ }^{14} \mathrm{C}$ analyses, when combined with ${ }^{13} \mathrm{C}$ measurements, allow two-dimensional isotopic discrimination of organic matter sources (this chapter) and provide additional constraints for quantitative mass-balance models (Chapter 7).

The goal of this study was to generate the first comprehensive molecular-level ${ }^{14} \mathrm{C}$ data set for a suite of lipid biomarker compounds. It specifically examines some of the mechanisms responsible for contributing organic carbon of non-marine photosynthetic source to ocean sediments. The work focuses on the upper $10 \mathrm{~cm}$ of a core from Santa Monica Basin, California, USA, and is supplemented by a core-top sample from the adjacent Santa Barbara Basin. These cores were chosen because of the well-studied environments from which they were taken, the availability of ancillary data, and because on a radiocarbon time-scale, they are "contemporary". The variability in biomarker $\Delta^{14} \mathrm{C}$ values reflects differences in isotopic composition of the endmember sources only, with minimal in-situ ${ }^{14} \mathrm{C}$ decay. These endmembers have changed because of the increase in atmospheric ${ }^{14} \mathrm{C}$ concentration caused by above-ground testing of nuclear weapons in the 1950 s and 1960 s. This excess "bomb- ${ }^{14} \mathrm{C}$ " has invaded the modern surface ocean and terrestrial biota and allows the products of recent biological production to be identified. Contemporary marine biomarkers that exhibit no increase in $\Delta^{14} \mathrm{C}$ compared to their $\Delta^{14} \mathrm{C}$ values in "pre-bomb" horizons must be formed from carbon pools physically removed from the influence of atmospheric $\mathrm{CO}_{2}$ (i.e. the deep ocean). In the case of terrestrial compounds, only carbon sequestered in soils for longer than 50 years will be free of the bomb- ${ }^{14} \mathrm{C}$ influence; other, more recently-synthesized plant litter will have $\Delta^{14} \mathrm{C}$ values > 
$0 \%$. It is this contrast between "pre-bomb" and "post-bomb" $\Delta{ }^{14} \mathrm{C}$ values, or the relative rate of bomb $-{ }^{14} \mathrm{C}$ uptake, that serves as the primary tracer property utilized in this work.

In the initial phases of this study (Chapters 4 and 5), biomarkers or organic compound classes were sought which could serve as tracers of marine phytoplanktonic biomass and deep-water chemoautotrophic production. The steroidal lipids were found to serve as excellent planktonic biomass and surface water $\Delta^{14} \mathrm{C}_{\mathrm{DIC}}$ tracers for all isomers studied (Chapter 4). In Chapter 5, the biphytanyl $\left(\mathrm{C}_{40}\right)$ isoprenoid lipids of marine planktonic Archaea were found to exhibit no evidence of bomb- ${ }^{14} \mathrm{C}$ incorporation, indicating these organisms are chemoautotrophic and fix biomass from DIC deep in the water column. These previous data sets are combined here with $\Delta^{14} \mathrm{C}$ and $\delta^{13} \mathrm{C}$ data obtained for additional biomarker classes from SMB sediments. The new data include measurements for $n$-alkanes, fatty acids, $n$-alcohols, hopanols, $\mathrm{C}_{30}$-alkan-15-one-1-ol, and $\mathrm{C}_{30}$-alkan-1,15-diol. The $\Delta^{14} \mathrm{C}$ data, when combined with the $\delta^{13} \mathrm{C}$ values obtained by $\mathrm{irm}$-GC/MS analysis, currently provide the most thorough dual-carbon-isotopic assessment of the sources of organic carbon to marine sediments.

\subsection{Results}

\subsubsection{Bulk Core Data}

The Southern California Bight is a highly productive upwelling region, averaging $\sim 700 \mathrm{mgC} / \mathrm{m}^{2} /$ day of total primary production (Eppley, 1992). Approximately 50 $\mathrm{mgC} / \mathrm{m}^{2} /$ day of this carbon reaches the suboxic bottom waters of Santa Monica Basin (Landry et al., 1992). The resulting deep-basin sediments are laminated and organic-rich.

The absence of bioturbation in SMB allows decadal resolution of the changes in sedimentary ${ }^{14} \mathrm{C}$ concentrations due to the uptake of bomb-derived ${ }^{14} \mathrm{C}$. For the SMB core, $\Delta^{14} \mathrm{C}$ measurements were made on samples of bulk TOC, planktonic foraminifera, and benthic foraminifera. The benthic values were used to establish that the $\Delta^{14} \mathrm{C}$ of 
bottom water DIC has remained nearly constant over time (Chapter 4; and Figure 6.1, thin solid line). Surface ocean $\Delta^{14} \mathrm{C}_{\mathrm{DIC}}$ reached a maximum in the middle $1970 \mathrm{~s}$, about ten years after the maximum in atmospheric ${ }^{14} \mathrm{CO}_{2}$ concentration caused by nuclear weapons testing. A summary of $\Delta^{14} \mathrm{C}_{\mathrm{DIC}}$ measurements made in the Southern California Bight (SCB) was given in Chapter 4. The data are sufficient to make a time-series model of the evolution of surface water ${ }^{14} \mathrm{C}$ concentration during the $20^{\text {th }}$ century (dashed line, Figure 6.1; references in Chapter 4). The planktonic foraminiferal $\Delta^{14} \mathrm{C}$ values were compared with the $\Delta^{14} \mathrm{C}_{\text {DIC }}$ model in Chapter 4 and found to be somewhat ${ }^{14} \mathrm{C}$-depleted relative to the model.

Measurements of excess ${ }^{210} \mathrm{~Pb}$ activity were used to assign calendar dates to the sectioned horizons (Figure 6.1). This chronology agrees with previously published rates of sediment accumulation (Huh et al., 1987; Christensen et al., 1994) and laminae counts based on X-Ray stratigraphy (Hagadorn et al., 1995). The calendar year assignment in Figure 6.1 also accurately places the maximum entrainment of bomb $-{ }^{14} \mathrm{C}$ in the 19611985 horizon. The entire core represents very little time in comparison to the half-life of ${ }^{14} \mathrm{C}$ (5730 years), and minor decay corrections to all reported $\Delta{ }^{14} \mathrm{C}$ values were applied using the ${ }^{210} \mathrm{~Pb}$ chronology. 


\section{Figure 6.1}

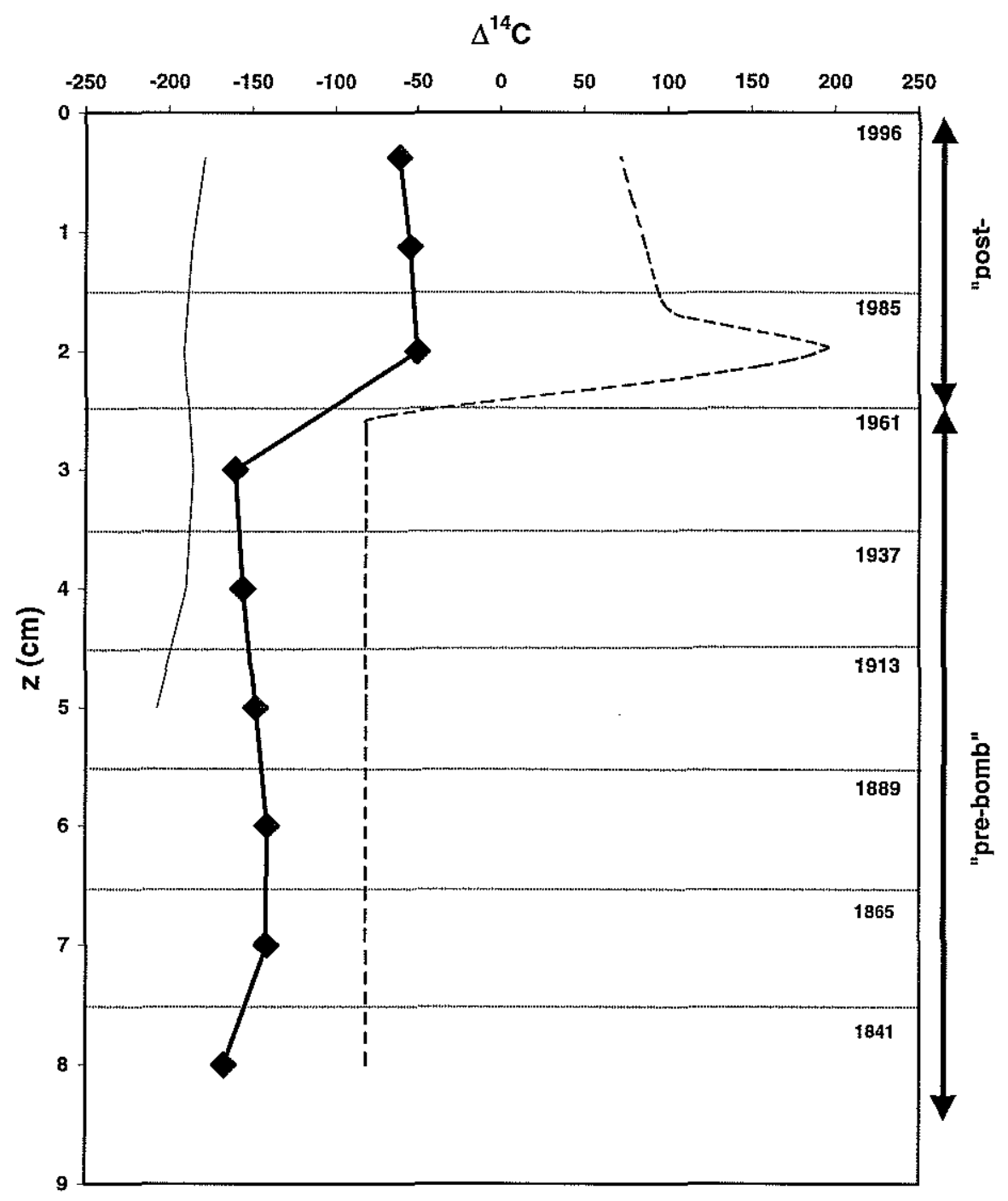

Figure 6.1 Bulk sample $\Delta^{14} \mathrm{C}$ data for the SMB core. Bottom water $\Delta^{14} \mathrm{C}_{\mathrm{DIC}}$ as recorded by benthic foraminifera is shown as a thin solid line; the surface water $\Delta^{14} C_{\text {DIC }}$ model created from literature data is shown as a dashed line. Sedimentary $\Delta^{14} C_{\mathrm{TOC}}$ (diamonds) is intermediate between the two water mass records. 


\subsubsection{Organic Geochemical Analysis}

The organic fractions selected for isotopic analysis are described below. HRGC chromatograms are shown and the individual compounds isolated for $\Delta^{14} \mathrm{C}$ measurement are indicated. All the fractions shown in the following figures were obtained from SMB surface sediment $(0-0.75 \mathrm{~cm})$ unless otherwise noted. Brief descriptions of each sample and the concentrations of the biomarkers in units of micrograms per gram dry weight $(\mu \mathrm{g} / \mathrm{gdw})$ are also given. More detailed organic geochemical analysis is saved for the later discussion sections.

\subsubsection{Selection of Intervals for Compound-Specific Isotopic Analysis}

For all of the lipid classes analyzed, samples were selected in order to compare $\Delta^{14} \mathrm{C}$ values for the identical or similar biomarkers extracted from both post-bomb and pre-bomb sedimentary horizons. Depending on initial concentrations of the biomarkers and other analytical considerations, the selection of horizons varied. Because $n$-alkanes were present in very low concentrations, the core was simply divided into post-bomb $(0-$ $2.5 \mathrm{~cm})$ and pre-bomb material $(2.5-7.5 \mathrm{~cm})$ to assure enough carbon in each sample. For fatty acids and sterols, a single pre-bomb sediment horizon $(4.5-5.5 \mathrm{~cm})$ and the post-bomb, surface-most horizon $(0-0.75 \mathrm{~cm})$ were selected. (Additional "practice" runs on the $3.5-4.5 \mathrm{~cm}$ horizon also yielded a few useful data points.) These samples provide a clear contrast between lipids of photosynthetic origin derived from pre-bomb, ${ }^{14} \mathrm{C}$-poor surface waters and those from the ${ }^{14} \mathrm{C}$-enriched, post-bomb euphotic zone. The remaining $n$-alcohol, ketol, diol, and hopanol data generally originate from the $0.75-1.5$ $\mathrm{cm}$ (post-bomb) and $5.5-8.5 \mathrm{~cm}$ (pre-bomb) horizons. The initial PCGC series attempted for the $0-0.75 \mathrm{~cm}$ and $4.5-5.5 \mathrm{~cm}$ horizons were compromised by column bleed and low sample yields; the data for these series were discarded in favor of repeat analyses from the SMB $0.75-1.5 \mathrm{~cm}$ and SMB 5.5-8.5 cm horizons. An additional series of desmethyl-sterols from SBB $0-1 \mathrm{~cm}$ was also analyzed for the same reasons. 
The pre-bomb archaeal lipid data are from the SMB $5.5-8.5 \mathrm{~cm}$ horizon; low abundance and reaction yields for the archaeal lipids did not allow ${ }^{14} \mathrm{C}$ measurements for a SMB post-bomb horizon, so $\Delta^{14} \mathrm{C}$ data for SBB $0-1 \mathrm{~cm}$ archaeal lipids are reported instead.

\subsubsection{2 n-Alkanes}

A chromatogram of the total aliphatic hydrocarbon fraction from SMB $0-2.5 \mathrm{~cm}$ (post-bomb) sediment is shown in Figure 6.2(a). The total mixture is characterized by the presence of an abundant unresolved complex mixture (UCM) typical of samples containing degraded petroleum. SMB sediments are known to receive hydrocarbon inputs from both anthropogenic sources and natural petroleum seepage (Eganhouse and Venkatesan, 1993). For compound-specific isotopic analysis, the $n$-alkanes were separated from the background UCM by urea adduction. Figure 6.2(b) shows the same SMB $0-2.5 \mathrm{~cm}$ alkane fraction following this purification step and following the removal of linear alkenes by elution through $\mathrm{AgNO}_{3}$. The resulting sample for isotopic analysis contains an almost pure homologous series of $n$-alkanes. Similar results were obtained for the SMB pre-bomb $(2.5-7.5 \mathrm{~cm})$ aliphatic hydrocarbon fraction chromatogram not shown).

Figure 6.3 shows both the absolute and relative abundance of $n$-alkanes in each sample. In both surface and deeper sediments, the $n$-alkanes were present at concentrations of less than $1 \mu \mathrm{g} / \mathrm{gdw}$, less abundant than the functionalized lipid biomarkers analyzed in the rest of this study. The deeper, pre-bomb sample is slightly enriched in terms of absolute $n$-alkane concentrations, which either reflects the preservation of these lipids relative to other sedimentary components or signals a change in alkane source contributions over time. In both horizons, $n-\mathrm{C}_{29}$ was the most abundant $n$-alkane, and the strong even-odd predominance is consistent with a significant contribution from terrestrial plant waxes. A simplified carbon preference index (CPI)

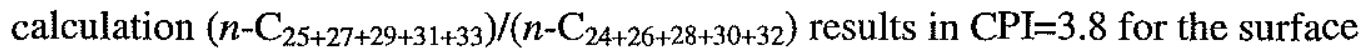
sediments and $\mathrm{CPI}=5.4$ for the deeper horizon. Although petroleum sources must 
contribute $n$-alkanes to SMB sediments, the high CPI values of the $n$-alkane distributions suggest this material is partially remineralized in preference to the fraction originating from terrestrial or shale sources.

Figure 6.2

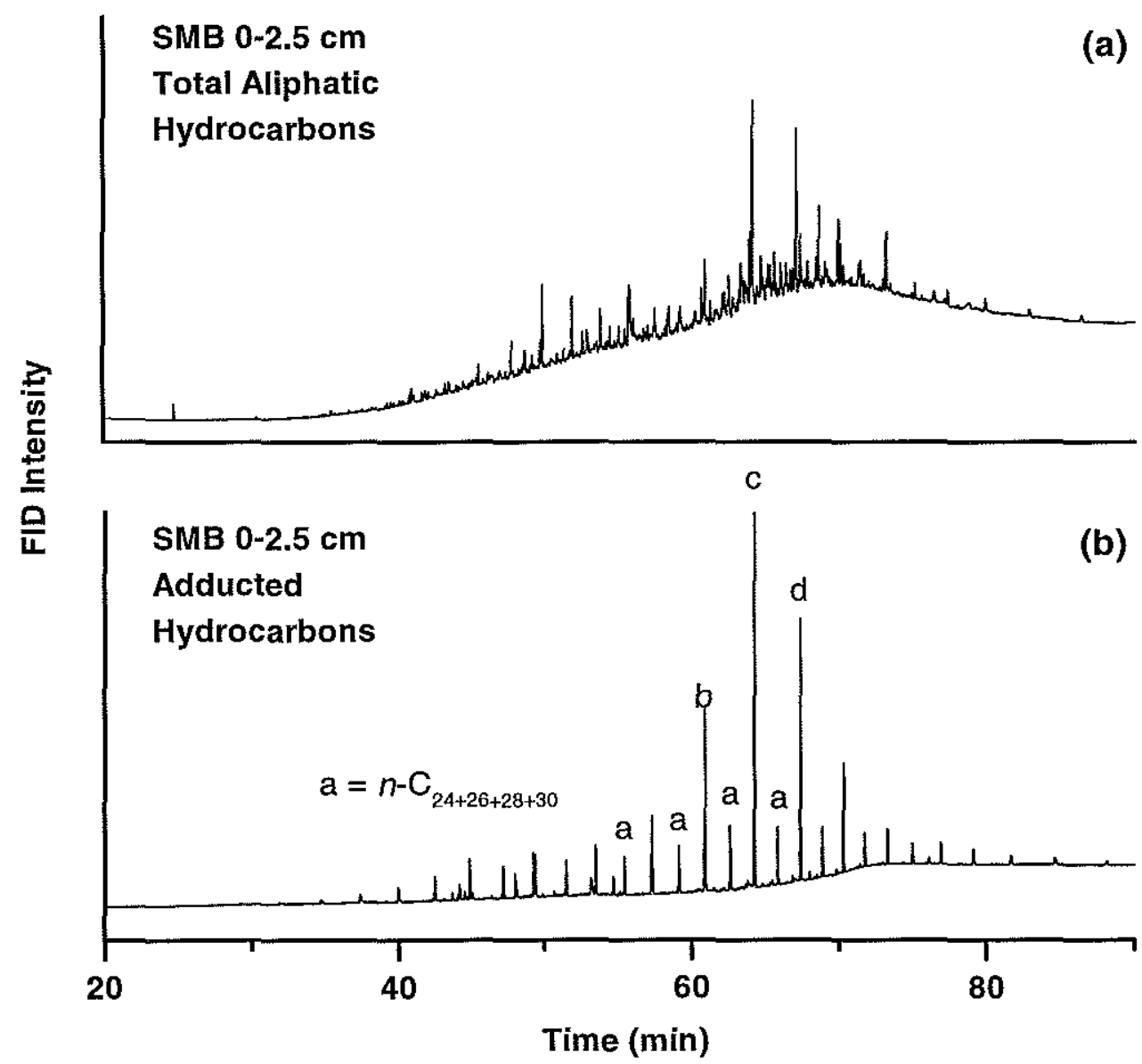

Figure 6.2 (a) Total aliphatic hydrocarbon fraction for SMB $0-2.5 \mathrm{~cm}$ sediment horizon and (b) $n$-alkane fraction obtained following urea adduction of the same sample; letters identify compounds collected by PCGC for ${ }^{14} \mathrm{C}$-AMS analysis (data in Table 6.2). 
Figure 6.3
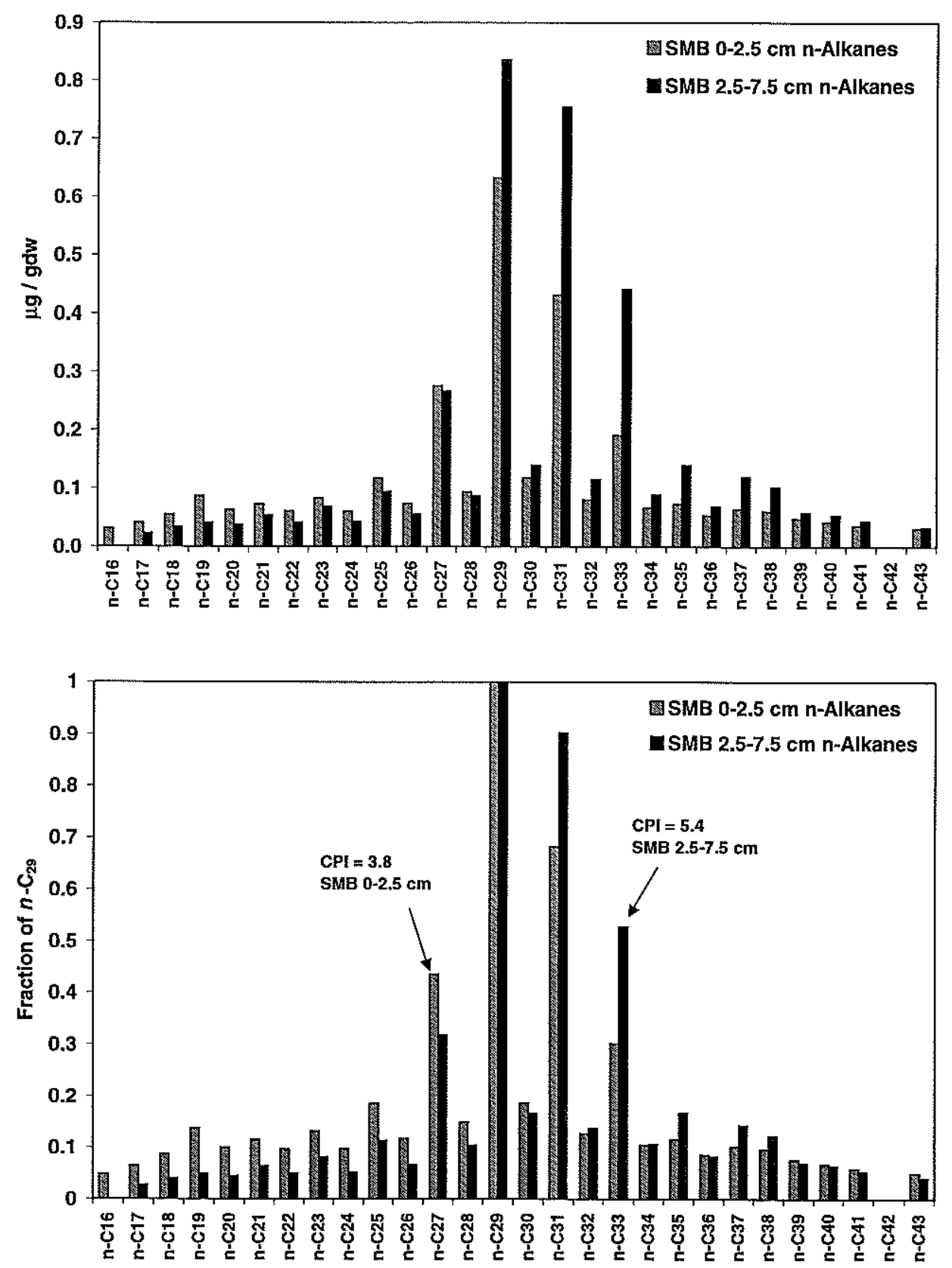

Figure 6.3 Absolute and relative abundance of $n$-alkanes in SMB sediment. 


\subsubsection{Fatty Acid Methyl Esters (FAMEs)}

No chromatogram for the original FAMEs plus ketone lipid fraction obtained from the SMB 0-0.75 cm (post-bomb) sedimentary horizon is available, so Figure 6.4(a) shows the equivalent pre-bomb $(4.5-5.5 \mathrm{~cm})$ sample utilized for this work. The general features of both samples were quite similar, except as noted below. The ketones in both samples were separated by sorption onto amino-propyl-bonded $\mathrm{SiO}_{2}$ gel; this was especially important to remove the $C_{19}$ ketone standard, which co-eluted with the $C_{18: 1}$ FAMEs in the original mixtures. Figure 6.4(b) shows the SMB 0-0.75 cm FAME sample following this purification step.

The absolute concentrations of fatty acids in both the $0-0.75 \mathrm{~cm}$ and $4.5-5.5 \mathrm{~cm}$ samples are shown in Figure 6.5. These lipids were the most abundant biomarkers studied in SMB sediments, with concentrations in the range of $5-40 \mu \mathrm{g} / \mathrm{gdw}$ in the surface horizon, decreasing to $1-10 \mu \mathrm{g} / \mathrm{gdw}$ in the deeper sample. The mixtures were dominated by palmitic acid $\left(\mathrm{C}_{16: 0}\right)$, which is generally the most common fatty acid of the phospholipid bilayer membranes of all eukaryotes. The chromatograms also show strong $\mathrm{C}_{14: 0}$ and $\mathrm{C}_{18: 0}$ peaks, which probably have similar sources. High-molecular weight fatty acids ( $\geq \mathrm{C}_{20}$ ) occur in both horizons as homologous series with even-odd predominance and with a concentration maximum at $\mathrm{C}_{24: 0}$. The surface horizon also showed a strong contribution of fatty acids characteristic of anaerobic bacterial sources, especially the monounsaturated $\mathrm{C}_{16: 1 \omega 7}$ and $\mathrm{C}_{18: 1 \omega 7}$ isomers (Perry et al., 1979). Branched-chain (isoand anteiso-) $\mathrm{C}_{15: 0}$ and to a lesser extent, $\mathrm{C}_{13: 0}$ and $\mathrm{C}_{17: 0}$, fatty acids typical of grampositive bacteria (Kaneda, 1991) were also present in both samples.

The concentrations of the major fatty acids in both samples relative to palmitic acid are also compared in Figure 6.5. The changing relative importance of unsaturated, bacterial, and long-chain fatty acids can be seen more clearly in this representation. In both the surface and deep horizons, $\mathrm{C}_{14: 0}$ and $\mathrm{C}_{18: 0}$ do not experience any enrichment or depletion relative to $\mathrm{C}_{16: 0}$. This suggests that the down-core decrease in absolute concentrations of these isomers is simply the result of remineralization. Unsaturated fatty 
acids are more abundant in the surface horizon, both in absolute and relative terms. $\left(\mathrm{C}_{16: 1}\right.$ isomers were not quantified in deeper horizon, but were greatly depleted relative to the surface sample.) The higher concentrations of these monounsaturated fatty acids in the 0 $-0.75 \mathrm{~cm}$ sample may be due to the presence of live bacterial mats at the sediment-water interface. The major lipids of the filamentous sulfur bacteria, Thioploca and Beggiatoa spp., are $\mathrm{C}_{16: 1 \omega 7}, \mathrm{C}_{16: 0}$, and $\mathrm{C}_{18: 1 \omega 7}$ (McCaffrey, 1990). The relative concentrations of branched-chain bacterial fatty acids do not vary greatly with depth in the sediment. These isomers may represent bacterial species living throughout the core, rather than focused at the sediment-water interface; or they may simply experience more resistance to degradation than the unsaturated, straight-chain bacterial fatty acids.

In contrast to the planktonic and bacterial compounds $\left(\mathrm{C}_{12: 0}-\mathrm{C}_{18: 0}\right)$, the long-chain homologues $\left(\geq \mathrm{C}_{20: 0}\right)$ are relatively enriched in the $4.5-5.5 \mathrm{~cm}$ horizon when compared to the $0-0.75 \mathrm{~cm}$ horizon. The two series are otherwise identical in even-odd preference and distribution (maximum at $\mathrm{C}_{24: 0}$ ). These fatty acids are traditionally interpreted as originating from terrestrial sources, although more recent work based on the $\delta^{13} \mathrm{C}$ values of fatty acids from anoxic SMB sediments has suggested they could have a marine origin (Gong and Hollander, 1997). Gong and Hollander (1997) also found nearly identical concentration distributions at comparable sedimentary depths for all the fatty acid isomers discussed here. 


\section{Figure 6.4}

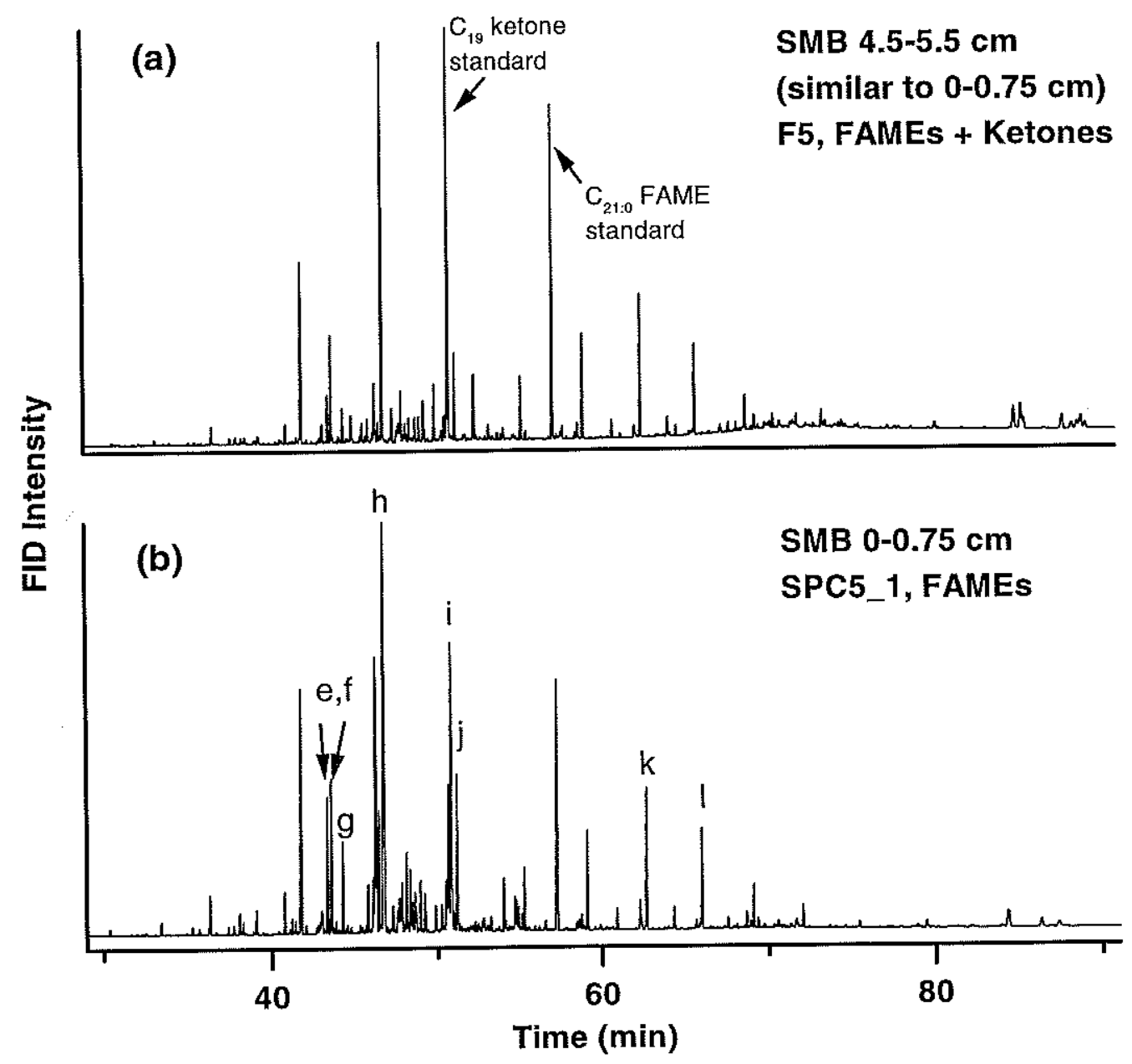

Figure 6.4 (a) Total FAME plus ketone fraction for SMB $4.5-5.5 \mathrm{~cm}$ sediment horizon (original chromatogram of SMB $0-0.75 \mathrm{~cm}$ fraction not available) and (b) purified FAME fraction from SMB $0-0.75 \mathrm{~cm}$ horizon; letters identify compounds collected by PCGC for ${ }^{14} \mathrm{C}$-AMS analysis (data in Table 6.2). 
Figure 6.5
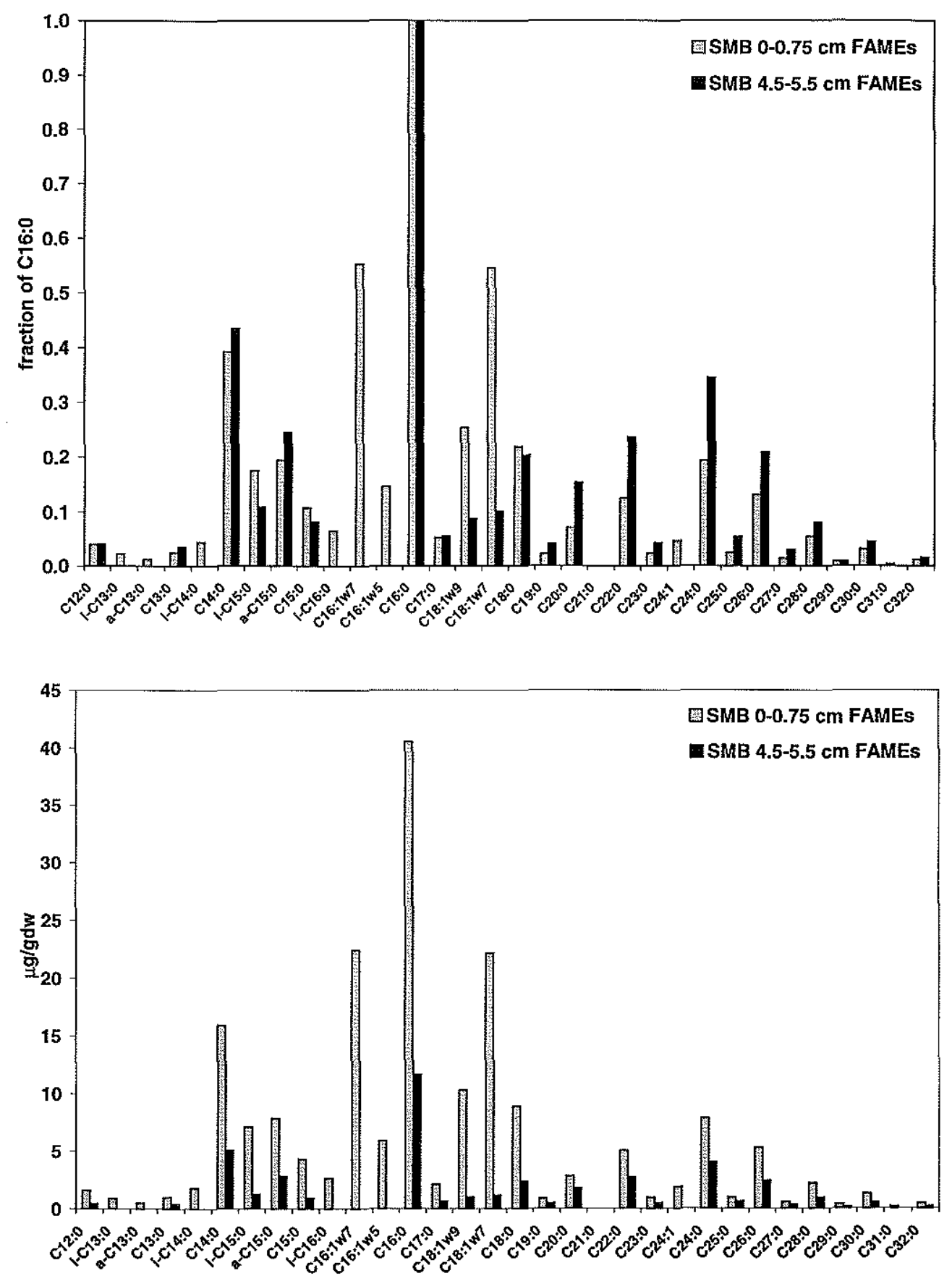

Figure 6.5 Absolute and relative abundance of fatty acids (as FAMEs) in SMB sediment. 


\subsubsection{Alcohols}

Figures 6.6 and 6.8 show representative chromatograms of the alcohol fractions used in this study. Figure 6.6(a) shows the total Fraction 7 obtained by flash $\mathrm{SiO}_{2}$-gel chromatography from the SMB $0-0.75 \mathrm{~cm}$ sedimentary horizon. It is a mixture of $n$ alcohols, 4-methyl-sterols, alkan-15-one-1-ols, and hopanols (here derivatized to acetates). The sample from the SMB $5.5-8.5 \mathrm{~cm}$ pre-bomb horizon was just as complex (chromatogram not shown). Urea adduction was used to split these fractions into straight-chain components ( $n$-alcohols and ketols) and branched-chain and cyclic structures (4-methyl-sterols and hopanols) as shown in Figure 6.6(b) and (c). The absolute abundance of all alcohols decreases with depth in the core as is seen for the other lipid biomarker classes (Figure 6.7). The relative distribution of the different alcohol groups changed between the pre-bomb and post-bomb horizons, however.

The $n$-alcohols are characterized by high even-odd predominance with a maximum at $n-\mathrm{C}_{24}-\mathrm{OH}$ for the post-bomb, $0.75-1.5 \mathrm{~cm}$ sample, but with a maximum at $n-\mathrm{C}_{22}-\mathrm{OH}$ for the pre-bomb, $5.5-8.5 \mathrm{~cm}$ sample. Qualitative evaluation of the additional SMB $0-0.75 \mathrm{~cm}$ and $4.5-5.5 \mathrm{~cm}$ horizons suggested this change in distribution was a general trend, with $n-\mathrm{C}_{24}-\mathrm{OH}$ more abundant toward the sediment-water interface and $n$ $\mathrm{C}_{22}-\mathrm{OH}$ becoming gradually enriched with depth. The relative concentrations of "zooplanktonic" (Sargent et al., 1977) $n$-alcohols $\left(n-\mathrm{C}_{16}-\mathrm{OH}, n-\mathrm{C}_{18}-\mathrm{OH}\right)$ do not change with respect to $n-\mathrm{C}_{24}-\mathrm{OH}$ between the two horizons.

$\mathrm{C}_{30}$-alkan-15-one-1-ol and the $\mathrm{C}_{31}$ and $\mathrm{C}_{32}$ hopanols are enriched in the deeper horizon (Figure 6.7). The absolute concentration of $\mathrm{C}_{32}$ hopanol, especially, did not change from its value in the $0.75-1.5 \mathrm{~cm}$ sample. There may be sedimentary bacterial sources of the $C_{31}$ and $C_{32}$ hopanols at depth, in contrast to $C_{30}$ hopanol and especially tetrahymanol, which are quite depleted relative to their near-surface concentrations. $\mathrm{C}_{30^{-}}$ alkan-15-one-1-ol may be preferentially preserved relative to other planktonic lipids (e.g. dinosterol). 
A partial gas chromatogram of the SMB post-bomb $(0-0.75 \mathrm{~cm})$ 4-desmethylsterol fraction used for isotopic analysis is shown in Figure 6.8. The chromatogram from the pre-bomb sample $(4.5-5.5 \mathrm{~cm})$ was very similar. Like the other alcohols, the sterols were derivatized to acetates for preparative capillary gas chromatographic (PCGC) separation of individual compounds for ${ }^{14} \mathrm{C}$ analysis. No further purification of the desmethyl-sterol fractions was necessary. Sterols were also isolated from SBB $0-1 \mathrm{~cm}$ post-bomb sediment. The distribution of isomers in this sample was similar to SMB sediment, so a chromatogram is not shown here.

The sterol isomers selected for ${ }^{14} \mathrm{C}$ analysis are identified by the same letters used in Tables 6.1 and 6.2 (next section). The structures and their common abbreviations are as follows: $\mathbf{u}(i), 24$-nor-cholesta-5,22-dien-3 $\beta$-ol $\left(\mathrm{C}_{26} \Delta^{5,22}\right)$; $\mathbf{u}(i i), 24$-nor-5 $\alpha$-cholest-22-

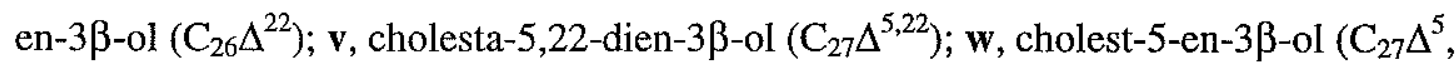
cholesterol); $\mathbf{x}, 5 \alpha$-cholestan-3 $\beta$-ol ( $5 \alpha$-C 27 , cholestanol); $\mathbf{y}, 24$-methylcholesta-5,22-

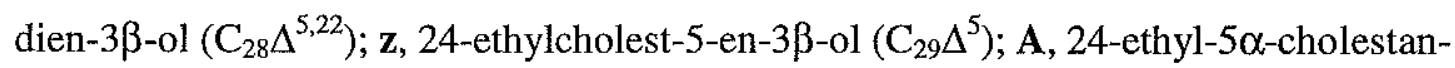
$3 \beta-o l\left(5 \alpha-\mathrm{C}_{29}\right)$. 
Figure 6.6
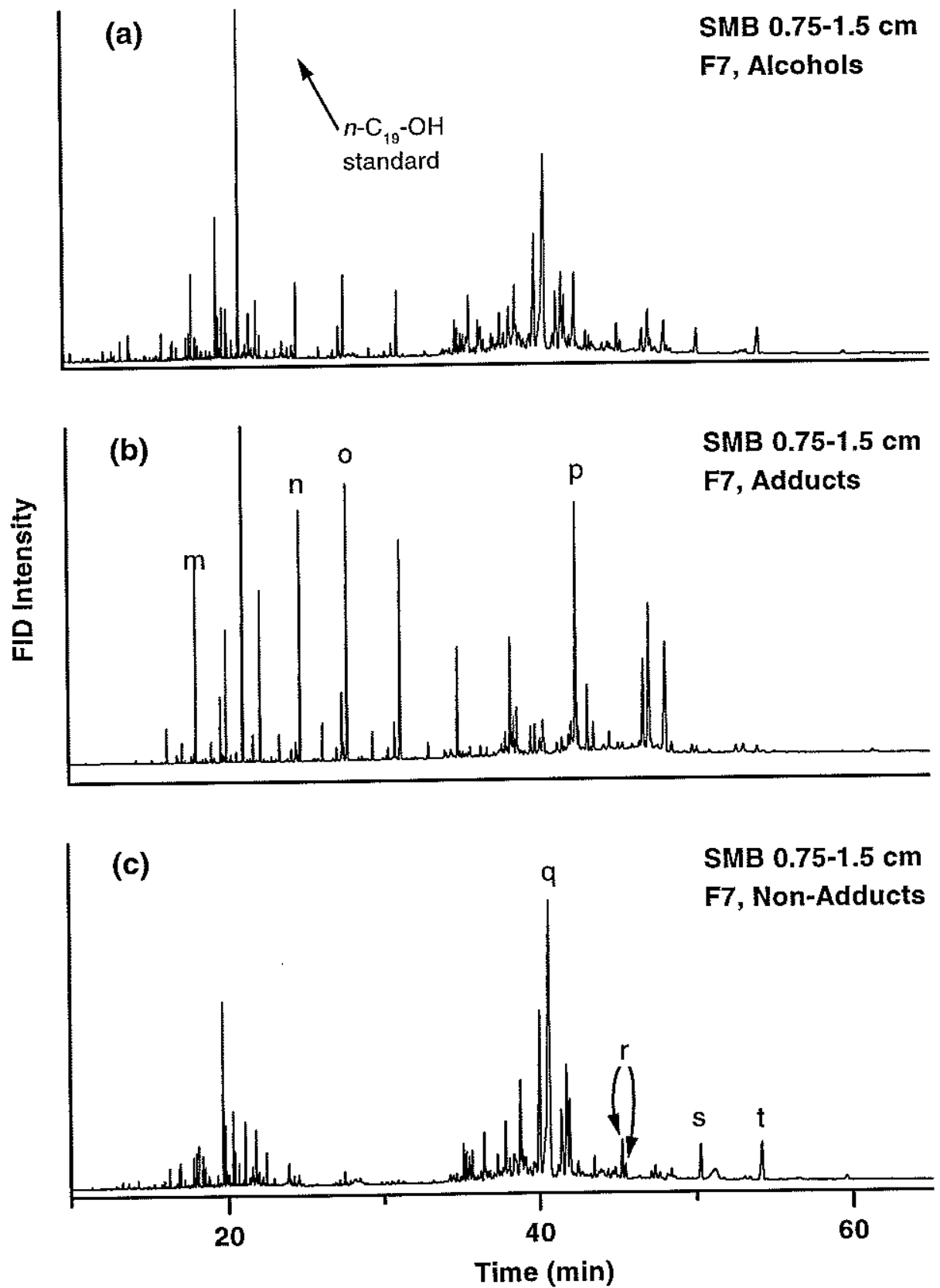

Figure 6.6 (a) Total alcohols (as acetates) (Fraction 7) from the SMB $0.75-1.5 \mathrm{~cm}$ horizon and $(\mathbf{b}, \mathbf{c}) n$-alcohol and non-adducted fractions obtained following urea adduction of the same sample; letters identify compounds collected by PCGC for ${ }^{14} \mathrm{C}$ AMS analysis (data in Table 6.2). 
Figure 6.7
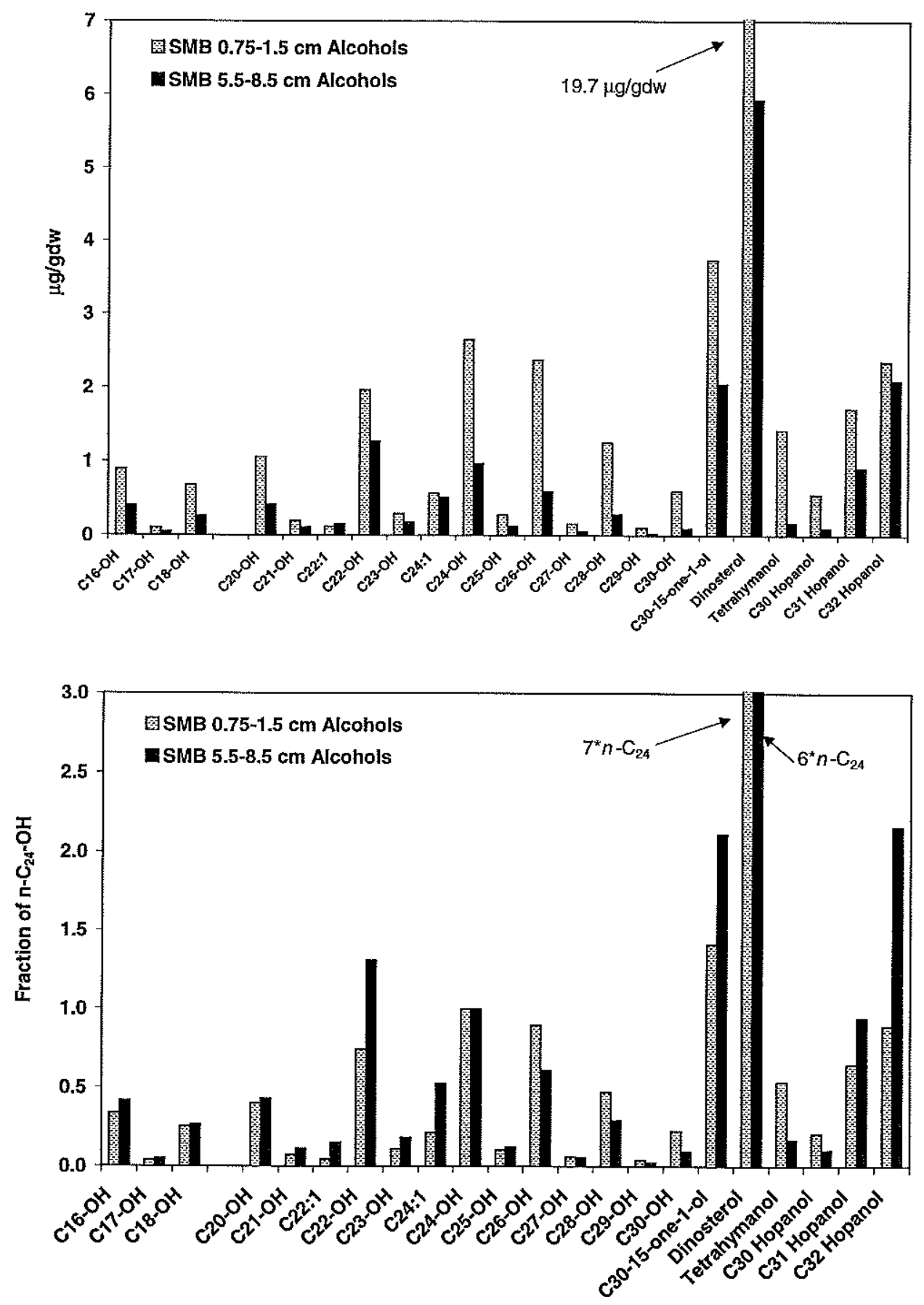

Figure 6.7 Absolute and relative abundance of $n$-alcohols and $\mathrm{C}_{30}$-alkan-15-one-1-ol in SMB sediments. $\left(7^{*} n-\mathrm{C}_{24}=\right.$ seven times the abundance of $n-\mathrm{C}_{24} ; 6^{*} n-\mathrm{C}_{24}=$ six times the abundance of $n-\mathrm{C}_{24}$.) 


\section{Figure 6.8}

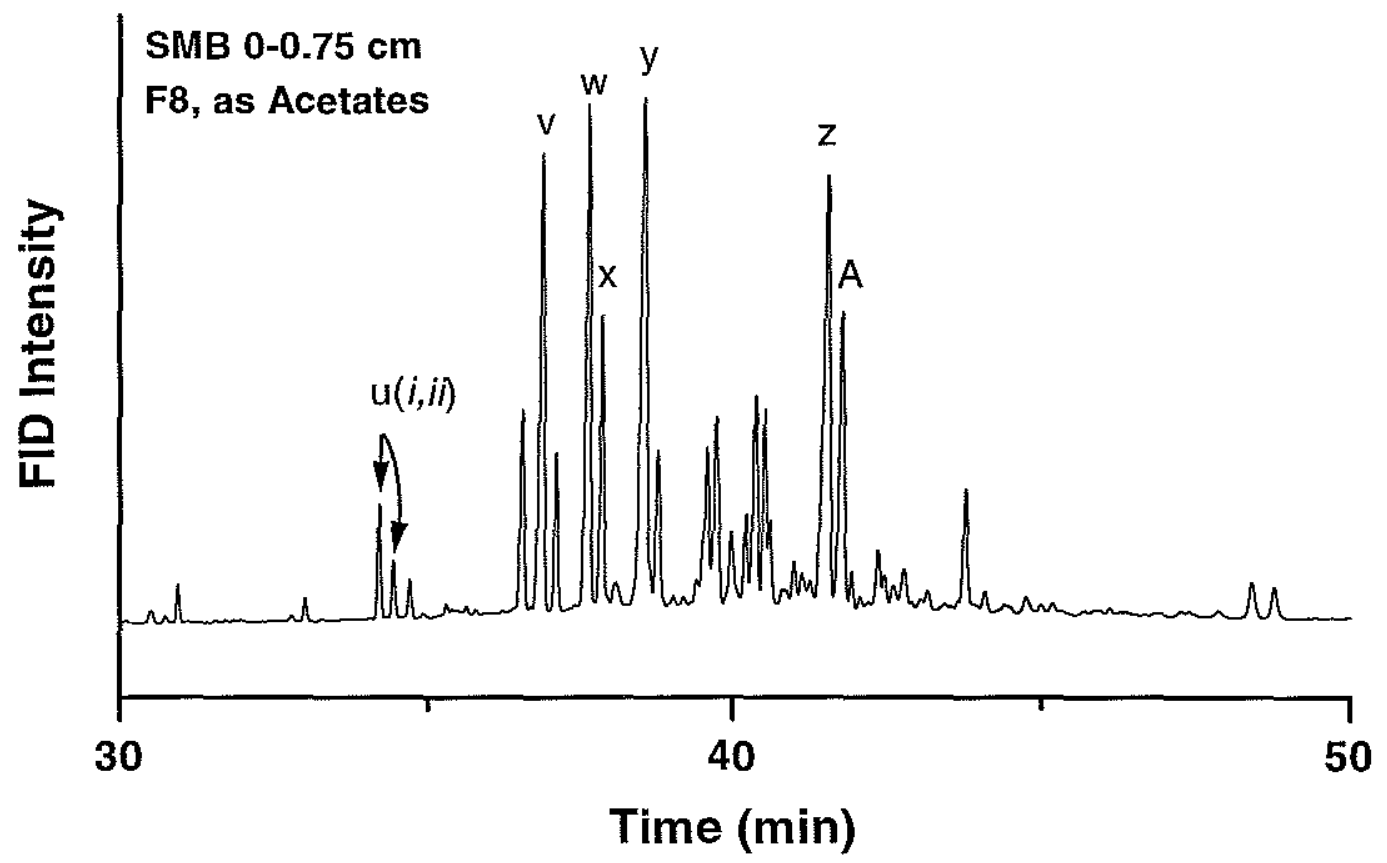

Figure 6.8 4-Desmethyl-sterols (as acetates) (Fraction 8) from the SMB $0-0.75 \mathrm{~cm}$ horizon; letters identify compounds collected by PCGC for ${ }^{14} \mathrm{C}$-AMS analysis (data in Table 6.2).

In Figure 6.9, the absolute concentrations of all the major sterols as well as their abundance relative to cholesterol are shown. Cholesterol was chosen as the comparison compound for relative abundance, because Grice et al. (1998) suggested adopting cholesterol as a tracer of integrated marine planktonic production. For both SMB horizons, $\mathrm{C}_{28} \Delta^{5,22}$ is the most abundant sterol isomer. $\mathrm{C}_{29} \Delta^{5}$ and dinosterol were also more abundant than cholesterol in both SMB horizons, while $C_{27} \Delta^{5,22}$ and $5 \alpha-C_{29}$ exceeded cholesterol in the deeper SMB horizon only. The absolute abundance of all sterols was lower in the pre-bomb sample, similar to what was observed previously for 
the fatty acids and the other alcohols. This is consistent with diagenetic loss of all labile lipids with increasing depth in the sediment. The stanol/stenol ratios for isomeric pairs (e.g. $5 \alpha-\mathrm{C}_{27} / \mathrm{C}_{27} \Delta^{5}$ ) increase in the deeper horizon. In other words, the pre-bomb sample is relatively enriched in stanols, probably due to in-situ transformation processes.

Anaerobic microbial reduction of $\Delta^{5}$ stenols is a well-known diagenetic source of $5 \alpha-$ stanols (Eyssen et al., 1973) and is considered the dominant source of these compounds in marine sediments.

The concentrations of sterols in SBB $0-1 \mathrm{~cm}$ sediment were three times greater than for SMB $0-0.75 \mathrm{~cm}$. Cholesterol was the most abundant isomer (Chapter 4).

Figure 6.9

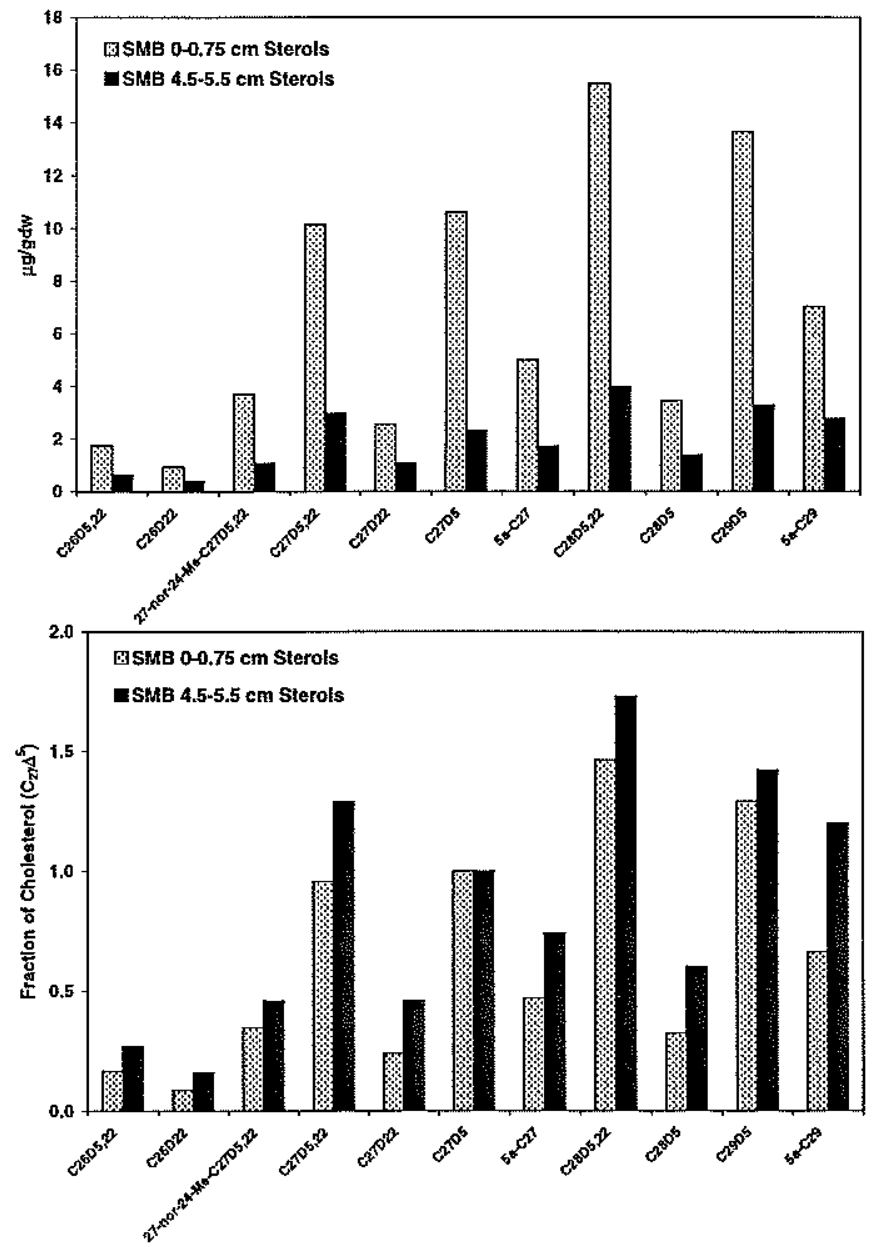

Figure 6.9 Absolute and relative abundance of sterols in SMB sediments. 


\subsubsection{Diols and Archaeal Ether Lipids}

The polar lipid fraction containing alkyl-1,15-diols and ether-linked lipids of Archaea is shown in Figure 6.10(a). In the original mixture (derivatized as acetates), the $\mathrm{C}_{30}$-1,15-diol isomer is easily identified, but the diols of lower carbon number are not easily located. The archaeal lipids, prior to cleavage of the ether linkages during reaction with $\mathrm{HI}$, are $\mathrm{C}_{80}$ structures (see Chapter 5) not easily amenable to analysis by $\mathrm{GC}$, although the peak at the far right of the chromatogram may be one of these compounds.

Following the reaction with $\mathrm{HI}$ and subsequent reduction of the products to hydrocarbons using $\mathrm{LiAlH}_{4}$, the SMB pre-bomb and post-bomb samples both resembled the chromatogram shown in Figure 6.10(b). A regular series of $n$-alkanes derived from the reduction of alkyl-diols is observed. These compounds have extremely high evenodd predominance, and although the maximum occurs at $n-\mathrm{C}_{30}$, the distribution is weighted toward lower carbon numbers $\left(n-\mathrm{C}_{28}, n-\mathrm{C}_{26}, \ldots n-\mathrm{C}_{20}\right)$. Above $n-\mathrm{C}_{30}$, there is only a small amount of $n-\mathrm{C}_{32}$, and the concentration of $n-\mathrm{C}_{34}$ is lower than the concentration of $n-\mathrm{C}_{20}$. Four archaeal biphytanes $\left(\mathrm{C}_{40}\right.$ isoprenoids, see Chapter 5 for structures) derived from caldarchaeol were observed in both samples, consistent with previous descriptions of sedimentary extracts and water-column POC (Hoefs et al., 1997; DeLong et al., 1998; King et al., 1998).

The absolute and relative concentrations of $\mathrm{C}_{30}-1,15$-diol and the archaeal lipids are shown in Figure 6.11. The $\mathrm{C}_{40}$ isoprenoids are present in low concentrations relative to other sedimentary biomarkers. The distinguishing feature of these lipids in SMB sediment is the relative enrichment of archaeal products compared to $\mathrm{C}_{30}-1,15$-diol in the deeper horizon. The diols are thought to have the same microalgal (references in Volkman et al., 1998) source as $\mathrm{C}_{30}$-alkan-15-one-1-ol. The Archaea are also thought to be of planktonic rather than sedimentary origin (e.g. DeLong, 1992). The enrichment of archaeal lipids relative to diols in deeper sediments may be a preservation effect. The ether linkage and large size of the original caldarchaeol may render the lipids of marine Archaea more resistant to degradation. 
The abundance of archaeal lipids in the SMB $0-0.75 \mathrm{~cm}$ horizon was not high enough for compound-specific ${ }^{14} \mathrm{C}$ analysis, but the pre-bomb $5.5-8.5 \mathrm{~cm}$ sample was used. Archaeal lipids from the SBB sediment-water interface $(0-1 \mathrm{~cm})$ were analyzed for the post-bomb isotopic comparison. The relative concentration distribution of archaeal lipids was identical in the SBB sample, but the absolute concentration was ten times higher.

Figure 6.10

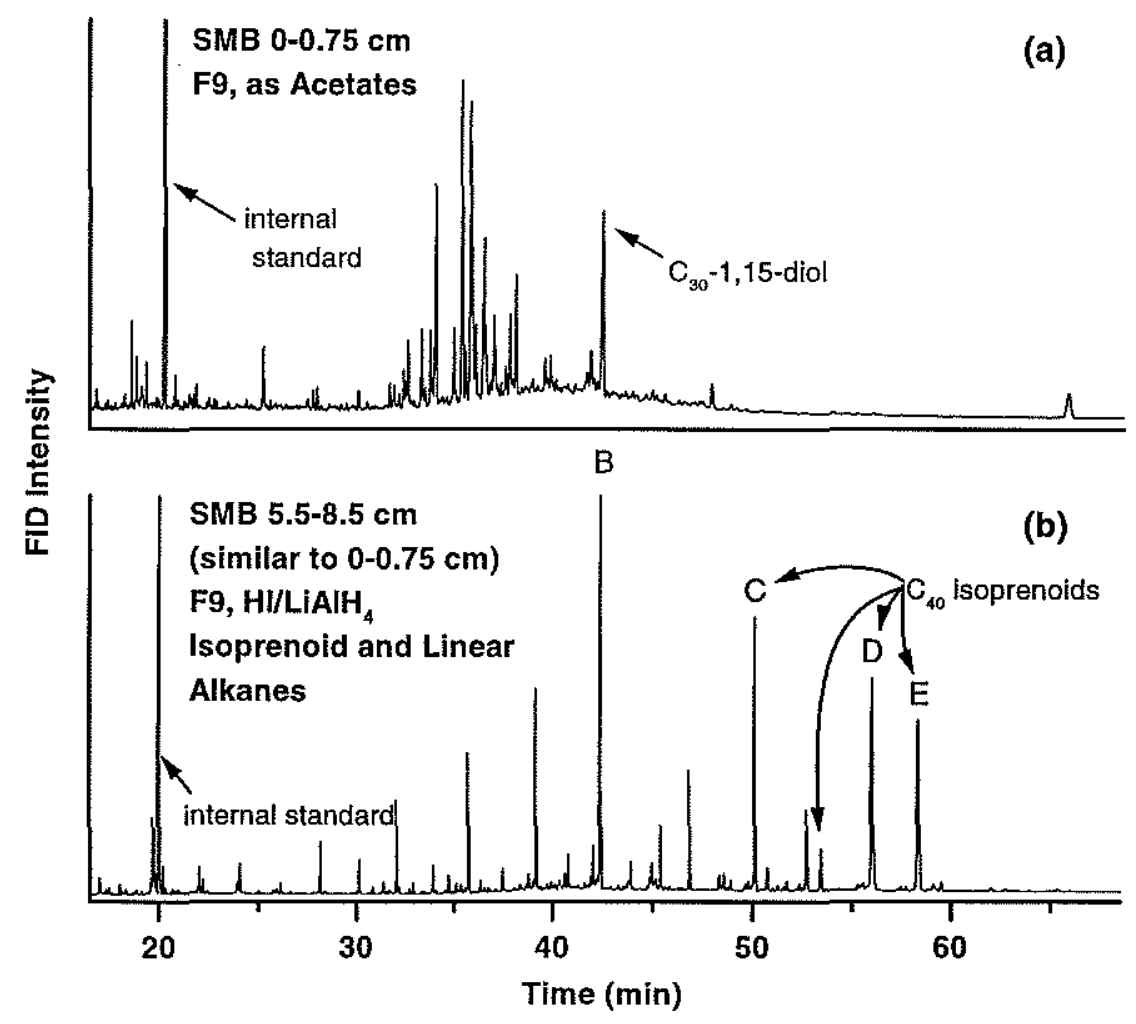

Figure 6.10 (a) Total diols and archaeal ether-linked isoprenoid lipids (Fraction 9) from the SMB $0-0.75 \mathrm{~cm}$ horizon (not abundant enough for compound-specific ${ }^{14} \mathrm{C}$ analysis) and (b) hydrocarbon fraction generated by $\mathrm{HI}$ cleavage and $\mathrm{LiAlH}_{4}$ reduction of SMB $5.5-8.5 \mathrm{~cm}$ Fraction 9; letters identify compounds collected by PCGC for ${ }^{14} \mathrm{C}-\mathrm{AMS}$ analysis (data in Table 6.2). 
Figure 6.11
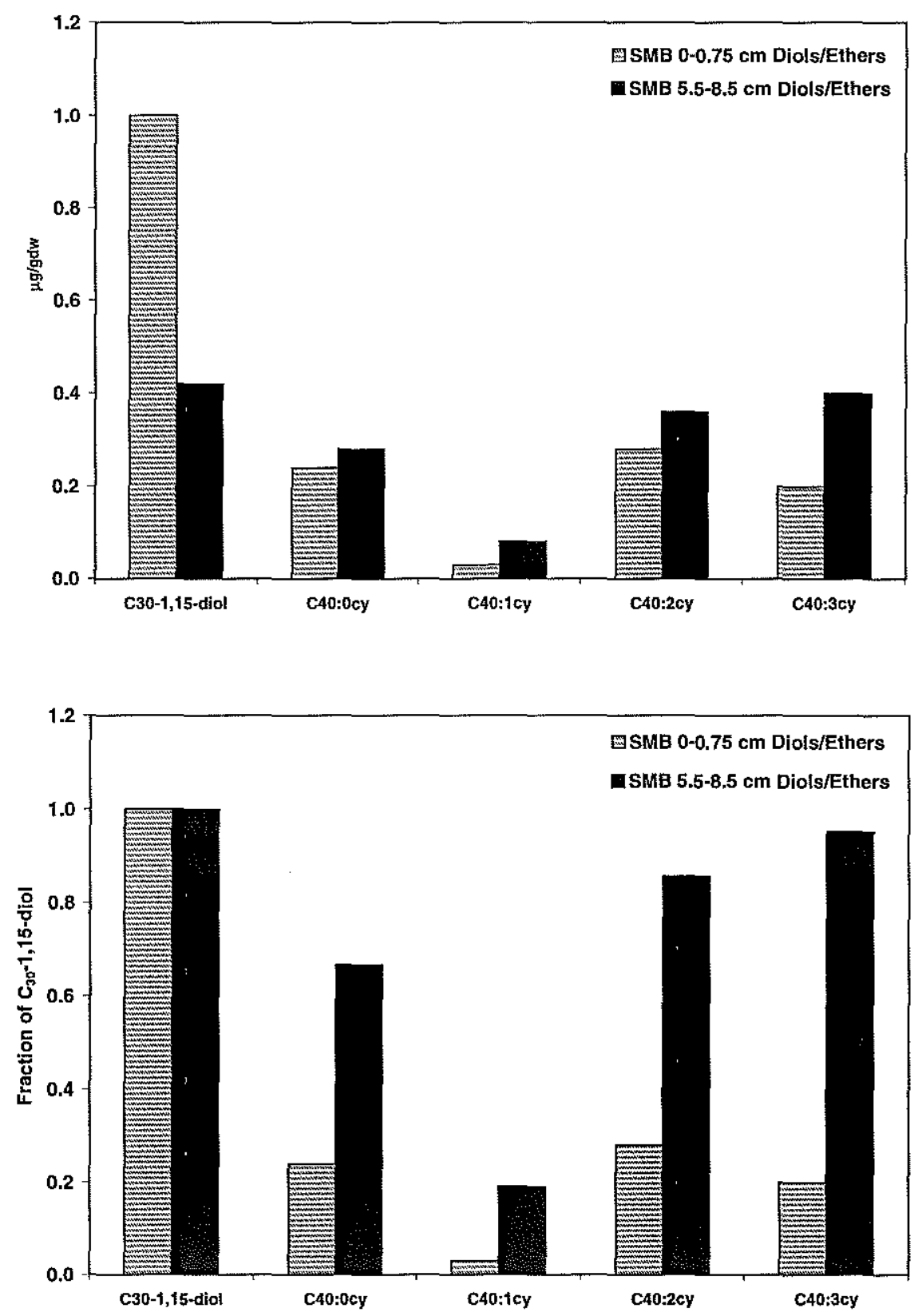

Figure 6.11 Absolute and relative abundance of $\mathrm{C}_{30}$-alkan-1,15-diol and $\mathrm{C}_{40}$ isoprenoid ether linked lipids of Archaea in SMB sediment. 


\subsubsection{PCGC Separations}

Automated preparative capillary gas chromatography (PCGC) methods were developed for the purpose of isolating individual biomarker lipids in sufficient quantity and purity for $\Delta^{14} \mathrm{C}$ analysis by AMS. The PCGC preparative trapping device allows up to six individual compounds to be recovered from each lipid fraction selected for compound-specific isotopic analysis. A typical run consists of about 100 consecutive injections at a concentration of $\sim 0.5-1.5 \mu \mathrm{gC} /$ peak/injection. A drawing of the PCGC system is shown in Chapter 2.

An example of a typical PCGC separation is shown in Figure 6.12. Six compounds were purified from the SMB 0-0.75 cm FAME fraction (batch \#1, BGseries). Aliquots of each trapped compound were subsequently re-analyzed by HRGC to verify compound identity and purity. Although the resolution of the "megabore" PCGC column is adequate, it is not as high as the analytical HRGC column, and small amounts $(<5 \%)$ of similar, closely-eluting isomers are typically entrained and trapped. This effect can be seen in the GC traces of compounds " $i$ " and " $j$ " in Figure 6.12. The isotopic effects caused by this small amount of material should be very minor. 
Figure 6.12

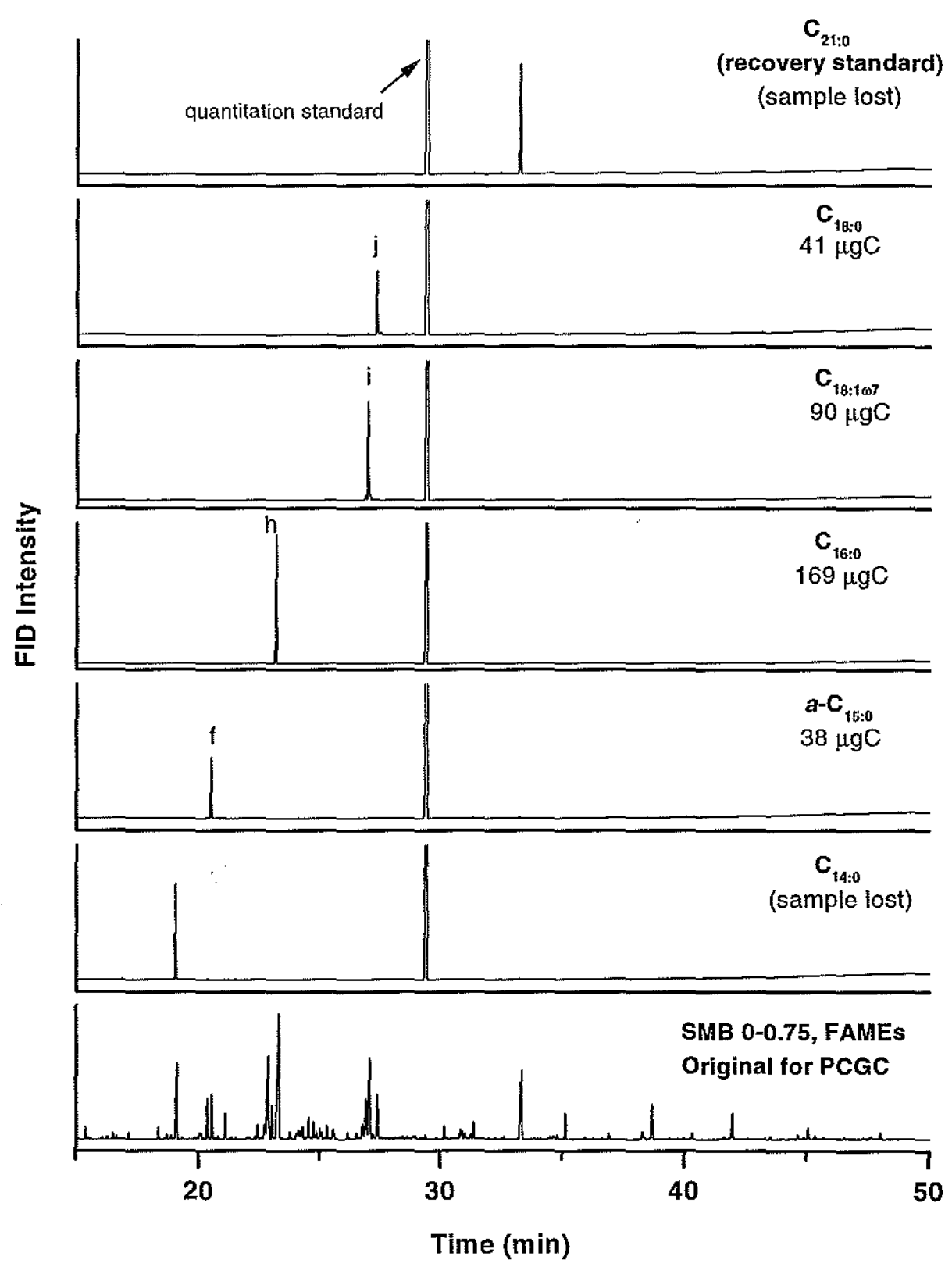

Figure 6.12 HRGC traces of SMB $0-0.75 \mathrm{~cm}$ FAME fraction. The original mixture is shown at the bottom. Re-analyzed aliquots of individual PCGC trap contents are shown above. FAME isomer peaks are labeled as in Figure 6.4 and Tables 6.1 and 6.2, and recovered quantities of the pure compounds are given. 
Twenty-one separate PCGC series make up the complete set of all attempts to obtain $\Delta^{14} \mathrm{C}$ values for SMB and SBB biomarker lipids. Of these 21 series, 3 yielded no usable data due to problems with sample contamination (usually column bleed) and/or low recoveries. The other 18 series yielded between 1 and the maximum of 6 individual lipid samples for isotopic analysis. Many of these PCGC separations represent method development work-in-progress and, in general, the number of successfully trapped compounds and high-quality ${ }^{14} \mathrm{C}$ results obtained per series increased over time. Table 6.1 lists the PCGC series in the order they were performed. All six PCGC traps were not always utilized for each series, so the overall efficiency of obtaining uncompromised samples and $\Delta^{14} \mathrm{C}$ data is better than the apparent $50 \%$ ( 66 data points $/ 6 * 21$ series). The complete table of PCGC series and trapped samples, including failed samples and the reason(s) for failure is given in the appendix to Chapter 2 . The letter identification codes in Table 6.1 correspond to the peak labels shown in the chromatograms (Figures 6.2, 6.4, $6.6,6.8,6.10$ ), in the table of isotopic data (Table 6.2), and in the plots of these data in the following discussions (Figures 6.20, 6.21). Representative structures of each of the biomarkers or biomarker classes were shown in Chapter 1.

The amount of carbon recovered and converted to graphite for ${ }^{14} \mathrm{C}$-AMS analysis is also given in Table 6.1. The sample sizes ranged from 19 to $172 \mu \mathrm{gC}$; the median value was $47 \mu \mathrm{gC}$ and the mean was $55 \mu \mathrm{gC}$. In the case of the SMB $0-0.75 \mathrm{~cm}$ postbomb horizon, the concentration of FAMEs was so high there was enough material to allow two PCGC separations. Two consecutive PCGC batches yielded 9 samples representing 8 different FAME compounds. To provide an independent replicate $\Delta^{14} \mathrm{C}$ measurement, $a$ - $\mathrm{C}_{15: 0}$ FAME was collected in both batches. Also, in several cases (e.g. trap AS-2, $\mathrm{C}_{16: 0}$ FAME) the amount of sample recovered was so high it was made into two separate AMS graphite targets. This approach provided a different kind of replicate. These samples are identical in every way except graphitization and accelerator performance and are used to assess the internal variability in $\Delta^{14} \mathrm{C}$ results due to AMS conditions rather than sample handling and PCGC purification. 
Table 6.1 List of individual compounds isolated by PCGC for which $\Delta^{14} \mathrm{C}$ values were obtained, in order of processing.

\begin{tabular}{|c|c|c|c|c|}
\hline $\begin{array}{c}\text { Series } \\
\text { and Trap }\end{array}$ & Compound & Horizon & Graphite Yield & $\begin{array}{c}\text { Letter Code } \\
\text { Identification }\end{array}$ \\
\hline AS-1 & $a-\mathrm{C}_{15: 0}$ & $\mathrm{SMB} 4.5-5.5 \mathrm{~cm}$, & 61 & f \\
\hline AS-2 & $\mathrm{C}_{16: 0}$ & Pre-Bomb & 86,159 & h \\
\hline AS-4 & $\mathrm{C}_{21: 0}$ standard & & 64,118 & \\
\hline AS-5 & $\mathrm{C}_{24: 0}$ & & 85 & $\mathrm{k}$ \\
\hline AS-6 & $\mathrm{C}_{26: 0}$ & & 49 & 1 \\
\hline AU-2 & $\mathrm{C}_{27} \Delta^{5}$ & SMB 4.5-5.5 cm, & 39 & $\mathrm{w}$ \\
\hline AU-4 & $\mathrm{C}_{28} \Delta^{5,22}$ & Pre-Bomb & 63 & $\mathrm{y}$ \\
\hline AU-5 & $\mathrm{C}_{29} \Delta^{5}$ & & 48 & $\mathrm{z}$ \\
\hline $\mathrm{AU}-6$ & $5 \alpha-C_{29}$ & & 37 & A \\
\hline AW-4 & Dinosterol & SMB $4.5-5.5 \mathrm{~cm}$ & 98 & $q$ \\
\hline AY -4 & $\mathrm{C}_{29} \Delta^{5}+5 \alpha-\mathrm{C}_{29}$ & SMB $3.5-4.5 \mathrm{~cm}$, & 172 & A \\
\hline AY -5 & $\mathrm{C}_{30}-15$-one-1-ol & Pre-Bomb & 47 & $\mathrm{p}$ \\
\hline BG-2 & $a-\mathrm{C}_{15: 0}$ & SMB 0-0.75 cm, & 31 & $\mathrm{f}$ \\
\hline BG-3 & $\mathrm{C}_{16: 0}$ & Post-Bomb & 81,57 & $\mathrm{~h}$ \\
\hline BG-4 & $\mathrm{C}_{18: 1 \omega 7}$ & & 78 & $\mathrm{i}$ \\
\hline BG-5 & $\mathrm{C}_{18: 0}$ & & 39 & j \\
\hline BH-1 & $i-\mathrm{C}_{15: 0}$ & SMB 0-0.75 cm, & 52 & $\mathrm{e}$ \\
\hline $\mathrm{BH}-2$ & $a-\mathrm{C}_{15: 0}$ & Post-Bomb & 46 & $\mathrm{f}$ \\
\hline BH-3 & $\mathrm{C}_{15: 0}$ & & 36 & $\mathrm{~g}$ \\
\hline BH-5 & $\mathrm{C}_{24: 0}$ & & 57 & $\mathrm{k}$ \\
\hline BH-6 & $\mathrm{C}_{26: 0}$ & & 44 & 1 \\
\hline BI-1 & $\mathrm{C}_{26} \Delta^{5,22}+\Delta^{22}$ & SMB $0-0.75 \mathrm{~cm}$, & 46 & $\mathrm{u}$ \\
\hline $\mathrm{BI}-2$ & $\mathrm{C}_{27} \mathrm{\Delta}^{5,22}$ & Post-Bomb & 113 & $\mathrm{v}$ \\
\hline BI-3 & $\mathrm{C}_{27} \Delta 5$ & & 50,74 & $\mathrm{w}$ \\
\hline BI-4 & $5 \alpha-C_{29}$ & & 96 & $\mathrm{z}$ \\
\hline BI-5 & $\mathrm{C}_{30^{-1}} 15$-one-1-ol & & 50 & $\mathrm{p}$ \\
\hline BJ-2 & $\mathrm{C}_{19}-\mathrm{OH}$ standard & SMB $0-0.75 \mathrm{~cm}$ & 60,94 & \\
\hline BK-1 & Dinosterol & SMB $0-0.75 \mathrm{~cm}$ & 48,85 & $q$ \\
\hline \multicolumn{5}{|c|}{$* * * * * *$ Began routine column bleed clean-up $* * * * * *$} \\
\hline BV-3 & $n-\mathrm{C}_{33}$ standard & SBB 0-1 cm, & 88 & \\
\hline BV-4 & $\mathrm{C}_{40: 2 \mathrm{cy}}$ & Post-Bomb & 22 & $\mathrm{D}$ \\
\hline BV-5 & $\mathrm{C}_{40: 3 c y}$ & & 20 & $\mathrm{E}$ \\
\hline BX-3 & $n-\mathrm{C}_{30}$ & SMB 5.5-8.5 cm, & 26 & B \\
\hline BX-4 & $\mathrm{C}_{40: 0 \mathrm{cy}}$ & Pre-Bomb & 20 & $\mathrm{C}$ \\
\hline BX-5 & $\mathrm{C}_{40: 2 c y}$ & & 22 & $\mathrm{D}$ \\
\hline BX-6 & $\mathrm{C}_{40: 3 \mathrm{cy}}$ & & 21 & $\mathrm{E}$ \\
\hline
\end{tabular}




\begin{tabular}{|c|c|c|c|c|}
\hline CA-1 & $\mathrm{C}_{27} \triangle^{5,22}$ & SBB $0-1 \mathrm{~cm}$, & 44 & $\mathrm{v}$ \\
\hline $\mathrm{CA}-2$ & $\mathrm{C}_{27} \Delta^{5}$ & Post-Bomb & 73 & $\mathrm{w}$ \\
\hline $\mathrm{CA}-3$ & $5 \alpha-C_{27}$ & & 39 & $\mathrm{x}$ \\
\hline $\mathrm{CA}-4$ & $\mathrm{C}_{28} \Delta^{5,22}$ & & 29 & $\mathrm{y}$ \\
\hline $\mathrm{CA}-5$ & $\mathrm{C}_{29} \Delta^{5}$ & & 38 & $\mathrm{z}$ \\
\hline CA-6 & $5 \alpha-C_{29}$ & & 24 & A \\
\hline $\mathrm{CB}-2$ & $\mathrm{C}_{31}$ hopanol & $\mathrm{SMB} 5.5-8.5 \mathrm{~cm}$ & 22 & $\mathrm{~s}$ \\
\hline $\mathrm{CB}-3$ & $\mathrm{C}_{32}$ hopanol & Pre-Bomb & 40 & $\mathrm{t}$ \\
\hline $\mathrm{CC}-2$ & Tetra/ $\mathrm{C}_{30}$ hopanol & SMB $0.75-1.5 \mathrm{~cm}$, & 33 & $\mathrm{r}$ \\
\hline $\mathrm{CC}-3$ & $\mathrm{C}_{31}$ hopanol & Post-Bomb & & \\
\hline $\mathrm{CC}-4$ & $\mathrm{C}_{32}$ hopanol & & 46 & $\mathrm{t}$ \\
\hline $\mathrm{CD}-1$ & $\mathrm{C}_{16}-\mathrm{OH}$ & SMB $0.75-1.5 \mathrm{~cm}$, & 33 & $\mathrm{~m}$ \\
\hline $\mathrm{CD}-3$ & $\mathrm{C}_{22}-\mathrm{OH}$ & Post-Bomb & 67 & $\mathrm{n}$ \\
\hline $\mathrm{CD}-4$ & $\mathrm{C}_{24}-\mathrm{OH}$ & & 74 & 0 \\
\hline $\mathrm{CD}-5$ & $\mathrm{C}_{30}$-15-one-1-ol & & 48 & $\mathrm{p}$ \\
\hline $\mathrm{CI}-2$ & $n-\mathrm{C}_{24+26+28+30}$ & $\mathrm{SMB} 0-2.5 \mathrm{~cm}$ & 27 & $\mathrm{a}$ \\
\hline $\mathrm{CI}-3$ & $n-\mathrm{C}_{27}$ & Post-Bomb & 19 & $\mathrm{~b}$ \\
\hline CI-4 & $n-\mathrm{C}_{29}$ & & 35 & $\mathrm{c}$ \\
\hline CI-5 & $n-\mathrm{C}_{31}$ & & 27 & d \\
\hline $\mathrm{CJ}-2$ & $n-\mathrm{C}_{24+26+28+30}$ & SMB $2.5-8.5 \mathrm{~cm}$ & 33 & a \\
\hline $\mathrm{CJ}-3$ & $n-\mathrm{C}_{27}$ & Pre-Bomb & 40 & $\mathrm{~b}$ \\
\hline $\mathrm{CJ}-4$ & $n-\mathrm{C}_{29}$ & & 86 & $\mathrm{c}$ \\
\hline $\mathrm{CJ}-5$ & $n-C_{31}$ & & 34 & $\mathrm{~d}$ \\
\hline $\mathrm{CN}-2$ & $\mathrm{C}_{19}-\mathrm{OH}$ standard & SMB $5.5-8.5 \mathrm{~cm}$ & 76 & \\
\hline $\mathrm{CN}-3$ & $\mathrm{C}_{22}-\mathrm{OH}$ & Pre-Bomb & 53 & $\mathrm{n}$ \\
\hline $\mathrm{CN}-4$ & $\mathrm{C}_{24^{4}} \mathrm{OH}$ & & 37 & o \\
\hline
\end{tabular}

\subsection{4 $\Delta^{14} \mathrm{C}$ Data}

The $\Delta^{14} \mathrm{C}$ data for SMB and SBB individual biomarker lipids are presented in Table 6.2. The data are organized by organic compound class and are divided into postbomb and pre-bomb samples. This facilitates a comparison of the changes in biomarker $\Delta^{14} \mathrm{C}$ values due to the uptake of bomb- ${ }^{14} \mathrm{C}$. In the cases where identical compounds were recovered from both pre-bomb and post-bomb sedimentary horizons, the difference in $\Delta^{14} \mathrm{C}$ between each pre-bomb/post-bomb pair is reported in the right-hand column as 
$\Delta\left(\Delta^{14} \mathrm{C}\right)$. The two sets of samples (PCGC series BV and CA) obtained from SBB rather than SMB surface sediments are noted. These data are also compared to SMB pre-bomb lipids, because no pre-bomb SBB sediments were obtained, and because the geographic and oceanic environments (i.e. surface water $\Delta^{14} \mathrm{C}_{\mathrm{DIC}}$ ) of SMB and SBB are quite similar.

The following sections are organized by organic compound class and describe the $\Delta^{14} \mathrm{C}$ data with minimal discussion. Interpretation of both the general features of the data and of the individual measurements is saved for the later discussion sections. The main features of the data can, however, be summarized as follows: (i) most lipids from SMB post-bomb sediment have post-bomb $\Delta^{14} \mathrm{C}$ values similar to the $\Delta^{14} \mathrm{C}$ of surface water DIC, and (ii) the lipids with $\Delta^{14} \mathrm{C}$ values that vary from this theme are not randomly distributed, but belong to distinct lipid classes. 
Table 6.2 Summary of compound-specific $\Delta^{14} \mathrm{C}$ and $\delta^{13} \mathrm{C}$ data. The $\delta^{13} \mathrm{C}$ values are based on irm-GC/MS measurements unless otherwise indicated.

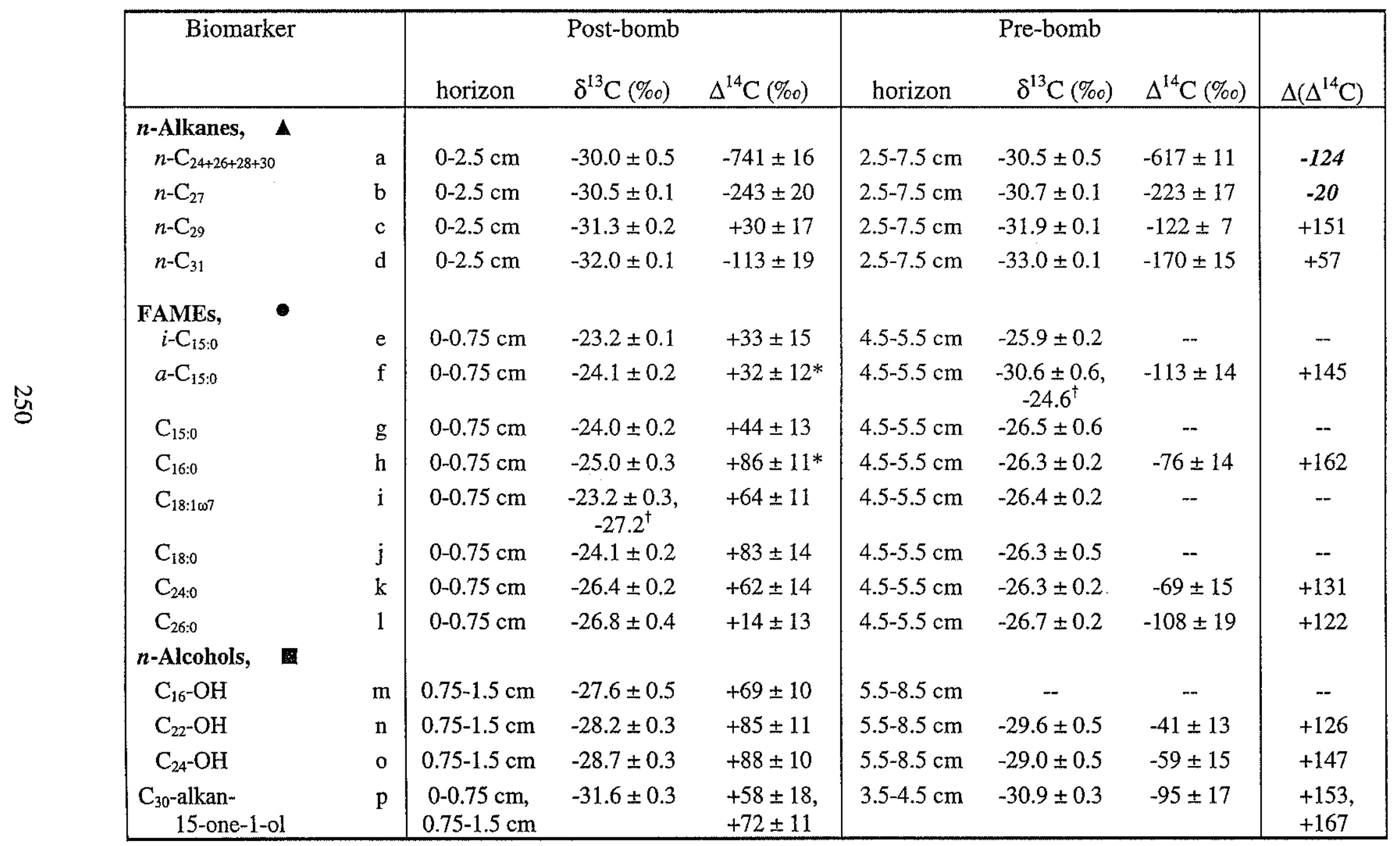




\begin{tabular}{|c|c|c|c|c|c|c|c|c|}
\hline \multicolumn{9}{|l|}{ Sterols/Hopanols, } \\
\hline Dinosterol & $q$ & $0-0.75 \mathrm{~cm}$ & $\begin{array}{c}-23.4 \pm 0.1 \\
-26.6^{\dagger}\end{array}$ & $+71 \pm 14^{*}$ & $4.5-5.5 \mathrm{~cm}$ & $-24.4 \pm 0.2$ & $-88 \pm 14$ & +159 \\
\hline $\begin{array}{r}\text { Tetrahymanol/ } \\
\mathrm{C}_{30} \text { hopanol }\end{array}$ & $\mathrm{r}$ & $0.75-1.5 \mathrm{~cm}$ & $-24.5^{\dagger}$ & $+47 \pm 12$ & -- & & & -- \\
\hline $\mathrm{C}_{31}$ hopanol & s & -- & - & - & $5.5-8.5 \mathrm{~cm}$ & $-24.0^{\dagger}$ & $-96 \pm 15$ & -- \\
\hline $\mathrm{C}_{32}$ hopanol & $\mathrm{t}$ & $0.75-1.5 \mathrm{~cm}$ & $-24.9^{\dagger}$ & $+16 \pm 11$ & $5.5-8.5 \mathrm{~cm}$ & $-26.1^{\dagger}$ & $-134 \pm 18$ & +150 \\
\hline$C_{26} \Delta^{5,22}+\Delta^{22}$ & $\mathrm{u}$ & $0-0.75 \mathrm{~cm}$ & $-27.6 \pm 0.8$ & $+62 \pm 19$ & $4.5-5.5 \mathrm{~cm}$ & $-26.9 \pm 1.4$ & -- & - \\
\hline $\mathrm{C}_{27} \Delta^{5,22}$ & $\mathrm{v}$ & $\begin{array}{c}0-0.75 \mathrm{~cm} \\
0-1 \mathrm{~cm}^{\S}\end{array}$ & $\begin{array}{l}-24.9 \pm 0.1 \\
-24.3 \pm 0.1^{\S}\end{array}$ & $\begin{array}{l}+71 \pm 10 \\
+50 \pm 11^{\S}\end{array}$ & $4.5-5.5 \mathrm{~cm}$ & $-25.4 \pm 0.2$ & - & - \\
\hline $\mathrm{C}_{27} \Delta^{5}$ & w & $\begin{array}{l}0-0.75 \mathrm{~cm} \\
0-1 \mathrm{~cm}^{\S}\end{array}$ & $\begin{array}{l}-24.9 \pm 0.2 \\
-23.9 \pm 0.2^{\S}\end{array}$ & $\begin{array}{l}+72 \pm 10^{*} \\
+70 \pm 10^{\S}\end{array}$ & $4.5-5.5 \mathrm{~cm}$ & $-23.8 \pm 0.1$ & $-64 \pm 23$ & $\begin{array}{l}+136 \\
+134\end{array}$ \\
\hline $5 \alpha-C_{27}$ & $\mathrm{x}$ & $0-1 \mathrm{~cm}^{\S}$ & $-24.7 \pm 0.2^{\S}$ & $+61 \pm 10^{\S}$ & & & & \\
\hline$C_{28} \Delta^{5,22}$ & $\mathrm{y}$ & $\begin{array}{c}0-0.75 \mathrm{~cm} \\
0-1 \mathrm{~cm}^{8}\end{array}$ & $\begin{array}{l}-26.6 \pm 0.2 \\
-25.9 \pm 0.1^{8}\end{array}$ & $\begin{array}{l}+58 \pm 11 \\
+71 \pm 14^{\S}\end{array}$ & $4.5-5.5 \mathrm{~cm}$ & $-25.2 \pm 0.1$ & $-61 \pm 15$ & $\begin{array}{l}+119 \\
+132\end{array}$ \\
\hline $\mathrm{C}_{29} \Delta^{5}$ & $\mathrm{z}$ & $\begin{array}{c}0-0.75 \mathrm{~cm} \\
0-1 \mathrm{~cm}^{\S}\end{array}$ & $\begin{array}{l}-25.5 \pm 0.2 \\
-24.4 \pm 0.2^{\S}\end{array}$ & $\begin{array}{c}-- \\
+72 \pm 10^{\S}\end{array}$ & $4.5-5.5 \mathrm{~cm}$ & $-25.3 \pm 0.1$ & $-59 \pm 20$ & +131 \\
\hline $5 \alpha-C_{29} \Delta^{0}$ & A & $\begin{array}{c}0-0.75 \mathrm{~cm} \\
0-1 \mathrm{~cm}^{\S}\end{array}$ & $\begin{array}{l}-25.5 \pm 0.2 \\
-25.4 \pm 0.2^{\S}\end{array}$ & $\begin{array}{l}+90 \pm 15 \\
+93 \pm 19^{\S}\end{array}$ & $\begin{array}{l}3.5-4.5 \mathrm{~cm} \\
4.5-5.5 \mathrm{~cm}\end{array}$ & $-25.3 \pm 0.1$ & $\begin{array}{c}-102 \pm 20 \\
-73 \pm 9\end{array}$ & $\begin{array}{l}+177 \\
+166\end{array}$ \\
\hline \multicolumn{9}{|l|}{ Diols and Archaeal } \\
\hline $\begin{array}{l}\text { Lipids, } \\
n \text {-C } \mathrm{C}_{30} \text { (diol) }\end{array}$ & $\mathrm{B}$ & - & - & - & $5.5-8.5 \mathrm{~cm}$ & $-33.5 \pm 0.4$ & $-101 \pm 20$ & - \\
\hline $\mathrm{C}_{40: 0 c y}$ & $\mathrm{C}$ & -- & - & -- & $5.5-8.5 \mathrm{~cm}$ & $-20.8 \pm 0.4$ & $-123 \pm 35$ & -- \\
\hline $\mathrm{C}_{40: 2 \mathrm{cy}}$ & $\mathrm{D}$ & $0-1 \mathrm{~cm}^{\S}$ & $-22.1 \pm 0.4^{\S}$ & $-101 \pm 21^{\S}$ & $5.5-8.5 \mathrm{~cm}$ & $-20.3 \pm 0.4$ & $-141 \pm 24$ & +40 \\
\hline $\mathrm{C}_{40: 3 c y}$ & $\mathrm{E}$ & $0-1 \mathrm{~cm}^{8}$ & $-22.5 \pm 0.4^{\S}$ & $-100 \pm 25^{\S}$ & $5.5-8.5 \mathrm{~cm}$ & $-20.5 \pm 0.4$ & $-121 \pm 21$ & +21 \\
\hline
\end{tabular}

* Average of two $\Delta^{14} \mathrm{C}$ values.

$\uparrow \delta^{13} \mathrm{C}$ determined by off-line irMS on splits of $\mathrm{CO}_{2}$.

$\S$ Samples from SBB 0-1 cm sediment. 


\subsubsection{1 n-Alkanes}

A brief summary of the $n$-alkane $\Delta^{14} \mathrm{C}$ measurements is given here; more extenstive discussion is saved for Chapter 7.

The $n$-alkanes represent the only lipid class in which individual $\Delta^{14} \mathrm{C}$ values obtained from a single homologous series varied greatly. The pre-bomb, odd-chain $n$ alkanes had $\Delta^{14} \mathrm{C}$ values between $-223 \%$ ( $\left.n-\mathrm{C}_{27}\right)$ and $-122 \%$ (n-C $\left.\mathrm{C}_{29}\right)$, while the composite sample of even-numbered $n$-alkanes $\left(n-\mathrm{C}_{24+26+28+30}\right)$ was greatly depleted in ${ }^{14} \mathrm{C}\left(-617 \%\right.$ ) . The post-bomb, odd-chain $n$-alkanes had an even larger $\Delta^{14} \mathrm{C}$ range, $-243 \%$ o $\left(n-\mathrm{C}_{27}\right)$ to $+30 \%$ ( $\left.n-\mathrm{C}_{29}\right)$. The even-numbered $n$-alkanes from post-bomb sediment were more ${ }^{14} \mathrm{C}$-depleted relative to pre-bomb sediment $(-741 \%$ ) .

This unusual distribution of results is consistent with prior expectations based on the $n$-alkane concentration distributions. Values of $-617 \%$ and $-741 \%$ for even-chain $n$ alkanes correspond to $\sim 62$ and $74 \%$ fossil carbon $\left(\Delta^{14} \mathrm{C}=-1000 \%\right)$, respectively. The odd carbon-number alkanes also contain both fossil components and material from modern plant waxes. The varying proportion of these components within the $n$ - $\mathrm{C}_{27}, n$ $\mathrm{C}_{29}$, and $n-\mathrm{C}_{31}$ homologues results in the large spread in $\Delta^{14} \mathrm{C}$ results for the different $n$ alkanes. The most informative of these values may be the $+30 \%$ measurement for postbomb $n-\mathrm{C}_{29}$. A positive $\Delta^{14} \mathrm{C}$ value indicates the quantitative majority of this compound in SMB sediment is post-bomb and therefore less than 50 years old.

A quantitative isotopic mass balance model for the $n$-alkanes is developed in the discussion of terrestrial carbon contributions to SMB sediment in Chapter 7. It uses the $\Delta^{14} \mathrm{C}$ (and $\delta^{13} \mathrm{C}$, next section) data to reconstruct both the isotopic signatures and the fractions of terrestrial and fossil carbon contributing to the total $n$-alkane distributions. The terrestrial $\Delta^{14} \mathrm{C}$ endmember values are then used in a model of the origin of SMB sedimentary TOC. 


\subsubsection{FAMEs}

The pre-bomb $\Delta^{14} \mathrm{C}$ value for $\mathrm{C}_{16: 0}(-76 \pm 14 \%$ ) agrees within measurement error with the estimate of pre-bomb surface water $\Delta^{14} \mathrm{C}_{\mathrm{DIC}}(-82 \%)$, consistent with a marine source for this compound. The post-bomb $\mathrm{C}_{16: 0}$ and $\mathrm{C}_{18: 0}(+86 \pm 11 \%$ and $+83 \pm 14 \%$, respectively) are slightly ${ }^{14} \mathrm{C}$-enriched relative to 1996 surface water $\Delta^{14} \mathrm{C}_{\text {DIC }}(+71 \%$ ); but because this sedimentary horizon integrates $\sim 5-10$ years' material and $\Delta^{14} \mathrm{C}_{\mathrm{DIC}}$ was $>+80 \%$ as recently as 1990 (based on linear extrapolation of data in Chapter 4), these values are also believed to indicate carbon fixed by marine photoautotrophs.

Another potential source for some of the $\mathrm{C}_{16: 0}$ and $\mathrm{C}_{18: 0}$ fatty acid carbon is the visible population of filamentous sulfur bacteria living at the SMB sediment-water interface. These organisms also produce $\mathrm{C}_{18: 1 \omega 7}$ (McCaffrey, 1990) and are probably the major source of this compound in SMB surface sediments. The $\Delta^{14} \mathrm{C}$ of $\mathrm{C}_{18: 1 \omega 7}$ in postbomb sediment is $+64 \pm 11 \%$, also not significantly different from the isotopic composition of surface water DIC. The positive $\Delta^{14} \mathrm{C}$ value indicates the bacteria responsible for producing this fatty acid are living primarily as heterotrophs, feeding on the remains of phytoplanktonic primary production. The branched-chain fatty acids, $i$ $\mathrm{C}_{15: 0}$ and $a-\mathrm{C}_{15: 0}$, as well as the linear $\mathrm{C}_{15: 0}$ isomer, are believed to derive from bacterial sources in marine sediments (e.g. Perry et al., 1979). Only one pre-bomb $\Delta^{14} \mathrm{C}$ value is available, $-113 \pm 14 \%$ for $a-\mathrm{C}_{15: 0}$. This number is significantly lower than pre-bomb surface water $\Delta^{14} \mathrm{C}_{\mathrm{DIC}}$. The same effect is observed for the post-bomb $\mathrm{C}_{15}$ fatty acids. $\Delta^{14} \mathrm{C}$ values for $i-\mathrm{C}_{15: 0}, a-\mathrm{C}_{15: 0}$, and $\mathrm{C}_{15: 0}$ range between $+32 \%$ and $+44 \%$, and include two independent replicates for $a-\mathrm{C}_{15: 0}$. The average value, $+35 \%$, while still clearly postbomb $(>0 \%$ ), is significantly lower than contemporary surface water DIC $(+71 \% o)$. These data may indicate that some of the bacteria responsible for producing $\mathrm{C}_{15}$ fatty acids in this environment obtain a fraction of their carbon from bottom water DIC $\left(\Delta^{14} \mathrm{C}\right.$ $\sim-190 \%$, Figure 6.1).

Data for the long-chain fatty acids from both pre-bomb and post-bomb sedimentary horizons show that $\mathrm{C}_{26: 0}$ is more ${ }^{14} \mathrm{C}$-depleted than $\mathrm{C}_{24: 0}$. The measured 
values ( $+62 \% o$ and $-69 \%$ ) for $\mathrm{C}_{24: 0}$ agree within measurement errors with the estimated $\Delta \Delta^{14} \mathrm{C}_{\text {DIC }}$ endmembers, $+71 \%$ and $-82 \%$. The $\mathrm{C}_{24: 0}$ data are in agreement with the $\Delta{ }^{14} \mathrm{C}$ of surface water DIC at the time of sediment deposition, indicating these lipids are of marine source. However, the $\Delta^{14} \mathrm{C}$ values measured for $\mathrm{C}_{26: 0}(+14 \% o$ and $-108 \%$ ) are ${ }^{14} \mathrm{C}$-depleted relative to $\Delta{ }^{14} \mathrm{C}_{\mathrm{DIC}}$, indicating that the $\mathrm{C}_{26: 0}$ samples have incorporated a portion of pre-aged carbon.

\subsubsection{3 n-Alcohols, $C_{30}$-alkan-15-one-1-ol, and $C_{30^{-}}$alkan-1,15-diol}

The $\Delta^{14} \mathrm{C}$ values reported for linear alcohols are based on lipid fractions extracted from the SMB $0.75-1.5 \mathrm{~cm}$ and $5.5-8.5 \mathrm{~cm}$ sedimentary horizons. Initial attempts using the SMB 0-0.75 cm and 4.5-5.5 cm alcohol fractions (PCGC-AV, AW, and BJ series) incurred so many problems with low yields and suspected contamination by column bleed that the data from these series were ultimately discarded. Instead, the entire organic geochemical preparation, PCGC separation, and AMS analysis was repeated for the SMB 0.75-1.5 cm and 5.5-8.5 cm samples (PCGC-CD and CN series). These horizons also represent a contrasting post-bomb/pre-bomb pair, and the compoundspecific ${ }^{14} \mathrm{C}$ data should be comparable to the $0-0.75$ and $4.5-5.5 \mathrm{~cm}$ sedimentary lipids. The advantages gained from these repeat experiments (larger sample sizes and column bleed removal steps) outweigh the uncertainties generated by this assumption.

The post-bomb $n$-alcohols have $\Delta^{14} \mathrm{C}$ values $>0 \%$, consistent with recent synthesis. The SMB $0.75-1.5 \mathrm{~cm}$ sedimentary horizon is estimated to correspond to the years 1985-1990, and SMB surface water $\Delta^{14} C_{D I C}$ during this time was higher than the present-day $+71 \%$. A reasonable estimate for $\Delta^{14} \mathrm{C}_{\mathrm{DIC}}$ during this time, based on the data in Chapter 4 and the surface water DIC isotopic model (Figure 6.1), is that it decreased from $\sim+95 \%$ in 1985 to $\sim+83 \%$ in 1990 . The values of $\Delta{ }^{14} \mathrm{C}$ for $\mathrm{C}_{22}$ and $\mathrm{C}_{24}$ alcohols $(+85 \pm 11 \% o,+88 \pm 10 \% o)$ fall within this range. The single value for $n-\mathrm{C}_{16}-\mathrm{OH}$ from post-bomb sediment is slightly lower $(+69 \pm 10 \%$ ) than the predicted range of surface water $\Delta{ }^{14} \mathrm{C}_{\mathrm{DIC}}\left(+83\right.$ to $+95 \%$ ) and the measured $\Delta \Delta^{14} \mathrm{C}$ of post-bomb $\mathrm{C}_{22}$ and $\mathrm{C}_{24}$ alcohols. 
The pre-bomb $\Delta{ }^{14} \mathrm{C}$ values for $n-\mathrm{C}_{22}-\mathrm{OH}$ and $n-\mathrm{C}_{24}-\mathrm{OH}(-41 \pm 13 \%$ and $-59 \pm$ $15 \%$ ) are significantly ${ }^{14} \mathrm{C}$-enriched compared to pre-bomb SMB surface water DIC $(-82 \% o)$. The pre-bomb and post-bomb $n$-alcohol data together suggest there may be an additional ${ }^{14} \mathrm{C}$-enriched source for these compounds in SMB sediment. The most likely candidate is terrestrial vascular plant carbon.

There are two $\Delta^{14} \mathrm{C}$ values available for post-bomb $\mathrm{C}_{30}$-alkan-15-one-1-ol. Some of this compound eluted and was recovered with the SMB 0-0.75 cm desmethyl-sterol lipid fraction (PCGC-BI; $\Delta{ }^{14} \mathrm{C}=+58 \pm 18 \%$ ), while a second sample was obtained from the SMB $0.75-1.5 \mathrm{~cm}$ alcohol fraction (PCGC-CD; $\Delta{ }^{14} \mathrm{C}=+72 \pm 11 \%$ ). The first value is potentially contaminated with a small amount of column bleed (no clean-up was performed), but the second measurement represents a sample that was isolated and measured under optimal PCGC preparative and AMS analytical conditions. The surface water $\Delta^{14} C_{\text {DIC }}$ values at the time of sediment deposition, $+71 \%$ or $\mathrm{SMB} 0-0.75 \mathrm{~cm}$ and +83 to $+95 \%$ for SMB $0.75-1.5 \mathrm{~cm}$, are slightly higher than the measured $\Delta^{14} \mathrm{C}$ values for this lipid.

Two pre-bomb $\Delta^{14} \mathrm{C}$ values are available for $\mathrm{C}_{30}$-alkan-15-one-1-ol and $\mathrm{C}_{30}$-alkan1,15-diol. One is a measurement based on a sample of SMB "practice mud" (3.5 - 4.5 $\mathrm{cm})$. This alkan-15-one-1-ol sample was not subjected to column bleed clean-up, so the measured $\Delta{ }^{14} \mathrm{C}=-95 \pm 17 \%$ is considered a minimum value. The other pre-bomb data point is the one sample of $n$ - $\mathrm{C}_{30}$ alkane isolated with the archaeal ether lipids (SMB 5.5 $8.5 \mathrm{~cm}$; PCGC-BX; $\Delta^{14} \mathrm{C}=-101 \pm 20 \%$ ). This compound was believed to be produced by the reduction of $\mathrm{C}_{30}$-alkan-1,15-diol during the reaction of the polar lipids (Fraction 9) with $\mathrm{LiAlH}_{4}$. Both $-95 \%$ and $-101 \%$ are slightly ${ }^{14} \mathrm{C}$-depleted relative to pre-bomb surface water $\Delta^{14} \mathrm{C}_{\mathrm{DIC}}(-82 \%)$ ). The difference is small, however, considering the large error bars associated with these particular measurements. Overall, the alkyl-diols and ketols primarily appear to be products of marine euphotic zone production. 


\subsubsection{Sterols}

The sterol $\Delta^{14} \mathrm{C}$ data were discussed thoroughly in Chapter 4 and are only briefly reviewed here. The initial batch of SMB 0-0.75 cm post-bomb sterols (PCGC-BF series) is eliminated from the data set in this chapter, however, while the data from SMB postbomb batch \#2 (PCGC-BI series) and from SBB 0-1 cm (PCGC-CA series) are all retained. The discussion in Chapter 4 showed that the $\Delta^{14} \mathrm{C}$ results from batch \#1 were significantly different $(\mathrm{P}<0.05)$ from the other two series of post-bomb sterols and were probably affected by column bleed due to the use of a new PCGC column.

The post-bomb sterol $\Delta^{14} \mathrm{C}$ data in Table 6.2 range from $+61 \%$ o to $+90 \%$ for the SMB $0-0.75 \mathrm{~cm}$ sterols and from $+50 \%$ o to $+93 \%$ o for the SBB $0-1 \mathrm{~cm}$ sterols. Average post-bomb values for the sterols $(+73 \pm 12 \%$, SMB; $+69 \pm 14 \%$ o, SBB $)$ are identical to the measured 1996 surface water $\Delta^{14} \mathrm{C}_{\text {DIC }}(+71 \%$ o). The data indicate these compounds represent marine phytoplanktonic and zooplanktonic products. All the individual sterol data points from SMB and SBB post-bomb sediment are insignificantly different from surface water $\Delta^{14} \mathrm{C}_{\mathrm{DIC}}$, with the possible exception of $5 \alpha-\mathrm{C}_{29}$ in both samples. This sterol isomer is slightly ${ }^{14} \mathrm{C}$-enriched $(+90 \%$ and $+93 \%$ ) and could include a small component of terrestrial biomass carbon.

The pre-bomb sterol $\Delta^{14} \mathrm{C}$ data (SMB $4.5-5.5 \mathrm{~cm}$ ) represent some of the earliest PCGC separations done for this thesis. As a result, the associated measurement errors are larger $(\sim \pm 20 \%$ o rather than $\sim \pm 10-15 \%$ ). For the 5 sterols studied, the data range from $-59 \%$ o to $-102 \%$ and average $-75 \pm 19 \%$. This average is close to the estimated prebomb surface water $\Delta^{14} C_{\text {DIC }}(-82 \%)$. The pre-bomb sterol data are consistent with the interpretation, based on the more extensive post-bomb sterol data set, that SMB and SBB sedimentary sterols are products of marine photoautotrophic carbon fixation and subsequent heterotrophic degradation of that material. 


\subsubsection{Hopanols}

The hopanols were analytically very difficult to obtain by PCGC. A clean separation of tetrahymanol and $\mathrm{C}_{30}$ hopanol was not possible, because the two compounds partially co-eluted. The high boiling points of these compounds also resulted in problems with low recoveries and contamination by PCGC column bleed. $\Delta^{14} \mathrm{C}$ data of sufficient quality were finally obtained for hopanols from the SMB $0.75-1.5 \mathrm{~cm}$ and SMB $5.5-8.5 \mathrm{~cm}$ sediment horizons. Column bleed clean-up procedures were performed for both sets of samples.

Post-bomb tetrahymanol plus $\mathrm{C}_{30}$ hopanol $\left(\Delta^{14} \mathrm{C}=+47 \pm 12 \%\right.$ o $)$ and $\mathrm{C}_{32}$ hopanol $\left(\Delta^{14} \mathrm{C}=+16 \pm 11 \%\right.$ ) both have post-bomb ${ }^{14} \mathrm{C}$ concentrations $(>0 \%$ ). However, these values are both significantly lower than the predicted $\Delta^{14} \mathrm{C}_{\text {DIC }}$ for this horizon $(\sim+83$ to $+95 \%$ ). The same is true for the pre-bomb, $\mathrm{C}_{32}$ hopanol $\Delta^{14} \mathrm{C}$ measurement $(-134 \pm$ $18 \%$ o), while pre-bomb $\mathrm{C}_{31}$ hopanol $\left(\Delta^{14} \mathrm{C}=-96 \pm 15 \%\right.$ ) is only slightly ${ }^{14} \mathrm{C}$-depleted relative to pre-bomb surface water DIC $(-82 \%)$.

\subsubsection{Archaeal Lipids}

The archaeal biphytane $\left(\mathrm{C}_{40}\right.$ isoprenoid) $\Delta^{14} \mathrm{C}$ data were discussed thoroughly in Chapter 5. The lipids isolated for $\Delta^{14} \mathrm{C}$ analysis were the acyclic $\mathrm{C}_{40: 0}$ isoprenoid and the isomers containing 2 and 3 cyclopentane rings $\left(\mathrm{C}_{40: 2 \mathrm{cy}}\right.$ and $\left.\mathrm{C}_{40: 3 \mathrm{cy}}\right)$. All three compounds were obtained from the SMB pre-bomb $(5.5-8.5 \mathrm{~cm})$ sedimentary horizon. There was not enough material to allow these lipids to be collected from SMB $0-0.75 \mathrm{~cm}$ or $0.75-$ $1.5 \mathrm{~cm}$ post-bomb sediment. However, because archaeal lipid concentrations were ten times higher in $\mathrm{SBB}, \Delta^{14} \mathrm{C}$ values were obtained for $\mathrm{SBB} 0-1 \mathrm{~cm}$ post-bomb sediment. For the SBB surface horizon, the two $\mathrm{C}_{40}$ compounds yielded the same ${ }^{14} \mathrm{C}$ concentration, $\sim-100 \%$ o. In the pre-bomb SMB sediment, more scatter was observed (-121\%o to $-141 \%$ ), although these values are all equivalent within measurement error. While the large error bars associated with these values statistically do make both data sets equal in 
${ }^{14} \mathrm{C}$ concentration, the SMB data do appear to be somewhat ${ }^{14} \mathrm{C}$-depleted relative to the SBB data. The important feature of the archaeal lipid data is the lack of bomb- ${ }^{14} \mathrm{C}$ in the SBB post-bomb samples. The Archaea producing these lipids apparently have experienced almost no change in the ${ }^{14} \mathrm{C}$ concentration of their carbon source with time, and therefore grow in an environment removed from the influence of surface water DIC.

\subsubsection{Measurement Errors: Replicates and Recovery Standards}

The post-bomb sterols provide the best data set with which to evaluate the overall precision and accuracy of these compound-specific $\Delta^{14} \mathrm{C}$ measurements. The data include 3 measurements for $\mathrm{C}_{27} \Delta^{5}$, two of which represent AMS analysis of identical splits of $\mathrm{CO}_{2}$ obtained from a single PCGC isolation (trap BI-3). These two $\Delta{ }^{14} \mathrm{C}$ values differ by $19 \%$ ( $+80 \%$ and $+61 \%$ ) , while the third $\mathrm{C}_{27} \Delta^{5}$ sample, isolated from SBB sediment, has a $\Delta^{14} \mathrm{C}$ value intermediate between the other two results $(+70 \%$ ). The same situation occurred for dinosterol. Two splits of $\mathrm{CO}_{2}$ generated from the contents of PCGC trap BK-1 yield $\Delta^{14} \mathrm{C}=+61 \%$ and $+81 \%$, a $20 \%$ difference. Since all aspects of PCGC purification were identical for these samples, the differences must be due only to graphite preparation to AMS instrumental effects. A reasonable estimate of the precision of the compound-specific $\Delta^{14} \mathrm{C}$ data is therefore $\sim \pm 20 \%$. This is slightly larger than the AMS measurement errors, which are typically $\sim \pm 15 \%$.

In addition to the previous discussion, the $\Delta^{14} \mathrm{C}$ values determined for recovery standards provide an additional means of evaluating the accuracy of the data. Table 6.3 summarizes all the AMS $\Delta^{14} \mathrm{C}$ data available for recovery standards and replicate samples. The two samples of $n-\mathrm{C}_{19}-\mathrm{OH}$ that were isolated from PCGC series BJ and $\mathrm{CN}$ yielded three $\Delta^{14} \mathrm{C}$ measurements $\left(\mathrm{CO}_{2}\right.$ from $\mathrm{BJ}-2$ was split into two samples). The expected $\Delta^{14} \mathrm{C}$ for $n-\mathrm{C}_{19}-\mathrm{OH}$ based on a large aliquot of combusted material and conventional ${ }^{14} \mathrm{C}$ AMS analysis was $-999 \%$. The three recovered samples had $\Delta{ }^{14} \mathrm{C}=$ $-990 \%$ o, $-990 \%$, and $-988 \%$. These values are in excellent agreement with the expected $\Delta{ }^{14} \mathrm{C}$, and indicate no more than $1 \%$ of the carbon recovered in these PCGC traps was of 
modern origin. However, most of the ${ }^{14} \mathrm{C}$ analytical difficulties experienced throughout this project involve negative ${ }^{14} \mathrm{C}$ biases, or the inclusion of dead carbon $\left(\Delta^{14} \mathrm{C}=-1000 \%\right.$ o contaminants. These components are invisible in a ${ }^{14} \mathrm{C}$-dead standard. One sample of $\mathrm{C}_{21: 0}$ fatty acid was recovered (PCGC series AS, trap 4) and two $\mathrm{CO}_{2}$ samples and AMS measurements were obtained. The $\Delta \Delta^{14} \mathrm{C}$ of pure, combusted $\mathrm{C}_{21: 0}$ fatty acid was determined to be $-389 \%$, while the small PCGC samples yielded $\Delta^{14} \mathrm{C}$ values of $-353 \%$ o and $-366 \%$. These values represent $36 \%$ and $23 \% o{ }^{14} \mathrm{C}$-enrichment, respectively. The two measurements differ by $13 \%$, which is within the $\pm 20 \%$ o precision expected for replicates. The positive bias in these numbers is at least partially caused by the presence of some natural $\mathrm{C}_{21: 0}$ fatty acid in the samples. The natural, pre-bomb $\mathrm{C}_{21: 0}$, if it has a $\Delta{ }^{14} \mathrm{C} \sim-82 \%$, would need to be present at a level of only $7-12 \%$ to account for this offset in the data. No large, negative $\Delta^{14} \mathrm{C}$ bias from contaminant carbon is apparent in the $\mathrm{C}_{21: 0}$ sample; this is consistent with the relatively low boiling point of this material and its elution before $320^{\circ} \mathrm{C}$, where thermal degradation of column stationary phase is visible in the PCGC chromatograms.

The $n-\mathrm{C}_{33}$ recovery standard collected with the archaeal lipid samples (Chapter 5) served to check whether there were additional problems associated with using the 1-m multicapillary column. The differences between the "known" standard $\Delta{ }^{14} \mathrm{C}$ values and the PCGC samples are generally larger, but are not greatly biased in the negative direction (one is more positive than the "true" value). The data do not indicate ${ }^{14} \mathrm{C}$ depleted contaminant carbon had a big effect on the archaeal lipid samples. 
Table 6.3 Recovery standards and replicate measurements used to assess the quality of the compound-specific $\Delta{ }^{\mathrm{I}} \mathrm{C}$ data.

\begin{tabular}{|c|c|c|c|}
\hline Compound & "True" $\Delta^{14} \mathrm{C}(\%)$ & Measured $\Delta^{14} \mathrm{C}(\% \circ)$ & Difference $(\% o)$ \\
\hline \multicolumn{4}{|l|}{ Recovery Standards } \\
\hline $\mathrm{C}_{21: 0}$ standard & -389 & $-353 \pm 9$ & +36 \\
\hline$(\mathrm{AS}-4)$ & & $-366 \pm 11$ & +23 \\
\hline$n-\mathrm{C}_{19}-\mathrm{OH}$ standard & -999 & $-988 \pm 3$ & +11 \\
\hline$(\mathrm{BJ}-2 \mathrm{a}, \mathrm{b})$ & & $-990 \pm 2$ & +9 \\
\hline $\begin{array}{c}n-\mathrm{C}_{19}-\mathrm{OH} \text { standard, } \\
(\mathrm{CN}-2)\end{array}$ & -999 & $-990 \pm 2$ & +9 \\
\hline $\begin{array}{c}n-\mathrm{C}_{33} \text { standard, } \\
(\mathrm{BV}-3)\end{array}$ & +146 & $+194 \pm 14$ & +48 \\
\hline $\begin{array}{c}n-\mathrm{C}_{33} \text { standard } \\
(\mathrm{BU}-3)\end{array}$ & +146 & $+125 \pm 8$ & -21 \\
\hline \multicolumn{4}{|l|}{ Identical $\mathrm{CO}_{2}$ Splits } \\
\hline C16:0 FAME & $+71^{*}$ & $+93 \pm 11$ & +22 \\
\hline (BG-3 a,b) & & $+80 \pm 11$ & +9 \\
\hline $\mathrm{C} 27 \mathrm{D} 5$ & $+71^{*}$ & $+80 \pm 16$ & +9 \\
\hline (BI-3 a,b) & & $+61 \pm 12$ & \\
\hline Dinosterol & $+71^{*}$ & $+61 \pm 13$ & -10 \\
\hline$(\mathrm{BK}-1 \mathrm{a}, \mathrm{b})$ & & $+81 \pm 14$ & +10 \\
\hline \multicolumn{4}{|l|}{ Independent Replicates } \\
\hline $\begin{array}{l}a-\mathrm{C}_{15: 0} \\
(\mathrm{BG}-2)\end{array}$ & (unknown) & $+21 \pm 11$ & \} difference $=$ \\
\hline $\begin{array}{l}a-\mathrm{C}_{15: 0} \\
(\mathrm{BH}-2)\end{array}$ & (unknown) & $+42 \pm 13$ & J 21 \\
\hline
\end{tabular}

* Assume "true" $\Delta^{14} \mathrm{C}=\Delta^{14} \mathrm{C}_{\mathrm{DIC}}$.

\subsection{5 $\delta^{13} \mathrm{C}$ Data}

Stable carbon isotopic abundances were measured by $\mathrm{irm}$-GC/MS for all the lipid fractions described in Figures 6.2, 6.4, 6.6, 6.8, and 6.10. This represents much more compound-specific $\delta^{13} \mathrm{C}$ data than $\Delta^{14} \mathrm{C}$ data for the individual biomarkers in SMB and SBB sediment. However, the objective of this work is to use the $\delta^{13} \mathrm{C}$ values to aid in the interpretation of the $\Delta^{14} \mathrm{C}$ results rather than as an independent analysis. In the following 
sections, the $\delta^{13} \mathrm{C}$ data are only presented graphically. Tables of raw numbers are included in the appendix to this chapter for reference purposes.

\subsubsection{1 n-Alkanes}

The data for SMB 0-2.5 $\mathrm{cm}$ and 2.5-7.5 $\mathrm{cm} n$-alkanes are shown in Figure 6.13. The ${ }^{13} \mathrm{C}$ distribution is similar in the two samples. In both cases, the even-chain homologues have $\delta^{13} \mathrm{C}$ values that are relatively more constant and more ${ }^{13} \mathrm{C}$-enriched than the odd-chain isomers. The average $\delta^{13} \mathrm{C}_{\text {even }}$ for $\mathrm{SMB} 0-2.5 \mathrm{~cm}$ is $-29.9 \%$, while the average $\delta^{13} \mathrm{C}_{\text {even }}$ for SMB $2.5-7.5 \mathrm{~cm}$ is $-30.4 \%$. This may be consistent with a dominant petroleum source for these compounds (e.g. Wilhelms et al., 1994). The slightly more negative $\delta^{13} \mathrm{C}_{\text {even }}$ in the deeper horizon probably indicates a slightly larger terrestrial plant contribution to the even-chain isomers in this sample. The odd-chain $n$-alkanes in both intervals are characterized by a minimum $\delta^{13} \mathrm{C}$ at $n-\mathrm{C}_{31}$ with significant isotopic depletion also observed for $n-\mathrm{C}_{29}$ and $n-\mathrm{C}_{33}$. Their negative $\delta^{13} \mathrm{C}$ values around $-32 \%$ are consistent with an at least partial $\mathrm{C}_{3}$ vascular plant source (Smith and Epstein, 1971; Collister et al., 1994a; Lockheart et al., 1996). The even-chain and odd-chain $n$-alkane data together indicate there are multiple hydrocarbon sources with different ${ }^{13} \mathrm{C}$ isotopic compositions contributing to SMB sediment. In Chapter 7 the $\delta^{13} \mathrm{C}$ and $\Delta^{14} \mathrm{C}$ data are used together to formulate a quantitative mixing model for the contributions of potential $n$-alkane sources to SMB sediment. 
Figure 6.13
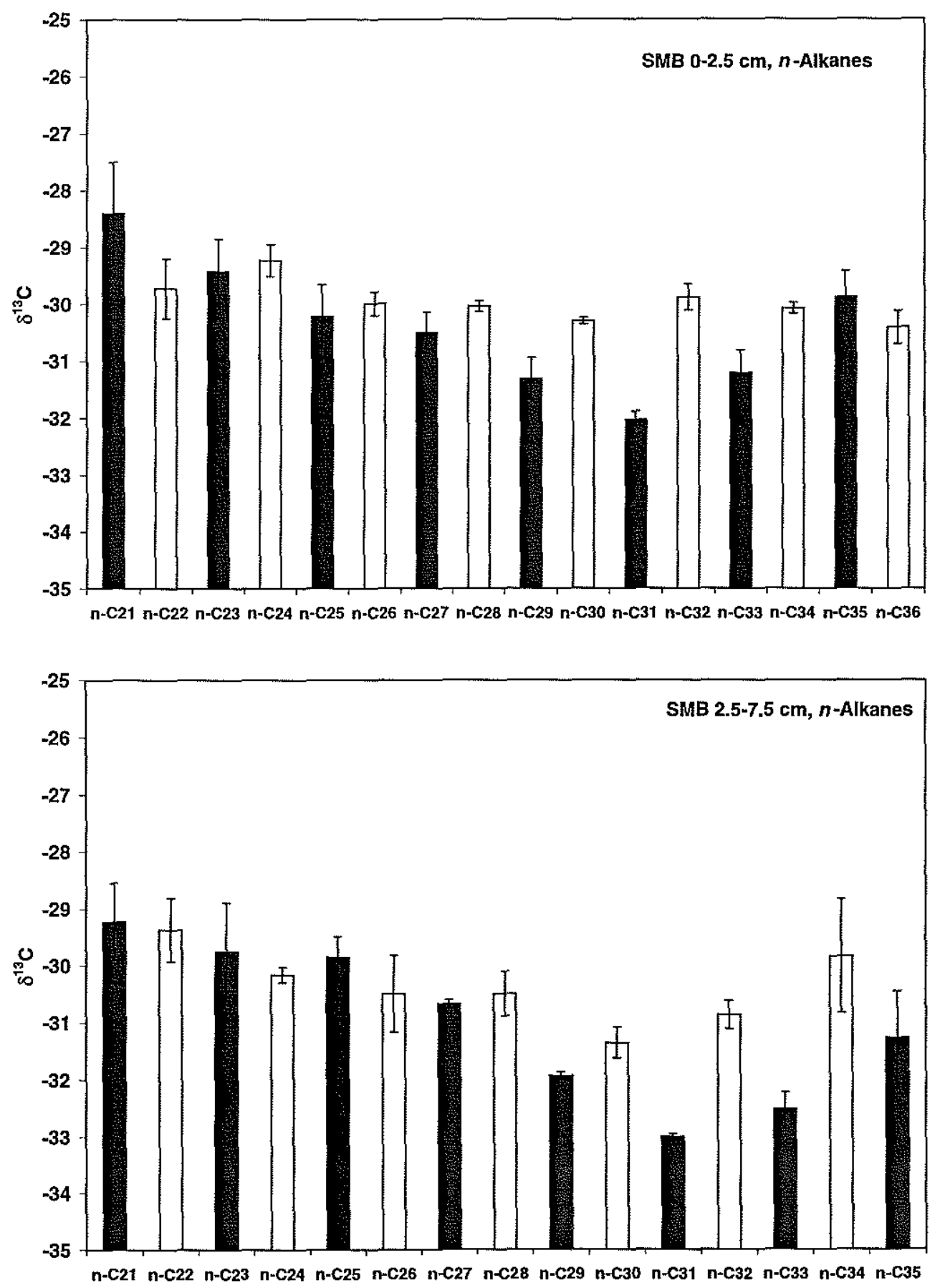

Figure 6.13 irm-GC/MS data for SMB sediment $n$-alkanes. Dark colored bars indicate the odd-chain $n$-alkanes, and colorless bars indicate the even-chain $n$-alkanes. 


\subsubsection{FAMEs}

The $\delta^{13} \mathrm{C}$ data (corrected for derivative carbon) for the SMB $0-0.75 \mathrm{~cm}$ and $4.5-$ $5.5 \mathrm{~cm}$ FAME fractions are shown in Figure 6.14. An additional set of $\delta^{13} \mathrm{C}$ data was obtained for FAMEs extracted from the SBB $0-1 \mathrm{~cm}$ horizon, and these values are also shown. The ${ }^{13} \mathrm{C}$ distribution has similar features in all three samples. Their $\delta^{13} \mathrm{C}$ values are approximately constant within the individual horizons, but these compounds are more ${ }^{13} \mathrm{C}$-enriched in the SBB $0-1 \mathrm{~cm}$ sample, and relatively more ${ }^{13} \mathrm{C}$-depleted in the deeper, SMB $4.5-5.5 \mathrm{~cm}$ horizon. This could reflect the growth rate or nutritional state of the organisms producing these lipids (e.g. Laws et al., 1995). The odd-chain, branchedchain, and unsaturated fatty acids are all thought to be more representative of bacterial sources in these sediments. In general, these isomers have ${ }^{13} \mathrm{C}$ concentrations equal to or slightly higher than the $\mathrm{C}_{12}-\mathrm{C}_{18}$ even-chain fatty acids. The ${ }^{13} \mathrm{C}$-enrichment may indicate isotopic effects associated with heterotrophic processes (e.g. DeNiro and Epstein, 1977).

On the right-hand side of all the figures, the long-chain $\left(\mathrm{C}_{20}-\mathrm{C}_{30}\right)$ even-numbered FAMEs are shown. The maximum $\delta^{13} \mathrm{C}$ for these compounds is always measured for $\mathrm{C}_{24: 0}$, which is also the most abundant of these homologues. The $\delta^{13} \mathrm{C}$ value for $\mathrm{C}_{24: 0}$ fatty acid is approximately equal to the minimum $\delta^{13} \mathrm{C}$ observed among the $\mathrm{C}_{12}-\mathrm{C}_{18}$ series in each sample. At both higher and lower carbon number, the $\delta^{13} \mathrm{C}$ values are ${ }^{13} \mathrm{C}$ depleted relative to $\mathrm{C}_{24: 0}$. The odd-chain $\mathrm{C}_{23}-\mathrm{C}_{27}$ fatty acids are uniformly $\sim 1 \%$ o depleted relative to the even-numbered compounds (striped bars). In general, the long-chain fatty acids appear to exhibit different isotopic characteristics than the low carbon-numbered isomers $\left(\mathrm{C}_{12: 0}-\mathrm{C}_{18: 0}\right)$, perhaps suggesting different sources for these compounds.

The single, colorless bar on the right-hand side of the figures indicates $\mathrm{C}_{24: 1}$ fatty acid in all samples. This isomer is consistently ${ }^{13} \mathrm{C}$-enriched relative to all other longchain fatty acids, and it may reflect a zooplanktonic source similar to $n$ - $\mathrm{C}_{22: 1}-\mathrm{OH}$ and $n$ $\mathrm{C}_{24: 1^{-}} \mathrm{OH}$, which also have heavier $\delta^{13} \mathrm{C}$ values (next section). 
Figure 6.14
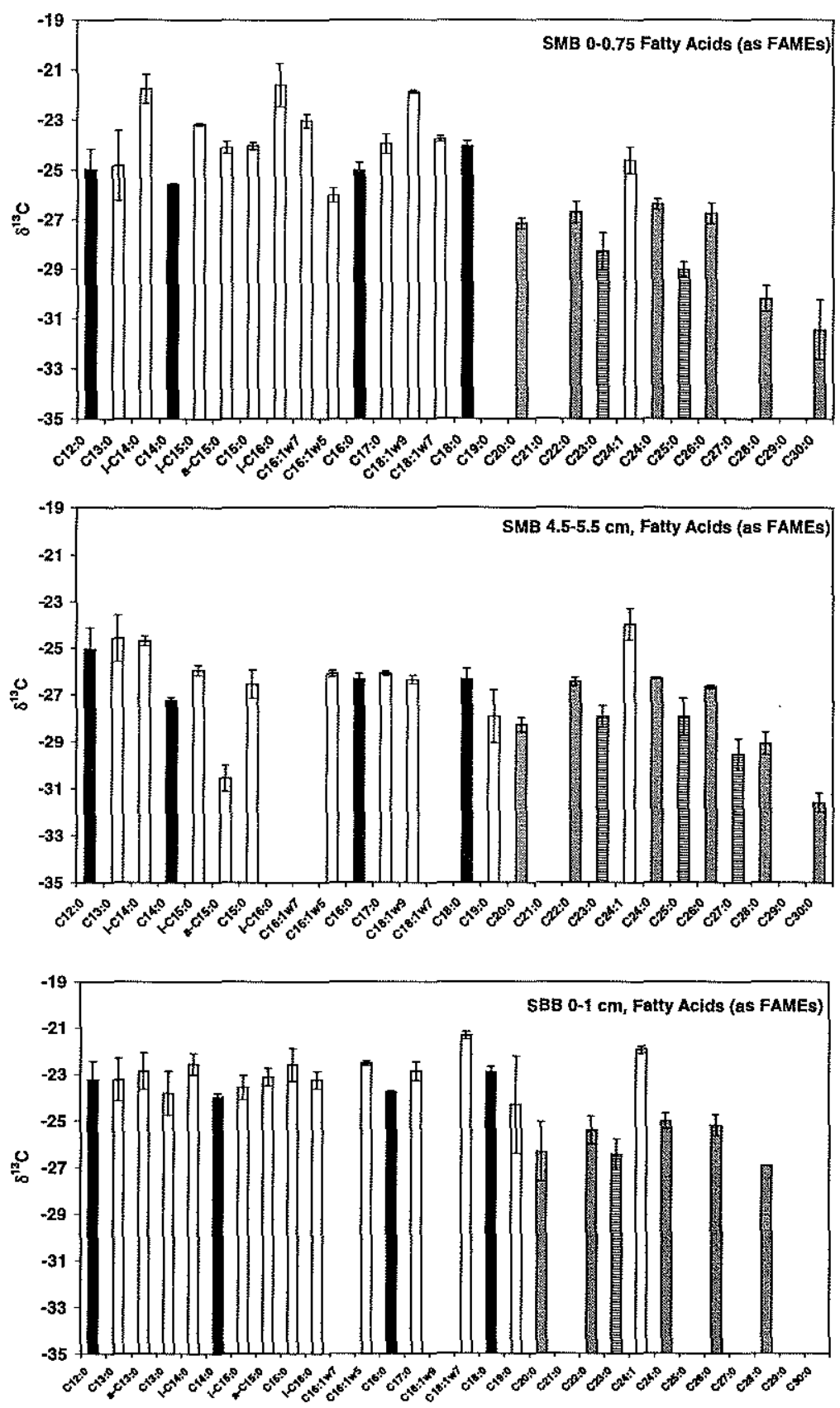

Figure 6.14 irm-GC/MS data for SMB and SBB sediment FAMEs. The saturated fatty acids, $\mathrm{C}_{12: 0}, \mathrm{C}_{14: 0}, \mathrm{C}_{16: 0}$, and $\mathrm{C}_{18: 0}$ are shown with black bars. The odd-chain, branchedchain, and unsaturated fatty acids are shown with colorless bars. Even-numbered, longchain alkanes are shown with gray bars. 


\subsubsection{3 n-Alcohols and Alkan-15-one-1-ols}

The $\delta^{13} \mathrm{C}$ data for $n$-alcohols and $\mathrm{C}_{30^{-}}$and $\mathrm{C}_{32}$-alkan-15-one-1-ols are shown in Figures 6.15 and 6.16. The data for $S M B-0.75 \mathrm{~cm}$ and $0.75-1.5 \mathrm{~cm}$ alcohols are shown in Figure 6.15; while the deeper horizons, SMB $4.5-5.5 \mathrm{~cm}$ and $5.5-8.5 \mathrm{~cm}$ are shown in Figure 6.16.

The pattern of $n$-alkanol $\delta^{13} \mathrm{C}$ values is quite similar in both of the surface sediment samples (Figure 6.15). However, this ${ }^{13} \mathrm{C}$ distribution does not resemble either of the other classes of $n$-alkyl lipids ( $n$-alkanes and FAMEs). All of the saturated $n$ alcohol isomers are isotopically lighter than the FAMEs of equal carbon chain length. Also unlike the fatty acids and $n$-alkanes, there is no strong isotopic contrast between even-chain and odd-chain $n$-alkanols in these surface sedimentary horizons. The $\delta^{13} \mathrm{C}$ values in both samples decrease from a maximum of $\sim-28 \%$ for $n-\mathrm{C}_{20}$ and $n-\mathrm{C}_{21}$ alcohols to a minimum of $\sim-32 \%$ for $n-\mathrm{C}_{27}$ through $n-\mathrm{C}_{30}$ alcohols.

A change in the $\delta^{13} \mathrm{C}$ distribution for the odd-carbon $n$-alkanols becomes apparent in the deeper SMB horizons, $4.5-5.5 \mathrm{~cm}$ and $5.5-8.5 \mathrm{~cm}$ (Figure 6.16). A hint of this developing pattern is visible in the SMB $0.75-1.5 \mathrm{~cm}$ horizon. The odd-chain compounds develop a strong minimum in $\delta^{13} \mathrm{C}$ at $\mathrm{C}_{25}$, while $\mathrm{C}_{27}$ is isotopically enriched relative to the surface sediment samples. The ${ }^{13} \mathrm{C}$ distribution for the even-chain $n$ alkanols also changes in the deeper sediments. Even-numbered alcohols in the surface horizons have $\delta^{13} \mathrm{C}$ values that decrease toward higher carbon number, while at depth, these values remain more constant. The change reflects an increase in the $\delta^{13} \mathrm{C}$ values for the longer-chain compounds. $\mathrm{C}_{26}, \mathrm{C}_{28}$, and $\mathrm{C}_{30}$ alcohols average $\sim-31.5 \%$ at the surface and, except for $\mathrm{C}_{30}, \sim-29 \%$ o for deeper samples. The data suggest multiple sources for the $n$-alkanols in SMB sediments, and perhaps indicate that a component with lower $\delta^{13} \mathrm{C}$ values is somehow preferentially degraded relative to another source with higher $\delta^{13} \mathrm{C}$ values.

A similar trend is noted for the alkan-15-one-1-ols. The $\delta^{13} \mathrm{C}$ data for $\mathrm{C}_{30}$-alkan15-one-1-ol and $\mathrm{C}_{32}$-alkan-15-one-1-ol have minimum values at the sediment-water 
interface $(\sim-32 \%)$, but $\delta^{13} \mathrm{C}$ appears to increase with depth in the core, reaching $-30.5 \%$ in the $5.5-8.5 \mathrm{~cm}$ horizon. It is interesting to speculate that the isotopic trends for the $n-\mathrm{C}_{26-30}$ alcohols and the mid-chain ketols could be related.

In contrast to the saturated alcohols, $n-\mathrm{C}_{22: 1}-\mathrm{OH}$ and $n-\mathrm{C}_{24: 1}-\mathrm{OH}$ are quite isotopically enriched. The $\delta^{13} \mathrm{C}$ values for these compounds are similar to the values for other SMB lipids of supposed phytoplanktonic or zooplanktonic source, for example, $\mathrm{C}_{16: 0}$ fatty acid and cholesterol.

Figure 6.15
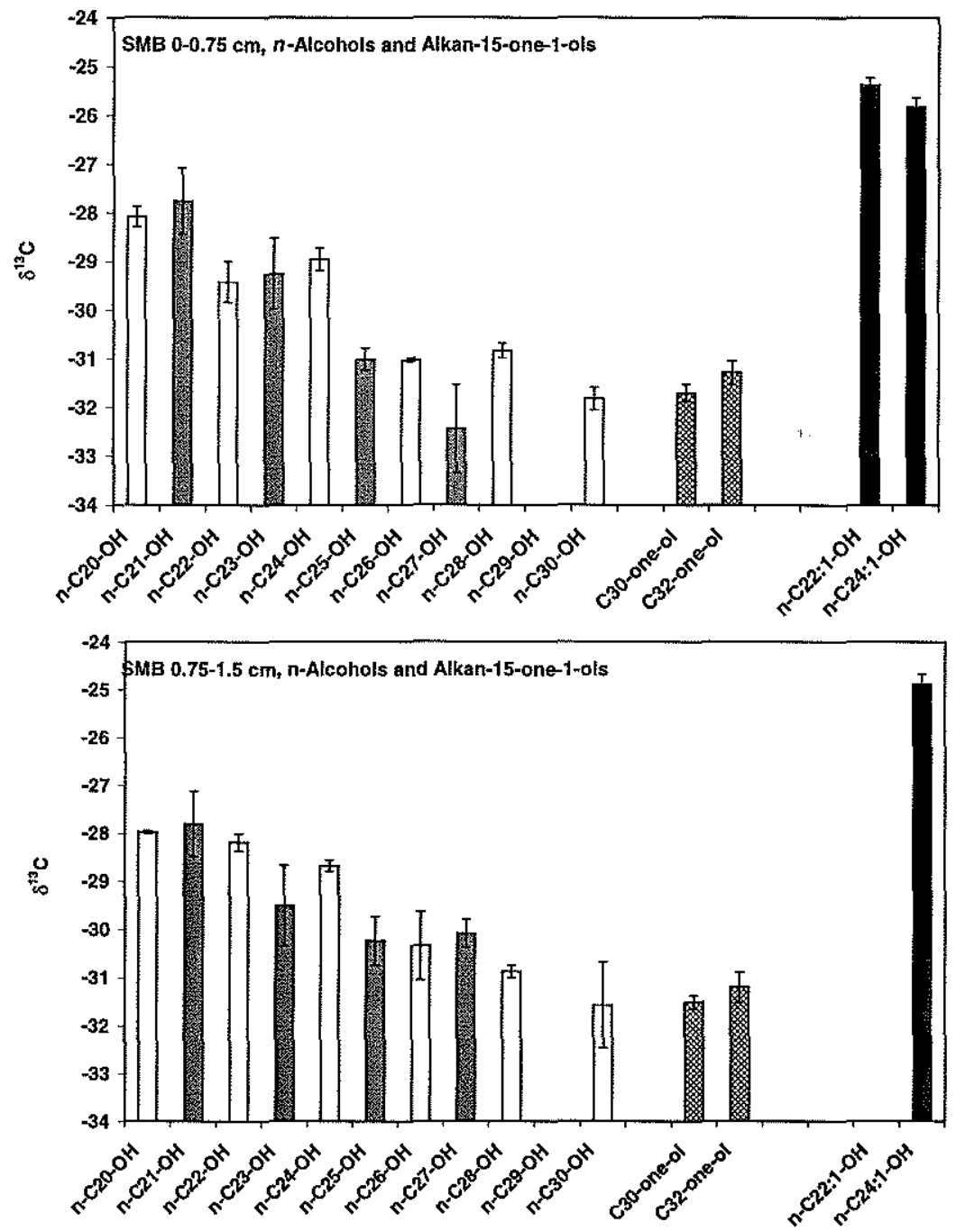

Figure 6.15 $\mathrm{irm}$-GC/MS data for SMB post-bomb sediment $n$-alkanols. 
Figure 6.16
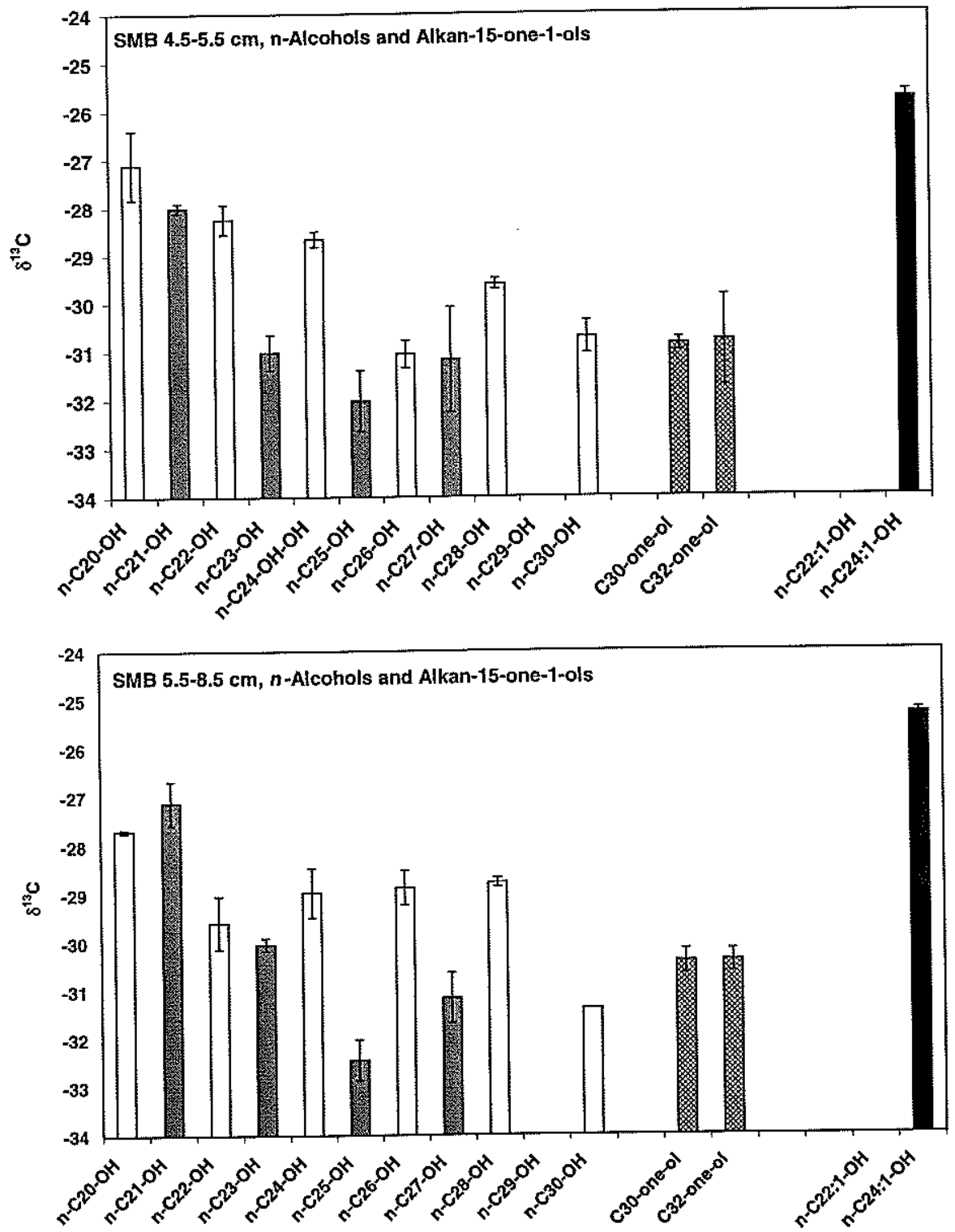

Figure 6.16 irm-GC/MS data for SMB pre-bomb sediment $n$-alkanols. 


\subsubsection{Sterols and Hopanols}

The SMB sterol isotopic data were already presented and discussed in Chapter 4. The plots of the data are reproduced and briefly summarized here (Figures 6.17, 6.18).

Figure 6.17 shows the $\delta^{13} \mathrm{C}$ data obtained by $\mathrm{irm}$-GC/MS for the three sterol fractions (plus dinosterol) used for compound-specific $\Delta^{14} \mathrm{C}$ analysis. The $\delta^{13} \mathrm{C}$ values for the SMB $0-0.75 \mathrm{~cm}$ sterol fraction ranged from low values of $-28.4 \%$ o for $\mathrm{C}_{26} \Delta^{22}$ and $\mathrm{C}_{28} \Delta^{22}$ to high values of $-24.9 \%$ for $\mathrm{C}_{27} \Delta^{5,22}$ and $\mathrm{C}_{27} \Delta^{5}$ (cholesterol) and $-23.4 \%$ for dinosterol. A similar ${ }^{13} \mathrm{C}$ distribution was observed for the SMB $4.5-5.5 \mathrm{~cm}$ horizon, where $\mathrm{C}_{26} \Delta^{22}$ and $\mathrm{C}_{28} \Delta^{22}$ are again the most isotopically depleted isomers ( $-28.3 \%$ and $-26.9 \%$, respectively), while $\mathrm{C}_{27} \Delta^{5,22}, \mathrm{C}_{27} \Delta^{5}$, and dinosterol are again the most ${ }^{13} \mathrm{C}$ enriched. Isotopic enrichment of the zooplanktonic sterols, $C_{27} \Delta^{5}$ and $C_{27} \Delta^{5,22}$, relative to the algal sterol precursors of these compounds $\left(\mathrm{C}_{28}\right.$ and $\mathrm{C}_{29}$ sterols), is consistent with a heterotrophic source for these isomers (DeNiro and Epstein, 1977). Dinosterol is apparently even more ${ }^{13} \mathrm{C}$-enriched in the SMB surface sample, but it had poor chromatographic separation, so the accuracy of the dinosterol numbers is more uncertain than for the other sterol isomers. The other consistent feature in all samples is the ${ }^{13} \mathrm{C}$ depletion of $5 \alpha$-stanol isomers relative to their $\Delta^{5}$ counterparts. This difference is approximately $1 \%$ to $1.5 \%$ in the surface sediments of both SMB and SBB and is between $1.5 \%$ and $2 \%$ in the deeper SMB horizon; it may be due to isotopic discrimination against ${ }^{13} \mathrm{C}$ during bacterial hydrogenation of $\Delta^{5}$ stenols.

The same relative pattern of $\delta^{13} \mathrm{C}$ values was also observed for two additional SMB sedimentary horizons $(0.75-1.5 \mathrm{~cm}$ and $5.5-6.5 \mathrm{~cm}$, Figure 6.18$)$. These additional data help show the ${ }^{13} \mathrm{C}$ distribution among the major sterol isomers in SMB sediments is quite uniform with depth in the sediment. 
Figure 6.17

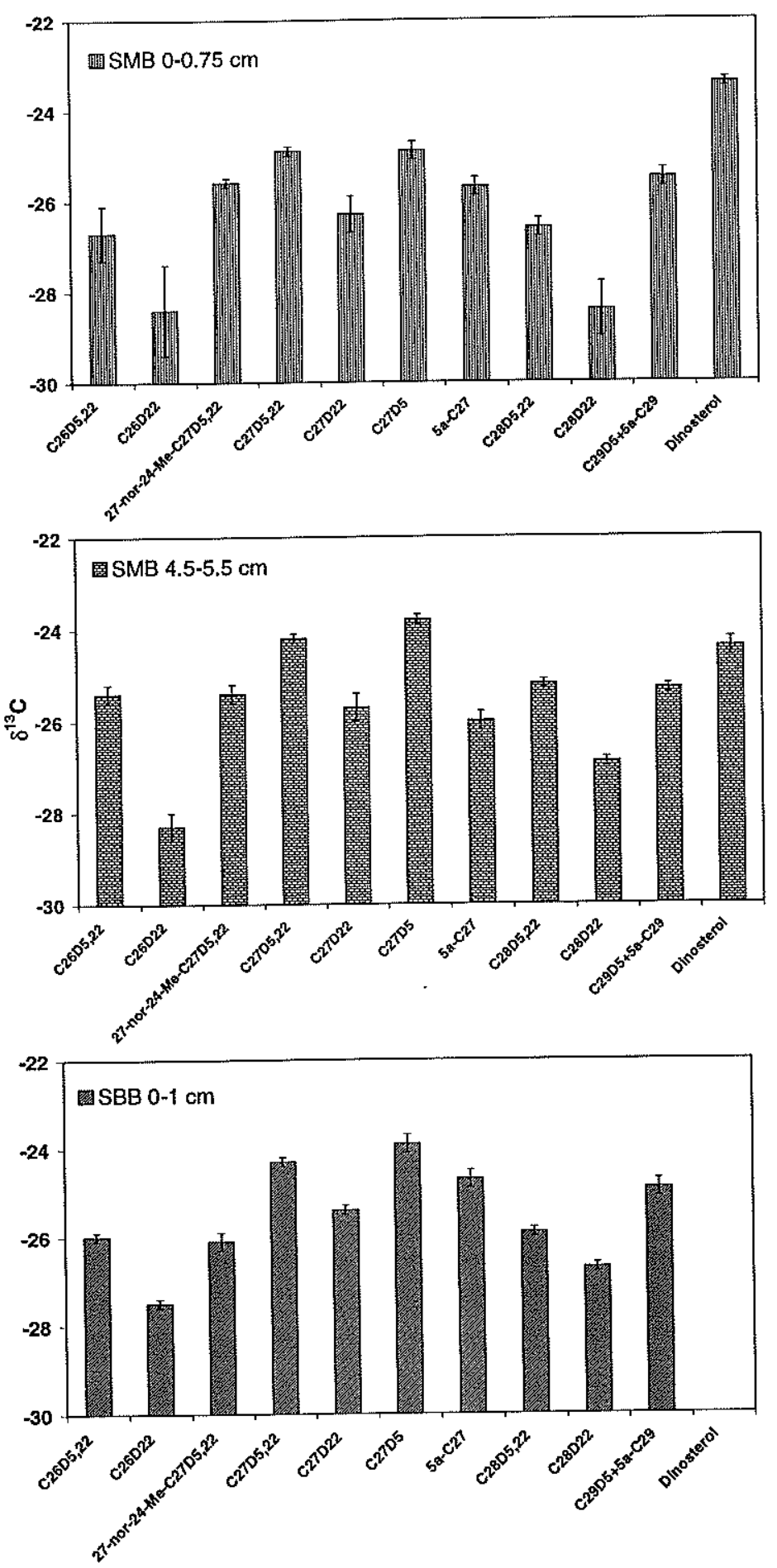

Figure 6.17 irm-GC/MS data for individual sterols from SMB and SBB sediments. 
Figure 6.18
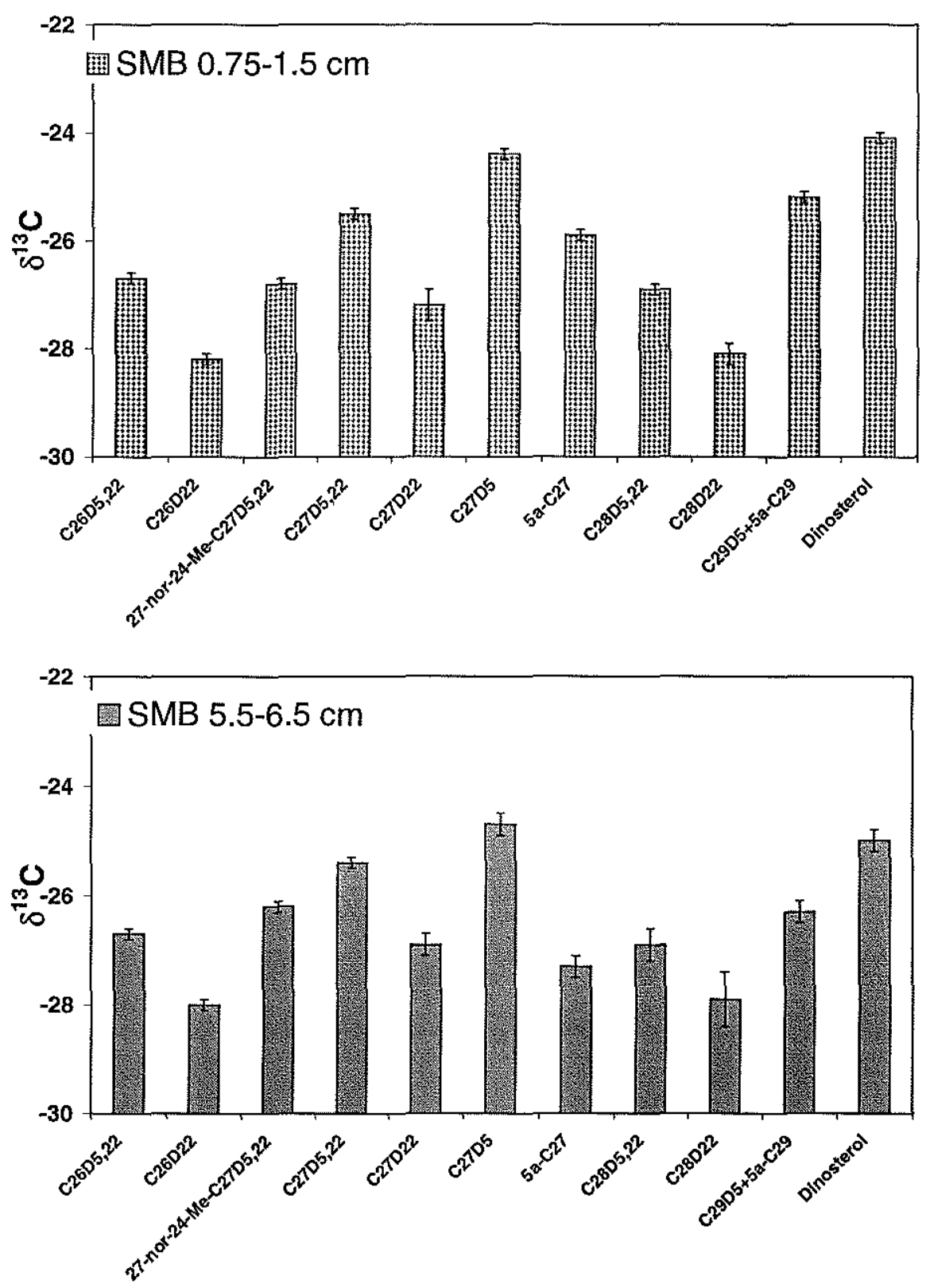

Figure 6.18 irm-GC/MS data for sterols from the additional SMB sedimentary horizons, $0.75-1.5 \mathrm{~cm}$ and $5.5-6.5 \mathrm{~cm}$, for which ${ }^{14} \mathrm{C}$ isotopic data were not obtained. 
There are no irm-GC/MS data available for tetrahymanol, $\mathrm{C}_{30}$ hopanol, $\mathrm{C}_{31}$ hopanol, or $\mathrm{C}_{32}$ hopanol. Problems with peak resolution, background integration, and a lack of appropriately placed standards interfered with the irm-GC/MS chromatograms. Instead, the only $\delta^{13} \mathrm{C}$ numbers available for these compounds are from splits of the $\mathrm{CO}_{2}$ gas generated from PCGC samples (Table 6.2). $\delta^{13} \mathrm{C}$ values for the hopanols were therefore measured on acetate derivatives. Although the contribution of acetate carbon was subtracted from the data, the irregular fractionation during acetylation (Chapter 4 appendix) means these $\delta^{13} \mathrm{C}$ values are probably $0-2 \%$ depleted relative to the "true" $\delta^{13} \mathrm{C}$ of the hopanols. The hopanol acetate data range from $-24 \%$ o to $-24.5 \%$ for tetrahymanol, $\mathrm{C}_{30}$ hopanol and $\mathrm{C}_{31}$ hopanol to $-25 \%$ and $-26 \%$ for the two measurements of $\mathrm{C}_{32}$ hopanol. The values for tetrahymanol, $\mathrm{C}_{30}$ hopanol, and $\mathrm{C}_{31}$ hopanol are all relatively isotopically "heavy", and may reflect isotopic enrichment caused by a heterotrophic bacterial source. The $\mathrm{C}_{32}$ hopanol is slightly ${ }^{13} \mathrm{C}$-depleted and could reflect the partial influence of autotrophic biomass production.

\subsubsection{Archaeal Lipids and Alkan-1,15-diols}

The polar lipids (Fraction 9) were reduced to hydrocarbons with $\mathrm{LiAlH}_{4}$. This generated a series of $n$-alkanes believed to be derived from alkan-1,15-diols contained in the original lipid fraction. The ether-linked isoprenoid lipids of planktonic Archaea were also present in this fraction, and $\delta^{13} \mathrm{C}$ data for these compounds were described in Chapter 5. The irm-GC/MS data for both of these lipid classes are presented here in Figure 5.20 for the SMB $0-0.75 \mathrm{~cm}, \mathrm{SMB} 5.5-8.5 \mathrm{~cm}$, and SBB $0-1 \mathrm{~cm}$ sedimentary horizons.

The $\delta^{13} \mathrm{C}$ values for the alkan-1,15-diols reach minimum values of $\sim-33 \%$ for $n$ $\mathrm{C}_{30}$ in both surface sediment samples. In general, these $\delta^{13} \mathrm{C}$ values are lighter than the values for the corresponding $\mathrm{C}_{30}$-alkan-15-one-1-ols by about 2-3\%o. The alkan-1,15diols are even more ${ }^{13} \mathrm{C}$-depleted in the deeper SMB sediments, where $\delta^{13} \mathrm{C}$ is between 
$-33 \%$ and $-34 \%$ for $n-\mathrm{C}_{26}, n-\mathrm{C}_{28}$ and $n$ - $\mathrm{C}_{30}$. In contrast, $\mathrm{SMB} 5.5-8.5 \mathrm{~cm} \mathrm{C}_{30}$-alkan15-one-1-ol was ${ }^{13} \mathrm{C}$-enriched in comparison to its value in surface sediments. In all three samples, the odd-numbered carbon chains are also more ${ }^{13} \mathrm{C}$-enriched than the evennumbered compounds by $\sim 1-3 \%$. This pattern is in the opposite direction to the isotopic distribution observed for $n$-alkanes, long-chain fatty acids, and long-chain $n$-alkanols. In all of those classes of acetogenic lipids, odd-carbon numbered homologues have more negative $\delta^{13} \mathrm{C}$ values than their even-numbered counterparts.

The $\mathrm{C}_{40}$ isoprenoid lipids of Archaea have the highest $\delta^{13} \mathrm{C}$ values of all lipids in this study (Figure 6.19). The values of $-20 \%$ o to $-23 \%$ are very heavy for lipids of marine organisms. These ${ }^{13} \mathrm{C}$ concentrations are believed to be too high to be explained by isotopic enrichment associated with heterotrophic consumption of organic carbon Instead, the data suggest the Archaea may be chemoautotrophs (discussion, Chapter 5). 
Figure 6.19
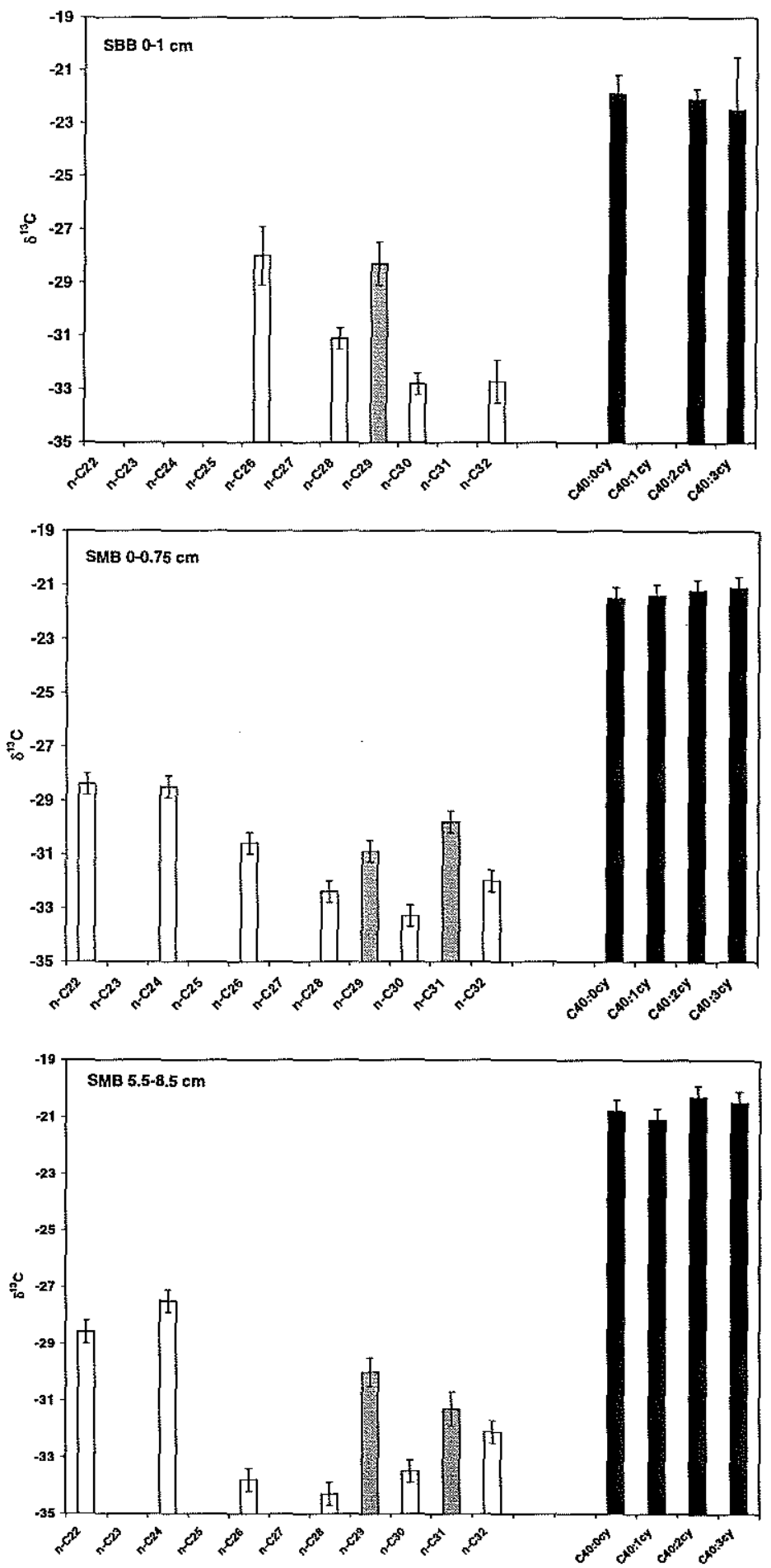

Figure 6.19 irm-GC/MS data for Fraction 9, alkyl-1,15-diols and archaeal lipids. 


\subsection{DisCusSION}

\subsubsection{Multi-Dimensional Carbon Isotope Distribution(s): $\delta^{13} \mathrm{C}, \Delta^{14} \mathrm{C}$, and $\Delta\left(\Delta^{14} \mathrm{C}\right)$}

Some general characteristics of the compound-specific carbon isotopic data can be described before attempting a more thorough analysis and discussion of the individual measurements. Here a two-dimensional isotopic comparison $\left(\Delta^{14} \mathrm{C}\right.$ vs. $\left.\delta^{13} \mathrm{C}\right)$ is used to examine patterns within the entire data set. The compound-specific $\Delta^{14} \mathrm{C}$ measurements for SMB and SBB lipid biomarkers are combined with the $\delta^{13} \mathrm{C}$ values as determined by $\mathrm{irm}$-GC/MS, and each compound is plotted as a single point in Figure 6.20 (data, Table 6.2). The distribution of the data along the $\delta^{13} \mathrm{C}$ axis allows discrimination among the different organic matter sources and/or biosynthetic pathways of carbon incorporation for the organisms producing these lipids. The $\Delta^{14} \mathrm{C}$ axis serves as an index of the endmember $\Delta^{14} \mathrm{C}$ values and especially of the relative amount of bomb- ${ }^{14} \mathrm{C}$ contained within each sample.

The solid line near the top of Figure 6.20 is the $\Delta^{14} \mathrm{C}$ value for surface water DIC in $1996(+71 \%$ o). The solid symbols all represent compounds isolated from post-bomb sediment horizons, and each data point is identified by the letters and symbols used in Table 6.2. The dashed line is the $\Delta^{14} C_{\text {DIC }}$ value estimated for pre-bomb surface waters in this region $(-82 \%$ ). All pre-bomb lipid biomarkers are shown with hollow symbols.

The data distribution within this figure leads easily to a visual cluster analysis of the different lipid biomarker classes. One of the most distinct characteristics of the data is that all of the lipids containing an oxygenated functional group, including fatty acids (as FAMEs), linear alcohols, and isoprenoid alcohols, have $\Delta^{14} \mathrm{C}$ values $>0 \%$ in the postbomb sedimentary horizon. (The archaeal data are an exception, as noted below.) The presence of bomb- ${ }^{14} \mathrm{C}$ indicates these lipids are all derived from contemporary biomass production. An oval shape is drawn around these data, and the oval shows that the group clusters around the $\Delta^{14} C_{\text {DIC }}=+71 \%$ o line. The data points for $C_{30}$-alkan-15-one-1-ol, $n$ $\mathrm{C}_{22}-\mathrm{OH}$, and $n-\mathrm{C}_{24}-\mathrm{OH}$ fall outside the cluster because they have depleted $\delta^{13} \mathrm{C}$ values compared to the rest of the functionalized biomarker lipids. The $\Delta^{14} \mathrm{C}$ data for these three 
samples would otherwise place them within the range of the other post-bomb alcohols and fatty acids.

The same situation is observed without exception for the pre-bomb sedimentary lipids. The sterols, hopanols, and fatty acids fall within the lower oval shape on the figure. This cluster is bisected by the pre-bomb $\Delta^{14} \mathrm{C}_{\mathrm{DIC}}$ line $\left(-82 \%\right.$ ). The data for $\mathrm{C}_{30^{-}}$ alkan-15-one-1-ol, $\mathrm{C}_{30}$-alkan-1,15-diol, $n$ - $\mathrm{C}_{22}-\mathrm{OH}$, and $n-\mathrm{C}_{24}-\mathrm{OH}$ also fall outside this region due to more negative $\delta^{13} \mathrm{C}$ values rather than because of differences in $\Delta^{14} \mathrm{C}$ (one exception may be $n-\mathrm{C}_{22}-\mathrm{OH}$, compound " $\mathrm{n}$ ").

\section{Figure 6.20}

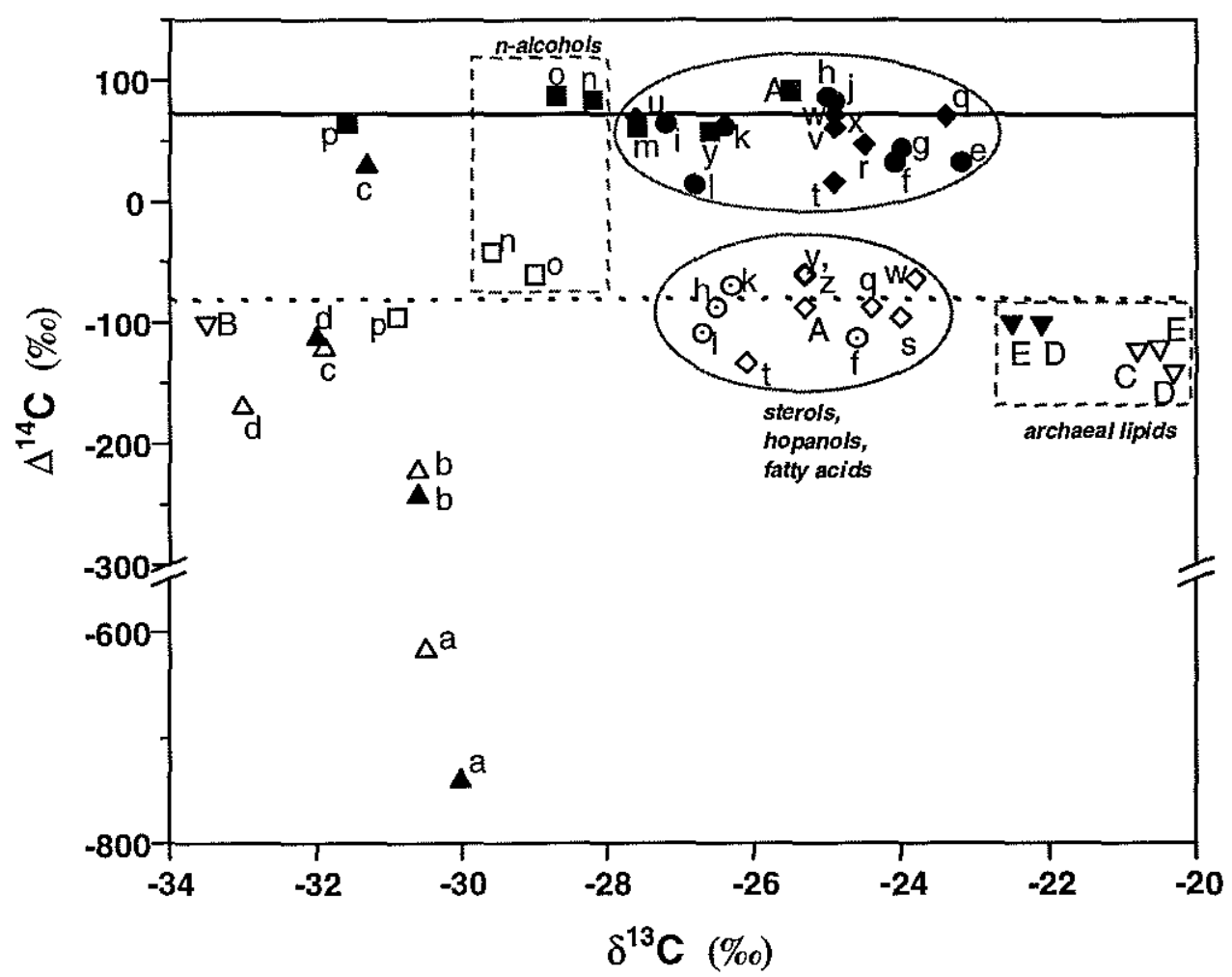

Figure 6.20 $\Delta^{14} \mathrm{C}$ vs. $\delta^{13} \mathrm{C}$ distribution for SMB biomarkers. Post-bomb data $(0-0.75$, $0.75-1.5,0-2.5 \mathrm{~cm}$ horizons) are shown with solid symbols and pre-bomb data (4.5-5.5, $5.5-8.5,2.5-7.5 \mathrm{~cm}$ horizons) with hollow symbols. $\boldsymbol{\Delta}, n$-alkanes; $\bullet$, FAMEs; $\mathbf{n}, n-$ alcohols; $\downarrow$, sterols and hopanols; $\boldsymbol{\nabla}$, archaeal lipids and $\mathrm{C}_{30}$-diol (post-bomb data from SBB 0-1 cm). Letters identify individual compounds as in Table 6.2. 
The other two lipid classes studied, $n$-alkanes and archaeal ether-linked isoprenoids, contain the only significant exceptions to the general pattern of $\Delta^{14} \mathrm{C}_{\text {pre-bomb }}$ $\sim-80 \%$ and $\Delta^{14} \mathrm{C}_{\text {post-bomb }} \sim+70 \%$ o. The $\Delta^{14} \mathrm{C}$ values for two of the $n$-alkane samples became more ${ }^{14} \mathrm{C}$-depleted in the post-bomb sediment. This signals that at least one fractional component of the $n$-alkane series has not incorporated bomb- ${ }^{14} \mathrm{CO}_{2}$. Also, the proportion of this component is higher in the SMB $0-2.5 \mathrm{~cm}$, post-bomb horizon than it is in the pre-bomb horizon. The odd-chain homologues had different changes in measured values of $\Delta^{14} \mathrm{C}$ between the two sedimentary horizons. The $n$-alkanes are clearly behaving differently than the other biomarker classes with respect to mechanisms of bomb- ${ }^{14} \mathrm{C}$ incorporation. The same is true of the two archaeal lipids for which both prebomb and post-bomb $\Delta^{14} \mathrm{C}$ data were obtained. Within the uncertainties caused by comparing the data between samples from different locations (SMB and SBB), the prebomb and post-bomb $\Delta^{14} \mathrm{C}$ values remain essentially constant. Again, these data do not reflect the pattern of bomb- ${ }^{14} \mathrm{C}$ uptake apparent within the FAMEs and alcohols.

It is not surprising that the main feature that distinguishes the surface sedimentary (post-bomb) lipids from the lipids of deeper horizons is the uptake of bomb- ${ }^{14} \mathrm{C}$. What is surprising, perhaps, is the relative uniformity of this change in ${ }^{14} \mathrm{C}$ concentration for most of the biomarkers analyzed. The $n$-alkane and archaeal lipid classes are therefore distinguished by their unusual functional rate of change in $\Delta^{14} \mathrm{C}$, or their $\Delta\left(\Delta^{14} \mathrm{C}\right)$. This $\Delta\left(\Delta^{14} \mathrm{C}\right)$ parameter can be added as a third dimension to the multi-dimensional carbon isotope distribution. Only the biomarkers for which data were obtained in both pre-bomb and post-bomb sedimentary horizons can be described in this way. The $\Delta\left(\Delta^{14} \mathrm{C}\right)$ values for these pre-bomb/post-bomb pairs range between $+119 \%$ and $+194 \%$ for all FAMEs, $n$-alcohols, sterols, and hopanols (Table 6.2). The average difference for these lipid classes is $+147 \pm 21 \%$. In comparison, the estimated change in $\Delta^{14} \mathrm{C}$ of surface water DIC over the same time interval is $+71-(-82)=+153 \%$. On average, the organisms producing these lipids have incorporated bomb- ${ }^{14} \mathrm{C}$ at a rate that is statistically equal to the rate of invasion of atmospheric ${ }^{14} \mathrm{CO}_{2}$ into the surface water DIC pool. 
The third, $\Delta\left(\Delta^{14} \mathrm{C}\right)$ dimension is included in the plot shown in Figure 6.21. The horizontal plane at $\Delta\left(\Delta^{14} \mathrm{C}\right) \sim+150 \%$ corresponds to the incorporation of bomb- ${ }^{14} \mathrm{C}$ into surface water DIC. The functionalized lipid biomarkers are again designated by the 3 dimensional oval cluster. The sharp contrast between these lipids and the archaeal lipids (compounds $\mathrm{D}$ and $\mathrm{E}$ ) and $n$-alkanes (compounds $\mathrm{a}, \mathrm{b}, \mathrm{c}, \mathrm{d}$ ) is apparent.

Figure 6.21

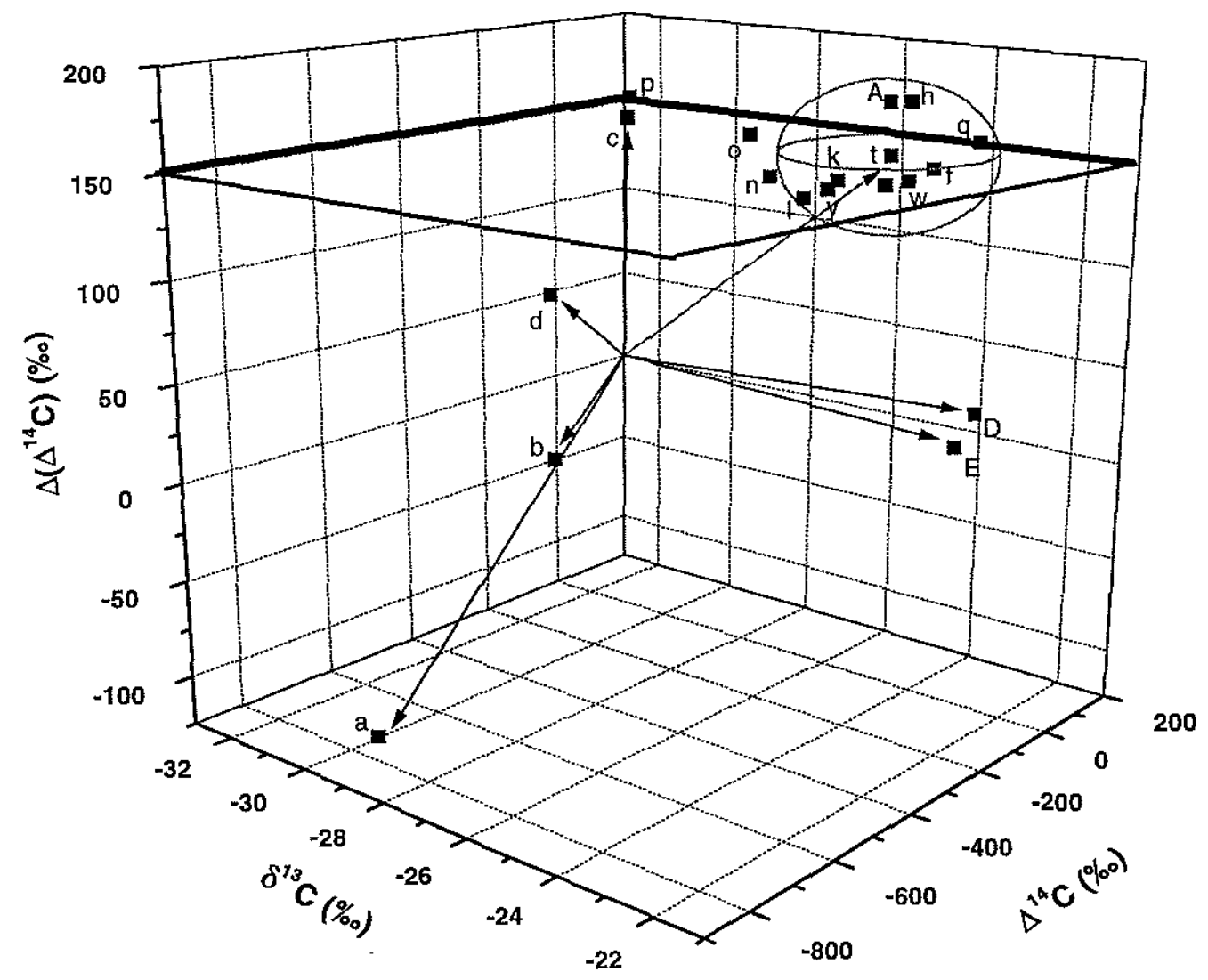

Figure 6.21 Three-dimensional plot of the post-bomb data presented in Figure 6.20. The $\mathrm{z}$-axis shows the change in $\Delta^{14} \mathrm{C}$ recorded by individual biomarkers between pre-bomb and post-bomb horizons $\left(\Delta\left(\Delta^{14} \mathrm{C}\right)=\Delta^{14}\right.$ Cpost-bomb $-\Delta^{14}$ Cpre-bomb $)$. The horizontal plane at $\Delta\left(\Delta^{14} \mathrm{C}\right)=+150 \%$ represents the change in surface water $\Delta^{14} \mathrm{C}_{\mathrm{DIC}}$ over the same time interval. All of the analyzed lipids except $n$-alkanes and archaeal isoprenoids fall within $\pm 30 \%$ of this plane. 
As a first-order approximation, therefore, the $\Delta^{14} \mathrm{C}$ values of all FAMEs, linear alcohols, sterols, and hopanols indicate these compounds are marine in origin. The carbon in these molecules reflects the production of photosynthetic biomass in the surface waters of SMB and SBB. The individual compounds within these lipid classes include products derived directly from photoautotrophs (e.g. dinosterol), lipids of herbivorous zooplankton (e.g. $\mathrm{C}_{27} \Delta^{5}$, cholesterol), lipids of heterotrophic bacteria (e.g. $\mathrm{C}_{31}$ hopanol), and products representing mixed sources (e.g. $\mathrm{C}_{16: 0}$ fatty acid). The relatively close agreement of bacterial lipid $\Delta^{14} \mathrm{C}$ data with the $\Delta^{14} \mathrm{C}$ of phytoplanktonic carbon also indicates the deep SMB is a dominantly heterotrophic environment. This generality will be examined in more detail in the following discussion.

\subsubsection{Sources of Lipid Biomarkers to SMB Sediment}

Compound-specific isotopic measurements (Table 6.2) indicate the carbon in most SMB sedimentary biomarkers derived from surface water DIC through photoautotrophic primary production or by heterotrophic consumption of phytoplanktonic biomass. The exceptions to this general observation are the $n$-alkanes (treated separately, Chapter 7) and the archaeal lipids (Chapter 5). The sterol data were discussed thoroughly in Chapter 4 and found to represent marine production with no apparent exceptions. Here the $\Delta^{14} \mathrm{C}$ data for the fatty acids (as FAMEs), linear alcohols, and hopanols are examined in further detail to build on these previous discussions.

The models in Chapter 7 yield estimates of the expected $\Delta^{14} \mathrm{C}$ values of terrestrial and chemoautotrophic lipid components. The following discussion incorporates two assumptions based on the conclusions of Chapter 7. These assumptions are that any terrestrial lipid fraction will have a $\Delta^{14} \mathrm{C}_{\text {terrestrial }}$ endmember value that is more modern than surface water DIC, while any chemoautotrophic component will have $\Delta^{14} \mathrm{C}_{\text {chemoautotroph }}$ that is more ${ }^{14} \mathrm{C}$-depleted than surface water DIC. 


\subsubsection{FAMES}

The FAME isotopic data can be evaluated in terms of the expected biosynthetic sources of the various compounds as previously predicted by the concentration data and other biogeochemical considerations. In both the surface and deep horizons, $\mathrm{C}_{14: 0}$ and $\mathrm{C}_{18: 0}$ are not enriched or depleted in ${ }^{14} \mathrm{C}$ relative to $\mathrm{C}_{16: 0}$. This indicates a common origin (or unvarying relative contributions from multiple sources) for these compounds. It also suggests that the down-core decrease in absolute concentrations of these isomers is simply the result of remineralization. There is no difference in "packaging" leading to altered preservation potential, and these compounds appear to be easily metabolized. $\mathrm{C}_{16: 0}$ and $\mathrm{C}_{14: 0}$ are the most common fatty acids of diatoms (Volkman et al., 1980), the dominant primary producers in the Southern California Bight, so a large fraction of the $\mathrm{C}_{16: 0}$ in anoxic SMB sediments may come from this source. $\mathrm{C}_{18: 0}$ is less common in diatoms, but is found in green algae and zooplankton (references in Wakeham and Beier, 1991). The isotopic data for $\mathrm{C}_{16: 0}$ and $\mathrm{C}_{18: 0}$ are therefore expected to reflect integrated phytoplanktonic biomass and perhaps also include components from bacterial transformation, degradation and/or synthetic processes. The pre-bomb $\Delta^{14} \mathrm{C}$ value for $\mathrm{C}_{16: 0}(-76 \pm 14 \%$ o $)$ agrees within measurement error with the estimate of pre-bomb surface water $\Delta^{14} \mathrm{C}_{\mathrm{DIC}}(-82 \%)$, indicating a marine source for this compound. The postbomb $\Delta^{14} \mathrm{C}$ values average $+83 \pm 14 \%$, also consistent with a euphotic zone source $\left(\Delta^{14} \mathrm{C}_{\text {DIC }}=+71 \%\right.$ )

Bacterial biomass may, however, provide an additional source of these fatty acids, especially for the $\mathrm{C}_{16}$ and $\mathrm{C}_{18}$ compounds. Bacteria have been proposed to contribute a large fraction of $\mathrm{C}_{16: 0}$ in organic-rich marine sediments (e.g. Perry et al., 1979; Volkman et al., 1980), and $\mathrm{C}_{18: 0}$ is also a major lipid of marine bacteria (Oliver and Colwell, 1973). The bacterial contribution to the $\mathrm{C}_{16}$ and $\mathrm{C}_{18}$ fatty acids is even more certain for the monounsaturated isomers. $C_{16: 1 \omega 7}$ and $C_{18: 1 \omega 7}$ are products of anaerobic fatty acid biosynthesis and these compounds are abundant in the lipids of sedimentary bacteria (e.g. Perry et al., 1979) 
The higher concentrations of monounsaturated fatty acids in the $0-0.75 \mathrm{~cm}$ sample may be due to the presence of live bacterial mats at the sediment-water interface. The major lipids of the filamentous sulfur bacteria, Thioploca and Beggiatoa spp., are $\mathrm{C}_{16: 107}, \mathrm{C}_{16: 0}$, and $\mathrm{C}_{18: 1 \omega 7}$ (McCaffrey, 1990). Bacterial filaments were visible when the core was collected, and the $\mathrm{C}_{16: 1 \omega 7}$ and $\mathrm{C}_{18: 1 \omega 7}$ in $\mathrm{SMB}$ 0-0.75 cm sediment, especially, may be contributed by these organisms. Beggiatoa spp. are known to function both as autotrophic and heterotrophic organisms, depending on the environment (e.g. Hagen and Nelson, 1996), but in SMB they are apparently growing as heterotrophs. The $\Delta^{14} \mathrm{C}$ measured for $\mathrm{C}_{18: 1 \omega 7}(+64 \pm 11 \%$ ) in SMB post-bomb sediment is not significantly different from surface water $\Delta^{14} \mathrm{C}_{\mathrm{DIC}}(+71 \%$ ) , and contrasts with the expected benthic DIC source for chemoautotrophic production $(\sim-190 \% o)$ and the $\Delta^{14} \mathrm{C}$ values measured for the lipids of apparently autotrophic Archaea ( -120 to $-140 \%$ o).

The relative abundances of bacterial lipids (both branched and straight-chain) are in general consistent with previous studies of the SMB sedimentary environment. Concentrations of ATP and results of tracer incubation experiments suggest that living bacterial biomass accounts for $\sim 10-40 \%$ of TOC in the upper $5-10 \mathrm{~mm}$ but decreases exponentially with depth in anoxic SMB sediments (Craven and Jahnke, 1992).

However, the branched-chain fatty acids are apparently less quickly remineralized than the monounsaturated $\mathrm{C}_{16}$ and $\mathrm{C}_{18}$ fatty acids, or they may have in-situ sources. Branchedchain fatty acids, $i-\mathrm{C}_{15: 0}$ and $a-\mathrm{C}_{15: 0}$, as well as the linear $\mathrm{C}_{15: 0}$ isomer, are believed to derive from bacterial sources in marine sediments (e.g. Perry et al., 1979). They are abundant in sulfate reducers (Boon, 1977; Parkes and Taylor, 1983) and in gram-positive bacteria (Kaneda, 1991). The presence of these compounds has been correlated previously with sulfate reduction in Cape Lookout Bight (Haddad et al., 1992). Relative enrichment of $a-\mathrm{C}_{15: 0}$ beneath the sediment-water interface was also identified in other anoxic sediments, including the Black Sea (Wakeham and Beier, 1991) and in previous work in SMB (Gong and Hollander, 1997).

The $\Delta^{14} \mathrm{C}$ isotopic data suggest there is a component of both pre-bomb and postbomb $\mathrm{C}_{15}$ fatty acids that is not derived from bacterial heterotrophic consumption of 
phytoplanktonic detritus. Post-bomb $\Delta^{14} \mathrm{C}$ values are near $+35 \%$, compared to surface water $\mathrm{DIC}=+71 \%$; the single pre-bomb value for $a-\mathrm{C}_{15: 0}$ is $-113 \%$, compared to $\mathrm{DIC}=$ $-82 \%$. The most likely explanation is that the bacteria responsible for producing these compounds contain some carbon derived from chemoautotrophic incorporation of bottom water DIC $(\sim-190 \%)$ ). How much DIC uptake is needed to produce the observed ${ }^{14} \mathrm{C}$ depletions? Mass-balance estimates indicate $13 \pm 5 \%$ and $29 \pm 15 \%$ of the $\mathrm{C}_{15}$ fatty acid carbon in SMB 0-0.75 cm and SMB 4.5-5.5 cm sediments, respectively, would need to derive from bacterial autotrophy. This may be consistent with an in-situ source at depth for $a-\mathrm{C}_{15: 0}$, especially.

Bacteria require branched-chain or unsaturated lipids in order to regulate membrane fluidity. The biosynthetic pathways leading to these two bacterial fatty acid classes are different, and bacteria regulate one or the other, but not both (Kaneda, 1991). The distribution of these pathways is not well organized phylogenetically. This leads, for example, to branched-chain products in Desulfovibrio and other sulfate reducers but to $\mathrm{C}_{18: 1 \omega 7}$ and $\mathrm{C}_{16: 1 \omega 7}$ in Beggiatoa and other sulfide oxidizers. Both organisms are members of the purple bacteria. The $\Delta^{14} \mathrm{C}$ data for SMB bacterial fatty acids apparently trace two separate groups of organisms with slightly different metabolic properties. One set may include sulfide metabolizers that produce $\mathrm{C}_{18: 1 \omega 7}$ and which are apparently consuming photosynthetically-derived carbon, either through organotrophy or by uptake of respired $\mathrm{CO}_{2}$ produced in the immediate vicinity of the bacterial cells (before mixing with bottom water DIC). The other group must include both heterotrophic dissimilatory sulfate reducers and a minor component of unidentified species with partial or obligate chemoautotrophic metabolism. This fraction may increase with depth in the core and lead to enrichment of the ${ }^{14} \mathrm{C}$-depleted $a-\mathrm{C}_{15: 0}$ isomer.

The long-chain $\left(>\mathrm{C}_{20: 0}\right)$ fatty acids are usually interpreted as originating from terrestrial sources (Cranwell, 1974). These isomers often become relatively enriched in concentration with depth in marine sediments (e.g. Gong and Hollander, 1997; Colombo et al., 1997). This observation has been used frequently to support the hypothesis of a terrestrial origin, by invoking differential packaging and/or association with terrestrially- 
derived particles. Long-chain alkanoic acids, however, have been found in bacteria (Schweizer, 1988) and could also come from the reduction of monounsaturated longchain acids (e.g. $\mathrm{C}_{24: 1}$ ) common in zooplankton (Sargent, 1976). Haddad et al. (1992) suggested that fatty acids $>\mathrm{C}_{20: 0}$ are poor substrates for heterotrophic organisms and are not utilized as rapidly as fatty acids of lower carbon number in marine sediment. Recent work based on the $\delta^{13} \mathrm{C}$ values of fatty acids from anoxic SMB sediments has also suggested they could have a marine bacterial origin (Gong and Hollander, 1997).

The $\Delta^{14} \mathrm{C}$ data for $S M B C_{24: 0}$ and $\mathrm{C}_{26: 0}$ fatty acids are difficult to interpret. For long-chain fatty acids from both pre-bomb and post-bomb sedimentary horizons, $\mathrm{C}_{26: 0}$ is more ${ }^{14} \mathrm{C}$-depleted than $\mathrm{C}_{24: 0}$ (Table 6.2). The $\Delta^{14} \mathrm{C}$ values for $\mathrm{C}_{24: 0}$ are not significantly different from $\Delta^{14} \mathrm{C}_{\mathrm{DIC}}$ in both horizons, clearly indicating a marine planktonic or heterotrophic bacterial source. The values for $\mathrm{C}_{26: 0}$ are lower than $\Delta^{14} \mathrm{C}_{\mathrm{DIC}}$. This could occur because of a higher contribution of pre-aged terrestrial carbon to the $\mathrm{C}_{26: 0}$ isolates, which would be consistent with a higher contribution of terrestrial products at longer chain length. However, the $n$-alkane data indicate the terrestrial lipid contributions are "fresh" and arrive in the SMB environment with $\Delta^{14} \mathrm{C}$ values more positive than the marine carbon endmembers. Therefore, another explanation for the low $\Delta^{14} \mathrm{C}$ values of $\mathrm{C}_{26: 0}$ fatty acid is needed. One possibility is that the $\mathrm{C}_{26: 0}$ samples, which were not subjected to the column bleed clean-up step before analysis, are more affected by PCGC column bleed. This contamination would affect the higher-boiling $\mathrm{C}_{26: 0}$ more strongly than $\mathrm{C}_{24: 0}$, as $\mathrm{C}_{26: 0}$ eluted in the region of the chromatogram where thermal degradation of the column stationary phase was observed, but $\mathrm{C}_{24: 0}$ eluted in the area where the baseline remains flat. An additional possibility is that $\mathrm{C}_{26: 0}$, like the $\mathrm{C}_{15}$ fatty acids, is more strongly affected by contributions from bacterial chemoautotrophic biomass production, although without more data, this is difficult to evaluate. 


\subsubsection{2 n-Alcohols, Alkan-15-one-1-ols, Alkan-1,15-diols}

Long-chain $n$-alcohols in marine sediments are usually attributed to terrestrial sources, including fresh-water algae and higher plants. Distributions of $n$-alkanols in lake sediments have been studied extensively, and several different concentration distributions have been observed. These include a single maximum at $\mathrm{C}_{22}$ (Cranwell, 1981) or at $\mathrm{C}_{26}$ (Cranwell, 1984) and a bi-modal distribution showing two apparent sources with maxima at $\mathrm{C}_{22}$ and $\mathrm{C}_{28}$ (Cranwell, 1981). In the marine environment, $\mathrm{C}_{22}$ and $\mathrm{C}_{22: 1}$ can be the dominant alcohol of the wax esters of copepods (Sargent $e t a l$., 1977 ), and by extension, $\mathrm{C}_{24}$ and $\mathrm{C}_{24: 1}$ may have similar origins. Bacteria could also be sources of $n$-alcohols either through direct biosynthesis or by reduction of long-chain fatty acids. It may be difficult, therefore to decipher the origins of SMB sedimentary alcohols.

The most abundant $n$-alcohols in SMB sediment are $\mathrm{C}_{22}$ and $\mathrm{C}_{24} \cdot \mathrm{C}_{22}$ is relatively enriched with depth in the core. There have been previous reports that the $\mathrm{C}_{22} n$-alkanol is dominant in the marine environment, especially in deeper sediments (e.g. Johns, et al., 1978). This profile might suggest that the terrestrial higher-plant fraction, which is expected to contribute more $n-\mathrm{C}_{24}, \mathrm{C}_{26}$, and $\mathrm{C}_{28}-\mathrm{OH}$, is preferentially remineralized at depth in the core, while a zooplanktonic or fresh-water algal component containing abundant $\mathrm{C}_{22}$ is preserved. Alternatively, there could be an in-situ source for $\mathrm{C}_{22}$ or a change in the fractional contributions of multiple sources. The relative concentrations of typical zooplanktonic $n$-alcohols $\left(\mathrm{C}_{16}, \mathrm{C}_{18}\right)$ (Sargent et al., 1977) vary in synchrony with the longer chain alcohols (except $\mathrm{C}_{22}$ ). This contrasts with the diagenetic differences observed between the short-chain and long-chain fatty acids. Hence, most of the $n$ alcohols in SMB sediment may have a marine zooplanktonic or fresh water algal source.

The post-bomb $n-\mathrm{C}_{22}-\mathrm{OH}$ and $n-\mathrm{C}_{24}-\mathrm{OH} \Delta^{14} \mathrm{C}$ data $(+85 \%,+88 \%$ ) are similar to the $\Delta^{14} \mathrm{C}$ of SMB surface water DIC $(+83 \%$ o to $+95 \%$ in the $0.75-1.5 \mathrm{~cm}$ horizon). The majority of these biomarkers in SMB sediment apparently originate from marine sources. It is somewhat difficult to tell if there is a terrestrial component to these samples, 
however, as terrestrial biomass also has a positive $\Delta^{14} \mathrm{C}$ value. The $\Delta^{14} \mathrm{C}$ of atmospheric $\mathrm{CO}_{2}$ was $>+200 \%$ during this time. If the $\Delta^{14} \mathrm{C}$ of any fresh-water algal or terrestrial plant component was also $>+200 \%$, then only a small fraction $(\sim 10 \%)$ of $\mathrm{C}_{22}$ and $\mathrm{C}_{24}$ could originate from terrestrial sources.

A similar conclusion is reached for the pre-bomb long-chain $n$-alkanols, although terrestrial material may be relatively enriched in these samples. The $\Delta^{14} \mathrm{C}$ values for $\mathrm{C}_{22}$ and $\mathrm{C}_{24}(-41 \%$ and $-59 \%$ ) are not consistent with an exclusive source from fresh terrestrial land-plant or aquatic biomass, which would have $\Delta^{14} \mathrm{C}$ equal to the pre-bomb atmosphere $(\sim 0 \%)$. However, these numbers are significantly ${ }^{14} \mathrm{C}$-enriched compared to pre-bomb SMB surface water DIC $(-82 \%)$. Terrestrial materials are the only possible sources of ${ }^{14} \mathrm{C}$-enriched carbon in marine sediments. A mass-balance estimate for prebomb $n$-alkanols indicates that $50 \%$ of the $\mathrm{C}_{22}$ and $28 \%$ of the $\mathrm{C}_{24}$ could come from terrestrial input. The uncertainties in this calculation are about $\pm 15-20 \%$, so the ${ }^{14} \mathrm{C}$ enrichment apparently is significant. It is unlikely, however, that $\mathrm{C}_{22}$ would have a more modern ${ }^{14} \mathrm{C}$ signature than $\mathrm{C}_{24}$ if terrestrial higher plants were the primary source of these alkanols. Alkanols of higher carbon number, i.e. $\mathrm{C}_{24}$, should contain more plant input (Cranwell, 1981; Yunker et al., 1995). Also, the abundance of $C_{22}$ becomes relatively enriched with depth in SMB sediment, perhaps indicating preferential preservation of zooplanktonic components compared to longer-chain isomers. It is possible the ${ }^{14} \mathrm{C}$ enriched component of these $n$-alkanols derives from the input of terrestrial aquatic production. There also must be a marine source for these lipids, however, since at least $50 \%$ of the pre-bomb and up to $100 \%$ of the post-bomb $n$-alcohols have the isotopic composition of marine surface water DIC. One additional possiblity in these anoxic SMB sediments is that $\mathrm{C}_{22}$ derives from a mixture of higher plant or terrestrial aquatic $\mathrm{C}_{22: 0}$ and from the microbial reduction of marine zooplanktonic $\mathrm{C}_{22: 1}$ to $\mathrm{C}_{22: 0}$.

The single value for $n-\mathrm{C}_{16}-\mathrm{OH}$ from post-bomb sediment is slightly lower $(+69 \pm$ $10 \%$ ) than the predicted range of surface water $\Delta^{14} \mathrm{C}_{\mathrm{DIC}}(+83$ to $+95 \%$ ) and the measured $\Delta^{14} \mathrm{C}$ of post-bomb $\mathrm{C}_{22}$ and $\mathrm{C}_{24}$ alcohols. The shorter-chain $n$-alcohols are believed to have both zooplanktonic and bacterial sources in aquatic environments (Sargent $e t$ al., 
1977; Cranwell, 1984). The slight ${ }^{14} \mathrm{C}$-depletion in $\mathrm{C}_{16}$, if significant, could reflect a primarily zooplanktonic source, with a minor contribution of ${ }^{14} \mathrm{C}$-depleted bacterial carbon. In general, however, the data for short-chain and long-chain $n$-alkanols are similar. This suggests that, except for the enrichment of $\mathrm{C}_{22}$ at depth, the $n$-alcohols in this environment derive from a common source. The $n$-alcohol $\Delta^{14} \mathrm{C}$ data are consistent with a primarily marine zooplanktonic origin for these compounds, with a partial contribution from terrestrial sources.

The $\Delta^{14} \mathrm{C}$ data for $\mathrm{SMB} \mathrm{C}_{30}$-alkan-15-one-1-ol are generally consistent with a phytoplanktonic origin for this compound. Post-bomb $\Delta^{14} \mathrm{C}$ values for $\mathrm{C}_{30}$-alkan-15-one1 -ol averaged $+65 \%$, while the pre-bomb value was measured to be $-95 \%$. Alkan-15one-1-ols and alkan-1,15-diols in marine and fresh water environments are believed to originate from microalgal sources (references in Volkman et al., 1998). The main phytoplanktonic species in which these compounds have been found are members of the Eustigmatophyceae, including species of Nannochloropsis and in the Chlorophyceae, including Chlorella and Nannochloris species (Gelin et al., 1997). These organisms are believed to be the major sources of alkyl diols and ketols in fresh water environments, but Eustigmatophytes are not usually a major fraction of the marine algal population. Other unidentified planktonic groups may also produce these compounds. However, the Eustigmatophyceae are also known producers of algaenans (references in Gelin et al., 1999). These complex aliphatic biopolymers are resistant to degradation, and the association of $\mathrm{C}_{30}$-alkan-15-one-1-ol with a complex matrix could help explain its apparent resistance to degradation in SMB sediment. High concentrations of the longchain ketols and diols are also observed in Black Sea sediments, the environment in which these lipids were first identified (deLeeuw et al., 1981).

Compound-specific $\delta^{13} \mathrm{C}$ data indicate that the $\mathrm{C}_{30}$-alkan-1,15-diols in Black Sea sediments $\left(\delta^{13} \mathrm{C} \sim-32 \%\right.$ ) apparently are related to the pyrolysis products of sedimentary aliphatic biopolymers showing similar levels of ${ }^{13} \mathrm{C}$-depletion (Eglinton et al., manuscript in preparation). These data support the hypothesis that the ketols and diols are metabolically related to the biosynthesis of algaenans by marine phytoplankton (Gelin $e t$ 
$a l ., 1997)$. The $\delta^{13} \mathrm{C}$ values measured for SMB $\mathrm{C}_{30}$-alkyl-diols and $\mathrm{C}_{30}$-alkan-15-one-1ols (also $\sim-32 \%$ ) are much more ${ }^{13} \mathrm{C}$-depleted than the values measured for the rest of the phytoplanktonic lipids. $\mathrm{CO}_{2}$ fixation by these organisms apparently has a larger photosynthetic fractionation than observed in other phytoplanktonic species. The greater fractionation may be the result of higher internal cellular $\mathrm{CO}_{2}$ concentrations (e.g. Laws et al., 1995). The Eustigmatophyceae are nannoplankton (2-18 $\mu \mathrm{m}$ Hibberd and Leedale, 1970). Their small cell size may permit a closer equilibrium between internal cellular and external seawater $\mathrm{CO}_{2}$ concentrations, because they certainly have a high surface area to volume ratio (e.g. Popp et al., 1998).

The Eustigmatophyceae are also implicated as sources of $n-\mathrm{C}_{22-28}-\mathrm{OH}$ in aquatic environments (Volkman et al., 1999). The $\delta^{13} \mathrm{C}$ depletion observed for $n$-alcohols in SMB sediments could also reflect a partial contribution from these organisms. The $\delta^{13} \mathrm{C}$ values of SMB $n$-alcohols $\left(-28\right.$ to $-32 \%$ ) are too ${ }^{13} \mathrm{C}$-depleted to be explained by marine zooplanktonic sources alone, so partial contributions from terrestrial and/or microalgal sources are required to explain the $\delta^{13} \mathrm{C}$ data as well as the $\Delta^{14} \mathrm{C}$ data.

\subsubsection{Hopanols}

The concentration data for SMB sedimentary hopanols and tetrahymanol are consistent with a previous report by Venkatesan et al., (1990). Tetrahymanol and the $\mathrm{C}_{30}$, $\mathrm{C}_{31}$, and $\mathrm{C}_{32}$ hopanols are all abundant in the surface horizon, but $\mathrm{C}_{30}$ hopanol and especially tetrahymanol are quite depleted in the deeper sediments. The relative abundance of $\mathrm{C}_{32}$ hopanol increases because its absolute concentration is nearly constant between the $0.75-1.5 \mathrm{~cm}$ sample and the $5.5-8.5 \mathrm{~cm}$ sample (Figure 6.7). This may be due to a different sedimentary degradation rates for $\mathrm{C}_{32}$ hopanol, $\mathrm{C}_{30}$ hopanol and especially tetrahymanol. The latter two apparently are degraded more easily, as it is unlikely there is an in-situ biosynthetic source for $\mathrm{C}_{32}$ hopanol.

Oxygen is not required for hopanoid synthesis and thus the hopanoid-producing organisms utilize a more "primitive" biosynthetic pathway. However, all known 
hopanoid producers are aerobic (Ourisson et al., 1987). This discounts the possibility of in-situ hopanol biosynthesis below the upper few mm of the anoxic SMB sediments. The hopanols found in deeper SMB sediments probably derive from hydrolysis of the precursor molecule, $\mathrm{C}_{35}$ bacteriohopane-tetrol, formed by bacteria in oxic regions of the water column and at the sediment-water interface (Rohmer et al., 1984). Tetrahymanol is produced by fresh-water protozoa of the genus Tetrahymena (Mallory et al., 1963). It was also recently identified in a phototrophic species of purple bacteria, Rhodopseudomonas palustris (Kleeman et al., 1990). Even before a specific bacterial species was identified, a ubiquitous marine prokaryotic source was postulated because of the common occurrence of tetrahymanol in marine sediments (ten Haven et al., 1989, Venkatesan $e t a l ., 1990$ ). It is likely that there are additional, non-phototrophic bacterial sources for tetrahymanol; but currently it is still reasonable to assume that like the regular hopanols, these sources will not include strict anaerobes.

The $\Delta^{14} \mathrm{C}$ values for the individual hopanols, especially $\mathrm{C}_{32}$ hopanol, were significantly depleted relative to SMB surface water DIC. This may suggest a fraction of the hopanoid carbon originates from chemoautotrophic biomass production. In general, the hopanols in SMB sediment appear to present a pattern of ${ }^{14} \mathrm{C}$ concentrations similar to the values obtained for the $\mathrm{C}_{15}$ bacterial fatty acids. However, hopanols are the bacterial analogue to eukaryotic sterols and are present in numerous classes of bacteria (Ourisson et al., 1987). The hopanol $\Delta^{14} \mathrm{C}$ data therefore may integrate a larger fraction of the total sedimentary bacterial population than the $\mathrm{C}_{15}$ fatty acids. Isotopic mass balance can be used to estimate what fraction of the bacterial hopanols might originate from chemoautotrophic utilization of bottom water DIC. $\mathrm{C}_{32}$ hopanol in both horizons appears to have the largest chemoautotrophic component. A calculation made in the same manner as for the $\mathrm{C}_{15}$ fatty acids suggests bottom water DIC $(\sim-190 \%$ ) could account for $\sim 25 \%$ and $\sim 50 \%$ of the carbon in $\mathrm{C}_{32}$ hopanol from the SMB $0.75-1.5 \mathrm{~cm}$ and SMB $5.5-8.5 \mathrm{~cm}$ horizons, respectively. This is consistent with the prior speculation based on concentration data that there could be an in-situ sedimentary source for $\mathrm{C}_{32}$ hopanol. 
Hopanols have been found in cyanobacteria, purple non-sulfur bacteria, and gramnegative and gram-positive heterotrophs and autotrophs (including marine Nitrosomonas spp.) (Ourisson et al, 1987). Hopanols have not been found in the filamentous sulfur bacteria, however, so are not expected to reflect the ${ }^{14} \mathrm{C}$ concentration of the SMB Beggiatoa population. The fatty acid and hopanol data together appear to represent two distinct groups of prokaryotes. The linear fatty acids, including monounsaturated $\mathrm{C}_{16}$ and $\mathrm{C}_{18}$ compounds, may (partially) trace the sulfide-metabolizing organisms in SMB sediment. $\Delta^{14} \mathrm{C}$ data for these compounds suggest these organisms are dominantly heterotrophic in metabolism. The branched-chain fatty acids and the hopanols may trace other bacterial groups such as sulfate-respiring heterotrophs and ammonium-oxidizing autotrophs. These bacterial lipids appear to contain a small chemoautotrophic component. Mass-balance estimates suggest autotrophic production could account for between $13 \%$ and $50 \%$ of the biomass of these organisms. However, it is unknown what fraction of either the total bacterial population or the TOC in SMB sediment derives from these sources. Thus it is difficult to estimate the contribution of the various bacterial (and archaeal) carbon pools to the $f_{U}$ (fraction of TOC with "unknown" origin, $U$ ) and $\Delta^{14} \mathrm{C}_{\mathrm{U}}$ $\left(\Delta^{14} \mathrm{C}\right.$ of " $U$ ") parameters developed in the next chapter. 


\subsection{Synthesis ANd CONClusions}

In this chapter, 64 compound-specific $\Delta^{14} \mathrm{C}$ measurements were presented for 31 different lipid biomarkers extracted from sediments of Santa Monica Basin and Santa Barbara Basin, California. The data were obtained through PCGC isolation of the pure lipids and subsequent ${ }^{14} \mathrm{C}$-AMS analysis of these very small samples. The majority of the study focused on examining the ${ }^{14} \mathrm{C}$ distribution in lipids of the SMB anoxic depocenter. Supporting data was also obtained in the form of compound-specific $\delta^{13} \mathrm{C}$ measurements for all lipid fractions studied.

The most valuable tracer property of the $\Delta^{14} \mathrm{C}$ data was the change in $\Delta^{14} \mathrm{C}$ values of these lipid biomarkers in contemporary, "post-bomb" sediments relative to their values in deeper, "pre-bomb" sediments. This $\Delta\left(\Delta^{14} \mathrm{C}\right)$ parameter allowed easy identification of all biomarkers for which the rate of ${ }^{14} \mathrm{C}$-uptake equaled the rate of bomb- ${ }^{14} \mathrm{C}$ incorporation into SMB surface water DIC. The $\Delta^{14} \mathrm{C}$ results indicated that the majority of these lipids in SMB sediment were of marine euphotic zone origin, either through photosynthetic primary production or heterotrophic secondary production. Further $\because$ examination of the data allowed division of these marine lipids into sub-groups reflecting minor contributions of other (chemoautotrophic bacterial or modern terrestrial) sources. The major exceptions to the general pattern of bomb ${ }^{14} \mathrm{C}$-uptake were the $n$-alkanes and the isoprenoid ether-linked lipids of Archaea, and these lipid classes were allocated separate chapters as a result of these differences (Chapters 5 and 7).

The primary sources and hypothesized sub-fractions of the SMB biomarker lipids are summarized in Table 6.4. 
Table 6.4 Sources of lipid biomarkers in SMB surface sediments.

\section{$\underline{\text { Lipid Class }}$}

n-Alkanes

FAMEs

Hopanols

Marine

Marine

Marine

Terrestrial(?)

Alkan-15-one-1-ols, Alkan-1,15-diols

Archaeal Lipids

Marine

Modern Terrestrial

Fossil

Sterols

n-Alcohols

Marine

Marine
Sub-Fractions

-Higher Plants

-Petroleum

-Shale

-Phytoplankton

-Bacteria(1) (heterotrophic)

-Bacteria(2)

(partially autotrophic)

-Bacteria(2)

(partially autotrophic)

-Phytoplankton

-Zooplankton

-Zooplankton

-Phytoplankton(?)

-Aquatic(?)

-Phytoplankton

-Chemoautotrophic Archaea 


\subsection{REFERENCES}

Benoit, G. J., Turekian, K. K., and Benninger L. K. (1979) Radiocarbon dating of a core from Long Island Sound. Estuarine Coastal Mar. Sci. 9, 171-180.

Boon, J. J., deLeeuw, J. W., Hoek, G. J., and Vosjan, J. H. (1977) Significance and taxonomic value of iso and anteiso monoenoic fatty acids and branched $\beta$ hydroxy acids in Desulfovibrio desulfuricans, J. Bacteriol. 129, 631-644.

Christensen, C. J., Gorsline, D. S., Hammond, D. E., and Lund, S. P. (1994) Non-annual laminations and expansion of anoxic basin-floor conditions in Santa Monica Basin, California Borderland, over the past four centuries. Mar. Geol. 116, 399418.

Collister, J. W., Rieley, G., Stern, B., Eglinton, G., and Fry, B. (1994a) Compoundspecific $\delta^{13} \mathrm{C}$ analyses of leaf lipids from plants with differing carbon dioxide metabolisms. Org. Geochem. 21, 619-627.

Collister, J. W., Lichtfouse, E., Hieshima, G., and Hayes, J. M. (1994b) Partial resolution of sources of $n$-alkanes in the saline portion of the Parachute Creek Member, Green River Formation (Piceance Creek Basin, Colorado). Org. Geochem. 21, 645-659.

Colombo, J. C., Silverberg, N., and Gearing, J. N. (1997) Lipid biogeochemistry in the Laurentian Trough-II. Changes in composition of fatty acids, sterols, and aliphatic hydrocarbons during early diagenesis. Org. Geochem. 26, 257-274.

Cranwell, P. A. (1974) Monocarboxylic acids in lake sediments: Indicators, derived from terresrial and aquatic biota, of paleoenvironmental trophic levels. Chem. Geol. 14, 1-14.

Cranwell, P. A. (1981) Diagenesis of free and bound lipids in terrestrial detritus deposited in a lacustrine sediment. Org. Geochem. 3, 79-89.

Cranwell, P. A. (1984) Lipid geochemistry of sediments from Upton Broad, a small productive lake. Org. Geochem. 7, 25-37.

Craven, D. B. and Jahnke, R. A. (1992) Microbial utilization and turnover of organic carbon in Santa Monica Basin sediments. Prog. Oceanog. 30, 313-333.

De Leeuw, J. W., Rijpstra, I. C., and Schenck, P. A. (1981) The occurrence and identification of $\mathrm{C}_{30}, \mathrm{C}_{31}$ and $\mathrm{C}_{32}$ alkan-1,15-diols and alkan-15-one-1-ols in Unit I and Unit II Black Sea sediments. Geochim. Cosmochim. Acta 45, 2281-2285.

DeLong, E. F. (1992) Archaea in coastal marine environments. Proc. Natl. Acad. Sci. 89, 5685-5689.

DeLong, E. F., King, L. L., Massana, R., Cittone, H., Murray, A., Schleper, C., and Wakeham, S. G. (1998) Dibiphytanyl ether lipids in nonthermophilic crenarchaeotes. Appl. Environ. Microbiol. 64, 1133-1138.

DeNiro, M. J. and Epstein, S. (1977) Mechanism of carbon isotope fractionation associated with lipid synthesis. Science 197, 261-263. 
Eganhouse, R. P. and Venkatesan, M. I. (1993) Chemical Oceanography and Geochemistry, In: Ecology of the Southern California Bight, A Synthesis and Interpretation. M. D. Dailey, D. J. Reish, and J. W. Anderson, Eds. University of California Press, Berkeley, p 71-171.

Eglinton, T. I., Aluwihare, L. I., Bauer, J. E., Druffel, E. R. M., and McNichol, A. P. (1996) Gas chromatographic isolation of individual compounds from complex matrices for radiocarbon dating. Anal. Chem. 68, 904-912.

Eglinton, T. I., Benitez-Nelson, B. C., Pearson, A., McNichol, A. P., Bauer, J. E., and Druffel, E. R. M. (1997) Variability in radiocarbon ages of individual organic compounds from marine sediments. Science 277, 796-799.

Eglinton, T. I., Gustafsson, O., Schouten, S., and Sinninghe Damste, J. S. (in preparation) Isotopic evidence for common biological precursor(s) of long-chain diols and $n$ hydrocarbon pyrolysis products from Black Sea sediments.

Emery, K. O. and Bray, E. E. (1962) Radiocarbon dating of California Basin sediments. Bull. Am. Assoc. Petrol. Geol. 46, 1839-1856.

Eppley, R. W. (1992) Chlorophyll, photosynthesis and new production in the Southern California Bight. Prog. Oceanog. 30, 117-150.

Eyssen, H. J., Parmentier., G. G., Compernolle, F. C., De Pauw, G. and Piessens-Denef, M. (1973) Biohydrogenation of sterols by Eubacterium ATCC 21,408-Nova species. Eur. J. Biochem. 36, 411-421.

Filley, T. R., Freeman, K. H., and Hatcher, P. G. (1997) Carbon isotope relationships between sulfide-bound steroids and proposed functionalized lipid precursors in sediments from the Santa Barbara Basin, California. Org. Geochem. 25, 367-377.

Freeman, K. H., Hayes, J. M., Trendel, J.-M. and Albrecht, P. (1990) Evidence from GCMS carbon-isotopic measurements for multiple origins of sedimentary hydrocarbons. Nature 353, 254-256.

Gelin, F., Boogers, I., Noordeloos, A. A. M., Sinninghe Damsté, J. S., Riegman, R. and de Leeuw, J. W. (1997) Resistant biomacromolecules in marine microalgae of the classes Eustigmatophyceae and Chlorophyceae: geochemical implications. Org. Geochem. 26, 659-675.

Gelin, F., Volkman, J. K., Largeau, C., Derenne, S., Sinninghe Damsté, J. S. and de Leeuw, J. W. (1999) Distribution of aliphatic, nonhydrolyzable biopolymers in marine microalgae. Org. Geochem. 30, 147-159.

Gong, C. and Hollander, D. J. (1997) Differential contribution of bacteria to sedimentary organic matter in oxic and anoxic environments, Santa Monica Basin, California. Org. Geochem. 26, 545-563.

Grice, K., Klein Breteler, W. C. M., Schouten, S., Grossi, V., de Leew, J. W., and Sinninghe Damsté, J. S. (1998) Effects of zooplankton herbivory on biomarker proxy records. Paleoceanography 13, 686-693.

Haddad, R. I., Martens, C. S. and Farrington, J. W. (1992) Quantifying early diagenesis of fatty acids in a rapidly accumulating coastal marine sediment. Org. Geochem. 19, 205-211. 
Hagadorn, J. W., Stott, L. D., Sinha, A. and Rincon, M. (1995) Geochemical and sedimentologic variations in inter-annually laminated sediments from Santa Monica Basin. Mar. Geology 125, 111-131.

Hagen, K. D. and Nelson, D. C. (1996) Organic carbon utilization by obligately and facultatively autotrophic Beggiatoa strains in homogeneous and gradient cultures. Appl. Environ. Microbiol. 62, 947-953.

Hayes, J. M. (1993) Factors controlling the ${ }^{13} \mathrm{C}$ content of sedimentary organic compounds: Principles and evidence. Mar. Geol. 113, 111-125.

Hayes, J. M., Freeman, K. H., Popp, B. N., and Hoham, C. H. (1990) Compound-specific isotopic analyses: A novel tool for reconstruction of ancient biogeochemical processes. Org. Geochem. 16, 1115-1128.

Hedges, J. I. and Parker, P. L. (1976) Land-derived organic matter in surface sediments from the Gulf of Mexico. Geochim. et Cosmochim. Acta 40, 1019-1029.

Hibberd, D. J. and Leedale, G. F. (1970) Eustigmatophyceae-a new algal class with unique organization of the motile cell. Nature 225, 758-760.

Hinrichs, K.-U., Hayes, J. M, Sylva, S. P., Brewer, P. G. and DeLong, E. F. (1999) Methane-consuming archaebacteria in marine sediments. Nature 398, 802-805.

Hoefs, M. J. L., Schouten, S., deLeeuw, J. W., King, L. L., Wakeham, S. G., and Sinninghe Damsté, J. S. (1997) Ether lipids of planktonic Archaea in the marine water column. Appl. Environ. Microbiol. 63, 3090-3095.

Huh, C.-A., Zahnle, D. L., and Small, L. F. (1987) Budgets and behaviors of uranium and thorium series isotopes in Santa Monica Basin sediments. Geochim. et Cosmochim. Acta 51, 1743-1754.

Jahnke, R. A. (1990) Early diagenesis and recycling of biogenic debris at the seafloor, Santa Monica Basin, California. J. Marine Res. 48, 413-436.

Jasper, J. P. and Hayes, J. M. (1990) A carbon isotope record of $\mathrm{CO}_{2}$ levels during the late Quaternary. Nature 347, 462-464.

Johns, R. B., Gillan, F. T. and Volkman, J. K. (1978) Kerogen precursors: Chemical and biological alteration of lipids in the sedimentary surface layer: APEA Journal 18, 157-160.

Kaneda, T. (1991) Iso- and anteiso-fatty acids in bacteria: Biosynthesis, function, and taxonomic significance. Microbiol. Reviews 55, 288-302.

King, L. L., Pease, T. K., and Wakeham, S. G. (1998) Archaea in Black Sea water colummn particulate matter and sediments - evidence from ether lipid derivatives. Org. Geochem. 28, 677-688.

Kleeman, G., Poralla, K., Englert, G., Kjøsen, H., Liaaen-Jensen, S., Neunlist, S., and Rohmer, M. (1990) Tetrahymanol from the phototrophic bacterium Rhodopseudomonas palustris: first report of a gammacerane triterpene from a prokaryote. J. Gen. Microbiol. 136, 2551-2553.

Kohnen, M. E. L., Schouten, S., Sinninghe Damsté, J. S., de Leew, J. W., Merritt, D. A., and Hayes, J. M. (1992) Recognition of paleobiochemicals by a combined molecular sulfur and isotope geochemical approach. Science 256, 358-362.

Landry, M. R., Peterson, W. K. and Andrews, C. C. (1992) Particulate flux on the water column overlying Santa Monica Basin. Prog. Oceanog. 30, 167-195. 
Laws, E. A., Popp, B. N., Bidigare, R. R., Kennicutt, M. C., and Macko, S. A. (1995) Dependence of phytoplankton isotopic composition on growth rate and $\left[\mathrm{CO}_{2}\right]_{\text {aq }}$ : Theoretical considerations and experimental results. Geochim. Cosmochim. Acta 59, 1131-1138.

Lockheart, M. J., van Bergen, P. F. and Evershed, R. P. (1996) Variations in the stable carbon isotope compositions of individual lipids from the leaves of modern angiosperms: implications for the study of higher land plant-derived sedimentary organic matter. Org. Geochem. 26, 137-153.

Mallory, F. B., Gordon, J. T., and Connor, R. L. (1963) The isolation of a pentacyclic triterpenoid alcohol from a protozan. J. Am. Chem. Soc. 85, 1362-1363.

Marlowe, I. T., Brassell, S. C., Eglinton, G., and Green, J. C. (1990) Long-chain alkenones and alkyl alkenoates and the fossil coccolith record of marine sediments. Chem. Geol. 88, 349-375.

McCaffrey, M. A. (1990) Sedimentary lipids as indicators of depositional conditions in the coastal Peruvian upwelling regime. Ph.D. thesis, Woods Hole Oceanographic Institution/Massachusetts Institute of Technology.

Oliver, J. D. and Colwell, R. R. (1973) Extractable lipids of gram-negative marine bacteria: fatty acid composition. Int. J. Systematic Bacteriology 23, 442-458.

Ourisson, G., Rohmer, M., and Poralla, K. (1987) Prokaryotic hopanoids and other polyterpenoid sterol surrogates. Ann. Rev. Microbiol. 41, 301-333.

Parkes, R. J. and Taylor, J. (1983) The relationship between fatty acid distributions and bacterial respiratory types in contemporary marine sediments. Estuarine, Coastal and Shelf Science 16, 173-189.

Perry, G. J., Volkman, J. K., Johns, R. B., and Bavor, H. J., Jr. (1979) Fatty acids of bacterial origin in contemporary marine sediments. Geochim. Cosmochim. Acta 43, 1715-1725.

Philp, R. P. and Calvin, M. (1976) Possible origin for insoluble organic (kerogen) debris in sediments from insoluble cell-wall materials of algae and bacteria. Nature $\mathbf{2 6 2}$, 134-136.

Popp, B. N., Laws, E. A., Bidigare, R. R., Dore, J. E., Hanson, K. L., and Wakeham, S. G. (1998) Effect of phytoplankton cell geometry on carbon isotopic fractionation. Geochim. Cosmochim. Acta 62, 69-77.

Rau, G.H., Karl, D.M. and Carney, R.S. (1986) Does inorganic carbon assimilation cause ${ }^{14} \mathrm{C}$ depletion in deep-sea organisms? Deep-Sea Res. 33, 349-357.

Rau, G.H. Another recipe for bomb ${ }^{14} \mathrm{C}$ dilution. (1991) Nature 350, 116.

Rohmer, M., Bouvier-Nave, P., and Ourisson, G. (1984) Distribution of hopanoid triterpenes in prokaryotes. J. Gen. Microbiology 130, 1137-1150.

Sargent, J. R. (1976) The structure, function, and metabolism of lipids in marine organisms. In, Biochemical and biophysical perspectives in marine biology. Vol. 3, D. C. Malins and J. R. Sargent, Eds., pp. 149-212, Academic Press, New York.

Sargent, J. R., Gatten, R. R., and McIntosh, R. (1977) Wax esters in the marine environment - Their occurrence, formation, transformation, and ultimate fates. Marine Chemistry 5, 573-584. 
Schweizer, E. (1988) Biosynthesis of fatty acids and related compounds. In, Microbial Lipids, C. Ratledge and S. G. Wilkinson, Eds., Vol. 2, pp. 3-50. Academic Press, London.

Sinninghe Damsté, J. S., Wakeham, S. G., Kohnen, M. E. L., Hayes, J. M., and de Leeuw, J. W. (1993) A 6,000 year sedimentary molecular record of chemocline excursions in the Black Sea. Nature 362, 827-829.

Smith, B. N. and Epstein, S. (1971) Two categories of ${ }^{13} \mathrm{C} /{ }^{12} \mathrm{C}$ ratios for higher plants. Plant Physiol. 47, 380-384.

ten Haven, H. L., Rohmer, M., Rullkötter, J., and Bisseret, P. (1989) Tetrahymanol, the most likely precursor of gammacerane, occurs ubiquitously in marine sediments. Geochim. Cosmochim. Acta 53, 3073-3079.

Venkatesan, M. I., Ruth, E., and Kaplan, I. R. (1990) Triterpenols from sediments of Santa Monica Basin, Southern California Bight, USA. Org. Geochem. 16, 10151024.

Volkman, J. K., Johns, R. B., Gillan, F. T., Perry, G. J., and Bavor, H. J. Jr. (1980) Microbial lipids of an intertidal sediment - I. Fatty acids and hydrocarbons. Geochim. Cosmochim. Acta. 44, 1133-1143.

Volkman, J. K. (1986) A review of sterol markers for marine and terrigenous organic matter. Org. Geochem. 9, 83-99.

Volkman, J. K., Barrett, S. M., Dunstan, G. A., and Jeffrey, S. W. (1992) $\mathrm{C}_{30}-\mathrm{C}_{32}$ alkyl diols and unsaturated alcohols in microalgae of the class Eustigmatophyceae. Org. Geochem. 18, 131-138.

Volkman, J. K., Barrett, S. J., Blackburn, S. I., Mansour, M. P., Sikes, E. L. and Gelin, F. (1998) Microalgal biomarkers: A review of recent research developments. Org. Geochem. 29, 1163-1179.

Volkman, J .K., Barrett, S. M. and Blackburn S. I. (1999) Eustigmatophyte microalgae are potential sources of $\mathrm{C}_{29}$ sterols, $\mathrm{C}_{22}$ - $\mathrm{C}_{28} n$-alcohols and $\mathrm{C}_{28}-\mathrm{C}_{32} n$-alkyl diols in freshwater environments. Org. Geochem. 30, 307-318.

Wakeham, S. G. and Beier, J. A. (1991) Fatty acid and sterol biomarkers as indicators of particulate matter source and alteration processes in the Black Sea. Deep-Sea Research 38, S943-S968.

Wang, X.-C., Druffel, E. R. M., Griffin, S., Lee, C., and Kashgarian, M. (1998) Radiocarbon studies of organic compound classes in plankton and sediment of the northeastern Pacific Ocean. Geochim. Cosmochim. Acta 62, 1365-1378.

Wilhelms, A., Larter, S. R., and Hall, K. (1994) A comparative study of the stable carbon isotopic composition of crude oil alkanes and associated crude oil asphaltene pyrolysate alkanes. Org. Geochem. 21, 751-759.

Yunker, M. B., Macdonald, R. W., Veltkamp, D. J., and Cretney, W. J. (1995) Terrestrial and marine biomarkers in a seasonally ice-covered Arctic estuary - integration of multivariate and biomarker approaches. Marine Chemistry 49, 1-50. 


\title{
CHAPTER 7
}

\section{MODELS FOR THE ORIGIN OF $N$-ALKANES AND TOTAL ORGANIC CARBON IN SANTA MONICA BASIN SURFACE SEDIMENT}

\begin{abstract}
The compound-specific $\Delta^{14} \mathrm{C}$ and $\delta^{13} \mathrm{C}$ values measured for SMB long-chain $n$ alkanes were simulated using a 3-component, quantitative mixing model. The three components were selected to represent the contributions of petroleum, shale-derived, and modern vascular plant wax alkanes. The model indicated that petroleum accounted for $12 \%$ and $5 \%$ of the total post-bomb and pre-bomb alkanes, respectively. The amount from modern plant waxes was $80 \%$ (post-bomb) and $87 \%$ (pre-bomb), and the remaining $8 \%$ of each sample was attributed to the Monterey Shale source. The $\Delta^{14} \mathrm{C}$ values calculated for the modern terrestrial fraction were $\sim 0 \%$ for the pre-bomb horizon and $\sim+235 \%$ for the post-bomb horizon.

The $\Delta^{14} \mathrm{C}_{\text {ter }}$ values generated by the alkane model were used in a 4-component algebraic model for the origin of SMB sedimentary TOC. Marine planktonic, modern terrestrial, fossil, and unknown (unidentified) organic components account for $40-66 \%$, $0-16 \%, 0-12 \%$, and $24-43 \%$ of the TOC, respectively. These results are generally consistent with sedimentary carbon budgets published by other investigators. The $\Delta^{14} \mathrm{C}$ of the unidentified component(s) is between $-100 \%$ and $-200 \%$, within the range of deep basin DIC, but more modern than deep basin DOC.
\end{abstract}




\subsection{INTRODUCTION}

Preservation of organic carbon in marine sediments is a fundamental part of the global carbon cycle. The processes controlling the arrival of organic material at the sediment-water interface, its remineralization and diagenesis, and its ultimate burial affect the concentration of $\mathrm{CO}_{2}$ in the atmosphere and the redox state of the global environment. In most oceanic sediments, the majority of the total organic carbon (TOC) is believed to originate from autochthonous phytoplanktonic biomass and subsequent heterotrophic degradation of this material. The high efficiency of water-column heterotrophy ( $\gg 99 \%$ ) allows burial of $\ll 1 \%$ of total marine primary production.

Both open-ocean and continental margin sediments contain organic matter from sources other than marine photosynthesis, however. Most organic carbon burial (> 80\%) occurs in coastal deltaic and continental shelf sediments (Berner, 1982). These locations are also the primary repositories of material derived from terrestrial sources by erosion or short-range atmospheric deposition. One of the most important and difficult remaining questions in biogeochemistry is the extent to which allochthonous carbon derived from terrestrial biota and soils, weathered kerogen, and other fossil carbon reservoirs is preserved in comparison to marine carbon (Hedges, 1992). Some of the eroded continental material must escape remineralization, because coastal sediments contain a heterogeneous mixture of products from both marine and terrestrial sources (e.g. Hedges and Parker, 1976; Prahl et al., 1994; Goñi et al., 1998).

The continental margins also contain the only localized regions in which $>1 \%$ of sedimentary organic carbon consistently escapes remineralization. In sediments underlying the water column oxygen minimum zone (500-1500 m) (e.g. Peru Margin, Oman Margin) and in confined basins having restricted deep-water ventilation (e.g. Cariaco Basin, Santa Monica and Santa Barbara Basins), concentrations of organic carbon are typically around 5\%. Carbon buried within anoxic sediments is believed to be the source of organic-rich shales and petroleum. In these environments, organic matter derived from chemoautotrophic, prokaryotic biomass may be preserved in addition to 
planktonic detritus and allochthonous materials. Biomarker molecules reflecting autotrophic bacterial sources have been found in anoxic sediments and their ancient analogues (e.g. Messel Shale, Hayes et al., 1990; Vena del Gesso Basin, Kohnen et al., 1992; Monterey Shale, Schouten, 1995). In the extreme case of euphotic zone anoxia, these compounds include the products of anoxygenic, photosynthetic bacteria (e.g. Black Sea; Sinninghe Damsté et al., 1993).

Considering the number of potential carbon sources and metabolic pathways, it is not surprising that the $\Delta^{14} \mathrm{C}$ of bulk TOC commonly does not correspond to the known depositional age of its associated sediment (Benoit et al., 1979; Jones and Gagnon, 1994); or in the case of core-tops, does not equal the $\Delta^{14} \mathrm{C}$ of overlying surface water dissolved inorganic carbon (DIC), even in regions of high primary productivity (Emery and Bray, 1962; Bauer et al., 1995; Wang et al., 1998). The $\Delta^{14} \mathrm{C}$ of TOC in these studies is always more negative than the $\Delta^{14} \mathrm{C}$ of euphotic zone DIC or phytoplanktonic detritus. Most of the additional allochthonous or chemosynthetic carbon sources represent organic matter with lower ${ }^{14} \mathrm{C}$ concentrations than the fraction of TOC originating from autochthonous marine production. Only the rapid transport of recently synthesized terrestrial plant material, which has a ${ }^{14} \mathrm{C}$ concentration in equilibrium with atmospheric $\mathrm{CO}_{2}$ can provide a fraction of TOC with a $\Delta^{14} \mathrm{C}$ value higher than marine primary production.

Even though lipid biomarkers characteristic of different organic carbon sources are readily identified in continental margin and anoxic basin sediments, quantifying the fraction of TOC originating from any particular endmember has proved challenging. Compound-specific and bulk-phase analyses of ${ }^{14} \mathrm{C}$ can be used together to provide additional constraints for quantitative mass-balance models. In this chapter, mixing models for SMB sedimentary $n$-alkanes and TOC are constructed. Both models rely on the contrast between "pre-bomb" and "post-bomb" $\Delta^{14} \mathrm{C}$ values for the individual lipids and the TOC. These models are more tightly constrained than estimates based on biomarker concentrations or $\delta^{13} \mathrm{C}$ alone and represent additional progress toward understanding the diversity of sources of organic carbon to the marine environment. 


\subsection{ISOTOPIC DATA}

\subsubsection{TOC}

The Southern California Bight is a highly productive upwelling region, averaging $\sim 700 \mathrm{mgC} / \mathrm{m}^{2} /$ day of total primary production (Eppley, 1992). Approximately 50 $\mathrm{mgC} / \mathrm{m}^{2} /$ day of this carbon reaches the suboxic bottom waters of Santa Monica Basin (Landry et al., 1992). The resulting deep-basin sediments are laminated and organic-rich. The absence of bioturbation in SMB allows decadal resolution of the changes in sedimentary ${ }^{14} \mathrm{C}$ concentrations due to the uptake of bomb-derived ${ }^{14} \mathrm{C}$.

The $\Delta^{14} C_{\text {TOC }}$ record determined for the SMB core is used both in Chapter 4 and again in this chapter to assess the non-marine fraction of TOC (data, Table 7.1). Bomb${ }^{14} \mathrm{C}$ appears in the TOC pool in the upper three sedimentary horizons. The change in organic carbon ${ }^{14} \mathrm{C}$ concentration reflects DIC uptake by phytoplankton during photosynthesis, partial re-working by heterotrophic consumers, and subsequent sedimentation of organic detritus. The critical characteristic for $\Delta^{14} \mathrm{C}_{\mathrm{TOC}}$ in this core, however, is that even though the timing of bomb- ${ }^{14} \mathrm{C}$ uptake is identical to that observed for the DIC pool, there are clearly component(s) of the heterogeneous TOC mixture that are not derived from surface water primary production. This pre-aged, possibly nonmarine fraction of TOC has a net $\Delta^{14} \mathrm{C}$ value lower than surface water $\Delta^{14} \mathrm{C}_{\mathrm{DIC}}$. Whether its primary source is old terrigenous carbon (e.g. Eglinton et al., 1997; Goñi et al., 1998), weathered shale or kerogen (i.e. from the Monterey Formation; Schouten, 1995; Petsch $e t$ al., 1999), incorporation of deep-water DIC (Rau et al., 1986; Rau, 1991), refractory dissolved organic carbon (DOC) (e.g. Druffel et al., 1992; Wang et al., 1998), or resuspended and advected shelf sediments, this component of TOC has not incorporated recent atmospheric $\mathrm{CO}_{2}$. 
Table 7.1 Sediment horizons as sectioned for the SMB core, the chronology determined by ${ }^{210} \mathrm{~Pb}$ dating, and the associated $\Delta{ }^{14} \mathrm{C}_{\mathrm{TOC}}$ values.

$\left.\begin{array}{ccc}\hline \text { Horizon } & { }^{210} \mathrm{~Pb} \text { Date }(\mathrm{yr} \mathrm{AD}) & \Delta^{14} \mathrm{C}_{\mathrm{TOC}}(\% o) \\ \hline 0-0.75 \mathrm{~cm} & 1996- & -62 \pm 3 \\ 0.75-1.5 \mathrm{~cm} & -1985 & -55 \pm 2 \\ 1.5-2.5 \mathrm{~cm} & 1985-1961 & -51 \pm 3\end{array}\right\} \sim \begin{aligned} & \text { Average } \\ & \text { Post-bomb } \\ & 2.55 \%\end{aligned}$




\subsection{2 $n$-Alkanes}

Chromatograms and concentration distributions for SMB $n$-alkanes were presented in Chapter 6, along with a brief description of the isotopic data. Here the data are presented again for reference purposes (Table 7.2). Only the long-chain $\left(n-\mathrm{C}_{24-33}\right)$ alkanes are addressed in the following models and discussion.

Table 7.2 SMB $n$-alkane isotopic data.

\begin{tabular}{lcccc}
\hline \multicolumn{1}{c}{$n$-Alkane } & \multicolumn{2}{c}{ Pre-Bomb $(2.5-7.5 \mathrm{~cm})$} & \multicolumn{2}{c}{ Post-Bomb $(0-2.5 \mathrm{~cm})$} \\
& $\delta^{13} \mathrm{C}(\%)$ & $\Delta^{14} \mathrm{C}(\% o)$ & $\delta^{13} \mathrm{C}(\% o)$ & $\Delta^{14} \mathrm{C}(\% o)$ \\
\hline$n-\mathrm{C}_{24}$ & $-30.2 \pm 0.1$ & $-617 \pm 11^{*}$ & $-29.2 \pm 0.4$ & $-741 \pm 16^{*}$ \\
$n-\mathrm{C}_{25}$ & $-29.8 \pm 0.4$ & & $-30.2 \pm 0.1$ & \\
$n-\mathrm{C}_{26}$ & $-30.5 \pm 0.7$ & & $-30.0 \pm 0.4$ & \\
$n-\mathrm{C}_{27}$ & $-30.7 \pm 0.1$ & $-223 \pm 17$ & $-30.5 \pm 0.1$ & $-243 \pm 20$ \\
$n-\mathrm{C}_{28}$ & $-30.5 \pm 0.4$ & & $-30.0 \pm 0.2$ & \\
$n-\mathrm{C}_{29}$ & $-31.9 \pm 0.1$ & $-122 \pm 7$ & $-31.3 \pm 0.2$ & $+30 \pm 17$ \\
$n-\mathrm{C}_{30}$ & $-31.4 \pm 0.3$ & & $-30.3 \pm 0.4$ & \\
$n-\mathrm{C}_{31}$ & $-33.0 \pm 0.1$ & $-170 \pm 15$ & $-32.0 \pm 0.1$ & $-113 \pm 19$ \\
$n-\mathrm{C}_{32}$ & $-30.9 \pm 0.2$ & & $-29.9 \pm 0.4$ & \\
$n-\mathrm{C}_{33}$ & $-32.5 \pm 0.3$ & & $-31.2 \pm 0.3$ & \\
& & & & \\
\hline
\end{tabular}

$* \Delta^{14} \mathrm{C}$ for $n-\mathrm{C}_{24+26+28+30}$ collected together as a single sample.

Stable carbon isotope compositions were determined by irm-GC/MS for the SMB post-bomb $(0-2.5 \mathrm{~cm})$ and pre-bomb $(2.5-7.5 \mathrm{~cm}) n$-alkane fractions. For these compound-specific analyses, the $n$-alkanes were separated from the background UCM by urea adduction. The resulting samples contained almost pure homologous series of $n$ alkanes. The distribution of ${ }^{13} \mathrm{C}$ is similar in both of the fractions analyzed. In both 
cases, the even-chain homologues have $\delta^{13} \mathrm{C}$ values that are relatively more constant and more ${ }^{13} \mathrm{C}$-enriched than the odd-chain isomers. The average $\delta^{13} \mathrm{C}_{\mathrm{even}}$ for SMB $0-2.5 \mathrm{~cm}$ is $-29.9 \%$, while the average $\delta^{13} \mathrm{C}_{\text {even }}$ for SMB $2.5-7.5 \mathrm{~cm}$ is $-30.4 \%$. This would be consistent with a dominant petroleum source for these compounds (e.g. Wilhelms et al., 1994). The slightly more negative $\delta^{13} \mathrm{C}_{\text {even }}$ in the deeper horizon probably indicates a slightly larger terrestrial plant contribution to the even-chain isomers in this sample. The odd-chain $n$-alkanes in both intervals are characterized by a minimum $\delta^{13} \mathrm{C}$ at $n-\mathrm{C}_{31}$ with significant isotopic depletion also observed for $n-\mathrm{C}_{29}$ and $n-\mathrm{C}_{33}$. Their negative $\delta^{13} \mathrm{C}$ values around $-32 \%$ are consistent with $\mathrm{a}_{3}$ vascular plant source for these compounds (Smith and Epstein, 1971; Collister et al., 1994a; Lockheart et al., 1996). It is interesting, however, that the maximum $n$-alkane concentration occurs at $n-\mathrm{C}_{29}$ rather than $n-\mathrm{C}_{31}$ in both intervals. The even-chain and odd-chain $n$-alkane data together suggest there are multiple hydrocarbon sources with different ${ }^{13} \mathrm{C}$ isotopic compositions contributing to SMB sediment.

The $n$-alkanes also represented the only lipid class investigated in this thesis in which individual $\Delta^{14} \mathrm{C}$ values obtained within a single homologous series varied greatly. In pre-bomb and post-bomb samples, the range of $\Delta^{14} \mathrm{C}$ values observed was $\sim 500 \%$ and $\sim 750 \%$, respectively. The pre-bomb, odd-chain $n$-alkanes had $\Delta^{14} \mathrm{C}$ values between $-223 \% o\left(n-\mathrm{C}_{27}\right)$ and $-122 \% o\left(n-\mathrm{C}_{29}\right)$, while the composite sample of even-numbered $n$ alkanes $\left(n-\mathrm{C}_{24+26+28+30}\right)$ was greatly depleted in ${ }^{14} \mathrm{C}(-617 \%)$. The post-bomb, odd-chain $n$-alkanes had an even larger $\Delta^{14} \mathrm{C}$ range, $-243 \%$ o $\left(n-\mathrm{C}_{27}\right)$ to $+30 \% \circ\left(n-\mathrm{C}_{29}\right)$. The evennumbered $n$-alkanes from post-bomb sediment were also quite ${ }^{14} \mathrm{C}$-depleted $(-741 \%$ o). The $\Delta^{14} \mathrm{C}$ measurements for the even-numbered $n$-alkanes and $n-\mathrm{C}_{27}$ alkanes indicate these lipids became more ${ }^{14} \mathrm{C}$-depleted in the post-bomb sediment. This signals two important processes. First, at least one fractional component of the $n$-alkane series has not recently equilibrated with atmospheric $\mathrm{CO}_{2}$. Second, the proportion of this component is higher in the SMB $0-2.5 \mathrm{~cm}$, post-bomb horizon than it is in the pre-bomb horizon. The other $n$-alkane homologues experienced a variable increase in $\Delta^{14} \mathrm{C}$ between the two sets of samples. 
A quantitative isotopic mass balance model for the $n$-alkanes is developed as the first model in this chapter. It uses the $\Delta^{14} \mathrm{C}$ and $\delta^{13} \mathrm{C}$ data to reconstruct both the isotopic signatures and the fractions of modern terrestrial and fossil carbon contributing to the total $n$-alkane distributions. The terrestrial $\Delta^{14} \mathrm{C}$ endmember values generated by the $n$ alkane model are then used in a model of the origin of SMB sedimentary TOC.

\subsection{N-ALKANe Mixing MODEL}

The overall goal of this thesis is to investigate both the isotopic compositions and the fractional contributions of the endmember sources of SMB sedimentary TOC. In this discussion, the $n$-alkane isotopic data and concentration distributions are used in a massbalance mixing model to reconstruct the $\Delta^{14} \mathrm{C}$ of the non-fossil terrestrial fraction of the alkanes. Then the $\Delta^{14} \mathrm{C}_{\text {terrestrial }}$ that was derived from this model is used in a second model (section 7.4) to estimate the fractions of terrestrial, planktonic, fossil, and unidentified detrital carbon contributing to SMB TOC. This model is an extension of the preliminary calculation presented in Chapter 4. The new model assumes the $\Delta{ }^{14} \mathrm{C}_{\text {terrestrial }}$ is equal to the $\Delta^{14} \mathrm{C}$ value determined in this section for the modern terrestrial component of the $n$ alkanes. This is a large and possibly unjustified assumption, and the implications of taking this approach are discussed along with the results of the TOC model.

The long-chain $\left(\geq n-\mathrm{C}_{24}\right)$ alkanes recovered from SMB sediments contain components from at least two isotopically distinct sources, terrestrial vascular plant leaf waxes and fossil carbon. The terrestrial components represent freshly-synthesized plant biomass, degraded vascular plant material eroded from soils, or some combination of both. The fossil components are ${ }^{14} \mathrm{C}$-dead $\left(\Delta^{14} \mathrm{C}=-1000 \%\right)$ and may come from natural oil seeps, petroleum spills of anthropogenic origin, and/or shale erosion. Because studies of long-chain $n$-alkanes in marine organisms indicate they are minor components or perhaps merely analytical contamination (references in Sakata et al., 1997), no marine 
endmember is considered to contribute to the long-chain $n$-alkanes in the following models.

SMB sediments contain fossil hydrocarbons from both anthropogenic sources and natural petroleum seepage. SMB is suspected of receiving one of the highest contributions of anthropogenic hydrocarbons of any of the California basins due to runoff and deposition from sources in nearby Los Angeles. Total hydrocarbon fluxes to the sediments are estimated to be about $12 \%$ natural seepage, $85 \%$ anthropogenic, and $3 \%$ marine biogenic (Eganhouse and Venkatesan, 1993). Differing diagenetic influences could change the relative preservation ratios of these fossil components after deposition. Additional hydrocarbons are probably contributed by weathering of outcrops of the Miocene Monterey Shale formation (Petsch et al., 1999; hydrocarbon geochemistry reported by Schouten, 1995). Despite the importance of petroleum sources, the $n$-alkane distribution in both SMB sediment samples had a maximum at $n-\mathrm{C}_{29}$ and strong odd-even predominance (Figure 6.3). This distribution is characteristic of higher plant waxes (Eglinton et al., 1962) and contrasts with the expected importance of fossil $n$-alkanes. Terrestrial compounds may be preferentially preserved within the sediments, while the petroleum-derived alkanes are degraded. The terrestrial waxes may be associated with an inorganic or other protective matrix that aids preservation, while the petroleum alkanes are probably introduced in liquid form to the SMB environment. The abundant UCM in these hydrocarbon fractions is characteristic of weathered petroleum. This hypothesis is also consistent with the change in $n$-alkane CPI observed with depth in the core.

Terrestrial $n$-alkanes are apparently enriched in the deeper, pre-bomb horizon $(2.5-7.5$ $\mathrm{cm}$ ) as suggested by its higher concentration of $n-\mathrm{C}_{31}$ and $n-\mathrm{C}_{33}$ and its higher carbon preference index $(\mathrm{CPI}=5.4)$ relative to the surface sediments $(\mathrm{CPI}=3.8)$. CPI values between $\sim 5$ and 40 were recently reported for the waxes of 16 different plant species (Collister et al., 1994a), while ancient sediments and petroleums have CPI values $\sim 1$ (e.g. Tissot and Welte, 1984).

The $\delta^{13} \mathrm{C}$ data for the $n$-alkanes lead to a similar qualitative conclusion. The even-numbered $n$-alkanes in the surface horizon have a relatively constant $\delta^{13} \mathrm{C}$ value 
between $\sim-29.5 \%$ and $-30 \%$ (Figure 6.14, Table 7.2). The odd-carbon chain alkanes in this sample reach a minimum $\delta^{13} \mathrm{C}$ at $n-\mathrm{C}_{31}(-32 \%$ ) with significant depletion also at $n-\mathrm{C}_{29}$ and $n-\mathrm{C}_{33}$. Terrestrial $\mathrm{C}_{3}$ plant waxes with typical $\delta^{13} \mathrm{C}$ values between $-30 \%$ and $-36 \%$ o (e.g. Collister et al., 1994a; Bird et al., 1995) are probably the origin of this isotopic depletion. The deeper, pre-bomb sediments contrast with the surface sample by the presence of isotopic trends in both odd-chain and even-chain homologues. The evennumbered alkanes reach a minimum value of $\sim-31 \%$ at $n-\mathrm{C}_{30}$. The odd-carbon isomers show a stronger minimum $(-33 \%)$ at $n-\mathrm{C}_{31}$. Both trends are consistent with a greater contribution from terrestrial leaf waxes at this depth.

The expectations based on the above organic geochemical analysis of the $n$-alkane distributions and $\delta^{13} \mathrm{C}$ values are consistent with the compound-specific $\Delta^{14} \mathrm{C}$ data. The even-chain $n$-alkanes are expected to primarily reflect primary contributions from fossil carbon sources, including petroleum and weathered shales. The observed $\Delta^{14} \mathrm{C}$ values of $-741 \%$ and $-617 \%$ (Table 7.2 ) are equivalent to $\sim 74 \%$ and $\sim 62 \%$ fossil carbon, respectively. The $\Delta\left(\Delta^{14} \mathrm{C}\right)$ values for the even-numbered $n$-alkanes $\left(n-\mathrm{C}_{24+26+28+30}\right)$ and $n$ $\mathrm{C}_{27}$ were negative, reflecting a $\Delta^{14} \mathrm{C}$ decrease in the post-bomb sediment. The lower ${ }^{14} \mathrm{C}$ concentration is a consequence of the greater fraction of fossil carbon in these two samples. This effect is masked in the post-bomb $n-\mathrm{C}_{29}$ and $n-\mathrm{C}_{31}$ samples, because they are more highly dominated by the terrestrial component. Some fraction of the carbon in the odd-chain $n-\mathrm{C}_{29}$ and $n-\mathrm{C}_{31}$ alkane samples must derive from these fossil sources, however. The most informative $\Delta^{14} \mathrm{C}$ value obtained for the alkanes therefore may be the $+30 \%$ measured for post-bomb $n-\mathrm{C}_{29}$. The positive (post-bomb) $\Delta{ }^{14} \mathrm{C}$ value by itself indicates the quantitative majority of this sample was synthesized and transported to marine sediments without spending longer than 50 years in an intermediate (soil) reservoir. However, this $+30 \%$ value includes the fractional component derived from fossil $n-\mathrm{C}_{29}\left(\Delta^{14} \mathrm{C}=-1000 \%\right)$, and therefore the $\Delta^{14} \mathrm{C}$ of the terrestrial fraction must be $>+30 \%$. 


\subsubsection{Quantitative Approach}

The above discussion can be used to make an estimate of the post-bomb $\Delta{ }^{14} \mathrm{C}_{\text {terrestrial }}$ before proceeding with a more quantitative mixing model. This initial estimate is based on the following assumptions: $(i)$ the fossil $n$-alkanes source(s) must have CPI $\geq 1$ and, (ii) fossil carbon accounts for nearly all the ${ }^{14} \mathrm{C}$-depletion observed in the $n-\mathrm{C}_{24+26+28+30}$ sample $\left(\Delta^{14} \mathrm{C}=-741 \%\right)$. If $\sim 75 \%$ of the carbon in $n-\mathrm{C}_{28}$ and $n-\mathrm{C}_{30}$ is of fossil origin, the concentrations of these alkanes and the CPI $\geq 1$ assumption can be used to estimate that at least $10 \%$ of the carbon contained in the $n-\mathrm{C}_{29}$ sample is of fossil origin. This value is probably an underestimate, because the fossil $n$-alkanes are likely to have origins from both petroleum $(\mathrm{CPI} \sim 1)$ and weathered Monterey Shale (CPI 3; Schouten, 1995). A mass balance calculation applied to the $\Delta^{14} \mathrm{C}$ of post-bomb $n-C_{29}$,

$$
(0.1)(-1000 \%)+(0.9)\left(\Delta^{14} C_{\text {terrestrial }}\right)=+30 \% \text {, }
$$

indicates $\Delta^{14} \mathrm{C}_{\text {terrestrial }}$ is at least $+150 \%$ in the post-bomb sedimentary environment.

The terrestrial $n$-alkanes, as stated above, may derive from multiple sources with a spectrum of ages. The $\Delta^{14} \mathrm{C}$ value for pre-bomb $n-\mathrm{C}_{29}(-122 \%)$, however, indicates that the net terrestrial fraction does not have $\Delta^{14} \mathrm{C}<\sim-100 \%$. Pre-bomb $\Delta^{14} \mathrm{C}_{\text {terrestrial }}$ is probably considerably higher because there is a fossil component to the $n-\mathrm{C}_{29}$ sample. The same mass balance approach that was used above for the post-bomb data can also be used for the pre-bomb data. An additional constraint is provided because in this case the maximum $\Delta^{14} \mathrm{C}_{\text {terrestrial }}(0 \%)$ is already defined. The results of the rough mass balance calculation indicate pre-bomb $\Delta^{14} \mathrm{C}_{\text {terrestrial }}$ is between $-50 \%$ (equivalent to $\sim 400$ years) and $0 \%$ (0 years).

The above approximations are significant because they show a contemporary origin for the majority of higher-plant wax alkanes in this environment. This analysis did not utilize the complete data set, however. The more intriguing question is whether a 
model of both the magnitude and isotopic compositions of the fossil, modern terrestrial, and (possible) pre-aged or soil terrestrial components can predict the $\delta^{13} \mathrm{C}$ and $\Delta{ }^{14} \mathrm{C}$ values for the entire set of measurements in Table 7.2. For this analysis, a mixing model based on the formula used by Collister et al. (1994b) was created. The model of Collister et al. evaluated the relative contributions of different carbon sources to the $n$-alkanes of the Green River Formation, based on $\delta^{13} \mathrm{C}$ and concentration distributions only. Both $\delta^{13} \mathrm{C}$ and $\Delta^{14} \mathrm{C}$ data are used to constrain the version of the mixing model used here for the SMB data. The two sets of isotopic values (compound-specific ${ }^{13} \mathrm{C}$ and ${ }^{14} \mathrm{C}$ ) were evaluated for each sedimentary horizon (pre-bomb and post-bomb). The confidence in the model is correspondingly increased because the fractional contribution of each endmember must independently agree for both isotopes.

The notation for the model is based on the conventions of Collister (1992) and Collister et al. (1994b). It is also similar to the approach used by Lichtfouse and Eglinton (1996). The calculations for $\delta^{13} \mathrm{C}$ and $\Delta^{14} \mathrm{C}$ follow the analogous equations:

$$
\delta^{13} C_{i, j}=\sum_{k} X_{i, k} W_{j, k} \delta^{13} C_{i, j, k} / \sum_{k} X_{i, k} W_{j, k}^{\prime}
$$

and

$$
\Delta^{14} C_{i, j}=\sum_{k} X_{i, k} W_{j, k} \Delta^{14} C_{i, j, k} / \sum_{k} X_{i, k} W_{j, k}
$$

The terms of the equations are defined as follows:

$\mathrm{W}_{\mathrm{j}, \mathrm{k}} \equiv$ fraction of the carbon derived from source " $\mathrm{k}$ " in sample " $\mathrm{j}$ ".
$\mathrm{X}_{\mathrm{i}, \mathrm{k}} \equiv$ fraction of the total $n$-alkane carbon in source " $\mathrm{k}$ " that belongs to alkane " $\mathrm{i}$ ", where all sources and samples are calculated in units of concentration relative to $n-\mathrm{C}_{29}$.

The product $\mathrm{X}_{\mathrm{i}, \mathrm{k}} \mathrm{W}_{\mathrm{j}, \mathrm{k}}$ is the amount of carbon in alkane " $\mathrm{i}$ " contributed by source " $\mathrm{k}$ ", and the sum of these terms $\left(\Sigma \mathrm{X}_{\mathrm{i}, \mathrm{k}} \mathrm{W}_{\mathrm{j}, \mathrm{k}}\right)$ is the total concentration of a particular $n$-alkane. The 
fractional contributions, $\mathrm{W}$, as well as the concentration distributions, $\mathrm{X}$, (e.g. CPI, weighting of $n-\mathrm{C}_{29}$ or $n-\mathrm{C}_{31}$, etc.) were adjusted through iterations to produce the best possible agreement with the data.

$\delta^{13} \mathrm{C}_{\mathrm{i}, \mathrm{j}, \mathrm{k}}$ and $\Delta^{14} \mathrm{C}_{\mathrm{i}, \mathrm{j}, \mathrm{k}} \equiv$ the isotopic composition of the portion of individual $n$-alkane, "i", in sample " $j$ ", that was derived from source " $k$ ".

$\delta^{13} \mathrm{C}_{\mathrm{i}, \mathrm{j}}$ and $\Delta^{14} \mathrm{C}_{\mathrm{i}, \mathrm{j}} \equiv$ the weighted average isotopic composition of $n$-alkane, " $\mathrm{i}$ ", in sample " $\mathrm{j}$ ". The model is calculated to maximize the agreement between these output values and the data.

The initial constraints on the model were chosen as follows.

(i) Concentration distribution: The $n$-alkanes were assumed to derive from three sources. A high-wax oil that has experienced some water-column degradation of lower carbon-number alkanes was chosen to represent the petroleum signature. This oil was assumed to have a $\mathrm{CPI}=1$, a maximum concentration around $n-\mathrm{C}_{26}$ and $n-\mathrm{C}_{27}$, and a linear decrease in concentration, reaching zero abundance at $n-\mathrm{C}_{45}\left(n-\mathrm{C}_{43-45}\right.$ were the longest detectable chain lengths for SMB alkanes). A second fossil source of $n$-alkanes derived from weathered shale was also selected. The average $n$-alkane concentration distribution of the outcrops of the Monterey Shale was estimated from the work of Schouten (1995). Free alkanes in these outcrops have an average CPI $\sim 3$, a maximum at $n-\mathrm{C}_{29}$, and are weighted toward $n-\mathrm{C}_{31}$ rather than $n-\mathrm{C}_{27}$. The third endmember was assumed to be the leaf waxes and degraded tissues of vascular plants. An arbitrary CPI $\sim 10$ with a concentration maximum at $n-C_{29}$ was chosen for this endmember $\left(n-C_{29}\right.$ is the most abundant $n$-alkane in SMB sediments). Like the Monterey Shale, the terrestrial waxes were weighted more heavily toward $n-C_{31}$ rather than $n-C_{27}$ in the model. Minor adjustments to the shale and terrestrial components were made during the model iterations. The final concentration distributions (and $\delta^{13} \mathrm{C}$ values) of these three components are shown in Figure 7.1. 
(ii) $\delta^{13} \mathrm{C}$ distribution: The petroleum endmember was given a uniform value of $-29.5 \%$ for all isomers. $\delta^{13} \mathrm{C}$ values for fossil fuel alkanes are usually similar (Clayton and Bjorøy, 1994). The $-29.5 \%$ value is approximately the same as the "heaviest" measured $\delta^{13} \mathrm{C}$ for $n-\mathrm{C}_{24}$ alkane, which is the compound believed to have the largest petroleum contribution of all the $n-\mathrm{C}_{24-33}$ isomers. The $\delta^{13} \mathrm{C}$ model inputs for the Monterey Shale endmember varied for each alkane. The values were chosen based on the average $\delta^{13} \mathrm{C}$ values measured for individual, free $n$-alkanes from 7 shale samples as reported by Schouten (1995). These numbers vary from $\sim-28 \%$ at $n-\mathrm{C}_{24-25}$ to $\sim-32 \%$ o at $n$ - $\mathrm{C}_{31-33}$. For both the petroleum and shale sources, the $\delta^{13} \mathrm{C}$ values were estimated only to $\pm 0.5 \%$ and were not subsequently adjusted in further model iterations. The terrestrial $n$-alkane endmember initially was given a uniform $\delta^{13} \mathrm{C}=-32 \%$. This value was chosen based on the $\delta^{13} \mathrm{C}$ of $n$ - $\mathrm{C}_{29}$, the compound most affected by terrestrial contributions. Through subsequent iterations, the $\delta^{13} \mathrm{C}$ values for $n-\mathrm{C}_{31-33}$ were decreased to $-33 \%$ to improve the agreement between the model and the data. Some evidence for a trend toward lower $\delta^{13} \mathrm{C}$ at higher chain length has been found in some plants (Collister $e t$ al., 1994a).

(iii) $\Delta^{14} \mathrm{C}$ distribution: The $\Delta{ }^{14} \mathrm{C}$ of both fossil sources is defined as $-1000 \%$. In each of the pre-bomb and post-bomb sedimentary horizons, the terrestrial endmember is assumed to have a uniform $\Delta^{14} \mathrm{C}$ for all $n$-alkanes. Therefore, only two values can be selected and manipulated, $\Delta^{14} \mathrm{C}_{\text {pre-bonb }}$ and $\Delta{ }^{14} \mathrm{C}_{\text {post-bomb. The initial assumption was }}$ $\Delta \Delta^{14} \mathrm{C}_{\text {pre-bomb }}=0 \%$ and $\Delta^{14} \mathrm{C}_{\text {post-bomb }}=+200 \%$. The final iteration of the model resulted in no change in $\Delta{ }^{14} \mathrm{C}_{\text {pre-bomb}}$, while $\Delta{ }^{14} \mathrm{C}_{\text {post-bomb }}$ yielded maximum agreement with the data at a value of $+235 \%$. 


\subsubsection{Results and Discussion}

The initial goal was to see how closely the data could be simulated by mixing different fractions of the three simple endmembers described above. Very few iterations were needed before reaching good agreement between the calculated model and the data. Only a few minor adjustments to the endmember concentrations and isotopic values were made. The changes between the assumed initial values and the final "best fit" values were noted above. The majority of the manipulation involved only adjusting the fractional contributions of the three endmembers in each of the sediment horizons. The following table summarizes the final results.

Table 7.3 Results of $n$-Alkane mixing model.

\begin{tabular}{|c|c|c|c|}
\hline & Petroleum & Monterey Shale & Modern Terrestrial \\
\hline SMB $0-2.5 \mathrm{~cm}$ & $12 \%$ & $8 \%$ & $80 \%$ \\
\hline $\mathrm{SMB} 2.5-7.5 \mathrm{~cm}$ & $5 \%$ & $8 \%$ & $87 \%$ \\
\hline SMB $0-2.5 \mathrm{~cm}$ & $\Delta^{14} \mathrm{C}_{\text {measured }}(\% o)$ & $\Delta^{14} C_{\text {model }}(\% o)$ & Difference $(\% o)$ \\
\hline $\begin{array}{l}n-\mathrm{C}_{24+26+28+30} \\
n-\mathrm{C}_{27} \\
n-\mathrm{C}_{29} \\
n-\mathrm{C}_{31}\end{array}$ & $\begin{array}{l}-741 \\
-243 \\
30 \\
-113\end{array}$ & $\begin{array}{l}-733 \\
-216 \\
-5 \\
-89\end{array}$ & $\begin{array}{l}8 \\
27 \\
-35 \\
24\end{array}$ \\
\hline SMB $2.5-7.5 \mathrm{~cm}$ & $\Delta^{14} \mathrm{C}_{\text {measured }}(\% o)$ & $\Delta^{14} \mathrm{C}_{\text {model }} \quad(\% o)$ & Difference $(\% o)$ \\
\hline $\begin{array}{l}n-\mathrm{C}_{24+26+28+30} \\
n-\mathrm{C}_{27} \\
n-\mathrm{C}_{29} \\
n-\mathrm{C}_{31}\end{array}$ & $\begin{array}{l}-617 \\
-223 \\
-122 \\
-170\end{array}$ & $\begin{array}{l}-622 \\
-237 \\
-126 \\
-176\end{array}$ & $\begin{array}{l}-5 \\
-14 \\
-4 \\
-6\end{array}$ \\
\hline
\end{tabular}


Figure 7.1
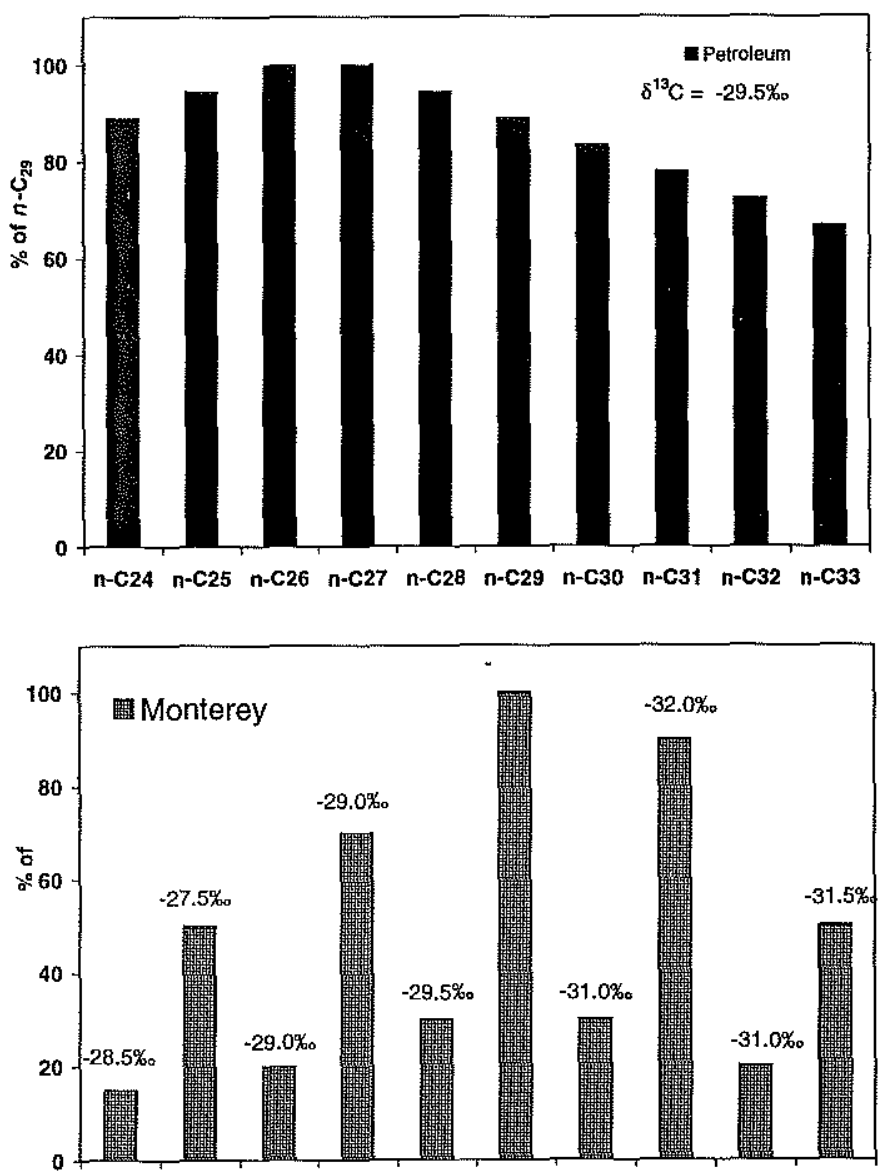

$n-C 24 \quad n-C 25 \quad n-C 26 \quad n-C 27 \quad n-C 28 \quad n-C 29 \quad n-C 30 \quad n-C 31 \quad n-C 32 \quad n-C 33$

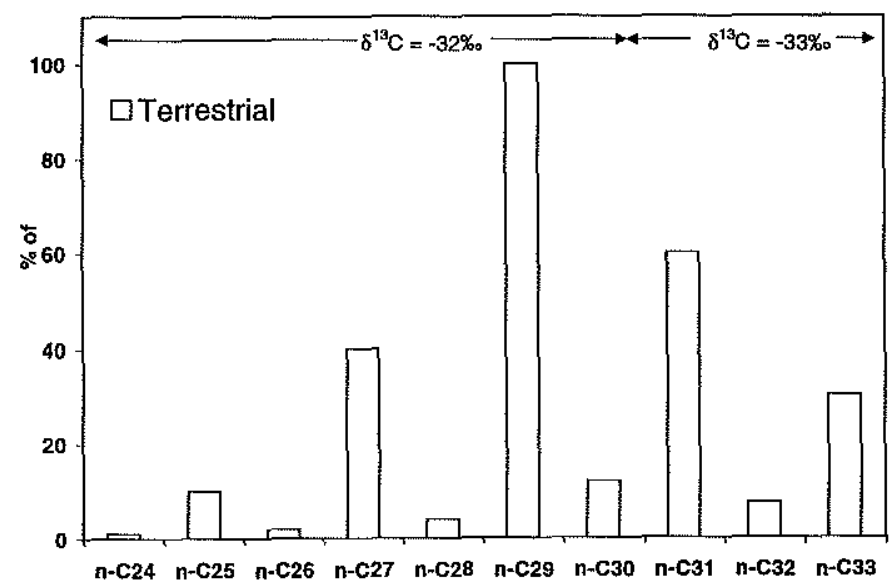

Figure 7.1 Concentration distributions and $\delta^{13} \mathrm{C}$ values of the three assumed $n$-alkane sources used to create the $n$-alkane mixing model. 
Figure 7.2
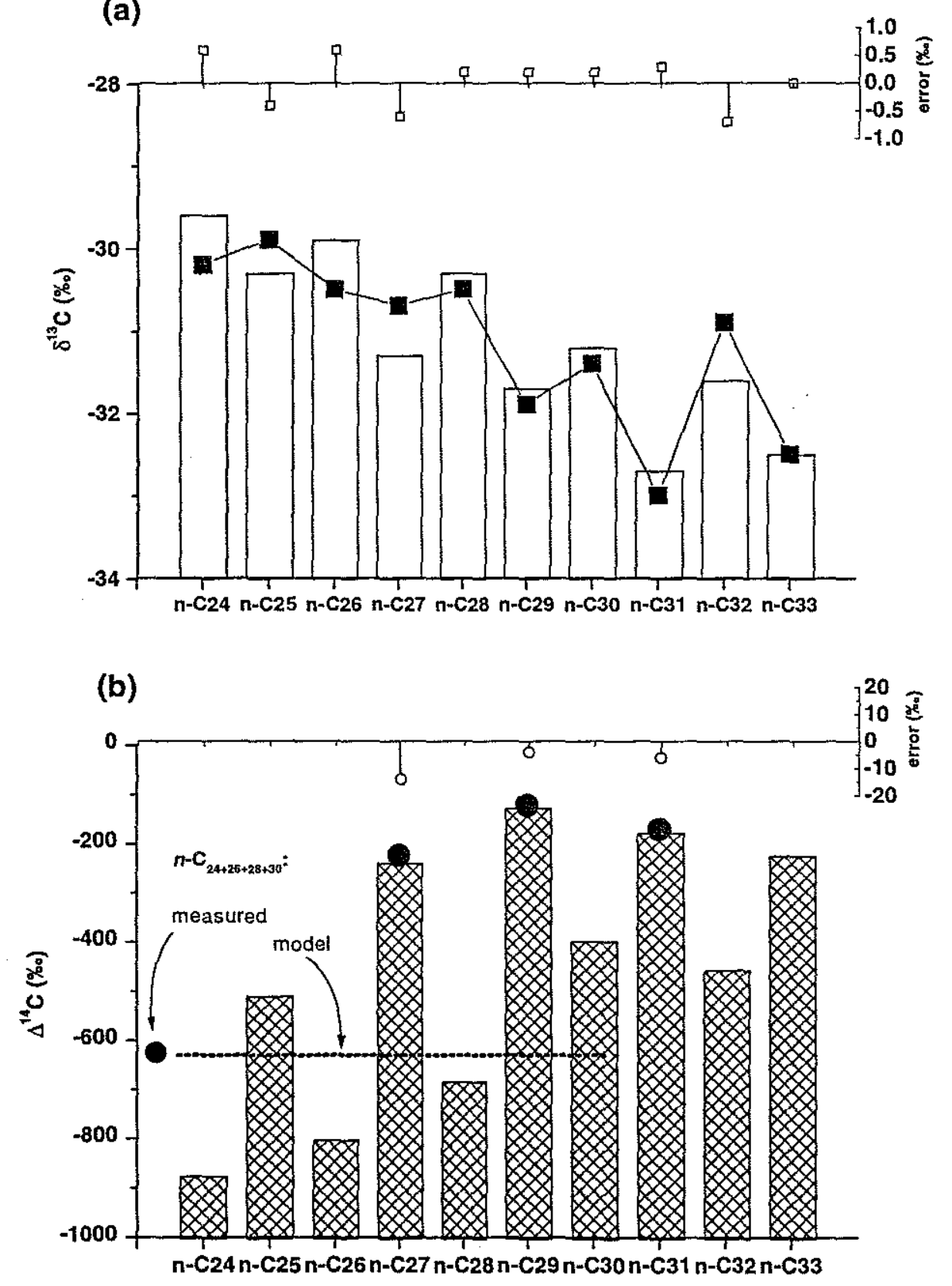

Figure 7.2 Results of the mixing model for SMB pre-bomb $(2.5-7.5 \mathrm{~cm}) n$-alkanes. (a) $\delta^{13} \mathrm{C}$ data for $n$ - $\mathrm{C}_{24}$ to $n-\mathrm{C}_{33} n$-alkanes (squares) and $\delta^{13} \mathrm{C}$ predicted by the best-fit model solution (bars). Residuals shown above are all $<1.0 \%$. (b) $\Delta^{14} \mathrm{C}$ data for composite even numbered $n$-alkanes $\left(n-\mathrm{C}_{24+26+28+30}\right)$, and individual $n-\mathrm{C}_{27}, n-\mathrm{C}_{29}$, and $n-\mathrm{C}_{31}$ alkanes (circles) and $\Delta^{14} \mathrm{C}$ for all $n$ - $\mathrm{C}_{24}$ to $n$ - $\mathrm{C}_{33}$ alkanes predicted by the best-fit model solution (bars). 

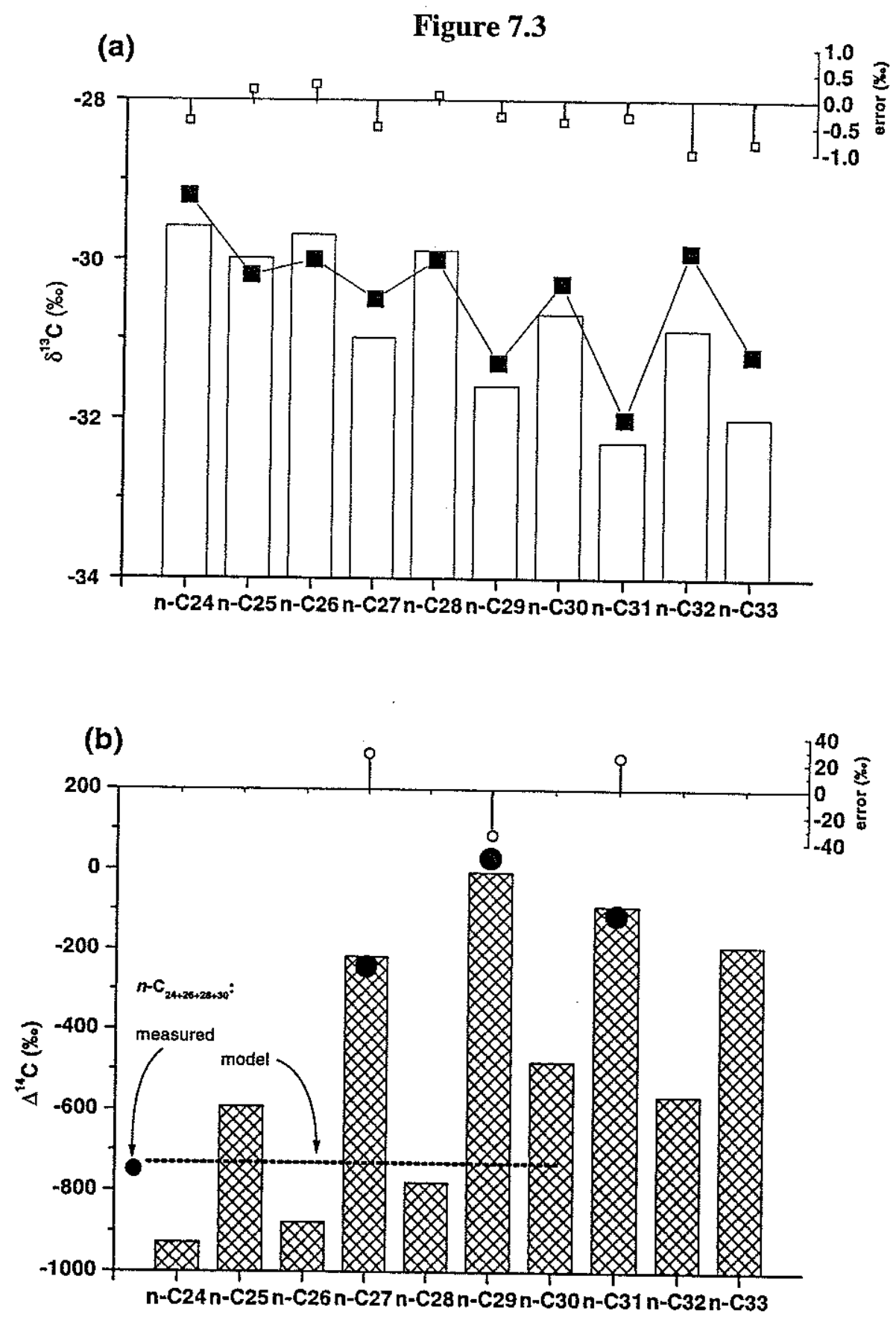

Figure 7.3 Results of the mixing model for SMB post-bomb $(0-2.5 \mathrm{~cm}) n$-alkanes. (a) $\delta^{13} \mathrm{C}$ data for $n$ - $\mathrm{C}_{24}$ to $n$ - $\mathrm{C}_{33} n$-alkanes (squares) and $\delta^{13} \mathrm{C}$ predicted by the best-fit model solution (bars). Residuals shown above are all $<1.0 \%$. (b) $\Delta^{14} \mathrm{C}$ data for composite even numbered $n$-alkanes $\left(n-\mathrm{C}_{24+26+28+30}\right)$, and individual $n$ - $\mathrm{C}_{27}, n-\mathrm{C}_{29}$, and $n$ - $\mathrm{C}_{31}$ alkanes (circles) and $\Delta^{14} \mathrm{C}$ for all $n$ - $\mathrm{C}_{24}$ to $n$ - $\mathrm{C}_{33}$ alkanes predicted by the best-fit model solution (bars). 
Figure 7.4
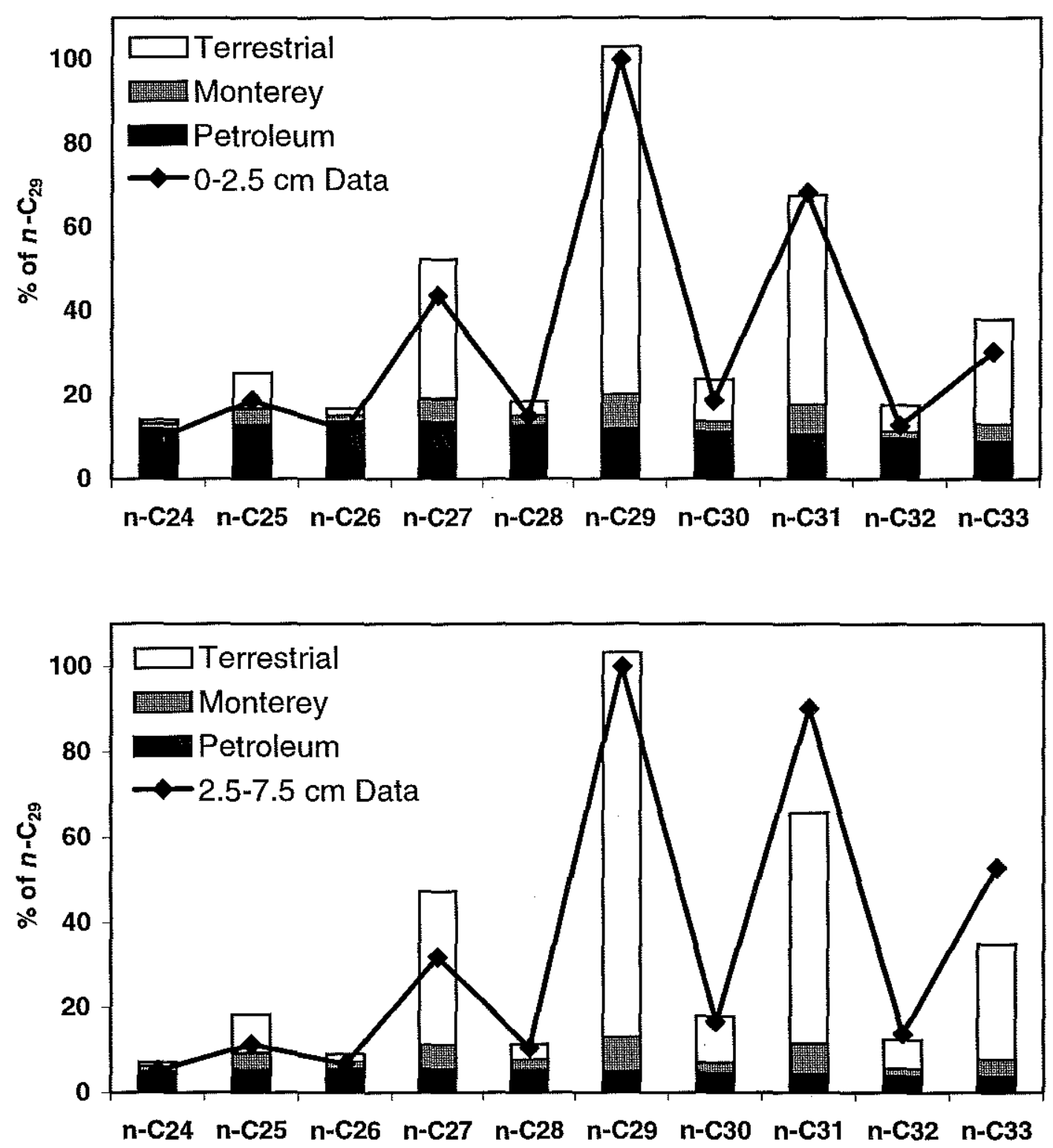

Figure 7.4 Relative contributions of each of the three endmembers to the $n$-alkane samples. The petroleum source is relatively more important in the $0-2.5 \mathrm{~cm}$ horizon, terrestrial material is relatively enriched in the $2.5-7.5 \mathrm{~cm}$ horizon, and the shale fraction is the same in both. Agreement between the data and model is within $10 \%$ in the surface sediment and within $20 \%$ in the deeper sample. 
The isotopic results $\left(\delta^{13} \mathrm{C}_{\mathrm{i}, \mathrm{j}}\right.$ and $\left.\Delta^{14} \mathrm{C}_{\mathrm{i}, \mathrm{j}}\right)$ of the $n$-alkane mixing models are shown graphically in Figures 7.2 and 7.3. The model and data for the SMB pre-bomb sediment horizon $(2.5-7.5 \mathrm{~cm})$ is presented in Figure 7.2 , while the post-bomb $(0-2.5 \mathrm{~cm})$ model and data are shown in Figure 7.3. The model output for $\delta^{13} \mathrm{C}$ is shown with colorless bars, while the model results for $\Delta{ }^{14} \mathrm{C}$ are represented by shaded bars. The measured $n$ alkane data are shown with symbols. The differences between the two values are shown at the top of each figure. The agreement between the model and the $\Delta^{14} \mathrm{C}$ data is believed to be within the compounded error of the compound-specific isotopic measurements, while the $\delta^{13} \mathrm{C}$ model is also nearly as accurate.

In both Figures 7.2 and 7.3 , the $\delta^{13} \mathrm{C}$ model agrees within $\pm 1 \%$ of the data for all of the $n$-alkanes. The model reproduces the odd-even pattern seen in the data, showing ${ }^{13} \mathrm{C}$-enrichment in the even-numbered $n$-alkanes and ${ }^{13} \mathrm{C}$-depletion in the odd-numbered compounds. The model is offset from the data most clearly in the post-bomb sample, where it significantly under-predicts the $\delta^{13} \mathrm{C}$ values of the longer chain $\left(\geq n-\mathrm{C}_{29}\right)$ isomers. There may be an additional, ${ }^{13} \mathrm{C}$-enriched component to the post-bomb $n$-alkanes, or the ${ }^{13} \mathrm{C}$ differences between the surface and deeper sediments could represent a diagenetic effect. Another possibility is that the $\delta^{13} \mathrm{C}$ of one (or more) of the $n$-alkane sources has not remained uniform over time. Within the uncertainties of the model, however, the $\delta^{13} \mathrm{C}$ results appear to agree with the data.

The $\Delta^{14} \mathrm{C}$ model exactly matches the compound-specific $\Delta{ }^{14} \mathrm{C}$ data for the SMB pre-bomb sediments. The agreement for the post-bomb horizon is nearly as good, and in both cases the errors are probably insignificant. The error associated with these compound-specific $\Delta{ }^{14} \mathrm{C}$ measurements has already been estimated to equal $\sim \pm 20 \%$. All of the pre-bomb model residuals are smaller than $20 \%$, while the post-bomb residuals are slightly larger. However, the compounded error associated with comparing the data to the model, if the model uncertainty is also $\pm 20 \%$ o, is $\sim \pm 30 \%$. This is probably still a very optimistic estimate of the true uncertainty associated with the model, and it indicates the post-bomb model and data are insignificantly different. 
The ability of these models to reproduce the $\Delta^{14} \mathrm{C}$ data has several interesting implications. First, the model is able to explain the decrease in $\Delta^{14} \mathrm{C}$ of the evennumbered alkanes in the post-bomb sedimentary horizon. The model result for $n$ $\mathrm{C}_{24+26+28+30}$ was calculated by multiplying the modeled $\Delta{ }^{14} \mathrm{C}$ of each even-numbered ( $n$ $\mathrm{C}_{24-30}$ ) compound by the modeled total abundance of each compound in the samples. The ability of the model to generate the measured $\Delta^{14} \mathrm{C}$ value is especially important, because it means that both the relative fractions of the three endmembers and the overall concentration distributions of the $n-\mathrm{C}_{24-30}$ isomers are both correct. The model therefore confirms the hypothesis, based on relative abundance and $\delta^{13} \mathrm{C}$ alone, that there is a significant fossil component to the even-numbered alkanes. It also confirms that the relative concentration of this component is higher in the surface horizon in comparison to the deeper sediments.

A second implication of the $\Delta^{14} \mathrm{C}$ data is that there is apparently no need to invoke an additional source of pre-aged terrestrial carbon to explain the $n$-alkane isotopic results. The terrestrial endmembers satisfy the data using modern $\Delta^{14} \mathrm{C}$ values. The pre-bomb $\Delta{ }^{14} \mathrm{C}_{\text {terrestrial }}$ used in the model is $0 \%$ o. The associated uncertainties in the $\Delta^{14} \mathrm{C}$ data alone mean the true $\Delta^{14} \mathrm{C}_{\text {terrestrial }}$ value could easily be as low as $-20 \%$ (equivalent to $\sim 150$ years), but the post-bomb data suggest that it is unlikely $\Delta^{14} \mathrm{C}_{\text {terrestrial }}$ could be much lower than $-10 \%$ o (equivalent to $\sim 80$ year residence time, explained below).

The post-bomb $\Delta{ }^{14} \mathrm{C}_{\text {terrestrial }}$ is more difficult to interpret, because the atmospheric $\Delta{ }^{14} \mathrm{C}$ record has not been constant over time. The average $\Delta^{14} \mathrm{C}$ of atmospheric $\mathrm{CO}_{2}$ between 1980 and the present is estimated to be $\sim+180 \%$ based on data in Levin and Kromer (1997). However, the SMB $0-2.5 \mathrm{~cm}$ sediment horizon dates to $~ 1960$, and the average $\Delta{ }^{14} \mathrm{C}_{\mathrm{CO} 2}$ is closer to $+400 \%$ over this longer time interval. The majority of the $n$ alkanes in these samples are of terrestrial origin, and based on geochemical considerations this component apparently is resistant to degradation. This makes it unlikely that the $n$-alkanes in the $0-2.5 \mathrm{~cm}$ horizon are derived exclusively from products dating only from the last two decades. Instead, it is more likely that the modeled $\Delta{ }^{14} \mathrm{C}_{\text {terrestrial }}=+235 \%$ o reflects plant waxes derived from throughout the years 
1960-1996 plus some relatively modern material dating from prior to nuclear weapons testing $\left(\Delta^{14} \mathrm{C}=0 \%\right.$ ). This scenario would be consistent with an average age for the terrestrial component of $\sim 77$ years. The $\Delta^{14} \mathrm{C}$ value of $\sim+235 \%$ ( $~ 45$ years at $+400 \%$, plus $\sim 32$ years at $0 \%$ ) represents a mixture of (recent) pre-bomb and post-bomb material. This is curiously (and probably coincidentally) close to the estimated global average 80year residence time of carbon in the upper $1 \mathrm{~m}$ of soil humus (Hedges and Oades, 1997).

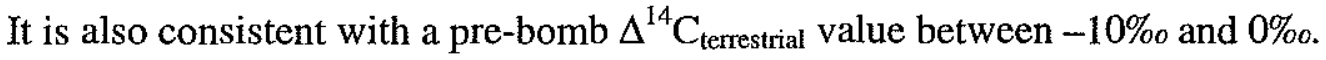

In Figure 7.4, the fractions of each endmember contributing to the total modeled $n$-alkane concentrations are shown. The post-bomb model and data agree within $\sim 10 \%$, while the pre-bomb agreement is less good. The $\sim 20 \%$ errors for $n-\mathrm{C}_{31}$ and $n$ - $\mathrm{C}_{33}$ in the pre-bomb sample are larger, perhaps, than the errors associated with GC-FID quantitation (estimated to be $\sim 10 \%$ ). Nevertheless, this figure clearly shows the dominance of the terrestrial $n$-alkane sources over the fossil components. The higher concentration (12\%) of petroleum-derived alkanes is apparent in the surface horizon compared to the deeper sediments (5\%). It is unknown whether this is a diagenetic effect, the result of more anthropogenic influence in the upper horizon, or a combination of both. Due to the presence of the unique biomarker, $\mathrm{C}_{28}$ bisnorhopane, some portion of the petroleum fraction is undoubtedly natural seepage originating from the Monterey Shale (Simoneit and Kaplan, 1980). Anthropogenic sources of petroleum-derived alkanes include sewage outfall and local shipping traffic (Venkatesan and Kaplan, 1992). Sedimentary profiles of total hydrocarbons in California Borderland basin sediments show a clear increase in concentration beginning in the early to mid-1900s, presumably due to human activity (Eganhouse and Venkatesan, 1993). In SMB, the maximum total hydrocarbon (and individual PAH; A. Pearson, unpublished data) concentrations occur slightly below 2.5 $\mathrm{cm}$, suggesting that there should be substantial anthropogenic influence on the $n$-alkanes in both samples studied here. Since the hydrocarbon sources to both horizons apparently are similar, the relative distributions of the different alkane components (especially the smaller percentage of petroleum-derived alkanes at depth) may reflect differing rates of diagenesis for petroleum, shale, and plant wax alkanes. 
Interestingly, the percentage contribution of shale-derived $n$-alkanes (8\%) appears to remain constant. This uniformity apparently indicates the shale component is resistant to remineralization and that its delivery to SMB sediment has remained fairly constant over time. This observation helps address the question of whether ancient organic carbon on the continents experiences complete oxidation or whether a fraction survives and is reburied in marine sediments (Hedges, 1992). The model suggests incomplete weathering of eroded continental materials, which is consistent with the results of other studies (e.g. Barrick et al., 1980; Petsch et al., 1999).

These mixing models allow the fossil component of the compound-specific $n$ alkane data to be decoupled from the modern terrestrial component. It is interesting to reexamine the $\Delta\left(\Delta^{14} C\right)$ parameter by incorporating the new estimates of $\Delta^{14} C_{\text {terrestrial into the }}$ compound-specific data. Figure 7.5 re-plots the same data as was shown previously in Figure 6.21, except that the $\Delta\left(\Delta^{14} \mathrm{C}\right)$ values for $n-\mathrm{C}_{27}, n-\mathrm{C}_{29}$, and $n-\mathrm{C}_{31}$ alkanes have been changed to $+235 \%$ o to represent the modeled transition between pre-bomb and post-bomb $\Delta^{14} \mathrm{C}_{\text {terrestrial }}$ ( (The data point for $n-\mathrm{C}_{24+26+28+30}$ is not shown in this figure.) The new perspective gained from this view is that there are only three distinct groups of compound-specific isotopic data for the SMB sedimentary lipids extracted and analyzed in this study. The terrestrial $n$-alkanes represent a carbon endmember with low $\delta^{13} \mathrm{C}$ values and a high rate of uptake of bomb- ${ }^{14} \mathrm{C}$. They trace the carbon pool with the fastest kinetic response to changes in atmospheric $\Delta^{14} \mathrm{C} C \mathrm{CO}$. The other lipids all have $\delta^{13} \mathrm{C}$. values in an intermediate range, approximately around $-26 \%$, but ranging from $-23 \%$ to $-28 \% o$ (except ketols and diols, $-30 \%$ o to $-33 \%$ ). These lipids have $\Delta\left(\Delta^{14} \mathrm{C}\right)$ values that reflect the kinetics of ${ }^{14} \mathrm{CO}_{2}$ incorporation into surface water DIC. The final group belongs to the marine Archaea, in this case hypothesized to represent a marine water column chemoautotrophic endmember. The archaeal lipids are ${ }^{13} \mathrm{C}$-enriched, probably due to an alternate metabolism in these organisms, and their $\Delta\left(\Delta^{14} \mathrm{C}\right)$ values indicate isolation from the influence of bomb- ${ }^{14} \mathrm{C}$, apparently due to biosynthesis beneath the surface ocean mixed layer. 
Figure 7.5

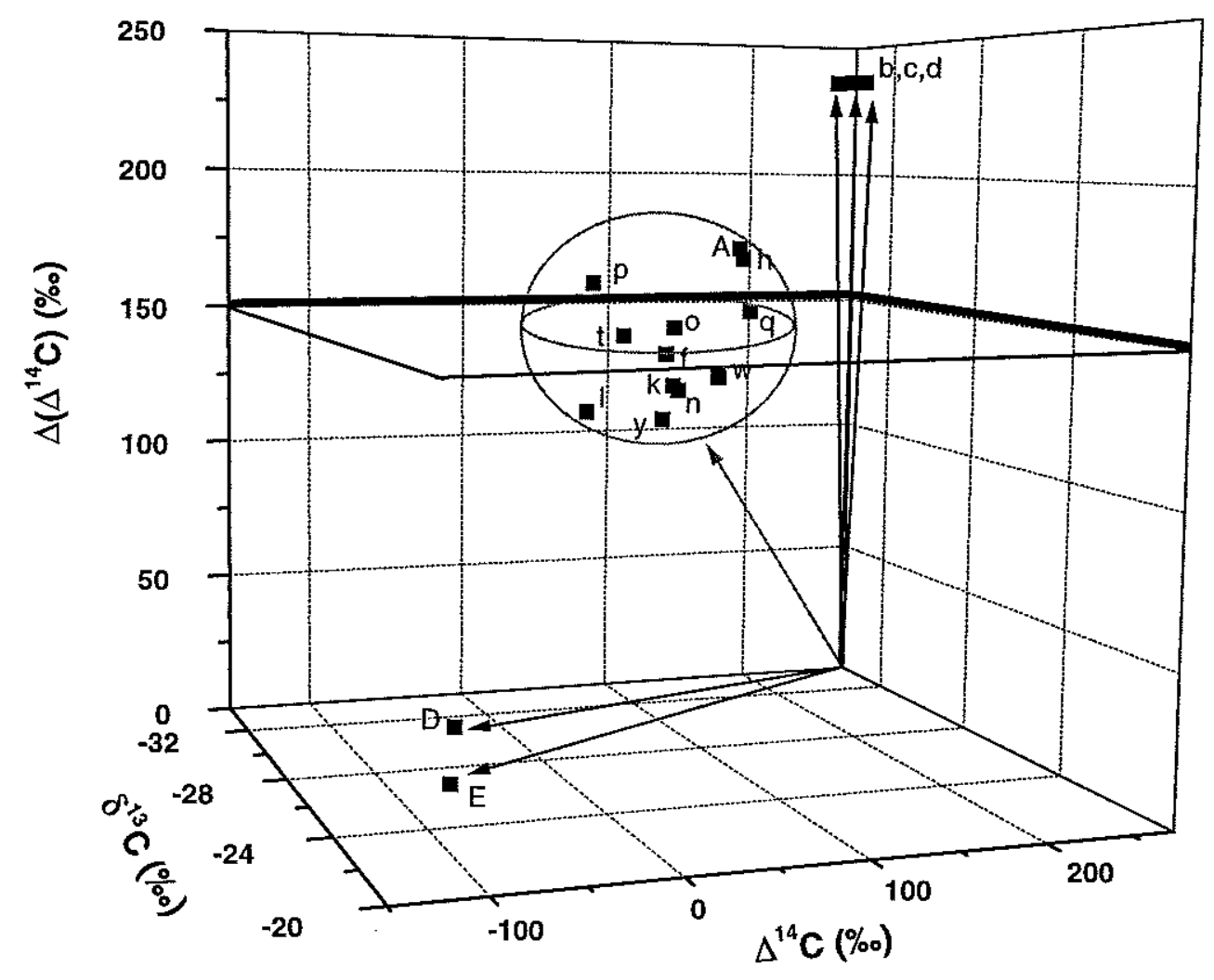

Figure 7.5 A new representation of Figure 6.21. The $\Delta\left(\Delta^{14} \mathrm{C}\right)$ values for the $n$-alkanes are replaced with the modeled result $\Delta\left(\Delta^{14} \mathrm{C}_{\text {terrestrial }}\right)=+235 \%$. The horizontal plane at $\Delta\left(\Delta^{14} \mathrm{C}\right)=+150 \%$ represents the change in surface water $\Delta^{14} \mathrm{C}$ since pre-bomb conditions. 


\subsubsection{Comparison to 2-Component $\boldsymbol{n}$-Alkane Model}

The 3-component $n$-alkane model is able to reproduce the $\Delta^{14} \mathrm{C}, \delta^{13} \mathrm{C}$, and concentration data very well. However, the question arises as to whether all three components are necessary. The primary goal of the model is to explain the individual compound $\Delta^{14} \mathrm{C}$ values, and two of the three model components (petroleum and Monterey Shale) have identical $\Delta^{14} \mathrm{C}$ values (defined as $-1000 \%$ ). Can the Monterey Shale fraction simply be eliminated, creating a 2-component mixture representing fossil (petroleum) and modern terrestrial alkane sources? Qualitatively, it is possible to argue that the third component is necessary, because without it, the total fossil fraction would have a $\mathrm{CPI}=1$. This would then make it impossible to adjust the model to account for varying amounts of fossil-derived carbon in the odd-carbon numbered alkanes relative to the even-numbered alkanes. However, to test this hypothesis both the 3-component model and a Monterey Shale-free 2-component model were re-run (Table 7.4).

Comparing the results in Table 7.4 shows that for both the pre-bomb and postbomb sediment samples, the 3-component model is superior. The primary diagnostic used in reaching this conclusion is the range in $\Delta^{14} \mathrm{C}$ errors for the individual $n$-alkanes. In the table, the $\Delta\left(\Delta^{14} \mathrm{C}\right)$ row represents the difference between measured and modelgenerated $\Delta^{14} \mathrm{C}$ values for the four data points $\left(n-\mathrm{C}_{24+26+28+30}, n-\mathrm{C}_{27}, n-\mathrm{C}_{29}, n-\mathrm{C}_{31}\right)$. The span of these differences is shown immediately beneath. The original runs of the $2-$ component model had error ranges of $83 \%$ and $137 \%$. These results were obtained by setting the total fraction of fossil carbon $\left(f_{f}\right)$ in the 2-component model to be approximately the same as in the 3-component model. Then the simulations were improved by setting the post-bomb $\Delta^{14} \mathrm{C}_{\text {terr }}$ to its minimum allowable value $(+150 \%$ ) and by adjusting $f_{f}$ and $f_{t}$ for both samples to minimize the errors. However, the range of errors could not be improved to better than 74\%o and 75\%. The 3-component model had error ranges of $10 \% o$ and $61 \%$. The primary reason why the Monterey Shale fraction helps the 3-component model is because it effectively allows the CPI of the fossil component to be adjusted. 
Table 7.4 Comparison of 2-component and 3-component $n$-alkane mixing models.

\begin{tabular}{|c|c|c|c|c|c|c|c|c|c|}
\hline & $3-F$ & tion $n$-Alka & Model & & & 2-Fra & ion $n$-Alka & Model & \\
\hline & $\operatorname{Pr}$ & omb & Post & 3omb & & Pre-1 & $\mathrm{mb}$ & Post- & $\mathrm{mb}$ \\
\hline$f_{\text {petroleum }}$ & 0.05 & & 0.12 & & $f_{\text {petroleum }}$ & 0.13 & 0.07 & 0.21 & 0.17 \\
\hline$f_{\text {monterey }}$ & 0.08 & total fossil & 0.08 & total fossil & $f_{\text {monterey }}$ & - & -- & -- & -- \\
\hline$f_{\text {terr. }}$ & 0.87 & & 0.80 & & $f_{\text {terr. }}$ & 0.87 & 0.93 & 0.79 & 0.83 \\
\hline$\Delta^{14} C_{\text {terr }}$ & $0 \%$ & & $+235 \%$ & & $\Delta^{14} \mathrm{C}_{\text {terr }}$ & $0 \%$ & $0 \%$ & $+235 \%$ & $+150 \%$ \\
\hline$\Delta\left(\Delta^{14} \mathrm{C}\right)$ & -14 to -4 & & -34 to +27 & & $\Delta\left(\Delta^{14} \mathrm{C}\right)$ & -141 to -4 & -2 to +72 & -71 to +12 & -69 to +6 \\
\hline Span & $10 \%$ & & $61 \%$ & & Span & $137 \%$ & $74 \%$ & $83 \%$ & $75 \%$ \\
\hline
\end{tabular}




\subsection{TOC MODEL}

The three identified endmembers, marine primary production $(P)$, modern terrestrial carbon $(T)$, and fossil carbon $(F)$ can be used to create a mixing model for the $\Delta^{14} \mathrm{C}$ of SMB sedimentary TOC. The $\Delta^{14} \mathrm{C}$ of the chemoautotrophic endmember is not as easy to define isotopically, so in this model it will be included in the term reserved for the remaining unidentified organic components $(U)$. This model is formulated based on the same principles that were used to create the TOC model in Chapter 4. Both the original model and this newly expanded version assume that the relative fractions of all contributing endmembers do not vary with depth in the core. This assumption is probably not entirely valid, especially in the upper $0-1 \mathrm{~cm}$ where most diagenetic alteration takes place. However, the following calculations are based on a comparison of average post-bomb $(0-2.5 \mathrm{~cm})$ and average pre-bomb $(2.5-8.5 \mathrm{~cm})$ TOC. The assumption of steady-state fractional contributions is probably reasonable given the other uncertainties associated with this approach.

The preliminary conclusion of the model in Chapter 4 was that $\sim 60 \%$ of the TOC in SMB sediment is of marine origin. This fraction includes surface water photosynthetic biomass as well as the products of heterotrophic consumers, both eukaryotic (zooplanktonic, protozoan) and prokaryotic (bacterial). The remaining 40\% was termed net detrital carbon, and its average $\Delta^{14} \mathrm{C}$ was estimated to be $\sim-260 \%$. The new model developed here is used to examine this other material more closely. It attempts to account for some of the additional components contained within this term.

The model is based on the following equations:

$$
f_{P} \Delta^{14} C_{P}+f_{T} \Delta^{14} C_{T}+f_{F} \Delta^{14} C_{F}+f_{U} \Delta^{14} C_{U}=\Delta^{14} C_{T O C}
$$

and

$$
f_{P}+f_{T}+f_{F}+f_{U}=1 \text {. }
$$


In these equations, $f_{P}, f_{T}, f_{F}$, and $f_{U}$ are the fractions of marine planktonic, modern terrestrial, fossil, and unknown (including chemoautotrophic) carbon, respectively. The model uses "known" $\Delta^{14} \mathrm{C}$ values for the SMB system based on compound-specific and bulk sample data from this thesis. The values used in the model are given in Table 7.5.

Table 7.5 Assumed $\Delta^{14} \mathrm{C}$ values used in the TOC mixing model.

\begin{tabular}{|c|c|c|}
\hline & Pre-Bomb & Post-Bomb \\
\hline$\Delta^{14} \mathrm{C}_{\mathrm{TOC}}{ }^{*}$ & $-155 \%$ & $-55 \%$ \\
\hline$\Delta^{14} \mathrm{C}_{\mathrm{p}}^{\dagger}$ & $-82 \%$ & $+71 \% o$ \\
\hline$\Delta^{14} \mathrm{C}_{\mathrm{T}}^{\ddagger}$ & $0 \%$ & $+235 \%$ \\
\hline$\Delta^{14} C_{F}$ & $-1000 \%$ & $-1000 \%$ \\
\hline
\end{tabular}

*The values $-55 \%$ and $-155 \%$ are the average $\Delta^{14} \mathrm{C}_{\mathrm{TOC}}$ values determined for SMB $0-2.5 \mathrm{~cm}$ and $2.5-8.5 \mathrm{~cm}$, respectively.

$\dagger$ From the SMB surface water $\Delta^{14} C_{\text {DrC }}$ estimates, Chapter 4.

$\$$ From the results of the $n$-alkane mixing model, this chapter.

For the model, the further assumption is made that $\Delta^{14} \mathrm{C}_{\mathrm{U}}$ has remained unchanged between pre-bomb and present times. This is probably valid, as the rough estimate for $\Delta^{14} \mathrm{C}_{\mathrm{D}}$ (net detrital carbon ) in Chapter 4 indicated a value $\ll 0 \%$, so this pool is probably not experiencing significant bomb- ${ }^{14} \mathrm{C}$ incorporation.

The resulting system has 3 equations in 5 unknowns:

$$
\begin{aligned}
& 71 f_{P}+235 f_{T}-1000 f_{F}+\Delta^{14} C_{U} f_{U}=-55, \\
& -82 f_{P}-1000 f_{F}+\Delta^{14} C_{U} f_{U}=-155
\end{aligned}
$$

and

$$
f_{P}+f_{T}+f_{F}+f_{U}=1
$$


If values are specified for any two of the variables, the system of equations can be solved. The approach taken was to create a matrix of values for $f_{P}$ and $\Delta^{14} \mathrm{C}_{\mathrm{U}}$ and solve the system for every possible solution. The preliminary analysis in Chapter 4 indicates $f_{P} \sim$ 0.6. A reasonable range for $f_{P}$ in the model might therefore be $0.4-0.8$, so these were chosen as the boundary conditions for the $\mathrm{x}$-axis. Boundary values of $-500 \%$ and $0 \%$ were initially assumed for $\Delta^{14} \mathrm{C}_{U}$ on the $\mathrm{y}$-axis. The solutions, therefore, are the values $f_{T}$, $f_{F}$, and $f_{U}$. The model was solved in $\mathrm{Matlab}^{\circledR}$, and the output is shown in Figure 7.6.

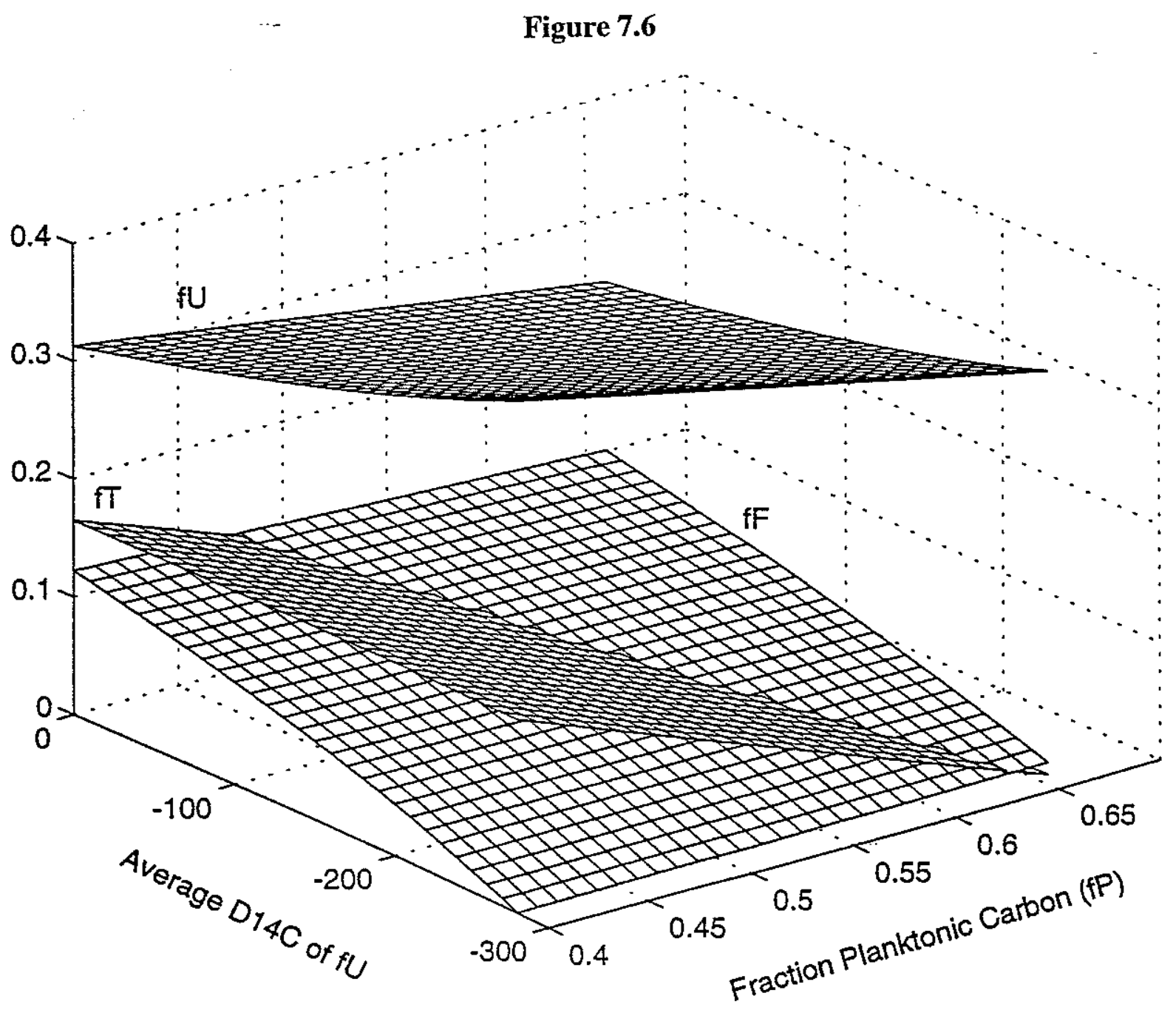

Figure 7.6 Matlab model solution for the fractional contributions of planktonic $(P)$, terrestrial $(T)$, fossil $(F)$, and unknown $(U)$ carbon to SMB TOC. 
The results as shown in Figure 7.6 are more constrained than the initial boundary conditions. The model solution is undefined at values of $\Delta{ }^{14} \mathrm{C}_{U}$ less than $-280 \%$ and at values of $f_{P}$ greater than 0.66 . This serves to limit the possible fractional TOC components to the ranges of values shown in Table 7.6.

Table 7.6 TOC mixing model solution.

\begin{tabular}{lll}
\hline Variable & Minimum & Maximum \\
\hline$f_{P}$ & 0.40 (original boundary) & 0.66 \\
$\Delta^{14} \mathrm{C}_{\mathrm{U}}$ & $-280 \% o$ & $0 \%$ (original boundary) \\
$f_{T}$ & 0 & \\
$f_{F}$ & 0 & 0.16 \\
$f_{U}$ & 0.24 & 0.12 \\
\hline
\end{tabular}

The model, in agreement with the preliminary calculation in Chapter 4, indicates a maximum of $66 \%$ of SMB TOC is derived from marine primary production. The remaining material is divided among the modern terrestrial, fossil, and unknown detrital pools. The boundaries set by the model for these $f_{T}, f_{F}$, and $f_{U}$ values are relatively narrow and provide some interesting constraints on the system. If the "true" solution falls somewhere in the middle of Figure 7.6, in the range of 50-60\% planktonic carbon and with an intermediate value of $\Delta{ }^{14} \mathrm{C}_{\mathrm{U}}$, the TOC contains $<10 \%$ fossil carbon, $\sim 10 \%$ modern terrestrial carbon, and $\sim 30 \%$ carbon of unknown origin. This unknown detrital material also includes prokaryotic biomass derived from benthic chemoautotrophic production and/or carbon delivered by re-suspension of older sediments.

There are two possible interpretations of the results for $f_{U}$ and $\Delta{ }^{14} \mathrm{C}_{\mathrm{U}}$. One possibility is that the delivery of allochthonous material to SMB sediment is completely accounted for within the modern terrestrial and fossil terms. This interpretation would imply that the terrestrial flux is essentially a two-component system composed of very modern carbon $(<\sim 100$ years) rapidly delivered to sediments and very ancient carbon 
( $>50,000$ years) that survives extensive geological recycling. This scenario would imply that the $f_{U}$ and $\Delta^{14} \mathrm{C}_{U}$ terms primarily represent the fraction of carbon that is traced to chemoautotrophic (and/or re-suspension) processes within the anoxic environment of the deep SMB. The autotrophic fraction can be evaluated further by examining the sedimentary redox budget for the central SMB.

Previous studies by Jahnke (1990) and Craven and Jahnke (1992) used both insitu benthic chamber experiments and pore-water profiles of reduced inorganic species to examine the recycling of carbon and energy in SMB sediments. The results of this work, based on the total availability of $\mathrm{Fe}^{2+}, \mathrm{Mn}^{2+}, \mathrm{S}^{2-}$, and $\mathrm{NH}_{4}{ }^{+}$, suggested that 0.28 molecules of $\mathrm{CO}_{2}$ could be fixed by chemolithotrophic re-oxidation of these reduced substrates for every $1.0 \mathrm{CO}_{2}$ released by respiration processes (Craven and Jahnke, 1992). If most of this chemolithotrophic production occurs at the sediment-water interface, no more than $28 \%$ of the flux of freshly-deposited phytoplanktonic detritus could be replaced by the biomass of prokaryotic autotrophs. This number is also a maximum estimate, because it assumes the reduced species are utilized with $100 \%$ efficiency for the production of fixed carbon. Metabolic losses of energy or substrates are not included in the estimate. Therefore the amount of chemoautotrophic carbon produced is likely to be smaller than the theoretical $28 \%$ maximum. It seems unlikely that all of the $24-43 \%$ (Table 7.6) of the TOC in the "unidentified carbon" pool could be derived from these processes, even in this reducing environment. It is interesting to note, however, that the most reasonable range of $\Delta^{14} \mathrm{C}_{U}$ is $\sim-100 \%$ to $-200 \%$, which does correspond to the $\Delta^{14} \mathrm{C}$ of SMB deep basin DIC $(\sim-190 \%)$.

The other option to explain the high fraction and ${ }^{14} \mathrm{C}$-depleted age of $f_{U}$ is that there is a component of allochthonous, detrital carbon that remains unaccounted for when the model is evaluated using lipid-derived $\Delta^{14} \mathrm{C}$ values only. The value calculated for $f_{T}$ by the model seems relatively small compared to other recent estimates of the importance of land-derived carbon in continental margin sediments (e.g. Prahl et al., 1994; Goñi et $a l ., 1998)$. It is possible that the $\Delta^{14} \mathrm{C}_{\mathrm{T}}$ value used in the model is not representative of the entire terrestrial carbon contribution to SMB sediment. This $\Delta^{14} \mathrm{C}_{\mathrm{T}}$ value was based 
on the $\Delta^{14} \mathrm{C}$ determined for terrestrial $n$-alkanes. These lipids do not necessarily represent the ${ }^{14} \mathrm{C}$ concentration of other terrestrial components such as complex carbohydrates, lignin, and other biopolymers. Terrestrial soils receive a continuous input of leaf litter, which through degradation and transformation processes is cycled through at least three different pools representing different time-scales; these are loosely defined as the 10year, 100-year, and 1000-year pools (Trumbore, 1993). The relative importance of the recalcitrant, 1000-year pool apparently increases in dry and/or temperate environments. It is this pool that would contribute to a $\Delta^{14} \mathrm{C}_{\mathrm{U}}$ between $-100 \%$ and $-200 \%$. Trumbore (1993) found that approximately $30 \%$ of the carbon in a soil from the Sierra Nevada mountains (California) belonged to the fraction with a $10^{3}$-year residence time, so this material does constitute a significant amount of the potential carbon flux to SMB sediment. Carbon eroded from the more degraded fraction of soil material may no longer contain the labile lipid biomarkers used here to investigate sedimentary $\Delta{ }^{14} \mathrm{C}$. This suggests that terrestrial carbon in marine sediments is not easy to investigate using a single biomarker or compound class. Instead the evidence supports the suggestion of Prahl et al. (1994) that multiple-tracer approaches are more suitable. Isotopic studies based on lignin, especially, may provide better information about the fraction of pre-aged terrestrial carbon.

It is proposed here that the $f_{U}$ and $\Delta^{14} \mathrm{C}_{U}$ terms in the SMB TOC mixing model contain contributions from both chemoautotrophic prokaryotic biomass $\left(\Delta^{14} \mathrm{C} \sim-190\right)$ and from the weathering of degraded, chemically recalcitrant terrestrial soil carbon $\left(\Delta^{14} \mathrm{C}\right.$ $\sim-100 \%$ to $-200 \%$; $\sim 1000$ to 2000 radiocarbon years). It is not yet possible to determine which is quantitatively more important.

This 4-fraction model for the sources of SMB sedimentary TOC is based only on $\Delta{ }^{14} \mathrm{C}$ data. The conclusions reached here can be compared to the results of other studies that used different approaches. These values are summarized in Table 7.7. 
Table 7.7 Comparison of the $\Delta^{14} \mathrm{C}$ model with the results of other approaches to SMB sedimentary TOC.

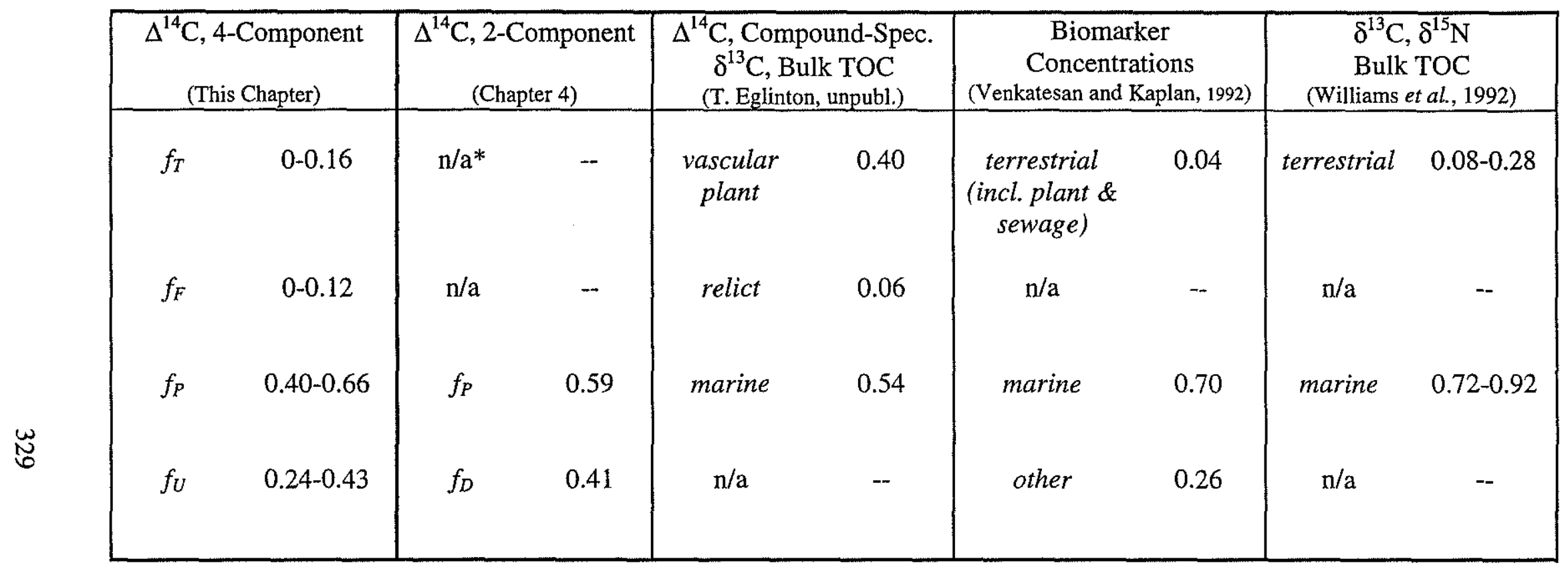

$*_{\mathrm{n}} / \mathrm{a}=$ Particular fraction or its isotopic equivalent was not addressed in the model. 
The results for the marine fraction of TOC are quite similar for all of the different mass-balance approaches summarized in Table 7.7. Except for the high end of the Williams et al. (1992) estimate, the consensus appears to be that SMB sediments contain $\sim 50-70 \%$ organic carbon of marine photosynthetic origin. The differences among these approaches appear in the manner in which the remainder of the carbon is distributed.

Within the row of values representing terrestrial vascular plant carbon, three of the four models produce similar results, attributing approximately $10 \%$ of the TOC to this source. The one significantly different model $\left(\Delta^{14} \mathrm{C} / \delta^{13} \mathrm{C}\right.$ model $)$ assigns about $40 \%$ of the TOC to terrestrial sources. It is useful to examine why there is apparently $30 \%$ excess terrestrial carbon appearing in this result. Three of the other models include a fraction of "other" or "unknown" carbon, and in general, the sum of the "other" plus terrestrial fractions together approaches $40 \%$. This suggests that the balance of the material (30\%) from the $\Delta^{14} \mathrm{C} / \delta^{13} \mathrm{C}$ model actually belongs to the "other" category. The carbon contained within this "unknown" fraction may mimic the terrestrial pool with respect to $\delta^{13} \mathrm{C}$. Thus, it is grouped with the terrestrial fraction in the $\Delta^{14} \mathrm{C} / \delta^{13} \mathrm{C}$ model. Alternatively, its concentration may co-vary with the terrestrial endmember. However, the 4-component $\Delta^{14} \mathrm{C}$ model requires that this material have a different $\Delta^{14} \mathrm{C}$ signature than $f_{T}$, so if it is of terrestrial origin, it must have a different continental residence time. This supports the suggestion that $f_{U}$ may represent highly-degraded organic material that lacks identifiable biomarker components.

In Table 7.7, the models that attempted to quantify fossil or relict carbon agree that this fraction represents $\sim 10 \%$ of SMB sedimentary TOC. Similarly, the "other" or "unknown" carbon, when estimated, is found to be between $25-45 \%$ for the different approaches. In general, the five different approaches are relatively congruent. However, although evidence is strong for the presence of a significant fraction of organic matter of unidentified source, its origin remains largely unexplained. 


\subsection{SYNTHESIS AND CONClUSIONS}

A 3-component mixing model was created to deconvolve the fossil sources of SMB sedimentary $n$-alkanes from the modern plant wax contribution. The results of this model were able to reproduce accurately both the compound-specific $\delta^{13} \mathrm{C}$ and $\Delta^{14} \mathrm{C}$ data, while remaining consistent with the interpretations based only on organic geochemical considerations (the relative concentration data). The model indicates the terrestrial vascular plant $n$-alkanes delivered to SMB sediment are of contemporary biosynthetic origin ( $\sim 0 \%$, pre-bomb; $>0 \%$, post-bomb). The predicted $\Delta^{14} \mathrm{C}$ of the terrestrial contribution was needed in order to construct a budget for the origin of SMB sedimentary TOC.

The inferred $\Delta^{14} \mathrm{C}$ values of the various organic carbon sources were divided into 4 basic pools, marine planktonic $(P)$, terrestrial $(T)$, fossil $(F)$, and unknown plus chemoautotrophic carbon $(U)$. These components constitute potential sources of organic carbon to SMB sediments, and each one has an isotopically distinct ${ }^{14} \mathrm{C}$ signature. The 4 endmembers were used to create a mass-balance mixing model for the sedimentary TOC. The results of the model suggest that the fraction of marine planktonic carbon in the anoxic central SMB sediment is $\sim 50-60 \%$. The other components apparently contribute $<10 \%$ (fossil), $\sim 10 \%$ (modern terrestrial), and $\sim 30 \%$ (component " $U$ "). The average $\Delta^{14} \mathrm{C}$ value of this unknown detrital plus chemoautotrophic material is limited to between $0 \%$ and $-280 \%$, but the most likely range appears to be $\sim-100 \%$ to $-200 \%$. This makes it difficult to determine how much of this endmember could be from autotrophic incorporation of bottom water DIC ( -190\%o) into prokaryotic biomass and how much could be from the pre-aged pool of terrestrial soil carbon $(\sim-100 \%$ o to $-200 \%$ o). Compound-specific $\Delta^{14} \mathrm{C}$ measurements based on sedimentary lipid biomarkers were not adequate to answer this question. The lipid data resolved only two ${ }^{14} \mathrm{C}$-depleted sources of organic carbon, fossil alkanes and lipids of obligate chemoautotrophs.

A fraction of allochthonous carbon with an intermediate degree of ${ }^{14} \mathrm{C}$ depletion must also exist, but it may not contain any easily extractable lipids. More work is needed 
to find a suitable tracer for this component of sedimentary TOC in order to refine the mixing model presented above. Studies incorporating isotopic analysis of the oxidation products of lignin are likely to yield useful insight into this problem. In addition, new methods for measuring the natural abundance of deuterium (D/H ratios) in lipids may help refine the terrestrial component of biomarkers representing multiple sources (Sessions et al., in press). Finally, if both the modern vascular plant and the "unknown" carbon fractions have terrestrial origins, experiments that sort particles by size (e.g. Keil et al., 1994) may allow the more highly-degraded components (fine particulates) to be separated from fresher (coarse-grained) materials and the chemical and isotopic compositions of both fractions to be investigated separately. 


\subsection{REFERENCES}

Barrick, R. C., Hedges, J. I., and Peterson, M. L. (1980) Hydrocarbon geochemistry of the Puget Sound region - I. sedimentary acyclic hydrocarbons. Geochim. Cosmochim. Acta 44, 1349-1362.

Bauer, J. E., Reimers, C. E., Druffel, E. R. M., and Williams, P. M. (1995) Isotopic constraints on carbon exchange between deep ocean sediments and sea water. Nature 373, 686-689.

Becker-Heidmann, P. Scharpenseel, H.-W. and Wiechman, H. (1996) Hamburg radiocarbon thin layer soils database. Radiocarbon 38, 295-345.

Benoit, G. J., Turekian, K. K., and Benninger L. K. (1979) Radiocarbon dating of a core from Long Island Sound. Estuarine Coastal Mar. Sci. 9, 171-180.

Berner, R. A. (1982) Burial of organic carbon and pyrite sulfur in the modern ocean: Its geochemical and environmental significance. Am. J. of Science 282, 451-473.

Bird, M. I., Summons, R. E., Gagan, M. K., Roksandic, Z., Dowling, L., Head, J., Fifield, L. K., Cresswell, R. G., and Johnson, D. P. (1995) Terrestrial vegetation change inferred from $n$-alkane $\delta^{13} \mathrm{C}$ analysis in the marine environment. Geochim. Cosmochim. Acta 59, 2853-2857.

Broecker, W. S. and Peng, T.-H. (1982) Tracers in the Sea, Lamont Doherty Geological Observatory Press, Columbia University, New York. pp. 383-439.

Clayton, C. J. and Bjoroy, M. (1994) Effect of maturity on ${ }^{13} \mathrm{C} /{ }^{12} \mathrm{C}$ ratios of individual compounds in North Sea oils. Org. Geochem. 21, 737-750.

Collister, J. W. (1992) An isotopic biogeochemical study of the Green River Oil Shale (Piceance Creek Basin, Colorado). Ph.D. Dissertation, Indiana University.

Collister, J. W., Rieley, G., Stern, B., Eglinton, G., and Fry, B. (1994a) Compoundspecific $\delta^{13} \mathrm{C}$ analyses of leaf lipids from plants with differing carbon dioxide metabolisms. Org. Geochem. 21, 619-627.

Collister, J. W., Lichtfouse, E., Hieshima, G., and Hayes, J. M. (1994b) Partial resolution of sources of $n$-alkanes in the saline portion of the Parachute Creek Member, Green River Formation (Piceance Creek Basin, Colorado). Org. Geochem. 21, 645-659.

Craven, D. B. and Jahnke, R. A. (1992) Microbial utilization and turnover of organic carbon in Santa Monica Basin sediments. Prog. Oceanog. 30, 313-333.

Druffel, E. R. M., Williams, P. M., Bauer, J. E., and Ertel, J. R. (1992) Cycling of dissolved and particulate organic matter in the open ocean. J. Geophys. Res. 97 (C10), 15,639-15,659.

Eganhouse, R. P. and Venkatesan, M. I. (1993) Chemical Oceanography and Geochemistry, In: Ecology of the Southern California Bight, A Synthesis and Interpretation. M. D. Dailey, D. J. Reish, and J. W. Anderson, Eds. University of California Press, Berkeley, p 71-171.

Eglinton, G., Gonzales, A. G., Hamilton, R. J., and Raphael, R. A. (1962) Hydrocarbon constituents of the wax coating of plant leaves: a taxonomic survey.

Phytochemistry 1, 89-102. 
Eglinton, T. I., Benitez-Nelson, B. C., Pearson, A., McNichol, A. P., Bauer, J. E., and Druffel, E. R. M. (1997) Variability in radiocarbon ages of individual organic compounds from marine sediments. Science 277, 796-799.

Eglinton, T. I., Gustafsson, O., Schouten, S., and Sinninghe Damste, J. S. (in preparation) Isotopic evidence for common biological precursor(s) of long-chain diols and $n$ hydrocarbon pyrolysis products from Black Sea sediments.

Emery, K. O. and Bray, E. E. (1962) Radiocarbon dating of California Basin sediments. Bull. Am. Assoc. Petrol. Geol. 46, 1839-1856.

Eppley, R. W. (1992) Chlorophyll, photosynthesis and new production in the Southern California Bight. Prog. Oceanog. 30, 117-150.

Goñi, M. A., Ruttenberg, K. C., and Eglinton, T. I. (1998) A reassessment of the sources and importance of land-derived organic matter in surface sediments from the Gulf of Mexico. Geochim. Cosmochim. Acta 62, 3055-3075.

Hayes, J. M., Freeman, K. H., Popp, B. N., and Hoham, C. H. (1990) Compound-specific isotopic analyses: A novel tool for reconstruction of ancient biogeochemical processes. Org. Geochem. 16, 1115-1128.

Hedges, J. I. (1992) Global biogeochemical cycles: progress and problems. Mar. Chem. 39, 67-93.

Hedges, J. I. and Parker, P. L. (1976) Land-derived organic matter in surface sediments from the Gulf of Mexico. Geochim. et Cosmochim. Acta 40, 1019-1029.

Hedges, J. I. and Oades, J. M. (1997) Comparative organic geochemistries of soils and marine sediments. Org. Geochem. 27, 319-361.

Hesshaimer, V., Heimann, M. and Levin, I. (1994) Radiocarbon evidence for a smaller oceanic carbon dioxide sink than previously believed. Nature 370, 201-203.

Jahnke, R. A. (1990) Early diagenesis and recycling of biogenic debris at the seafloor, Santa Monica Basin, California. J. Marine Res. 48, 413-436.

Jones, G.A. and Gagnon, A.R. (1994) Radiocarbon chronology of Black Sea sediments. Deep-Sea Res. 41, 531- .

Keil, R. G., Tsamakis, E., Fuh, C. B., Giddings, J. C., and Hedges, J. I. (1994) Mineralogical and textural controls on the organic composition of coastal marine sediments; hydrodynamic separation using SPLITT-fractionation. Geochim. Cosmochim. Acta 58, 879-893.

Kohnen, M. E. L., Schouten, S., Sinninghe Damsté, J. S., de Leew, J. W., Merritt, D. A., and Hayes, J. M. (1992) Recognition of paleobiochemicals by a combined molecular sulfur and isotope geochemical approach. Science 256, 358-362.

Landry, M. R., Peterson, W. K. and Andrews, C. C. (1992) Particulate flux on the water column overlying Santa Monica Basin. Prog. Oceanog. 30, 167-195.

Levin, I. and Kromer, B. (1997) Twenty years of atmospheric ${ }^{14} \mathrm{CO}_{2}$ observations at Schauinsland. Radiocarbon 39, 205-218.

Lichtfouse, E. and Eglinton, T. I. (1996) ${ }^{13} \mathrm{C}$ and ${ }^{14} \mathrm{C}$ evidence of pollution of a soil by fossil fuel and reconstruction of the composition of the pollutant. Org. Geochem. 23, 969-973.

Lockheart, M. J., van Bergen, P. F. and Evershed, R. P. (1996) Variations in the stable carbon isotope compositions of individual lipids from the leaves of modern 
angiosperms: implications for the study of higher land plant-derived sedimentary organic matter. Org. Geochem. 26, 137-153.

Petsch, S. T., Berner, R. A., and Eglinton, T. I. (1999) A field study of the chemical weathering of ancient sedimentary organic matter. Org. Geochem. Submitted.

Prahl, F. G., Erterl, J. R., Goni, M. A., Sparrow, M. A. and Eversmeyer, B. (1994) Terrestrial organic carbon contributions to sediments on the Washington margin. Geochim. Cosmochim. Acta 58, 3035-3048.

Rau, G.H., Karl, D.M. and Carney, R.S. (1986) Does inorganic carbon assimilation cause ${ }^{14} \mathrm{C}$ depletion in deep-sea organisms? Deep-Sea Res. 33, 349-357.

Rau, G.H. Another recipe for bomb ${ }^{14} \mathrm{C}$ dilution. (1991) Nature 350, 116.

Sakata, S., Hayes, J. M., McTaggert, A. R., Evans, R. A., Lekrone, K. J., and Togasaki, R. K. (1997) Carbon isotopic fractionation associated with lipid biosynthesis by a cyanobacterium: Relevance for interpretation of biomarker records. Geochim. Cosmochim. Acta 24, 5379-5389.

Schouten, S. (1995) Structural and stable carbon isotope studies of lipids in immature sulphur-rich sediments. Ph.D. Thesis, University of Groningen, The Netherlands.

Sessions, A. L., Burgoyne, T. W., Schimmelmann, A., and Hayes, J. M. (1999) Fractionation of hydrogen isotopes in lipid biomarkers. Org. Geochem., in press.

Simoneit, B. R. T. and Kaplan, I. R. (1980) Triterpenoids as molecular indicators of paleoseepage in recent sediment off the Southern California Bight. Marine Environmental Research 3, 113-128.

Sinninghe Damsté, J. S., Wakeham, S. G., Kohnen, M. E. L., Hayes, J. M., and de Leeuw, J. W. (1993) A 6,000 year sedimentary molecular record of chemocline excursions in the Black Sea. Nature 362, 827-829.

Smith, B. N. and Epstein, S. (1971) Two categories of ${ }^{13} \mathrm{C} /{ }^{12} \mathrm{C}$ ratios for higher plants. Plant Physiol. 47, 380-384.

Tissot, B. P. and Welte, D. H. (1984) Petroleum Formation and Occurrence, $2^{\text {nd }}$ ed., Springer.

Trumbore, S. E. (1993) Comparison of carbon dynamics in tropical and temperate soils using radiocarbon measurements. Global Biogeochem. Cycles 7, 275-290.

Venkatesan, M. I. and Kaplan, I. R. (1992) Vertical and lateral transport of organic carbon and the carbon budget in Santa Monica Basin, California. Prog. Oceanog. 30, 291-312.

Wang, X.-C., Druffel, E. R. M., Griffin, S., Lee, C., and Kashgarian, M. (1998) Radiocarbon studies of organic compound classes in plankton and sediment of the northeastern Pacific Ocean. Geochim. Cosmochim. Acta 62, 1365-1378.

Wilhelms, A., Larter, S. R., and Hall, K. (1994) A comparative study of the stable carbon isotopic composition of crude oil alkanes and associated crude oil asphaltene pyrolysate alkanes. Org. Geochem. 21, 751-759. 


\section{CHAPTER 8}

\section{CONCLUSIONS AND FUTURE WORK}




\subsection{Conclusions OF THIS THESIS}

This thesis helped show the utility of molecular-level, dual-isotopic $\left(\delta^{13} \mathrm{C}\right.$ and $\Delta^{14} \mathrm{C}$ ) study of lipid biomarkers as an approach to understanding the sources of organic carbon to marine sediments. The main focus on a single sampling location (Santa Monica Basin) also generated the most comprehensive compound-specific $\Delta^{14} \mathrm{C}$ data set currently available. The following topics were addressed.

\subsubsection{Quality Control for Small Sample AMS}

Measurement of natural abundance ${ }^{14} \mathrm{C}$ in individual lipid biomarkers requires two distin, , rigorous sets of laboratory procedures. These steps consist of $(i)$ the careful separation of pure compound from a complex total lipid extract or lipid fraction by PCGC, and (ii) the preparation and analysis of this sample by ${ }^{14} \mathrm{C}-\mathrm{AMS}$. The first step was developed and described thoroughly in Eglinton et al. (1996), while the second step is elaborated in this thesis.

The amount of carbon obtained during a PCGC separation is limited by sample availability and PCGC run conditions to less than the 500-1000 $\mu \mathrm{g}$ of carbon $(\mu \mathrm{gC})$ normally required for an AMS analysis. Commonly, an individual PCGC sample will generate less than $100 \mu \mathrm{gC}$, and occasionally as little as $10-20 \mu \mathrm{gC}$ is obtained. Several aspects of AMS ${ }^{14} \mathrm{C}$ analysis had to be adapted to accommodate these samples that contain orders of magnitude less material. Even at such small sample sizes, the precision of the ${ }^{14} \mathrm{C}$ measurement is not usually limited by conventional counting statistics. Instead, the analytical methods development focused on three topics, described in the manuscript re-printed in Chapter 3.

First, the conversion of a $\mathrm{CO}_{2}$ sample to the graphite matrix required for AMS analysis must be quantitative, reliable, and yield material that is physically manageable. Examination of all steps of the graphite production reaction led to the conclusion that two factors were important for the production of quality graphite: $(i)$ a cooler reaction oven 
$\left(605^{\circ} \mathrm{C}\right)$ and very cold dry ice/isopropanol water trap temperatures were necessary, apparently because the reaction is extremely sensitive to very low partial pressures of $\mathrm{H}_{2} \mathrm{O}(\mathrm{g})$, and (ii) a minimum of $1.0 \mathrm{mg}$ catalyst was used to keep samples physically large enough to handle. Second, all aspects of sample combustion, graphite production, sample handling, and AMS measurement were assessed for contamination and background. Combustion of organic samples to $\mathrm{CO}_{2}$ is apparently the largest source of contamination (excluding the possibility that the samples themselves are contaminated during PCGC preparation, prior to loading into combustion tubes). The excess carbon added during closed-tube combustion averages $0.08 \pm 0.02 \mu \mathrm{molC}$ and contains $\sim 25 \%$ modern carbon. Third, the AMS machine conditions affect small samples differently from conventional graphite targets, and run conditions must be optimized to minimize these effects. The measured isotopic ratio $\left({ }^{14} \mathrm{C} /{ }^{12} \mathrm{C}\right.$ ) varies with the ${ }^{12} \mathrm{C}$ ion current (itself a function of sample size). This was demonstrated most clearly by observing that ${ }^{14} \mathrm{C} /{ }^{12} \mathrm{C}$ would decrease as ${ }^{12} \mathrm{C}$ current decreased in samples that were exposed to the ion source long enough to "burn out".

\subsubsection{Phytoplanktonic Tracer Suitable for Paleoceanographic Applications}

The first scientific goal was to establish a baseline for systematic compoundspecific ${ }^{14} \mathrm{C}$ investigations by determining with confidence which lipids were the best phytoplanktonic biomass tracers. Criteria to be satisfied included $(i)$ commonly occuring biomarker(s) of high abundance, (ii) ease of chemical separation from the heterogeneous mixture, and (iii) accurate reproduction of surface water $\Delta^{14} \mathrm{C}_{\mathrm{DIC}}$ values, in lipid extracts obtained from sediments. Criterion (iii) was validated by simultaneous measurement of the surface water $\Delta^{14} \mathrm{C}_{\mathrm{DIC}}$ endmember carbon source.

The advantages of Santa Monica Basin as a primary study site included its laminated sedimentary record and the availability of ancillary data in the literature. In particular, temporal records of surface water $\Delta^{14} \mathrm{C}_{\mathrm{DIC}}$ since the $1950 \mathrm{~s}$ are available for this region and document the invasion of "bomb- ${ }^{14} \mathrm{C}$ "-labelled $\mathrm{CO}_{2}$. Chapter 4 initially 
described the bulk phase data for the SMB core used throughout the thesis. These data include profiles of $\Delta^{14} \mathrm{C}$ in TOC, in deep basin water DIC (from benthic foraminifera), and in surface water DIC (from planktonic foraminifera and from data found in the literature). The rapid sedimentation rate of the core allowed decadal-scale resolution of the changes in these values as a consequence of the uptake of "bomb- ${ }^{14} \mathrm{C}$ ". The complete sedimentary profile also allowed an estimate of the fraction of total carbon originating from surface water primary production, the fraction of integrated "detrital" (pre-aged) carbon, and the average $\Delta^{14} \mathrm{C}$ of this detrital carbon.

The main focus of Chapter 4, however, was to compare the compound-specific $\Delta^{14} \mathrm{C}$ values obtained for a suite of sterol biomarkers with the surface water $\Delta^{14} \mathrm{C}_{\mathrm{DIC}}$ record. This was done for a sedimentary horizon dating from prior to atmospheric weapons testing, and then it was repeated for material from the sediment-water interface to examine contemporary values. The sterols accurately record the change in surface water $\Delta^{14} C_{\text {DIC }}$ over this century. It is proposed that the sterols, as a lipid class, serve to record both the isotopic signature of primary production and the changes in the isotopic properties of the surface ocean mixed layer. The data also support the suggestion of Grice et al. (1998) that cholesterol, in particular, be utilized as an integrated marine planktonic biomass tracer. Paleoceanographic studies may now be initiated in sedimentary environments that experience no $\mathrm{CaCO}_{3}$ deposition.

\subsubsection{Exploration of Prokaryotic Metabolism}

In Chapter 5, a topical study was used to explore how compound-specific ${ }^{14} \mathrm{C}$ measurements can be used to provide information about the pathways of carbon incorporation in marine prokaryotes. This chapter exploited the information provided by the $\Delta^{14} \mathrm{C}_{\text {DIC }}$ gradient between surface and deep ocean waters. This gradient enables a clear distinction between the products of surface water carbon fixation (photosynthetic production) and deep water chemoautotrophic carbon incorporation. The supply of fresh algal biomass to the deep ocean feeds heterotrophic consumers throughout the water 
column, but carries the surface water $\Delta^{14} \mathrm{C}$ isotopic signature. The result is that organic material at the sediment-water interface contains biomarkers of heterotrophic bacteria with ${ }^{14} \mathrm{C}$ isotopic signatures nearly identical to the surface water-derived food source. However, chemoautotrophic production coincident with the water column oxygen minimum also produces ${ }^{14} \mathrm{C}$-depleted lipids that are eventually incorporated into the sediments.

Chapter 5 presented the results obtained for ether-linked lipids of nonextremophilic Archaea in Santa Monica and Santa Barbara Basins. These lipids represented the only non-hydrocarbon biomarkers studied throughout this entire thesis that showed a distinct ${ }^{14} \mathrm{C}$ isotopic signature different from the products of photosynthetic production. The planktonic Archaea appear to function as obligate chemoautotrophs, incorporating DIC into biomass below the euphotic zone of SMB and SBB. The archaeal lipid $\delta^{13} \mathrm{C}$ data were also used in conjunction with the $\Delta^{14} \mathrm{C}$ data in a discussion of the potential enzymatic pathways of carbon incorporation used by these organisms.

\subsubsection{Sources of Lipid Biomarkers to SMB Sediment}

The entire set of compound-specific $\Delta^{14} \mathrm{C}$ and $\delta^{13} \mathrm{C}$ data obtained for SMB sedimentary lipids was presented in Chapter 6. The data were examined as a whole in order to evaluate the number of potential organic carbon sources to SMB sediment that could be distinguished using the dual-isotopic $\left(\Delta^{14} \mathrm{C}\right.$ vs. $\left.\delta^{13} \mathrm{C}\right)$ approach.

The primary feature of the data was the general agreement of most biomarker lipids with the $\Delta^{14} \mathrm{C}$ of surface water DIC. This characteristic was especially apparent if the change in surface water $\Delta^{14} \mathrm{C}_{\mathrm{DIC}}$, or the $\Delta\left(\Delta^{14} \mathrm{C}_{\mathrm{DIC}}\right)$, between pre-bomb and post-bomb periods $(\sim+150 \%)$ was compared to the changes in biomarker $\Delta^{14} \mathrm{C}$, or $\Delta\left(\Delta^{14} \mathrm{C}_{\text {lipid }}\right)$, over the same time interval. $\Delta\left(\Delta^{14} \mathrm{C}_{\text {lipid }}\right)$ values for all FAMEs, sterols, hopanols, and $\mathrm{C}_{30^{-}}$ alkan-15-one-1-ol averaged $+147 \pm 21 \%$, indicating the ${ }^{14} \mathrm{C}$ isotopic composition of these lipids appears to be controlled primarily by the ${ }^{14} \mathrm{C}$ concentration of surface water DIC. 
The implications of the data are similar to the conclusions reached by evaluating the sterol data alone (Chapter 4). The data indicate SMB is primarily a heterotrophic environment, and that both zooplanktonic and bacterial heterotrophy primarily involves consumption of rapidly exported phytoplanktonic detritus. There are minor exceptions observed for some of the bacterial lipids, and this ${ }^{14} \mathrm{C}$-depletion is interpreted here to result from a component of autotrophic uptake of deep basin DIC.

The $n$-alkanes and the archaeal lipids had $\Delta^{14} \mathrm{C}$ values that clearly were tracing different processes than the other lipid classes. As a result, each of these lipid classes was designated the subject of a separate chapter (Chapters 5 and 7).

The combined ${ }^{14} \mathrm{C}$ and ${ }^{13} \mathrm{C}$ approach taken in this chapter also allowed some reexamination of traditional lipid biomarker source assignments. In particular, long-chain fatty acids and fatty alcohols commonly used as markers of terrigenous input are clearly, based on the $\Delta^{14} \mathrm{C}$ data, reflecting multiple origins - and they must include a large component from marine source(s).

\subsubsection{Terrigenous Component of Continental Margin Sediments}

It is commonly observed that the ${ }^{14} \mathrm{C}$ content of TOC in a given sedimentary horizon is less than would be expected based on the chronological age of the horizon. Even when the appropriate reservoir age correction for surface waters (about 400 years) is applied to the radiocarbon age of TOC, this measured age can be thousands of years "older" than the age obtained via sedimentation rates or varve counting (Benoit et al., 1979; Jones and Gagnon, 1994). Terrestrial plant detritus, soil organic matter, and partially-weathered fossil organic matter (kerogen, shale, petroleum) could all contribute to the allochthonous fraction of "pre-aged" carbon reaching marine sediments. It is not clear that there is a single appropriate biomarker compound for any or all of these carbon sources. In fact, these reservoirs all exhibit different continental residence times, and therefore radiocarbon ages. 
Several potential lipid biomarkers for terrestrial input were investigated in this work (Chapters 4, 6, and 7). These compounds included the $\mathrm{C}_{29}$ sterols, long-chain $n$ alkanols, and long-chain fatty acids as tracers of modern terrestrial plant detritus; and the $n$-alkanes as tracers of both modern terrestrial plant waxes and weathered fossil carbon and/or petroleum. Unfortunately, lignin phenols were inaccessible in sufficient quantity and purity to be analyzed; they would have provided an excellent record of the contribution of woody plant tissues.

The ultimate goal in Chapter 7 and indeed ultimately of this whole thesis was to deconvolve the marine planktonic, marine bacterial, terrestrial, and fossil organic carbon components of the total heterogeneous mixture contained within a given sample of sedimentary TOC. The models presented in Chapter 7 were a first step toward incorporating compound-specific $\Delta^{14} \mathrm{C}$ measurements into quantitative approaches to these questions.

A 3-component quantitative mixing model for the sources of high molecular weight $\left(\geq n-\mathrm{C}_{24}\right)$ alkanes to SMB sediment was developed to determine the fractional contributions of fossil alkane and modern terrestrial leaf wax alkane components. The model suggested that in SMB sediments, these compounds are overwhelmingly derived from modern plant waxes and that these lipids enter the SMB environment with a modern ${ }^{14} \mathrm{C}$ signature. The modern $\Delta^{14} \mathrm{C}_{\text {terrestrial }}$ value determined from the $n$-alkane model was subsequently utilized in a 4-component mass balance model for the sources of SMB sedimentary TOC. This model initially assumed that the $\Delta^{14} \mathrm{C}$ for modern plant wax alkanes would equal the $\Delta^{14} \mathrm{C}$ of non-fossil terrestrial organic carbon in SMB sediments. However, the solution to the TOC model suggests that while $~ 50-60 \%$ of the TOC originates from marine primary production, $\sim 10 \%$ comes from modern terrestrial plants, and $<10 \%$ is derived from the weathering of fossil organic materials, $\sim 30 \%$ comes from some combination of pre-aged soil organic carbon and/or deep basin chemoautrophic production. The specific origin(s) of this "unknown" fraction of TOC cannot be distinguished with the information currently available from $\Delta^{14} \mathrm{C}$ analysis based only on lipid biomarkers. 


\subsection{FutUre WORK}

The conclusions of this thesis, as well as the unanswered questions, lead to potential avenues for new research.

(1) The lipid biomakers investigated in this thesis are inadequate to assess the contributions of allochthonous organic carbon to the sediments of SMB. Lipid components were identified for both modern and fossil carbon, but no adequate tracer was determined for any soil organic fraction of intermediate reservoir age. This suggests that multiple-tracer studies should be initiated to investigate the complexities of continental carbon weathering and export. Both $n$-alkanes and the oxidation products of lignin should be investigated simultaneously on the molecular level. In addition, the ${ }^{14} \mathrm{C}$ signatures of operationally defined phases such as "black carbon" and humic and fulvic acids should be compared to the $\Delta^{14} \mathrm{C}$ values measured for specific compounds. Ideally, this approach would be taken in a well-studied sedimentary environment where a single river serves as the major source of continentally-derived sediment. This river could be simultaneously sampled (both POC and sediments) and $\Delta^{14} \mathrm{C}$ values determined for the same organic fractions.

(2) The uniformity of the ${ }^{14} \mathrm{C}$ data presented in this thesis argues for a marine origin for nearly all of the biomarker lipids in the SMB sedimentary environment that have an oxygen-containing functional group. The phytoplanktonic sterols, especially, appear to behave as excellent tracers for the $\Delta^{14} \mathrm{C}$ of surface water DIC. Identifying a class (or classes) of lipids that acts as a tracer of water masses opens new possibilities for studying the record of oceanic paleocirculation. This could be especially useful for investigating the paleoceanographic record contained within sediments underlying the Southern Ocean, where diatomaceous production overwhelmingly supplies the biogenic 
fraction of these sediments and isotopic records based on $\mathrm{CaCO}_{3}$ are unavailable. The evidence that an entire lipid class may trace surface water properties is especially promising, because it suggests that the PCGC compound-specific step may be eliminated entirely. Chemical purification of total lipid class fractions is potentially faster, cheaper, and would require less sediment per analysis, thereby increasing resolution in down-core profiles.

(3) The complexity of prokaryotic cycling and transformation of carbon in the marine environment was not revealed adequately by the compound-specific $\Delta^{14} \mathrm{C}$ analyses in this thesis. The range in $\delta^{13} \mathrm{C}$ values observed for prokaryotic lipids $(-20 \%$ o for archaeal lipids through $-28 \%$ for long-chain fatty acids) may also signal a diversity in metabolic rate, function, and pathways of carbon incorporation that cannot be distinguished based on carbon isotopic measurements of lipid biomarkers. In general, the lack of variety in lipid skeletons and the production of many lipids by numerous classes of organisms limits the degree of source-specificity of these compounds. There are cases where compounds unique to a particular group of organisms have been identified (e.g. Prymnesiophyte alkenones (Eukaryotic, however). However, in the other extreme, $\mathrm{C}_{16: 0}$ fatty acid integrates the contributions of all species containing phospholipid bilayer membranes - all Bacteria and Eukarya. Figure 8.1 shows a very simplified tree of life (adapted from Woese, 1987) as well as the presumed biosynthetic origins of the lipid classes studied in this thesis. Most lipids are seen to be specific only at the Domain level: Archaea, Bacteria, or Eukarya. To make further progress toward understanding specific processes regulating the transfer of carbon and energy in the marine environment, new approaches may need to be developed that yield isotopic data on the organism level. This may require approaches based on the same criteria used to classify species, namely the nucleic acids. 